\title{
Otimização de componentes de Concreto Pré-moldado Protendidos mediante Algoritmos Genéticos
}

\author{
Vanessa Cristina de Castilho
}

Tese apresentada à Escola de Engenharia de São Carlos da Universidade de São Paulo como requisitos para obtenção do título de Doutor em Engenharia de Estruturas.

Orientador: Prof. Dr. Mounir Khalil El Debs

Co-orientadora: Profa. Dra. Maria do Carmo Nicoletti

Fevereiro 
Aos meus pais, Lucas e Elza e aos meus irmãos Alessandra e Fabrício, pelo grande incentivo, compreensão e carinho 


\section{AGRADECIMENTOS}

Ao meu Deus, que sempre me iluminou, me dando força, coragem e paciência em todos os momentos.

Ao Prof. Dr. Mounir Khalil El Debs, pela orientação, paciência, amizade e incentivo, sem os quais este trabalho não existiria.

À Profa. Dra. Maria do Carmo Nicoletti, pela orientação, amizade e interesses demonstrados na elaboração deste trabalho.

Ao Engenheiro Noé Marcos Neto da empresa Marka - Sistemas Construtivos em concreto estrutural da região de Franca, SP, pela valiosa ajuda, sem a qual não seria possível a realização dos experimentos.

Ao Prof. Dr. Marcos Nereu Arenales, pela orientação aos métodos convencionais.

Aos meus grandes e eternos amigos Kristiane Mattar Accetti Holanda e Osvaldo Gomes de Holanda Júnior pelo grande carinho, amizade e incentivo, mesmo à distância.

A Cid Pereira, pelo grande carinho, e companheirismo, demonstrados durante esse período.

Aos inesquecíveis amigos do departamento de Engenharia de Estruturas da Escola de Engenharia de São Carlos - USP.

A Anamaria, Luciana, Suzana, Aline, Daniel, Mônica, Juliana, Tatiana, Luciane, Rejane, Silvana, Andréa, Sylvia e Felícia pela grande amizade e atenção dispensadas durante minha estada em São Carlos.

A Maria Nadir Minatel, pela amizade e pelas orientações fornecidas na elaboração do trabalho.

À CAPES, pelo apoio financeiro, sem o qual este trabalho não poderia ter sido realizado. 


\section{SUMÁRIO}

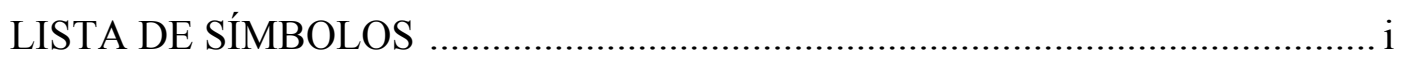

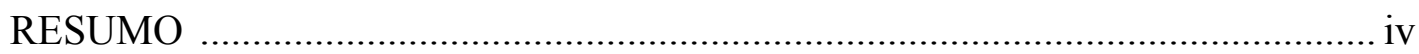

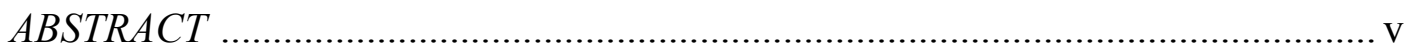

1. INTRODUÇÃ̃ ................................................................................................. 01

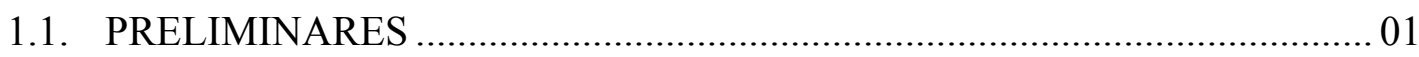

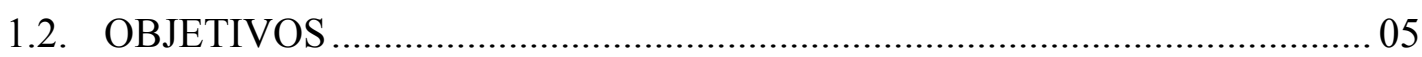

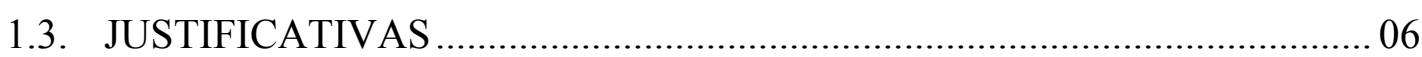

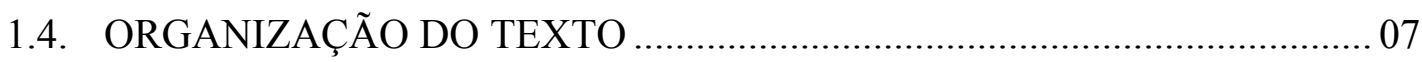

2. FUNDAMENTOS DE ALGORITMOS GENÉTICOS................................... 09

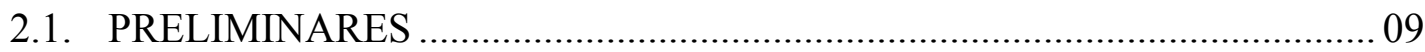

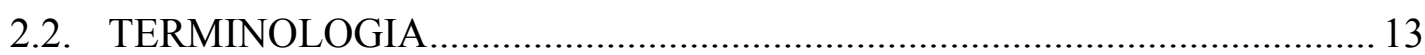

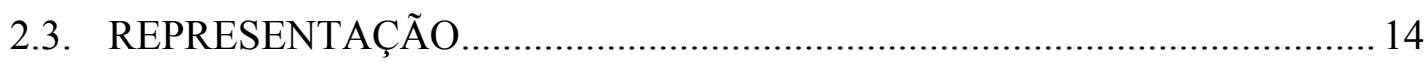

2.3.1 Representação Binária............................................................................. 15

2.3.2 Representação Real ................................................................................ 17

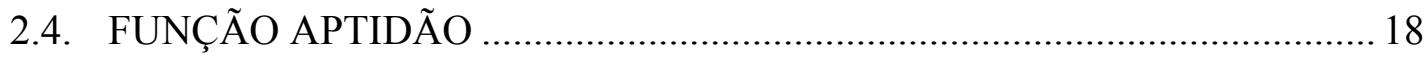

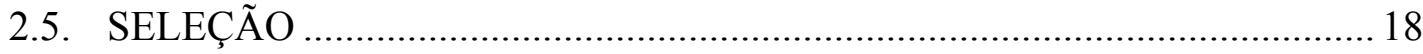

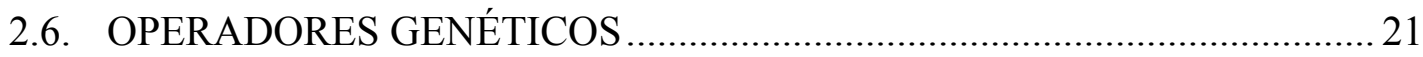

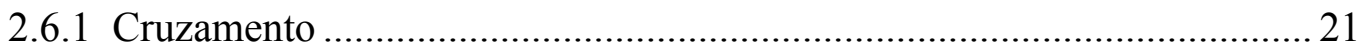

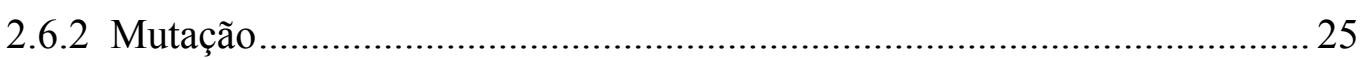

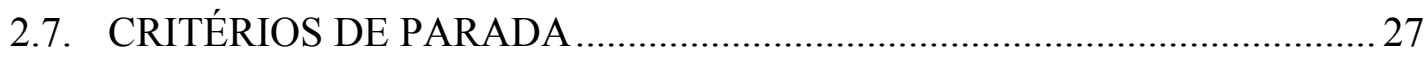

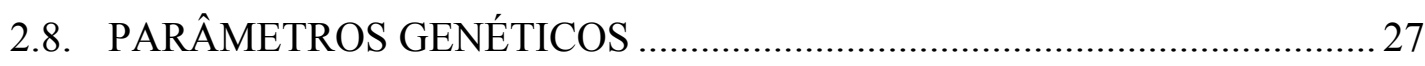

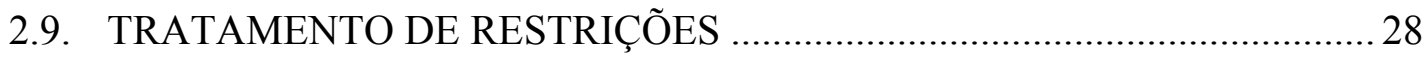

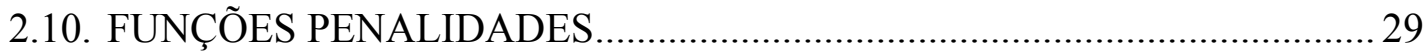

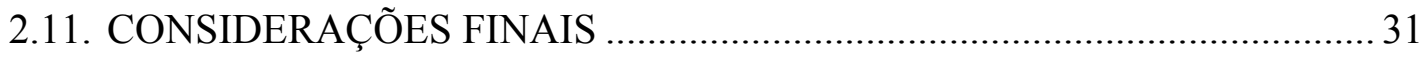

3. O USO DE AGS EM PROBLEMAS DE OTIMIZAÇÃO ESTRUTURAL ESTADO DA ARTE ....................................................................................... 32 


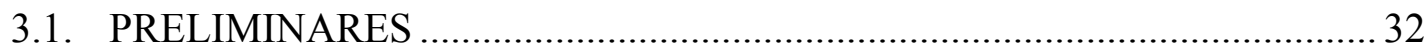

3.2. O USO DE AGS EM ESTRUTURAS DE AÇO.......................................... 32

3.3. O USO DE AG EM ESTRUTURAS DE CONCRETO................................. 54

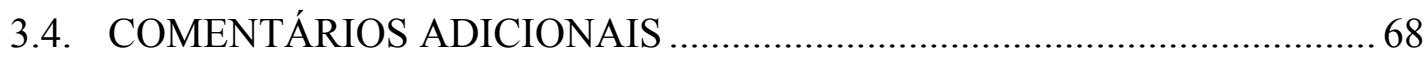

4. DESCRIÇÃO, REPRESENTAÇÃO E SOLUÇÃO DO PROBLEMA DE MINIMIZAÇÃO DO CUSTO DE PRODUÇÃO DE PAINÉIS ALVEOLARES.......................................................................................... 70

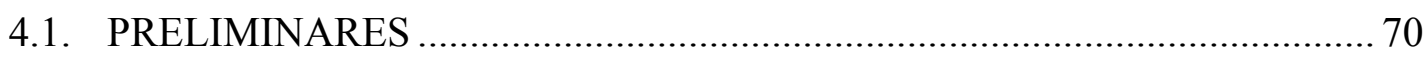

4.2. CONSIDERAÇÕES SOBRE O PROJETO E A APLICAÇÃO DE PAINEL

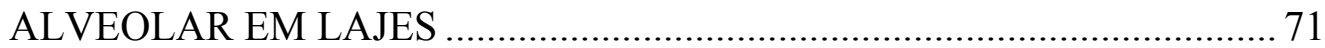

4.3. INVESTIGAÇÃO DO USO DE AG NUM PROBLEMA SOLUCIONADO VIA MÉTODO CONVENCIONAL …........................................................ 73

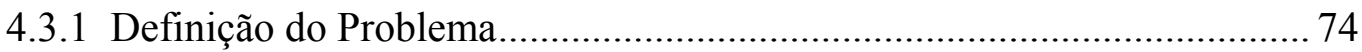

4.3.2 Função Custo Total ............................................................................ 75

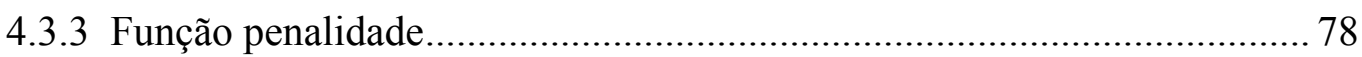

4.3.4 A Busca da Solução do Problema via AG .............................................. 78

4.3.5 Descrição dos Experimentos e Análise dos Resultados........................... 79

4.4. OTIMIZAÇÃO DE PAINEL ALVEOLAR SEM CAPA ESTRUTURAL .... 80

4.4.1 Definição do Problema.............................................................................. 80

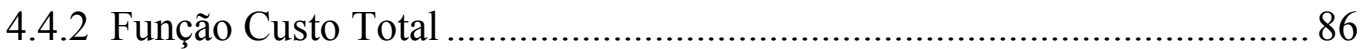

4.4.3 A Busca da Solução do Problema via AG ............................................... 90

4.4.4 Descrição dos Experimentos e Análise dos Resultados........................... 92

4.4.4.1 Família MGA ............................................................................ 92

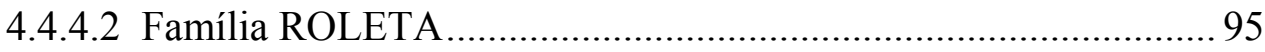

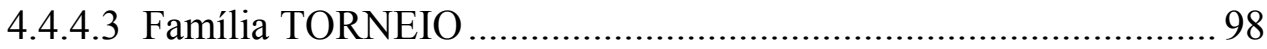

4.4.5 Considerações sobre os Resultados dos Experimentos de Minimização da Função Custo do elemento ........................................................................ 100

4.5. OTIMIZAÇÃO DE PAINEL ALVEOLAR COM CAPA ESTRUTURAL .. 101

4.5.1 Definição do Problema.............................................................................. 102

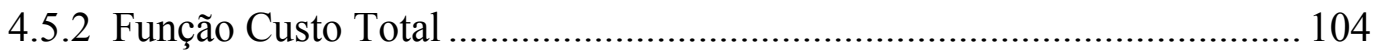

4.5.3 Busca da Solução do Problema via AG ................................................... 106 
4.5.4 Descrição dos Experimentos e Análise dos Resultados 107

4.5.4.1 O MGA1

4.5.4.2 ROLETA3

4.5.4.3 TORNEIO2

4.5.5 Considerações Sobre a Variação dos Valores do Custo Dos Materiais... 117

4.6. AVALIAÇÃO GERAL DOS RESULTADOS OBTIDOS NOS EXPERIMENTOS DESCRITOS NO CAPÍTULO.

5. DESCRIÇÃO, REPRESENTAÇÃO E SOLUÇÃO DO PROBLEMA DE MINIMIZAÇÃO DO CUSTO DE LAJES COM VIGOTAS

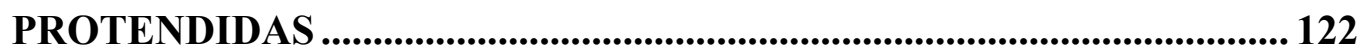

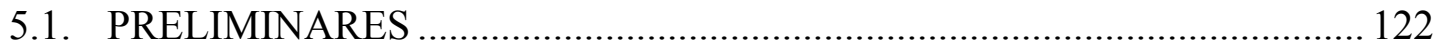

5.2. CONSIDERAÇÕES SOBRE O PROJETO E APLICAÇÃO DE VIGOTAS EM LAJES

5.3. OTIMIZAÇÃO DO ELEMENTO PARA UMA DETERMINADA APLICAÇÃO

5.3.1 Definição do Problema.............................................................................. 127

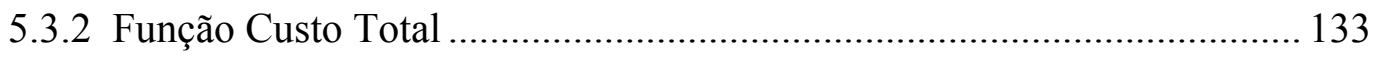

5.3.3 Busca da Solução do Problema via AG .................................................. 139

5.3.4 Descrição dos Experimentos e Análise dos Resultados........................... 139

5.4. OTIMIZAÇÃO DA APLICAÇÃO PARA UMA DETERMINADA VIGOTA 145

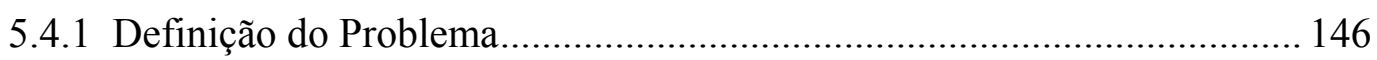

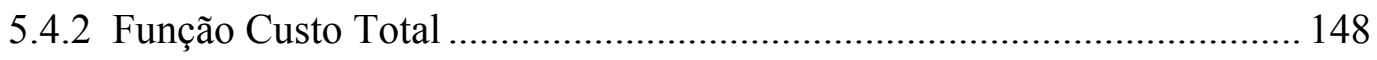

5.4.3 Busca da Solução do Problema via AG ................................................ 149

5.4.4 Descrição dos Experimentos e Análise dos Resultados........................... 150

5.5. OTIMIZAÇÃO DO ELEMENTO E DA APLICAÇÃO.................................. 154

5.5.1 Definição do Problema................................................................................. 155

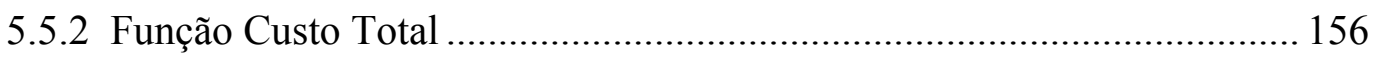

5.5.3 Busca da Solução do Problema via AG .................................................. 158

5.5.4 Descrição dos Experimentos e Análise dos Resultados........................... 158

5.5.5 Considerações Sobre a Variação dos Valores do Custo dos Materiais.... 163 
5.6. AVALIAÇÃO GERAL DOS RESULTADOS OBTIDOS NOS EXPERIMENTOS DESCRITOS NO CAPÍTULO......................................... 164

6. CONSIDERAÇÕES FINAIS E CONCLUSÕES .......................................... 169

REFERÊNCIAS BIBIOGRÁFICAS ............................................................. 175

Apêndice A - Análise de uma viga de concreto armado usando AG .................. 182

Apêndice B - Pseudocódigos das implementações ................................................ 187

Apêndice C - Teoria do Algoritmo Lagrangeano .................................................. 211

Apêndice D - Dimensionamento da laje alveolar sem capa estrutural ............. 223

Apêndice E - Dimensionamento da laje alveolar com capa estrutural...............242

Apêndice F - Dimensionamento da vigota protendida ......................................... 261 


\section{LISTA DE SÍMBOLOS}

\section{LETRAS MAÍSCULAS E MINÚSCULAS}

$\mathrm{a}_{\text {contflec }}$ - contraflecha devido a protensão

$\mathrm{a}_{\text {lim }}$ - flecha admissível devido ao carregamento

$a_{\text {limct }}$ - limite de contraflecha devido a protensão

$\mathrm{e}_{\mathrm{p}}$ - distância dos cabos à linha neutra

$\mathrm{E}_{\mathrm{c}}-$ módulo de elasticidade do concreto

$\mathrm{f}_{\mathrm{ck}}$ - resistência característica do concreto à compressão

$\mathrm{f}_{\mathrm{ctf}}$ - resistência à tração na flexão

$\mathrm{f}_{\text {pyk }}$ - resistência ao escoamento do aço

$\mathrm{g}$ - carregamento permanente

$\mathrm{h}_{\mathrm{n}}$ - espessura do painel

$\mathrm{M}$ - resistência à flexão do painel

$\mathrm{M}_{\mathrm{g}+\mathrm{q}}$ - momento devido ao peso próprio e sobrecarga

$\mathrm{M}_{\mathrm{g} 1}, \mathrm{M}_{\mathrm{g} 2}, \mathrm{M}_{\mathrm{g} 3}-$ momento devido ao peso próprio da vigota, do concreto moldado no local e de revestimento respectivamente

$\mathrm{M}_{\mathrm{k}_{\mathrm{g} 2}}-$ momento devido ao apoio

$\mathrm{M}_{\mathrm{g} 12 \mathrm{pos}}, \mathrm{M}_{\mathrm{g} 12 \mathrm{neg}}-$ momento positivo e negativo para 1 escora respectivamente

$\mathrm{M}_{\mathrm{g} 12 \mathrm{pos}}$ - momento positivo para 2 escoras

$\mathrm{M}_{\mathrm{qex}}$ - momento devido à sobrecarga de execução

$\mathrm{M}_{\mathrm{d}}$ - momento atuante da seção composta

$\mathrm{M}_{\mathrm{u}}$ - momento último da seção composta

$\mathrm{N}_{\text {pop }}$ - tamanho da população

pen(x) - função penalidade

$\mathrm{p}_{\mathrm{i}}$ - probabilidade de seleção

$\mathrm{p}_{\alpha}$ - probabilidade do indivíduo $\alpha$

$\mathrm{p}_{\mathrm{c}}$ - probabilidade de cruzamento

$\mathrm{p}_{\mathrm{m}}$ - probabilidade de mutação 
$\mathrm{q}$ - sobrecarga

$\mathrm{r}_{\alpha}-$ posição do indivíduo $\alpha$

$\mathrm{r}$ - número aleatório entre $[0,1]$

$\mathrm{T}_{\mathrm{dd}}$ - tensão solicitante dos dois concretos

$\mathrm{T}_{\text {sol }}$ - tensão solicitante em toda a superfície de contato

$\mathrm{V}_{\mathrm{d}}$ - força cortante de cálculo

$\mathrm{V}_{\mathrm{u}}, \mathrm{V}_{\mathrm{u} 0}-$ resistência à força cortante

$\mathrm{V}_{\mathrm{u} 0 \mathrm{c}}-$ resistência ao cisalhamento da interface

$\mathrm{W}$ - módulo de resistência à flexão

$\mathrm{W}_{1 \mathrm{~h}}, \mathrm{~W}_{\mathrm{lh}}$ - módulos resistentes da vigota nos bordos inferior e superior, respectivamente

$\mathrm{W}_{1 \mathrm{hh}}, \mathrm{W}_{\mathrm{lhh}}$ - módulos resistentes da laje nos bordos inferior e superior, respectivamente

\section{LETRAS GREGAS}

$\beta_{\mathrm{a} 1}$ - coeficiente de ação dinâmica $\left(\beta_{\mathrm{a} 1}=0,8\right)$

$\beta_{\mathrm{a} 2}$ - coeficiente de ação dinâmica $\left(\beta_{\mathrm{a} 2}=1,3\right)$

$\psi_{1}$ - fator de combinação freqüente de ações $\left(\psi_{1}=0,3\right)$

$\psi_{2}$ - fator de combinação quase permanente de ações $\left(\psi_{2}=0,2\right)$

$\rho$ - taxa de armadura

$\sigma_{\mathrm{I}}-$ tensão principal máxima na tração

$\sigma_{\mathrm{g}+\mathrm{q}}-$ tensão devido a protensão e o peso próprio

$\sigma_{1 \mathrm{~g}_{1}}, \sigma_{2 \mathrm{~g}_{1}}-$ tensão devido ao peso próprio da vigota no bordo inferior e superior

$\sigma_{\mathrm{gg}_{2}}, \sigma_{2 \mathrm{~g}_{2}}-$ tensão devido ao peso próprio do enchimento e do concreto moldado no local no bordo inferior e superior

$\sigma_{1 \mathrm{q}}, \sigma_{2 \mathrm{q}}$ - tensão devido à sobrecarga no bordo inferior e superior

$\sigma_{1 \mathrm{P}_{\mathrm{o}}}, \sigma_{2 \mathrm{P}_{\mathrm{o}}}-$ tensão devido à força de protensão instalada no concreto no bordo inferior e superior

$\sigma_{1 \mathrm{P}_{\mathrm{oo}}}, \sigma_{2 \mathrm{P}_{\mathrm{oo}}}$ - tensão devido à força de protensão após as perdas no bordo inferior e superior

$\sigma_{c t j}-$ tensão limite de tração em j dias

$\sigma_{c t}-$ tensão limite de tração

$\sigma_{\text {cj }}$ - tensão limite de compressão em j dias 
$\sigma_{c}-$ tensão limite de compressão

$\sigma_{\mathrm{q}}$ - tensão devido à sobrecarga

$\sigma_{1 \mathrm{P}_{\mathrm{o}}}, \sigma_{2 \mathrm{P}_{\mathrm{o}}}$ - tensão devido à força de protensão instalada no concreto no bordo inferior e superior

$\sigma_{1 \mathrm{P}_{\mathrm{oO}}}, \sigma_{2 \mathrm{P}_{\mathrm{oo}}}$ - tensão devido à força de protensão após as perdas no bordos inferior e superior

$\sigma_{\text {ct }}-$ tensão limite de tração

$\sigma_{\mathrm{c}}-$ tensão limite de compressão

$\tau$ - tensão cisalhante devida à aplicação das cargas

OBS. Esta lista de símbolos limita-se somente ao trabalho principal. Os símbolos restantes estão referenciados em cada apêndice. 


\section{RESUMO}

CASTILHO, V. C. (2003). Otimização de componentes de concreto pré-moldado protendidos mediante algoritmos genéticos. São Carlos, 283p. Tese (doutorado). Escola de Engenharia de São Carlos, Universidade de São Paulo.

Este trabalho trata da otimização de painéis alveolares e vigotas protendidas utilizando Algoritmos Genéticos (AGs). A proposta de tal algoritmo foi inspirada no princípio da seleção natural de indivíduos, onde o mais 'apto' tende a permanecer na população e se reproduzir, passando seu código genético para a próxima geração. Em alguns casos, esse método pode alcançar melhores soluções se comparados aos métodos tradicionais de otimização. O principal objetivo do trabalho é investigar o uso de AG como uma técnica para a minimização da função custo da aplicação de painéis alveolares e vigotas protendidas. $\mathrm{Na}$ análise estão incluídas as verificações dos elementos nas etapas transitórias referentes à produção, transporte e montagem. A função custo é avaliada considerando valores da realidade brasileira. $\mathrm{O}$ trabalho de pesquisa compara os resultados obtidos utilizando AGs com aqueles obtidos utilizando o método de otimização convencional conhecido como método do Lagrangiano Aumentado. Os resultados obtidos por ambos os métodos evidenciam a eficácia dos AGs com relação ao método convencional. Foram propostas e analisadas três famílias do AG simples, buscando identificar, dentre seus elementos, quais variantes mais adequados na busca da solução dos problemas.

Palavras-chave: painel alveolar, vigota protendida, lajes, algoritmos genéticos, otimização estrutural, custos, método Lagrangeano Aumentado 


\section{ABSTRACT}

CASTILHO, V. C. (2003). Optimization of precast prestressed elements using genetic algorithms. São Carlos, 283p. Ph.D Thesis. Escola de Engenharia de São Carlos, Universidade de São Paulo.

This work aims to optimize the production cost of hollow core panels and prestressed joists using Genetic Algorithms (GAs). The proposal of such an algorithm was inspired by the principle of natural selection of individuals, where the most 'capable' tends to remain in the population and reproduce, passing its genetic code onto the next generation. In some cases, this method can achieve good solutions when compared with conventional methods of optimization. The main goal of the work is to investigate $\mathrm{AG}$ as a technique for the minimization of the function cost of hollow core panel and prestressed joist applications. The analysis takes account of the verifications of the precast elements in the transitory stages as production, transportation and erection. The function cost is evaluated within the Brazilian context. The research compares the results using GAs with those using a conventional method, the Augmented Lagrangian. The results provide evidence the effectiveness of the GAs with relation to a conventional method. The research considers three families of the simple GA, searching to identify, among them, the adjusted variant in the search of the solution of the problems.

Key-words: hollow core panel, prestressed joist, slabs, genetic algorithm, structural optimization, Augmented Lagrangian 


\section{Introdução}

\subsection{PRELIMINARES}

Projetos com soluções otimizadas têm sempre atraído pesquisadores da área de Engenharia Estrutural. Poucos tópicos da análise estrutural têm chamado tanta atenção quanto o da otimização. Atualmente existem inúmeros estudos nesta área, quase sempre com o objetivo de desenvolver melhores métodos para representar de maneira eficiente o problema analisado e buscar sua rápida solução (ótima, quando possível).

Em geral, em um problema de otimização há a necessidade de identificar as variáveis envolvidas e seus limites de variação, bem como as constantes relevantes ao problema, de maneira a poder equacioná-las em relações matemáticas, com o objetivo de representar formalmente o problema e suas restrições para então buscar a sua solução. A solução do problema consiste, basicamente, em encontrar uma solução (a ótima) que identifica um ponto de máximo ou de mínimo de uma função objetivo, sujeita a algumas restrições.

Vários estudos e experimentos têm sido realizados na área de Engenharia Estrutural, utilizando, principalmente, métodos convencionais de otimização (o método Lagrangiano, por exemplo). As pesquisas nesta área, no âmbito mundial, focalizam quase sempre, a minimização do custo das estruturas em geral. Este trabalho investiga, especificamente, a minimização do custo no projeto dos elementos e das estruturas de concreto pré-moldado. Como esta tese trata do uso de uma técnica não convencional para o tratamento do problema de otimização de 
custos, i.e., Algoritmos Genéticos, uma revisão e uma discussão de trabalhos que utilizam essa técnica na área de Engenharia Estrutural são feitas no Capítulo 3.

Com o objetivo de fornecer um contexto inicial da pesquisa, as Tabelas 1-1 e 1-2 identificam alguns trabalhos relevantes realizados em otimização de custos, usando métodos convencionais, nas áreas de concreto armado e concreto prémoldado respectivamente, bem como apresentam suas principais características.

Tabela 1-1. Alguns trabalhos relevantes relacionados à otimização de custos em concreto armado

\begin{tabular}{|c|l|l|}
\cline { 2 - 3 } \multicolumn{1}{c|}{} & \multicolumn{2}{c|}{ Características } \\
\cline { 2 - 3 } \multicolumn{1}{c|}{} & \multicolumn{1}{c|}{ minimiza o custo de: } & \multicolumn{1}{c|}{ variáveis } \\
\hline PRAKASH, AGARWALA \& & vigas de concreto armado & $\bullet$ dimensões das seções da viga \\
\hline SINGER (1988) & $\begin{array}{l}\text { vigas retangulares de } \\
\text { concreto armado }\end{array}$ & $\begin{array}{l}\bullet \text { dimensões das seções da viga } \\
\text { CHAKRA da armadura longitudinal }\end{array}$ \\
\hline $\begin{array}{c}\text { SARMA \& ADELI (1998) e } \\
\text { KOUMOUSIS \& ARSENIS (1998) }\end{array}$ & $\begin{array}{l}\text { material para as estruturas } \\
\text { de concreto armado }\end{array}$ & $\bullet$ dimensões das seções transversais \\
\hline
\end{tabular}

Tabela 1- 2. Alguns trabalhos relevantes relacionados à otimização de custos em concreto pré-moldado

\begin{tabular}{|c|c|c|}
\hline & \multicolumn{2}{|c|}{ Características } \\
\hline & minimiza o custo de: & variáveis \\
\hline $\begin{array}{c}\text { LOUNIS \& COHN (1993) e } \\
\text { COHN et al (1994) }\end{array}$ & $\begin{array}{l}\text { produção e de montagem } \\
\text { para lajes e vigas I } \\
\text { protendidas de ponte }\end{array}$ & $\begin{array}{l}\text { - comprimento e largura do } \\
\text { sistema de ponte } \\
\text { - dimensões das vigas e lajes }\end{array}$ \\
\hline $\begin{array}{c}\text { KOSKISTO \& ELLINGWOOD } \\
\qquad(1997)\end{array}$ & $\begin{array}{l}\text { produção de um painel } \\
\text { alveolar }\end{array}$ & $\begin{array}{l}\text { - } \text { área da armadura de } \\
\text { protensão } \\
\text { - resistência do concreto } \\
\text { - altura do painel }\end{array}$ \\
\hline HASSANAIN \& LOOV (1999) & $\begin{array}{l}\text { produção, de transporte e } \\
\text { de montagem para vigas } \\
\text { protendidas de seção I de } \\
\text { ponte }\end{array}$ & $\begin{array}{l}\text { - força de protensão } \\
\text { - excentricidades dos cabos } \\
\text { - armadura de flexão } \\
\text { - resistência do concreto } \\
\text { - espessura do tablado }\end{array}$ \\
\hline
\end{tabular}


No Brasil a utilização dos métodos convencionais de otimização é bastante difundida na análise estrutural, focalizando principalmente a minimização de custos. Destacam-se, nesta área, vários trabalhos tal como o de MEDRANO (1994) que investiga a otimização do custo de vigas de concreto armado e a análise elastoplástica de sólidos e estruturas e os de ARAÚJO (1980) e de SANABIO (1984) que tratam da otimização estrutural de pórticos planos.

Dentre os trabalhos realizados na Escola de Engenharia de São Carlos no Departamento de Engenharia de Estruturas, destacam-se:

- SOARES (1997) - desenvolve uma formulação para a minimização do custo de uma seção transversal de uma viga e obtém, por meio de um método de aproximações combinadas, o custo mínimo do vigamento de um pavimento. $\mathrm{O}$ problema foi equacionado usando como variáveis a altura da viga e as áreas de aço;

- KRIPKA (1998) - investiga o uso de técnicas de programação matemática para reduzir e uniformizar os esforços em grelhas, em função do posicionamento dos apoios. O problema a ser resolvido se resume na minimização dos somatórios dos momentos fletores sobre os apoios internos, considerando como variáveis as coordenadas dos apoios em relação ao primeiro nó da estrutura;

- RIGO (1999) - investiga o uso de métodos de otimização como ferramentas para a análise do comportamento não-linear de estruturas reticulares tais como vigas, pórticos e treliças espaciais;

- PRUDENTE (1999) - busca a solução de mínimo peso para estruturas de aço treliçadas planas, considerando seções com perfis comerciais.

Apesar do relativo sucesso na utilização dos métodos convencionais de otimização na área de análise estrutural, tais métodos têm algumas limitações. Entre elas, conforme apontado em LEMONGE (1999), GOLDBERG (1989) e GEN \& CHENG (1997):

- dificuldades na identificação de soluções ótimas globais, em geral;

- dificuldades quando o problema envolve variáveis contínuas e discretas;

- não são aplicáveis à otimização multiobjetivos; 
- não são indicados para programação em paralelo;

- têm domínio de aplicação restrito;

- não podem ser aplicados a alguns problemas de otimização estrutural, onde as funções objetivo não são diferenciáveis. Nesses casos é preciso lançar mão de estratégias que não consideram derivadas ao longo do processo de otimização.

Devido principalmente a essas limitações, pesquisas nesta área têm se voltado para a identificação de métodos alternativos mais flexíveis, que possam alcançar os mesmos resultados obtidos pelos métodos convencionais. Os métodos heurísticos, como são denominados, utilizam estratégias mais simples e, geralmente, encontram uma boa solução para diversos problemas de otimização de um modo razoavelmente rápido e eficiente.

Os métodos heurísticos apresentam estratégias adicionais que buscam superar algumas limitações dos métodos convencionais. Dentre os métodos heurísticos mais utilizados estão: Redes Neurais Artificiais (RNA), Simulated Annealing (SA), Tabu Search (TS), GRASP e Computação Evolutiva incluindo Algoritmos Genéticos (AGs), Scatter Search e Programação Genética.

Dentre os inúmeros métodos existentes na literatura, o que se destaca pela eficiência e que é objetivo de pesquisa deste trabalho, é aquele baseado em Algoritmo Genético. A proposta de tal algoritmo foi inspirada no princípio da seleção natural de indivíduos, onde o mais 'apto' tende a sobreviver e se reproduzir, passando seu código genético para a próxima geração.

Vários trabalhos na área de otimização estrutural, principalmente os que envolvem estruturas de aço, vêm sendo desenvolvidos utilizando a técnica de AGs [JENKIS (1997)]. No caso do concreto, geralmente, os problemas de otimização são tratados via técnicas convencionais de programação matemática. Quando comparado ao problema do projeto ótimo de estruturas de aço, o problema do projeto ótimo de estruturas de concreto é mais complexo uma vez que envolve um número maior de variáveis. Quando do projeto ótimo de estruturas de aço, geralmente apenas um material (aço) é considerado e o custo da estrutura é proporcional a seu peso.

A otimização de estruturas de concreto pré-moldadas, bem como a de seus elementos, é de grande interesse principalmente devido à forma como tais elementos 
são produzidos. No caso do elemento pré-moldado, também fazem parte da descrição do problema as etapas transitórias correspondentes à produção, transporte, e montagem, que podem apresentar solicitações mais desfavoráveis que as de estruturas moldadas no local. Essas etapas, de acordo com EL DEBS (2000) e KONCZ (1975) podem ser definidas como:

- Produção - execução de elementos pré-moldados;

- Transporte - translado da área de execução até o local de montagem;

- Montagem - colocação dos elementos no local definitivo e efetuação das ligações.

Para representar o problema de minimização de custos de estruturas de concreto pré-moldado com vistas a obter uma solução mais robusta, os custos de todas essas etapas deverão fazer parte da representação do problema.

Tendo em vista tanto a facilidade de implementação quanto alguns resultados promissores encontrados na literatura, o uso de AG no domínio da Engenharia Estrutural parece ser uma alternativa viável para a solução de problemas de otimização. Embora existam trabalhos que usam tal método, principalmente na produção de estruturas de aço, não se tem ainda conhecimento de trabalho nesta linha relacionado a elementos pré-moldados e a estruturas de concreto pré-moldado.

\subsection{OBJETIVOS}

O principal objetivo deste trabalho de pesquisa é investigar AGs como técnica de otimização no domínio de Engenharia Estrutural, mais especificamente, concreto pré-moldado, focalizando principalmente a facilidade de representação do problema, a adeqüabilidade para a busca de solução, as vantagens e desvantagens, as limitações e o impacto da escolha da representação de dados e dos parâmetros genéticos na solução do problema.

O trabalho investiga o uso de AG na otimização da aplicação de elementos pré-moldados em lajes, focalizando dois elementos: painel alveolar e vigota protendida. 
Um objetivo subjacente ao objetivo principal do trabalho foi o de abordar os problemas listados anteriormente via um método convencional - o método do Lagrangiano Aumentado [MARTÍNEZ (1997), MARTÍNEZ (1998)]. Buscou-se com isso obter resultados que permitissem subsidiar uma análise empírica comparativa entre AGs e um método convencional de otimização.

\subsection{JUSTIFICATIVAS}

Embora possam ser evidenciados na literatura inúmeros trabalhos relacionados à aplicação de métodos convencionais na resolução de problemas de otimização estrutural, optou-se por utilizar métodos heurísticos, especificamente AGs, para resolver os problemas discutidos anteriormente, em virtude da flexibilidade deste método, de sua fácil aplicabilidade e de seus resultados promissores. AGs são métodos de busca que não utilizam cálculos matemáticos complexos, são relativamente fáceis de serem implementados e têm sido usados com relativo sucesso como uma técnica de otimização, em várias áreas de pesquisa. Atualmente há uma grande tendência em utilizar métodos mais flexíveis na solução de problemas complexos nos vários ramos da engenharia.

A inexistência de trabalhos de pesquisa envolvendo o uso de AGs na minimização da função custo em concreto pré-moldado foi também determinante para a escolha desta técnica como método de otimização. No caso de concreto pré-moldado há um grande número de variáveis envolvidas, referentes às etapas transitórias do elemento e, portanto, a utilização de AG se apresenta como uma opção viável para a solução desse tipo de problema.

Os problemas de minimização de custos tratados nesta tese focalizam painéis alveolares e vigotas protendidas devido ao fato que ambos os elementos são correntemente utilizados pelo mercado brasileiro.

Embora a vigota protendida seja um elemento relativamente novo no mercado, sua utilização em estruturas de pavimentos está se tornando cada vez mais difundida. A forma mecanizada de produção desses dois elementos facilitou uma abordagem mais sistemática na determinação dos custos envolvidos.

O trabalho de pesquisa realizado se justifica, também, pela investigação do uso de AGs em Engenharia Estrutural, pois evidencia a potencialidade desta técnica 
versus técnicas convencionais de otimização no domínio em questão e estabelece parâmetros para sua utilização futura em problemas similares.

\subsection{ORGANIZAÇÃO DO TEXTO}

No Capítulo 2 são apresentados e discutidos os principais conceitos relativos a Algoritmos Genéticos, abordados como técnica de otimização, relevantes ao trabalho de pesquisa conduzido. Um exemplo pequeno da utilização do método, num problema de Engenharia Estrutural, de maneira a mostrar a viabilidade do método, bem como a relativa facilidade de sua utilização é apresentado no Anexo A.

No Capítulo 3 são revistos os principais trabalhos de pesquisa envolvendo AGs aplicados à Engenharia Estrutural focalizando, principalmente, parâmetros genéticos adotados e resultados obtidos, de maneira a estabelecer o estado da arte na área. Buscou-se identificar a efetiva contribuição de cada um dos trabalhos revistos para o estabelecimento de AG como uma técnica de otimização.

O Capítulo 4 investiga o uso de AG como método de otimização para a minimização da função custo de painéis alveolares. São analisados dois problemas: a otimização do elemento sem capa estrutural e a otimização do elemento com capa estrutural. São propostos 22 AGs variantes, cujas descrições em pseudo-código fazem parte do Anexo B. Os critérios para a definição de cada um desses variantes foram as diferentes combinações de estratégia de seleção, esquema de reprodução e restauração da população ao seu número original. Os experimentos descritos buscam identificar o AG variante com o melhor desempenho (menor custo). São também descritos os resultados de experimentos para diferentes tamanhos de população, estratégias de cruzamento e valores do parâmetro $\lambda$ (operador aritmético). A representação de dados utilizada é a real. Resultados obtidos em ambos os problemas usando o método de otimização do Lagrangiano Aumentado são também apresentados para subsidiar a análise comparativa entre AG e um método convencional.

O Capítulo 5 investiga o uso de AG como método de otimização para a minimização da função custo de vigotas protendidas. São analisados três problemas: a otimização do elemento, a otimização da aplicação e a otimização do elemento e da aplicação. Devido aos resultados descritos no Capítulo 4, dentre os 22 AGs variantes 
foram escolhidos dois para a condução dos experimentos de minimização da função custo. São investigados a alteração dinâmica do operador de cruzamento, diferentes tamanhos de cromossomos e o uso de variáveis discretas. A representação de dados utilizada é a binária. Resultados obtidos para a solução dos três problemas usando o método de otimização do Lagrangiano Aumentado são também apresentados para subsidiar a análise comparativa entre $\mathrm{AG}$ e um método convencional.

No Capítulo 6 são apresentadas as conclusões obtidas das análises realizadas em todos experimentos e são evidenciadas as contribuições dos resultados obtidos para o direcionamento de pesquisas futuras, que envolvam a busca de solução para problemas similares, na área de Engenharia Estrutural. 


\section{Fundamentos de Algoritmos Genéticos}

\subsection{PRELIMINARES}

Algoritmo Genético (AG) é um método de otimização e busca que faz uso de conceitos da Genética e é baseado nos mecanismos de evolução de populações de seres vivos. Foi inspirado no princípio da seleção natural e sobrevivência do mais apto estabelecido por Charles Darwin em seu livro The Origin of Species em 1859. De acordo com esse princípio, em uma população de indivíduos aqueles com "boas" características genéticas apresentam maiores chances de sobrevivência e reprodução, enquanto indivíduos menos "aptos" tendem a desaparecer durante o processo evolutivo.

O AG realiza uma simulação de evolução biológica por meio de uma busca multidirecional no espaço de soluções potenciais do problema. Geralmente mantém constante um número de soluções potenciais (população) e, a cada geração, a população é modificada de maneira que as soluções "boas" possam se "reproduzir" e passar à geração seguinte e as "ruins" possam ser descartadas. O AG geralmente usa regras de transição probabilística para selecionar algumas soluções para a reprodução e outras para serem descartadas. Os princípios básicos de AGs foram rigorosamente estabelecidos em HOLLAND (1975) e podem ser encontrados em muitas referências 
bibliográficas (ver, por exemplo, GOLDBERG (1989), MICHALEWICZ (1996), COLEY (1999) e GEN \& CHEN (1997)).

Normalmente em um AG cada indivíduo da população, denominado cromossomo, corresponde a um ponto do espaço de busca e representa uma possível solução do problema - solução essa também chamada de hipótese. Com o mecanismo de reprodução aplicado sobre os indivíduos da população atual, o AG pode explorar o espaço de possíveis soluções, na tentativa de encontrar aquelas que são as "melhores". A "melhor" solução/hipótese geralmente é definida como aquela que otimiza um valor numérico predefinido para o problema em questão, que é chamado de 'adequabilidade da hipótese/solução'. De acordo com MITCHELL (1997), a popularidade de AGs se deve, entre outros, ao fato:

- de a evolução ser um método de adaptação reconhecidamente bem sucedido e robusto em sistemas biológicos;

- de poderem realizar buscas em espaços com hipóteses (soluções candidatas) contendo partes complexas que interagem entre si e onde o impacto de cada parte no desempenho da hipótese como um todo é de difícil modelagem;

- de serem facilmente indicados para programação em paralelo.

Além disso, como apontado em BEASLEY et al (1993a) "o poder de AGs vem do fato que a técnica é robusta e pode lidar com sucesso com um vasto número de áreas de problemas, incluindo aquelas consideradas difíceis para outros métodos resolverem. Não é garantido que AGs encontram a solução global do sistema mas eles geralmente são bons em encontrar soluções do problema que são 'aceitavelmente boas', de uma maneira 'aceitavelmente rápida' ".

Segundo GOLDBERG (1989) os AGs diferem dos métodos convencionais de busca e otimização em quatro aspectos:

- trabalham com uma codificação do conjunto de parâmetros e não com os próprios parâmetros;

- trabalham com uma população de soluções candidatas simultaneamente e não com uma única solução; 
- utilizam informações de custo ou recompensa e não derivadas de funções;

- utilizam regras de transição probabilísticas e não determinísticas.

Os AGs são muito eficientes na busca de soluções ótimas ou aproximadamente ótimas em uma grande diversidade de problemas, pois não impõem limitações que são encontradas, na maioria das vezes, nos métodos convencionais de busca. De uma maneira simplificada um AG típico consiste de (COLEY (1999)):

- um número ou população de soluções potenciais do problema;

- uma maneira de calcular quão 'boa' ou 'ruim' é cada uma das soluções individuais em uma população;

- um método para compor partes das melhores soluções, de maneira que novas possam ser formadas;

- um operador de mutação para evitar a perda permanente da diversidade na população.

Essas características articuladas como um procedimento podem ser reescritas como o pseudo-código mostrado na Figura 2-1.

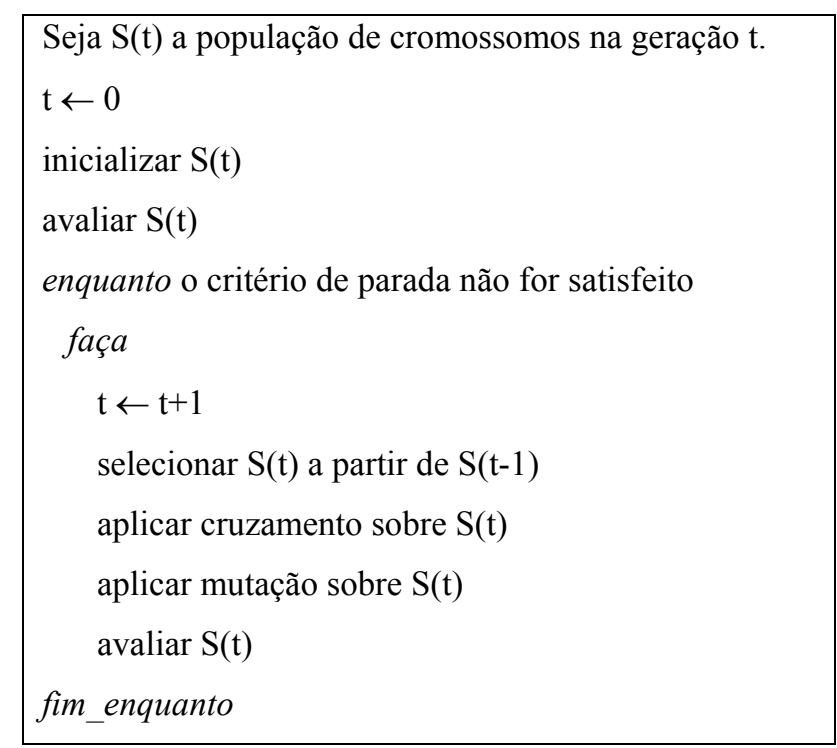

Figura 2-1. Algoritmo Genético Típico [LACERDA (1999)]

Ao invés de começar a partir de um único ponto (ou solução potencial) no espaço de busca, um AG é inicializado com uma população de soluções potenciais. 
Essas soluções potenciais são geralmente geradas randomicamente e representam pontos espalhados do espaço de busca. Existem, entretanto, outras possibilidades para a inicialização. Uma delas, como sugerida em BRAMLETTE (1991) é a de realizar uma série de inicializações para cada indivíduo e escolher as com melhor desempenho. Alternativamente, como sugere COLEY (1999), estimativas podem ser feitas por outros métodos numa tentativa de localizar soluções aproximadas e, então, o AG pode começar a busca a partir de tais soluções. Obviamente, se existir uma heurística disponível para a produção de boas soluções em um determinado domínio, ela pode ser usada para gerar a população inicial de soluções.

Um típico AG então usa três operadores, o de seleção, o de cruzamento e o de mutação para conduzir a população (por meio de várias gerações) na direção da convergência para o ponto ótimo global.

“O processo de seleção tenta aplicar 'pressão' sobre a população de maneira semelhante àquela exercida pela seleção natural em sistemas biológicos. Indivíduos cujo desempenho é baixo são descartados e indivíduos que têm um melhor desempenho têm uma chance maior que a chance média de passar a informação que eles contém, para a próxima geração. Cruzamento permite que soluções troquem informações de maneira semelhante àquela usada por organismos naturais via reprodução sexual. Mutação é usada para trocar, randomicamente, o valor de um único ponto, parte da configuração de um individuo.”(COLEY (1999))

Após a aplicação da seleção, cruzamento e mutação, uma nova população é formada. O processo se repete até que um determinado número de gerações tenha sido criado ou, então, que algum outro critério de parada tenha sido atingido.

Existem muitas decisões a serem tomadas antes de efetivamente usar um AG para tentar solucionar um determinado problema. Dentre as listadas em MICHALEWICZ (1996) e COLEY (1999) estão:

- a escolha da representação mais adequada para as soluções potenciais;

- o estabelecimento do critério para a criação da população inicial de soluções;

- a definição da função de avaliação que desempenha o papel do ambiente,

- a definição dos operadores genéticos a serem usados e, eventualmente, a sua customização ao problema; 
- a atribuição de valores para os vários parâmetros que o AG usa (tamanho de população, probabilidades de aplicação de operadores genéticos, etc.).

Existem vantagens na utilização de AGs. Em LEMONGE (1999) são citadas várias e, dentre elas, as de que:

- otimizam um número grande de variáveis;

- realizam buscas simultâneas em várias regiões do espaço de busca;

- são fáceis de serem implementados em computadores;

- fornecem uma lista de parâmetros ótimos e não uma única solução;

- são flexíveis para trabalhar com restrições e otimizar múltiplas funções com objetivos conflitantes;

- são facilmente hibridizados com outras técnicas heurísticas;

- não é necessário conhecimento matemático aprofundado do problema considerado.

Apesar das inúmeras vantagens não pode ser esquecido, parafraseando COLEY (1999), que muitas publicações e trabalhos de pesquisa sobre AGs discutem as vantagens de uma representação sobre outra ou então apresentam diretrizes para a escolha do tamanho da população para um determinado problema. Artigos analisam também a diferença em desempenho entre os vários mecanismos de cruzamento ou discutem e apresentam justificativas para o percentual de mutação ser alto ou baixo. Muitas dessas publicações descrevem experimentos computacionais de otimização de funções relativamente simples e, freqüentemente, não fica claro como o resultado obtido pode ser visto num contexto mais amplo. Na realidade, a única forma de proceder para a solução de um problema usando AG, é avaliar resultados obtidos na solução de problemas similares e, então, escolher uma abordagem que seja sensível ao problema em questão e que também seja viável de ser implementada.

\subsection{TERMINOLOGIA}

Um AG pode ser entendido como uma tentativa de metáfora da Evolução Darwiniana, que incorpora conceitos da Genética. Isto explica a razão dos AGs 
possuírem muitos termos originados da Biologia. Os principais termos encontrados na literatura e de relevância para este trabalho são:

- Gene: é uma informação do cromossomo; representa uma certa característica da solução-cromossomo;

- Indivíduo ou Cromossomo: um elemento da população. Um indivíduo é formado pelo cromossomo e sua função aptidão - representa uma possível solução do problema;

- População: conjunto de indivíduos (cromossomos) que representam os atuais pontos que fazem parte do espaço de soluções;

- Geração: identifica cada uma das várias populações criadas durante o processo evolutivo;

- Função Aptidão: função que 'mede' a adequabilidade de um cromossomo. Geralmente usada no mecanismo de seleção, para identificar quais indivíduos irão 'sobreviver' e recombinar. Está ligada ao valor da função objetivo (ver Seção 2.4) e pode incluir uma função penalidade.

\subsection{REPRESENTAÇÃO}

Como comentado no Capítulo 1, a representação de um problema visando a sua solução consiste, inicialmente, na identificação das variáveis e seus limites, suas constantes e na definição da função matemática que as combinam. Quando a técnica utilizada é AG, o processo é similar. Pode ser evidenciado na literatura que a representação adotada para o cromossomo é fundamental para a solução do problema e tem um impacto direto no desempenho do algoritmo.

"A escolha de uma representação apropriada para as soluções candidatas de um problema é a base para o uso de AG na resolução de problemas do mundo real e o que condiciona todos os passos subseqüentes do algoritmo. Para qualquer aplicação é necessário realizar uma análise cuidadosa para garantir uma representação adequada de soluções, bem como uma escolha de operadores genéticos específicos ao problema, que seja significativa" (GEN \& CHENG (1997)).

A representação de uma variável pode ser feita utilizando diferentes abordagens, destacando-se entre elas, a codificação binária e a real ou, então, 
representações que são típicas de um determinado problema e que tentam refletir, de alguma forma, a estrutura natural dos dados do problema. Geralmente a representação binária é utilizada para a representação de problemas com variáveis discretas e a representação real para problemas com variáveis contínuas.

\subsubsection{Representação Binária}

Os trabalhos iniciais realizados com AG usavam como codificação do cromossomo, a representação binária. Neste tipo de representação, os valores de variáveis são codificados como cadeias de caracteres binários ( 0 e 1). O tamanho da cadeira está diretamente ligado aos limites de valores que essas variáveis podem assumir.

No caso de uma variável contínua a determinação do número de bits $(\mathrm{m})$ para representar seus possíveis valores depende do limite inferior $(b)$ e superior $(c)$ do intervalo de valores que essa variável vai assumir, no domínio do problema, bem como da precisão que a solução vai requerer, dada pelo parâmetro $k$. Isso é feito determinando o número inteiro $m$ que satisfaz a equação (2.1).

$$
2^{\mathrm{m}-1} \leq(\mathrm{c}-\mathrm{b}) 10^{\mathrm{k}} \leq 2^{\mathrm{m}}-1
$$

Para ilustrar a codificação binária com variáveis contínuas, suponha um problema que envolva três variáveis $\mathrm{x}_{1}, \mathrm{x}_{2}$ e $\mathrm{x}_{3}$, cada uma delas com valores no intervalo $[-1,02,0]$ e que o problema exija precisão 2 . Usando a fórmula (1), o valor encontrado para m é 9 e, portanto, cada uma das variáveis será representada no cromossomo por uma cadeia de 9 bits. Suponha que uma possível solução inicial, gerada randomicamente, seja:

$$
\mathrm{s}_{1}=100001011101110101000111110
$$

onde podem ser identificados os seguintes valores para cada uma das variáveis:

$$
\begin{aligned}
& \mathrm{x}_{1}=100001011 \\
& \mathrm{x}_{2}=101110101 \\
& \mathrm{x}_{3}=000111110
\end{aligned}
$$


Quando do término do algoritmo genético, a solução está codificada em binário. A decodificação do valor binário de uma variável para o correspondente valor decimal, num intervalo [b,c], é dada pela equação (2.2).

$$
\mathrm{x}=\mathrm{b}+(\mathrm{c}-\mathrm{b}) \frac{\mathrm{b}_{10}}{2^{\mathrm{m}}-1}
$$

onde $\quad b_{10}-$ número decimal correspondente à cadeia de bits $\mathrm{m}$ - tamanho da cadeia de bits

A título de ilustração, como o intervalo de variação da variável $\mathrm{x}_{1}$ do exemplo considerado é $\left[\begin{array}{ll}-1,0 & 2,0\end{array}\right]$ o seu correspondente valor decimal, de acordo com (2.2) é:

$$
x_{1}=-1+(2+1) \frac{267}{\left(2^{9}-1\right)}=0,57
$$

De maneira análoga podem ser obtidos os valores decimais associados às variáveis $\mathrm{x}_{2}$ e $\mathrm{x}_{3}$. Portanto o cromossomo $\mathrm{s}_{1}$ 'traduzido' para a representação decimal é:

$$
\mathrm{s}_{1}=0,57 \quad 1,19-0,64
$$

É importante notar, entretanto, que a representação de números reais em forma binária tem limitações, com relação à precisão.

Suponha, por exemplo, uma variável real x, cujos possíveis valores estão compreendidos no intervalo real [2,2 3,9] que seja representada pela cadeia binária de cinco dígitos 10101 (note que $\left.(10101)_{2}=(21)_{10}\right)$. A decodificação final, em decimal, do valor binário relativo a x, é dada pela equação (2). Portanto, $\mathrm{x}=3,3516$. Note que o próximo número binário maior que 10101 é o $10110\left((10110)_{2}=(22)_{10}\right)$. Uma variável real com valores no intervalo [2,2 3,9] que fosse representada pela cadeia $(10110)_{2}$ seria decodificada, usando (2), como o número real 3,4065. Como pode ser observado neste exemplo, o uso da representação binária com 5 dígitos faz com que qualquer número real entre 3,3516 e 3,4065 não tenha representação. Uma 
solução para este problema é aumentar os números de bits que representa a variável. (COLEY 1999).

Quando se trata de uma variável discreta, o conjunto de valores que ela assume pode ser representado como uma lista. Por exemplo, a variável área de aço comercial pode ser representada pela lista $[1,2 ; 1,4 ; 1,6 ; 1,8 ; 2,0 ; 2,2 ; 2,4 ; 2,6 ; 2,8$; $3,0 ; 3,2 ; 3,4 ; 3,6 ; 3,8 ; 4,0 ; 4,4]\left(\mathrm{cm}^{2}\right)$. A variável em questão pode assumir qualquer dos 16 valores e, conseqüentemente, bastam 4 bits para representá-la, como pode ser verificado pela equação (2.3).

$$
\begin{array}{ll}
2^{\mathrm{nb}}=\mathrm{nv} & \\
\text { onde } \quad \mathrm{nb}-\text { número de bits } \\
\mathrm{nv}-\text { número de possíveis valores assumidos }
\end{array}
$$

Considere um problema que envolva a variável discreta área de aço comercial. Quando da geração aleatória da população inicial, suponha, por exemplo, que a variável seja representada pela cadeia de bits 0111. O valor da variável associado à essa representação binária é 2,6 , uma vez que o $7^{0}+1$ elemento $\left((0111)_{2}=\right.$ (7) ${ }_{10}$ ) da lista associada à área de aço comercial é 2,6. É importante lembrar que nesta convenção, o primeiro elemento da lista de valores associados à uma variável discreta ocupa a posição zero (RAJEV \& KRISHNAMOORTHY (1992)). Se o número de valores associados à variável discreta não for da forma $2^{\text {nb }}$, umas das abordagens sugeridas em WU \& CHOW (1995a) é a de usar uma estratégia de penalidade. Uma outra sugestão é a de utilizar o método de distribuição excessiva, proposto em LIN \& HAJELA (1992).

\subsubsection{Representação Real}

A representação de um cromossomo utilizando números reais é mais facilmente entendida pelo ser humano do que aquela usando uma cadeia de bits. Além disso, a representação usando números reais requer menos memória. Outra vantagem da representação real é a sua versatilidade quando da criação de novos operadores e variações dos operadores existentes (ver Seção 2.6). 
Para a codificação real de um problema que envolva três variáveis, um cromossomo, por exemplo, pode ser expresso por $(-0,8562 \quad 1,5667$ 0,9548).

\subsection{FUNÇÃO APTIDÃO}

A aptidão é um valor que expressa quão boa é a solução codificada por um cromossomo. Os cromossomos que têm melhores valores de aptidão terão maiores chances de passarem à geração seguinte (via cruzamento ou elitismo). Cada cromossomo tem um valor de aptidão a ele associado que, para um problema de otimização estrutural, é dado pela equação (2.4).

$$
F(x)=f(x)+\operatorname{pen}(x)
$$

onde $\mathrm{F}(\mathrm{x})$ - função aptidão

$$
\begin{aligned}
& f(x) \text { - função objetivo } \\
& \text { pen }(x) \text { - função penalidade }
\end{aligned}
$$

Quando o problema tratado não possuir nenhuma violação às restrições, o valor da função aptidão é o próprio valor da função objetivo, dado que o valor do termo penalidade será zero. Funções penalidade serão abordadas com mais detalhes na Seção 2.10. Uma das dificuldades na utilização dos AGs está na definição da função penalidade que representa as restrições particulares de cada problema.

\subsection{SELEÇÃO}

Inspirado no processo de seleção natural de seres vivos, o algoritmo genético via operador de seleção, escolhe os melhores cromossomos da população para determinar quais indivíduos podem participar da fase de reprodução e contribuir na formação da geração seguinte. O processo de reprodução se dá através de um operador genético denominado cruzamento. As principais formas de selecionar indivíduos da população para a reprodução são: seleção rank, seleção da roleta e seleção por torneio. 
- seleção rank: os cromossomos são classificados por valor de aptidão. Os melhores cromossomos possuem as melhores posições e, conseqüentemente, maiores chances de reprodução. Conforme apresentado por BENNETT (1997) é associado à posição 0 o elemento com o melhor valor da função aptidão e à posição $\mathrm{N}_{\text {pop }}-1$ o elemento com o pior valor da função aptidão. Portanto, um indivíduo $\alpha$ com posição $r_{\alpha}$ no rank é selecionado com probabilidade $p_{\alpha}$ dada pela equação (2.5).

$$
\mathrm{p}_{\alpha}=\frac{2 \mathrm{r}_{\alpha}}{\mathrm{N}_{\mathrm{pop}}\left(\mathrm{N}_{\mathrm{pop}}-1\right)}
$$

- $\quad$ seleção da roleta: nesta abordagem a probabilidade de seleção é proporcional à aptidão do indivíduo. A analogia com uma roleta é lembrada porque pode se imaginar os indivíduos da população dispostos como uma roleta, onde a cada indivíduo é alocado uma seção da roleta que é proporcional à sua aptidão (Figura 2-2). Portanto, a probabilidade de seleção $p_{i}$ de um cromossomo com aptidão $F_{i}$, em uma população de tamanho $\mathrm{N}_{\text {pop }}$ é dada pela equação (2.6).

$$
p_{i}=\frac{F_{i}}{\sum_{i=1}^{N \text { pop }} F_{i}}
$$

A partir de $\mathrm{p}_{\mathrm{i}}$, calcula-se a probabilidade acumulada $\left(\mathrm{q}_{\mathrm{i}}\right)$ de cada cromossomo, de acordo com a equação (2.7).

$$
\mathrm{q}_{\mathrm{i}}=\sum_{\mathrm{j}=1}^{\mathrm{i}} \mathrm{p}_{\mathrm{j}}
$$

Durante o processo de seleção a roleta é girada $\mathrm{N}_{\text {pop }}$ vezes, elegendo indivíduos para a reprodução. Indivíduos com maiores valores de probabilidade de seleção possuem maiores chances de serem escolhidos. Em alguns casos, esse esquema de seleção pode gerar problemas de convergência prematura, quando a função de avaliação atribui valores altos a um indivíduo, levando este indivíduo a monopolizar toda a geração.

Girar a roleta é equivalente a gerar aleatoriamente um número $r \in[0,1]$. Se $r \leq \mathrm{q}_{1}$ então o primeiro cromossomo é selecionado, caso contrário é selecionado o i-ésimo cromossomo $s_{i}$ tal que $q_{i-1}<r<q_{i}$. A Tabela 2-1 e a correspondente 
Figura 2-2 mostram um exemplo de utilização dessa técnica. Para os valores de $\mathrm{r}$ mostrados na Tabela 2-1 a nova população é $(2,4,2,1)$.

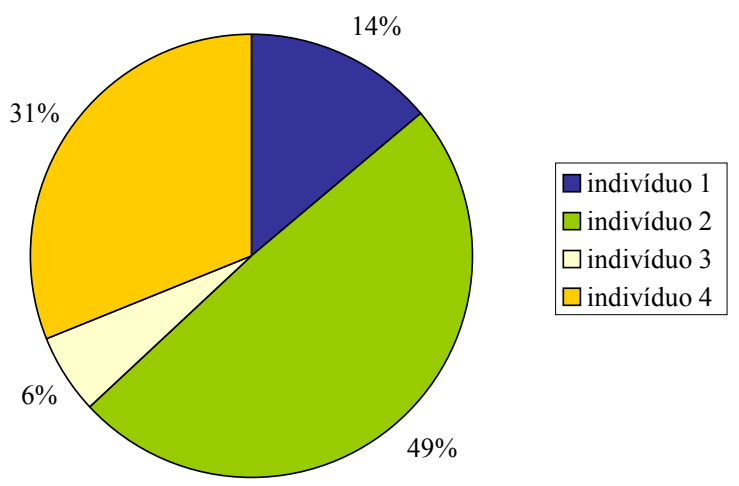

Figura 2-2. Roleta

Tabela 2-1. Seleção Roleta

\begin{tabular}{|c|c|c|}
\hline População & $\mathbf{f ( x )}$ & $\mathbf{p}_{\mathbf{i}}$ \\
\hline \hline 1 & 169 & 0,14 \\
\hline 2 & 576 & 0,49 \\
\hline 3 & 64 & 0,06 \\
\hline 4 & 361 & 0,31 \\
\hline & $\Sigma \mathrm{f}(\mathrm{x})=1170$ & \\
\hline
\end{tabular}

$\Rightarrow$\begin{tabular}{|c|c|c|}
\hline $\mathbf{q}_{\mathbf{i}}$ & $\mathbf{r}$ & $\begin{array}{c}\text { Nova } \\
\text { População }\end{array}$ \\
\hline \hline 0,14 & 0,30 & 2 \\
\hline 0,63 & 0,88 & 4 \\
\hline 0,69 & 0,35 & 2 \\
\hline 1,00 & 0,11 & 1 \\
\hline & & \\
\hline
\end{tabular}

- seleção por torneio: São escolhidos aleatoriamente (com probabilidades iguais) $n$ cromossomos da população (geralmente 2) e dentre eles o cromossomo com melhor aptidão é selecionado. $\mathrm{O}$ processo se repete até que toda a população esteja completa. Em outra variação, pares de indivíduos da população são selecionados randomicamente. Então, um número randômico $\mathrm{R}^{+}$(no intervalo [0 1]) é gerado. Se $\mathrm{R}^{+}>\mathrm{r}, 0,5<\mathrm{r} \leq 1$, o mais apto dentre os dois cromossomos é selecionado; caso contrário, o menos apto. $\mathrm{O}$ valor de $\mathrm{r}$ é dependente do problema e é estabelecido com base na ênfase que se quer dar, para que a escolha favoreça o menos apto. O processo se repete até que toda a população esteja completa.

É importante ressaltar que uma seleção baseada em aptidão não garante a seleção de qualquer indivíduo em particular, mesmo daquele que é o mais apto. 
Como comentado em COLEY (1999), "A menos que o indivíduo mais apto seja muito, mas muito mais apto do que qualquer outro, ocasionalmente ele não será selecionado. Não ser selecionado, é 'morrer'. Assim, com uma seleção baseada em aptidão, a melhor solução do problema descoberta até um determinado momento, pode ser descartada. Embora isto pareça contra-produtivo, pode ser vantajoso em alguns problemas, porque permite explorar mais o espaço de busca, antes da convergência. Este balanço entre explotação (exploration) do espaço de busca e explotação (exploitation) das descobertas é um tema recorrente de pesquisa em AG. Em muitas aplicações a velocidade de busca pode ser melhorada consideravelmente quando o melhor indivíduo de uma geração (elite) é passado para a seguinte, com a garantia que ele não se modifique via cruzamento ou mutação, num processo conhecido como elitismo."

\subsection{OPERADORES GENÉTICOS}

Os operadores genéticos aplicados à cromossomos da população têm o intuito de reproduzir novos indivíduos a partir de indivíduos já existentes; são necessários para que a população mantenha sua diversidade, ie, permitir que o algoritmo explore outras regiões do espaço de busca. Os principais operadores são cruzamento (crossover) e mutação.

\subsubsection{Cruzamento}

O cruzamento é o operador responsável pela recombinação de características dos pais durante a reprodução, permitindo que os filhos herdem essas características. É considerado o operador genético predominante e ocorre com uma probabilidade definida pela taxa de cruzamento $\mathrm{p}_{\mathrm{c}}\left(0,6 \leq \mathrm{p}_{\mathrm{c}} \leq 1,0\right)$. Uma taxa alta permite uma explotação maior do espaço de solução e reduz as chances de convergência para um ótimo local. Entretanto, se essa taxa for muito alta pode resultar na perda de tempo computacional devido à explotação de regiões não promissoras dentro do espaço de soluções. A seguir são apresentados os principais tipos de cruzamento abordados considerando cada uma das representações apresentadas anteriormente (Seções 2.3.1 e 2.3.2). 
- Representação binária:

a) um-ponto: um ponto de cruzamento é escolhido e a partir deste ponto as informações genéticas dos pais são trocadas. As informações anteriores a este ponto em um dos pais são concatenadas às informações posteriores à este ponto no outro pai, conforme mostra a Figura 2-3.

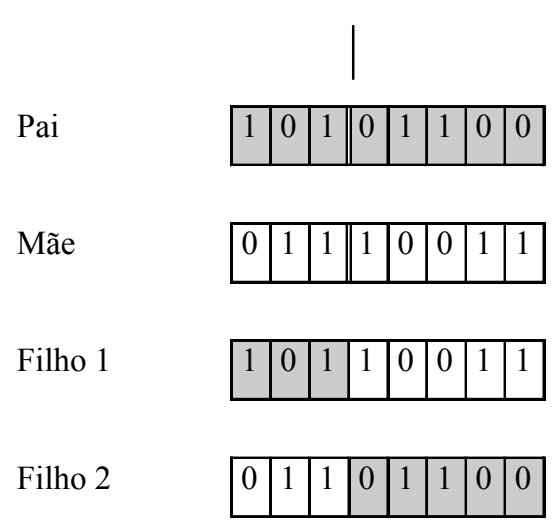

Figura 2-3. Cruzamento um-ponto

b) multipontos: troca de material genético usando mais de um ponto, como ilustra a Figura 2-4.

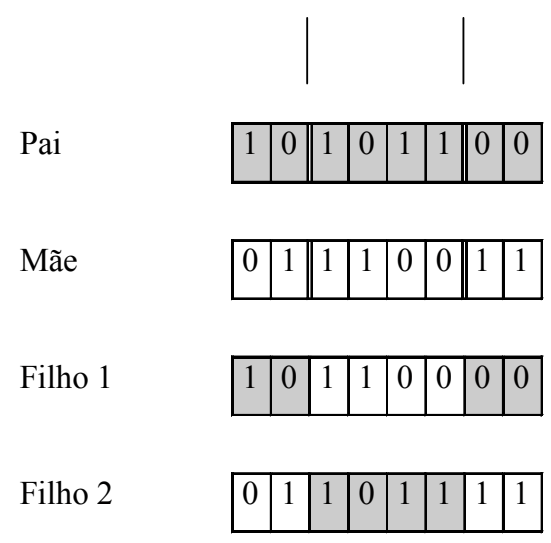

Figura 2-4. Cruzamento dois pontos

c) uniforme: não utiliza pontos de cruzamento mas determina, através de uma máscara de bits aleatórios, quais genes de cada pai serão herdados por cada um dos filhos. Se o primeiro bit da máscara for 1, o primeiro bit do pai é copiado para o primeiro bit do filho1; caso contrário, o primeiro bit da mãe é copiado para o primeiro bit do filho1. O processo se repete para todos os bits. Na geração do 
segundo filho o papel dos pais é invertido; se o bit da máscara for 1, então será copiado o bit da mãe; se o bit for 0 será copiado o bit do pai. O cruzamento uniforme está ilustrado na Figura 2-5.

$$
\begin{aligned}
& \begin{array}{ll|l|l|l|l|l|l|l|}
\text { Máscara } & \mathbf{1} & \mathbf{1} & 0 & 0 & \mathbf{1} & 0 & 0 & \mathbf{1} \\
\hline
\end{array} \\
& \text { Pai } \begin{array}{l|l|l|l|l|l|l|l|}
\hline 1 & 0 & 1 & 0 & 1 & 1 & 0 & 0 \\
\hline
\end{array} \\
& \begin{array}{ll|l|l|l|l|l|l|l|}
\text { Mãe } & 0 & 1 & 1 & 1 & 0 & 0 & 1 & 1 \\
\hline
\end{array} \\
& \begin{array}{ll|l|l|l|l|l|l|l|}
\text { Filho1 } & 1 & 0 & 1 & 1 & 1 & 0 & 1 & 0 \\
\cline { 2 - 7 }
\end{array} \\
& \text { Filho2 } \begin{array}{|l|l|l|l|l|l|l|l|}
\hline 0 & 1 & 1 & 0 & 0 & 1 & 0 & 1 \\
\hline
\end{array}
\end{aligned}
$$

Figura 2-5. Cruzamento uniforme

d) variável-a-variável: uma técnica de cruzamento proposta em HASANCEBI \& ERBATUR (1998) cujas justificativas são convincentes e os resultados são bastante promissores. Neste tipo de cruzamento os pares de indivíduos que serão cruzados, são decompostos nas substrings que representam cada uma das variáveis que equacionam o problema e estão representadas no cromossomo. Posteriormente define-se aleatoriamente um ponto de cruzamento próprio de cada substring e executa-se o cruzamento de um-ponto para cada variável (substring), como mostra a Figura 2-6. O fato da representação binária de cada variável envolvida ter seu próprio ponto de cruzamento confina a troca de informação dentro do escopo de cada uma das variáveis.

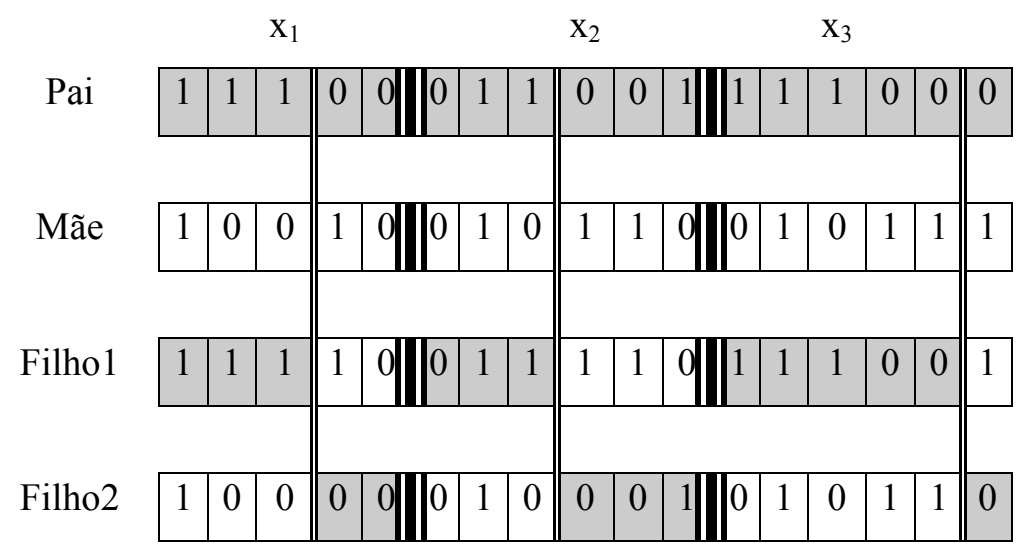

Figura 2-6. Técnica de cruzamento variável-a-variável 
- Representação real:

$\mathrm{Na}$ literatura existem diversas propostas de cruzamento usando representação real. As principais são apresentadas a seguir.

Considerando que os cromossomos pai, mãe e filhos, sejam notados respectivamente por:

$$
\begin{aligned}
& \text { pai }=\left(p_{1}, p_{2}, \ldots . ., p_{n}\right) \\
& \text { mãe }=\left(m_{1}, m_{2}, \ldots . ., m_{n}\right) \\
& \text { filho1 }=\left(a_{1}, a_{2}, \ldots . ., a_{n}\right) \\
& \text { filho2 }=\left(b_{1}, b_{2}, \ldots . ., b_{n}\right)
\end{aligned}
$$

Os dois filhos de $p_{i}$ e $m_{i}$, são calculados como:

$$
\begin{aligned}
& \mathrm{a}_{\mathrm{i}}=\lambda_{1} \mathrm{~m}_{\mathrm{i}}+\lambda_{2} \mathrm{p}_{\mathrm{i}} \\
& \begin{array}{l}
\mathrm{b}_{\mathrm{i}}=\lambda_{1} \mathrm{p}_{\mathrm{i}}+\lambda_{2} \mathrm{~m}_{\mathrm{i}} \\
\text { onde } \quad \lambda_{1}+\lambda_{2}=1 ; \\
\lambda_{1}>0 \text { e } \lambda_{2}>0 \\
1 \leq \mathrm{i} \leq \mathrm{n}
\end{array}
\end{aligned}
$$

Dependendo dos valores de $\lambda_{1}$ e $\lambda_{2}$ alguns cruzamentos recebem nomes especiais, como mostra a Tabela 2-2.

Tabela 2-2. Valores de $\lambda$ para diversos tipos de cruzamento [GEN \& CHENG (1997)]

\begin{tabular}{|c||c||c|}
\hline Cruzamento & $\lambda_{1}$ & $\lambda_{2}$ \\
\hline \hline média & 0,5 & 0,5 \\
\hline affine & 1,5 & $-0,5$ \\
\hline linear $-\lambda_{1}+\lambda_{2} \leq 2$ & $>0$ & $>0$ \\
\hline
\end{tabular}

Uma variação do cruzamento média é a média geométrica, dada pela equação (2.8). Este cruzamento gera apenas um filho.

$$
\mathrm{a}_{\mathrm{i}}=\sqrt{\mathrm{m}_{\mathrm{i}} \mathrm{p}_{\mathrm{i}}}
$$


Outra opção é proposta em MICHALEWICZ (1996), onde os filhos são obtidos pelas equações (2.9).

$$
\begin{aligned}
& \mathrm{a}_{\mathrm{i}}=\beta \mathrm{m}_{\mathrm{i}}+(1-\beta) \mathrm{p}_{\mathrm{i}} \\
& \mathrm{b}_{\mathrm{i}}=(\beta-1) \mathrm{m}_{\mathrm{i}}+\beta \mathrm{p}_{\mathrm{i}}
\end{aligned}
$$

onde $\beta$ é um número aleatório escolhido de uma distribuição uniforme no intervalo $[0,1]$.

Pode-se também utilizar um operador de cruzamento mais simples denominado na literatura de crossover uniforme. A partir desse cruzamento é gerado apenas um filho cujas componentes são escolhidas aleatórias (uniforme) no intervalo $\left[\mathrm{p}_{\mathrm{i}}, \mathrm{m}_{\mathrm{i}}\right]: \mathrm{p}_{\mathrm{i}}<\mathrm{a}_{\mathrm{i}}<\mathrm{m}_{\mathrm{i}}$.

Outro cruzamento utilizado na literatura é o cruzamento simples. Esse pode ser considerado como o crossover de um ponto da representação real, realizando a troca de informação entre cromossomos (pai e mãe) a partir de um ponto escolhido.

\subsubsection{Mutação}

A utilização do operador de mutação tem como objetivo a introdução e manutenção da diversidade genética da população. Desta forma, a mutação assegura que a probabilidade de examinar qualquer ponto do espaço de busca nunca será zero, e também contorna o problema de mínimos locais. O operador de mutação é aplicado aos indivíduos com uma probabilidade dada pela taxa de mutação $\mathrm{p}_{\mathrm{m}}$ $\left(0,001 \leq p_{m} \leq 0,1\right)$. Na maioria das vezes a mutação é aplicada após a operação de cruzamento. Se $\mathrm{p}_{\mathrm{m}}$ for muita baixa pode acontecer um comprometimento da diversidade na população. Se $\mathrm{p}_{\mathrm{m}}$ for muito alta, acontecerão muitas perturbações aleatórias e os filhos provavelmente começarão a perder suas semelhanças com os pais podendo comprometer a convergência.

Geralmente em AGs o operador de mutação é tratado apenas como um operador secundário com o papel de recuperar a perda de material genético. A seguinte situação, descrita em SRINIVAS \& PATNAIK (1994) exemplifica esse uso. Suponha que em uma determinada geração todos os cromossomos da população tenham, em uma determinada posição, o dígito 0 e suponha que a solução ótima 
tenha o dígito 1 naquela mesma posição. O operador de cruzamento não pode regenerar o 1 naquela posição enquanto que com o operador de mutação existe a chance de tal bit passar a ser 1 .

- Representação binária:

$\mathrm{Na}$ representação binária, altera-se arbitrariamente um ou mais genes de um indivíduo, como ilustrado pela Figura 2-7.

indivíduo

indivíduo mutado
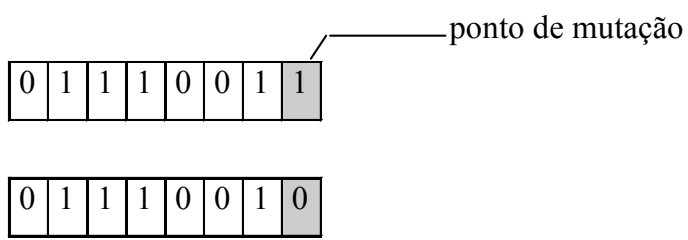

Figura 2-7. Exemplo de mutação

\section{- Representação real:}

Assim como para operadores de cruzamento, existem vários operadores de mutação na codificação real. Os principais são a mutação randômica e a mutação creep.

- mutação randômica: também chamada de mutação aleatória, é a simples substituição de um gene por um número escolhido aleatoriamente no intervalo permitido pelo problema;

- mutação creep: adiciona a um valor de variável um pequeno número aleatório obtido de uma distribuição normal ou uniforme. Alternativamente, a mutação creep pode ser realizada multiplicando o gene por um número aleatório próximo de 1 . A idéia por trás deste operador é a seguinte: se o cromossomo está perto do ponto máximo, uma pequena perturbação pode movê-lo rapidamente para esse ponto. A taxa de mutação creep pode ser relativamente alta, uma vez que esse operador é usado apenas para explorar localmente o espaço de busca. 


\subsection{CRITÉRIOS DE PARADA}

O algoritmo termina quando o critério de parada é satisfeito. Os principais critérios de parada em AGs encontrados na literatura são:

- número de gerações ou um tempo-limite,

- quando o valor ótimo da função objetivo é conhecido, o critério de parada é a obtenção deste valor;

- convergência, isto é, quando não ocorrer melhoramento significativo no cromossomo de maior aptidão;

- quando um alto percentual de população possuir o mesmo valor de função aptidão.

\subsection{PARÂMETROS GENÉTICOS}

Parâmetros genéticos representam características relacionadas ao algoritmo que influenciam fortemente o seu desempenho. A escolha do valor desses parâmetros é vital para o melhor comportamento desses algoritmos e, conseqüentemente, é determinante na obtenção de uma solução ótima ou quase ótima para o problema. Os principais parâmetros são os seguintes:

- tamanho da população: o tamanho da população afeta o desempenho global e a eficiência dos AGs, influenciando a identificação de soluções ótimas. Com uma população pequena o desempenho pode cair, pois a cobertura do espaço de busca do problema é limitada e pode resultar na convergência para uma solução sub-ótima (convergência prematura). Uma população grande geralmente fornece uma cobertura representativa do domínio do problema, além de prevenir convergências prematuras para soluções locais ao invés de globais. No entanto, para se trabalhar com grandes populações, são necessários maiores recursos computacionais ou, então, que o processamento se estenda por um tempo muito mais longo. Geralmente o AG investe tempo no processamento de indivíduos redundantes.

- taxa de cruzamento: quanto maior for esta taxa, mais rapidamente novas estruturas serão introduzidas na população. Entretanto se esta taxa for 
muito alta, indivíduos com boas aptidões poderão ser descartados a uma velocidade maior que a velocidade de geração de bons indivíduos; se esta taxa for muita baixa, a busca pode estagnar.

- taxa de mutação: uma baixa taxa de mutação previne que uma dada posição fique estagnada em um valor, além de possibilitar que se chegue em qualquer ponto do espaço de busca; com uma taxa muito alta a busca se torna essencialmente aleatória.

\subsection{TRATAMENTO DE RESTRIÇÕES}

Como comentado em GEN \& CHENG (1997), “o problema central para a aplicação de AGs a problemas de otimização com restrições é o de como tratar as restrições, dado que operadores genéticos usados para manipular cromossomos freqüentemente produzem filhos infactíveis." Conforme proposto em GEN \& CHENG (1997), as principais técnicas para o tratamento de restrições podem ser classificadas em:

- estratégia de rejeição: descarta os cromossomos infactíveis (aqueles que não satisfazem alguma restrição) criados ao longo das gerações. O método pode trabalhar razoavelmente bem, entretanto, pode apresentar problemas em muitos casos de otimização com restrições. Para que esta estratégia funcione razoavelmente bem é preciso que exista a garantia de um espaço de busca convexo;

- estratégia de reparação: reparar um cromossomo consiste basicamente em transformar um cromossomo infactível em um factível, através de alguma estratégia de reparação que é fortemente dependente do problema em questão. Para muitos problemas de otimização combinatória é relativamente fácil criar estratégias de reparação. A estratégia depende da existência de processos determinísticos de reparação que possam converter filhos infactíveis em factíveis. É importante lembrar que, para muitos problemas, o processo de reparação de cromossomos infactíveis pode ser tão complexo quanto o problema original o que, de certa forma, inviabiliza o uso da técnica; 
- estratégia de modificação de operadores genéticos: uma abordagem interessante para lidar com factibilidade é a de criar tanto a representação de dados quanto os operadores genéticos especificamente para $o$ problema, de maneira a manter a factibilidade dos cromossomos. Essa estratégia garante que os cromossomos estarão dentro da região factível;

- estratégia de penalidade: geralmente em problemas que possuem um número razoavelmente alto de restrições, um grande número de soluções infactíveis faz parte da população. Em tais casos, soluções factíveis são difíceis de serem geradas se a pesquisa genética for confinada dentro das regiões factíveis. A estratégia de penalidade é um tipo de técnica proposta que considera soluções infactíveis durante o processo de busca.

\subsection{FUNÇÕES PENALIDADES}

Neste trabalho foi adotada a técnica de penalidade que é, provavelmente, a mais comumente utilizada em implementações de AGs. Essencialmente, essa técnica penaliza as soluções infactíveis. Isso é feito alterando a função de aptidão por meio da adição de um termo de penalidade.

A maior dificuldade do seu uso é como escolher uma função de penalidade que acelere a convergência e evite o término prematuro. A técnica de penalidade é usada para manter uma certa quantidade de soluções infactíveis em cada geração a fim de guiar a pesquisa genética para uma solução ótima. A maior preocupação é como determinar o termo penalidade para descobrir um balanço entre a informação preservada (manter algumas soluções factíveis) e a pressão de seleção (rejeitar algumas soluções infactíveis).

O espaço de solução geralmente contêm duas áreas: a factível e a infactível, conforme ilustrado na Figura 2-8. A figura exibe uma situação em que a solução infactível $\boldsymbol{b}$ está muito mais próxima do ótimo $\boldsymbol{a}$ que a solução infactível $\boldsymbol{d}$ e a solução factível $\boldsymbol{c}$.

Espera-se penalizar menos $\boldsymbol{b}$ que $\boldsymbol{d}$ embora $\boldsymbol{b}$ esteja um pouco mais distante da área factível do que $\boldsymbol{d}$. Acredita-se que $\boldsymbol{b}$, mesmo infactível, contém muito mais informação sobre o ótimo que $c$. Como não se tem conhecimento, a priori sobre o ótimo, geralmente é muito difícil julgar qual é a melhor solução. A questão principal 
da estratégia de penalidade é como projetar uma função penalidade pen(x) que possa efetivamente guiar a busca em direção a áreas promissoras do espaço de soluções.

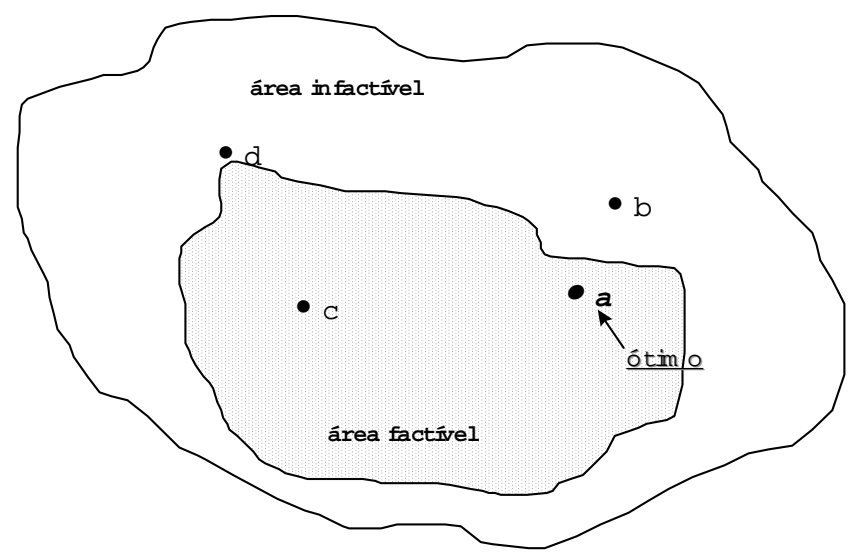

Figura 2-8. Espaço de soluções factíveis e infactíveis [GEN \& CHENG (1997)]

Não existe uma orientação geral que subsidie o projeto da função penalidade em problemas de otimização. Como sugerido em GEN \& CHEN (1997), em geral existem dois possíveis caminhos para construir a função de avaliação com um termo de penalidade. Uma delas é adicionar o termo penalidade à função objetivo como mostrado pela equação (2.10).

$$
\begin{aligned}
& F(x)=f(x)+\operatorname{pen}(x) \\
& \text { onde } \quad x-\text { cromossomo } \\
& \\
& \quad f(x)-\text { a função objetivo do problema } \\
& \text { pen }(x) \text { - função penalidade. }
\end{aligned}
$$

$$
\begin{aligned}
& \text { se } \mathrm{x} \text { é factível } \rightarrow \operatorname{pen}(\mathrm{x})=0 \\
& \text { caso contrário } \rightarrow \text { pen }(\mathrm{x})>0
\end{aligned}
$$

O segundo caminho é multiplicar o termo penalidade pela função objetivo como na equação (2.11).

$$
F(x)=f(x) \cdot \operatorname{pen}(x)
$$




$$
\begin{aligned}
& \text { se } x \text { é factível } \rightarrow \operatorname{pen}(x)=1 \\
& \text { caso contrário } \rightarrow \text { pen }(x)>1
\end{aligned}
$$

Em GEN \& CHENG (1997) podem ser encontradas várias outras definições de funções penalidade que podem ser incorporadas à função de aptidão.

\subsection{CONSIDERAÇÕES FINAIS}

Este capítulo apresentou e discutiu os principais conceitos e resultados relacionados a AGs com o objetivo de estabelecer claramente a terminologia e conceituações utilizadas, bem como evidenciar os aspectos relevantes desta técnica que são focalizados na pesquisa descrita nos próximos capítulos.

Com o objetivo de mostrar em detalhes o funcionamento de um AG aplicado a um problema de engenharia, o Apêndice A detalha todos os passos necessários desde a descrição do problema até a solução via AG. 


\section{O Uso de AGs em Problemas de Otimização Estrutural - Estado da Arte}

\subsection{PRELIMINARES}

A revisão bibliográfica foi feita com o intuito de fazer um levantamento o mais abrangente possível dos trabalhos que foram realizados na área de Engenharia Estrutural usando AGs. Buscou-se, com isso, identificar as vantagens e desvantagens do uso dessa técnica, facilidades/dificuldades em sua utilização em problemas práticos e avaliar a sua possível aplicabilidade a problemas relacionados a concreto pré-moldado. A seguir são apresentados os principais trabalhos evidenciados nesta área focalizando, respectivamente, o uso de $\mathrm{AG}$ em problemas envolvendo estruturas de aço e problemas envolvendo estruturas em concreto. A revisão bibliográfica focaliza, principalmente, o tipo de problema tratado em cada um dos trabalhos e as características da abordagem genética utilizada para a sua solução.

\subsection{O USO DE AGS EM ESTRUTURAS DE AÇO}

Nesta seção são discutidos trabalhos relevantes relativos ao uso de AGs na solução de problemas de otimização em estruturas de aço. 
JENKIS (1991) analisou o problema de minimização da massa em kg de uma viga treliçada, de comprimento L, ilustrada na Figura 3-1. As variáveis do problema foram as inclinações das escoras, a altura da treliça, definiçõos de seções da viga, do tirante principal e do montante.

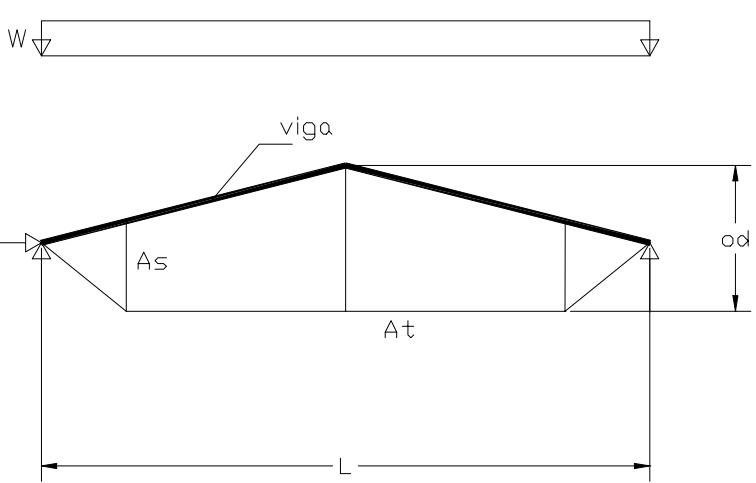

Figura 3-1. Viga treliçada, onde od: altura da treliça; At: seção do tirante principal; As: seção do tirante montante e W: carregamento distribuído

As características do AG usadas para a busca da solução do problema foram: dois tamanhos de população (50 e 200), representação de dados binária e a seleção roleta e todas as variáveis discretas.

Na Figura 3-2 são apresentados os resultados da minimização da massa da estrutura considerando seis diferentes sementes para a geração de números aleatórios, para os dois diferentes tamanhos de população considerados. 


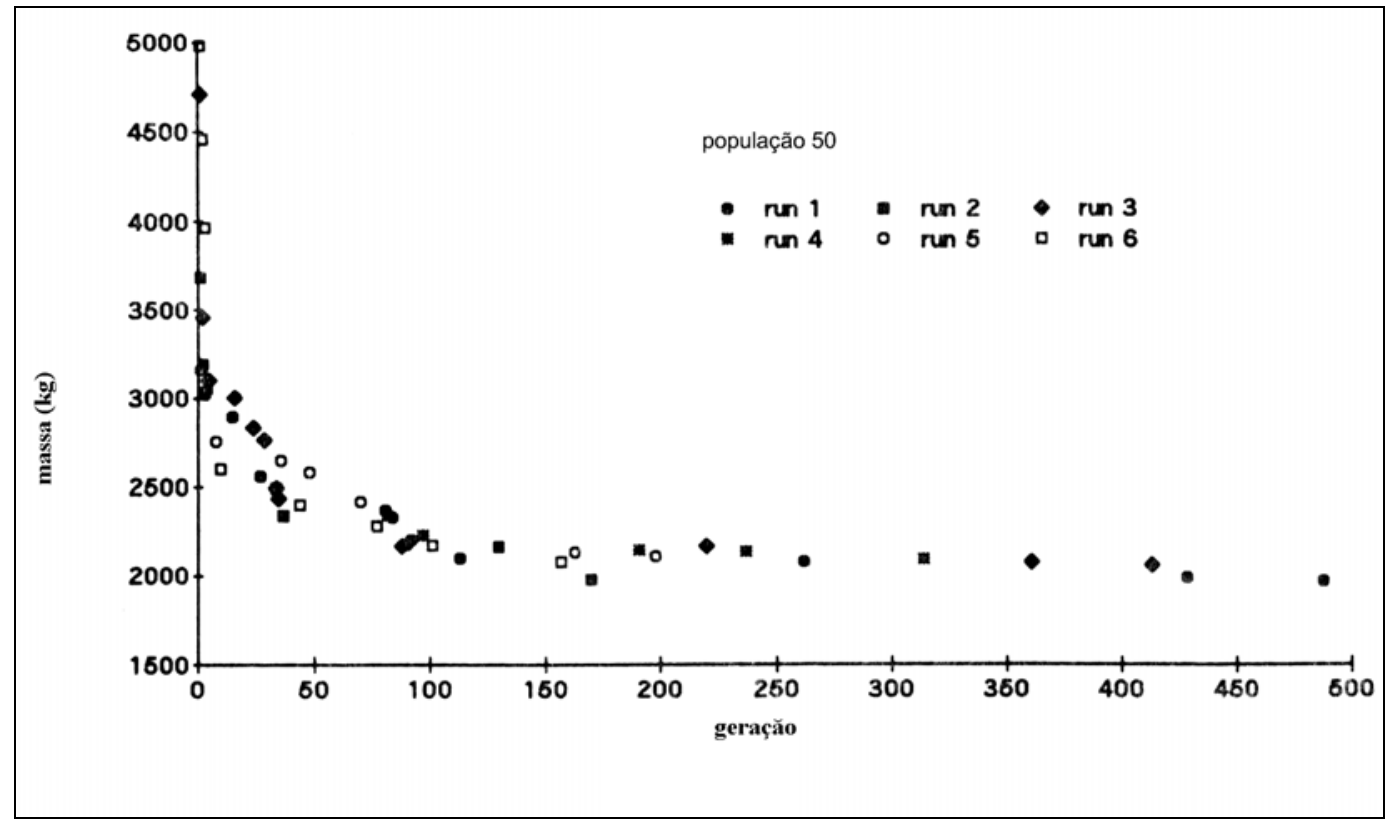

a) Resultados da função custo para a população de 50

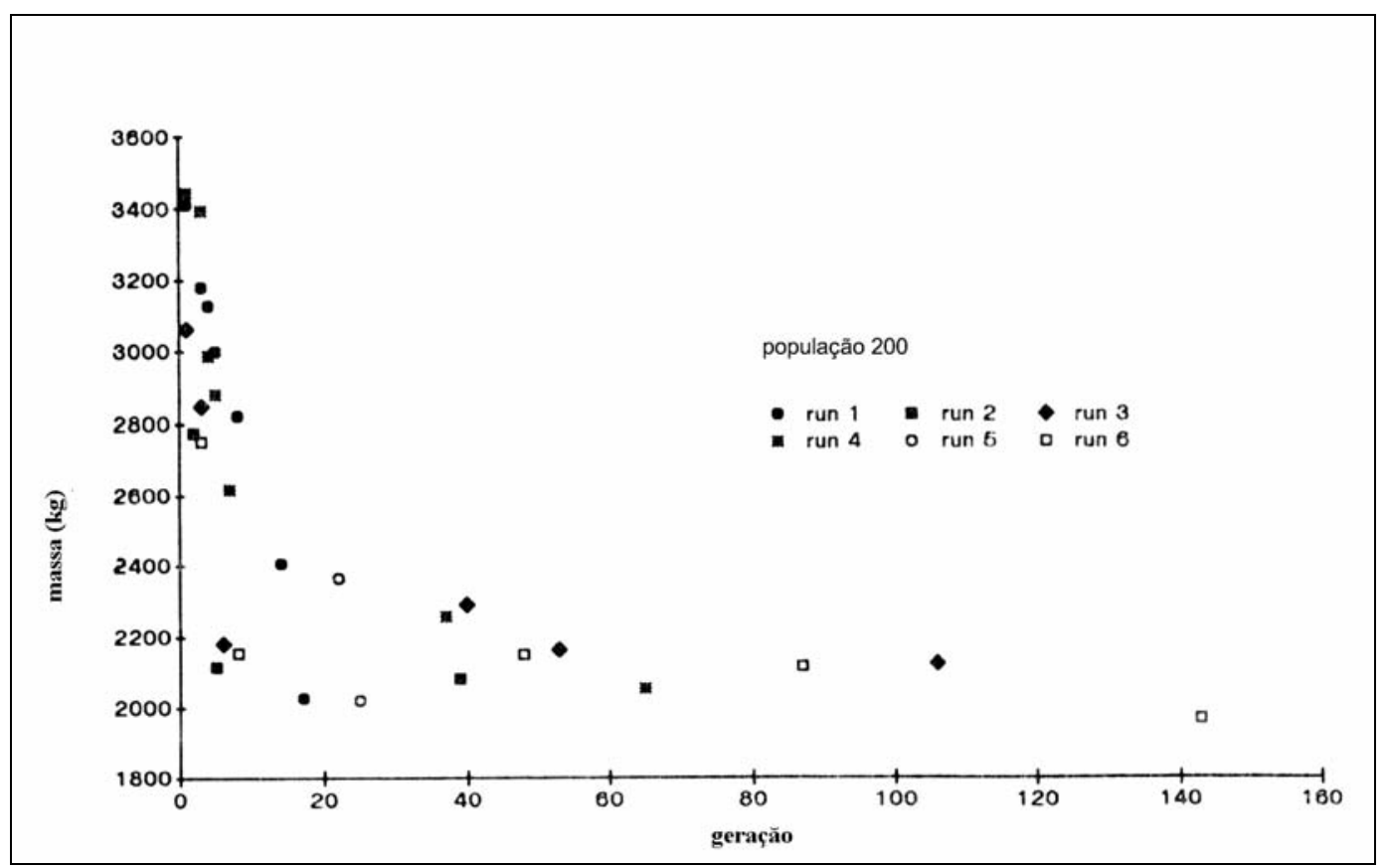

b) Resultados da função custo para a população de 200

Figura 3-2. Resultados para seis diferentes sementes para geração de números aleatórios considerando dois diferentes tamanhos de população [JENKIS (1991)]

Comparando os gráficos a) e b) da Figura 3-2 pode-se observar que para a população de 50 indivíduos, foram necessárias mais gerações para a determinação de uma solução aproximada do que para a população de 200 indivíduos. É importante 
lembrar, entretanto, que populações com um número maior de indivíduos geralmente usam um tempo computacional maior.

No mesmo artigo o autor ainda analisou uma treliça de três barras (Figura 3-3), a fim de encontrar as seções que minimizassem o volume total de material. O problema foi equacionado em função de duas variáveis representando áreas de aço. Os resultados obtidos são apresentados pela Tabela 3-1.

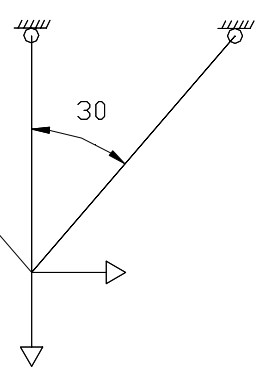

Figura 3-3. Treliça de 3 barras [JENKIS (1991)]

Tabela 3-1. Minimização do volume total de material em treliça de 3 barras

\begin{tabular}{|c|c|c|}
\cline { 2 - 3 } \multicolumn{1}{c|}{} & $\begin{array}{c}\text { Volume } \\
\mathbf{( c m}^{\mathbf{3}} \mathbf{c}\end{array}$ & $\begin{array}{c}\text { Tamanho da } \\
\text { população }\end{array}$ \\
\hline AG run1 & 4326 & 200 \\
\hline AG run2 & 4328 & 20 \\
\hline AG run3 & 4326 & 20 \\
\hline $\begin{array}{c}\text { Programação } \\
\text { linear sequencial }\end{array}$ & 4326 & \\
\hline
\end{tabular}

As notações AG run1, AG run2 e AG run3 da Tabela 3-1 identificam três execuções do AG com diferentes sementes de geração de números aleatórios e dois tamanhos diferentes de população. Segundo o autor os resultados se apresentaram satisfatórios dado que AG run1 e AG run3 se igualaram ao resultado obtido usando programação seqüencial linear.

Com relação à representação de dados adotada para a solução do primeiro problema, o autor escolheu uma representação binária de 5 bits, com o objetivo de representar 31 possíveis valores do espaço de busca. Entretanto, com 5 bits são possíveis 32 representações. $\mathrm{O}$ autor não comenta qual a estratégia usada para o 
tratamento da seqüência 00000 , dado que é uma possível seqüência que pode ser obtida via cruzamento ou mutação.

Outro ponto a ser notado é o número pequeno de experimentos, para o estabelecimento de um resultado. $\mathrm{O}$ autor deveria ter experimentado, pelo menos, 10 conjuntos aleatórios diferentes, como população inicial, para o estabelecimento de qualquer resultado. A publicação dos gráficos relativos à cada run não se justifica.

O trabalho ressalta ainda o cuidado que deve ser tomado com relação à escolha da função penalidade. Geralmente, uma função quadrática representa de maneira satisfatória o problema com restrições, mas é necessário definir com cautela o grau de violação para as restrições. Um grau de penalidade muito severo pode retardar o progresso do AG e às vezes inviabilizar seu uso.

Em outro trabalho, JENKIS (1992) analisou a estrutura de uma ponte de cabo estaiada mostrada na Figura 3-4, com o objetivo de minimizar uma função objetivo definida considerando parâmetros de projeto.

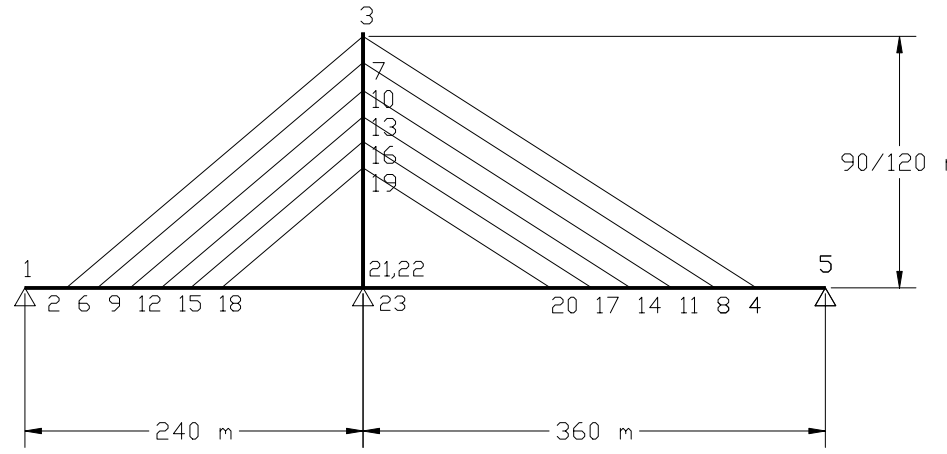

Figura 3-4. Ponte de cabo estaiada [JENKIS (1992)]

As variáveis de projeto que participam da função objetivo são as posições dos pontos de ligação dos cabos na longarina e na torre além das seções transversais dos doze cabos. O AG usado para a busca da solução do problema teve as seguintes características: representação binária, uso de variáveis discretas, a estratégia de seleção roleta e um modelo de escalonamento linear (para representar a pressão de seleção), proposto por GOLDBERG (1989). A função objetivo a ser minimizada corresponde à massa do material usado.

A Figura 3-5 mostra os resultados obtidos quando da minimização da massa considerando cinco diferentes gerações de números aleatórios. 


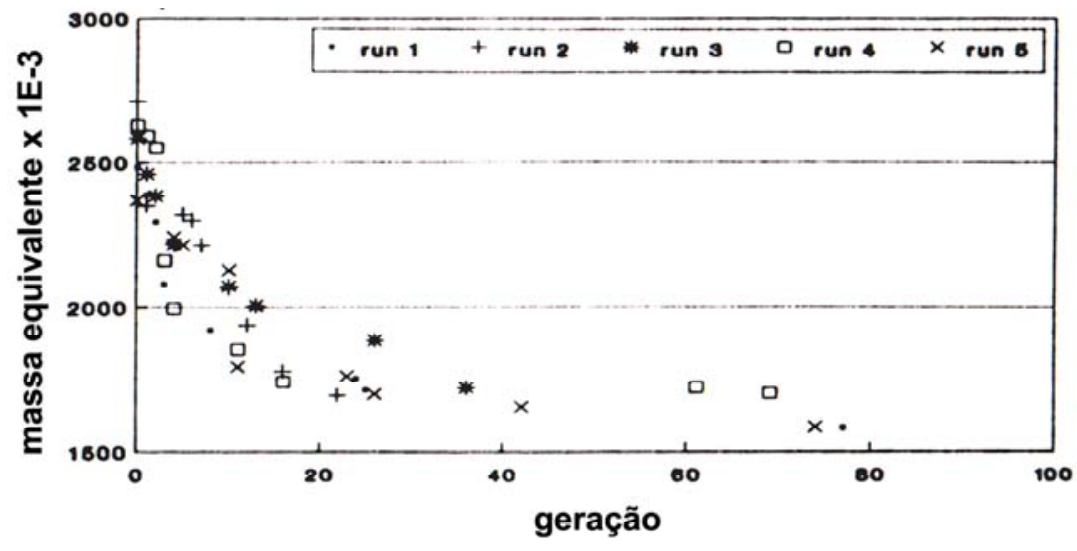

Figura 3-5. Resultados da otimização da ponte estaiada [JENKIS (1992)]

Valem aqui os mesmos comentários feitos com relação ao trabalho JENKIS (1991) relativos ao tamanho de 5 bits adotado para a representação das variáveis e aos experimentos descritos identificados por diferentes runs. O autor utilizou na busca da solução do problema a estratégia de seleção roleta e comenta que essa é a estratégia mais conhecida para a seleção de indivíduos. É importante lembrar que, apesar de ser bem conhecida, nem sempre essa estratégia é a que produz melhores resultados, razão pela qual o autor deveria ter experimentado outras. Em alguns problemas tal estratégia não obtém bons resultados. De qualquer forma as estratégias rank ou torneio são igualmente bem conhecidas.

Ainda com relação ao trabalho descrito em JENKIS (1992) foi utilizada uma função penalidade cujo valor depende do nível de violação da solução infactível; quanto maior for a violação, maior a penalidade atribuída à solução.

Com relação aos experimentos, segundo o autor, bons resultados foram obtidos usando tamanhos de população pequenos. Entretanto, para esses casos, geralmente, é necessário, um número de gerações maior para se obter o melhor valor de função objetivo.

RAJEV \& KRISHNAMOORTHY (1992) trabalharam no problema de minimização do peso de três tipos de sistemas de treliça tendo como variáveis discretas as áreas de aço. No trabalho foram analisados os sistemas de treliças plana, espacial e uma torre de transmissão.

Os autores comentam da importância do operador de mutação para manter a diversidade da população e, entretanto, não o incorpora no trabalho. No tratamento das violações para soluções infactíveis foi proposta uma formulação baseada nas 
violações de restrições normalizadas. O critério de parada foi definido quando $85 \%$ da população possue os mesmos valores de variáveis e de função objetivo ao longo do processo evolutivo. A representação de dados adotada foi a binária.

Como o desempenho do AG está relacionado com o tamanho da população, os autores investigaram diferentes valores de tamanhos de população. Ainda comentam que GOLDBERG (1989) conduz pesquisas neste aspecto e fornecem algumas diretrizes na escolha do tamanho da população. Segundo os autores, um extenso estudo de valores para o tamanho da população deve ser realizado, pois dependendo da quantidade de indivíduos, é necessário um número maior ou menor de gerações para atingir a convergência. Portanto, a experimentação dos autores se limitou a investigar o impacto nos resultados, somente no caso de diferentes tamanhos da população (20, 30 e 40 indivíduos). Vale comentar aqui que os tamanhos de população escolhidos não refletem muito qualquer impacto em resultados, dado que diferem apenas em 10 e 20 indivíduos. Teria sido interessante que os autores tivessem experimentado com populações sensivelmente maiores. Também, os experimentos não contemplam variações na configuração do AG (exceto pelas três populações diferentes).

Deve-se salientar que o trabalho detalha de maneira simplificada e bastante didática, a evolução numérica do AG para um problema de treliça plana de três barras.

O primeiro sistema investigado (treliça plana) é mostrado na Figura 3-6. Os autores abordaram o mesmo problema usando sete diferentes métodos de otimização convencional sobre os quais o artigo nada comenta. $\mathrm{O}$ artigo tampouco fornece o nome completo dos métodos convencionais, limitando-se a usar suas siglas e referenciar uma tese de doutorado sobre eles. Os resultados são apresentados na Tabela 3-2, considerando os sete diferentes tipos de métodos convencionais usados. Exceto nos casos de CONMIN e OPTDYN vê-se que os AGs apresentam resultados melhores que os demais. 


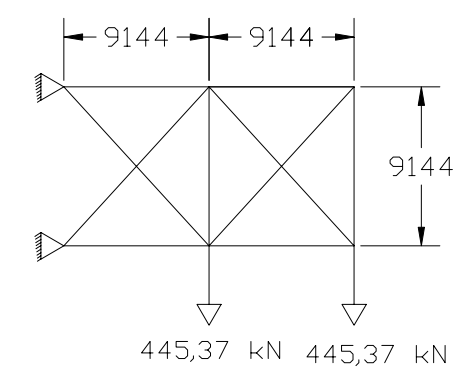

Figura 3-6. Treliça de 10 barras [RAJEV \& KRISHNAMOORTHY (1992)]

Tabela 3-2. Comparação dos resultados para a treliça de 10 barras

\begin{tabular}{|c||c|}
\hline Métodos & Peso $(\mathbf{k g})$ \\
\hline \hline AG - (tamanho da população $=20)$ & 2550,9 \\
\hline AG - (tamanho da população $=30)$ & 2548,1 \\
\hline AG - (tamanho da população $=40)$ & 2548,1 \\
\hline CONMIN & 2525,0 \\
\hline OPTDYN & $\mathbf{2 4 8 3 , 8}$ \\
\hline LINRM & 2836,4 \\
\hline SUMT & 2692,6 \\
\hline M-3 & 2595,8 \\
\hline M-5 & 2598,6 \\
\hline GRP-UI & 2599,5 \\
\hline
\end{tabular}

O segundo sistema (treliça espacial) com vinte e cinco barras, investigado por RAJEV \& KRISHNAMOORTHY (1992) é apresentado na Figura 3-7, juntamente com a configuração de carregamento.

\begin{tabular}{|c|c|c|c|}
\hline $\mathbf{N o ́}$ & $\mathbf{F}_{\mathbf{x}}(\mathbf{k N})$ & $\mathbf{F}_{\mathbf{y}}(\mathbf{k N})$ & $\mathbf{F}_{\mathbf{z}}(\mathbf{k N})$ \\
\hline \hline $\mathbf{1}$ & 4,45 & $-44,54$ & $-44,54$ \\
\hline $\mathbf{2}$ & 0,00 & $-44,54$ & $-44,54$ \\
\hline $\mathbf{3}$ & 2,23 & 0,00 & 0,00 \\
\hline $\mathbf{6}$ & 2,67 & 0,00 & 0,00 \\
\hline
\end{tabular}

a) Tabela de carregamento 


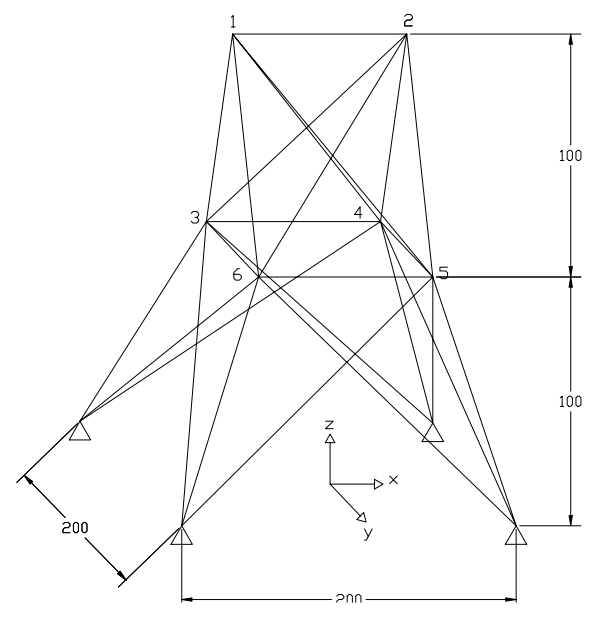

b) Treliça de 25 barras

Figura 3-7. Dados da treliça espacial de 25 barras [RAJEV \& KRISHNAMOORTHY (1992)]

Os resultados da otimização da massa dessa estrutura são apresentados na Figura 3-8. A partir da figura verifica-se, inicialmente, uma perturbação nos valores da função custo (peso) para tamanhos diferentes de população (Figura 3-8.a)). Os resultados obtidos pelos AGs foram satisfatórios, se apresentando melhores que aqueles obtidos na literatura técnica (Figura 3-8.b)). Aparentemente o resultado obtido e referenciado como 'literatura técnica' é relativo a um método de otimização convencional do qual nada é comentado.

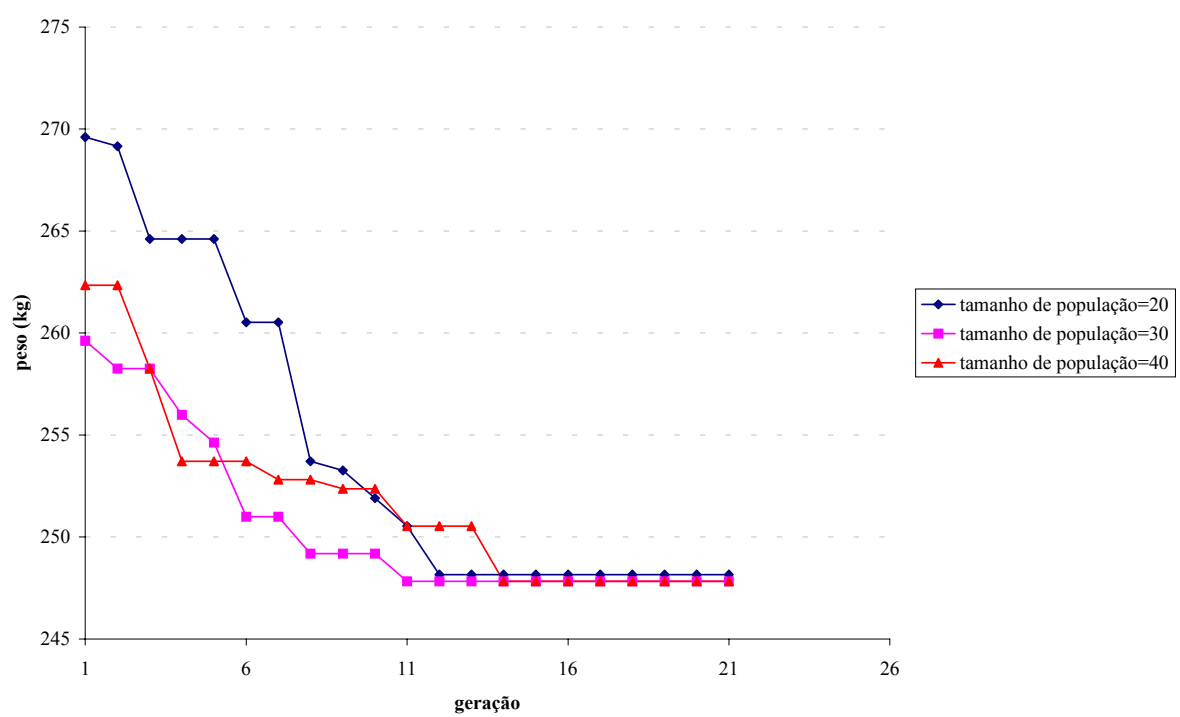

a) Resultados obtidos ao longo do processo 


\begin{tabular}{|c||c|}
\hline Métodos & Peso $(\mathbf{k g})$ \\
\hline \hline AG - (tamanho da população $=20)$ & 248,2 \\
\hline AG - (tamanho da população $=30)$ & 247,9 \\
\hline AG - (tamanho da população $=40)$ & 247,9 \\
\hline Literatura técnica & 255,5 \\
\hline
\end{tabular}

b) Comparação dos resultados finais

Figura 3-8. Resultados para a treliça espacial de 25 barras

[RAJEV \& KRISHNAMOORTHY (1992)]

O último sistema analisado (torre de transmissão) pelos autores está representado a seguir, na Figura 3-9. Os resultados são apresentados na Figura 3-10.

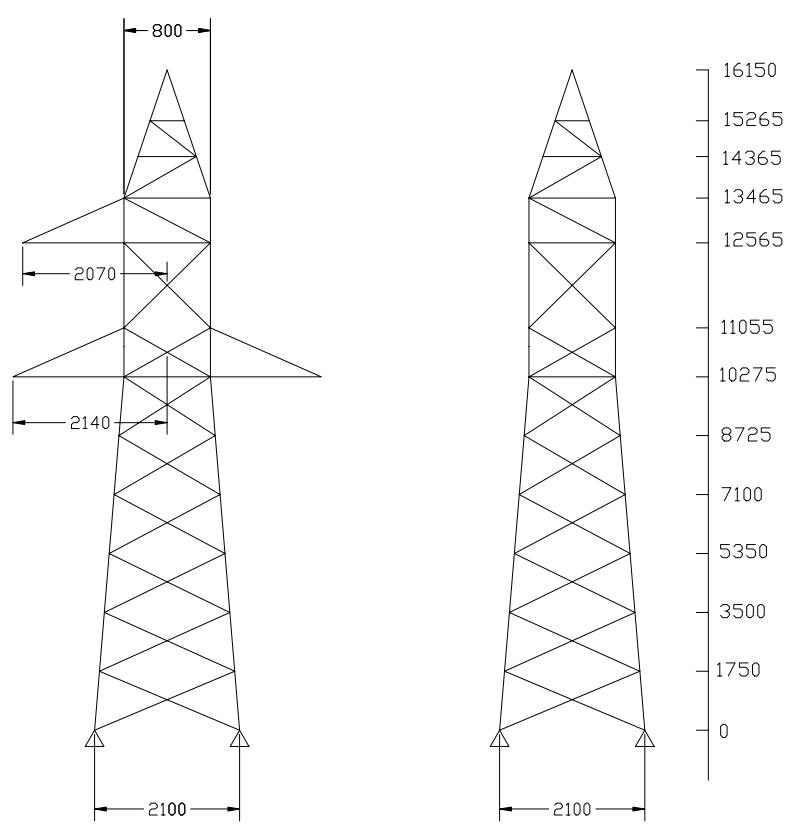

Figura 3-9. Torre de transmissão [RAJEV \& KRISHNAMOORTHY (1992)] 


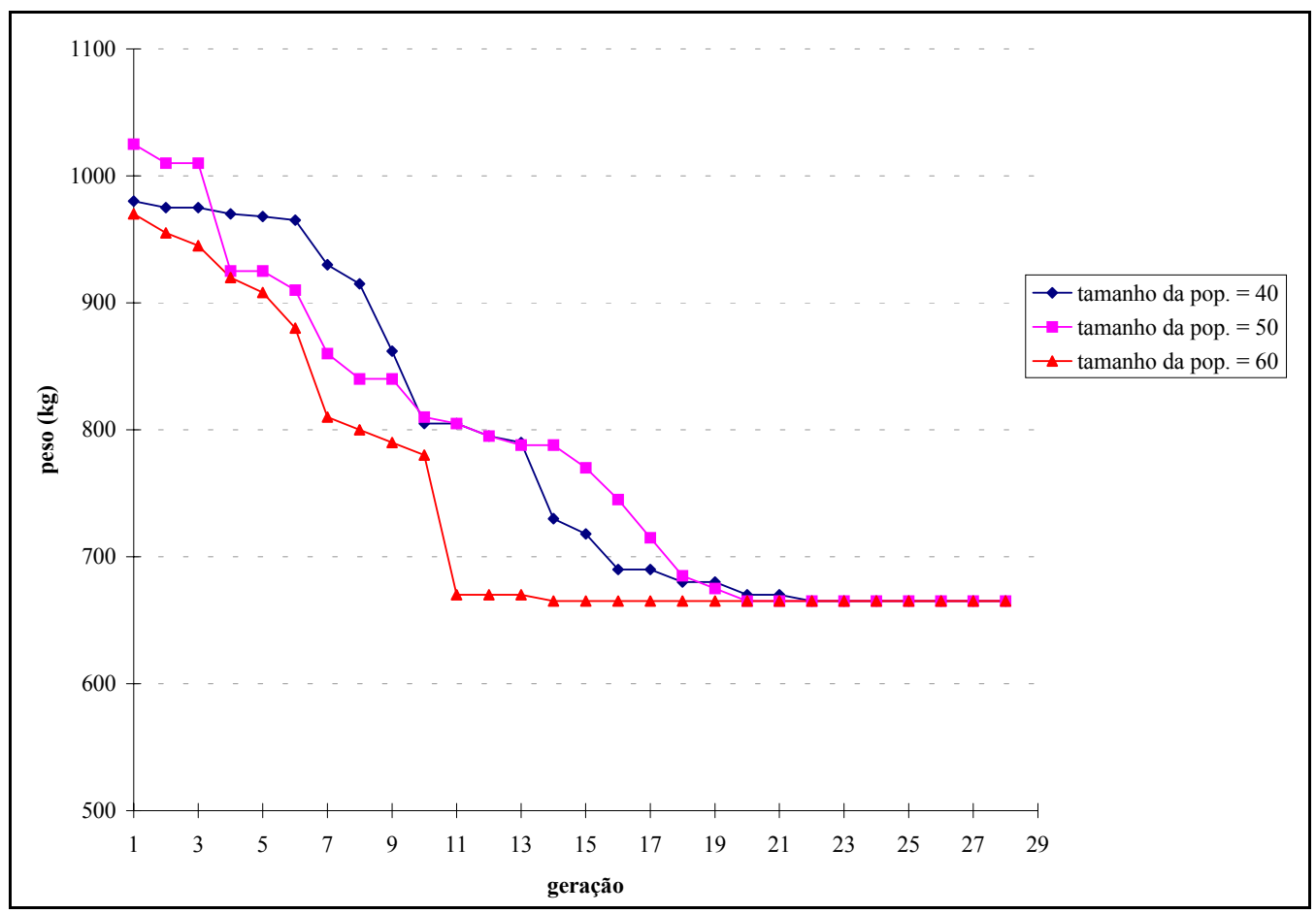

Figura 3-10. Resultados para a torre de transmissão [RAJEV \& KRISHNAMOORTHY

(1992)]

Os autores continuaram experimentando diferentes tamanhos de população (40, 50 e 60 neste caso) e, como pode ser verificado na Figura 3-10, o tamanho da população não influenciou a obtenção do resultado final do problema. Vale notar que os autores comentam do maior tempo computacional para a convergência, quando uma população maior é utilizada. Entretanto lembram que tamanhos pequenos de população podem provocar dificuldades de convergência, restringindo a busca da solução.

Os autores comentam que devido à natureza aleatória da busca é extremamente difícil sugerir diretrizes que indiquem um tamanho ótimo de população, tendo como base apenas o comprimento do cromossomo. Além disso, afirmam que os AGs são melhores e mais apropriados para o caso de otimização estrutural com variáveis discretas, uma vez que as manipulam de maneira eficiente. Os autores lembram que quase todas as variáveis de projeto, na maioria dos problemas de otimização estrutural, têm natureza discreta. 
WU \& CHOW (1995b) tratam da minimização do peso da estrutura de vários sistemas de treliças, sendo duas delas planas, tendo como variáveis discretas as áreas de aço.

A representação de dados utilizada na solução dos problemas via AG foi a binária com o tamanho em bits de cada variável definido como sugerido na literatura (ver Capítulo 2). O tamanho da população foi de 60 indivíduos (constante) e a estratégia de seleção foi a rank. Utilizou a substituição steady-state (descrita em detalhes no Capítulo 4) com a justificativa de evitar o alto tempo computacional nas avaliações dos indivíduos e se referencia ao AG utilizando este esquema como SSGA. Foram feitos experimentos usando diferentes tipos de cruzamentos: 1X, 2X, $3 \mathrm{X}$ e 4X. Posteriormente os autores compararam os resultados obtidos via SSGA com aqueles obtidos utilizando AG típico, disponíveis na literatura (RAJEV \& KRISHNAMOORTHY (1992)).

A otimização do peso de um dos sistemas de treliça, ilustrado na Figura 3-6, foi investigada por RAJEV \& KRISHNAMOORTHY (1992) e os resultados são usados por WU \& CHOW (1995b) para efeito de comparação, como mostra a Figura 3-11. A Figura 3-11.b) relaciona os valores finais de massa obtidos utilizando os vários operadores de cruzamento. Vale salientar que os autores nada comentam sobre o número de runs realizados e se os resultados apresentados são médias daqueles valores.

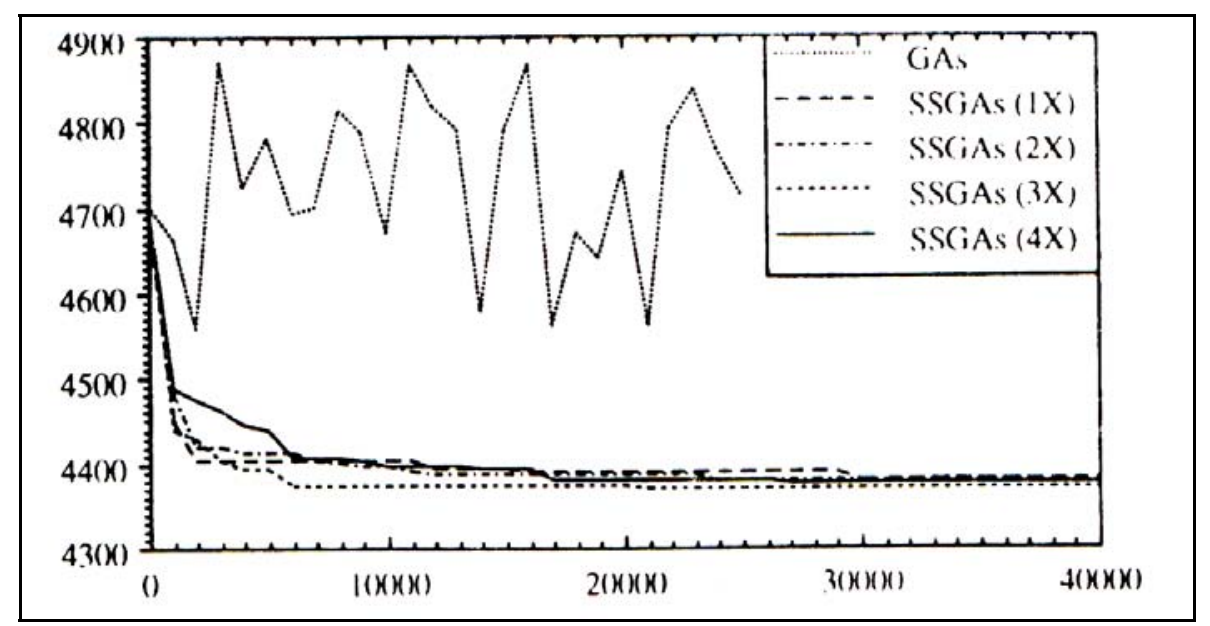

a) resultados obtidos ao longo do processo evolutivo 


\begin{tabular}{|c|c|c|c|c|}
\cline { 2 - 5 } \multicolumn{1}{c|}{} & \multicolumn{4}{|c|}{ AGs steady-state } \\
\hline \hline RAJEV \& KRISHNAMOORTHY & $\mathbf{1 X}$ & $\mathbf{2 X}$ & $\mathbf{3 X}$ & $\mathbf{4 X}$ \\
$(1992)$ & $\mathbf{( k g})$ & $\mathbf{( k g )}$ & $\mathbf{( k g )}$ & $\mathbf{( k g )}$ \\
\hline $2548,1 \mathrm{~kg}$ & 1987,7 & 1986,6 & 1983,5 & 1986,4 \\
\hline
\end{tabular}

b) Comparação do peso mínimo por AG simples e AGs steady-state

Figura 3-11. Resultados para o caso da treliça de 10 barras [WU \& CHOW (1995b)]

Na Figura 3-11.a) pode ser observado que a convergência é alcançada nas primeiras gerações, para todos os quatro tipos de cruzamento investigados. Nota-se na Figura 3-11.b) que os resultados obtidos usando o SSGA são melhores que aqueles obtidos por RAJEV \& KRISHNAMOORTHY (1992).

Deve-se salientar que a curva (GAs) apresentada na Figura 3-11.a) tem uma configuração bastante estranha (muita oscilação). Essa oscilação não deveria estar presente dado que, na solução do problema, foi usada a estratégia de seleção rank e este tipo de perturbação geralmente não se verifica quando do uso dessa estratégia de seleção.

Ainda em WU \& CHOW (1995b) foi investigada a otimização da massa de uma treliça com 52 barras, mostrada na Figura 3-12. Os resultados obtidos são apresentados na Tabela 3-3 e nela pode ser constatado que o melhor valor foi obtido com o cruzamento $2 \mathrm{X}$.

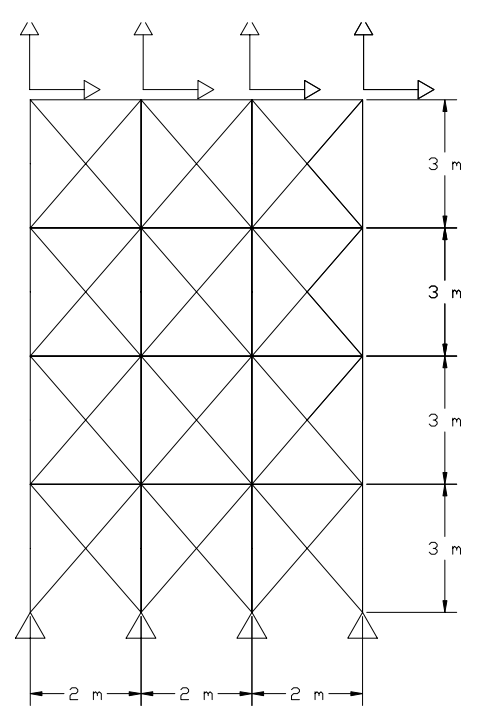

Figura 3-12. Treliça de 52 barras [WU \& CHOW (1995b)] 
Tabela 3-3. Resultados da massa mínima para a treliça de 52 barras

\begin{tabular}{|c|c|c|c|}
\hline \multicolumn{4}{|c|}{ SSGA } \\
\hline $\mathbf{1 X}(\mathbf{k g})$ & $\mathbf{2 X}(\mathbf{k g})$ & $\mathbf{3 X}(\mathbf{k g})$ & $\mathbf{4 X}(\mathbf{k g})$ \\
\hline 2294,521 & 1970,142 & 1980,445 & 1980,475 \\
\hline
\end{tabular}

Ainda, no trabalho de WU \& CHOW (1995b) foi introduzida a geração Gap (G) que é um parâmetro que controla a porcentagem de indivíduos da população que será substituída na próxima geração. $\mathrm{O}$ valor de $\mathrm{G}$ para os $\mathrm{AGs}$ tradicionais é 1,0, isto é, toda a população é substituída a cada geração. No trabalho em questão foi adotado $\mathrm{G}=\frac{2}{\mathrm{~N}_{\text {pop }}}$, ou seja, apenas 2 indivíduos são selecionados para reproduzir e 2 filhos são substituídos pelos dois piores indivíduos da população atual.

Segundo os autores AGs modificados com um $G$ pequeno podem reduzir significativamente o número de avaliações e promover a eficiência computacional. A partir dos resultados obtidos, os autores concluíram que o cruzamento $1 \mathrm{X}$ é o pior operador de cruzamento e que não existe diferença de desempenho entre os operadores de cruzamento $2 \mathrm{X}, 3 \mathrm{X}$ e $4 \mathrm{X}$.

CHEN \& CHEN (1997) analisaram algumas treliças, tratadas anteriormente em outros trabalhos, introduzindo melhoramentos nos AGs típicos. Para o problema em questão, a função a ser minimizada foi o peso da treliça considerando as áreas de aço como variáveis contínuas.

O tamanho da população foi de 30 indivíduos. Os autores nada comentam da estratégia de seleção usada nos experimentos. Foi analisado o impacto dos diferentes operadores de cruzamento (1X, 2X, 3X e 4X), da estratégia elitista, das variáveis de projeto passivas, do aumento gradual de penalidade e de uma pesquisa local. A seguir, são apresentados alguns detalhes das estratégias usadas.

- Cruzamento multi-ponto (PC);

- Estratégia elitista;

- Variáveis de projeto passivas (VPP): durante o processo de otimização, as variáveis assumem valores correspondentes aos seus limites superiores e inferiores; 
- Aumento gradual da penalidade (AP): acréscimo da penalidade de acordo com o número da geração;

- Pesquisa local de G-bit: esse método simplesmente muda um valor de bit 0 para 1 e vice-versa; o valor da função objetivo atual é comparado com o anterior; se a função é melhorada, então o cromossomo que foi mudado se mantêm na população e o anterior é descartado.

Os autores experimentaram, comparativamente, dois tipos de treliças. O primeiro tipo é uma treliça plana de 10 barras mostrada na Figura 3-13. O segundo, ilustrado na Figura 3-14, é uma treliça de 25 barras. Em ambos os problemas, as variáveis são as áreas de aço e o objetivo do problema é a minimização do peso da treliça.

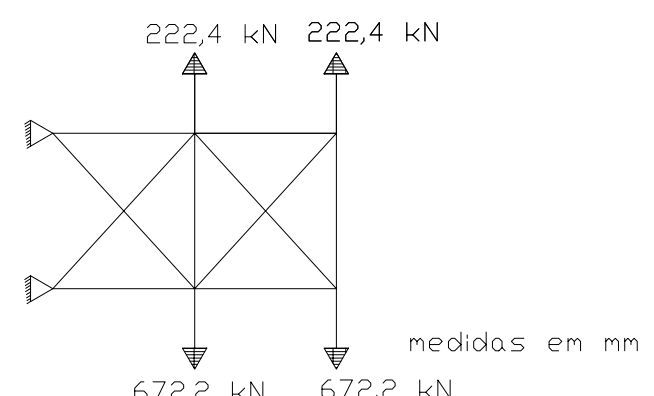

Figura 3-13. Treliça de 10 barras [CHEN \& CHEN (1997)]

\begin{tabular}{|c|c|c|c|}
\hline Nó & $\mathbf{F}_{\mathbf{x}}(\mathbf{k N})$ & $\mathbf{F}_{\mathbf{y}}(\mathbf{k N )}$ & $\mathbf{F}_{\mathbf{z}}(\mathbf{k N})$ \\
\hline $\mathbf{1}$ & 2,22 & 0,00 & 0,00 \\
\hline $\mathbf{2}$ & 2,22 & 0,00 & 0,00 \\
\hline $\mathbf{3}$ & 4,45 & 44,48 & $-22,24$ \\
\hline $\mathbf{4}$ & 0,00 & 44,48 & $-22,24$ \\
\hline
\end{tabular}

a) Dados do carregamento 


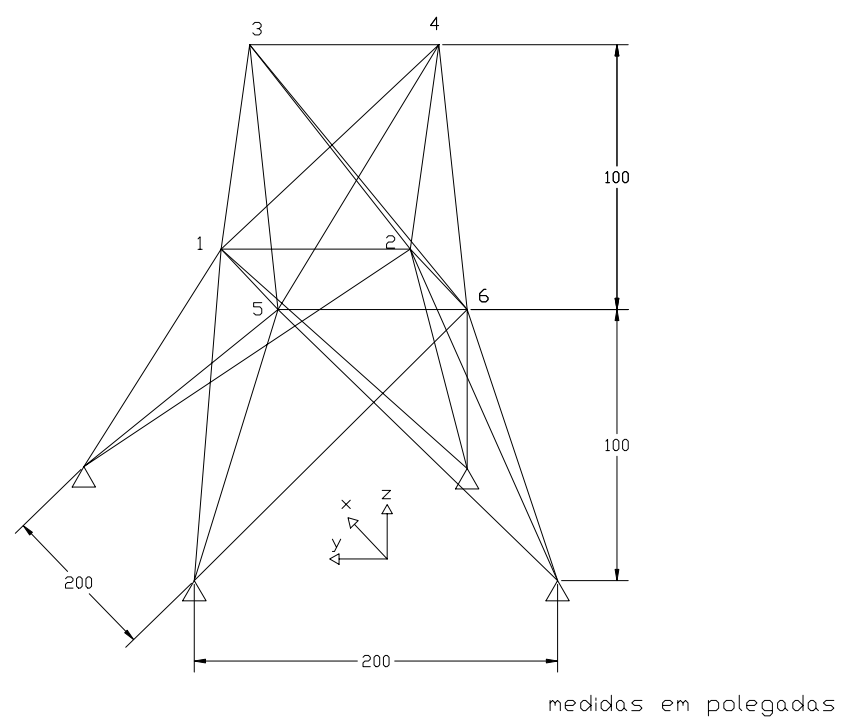

b) Treliça de 25 barras

Figura 3-14. Dados da treliça espacial de 25 barras [CHEN \& CHEN (1997)]

Na Tabela 3-4 são apresentados os resultados com todas as estratégias consideradas. Com relação aos quatro operadores de cruzamento nota-se que o melhor resultado foi obtido pelo operador $2 \mathrm{X}$ para o caso da treliça de 10 barras e $4 \mathrm{X}$ para o caso da treliça de 25 barras.

A partir dos resultados obtidos no trabalho de CHEN \& CHEN (1997), pode se notar que a busca local não apenas melhora como também acelera a convergência. O uso de variáveis de projeto passivas também acelera a convergência. Para o caso da treliça de 10 barras, o melhor resultado foi obtido considerando a busca local. Para a treliça de 25 barras, o ponto de cruzamento $4 \mathrm{X}$ apresentou resultados melhores que as outras estratégias.

Segundo os autores o cruzamento $2 \mathrm{X}$ fornece resultados confiáveis, estáveis e eficientes e a estratégia de aumento de penalidade gradualmente conduz as soluções infactíveis para as regiões factíveis, além de prevenir a convergência prematura. 
Tabela 3-4. Resultados para as treliças, onde PC - ponto de cruzamento, PL - pesquisa local, VPP - estratégia para variável de projeto passiva, AP - estratégia de aumento de penalidade

\begin{tabular}{|c|c||c|c|}
\hline \multicolumn{2}{|c||}{ Treliça de 10 barras } & \multicolumn{2}{c|}{ Treliça de 25 barras } \\
\hline \hline Tipo & Custo (kg) & Tipo & Custo (kg) \\
\hline $\mathrm{PC}=1$ & 2450,6 & $\mathrm{PC}=1$ & 223,4 \\
\hline $\mathrm{PC}=2$ & 2155,1 & $\mathrm{PC}=2$ & 213,6 \\
\hline $\mathrm{PC}=3$ & 2502,4 & $\mathrm{PC}=3$ & 195,1 \\
\hline $\mathrm{PC}=4$ & 2469,2 & $\mathrm{PC}=4$ & 186,6 \\
\hline $\mathrm{PL}$ & 2136,5 & $\mathrm{PL}$ & 188,0 \\
\hline $\mathrm{VPP}$ & 2147,4 & $\mathrm{AP}$ & 243,7 \\
\hline $\begin{array}{c}\text { Baseado no } \\
\text { método do } \\
\text { gradiente }\end{array}$ & $\mathbf{2 1 0 4 , 3}$ & $\begin{array}{c}\text { Baseado no } \\
\text { método do } \\
\text { gradiente }\end{array}$ & $\mathbf{2 4 7 , 4}$ \\
\hline
\end{tabular}

HASANCEBI \& ERBATUR (1998) analisaram várias técnicas de cruzamento em vários sistemas de treliças. As variáveis são as áreas de aço e o objetivo foi a minimização do peso das treliças considerando variáveis discretas. Foram analisados três tipos de treliças com o objetivo de avaliar o impacto de tamanhos diferentes de espaço de busca.

A representação de dados adotada foi a binária. Foi definida uma população de 100 indivíduos (constante nos experimentos) e a estratégia de seleção utilizada foi a rank. Foi avaliado o impacto de diferentes operadores de cruzamentos $1 \mathrm{X}, 2 \mathrm{X}, 3 \mathrm{X}$, 5X, 10X, 20X, variável-a-variável e uniforme. Todos os resultados representam a média dos valores obtidos em 8 execuções (runs), cada uma delas tendo uma população inicial gerada randomicamente. O critério de parada foi o número de gerações 100 .

Uma das treliças analisada está ilustrada, a seguir, na Figura 3-15, e corresponde a uma treliça plana de 10 barras. 


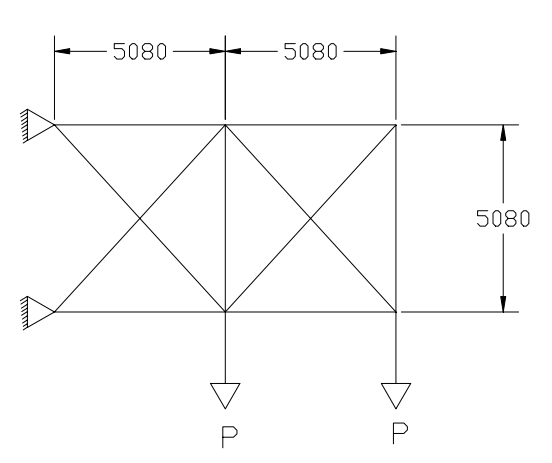

Figura 3-15. Treliça de 10 barras [HASANCEBI \& ERBATUR (1998)]

Os autores otimizaram a treliça da Figura 3-15, considerando dois diferentes valores do carregamento $(\mathrm{P})$. Os resultados são apresentados na Tabela 3-5 e na Tabela 3-6, relacionando para os dois casos, as várias técnicas de cruzamento consideradas. Os autores apenas se limitaram a fornecer os valores finais da função custo, não apresentando os valores para as variáveis que definem a função.

O operador de cruzamento proposto pelos autores no trabalho em questão, nomeada aqui de variável-a-variável, divide o vetor de valores binários separando cada variável do problema, realizando posteriormente, para cada uma, o cruzamento através de ponto simples. O cruzamento variável-a-variável está descrito em detalhes no Capítulo 2, uma vez que foi utilizado em alguns dos experimentos realizados nesta tese.

Tabela 3-5. Valores em $\mathrm{kg}$ do peso da estrutura para o caso I

\begin{tabular}{|c|c|c|c|c|c|c|c|}
\hline \multicolumn{7}{|c|}{ Técnicas de cruzamento } \\
Caso I $-\boldsymbol{P}=333, \mathbf{k} \boldsymbol{N}$ \\
\hline $\begin{array}{c}\text { ponto } \\
\text { simples }\end{array}$ & dois pts & três pts & $\mathbf{5}$ pts & $\mathbf{1 0}$ pts & $\mathbf{2 0}$ pts & $\begin{array}{c}\text { var. a } \\
\text { var. }\end{array}$ & unifor. \\
\hline \hline 2453,6 & 2452,3 & 2479,1 & 2473,7 & 2493,6 & 2511,2 & 2492,8 & 2516,2 \\
\hline
\end{tabular}

Tabela 3-6. Valores em $\mathrm{kg}$ do peso da estrutura para o caso II

\begin{tabular}{|c|c|c|c|c|c|c|c|}
\hline \multicolumn{7}{|c|}{ Técnicas de cruzamento } \\
Caso II - P=111,2kN \\
\hline $\begin{array}{c}\text { ponto } \\
\text { simples }\end{array}$ & $\mathbf{2}$ X & três pts & $\mathbf{5}$ pts & $\mathbf{1 0}$ pts & $\mathbf{2 0}$ pts & var. a var. & unifor. \\
\hline 951,9 & 957,2 & 946,8 & 969,1 & 980,7 & 1019,2 & 988,4 & 1034,6 \\
\hline
\end{tabular}


Pode ser observado nas Tabela 3-5 e Tabela 3-6 que os resultados pioraram à medida que o número de pontos de cruzamento aumentou.

HASANCEBI \& ERBATUR (1998) ainda implementaram um outro tipo de operador de cruzamento que corresponde a uma mistura de um ponto, $2 \mathrm{X}$ e $3 \mathrm{X}$. Para um número fixo de total de gerações, os autores usaram uma determinada seqüência de operadores de cruzamentos com proporções diferentes: as primeiras $20 \%$ gerações são criadas usando cruzamento $3 \mathrm{X}$, as $40 \%$ gerações seguintes, usando cruzamento de um ponto e as $40 \%$ gerações finais, com cruzamento $2 \mathrm{X}$. A idéia é aplicar uma determinada seqüência de técnicas utilizando uma mistura de cruzamentos a fim de abranger todo o espaço de busca. No problema, primeiramente foi adotado o cruzamento $3 \mathrm{X}$, depois o de um ponto e finalmente o $2 \mathrm{X}$.

Outra técnica utilizada foi a troca de variável direta. Nesse caso cada variável de projeto é trocada entre pares de indivíduos de acordo com a função de probabilidade dada pela equação a seguir.

$$
\begin{aligned}
& \mathrm{p}_{\text {cros }}=\left[0,50-0,35\left(\frac{\text { genc }}{\text { max gen }}\right)^{0,5}\right]\left(\frac{10}{\mathrm{~N}_{\mathrm{d}}}\right)^{0,3} \mathrm{f} \\
& \mathrm{f}=\left\{\begin{array}{l}
1,0 \text { caso indivíduo factível } \\
1,5-\left(\frac{\text { genc }}{\text { max gen }}\right) \text { caso contrário }
\end{array}\right.
\end{aligned}
$$

onde $p_{\text {cros }}-$ probabilidade de cruzamento

genc - contador da geração

max gen - número máximo da geração

$\mathrm{N}_{\mathrm{d}}$ - número de variáveis de projeto

f - parâmetro de factibilidade

Ambas as técnicas foram aplicadas em um problema de otimização da massa de uma treliça espacial de 72 barras. A Tabela 3-7 relaciona os resultados obtidos pelos métodos apresentados anteriormente, comparando-os com um valor ótimo já conhecido da literatura. Pelos resultados obtidos vê-se que o melhor valor da função foi obtido com a técnica de troca de variável direta. Os resultados apresentados pela 
mistura de cruzamento obtiveram melhores valores quando comparados aos operadores de cruzamento $1 \mathrm{X}, 2 \mathrm{X}$ e $3 \mathrm{X}$.

Tabela 3-7. Valores obtidos pela função objetivo para as técnicas de cruzamento

\begin{tabular}{|c|c|c|c|c|c|}
\hline $\mathbf{1 X}$ & $\mathbf{2 X}$ & $\mathbf{3 X}$ & $\begin{array}{c}\text { Mistura de } \\
\text { cruzamento }\end{array}$ & $\begin{array}{c}\text { Troca de variável de } \\
\text { projeto }\end{array}$ & $\begin{array}{c}\text { Valor } \\
\text { ótimo } \\
(\mathbf{k g})\end{array}$ \\
\hline $\mathbf{( k g )}$ & $\mathbf{( k g )}$ & $\mathbf{( k g )}$ & $\mathbf{( k g )}$ & $\mathbf{( k g )}$ & 6522,26 \\
\hline 6904,26 & 6769,05 & 6948,65 & 6702,32 & 4887,43 \\
\hline
\end{tabular}

Devido aos bons resultados obtidos tanto pelo operador variável-a-variável quanto pela técnica de mistura de cruzamento, achou-se interessante uma investigação tanto do novo operador quanto da seqüência proposta pelos autores, quando dos problemas tratados nesta tese.

LEITE \& TOPPING (1998) analisaram a minimização dos custos de material e mão de obra de execução de uma viga soldada, ilustrada na Figura 3-16. As variáveis envolvidas na definição da função custo são as dimensões b, h, 1 e t, mostrados na figura. O comprimento L assume o valor de 14 in.

A busca da solução do problema via AG usou a representação de dados real. O tamanho da população foi de 100 indivíduos (constante para os experimentos) e a estratégia de seleção foi a do torneio. Os experimentos usaram um número máximo de gerações limitado por 100 e os valores mostrados correspondem à média dos valores obtidos em 20 runs.

Os experimentos levaram em consideração variação da taxa da probabilidade de mutação bem como uma reprodução com múltiplos filhos. $\mathrm{Na}$ análise dos experimentos foi avaliado o impacto do operador de cruzamento multi-ponto.

A viga foi otimizada por métodos convencionais e os resultados estão apresentados na Tabela 3-8. Os métodos APPROX, DAVID, GP, SIMPLEX e RANDOM envolvem programação matemática. Já o GEBENOPT (Genetic Based Engineering Optimization Tool) e CGA (Canonical Genetic Algorithm) são sistemas que implementam AG. 


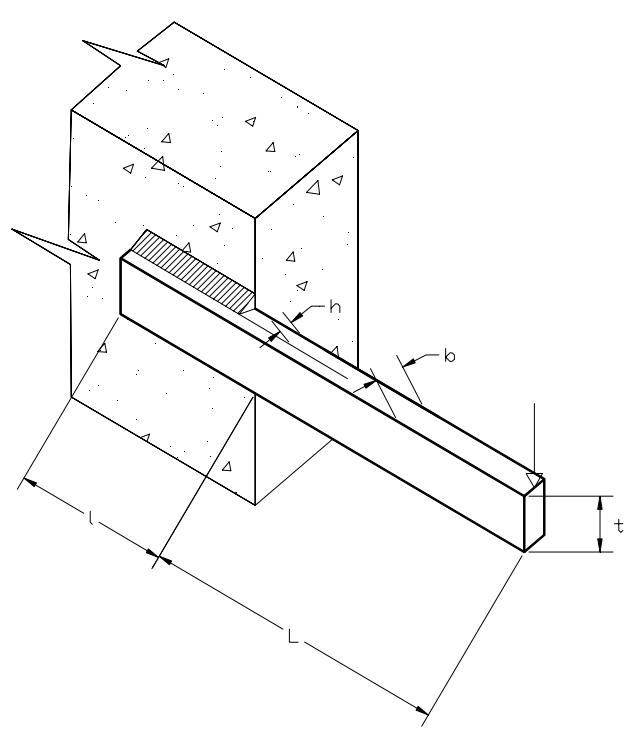

Figura 3-16. Viga soldada [LEITE \& TOPPING (1998)]

Tabela 3-8. Resultados finais para a viga soldada

\begin{tabular}{|c||c|}
\hline Métodos & Custo (\$) \\
\hline \hline APPROX & 2,38 \\
\hline DAVID & 2,38 \\
\hline GP & 2,39 \\
\hline SIMPLEX & 2,53 \\
\hline RANDOM & 4,12 \\
\hline GEBENOPT & 2,40 \\
\hline CGA & 2,43 \\
\hline
\end{tabular}

Pode ser visto na Tabela 3-8 que os resultados obtidos pelos AGs se mostraram satisfatórios, chegando bem próximos àquele obtido por APPROX e DAVID.

Os autores também analisaram a topologia de treliças com o objetivo de minimizar o seu peso considerando como variáveis as áreas de aço e a topologia. Uma das treliças está mostrada na Figura 3-17 a). A Figura 3-17 b) ilustra a topologia final depois do processo de otimização. A Tabela 3-9 mostra os resultados numéricos finais comparando-os com outros métodos de otimização. Uma outra técnica heurística utilizada pelo autor foi o SA (Simulated Annealing). Nesta técnica, para se obter o ponto ótimo, é feita uma analogia com o fenômeno físico do comportamento de moléculas durante o processo de cristalização em recozimento de 
metais. Para maior esclarecimento do processo, consultar DIAZ (1996) e REEVES (1995).

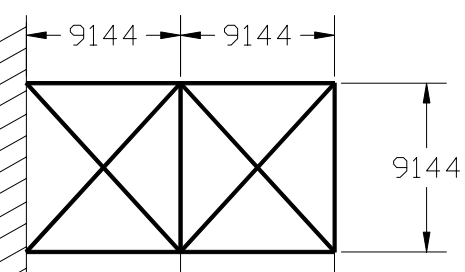

a) Configuração original

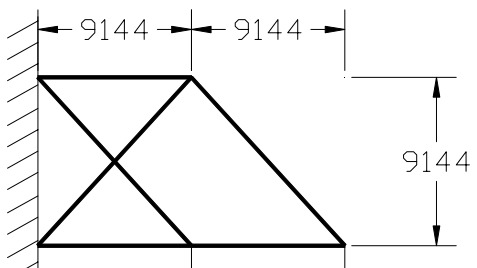

b) Configuração final otimizada

Figura 3-17. Treliça de 10 barras [LEITE \& TOPPING (1998)]

Tabela 3-9. Resultados finais para a treliça de 10 barras

\begin{tabular}{|c||c|}
\hline Métodos & Peso $\mathbf{( k g )}$ \\
\hline \hline SA (Simulated Annealing) & 725,3 \\
\hline GEBENOPT & 719,9 \\
\hline Métodos convencionais & $\mathbf{7 1 9 , 0}$ \\
\hline
\end{tabular}

Pode ser verificado na Tabela 3-9, que o resultado obtido pelo AG praticamente se iguala àquele obtido pelos métodos convencionais.

ERBATUR et al (2000) analisaram vários sistemas de treliças a fim de minimizar o peso da estrutura. Um dos exemplos analisados foi uma treliça de 25 barras, exatamente a mesma descrita em RAJEV \& KRISHNAMOORTHY (1992) (Figura 3-7). Os resultados são apresentados pela Tabela 3-10.

Tabela 3-10. Resultados do peso para a treliça de 25 barras

\begin{tabular}{|c||c|}
\hline Métodos & Peso (kg) \\
\hline \hline RAJEV \& & 247,8 \\
KRISHNAMOORTHY (1992) & \\
\hline AG (EBARTUR et. al (2000)) & 224,2 \\
\hline Literatura técnica & 255,5 \\
\hline
\end{tabular}

Outros trabalhos que foram realizados e que merecem destaque nessa linha são listados a seguir. 
a) OHSAKI (1995) analisou um problema de otimização que procura encontrar topologias ótimas para uma treliça de 3 e 20 barras;

b) WU \& CHOW (1995a) realizaram a otimização do peso de treliças considerando variáveis discretas para as seções transversais e contínuas para os deslocamentos;

c) KALLASSY \& MARCELIN (1997) apresentaram a otimização das posições dos enrijecedores em placas. O objetivo do problema é encontrar o menor deslocamento perpendicular à superfície neutra da placa, sendo dados o comprimento da placa, o carregamento e as condições de contorno;

d) CHENG \& LI (1998) definiram o Pareto GA que localiza o ótimo de Pareto para um problema de otimização multiobjetivo. Foram analisados dois sistemas de treliça descritos na literatura com o objetivo de minimizar o peso da estrutura;

e) KOUMOUSIS \& ARSENIS (1998) analisaram uma viga retangular contínua para dois vãos. A quantidade e a área utilizada de armadura são as variáveis do problema e o objetivo é a minimização do seu peso;

f) KWAN (1998) apresentou a otimização para as estruturas de treliças. As variáveis são os números de barras, as juntas e sua localização no sistema de treliça. O objetivo é minimizar o peso final do sistema.

\subsection{O USO DE AG EM ESTRUTURAS DE CONCRETO}

Nesta seção são discutidos trabalhos relevantes relativos ao uso de AGs na solução de problemas de otimização em estruturas de concreto.

NAGENDRA et al (1996) minimizaram o peso dos painéis compostos para uma seqüência de empilhamento. As variáveis usadas foram o número de camadas na superfície, número de camadas de enrijecedores e áreas da flange, da superfície e da lâmina. O problema se resume em encontrar as seqüências de empilhamento do painel, da superfície e das lâminas enrijecedoras, bem como a altura do enrijecedor $\left(\mathrm{H}_{\mathrm{b}}\right)$ a fim de minimizar o peso do painel. A Figura 3-18 ilustra o painel com suas dimensões. $\mathrm{O}$ artigo não fornece muitos dados sobre como o $\mathrm{AG}$ foi implementado para solucionar o problema proposto. 


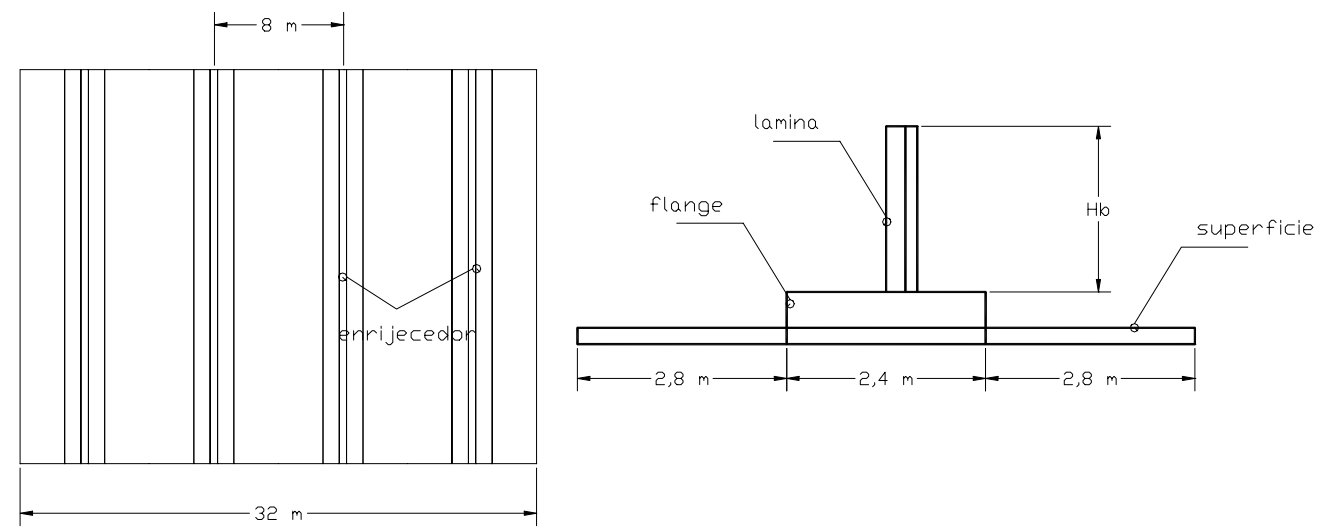

Figura 3-18. Painel analisado por NAGENDRA et al (1996)

COELLO et al (1997) analisaram vigas de concreto armado utilizando o método dos AGs, minimizando o custo dos materiais. As variáveis estão mostradas na Figura 3-19 e correspondem à altura e largura do concreto e a armadura da seção transversal.

Os autores usaram o AG simples proposto por GOLDBERG (1989) e experimentaram com diversos esquemas de representação: binário, código de Gray e real. Foram usados o operador de cruzamento $2 \mathrm{X}$ e a estratégia de seleção torneio nos experimentos. Os autores nada comentam sobre o tamanho de população utilizada nos testes.

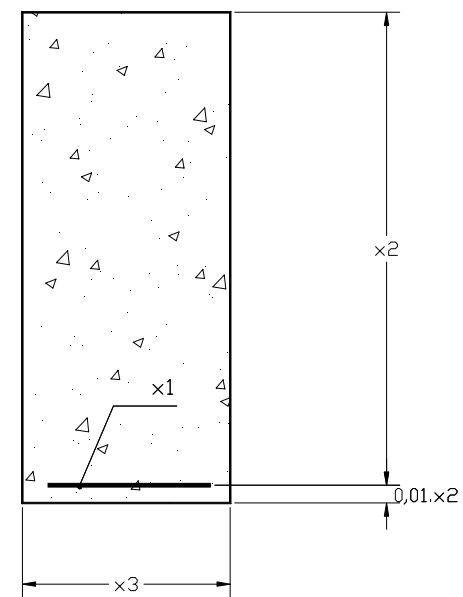

Figura 3-19. Seção transversal da viga a ser otimizada [COELLO et al (1997)]

No código de Gray a representação de dois valores consecutivos difere somente pela permuta de 1 bit, fazendo com que a mudança de uma unidade na variável corresponda apenas a troca de 1 bit na codificação. Os resultados das 
representações foram comparados com o modelo de CHAKRABARTY (1992), que usa algoritmos de programação não-linear. A Tabela 3-11 mostra os valores de custo da viga para as diferentes abordagens.

Tabela 3-11. Custo total da viga

\begin{tabular}{|c|c|c|c|}
\hline $\begin{array}{c}\text { CHAKRABARTY (1992) } \\
\$ / \mathrm{cm}\end{array}$ & $\begin{array}{c}\text { AG (binário) } \\
\$ / \mathrm{cm}\end{array}$ & $\begin{array}{c}\text { AG (código de Gray) } \\
\$ / \mathrm{cm}\end{array}$ & $\begin{array}{c}\text { AG (real) } \\
\$ / \mathrm{cm}\end{array}$ \\
\hline \hline 0,4435 & 0,4442 & 0,4464 & 0,4436 \\
\hline
\end{tabular}

Na tabela vê-se que os resultados se apresentaram próximos, sendo o melhor obtido pela representação real e o pior pelo código de Gray. Os autores pretendem, em trabalhos futuros, ajustar os parâmetros genéticos com outra técnica heurística como a lógica fuzzy.

JENKIS (1997) analisou uma estrutura aporticada, mostrada na Figura 3-20. As variáveis são as seções transversais das vigas e pilares, as áreas e a altura da treliça, o comprimento do balanço e as seções dos tirantes. O autor minimizou o volume mínimo de material da estrutura considerando o caso de variáveis discretas.

Para a busca da solução via AG foram usados a representação binária, tamanho de população de 50 indivíduos e estratégia de seleção roleta.

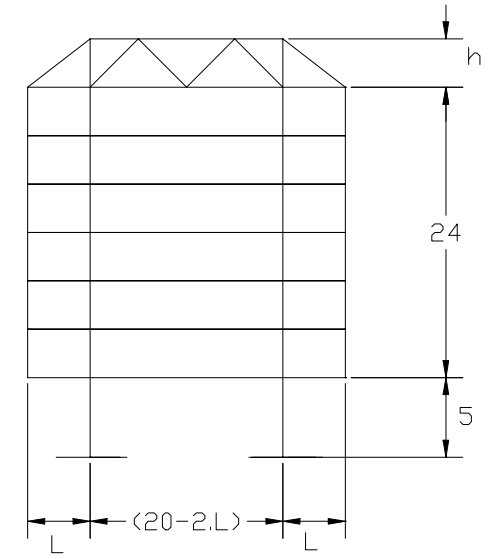

Figura 3-20. Estrutura aporticada analisada [JENKIS (1997)]

O trabalho propõe ainda um melhoramento para os operadores genéticos dado pela equação (3.1). 


$$
\begin{aligned}
& \mathrm{p}_{\mathrm{c}}[\mathrm{i}]=\mathrm{p}_{\mathrm{co}}+\left(1-\mathrm{p}_{\mathrm{co}}\right) \mathrm{r} \\
& \mathrm{p}_{\mathrm{m}}[\mathrm{i}]=\mathrm{p}_{\mathrm{mo}}(1-\mathrm{r})
\end{aligned}
$$

onde $\mathrm{p}_{\mathrm{c}}[\mathrm{i}]$ - probabilidade de cruzamento do vetor representando pela variável $\mathrm{i}$;

$\mathrm{p}_{\mathrm{m}}[\mathrm{i}]$ - probabilidade de mutação do vetor representando pela variável i;

$\mathrm{p}_{\mathrm{co}}, \mathrm{p}_{\mathrm{mo}}$ - valores iniciais das probabilidades de cruzamento e mutação, respectivamente;

$\mathrm{r}$ - razão do número da geração e do número máximo de geração.

O problema foi solucionado para 10 gerações diferentes de números aleatórios. Os resultados obtidos são apresentados pela Tabela 3-12, considerando ou não probabilidades diferentes de cruzamento e mutação para cada geração. Não se tem o valor correto na literatura, mas sabe-se que o peso mínimo é da ordem de $11000 \mathrm{~kg}$.

Tabela 3-12. Valores encontrados da otimização do pórtico

\begin{tabular}{|c|c|c|}
\hline Run & $\begin{array}{c}\text { Massa (kg) } \\
\text { sem o melhoramento dos } \\
\text { operadores }\end{array}$ & $\begin{array}{c}\text { Massa (kg) } \\
\text { com o melhoramento } \\
\text { dos operadores }\end{array}$ \\
\hline \hline 1 & 12228 & 10844 \\
\hline 2 & 12567 & 10775 \\
\hline 3 & 12991 & 10961 \\
\hline 4 & 11817 & 11191 \\
\hline 5 & 12485 & 11035 \\
\hline 6 & 12608 & 11256 \\
\hline 7 & 12020 & 10597 \\
\hline 8 & 11801 & 10823 \\
\hline 9 & 13076 & 10830 \\
\hline 10 & 13166 & 10931,2 \\
\hline média & 12475,9 & \\
\hline
\end{tabular}

A Tabela 3-12 mostra que o melhor peso obtido das 10 diferentes avaliações foi de $10931,20 \mathrm{~kg}$ no caso de utilizar o melhoramento proposto pela equação (10). Nota-se que utilizando alguma estratégia de melhoramento, o AG se apresentou muito mais eficiente que o AG simples. 
LI \& LOVE (1997) analisaram um projeto para a construção de uma casa residencial, com o objetivo da minimização do seu custo. As variáveis contínuas do problema foram definidas pelo tempo de duração de todas as atividades associadas à construção (da fundação à limpeza final da casa). A representação de dados adotada foi a real. Os autores não fornecem nenhuma indicação do tamanho de população e da estratégia de seleção usada.

Na implementação os autores impuseram a condição que, após o cruzamento, os filhos fossem factíveis. Através de cruzamentos melhorados, as soluções infactíveis seriam ajustadas por esses operadores a fim de torná-las factíveis. A Figura 3-21 ilustra os resultados da minimização. Nota-se que os AGs simples possuem um custo pior que os AGs melhorados.

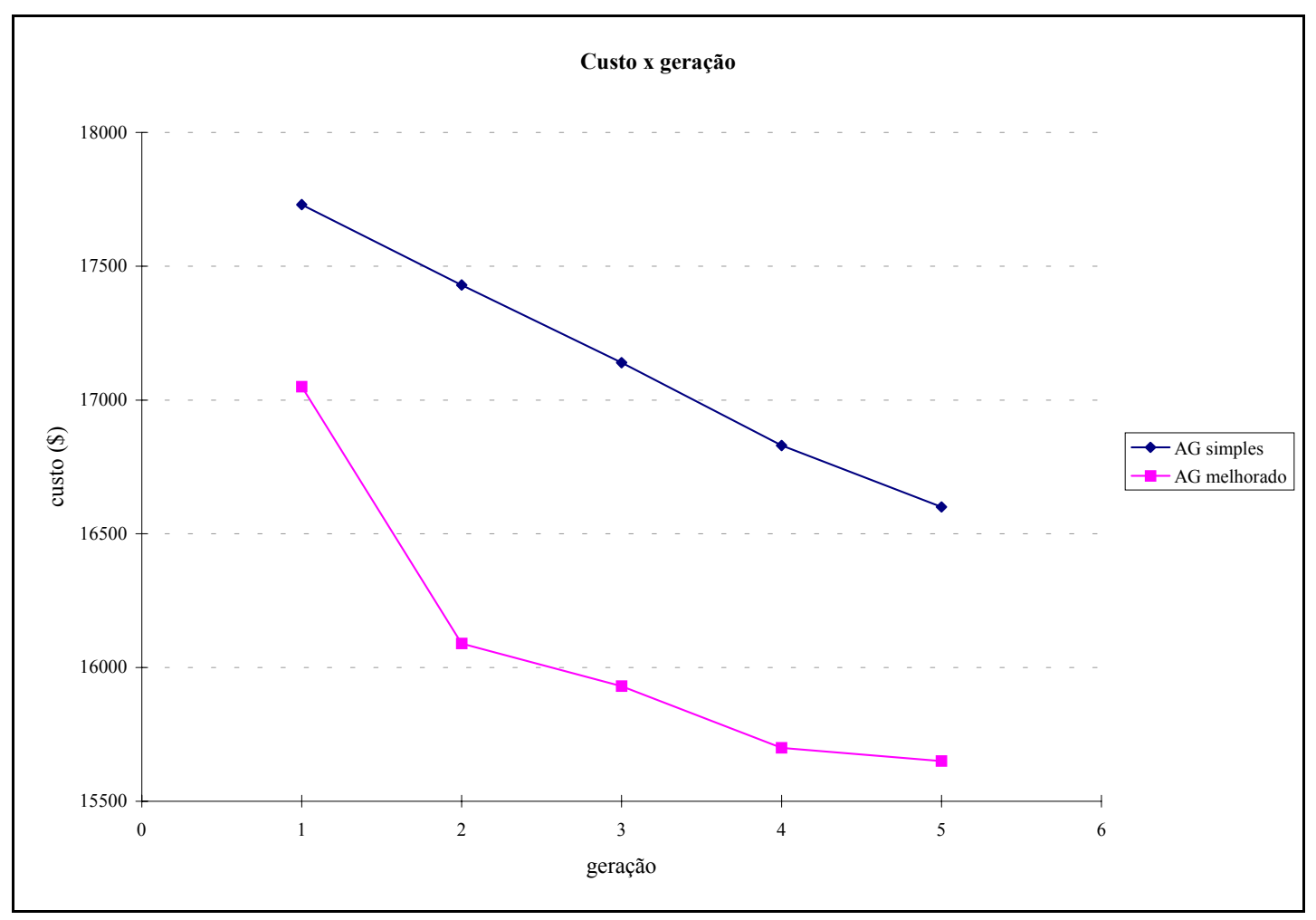

Figura 3-21. Comparação dos resultados para as duas análises [LI \& LOVE (1997)]

CERANIC \& FRYER (1998) analisaram a otimização do custo de uma viga contínua de concreto armado, ilustrada na Figura 3-22, considerando seção T. As variáveis contínuas consideradas foram a seção transversal e a altura da viga sendo a função objetivo dada pelo custo dos materiais. 
Foram definidos a representação binária, a população de tamanho 40 (constante nos experimentos) indivíduos, a estratégia de seleção rank, operadores de cruzamento $1 \mathrm{X}, 2 \mathrm{X}$ e uniforme. Foi introduzido um modelo elitista na busca da solução do problema.

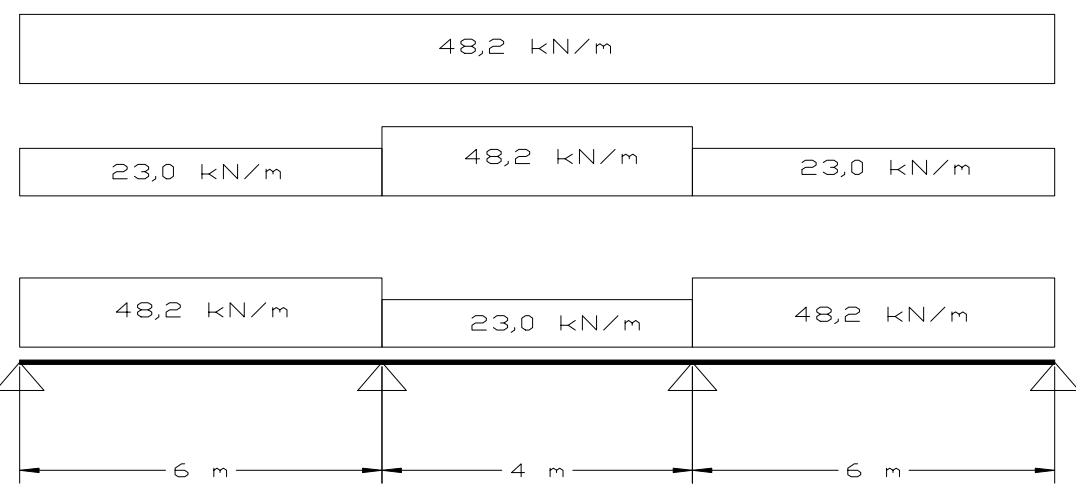

Figura 3-22. Viga contínua de seção T [CERANIC \& FRYER (1998)]

Os resultados obtidos são apresentados na Figura 3-23. Nela pode-se notar que o AG padrão apresenta um pior desempenho quando comparado com o $\mathrm{AG}$ considerando o elitismo.

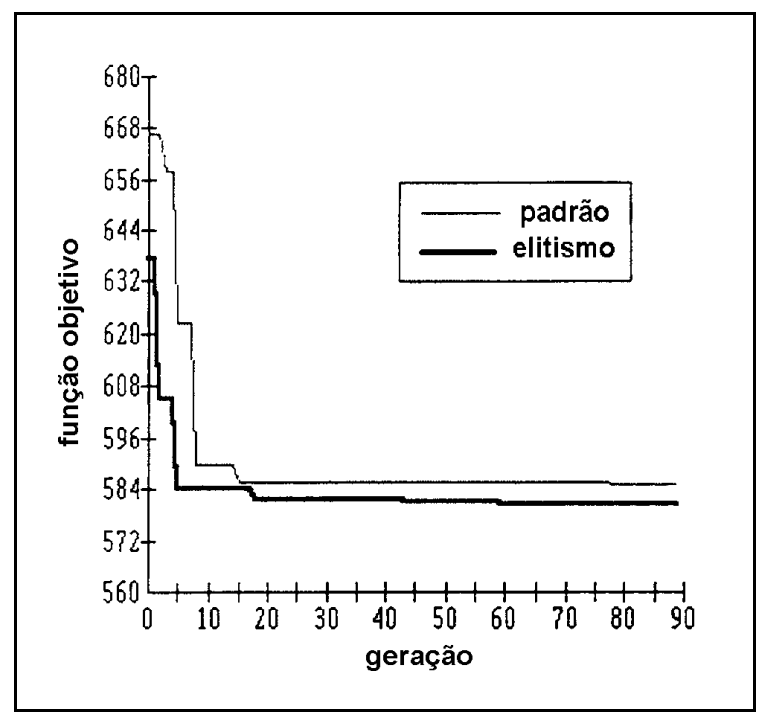

Figura 3-23. Comparação do método com e sem elitismo [CERANIC \& FRYER (1998)]

LEITE \& TOPPING (1998) ainda investigaram o problema de minimização do custo de material referente à vigas I de concreto protendido, usando AGs implementados como o sistema GEBENOPT (Genetic Based Engineering 
Optimization Tool). Este mesmo problema foi investigado por COHN \& LOUNIS (1993) usando métodos convencionais. A Figura 3-24 ilustra as características principais desta viga.

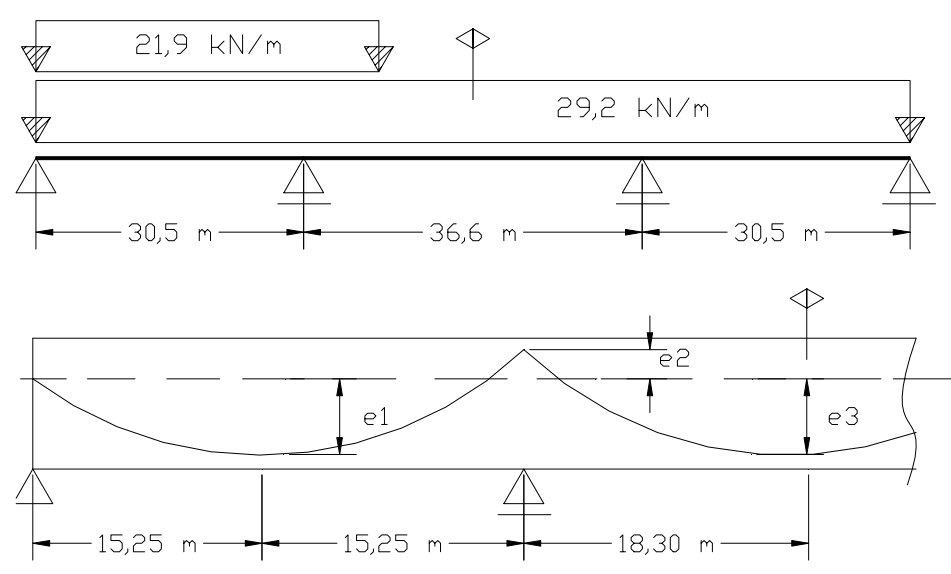

a) carregamento da viga e forma do cabo de protensão

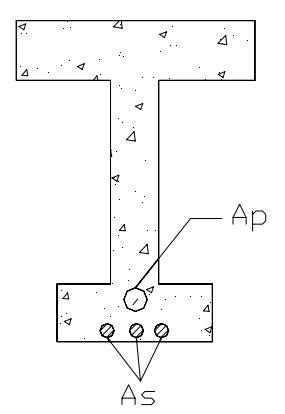

b) seção I considerada

Figura 3-24. Características da viga protendida [LEITE \& TOPPING (1998)]

Em COHN \& LOUNIS (1993) foram analisados dois problemas de minimização relativos à viga I. Para o primeiro, mostrado na Figura 3-25 (I), a seção da viga foi especificada a priori e para o segundo (II), as larguras da flange e da alma foram variáveis, enquanto que as alturas permaneceram constantes. Além dessas foram também consideradas variáveis o fator de redução do momento, a área de armadura passiva, as excentricidades e a força de protensão. O objetivo do problema foi minimizar o custo de material da viga. COHN \& LOUNIS (1993) utilizaram o programa GAMS/MINOS que é baseado no algoritmo Lagrangiano.

Com relação ao problema (I) os resultados do GEBENOPT ficaram 1\% melhores quando comparados com os obtidos com o GAMS/MINOS. Já com relação 
ao problema (II), as dimensões da largura e da flange foram diminuídas na solução encontrada pelo GEBENOPT, resultando uma economia de $11 \%$ com relação aos dados obtidos usando o GAMS/MINOS.
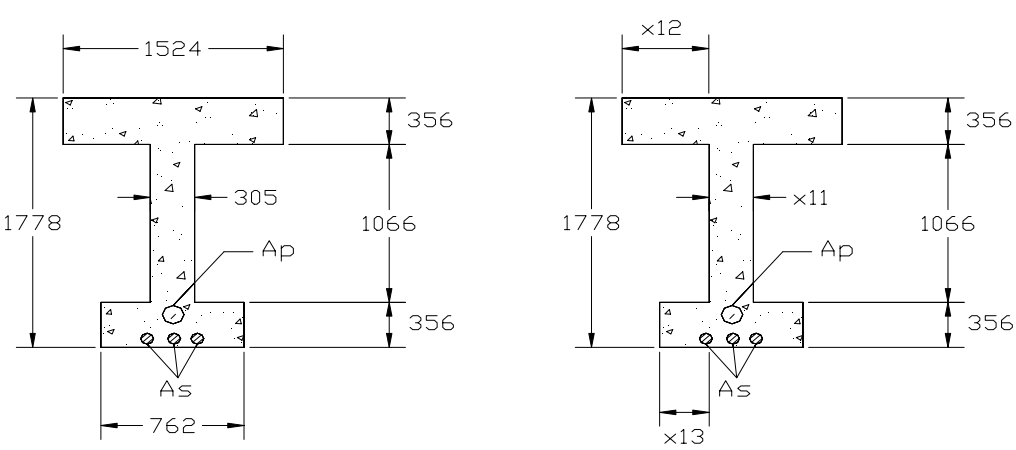

Figura 3-25. Características da viga protendida [LEITE \& TOPPING (1998)]

RAFIQ \& SOUTHCOMBE (1998) avaliaram o projeto de quatro pilares de concreto armado, incluindo seu detalhamento. O problema foi equacionado como uma função multiobjetivo que trata da minimização da armadura utilizada e da maximização da capacidade de flexão das seções nos dois eixos. Foi utilizado como referência a norma britânica.

Para a solução deste problema via $\mathrm{AG}$, a representação de dados adotada foi a binária para variáveis discretas. $\mathrm{O}$ tamanho da população foi de 50 indivíduos e o critério de parada adotado foi de 50 gerações. Os autores não fornecem mais informações sobre o AG utilizado.

Os valores obtidos para a armadura estão na Tabela 3-13 e a posição da armadura mostrada na Figura 3-26.

Tabela 3-13. Tabela de resultados da área de armadura [RAFIQ \& SOUTHCOMBE (1998)]

\begin{tabular}{|c||c||c||c|}
\hline Pilar & BS 8110 $\left.\mathbf{( m m}^{\mathbf{2}}\right)$ & AG $\mathbf{( m m}^{\mathbf{2}} \mathbf{| |}$ & Diferença \% \\
\hline \hline 1 & 1964 & 1608 & 22 \\
\hline 2 & 2592 & 2463 & 5 \\
\hline 3 & 12566 & 11467 & 10 \\
\hline 4 & 20970 & 17197 & 22 \\
\hline
\end{tabular}


Observa-se pelos resultados que o AG fornece uma maior economia de armadura chegando a uma redução de até 22\%. Na Figura 3-26 vê-se que além do AG apresentar melhores resultados, a disposição da armadura foi totalmente diferente que aquela obtida pelo método simplificado (seguindo norma britânica BS8110).

\section{BS 8110 - método simplificado}
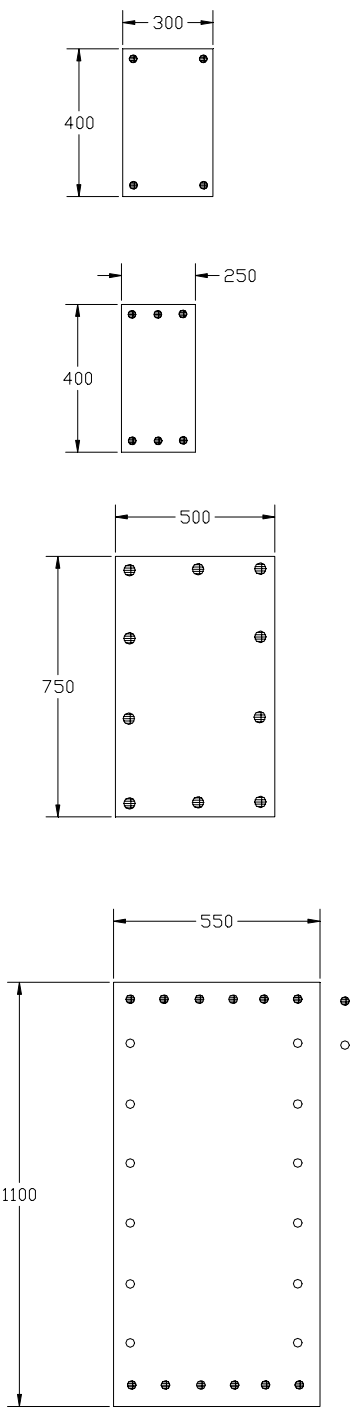

$\underline{\mathbf{A G}}$
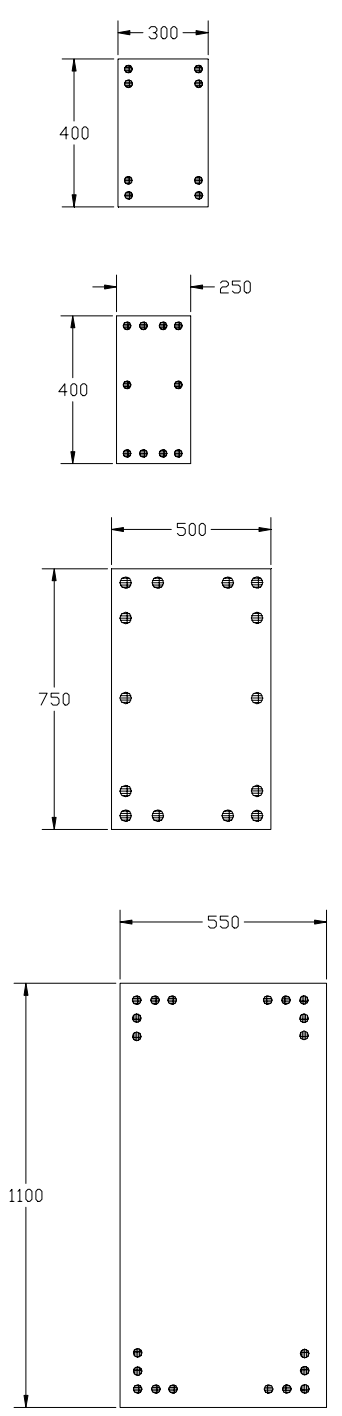

Figura 3-26. Resultados da disposição da armadura (medidas em mm) [RAFIQ \& SOUTHCOMBE (1998)]

RAJEV \& KRISHNAMOORTHY (1998) analisaram estruturas de pilares e vigas de um pórtico com o objetivo de minimizar o seu custo. As variáveis do 
problema foram as dimensões dos pilares e vigas e o detalhamento final (disposição da armadura). Para a busca da solução usando AG, foi adotada a representação binária usando variáveis discretas. Os autores nada comentam sobre o tamanho da população, estratégia de seleção usada e/ou qualquer outra característica genética.

Foram definidos dois tipos diferentes de problemas a fim de avaliar a aplicabilidade de AGs. O primeiro corresponde a um pórtico de quatro andares e o segundo a um pórtico de seis andares (Figura 3-27).

A Tabela 3-14 mostra os resultados finais dos dois exemplos do pórtico, considerando o método convencional, que usa uma técnica de busca direta (SUMT), e o AG. Observa-se que diferença entre os resultados foi bem significativa para ambos os casos analisados.

Tabela 3-14. Tabela final de custos para as duas análises

\begin{tabular}{|c||c||c||c|}
\cline { 2 - 4 } \multicolumn{1}{c|}{} & $\begin{array}{c}\text { SUMT } \\
\text { (\$) }\end{array}$ & $\begin{array}{c}\text { AG } \\
\mathbf{( \$ )}\end{array}$ & $\begin{array}{c}\text { Diferença } \\
\mathbf{\%}\end{array}$ \\
\hline \hline Pórtico de quatro andares & 22211,3 & $\mathbf{2 0 7 3 9 , 9}$ & 7,1 \\
\hline Pórtico de seis andares & 19480,0 & $\mathbf{1 7 8 0 4 , 1}$ & 8,6 \\
\hline
\end{tabular}

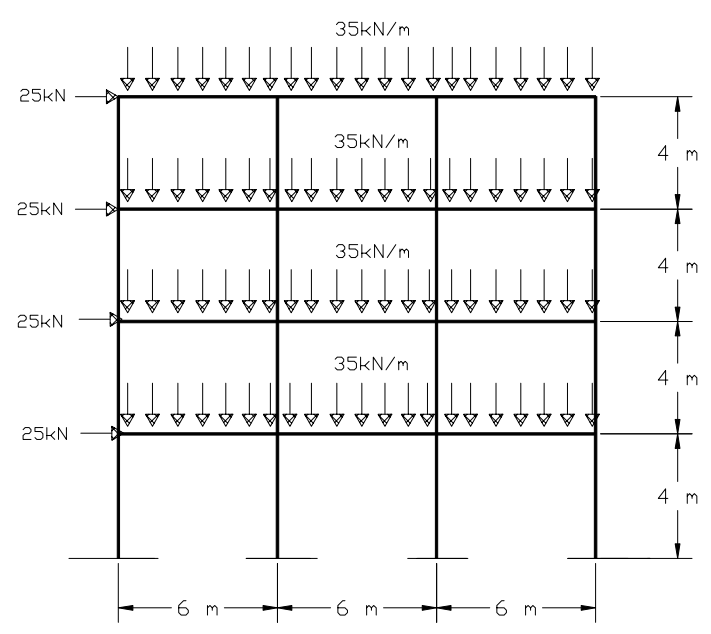

a) Características do pórtico de quatro andares

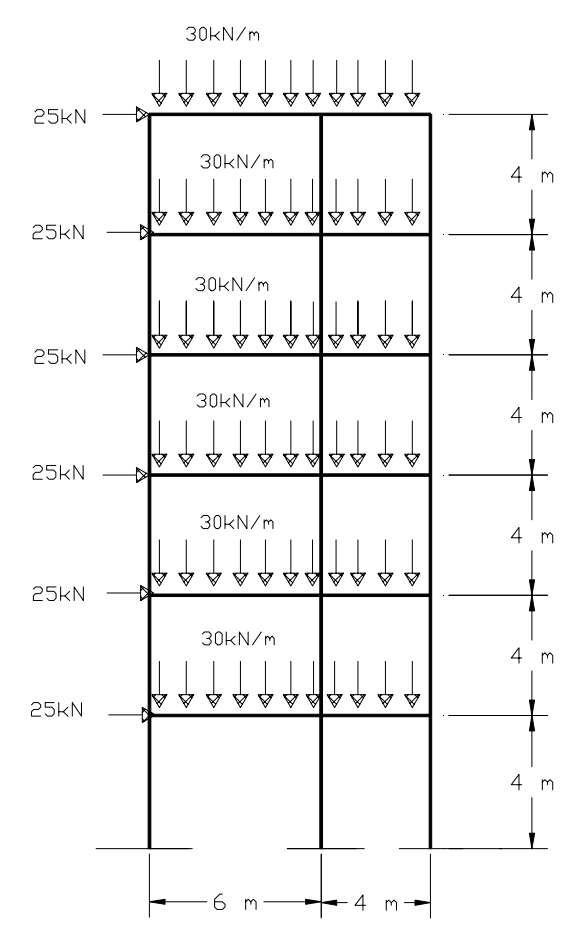

b) Características do pórtico de seis andares

Figura 3-27. Características principais das duas análises realizadas por RAJEV \& 
LEMONGE (1999) mostrou a utilização dos AGs na otimização de diversas estruturas. Foram analisados por ele problemas de minimização de peso para sistemas de treliças, otimização de parâmetros e topologia em estruturas reticuladas espaciais e planas, anteriormente analisadas por outros autores. Foram analisados vários exemplos numéricos comparando-os com os métodos convencionais. $\mathrm{O}$ autor evidencia a potencialidade do AG, além de sua facilidade de implementação, para a análise de diversos problemas de engenharia.

$\mathrm{O}$ autor ainda analisou a estrutura de uma ponte (Figura 3-28), considerando como variáveis as posições dos quatro pilares $\left(\mathrm{x}_{1}, \mathrm{x}_{2}, \mathrm{x}_{3}, \mathrm{x}_{4}\right)$ além da altura da viga.

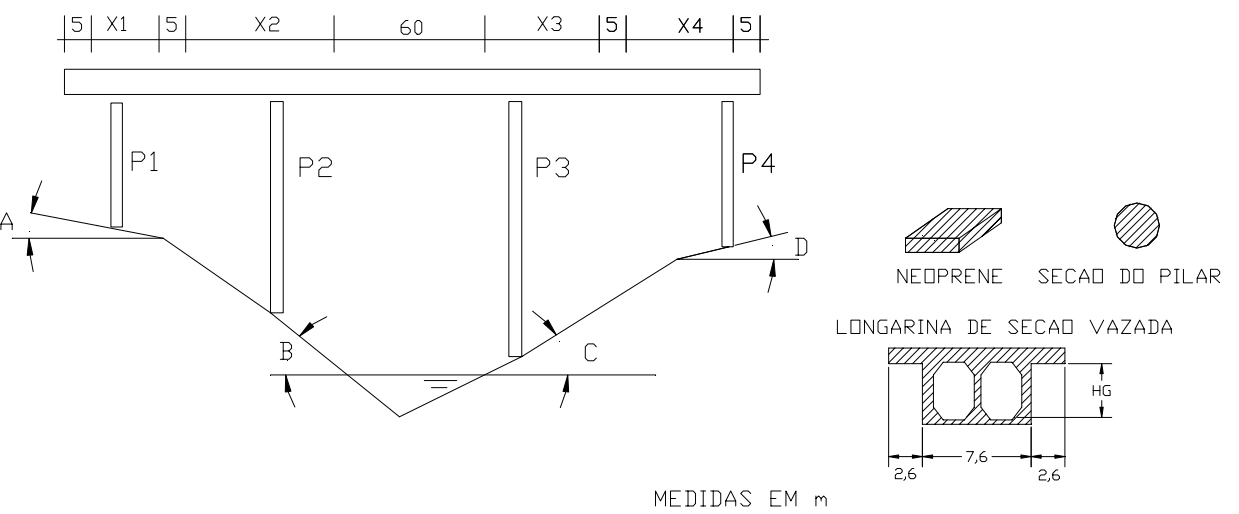

Figura 3-28. Estrutura de ponte analisada [LEMONGE (1999)]

No trabalho o autor propõe duas possíveis funções objetivo, dadas em (3.2).

$$
\mathrm{f}(\mathrm{x})=\int_{\mathrm{L}} \mathrm{qudL} \quad \mathrm{f}_{1}(\mathrm{x})=\max \left\{\mathrm{r}_{1}, \mathrm{r}_{2}, \mathrm{r}_{3}, \mathrm{r}_{4}\right\}
$$

onde $\mathrm{f}(\mathrm{x})$ - função objetivo definida como a compliance

$f_{1}(x)$ - função objetivo definida como a reação de apoio máxima

q - carregamento aplicado na estrutura

$\mathrm{u}$ - deslocamento correspondente

L - comprimento total da ponte

$\mathrm{r}_{1}, \mathrm{r}_{2}, \mathrm{r}_{3}, \mathrm{r}_{4}$ - reações de apoio positivas (compressão nos pilares) nos pontos 1, 2, 3 e 4, respectivamente

Foram propostos quatro diferentes critérios para a definição do diâmetro de cada pilar. São eles:

Critério 1: corresponde a uma escolha subjetiva de projetista em particular; 
Critério 2: emprega o coeficiente de flambagem $\lambda$. Quatro variáveis adicionais $\left(\mathrm{x}_{6}\right.$, $\left.\mathrm{x}_{7}, \mathrm{X}_{8}, \mathrm{X}_{9}\right)$ são introduzidas e correspondem aos coeficientes de flambagem dos pilares $1,2,3$ e 4 , respectivamente;

Critério 3: após a aplicação do critério 2, um único valor é adotado, o maior deles; Critério 4: o coeficiente de flambagem $\lambda$ não é explicitamente utilizado. Para tanto, é introduzida uma variável adicional, $\mathrm{x}_{6}$, que representa um único valor de diâmetro.

Para os critérios 2 a 4 multiplica-se o volume total de concreto dos pilares nas duas funções objetivos. No trabalho adotou-se “(x)" como notação para indicar este critério.

A Tabela 3-15 mostra as variáveis de projeto obtidas na otimização da compliance. A Tabela 3-16 mostra alguns dos resultados obtidos considerando-se a minimização da compliance.

Pode ser observado na Tabela 3-16 que o critério 3b acarreta o mínimo valor da compliance com um maior volume de concreto, $\mathrm{VC}=63305 \mathrm{~m}^{3}$. Tal solução não é aceitável, pois geram pilares com diâmetros excessivos. O critério 1 produz o maior valor de compliance com o menor valor de concreto $\mathrm{VC}=3140 \mathrm{~m}^{3}$. Entretanto, as melhores soluções são aquelas obtidas pela minimização do produto da compliance por VP. Neste caso, o critério 4(x) possui um volume de concreto $\mathrm{VC}=2180,0 \mathrm{~m}^{3}$ para pilares com um único diâmetro $(2,4 \mathrm{~m})$ sendo então a melhor solução encontrada.

Tabela 3-15. Variáveis de projeto para a minimização da compliance $\mathrm{x}_{1} \mathrm{a} \mathrm{x}_{4}$ - vão dos pilares, $\mathrm{x}_{5}$ - associada à altura da viga, $\mathrm{x}_{6} \mathrm{a} \mathrm{x}_{9}$ - reações de apoio

\begin{tabular}{|c|c|c|c|c|c|c|c|c|c|}
\hline critério & $\mathbf{x}_{\mathbf{1}}$ & $\mathbf{x}_{\mathbf{2}}$ & $\mathbf{x}_{\mathbf{3}}$ & $\mathbf{x}_{\mathbf{4}}$ & $\mathbf{x}_{\mathbf{5}}$ & $\mathbf{x}_{\mathbf{6}}$ & $\mathbf{x}_{\mathbf{7}}$ & $\mathbf{x}_{\mathbf{8}}$ & $\mathbf{x}_{\mathbf{9}}$ \\
\hline 1 & 5,0 & 3,748 & 0,0 & 5,521 & 24,0 & - & - & - & - \\
\hline $2 \mathrm{a}(\mathrm{x})$ & 5,0 & 4,310 & 0,0 & 3,808 & 24,0 & 40,0 & 186,08 & 148,231 & 40,0 \\
\hline $2 \mathrm{a}$ & 5,0 & 4,066 & 0,0 & 5,654 & 24,0 & 20,0 & 40,0 & 40,0 & 20,0 \\
\hline $2 \mathrm{~b}(\mathrm{x})$ & 5,0 & 5,397 & 0,0 & 5,419 & 24,0 & 115,718 & 200,0 & 200,0 & 148,973 \\
\hline $2 \mathrm{~b}$ & 5,0 & 4,139 & 0,0 & 5,591 & 24,0 & 20,0 & 20,0 & 20,0 & 20,0 \\
\hline $3 \mathrm{a}(\mathrm{x})$ & 5,0 & 5,092 & 0,0 & 2,315 & 24,0 & 38,749 & 175,914 & 181,075 & 40,0 \\
\hline $3 \mathrm{a}$ & 5,0 & 4,066 & 0,0 & 5,63 & 24,0 & 32,532 & 40,0 & 190,928 & 24,125 \\
\hline $3 \mathrm{~b}(\mathrm{x})$ & 5,0 & 5,25 & 0,0 & 5,45 & 24,0 & 110,968 & 200,0 & 192,258 & 146,686 \\
\hline $3 \mathrm{~b}$ & 5,0 & 4,127 & 0,0 & 5,591 & 24,0 & 30,029 & 20,0 & 91,789 & 65,572 \\
\hline $4(\mathrm{x})$ & 5,0 & 4,115 & 0,0 & 5,505 & 24,0 & 2,4 & - & - & - \\
\hline 4 & 5,0 & 4,139 & 0,0 & 5,591 & 24,0 & 20,0 & - & - & - \\
\hline
\end{tabular}


Tabela 3-16. Resumo das análises para a minimização da compliance onde $\mathrm{D}_{1}$ a $\mathrm{D}_{4}$ - seção dos pilares $(\mathrm{m}), \mathrm{VP}-$ volume de concreto dos pilares $\left(\mathrm{m}^{3}\right), \mathrm{VC}$ - volume de concreto total da ponte $\left(\mathrm{m}^{3}\right)$, comp - resultado da minimização da compliance

\begin{tabular}{|c|c|c|c|c|c|c|c|c|}
\hline critério & $\mathbf{D}_{\mathbf{1}}$ & $\mathbf{D}_{\mathbf{2}}$ & $\mathbf{D}_{\mathbf{3}}$ & $\mathbf{D}_{\mathbf{4}}$ & $\mathbf{V P}$ & $\mathbf{V C}$ & comp. & comp.xVP \\
\hline 1 & 1,788 & 4,708 & 3,6 & 2,201 & 1611,5 & 3140,0 & 15,36 & \\
\hline $2 \mathrm{a}(\mathrm{x})$ & 3,577 & 2,510 & 2,429 & 4,277 & 984,4 & 2518,0 & & 21379 \\
\hline $2 \mathrm{a}$ & 7,155 & 11,718 & 9,0 & 8,823 & 11248,6 & 12780,0 & 10,86 & \\
\hline $2 \mathrm{~b}(\mathrm{x})$ & 1,236 & 2,299 & 1,8 & 1,18 & 398,6 & 1941,8 & & 11875 \\
\hline $2 \mathrm{~b}$ & 7,155 & 23,411 & 18,0 & 8,814 & 38707,4 & 40239,4 & 10,4 & \\
\hline $3 \mathrm{a}(\mathrm{x})$ & 4,169 & 4,169 & 4,169 & 4,169 & 1930,5 & 3471,0 & & 291717 \\
\hline $3 \mathrm{a}$ & 11,718 & 11,718 & 11,718 & 11,718 & 15477,4 & 17008,7 & 10,68 & \\
\hline $3 \mathrm{~b}(\mathrm{x})$ & 2,304 & 2,304 & 2,304 & 2,304 & 593,9 & 2135,8 & & 14237 \\
\hline $3 \mathrm{~b}$ & 23,415 & 23,415 & 23,415 & 23,415 & 61773,0 & 63305,0 & 10,29 & \\
\hline $\mathbf{4 ( x )}$ & $\mathbf{2 , 4}$ & $\mathbf{2 , 4}$ & $\mathbf{2 , 4}$ & $\mathbf{2 , 4}$ & $\mathbf{6 4 8 , 9}$ & $\mathbf{2 1 8 0 , 0}$ & & $\mathbf{1 4 6 5 1}$ \\
\hline 4 & 20,0 & 20,0 & 20,0 & 20,0 & 45065,7 & 46697,8 & 10,34 & \\
\hline
\end{tabular}

A Tabela 3-17 mostra as variáveis de projeto obtidas na otimização da reação máxima.

Tabela 3-17. Variáveis de projeto para a minimização da reação máxima, onde $\mathrm{x}_{1}$ a $\mathrm{x}_{4}$-vão dos pilares, $\mathrm{x}_{5}$ - associada à altura da viga, $\mathrm{x}_{6} \mathrm{a} \mathrm{x}_{9}$ - reações de apoio

\begin{tabular}{|c|c|c|c|c|c|c|c|c|c|}
\hline critério & $\mathbf{x}_{\mathbf{1}}$ & $\mathbf{x}_{\mathbf{2}}$ & $\mathbf{x}_{\mathbf{3}}$ & $\mathbf{x}_{\mathbf{4}}$ & $\mathbf{x}_{\mathbf{5}}$ & $\mathbf{x}_{\mathbf{6}}$ & $\mathbf{x}_{\mathbf{7}}$ & $\mathbf{x}_{\mathbf{8}}$ & $\mathbf{x}_{\mathbf{9}}$ \\
\hline 1 & 5,0 & 0,0 & 0,0 & 0,0 & 28,0 & - & - & - & - \\
\hline $2 \mathrm{a}(\mathrm{x})$ & 0,0 & 13,419 & 1,197 & 0,0 & 28,0 & 40,0 & 200,0 & 200,0 & 40,0 \\
\hline $2 \mathrm{a}$ & 5,0 & 0,0 & 0,0 & 0,0 & 28,0 & 20,0 & 200,0 & 40,0 & 40,0 \\
\hline $2 \mathrm{~b}(\mathrm{x})$ & 0,0 & 27,741 & 12,077 & 0,0 & 28,0 & 199,824 & 200,0 & 200,0 & 200,0 \\
\hline $2 \mathrm{~b}$ & 5,0 & 0,0 & 0,0 & 0,0 & 28,0 & 20,0 & 200,0 & 20,0 & 200,0 \\
\hline $3 \mathrm{a}(\mathrm{x})$ & 0,0 & 29,06 & 7,39 & 0,0 & 28,0 & 189,619 & 200,0 & 200,0 & 193,314 \\
\hline $3 \mathrm{a}$ & 5,0 & 0,0 & 0,0 & 0,0 & 28,0 & 135,249 & 200,0 & 158,651 & 159,179 \\
\hline $3 \mathrm{~b}(\mathrm{x})$ & 5,0 & 5,092 & 0,0 & 0,0 & 28,0 & 37,087 & 186,237 & 157,458 & 40,0 \\
\hline $3 \mathrm{~b}$ & 5,0 & 0,0 & 0,0 & 0,0 & 28,0 & 39,374 & 178,104 & 152,766 & 40,0 \\
\hline $4(\mathrm{x})$ & 5,0 & 5,018 & 0,0 & 0,0 & 28,0 & 2,4 & - & - & - \\
\hline 4 & 5,0 & 0,0 & 0,0 & 0,0 & 28,0 & 2,4 & - & - & - \\
\hline
\end{tabular}

A Tabela 3-18 mostra alguns dos resultados obtidos considerando-se a minimização da reação máxima. 
Tabela 3-18. Resumo das análises para a minimização da reação máxima, onde $D_{1}$ a $D_{4}-$ seção dos pilares (m), VP - volume de concreto dos pilares $\left(\mathrm{m}^{3}\right), \mathrm{VC}$ - volume de concreto total da ponte $\left(\mathrm{m}^{3}\right)$, comp. - resultado da minimização da reação de apoio

\begin{tabular}{|c|c|c|c|c|c|c|c|c|}
\hline critério & $\mathbf{D}_{\mathbf{1}}$ & $\mathbf{D}_{\mathbf{2}}$ & $\mathbf{D}_{\mathbf{3}}$ & $\mathbf{D}_{\mathbf{4}}$ & $\mathbf{V P}$ & $\mathbf{V C}$ & max. r. & max. $\mathbf{r} \mathbf{x} \mathbf{P}$ \\
\hline 1 & 1,786 & 4,96 & 3,6 & 2,0 & 1763,8 & 3182,7 & 1262,9 & \\
\hline $2 \mathrm{a}(\mathrm{x})$ & 3,0 & 2,029 & 1,752 & 4,0 & 627,1 & 2157,5 & & 930017 \\
\hline $2 \mathrm{a}$ & 3,0 & 1,929 & 1,64 & 4,0 & 584,9 & 2159,6 & 1258,5 & \\
\hline $2 \mathrm{~b}(\mathrm{x})$ & 0,6 & 1,549 & 1,317 & 0,83 & 132,1 & 1854,8 & & 279039 \\
\hline $2 \mathrm{~b}$ & 7,156 & 2,48 & 18,0 & 0,8 & 12479,8 & 13898,7 & 1257,0 & \\
\hline $3 \mathrm{a}(\mathrm{x})$ & 1,505 & 1,505 & 1,505 & 1,505 & 196,0 & 1893,0 & & 393541 \\
\hline $3 \mathrm{a}$ & 2,48 & 2,48 & 2,48 & 2,48 & 699,9 & 2118,8 & 1261,0 & \\
\hline $3 \mathrm{~b}(\mathrm{x})$ & 4,0 & 4,0 & 4,0 & 4,0 & 1767,0 & 3224,8 & & 2283767 \\
\hline $3 \mathrm{~b}$ & 4,0 & 4,0 & 4,0 & 4,0 & 1820,7 & 3239,6 & 1261,0 & \\
\hline $4(\mathrm{x})$ & 2,4 & 2,4 & 2,4 & 2,4 & 636,4 & 2093,6 & & 8215257 \\
\hline $\mathbf{4}$ & $\mathbf{2 , 4}$ & $\mathbf{2 , 4}$ & $\mathbf{2 , 4}$ & $\mathbf{2 , 4}$ & $\mathbf{6 5 5 , 5}$ & $\mathbf{2 0 7 4 , 4}$ & $\mathbf{1 2 6 0 , 9}$ & \\
\hline
\end{tabular}

Observa-se pela Tabela 3-18 que os valores das reações máximas de apoio são semelhantes e foram encontradas com volumes também similares com exceção do critério $2 \mathrm{~b}$. Os critérios $3 \mathrm{a}, 3 \mathrm{~b}$ e 4 definem pilares com o mesmo diâmetro e com razoáveis valores para o projeto. O melhor resultado obtido das análises foi aquele usando o critério 4, com o menor volume de concreto, $\mathrm{VC}=2074,4 \mathrm{~m}^{3}$ e pilares com diâmetro de $2,4 \mathrm{~m}$.

ARGOLO (2000) trata do dimensionamento ótimo de seções retangulares de concreto armado submetidas a flexo-compressão reta. Para a solução do problema via $\mathrm{AG}$, as variáveis usadas foram a altura da seção transversal de concreto, a largura da seção transversal, o número de camadas de aço na seção de concreto, o número de barras em uma mesma camada de aço e o diâmetro das barras de uma mesma camada. Foram avaliadas ainda várias seções de concreto armado. A função objetivo foi definida como sendo a somatória dos custos dos materiais e o objetivo, sua minimização. A representação adotada foi a binária e o tamanho da população foi de 100 indivíduos tendo como critério de parada 80 gerações. O autor faz algumas análises quanto à variação de preços dos materiais e como tal mudança pode refletir nos resultados finais. 


\subsection{COMENTÁRIOS ADICIONAIS}

Os dados evidenciados na pesquisa bibliográfica realizada mostram que, na maioria dos casos, os AGs obtiveram melhores resultados que os métodos convencionais utilizados. Vale notar que a maioria dos trabalhos adota a representação binária. Para estruturas metálicas a codificação é exclusivamente binária, pois cada conjunto de binários corresponde a variáveis discretas cujos valores representam as áreas de aço já existentes no mercado.

Análises referentes ao tamanho de população, ao tipo de representação, às várias técnicas de cruzamento e às funções penalidades foram feitas por diversos autores referentes a diversos problemas. Nota-se que tais parâmetros podem influenciar bastante o resultado final.

Com base no levantamento bibliográfico e investigação dos trabalhos disponíveis na literatura sobre AGs usados para a solução de problemas de engenharia estrutural, pode ser dizer que:

- a convergência é mais rápida para tamanhos maiores de população. Nesses casos, há um aumento relativo do tempo computacional. Para tamanhos menores, é necessário um número maior de gerações;

- os operadores de cruzamento também influenciam o resultado final. Nota-se uma tendência dos resultados serem melhores para os casos de cruzamentos $2 \mathrm{X}$ e $3 \mathrm{X}$. O cruzamento uniforme não se mostrou tão eficiente no caso da representação binária;

- o mecanismo steady-state tende a fornecer bons resultados;

O que pode ser comentado com relação ao levantamento bibliográfico realizado é que:

- o mesmo problema de sistemas de treliças plana e espacial é analisado por vários autores, em várias publicações. Algumas sequer mencionam que o sistema foi investigado anteriormente. A única mudança que alguns contemplam é a relativa ao valor do carregamento; 
- em muitos dos experimentos usando AG há falta de informação de características genéticas básicas, como por exemplo, tamanho de população, estratégia de seleção usada, número de avaliações, etc.. Os autores limitam-se a dizer que usaram AG, mas não fornecem qualquer outra informação;

- poucos trabalhos mostraram o número de execuções (run) realizadas para o problema e apenas um artigo apresentou a média, o pior e melhor valor obtido para a função objetivo. Na maioria, pode-se concluir que apenas uma execução foi realizada o que, de certa forma, é incorreto;

- os artigos investem bastante na descrição do AG propriamente dita e, quando de sua aplicação ao problema em questão ou não fornecem informação ou então, são bastante vagos;

- a maioria dos experimentos descritos não explora $\mathrm{AGs}$ em suas várias características e se limitam a, quanto muito, a experimentar uma ou duas de suas características apenas.

De todos os trabalhos descritos neste Capítulo, os trabalhos HASANCEBI \& ERBATUR (1998), RAJEEV \& KRISHNAMOORTHY (1990), CHEN \& CHEN (1997) LEITE \& TOPPING (1998), ARGOLO (2000) foram realmente relevantes e contribuíram com alguma informação, tanto para a definição e norteamento de alguns experimentos quanto para o estabelecimento de sublinhas de pesquisa. Vários dos artigos examinados não trazem informações completas sobre os experimentos, o que não permitiu um completo entendimento dos resultados. 


\section{Descrição, Representação e Minimização do Custo de Produção de Painéis Alveolares}

\subsection{PRELIMINARES}

Neste capítulo é abordado em detalhes o uso de AG na solução de dois problemas típicos de Engenharia Estrutural: a otimização de um painel alveolar sem capa estrutural e a otimização de um painel alveolar com capa estrutural.

Em ambos os problemas foram analisados o impacto nos resultados de vários parâmetros genéticos, com o objetivo de identificar a melhor configuração desses parâmetros para a solução deste tipo de problema. Por essa razão foram propostos 22 AGs variantes, cujas definições foram determinadas pelas diferentes combinações da estratégia de seleção, esquema de reprodução e restauração da população ao tamanho original.

Para viabilizar uma análise comparativa entre AG e um método convencional de otimização de problemas não lineares, são discutidos os resultados obtidos usando o Método do Lagrangiano Aumentado na busca da solução de ambos os problemas.

Para a obtenção dos resultados usando $A G$ foram feitas 22 implementações em $\mathrm{C}++$, sob ambiente operacional Windows NT; as descrições dos algoritmos implementados encontram-se no Apêndice B. O software que implementa o Método do Lagrangiano Aumentado (EASY) foi obtido junto à 
www.ime.unicamp/ martinez. O Apêndice $\mathrm{C}$ apresenta uma breve descrição do método e algumas informações sobre o software utilizado. As próximas seções irão tratar dos seguintes problemas:

- a busca da solução via AG da otimização de um painel alveolar sem capa estrutural problema tratado no trabalho de KOSKITO \& ELLINGWOOD (1997) via método convencional. Será minimizado o custo de produção do painel, considerando como variáveis a altura do painel, a área de armadura e a resistência do concreto do elemento pré-moldado;

- a busca da solução via AG e via EASY da otimização do painel alveolar sem capa estrutural para uma determinada aplicação: será minimizado o custo de produção do painel considerando como variáveis a altura do painel alveolar, a área de armadura e a resistência do concreto;

- a busca da solução via AG e via EASY da otimização da aplicação do painel alveolar com uma capa estrutural: será minimizado o custo de produção, transporte e aplicação do painel considerando como variáveis a altura do painel alveolar, a área de armadura, a resistência do concreto do elemento pré-moldado, altura da capa de concreto e a resistência do concreto da capa.

\subsection{CONSIDERAÇÕES SOBRE O PROJETO E A APLICAÇÃO DE PAINEL ALVEOLAR EM LAJES}

As informações descritas nesta Seção foram compiladas da referência EL DEBS (2000).

Painéis alveolares são os elementos pré-moldados mais empregados no mundo, em especial na América do Norte e Europa Ocidental. A produção mundial desse tipo de elemento é estimada em 150 milhões de metros cúbicos por ano. Teve origem na Alemanha e tem evoluído ao longo dos anos, em termos de altura e de vão. A aplicação mais comum desse tipo de elemento é em lajes, mas podem também ser empregado em sistemas de fechamentos. No caso de lajes podem ou não ser compostos de uma capa de concreto moldado no local, formando seção composta. No caso de sistemas de fechamento podem ter camada adicional formando painel sanduíche. 
Geralmente os painéis alveolares são também chamados de laje vazada ou oca. Os vazamentos desses elementos podem assumir forma circular, oval, "pseudo" elipse, retangular, etc. Algumas dessas formas são apresentadas na Figura 4-1. Normalmente esses elementos são de concreto protendido e são projetados para funcionar simplesmente apoiados.
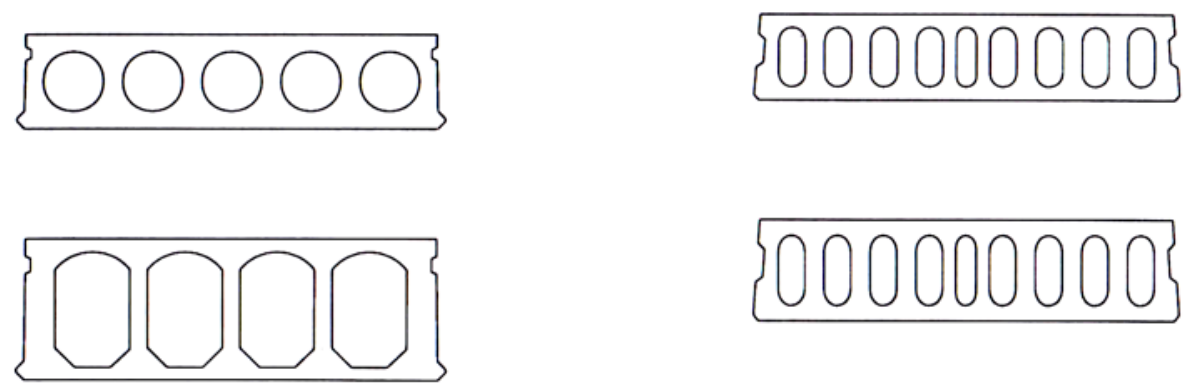

Figura 4-1. Formas de seção transversal de painéis alveolares [EL DEBS (2000)]

Painéis alveolares podem ser produzidos utilizando fôrmas fixas ou, mais comumente, usando uma extrusora ou fôrma deslizante, em uma pista de concretagem. Neste caso, os painéis são produzidos utilizando todo o comprimento da pista e, posteriormente, são serrados no comprimento desejado. A Figura 4-2 exibe as fases de montagem e acabamento desses painéis em uma obra, a título de ilustração.

$\mathrm{Na}$ análise estrutural das lajes executadas com painéis alveolares admite-se que o comportamento do elemento corresponda ao de laje armada em uma direção.

A faixa de vãos em que esse tipo de elemento é empregado está entre $5 \mathrm{~m}$ e $15 \mathrm{~m}$ e a largura entre $1,00 \mathrm{~m}$ a $1,20 \mathrm{~m}$, podendo chegar a $2,50 \mathrm{~m}$. As alturas variam de $15 \mathrm{~cm}$ até $30 \mathrm{~cm}$, podendo excepcionalmente atingir $50 \mathrm{~cm}$.

O uso desses painéis é vantajoso uma vez que dispensam escoramento e fôrmas na construção, economizam tempo, mão-de-obra e material. São compatíveis com estruturas de concreto convencionais ou metálicas, pré-fabricados ou alvenaria. Como são alveolares permitem a redução de peso e economia das fundações. 


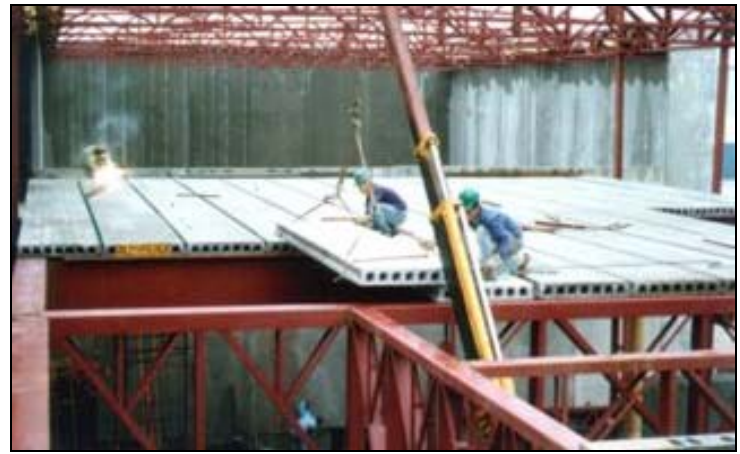

a) montagem dos painéis alveolares

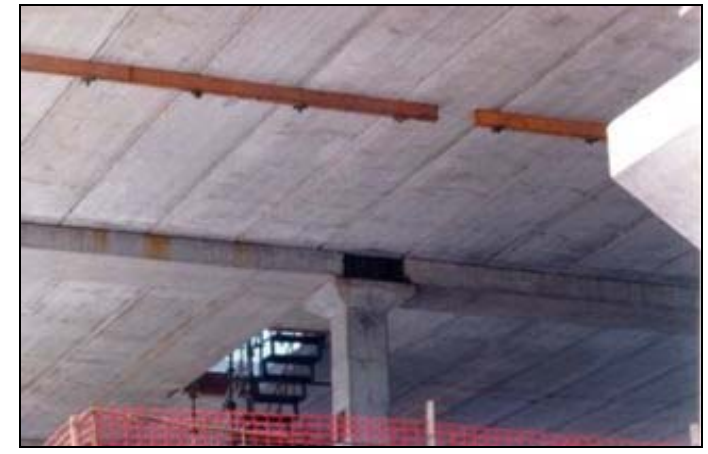

b) acabamento inferior

Figura 4-2. Fases de Montagem e acabamento de painéis alveolares ${ }^{1}$

Segundo EL DEBS (2000), o dimensionamento de painéis alveolares, feitos em pistas de protensão, apresenta as particularidades descritas a seguir.

- a armadura dos painéis é constituída apenas de armadura ativa, na parte inferior e, muitas vezes, também na mesa superior;

- não existe armadura especial para resistir à força cortante e nem para solicitações na direção transversal, o que obriga a contar com a resistência à tração do concreto para resistir a essas solicitações;

- a colocação de armaduras adicionais é praticamente inviável devido ao processo de execução e a colocação de conectores metálicos é usada em situações particulares.

O dimensionamento desses elementos segue recomendações das normas brasileiras NBR 7197 e NBR 6118 da ABNT (2001).

\subsection{INVESTIGAÇÃO DO USO DE AG NUM PROBLEMA SOLUCIONADO VIA MÉTODO CONVENCIONAL}

Nesta seção é investigado o uso de algoritmo genético na busca da solução para o problema de minimização do custo de produção de um painel alveolar, problema este analisado no trabalho de KOSKITO \& ELLINGWOOD (1997). Nesta referência são

\footnotetext{
${ }^{1}$ Fonte empresa Reago localizada em Jundiaí no Estado de São Paulo.
} 
apresentados e discutidos os resultados obtidos pelos autores usando o método do Lagrangeano projetado ${ }^{2}$.

\subsubsection{Definição do Problema}

O problema de otimização a ser tratado aqui é o da minimização da função custo de produção de um painel alveolar sem capa estrutural para vários vãos. O dimensionamento será realizado considerando apenas um nível de armadura, como apresentado no trabalho de KOSKITO \& ELLINGWOOD (1997). Como o trabalho descrito na referência acima será mencionado várias vezes nesta seção, para simplificar o texto, ele será referenciado pelas iniciais dos autores - K\&E.

O principal objetivo dos experimentos descritos nesta seção é comparar valores ótimos já conhecidos, obtidos via métodos convencionais, com aqueles obtidos usando AG (CASTILHO \& EL DEBS (2000)). A seção transversal do painel é mostrada na Figura 4-3. Será minimizada a mesma função custo apresentada pelos autores, dada pela equação (4.1).

$$
\mathrm{C}_{\mathrm{T}}=\mathrm{C}_{\mathrm{D}}+\mathrm{C}_{\mathrm{P}}+\mathrm{C}_{\mathrm{C}}+\mathrm{C}_{\mathrm{QA}}+\mathrm{C}_{\mathrm{M}}
$$

onde $\mathrm{C}_{\mathrm{T}}$ - custo total de projeto

$\mathrm{C}_{\mathrm{D}}$ - custo de planejamento e projeto

$\mathrm{C}_{\mathrm{P}}$ - custo de produção

$\mathrm{C}_{\mathrm{C}}$ - custo de construção

$\mathrm{C}_{\mathrm{QA}}$ - custo de garantia de qualidade

$\mathrm{C}_{\mathrm{M}}$ - custo de manutenção e inspeção de serviços

${ }^{2}$ Conforme apresentado no trabalho de SARMA \& ADELI (1998). 


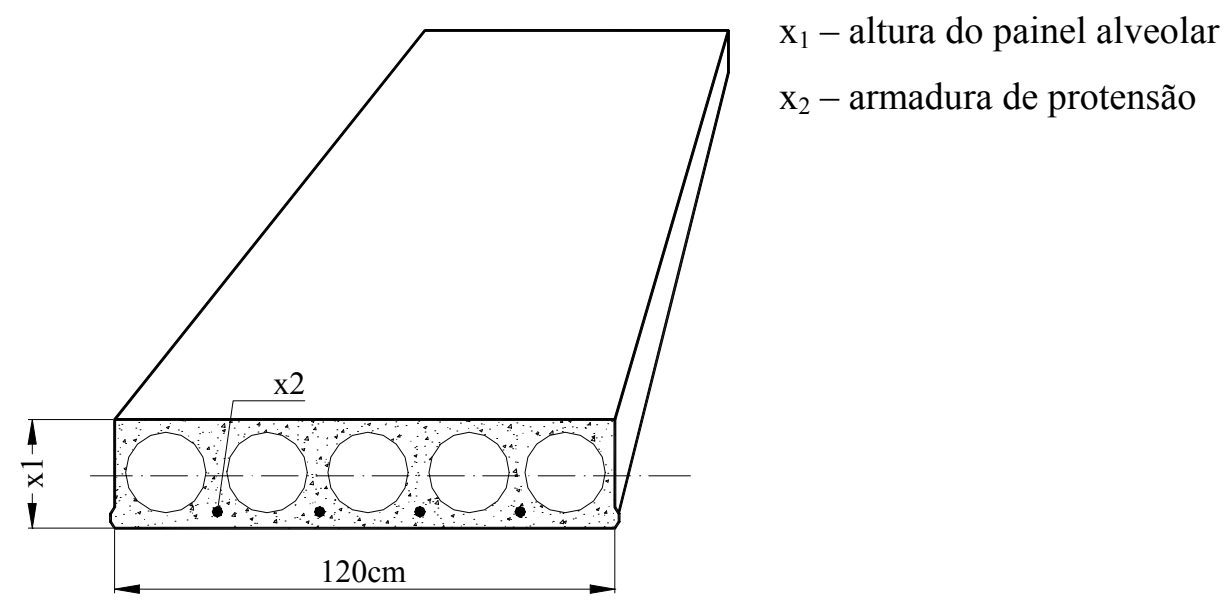

Figura 4-3. Laje alveolar sem capa estrutural

O custo dado pela equação (4.1) é baseado nas seguintes suposições:

- custo de projeto $\mathrm{C}_{\mathrm{D}}$ é $2,5 \%$ do custo de produção;

- custo de produção $\mathrm{C}_{\mathrm{P}}=\mathrm{C}_{\mathrm{Mat}}+\mathrm{C}_{\mathrm{W}}$, onde $\mathrm{C}_{\mathrm{Mat}}$ é o custo do material (concreto e aço) e $\mathrm{C}_{\mathrm{W}}$ é o salário;

- o custo do concreto depende da quantidade do cimento utilizado que é, de acordo com os produtores, igual a $7 \mathrm{f}_{\mathrm{ck}} \mathrm{kg} / \mathrm{m}^{3}$. O preço do cimento é $0,06512 \mathrm{US} \$ / \mathrm{kg}$;

- a massa específica do aço é $7800 \mathrm{~kg} / \mathrm{m}^{3}$ e seu preço é $0,3256 \mathrm{US} \$ / \mathrm{kg}$;

- $\mathrm{C}_{\mathrm{W}}$ é multiplicado por um fator $\left(55 / \mathrm{f}_{\mathrm{ck}}\right)^{2}$;

- o custo de construção, $\mathrm{C}_{\mathrm{C}}$, é representado pelo custo do concreto necessário para moldar as juntas no local incluindo o custo da mão-de-obra. Este custo depende da espessura da laje, da largura das juntas e do preço do concreto para as juntas. O custo da construção é dado então por $\mathrm{C}_{\mathrm{C}}=0,001628 \mathrm{Lh}_{\mathrm{n}} \mathrm{US \$}$, onde $\mathrm{L}$ - vão em $\mathrm{m}$ e $\mathrm{h}_{\mathrm{n}}$ - espessura do painel em mm;

\subsubsection{Função Custo Total}

Na subseção anterior os vários custos envolvidos na produção do painel, relatados em K\&E são somados e, combinados com as suposições listadas acima, resultam na equação (4.2) que define a função custo total.

$f(x)=0,01 \mathrm{Lx}_{1}+0,0159 \mathrm{Lx}_{2}+0,00144 \mathrm{Lx}_{1} \mathrm{x}_{3}+1,31 \mathrm{~L} \frac{\mathrm{x}_{1}}{\mathrm{x}_{3}}+14,44 \mathrm{~L} \frac{\mathrm{x}_{2}}{\left(\mathrm{x}_{3}\right)^{2}}$ 
onde $\mathrm{x}_{1}$ - altura do painel em $\mathrm{mm}\left(\mathrm{h}_{\mathrm{n}}\right)$

$\mathrm{x}_{2}-$ armadura da seção transversal em $\mathrm{mm}^{2}\left(\mathrm{~A}_{\mathrm{p}}\right)$

$\mathrm{x}_{3}$ - resistência à compressão do concreto em $\mathrm{MPa}\left(\mathrm{f}_{\mathrm{ck}}\right)$

$\mathrm{L}$ - comprimento do painel

$\mathrm{f}(\mathrm{x})$ - função objetivo

As variáveis são a armadura, a resistência do concreto e a altura do painel para diversos comprimentos de painel que estarão sujeitas às restrições de acordo com os estados limites últimos e de serviço. Para os estados limites últimos as restrições são a resistência à flexão, dada pela equação (4.3), e a resistência à tração, dada pela equação (4.4). No estado limite de serviço têm-se o limite da fissuração na flexão, dada pela equação (4.5) e a limitação da flecha, dada pela equação (4.6).

$$
\mathrm{M}=\mathrm{A}_{\mathrm{p}} \mathrm{f}_{\mathrm{pyk}} \mathrm{d}\left(1-0,5 \rho \frac{\mathrm{f}_{\mathrm{pyk}}}{0,9 \mathrm{f}_{\mathrm{ck}}}\right)
$$

onde $\quad \mathrm{M}-$ resistência à flexão

$\mathrm{f}_{\text {pyk }}$ - resistência ao escoamento do aço

$\mathrm{A}_{\mathrm{p}}$ - seção transversal da armadura em $\mathrm{mm}^{2}$

d - altura do centróide da armadura tracionada

$\rho-$ taxa de armadura dada por $\rho=\frac{A_{p}}{\text { b. } 120}$

$\mathrm{f}_{\mathrm{ck}}$ - resistência característica do concreto à compressão

$$
\sigma_{I}=-\frac{\sigma_{\mathrm{g}+\mathrm{q}}}{2}+\sqrt{\frac{\sigma_{\mathrm{g}+\mathrm{q}}^{2}}{4}+\tau^{2}} \leq \mathrm{f}_{\mathrm{ctf}}
$$

onde $\quad \sigma_{I}-$ tensão principal máxima na tração

$\sigma_{\mathrm{g}+\mathrm{q}}-$ tensão devido à protensão e ao peso próprio

$\tau$ - tensão cisalhante devido à aplicação das cargas

$\mathrm{f}_{\text {ctf }}$ - resistência do concreto à tração 


$$
f_{c t f}+\frac{P}{A}+\frac{P e_{p}}{W}-\frac{M_{g+q}}{W} \leq 0
$$

onde $\mathrm{f}_{\text {ctf }}$ - resistência à tração na flexão (igual a $1,5 \mathrm{f}_{\mathrm{ctk}}$ )

$\mathrm{P}$ - força de protensão

A - área da seção transversal

$\mathrm{e}_{\mathrm{p}}$ - distância dos cabos à linha neutra

W - módulo de resistência à flexão

$\mathrm{M}_{\mathrm{g}+\mathrm{q}}$ - momento devido ao peso próprio e sobrecarga

$$
\mathrm{a}=\frac{5(\mathrm{~g}+\mathrm{q}) \mathrm{L}^{4}}{384 \mathrm{E}_{\mathrm{c}} \mathrm{I}}-\frac{\mathrm{L}}{250} \leq 0
$$

onde $\mathrm{a}-$ valor da flecha

g e q-carregamento do peso próprio e da sobrecarga

$\mathrm{L}$ - vão do painel

$\mathrm{E}_{\mathrm{c}}-$ módulo de elasticidade do concreto

I - momento de inércia da seção transversal

Embora os coeficientes de segurança apresentados pela norma brasileira sejam de 1,3 ou 1,4 para ações permanentes e de 1,4 para ações variáveis, foram utilizados neste trabalho 1,2 para ações permanentes e 1,6 para ações variáveis, que coincidem com aqueles utilizados por K\&E.

Além dessas restrições, as variáveis não podem ultrapassar os seguintes limites:

$$
\begin{aligned}
& 10 \leq \mathrm{x}_{1} \leq 45 \quad(\mathrm{~cm}) \\
& 2,2 \leq \mathrm{x}_{2} \leq 12,0 \quad\left(\mathrm{~cm}^{2}\right) \\
& 35 \leq \mathrm{x}_{3} \leq 60(\mathrm{MPa})
\end{aligned}
$$

Foram consideradas ainda, as seguintes características: $\mathrm{E}_{\mathrm{c}}=25000 \mathrm{MPa}$, $\mathrm{f}_{\mathrm{ypk}}=1600 \mathrm{MPa}, \mathrm{g}=3,5 \mathrm{kN} / \mathrm{m}, \mathrm{q}=0,4 \mathrm{kN} / \mathrm{m}$. 
Como visto anteriormente no Capítulo 2, existem várias estratégias para o tratamento de um problema de otimização com restrições, usando AG. Para o problema descrito aqui foi adotada a estratégia da penalidade, uma vez que é bastante difundida, tem tido bons resultados e compartilha algumas idéias básicas com a otimização convencional.

\subsubsection{Função Penalidade}

Como visto no Capítulo 2, uma técnica de penalidade transforma um problema com restrições em um problema sem restrições por meio da penalização das soluções infactíveis. Uma das maneiras de definir a função de aptidão do AG é via a adição, à função a ser otimizada, de um termo de penalidade. Portanto, a função aptidão é equacionada como:

$$
F(\mathbf{x})=f(x)+\operatorname{pen}(x)
$$

Como comentado na Seção 2.10, não existe uma orientação geral quando da definição da função penalidade para problemas de otimização. Neste trabalho é adotada a função penalidade inspirada e usada em RAJEEV \& KRISHNAMOORTHY (1992) definida pela equação linear.

$$
\operatorname{pen}(\mathrm{x})=\mathrm{K} \mathrm{C}
$$

$$
\begin{aligned}
& \text { onde } \mathrm{C}=\sum_{\mathrm{i}=1}^{\mathrm{m}} \mathrm{c}_{\mathrm{i}} \\
& \mathrm{K}=1000 \\
& \text { m- número de restrições, } \\
& \mathrm{c}_{\mathrm{i}^{-}} \text {-valor associado à restrição } \mathrm{g}_{\mathrm{i}}(\mathrm{x}) \text {, calculado como: } \\
& \begin{array}{rr}
\text { se } g_{i}(x) \leq 0 & \text { se } g_{i}(x) \geq 0 \\
\text { então } c_{i}=0 & \text { então } c_{i}=0 \\
\text { senão } c_{i}=1 & \text { senão } c_{i}=1
\end{array}
\end{aligned}
$$

\subsubsection{A Busca da Solução do Problema via AG}

O AG típico descrito no Capítulo 2 foi refinado de maneira a adequá-lo melhor ao problema. Foram definidos a representação de dados, a estratégia de seleção, o tipo de cruzamento e mutação e o critério de parada. A seguir na Tabela 4-1 são 
discriminados os valores de várias características relativas a AGs, adotadas na implementação.

Tabela 4-1. Principais Características da Implementação do AG

\begin{tabular}{|l|l|}
\hline \multicolumn{1}{|c|}{ Características } & \multicolumn{1}{c|}{ Possíveis Valores } \\
\hline Elitismo & 2 indivíduos \\
\hline População & 30 \\
\hline Representação de dados & $\begin{array}{l}\text { Binária }-30 \text { bits } \\
1^{a} \text { variável }-12 \text { bits } \\
2^{a} \text { variável }-8 \text { bits } \\
3^{a} \text { variável }-10 \text { bits }\end{array}$ \\
\hline Estratégia de seleção & rank \\
\hline Cruzamento & uniforme \\
\hline Probabilidade de cruzamento & 0,80 \\
\hline Probabilidade de mutação & 0,01 \\
\hline Critério de parada & 10000 gerações \\
\hline
\end{tabular}

\subsubsection{Descrição dos Experimentos e Análise dos Resultados}

O valor relativo a cada um dos experimentos descritos nesta seção é a média de 6 execuções (run), cada uma delas tendo uma população gerada randomicamente.

Com a implementação do AG customizada aos valores descritos anteriormente, foram feitos tantos experimentos quantos os vários comprimentos de laje listados no trabalho em questão. A Tabela 4-2 é uma extensão da tabela apresentada em $\mathrm{K} \& \mathrm{E}$, onde foram acrescentados os valores obtidos nos experimentos usando AG.

Tabela 4-2. Resultados da otimização considerando algoritmos genéticos

\begin{tabular}{|c|c|c|c|c|c|c|c|c|}
\hline \multirow[b]{2}{*}{$\begin{array}{c}\mathbf{L} \\
(\mathbf{m}) \\
\end{array}$} & \multicolumn{4}{|c|}{$\mathbf{K} \& \mathbf{E}$} & \multicolumn{4}{|c|}{ AG } \\
\hline & $\begin{array}{c}\mathrm{h}_{\mathrm{n}} \\
(\mathrm{cm})\end{array}$ & $\begin{array}{c}A_{p_{2}} \\
\left(\mathrm{~cm}^{2}\right)\end{array}$ & $\begin{array}{c}\mathbf{f}_{\text {ck }} \\
(\mathrm{MPa})\end{array}$ & $\begin{array}{c}\text { custo } \\
\left(\mathrm{US} \$ / \mathbf{m}^{2}\right)\end{array}$ & $\begin{array}{c}\mathrm{h}_{\mathrm{n}} \\
(\mathrm{cm})\end{array}$ & $\begin{array}{c}A_{p} \\
\left(\mathrm{~cm}^{2}\right)\end{array}$ & $\begin{array}{c}\mathbf{f}_{\text {ck }} \\
(\mathrm{MPa})\end{array}$ & $\begin{array}{c}\text { custo } \\
\left(\mathrm{US} \$ / \mathbf{m}^{2}\right)\end{array}$ \\
\hline 8 & 15,0 & 3,95 & 46 & 3,34 & 15,0 & 3,93 & 50,10 & 3,36 \\
\hline 10 & 17,1 & 5,38 & 50 & 4,11 & 18,2 & 5,00 & 45,39 & 4,14 \\
\hline 18 & 40,0 & 9,22 & 45 & 8,51 & 34,3 & 11,11 & 47,55 & 8,30 \\
\hline 20 & 40,0 & 11,35 & 48 & 9,20 & 38,9 & 11,72 & 49,60 & 9,15 \\
\hline
\end{tabular}

Como pode ser observado na Tabela 4-2 os resultados obtidos utilizando-se AG se aproximam bastante dos resultados encontrados nos experimentos descritos na citada referência. Particularmente, em dois deles $(\mathrm{L}=18 \mathrm{~m}$ e $\mathrm{L}=20 \mathrm{~m})$ os valores 
usando AG foram melhores (menor custo). Para os dois primeiros comprimentos de laje, de $8 \mathrm{~m}$ e $10 \mathrm{~m}$, os resultados não foram melhorados, mas se aproximaram bastante daqueles descritos no trabalho. No caso do comprimento de $18 \mathrm{~m}$, o resultado obtido pelo AG apresentou um valor de custo 2,5\% aquém do que o obtido em K\&E. Para 20m a diferença entre os resultados não foi muito significativa chegando a apenas $0,5 \%$. É importante lembrar que no trabalho em questão várias análises foram realizadas com relação a algumas variáveis do problema. Entretanto, como essas variáveis eram apenas representativas do método de otimização adotado, elas não foram consideradas neste exemplo.

Uma das dificuldades apresentadas durante a implementação do AG foi quando da definição da função penalidade, que permite penalizar indivíduos infactíveis. A função penalidade, que entra no cálculo da função de avaliação, conforme descrito na Seção 4.3.3, foi definida como pen $(x)=C K$, para $K=1000$.

Os resultados mostrados na Tabela 4-2 são referentes apenas a um conjunto de valores das características elencadas anteriormente. Tais resultados evidenciam a aplicabilidade da técnica de AG no problema descrito e, com base neles, pode-se conjecturar a aplicabilidade de AG a problemas similares.

\subsection{OTIMIZAÇÃO DE PAINEL ALVEOLAR SEM CAPA ESTRUTURAL}

Nesta seção é investigado o uso de algoritmo genético na busca da solução para o problema de minimização do custo de um painel alveolar considerando uma capa de concreto moldado no local, para regularização, de $4 \mathrm{~cm}$, para uma determinada situação. São apresentados e discutidos também os resultados obtidos para a solução do mesmo problema, usando o Método do Lagrangiano Aumentado. Parte dos resultados apresentados nesta seção estão descritos em detalhes em CASTILHO et al (2002a).

\subsubsection{Definição do Problema}

Os critérios para o dimensionamento de um painel alveolar sem capa estrutural são apresentados no Apêndice D. O problema de otimização a ser tratado aqui é o da 
minimização da função custo total de um painel alveolar sem capa estrutural para uma determinada situação de projeto para um vão de $6 \mathrm{~m}$.

Com o objetivo de facilitar os cálculos das verificações desses painéis, o dimensionamento será realizado considerando apenas um nível de armadura, como apresentado no trabalho de KOSKITO \& ELLINGWOOD (1997), muito embora seja comum o emprego de dois níveis de armadura (um próximo à face inferior e outro próximo à face superior).

No equacionamento desta função serão inseridos os custos das etapas transitórias (produção, transporte e montagem) do painel, usando os valores cedidos pela empresa Marka situada em Franca, SP, e alguns obtidos na Revista Construção ${ }^{3}$.

As variáveis do problema são as mesmas da seção anterior: a altura do painel $\left(\mathrm{x}_{1}\right)$, a armadura $\left(\mathrm{x}_{2}\right)$ e a resistência do concreto $\left(\mathrm{x}_{3}\right)$. Vale notar que a largura é constante $(120 \mathrm{~cm})$. A seção transversal do painel é a mesma mostrada na Figura 4-3. Os próximos itens (I-Custo de Execução, II-Custo de Transporte Externo e III-Custo de Aplicação) discriminam os diferentes custos envolvidos no problema que, combinados, definem a função custo total, a ser minimizada.

Os custos fornecidos pela empresa Marka, utilizados nos itens I, II e III descritos a seguir foram calculados tendo como base os seguintes valores:

- Consumo de Concreto $/ \mathrm{m}^{2}=0,097 \mathrm{~m}^{3}$

- Mão-de-obra com encargos sociais (5 homens)

$\mathrm{R} \$ 192,00$ por dia

Produção diária $=180 \mathrm{~m}^{2}$

- Depreciação de equipamentos: extrusora, usina de concreto, máquina de corte Valor investimento $=\mathrm{R} \$ 680.000,00$

Vida útil $=15$ anos

Valor Residual $=20 \%$

Produção Anual $=45.000 \mathrm{~m}^{2}$

Todos os problemas tratados nesta tese envolvem de uma maneira ou de outra o custo associado a várias etapas, de produção, de transporte e de montagem.

${ }^{3}$ Construção, São Paulo, no 2782, 4/6/2001. 
Embora alguns custos tenham sido fornecidos pela empresa referenciada acima, houve uma grande dificuldade no levantamento e na definição de alguns valores adotados neste trabalho. Deve-se salientar que se tentou estimar da melhor maneira possível, valores de custos que pudessem representar uma situação tanto da produção do elemento em uma fábrica quanto da sua aplicação na obra. Futuramente uma análise mais criteriosa nos valores desses custos deve ser feita com o objetivo de representar mais fielmente uma situação real.

\section{I) CUSTOS DE EXECUÇÃO}

Os custos envolvidos na execução englobam:
A. Custos da matéria-prima
B. Custos adicionais
C. Custos indiretos administrativos
D. Custos tributários

\section{A.Custos da matéria-prima}

É a soma do custo do concreto (c_concreto) e do custo da armadura (c_armadura).

Concreto: material, mão de obra, equipamento (depreciação)

$\underline{\text { material: }}$ cimento, areia, brita, aditivo, etc

$$
\begin{aligned}
& \text { custo }\left(\mathrm{R} \$ / \mathrm{m}^{3}\right): \quad \text { custo } \_ \text {material }=\left(24,75 \mathrm{x}_{3}+74,25\right) \\
& \text { onde } \quad \mathrm{x}_{3} \text { - resistência do concreto em } \mathrm{kN} / \mathrm{cm}^{2}
\end{aligned}
$$

mão-de-obra: mão-de-obra de dois homens utilizada na mistura de concreto, no transporte e na operação dos equipamento de moldagem

$$
\text { custo }\left(\mathrm{R} \$ / \mathrm{m}^{3}\right) \text { : } \quad \text { custo_mão_de_obra }=4,40
$$

equipamentos: extrusora, betoneira

$$
\text { custo }\left(\mathrm{R} \$ / \mathrm{m}^{3}\right): \quad \quad \text { custo_equipamento }=8,35
$$

$\therefore$ c_concreto $=$ custo_material + custo_mão_de_obra + custo_equipamento 
material: aço (foi adotado cordoalhas de 7 fios CP175 RB9,5)

custo $(\mathrm{R} \$ / \mathrm{kg})$ : $\quad$ custo_material $=2,95$

mão-de-obra: mão de obra de um homem para utilização dos equipamentos e colocação dos cabos, efetuação da protensão e liberação da força.

custo $(\mathrm{R} \$ / \mathrm{kg})$ : $\quad$ custo_mão_de_obra $=0,295$

equipamentos: macaco hidráulico, máquina para cortar os fios

custo $(\mathrm{R} \$ / \mathrm{kg}): \quad$ custo_equipamento $=0,07$

$\therefore$ c_armadura $=$ custo_material + custo_mão_de_obra + custo_equipamento

B. Custos adicionais (c_adicional)

Envolve os custos referentes às atividades após a moldagem e anterior ao envio à obra (cura, desmoldagem e armazenamento). O custo adicional é a soma do custo de mão-de-obra e do custo de equipamentos (depreciação).

mão-de-obra: mão de obra para utilização dos equipamentos, cura, transporte, armazenamento

custo $\left(\mathrm{R} \$ / \mathrm{m}^{3}\right)$ : $\quad$ custo $\quad$ mão_de_obra $=4,40$

equipamentos: empilhadeira, equipamentos para cura, energia, combustível

custo $\left(\mathrm{R} \$ / \mathrm{m}^{3}\right)$ : $\quad$ custo_equipamento $=1,67$

$\therefore$ c_adicional $=$ custo_mão_de_obra + custo_equipamento

C. Custos indiretos administrativos (custo_ind)

Envolve os custos de: engenheiros, encarregados, recepcionista, execução do projeto, encargos sociais, propaganda, energia, impostos, aluguéis, seguros, materiais de escritório, despesas de manutenção, fretes, combustível, depreciação, retorno de investimento. 
custo $\left(\mathrm{R} \$ / \mathrm{m}^{3}\right)$ : custo_ind $=0,1\left(\mathrm{c} \_\right.$concreto $+\mathrm{c}$ _armadura $+\mathrm{c}$ _adicional $)$

D. Custos tributários (c_tributario)

Envolve os custos de Confins, PIS, ICMS, IPI avaliados em $12 \%$ do preço final de venda.

$$
\text { custo }\left(\mathrm{R} \$ / \mathrm{m}^{3}\right) \text { : } \quad \text { c_tributario }=84,00
$$

\section{II) CUSTOS DE TRANSPORTE EXTERNO}

Envolve os custos de transporte da fábrica ao local da obra. Com o intuito de melhor avaliar o custo de produção do painel neste trabalho considerou-se uma obra hipotética sendo realizada a 100km de Franca (custo_transp).

serviços: mão de obra, caminhões, combustível, seguros, despesas com manutenção

Considerando que:

custo $\left(\mathrm{R} \$ / \mathrm{m}^{3} \mathrm{Km}\right): \quad$ custo_transporte $=0,52$

e como o obra hipoteticamente está localizada a 100km de Franca, tem-se:

custo $\left(\mathrm{R} \$ / \mathrm{m}^{3}\right)$ : $\quad$ custo_transp $=52$

\section{III) CUSTOS DA APLICAÇÃO}

Os custos envolvidos na aplicação do elemento englobam:

A. Custos da montagem do painel alveolar

B. Custos do concreto para regularização

C. Custos das ligações

D. Custos indiretos administrativos

A. Custos da montagem do painel alveolar (c_montagem)

É a soma dos custos de mão-de-obra e equipamentos.

mão-de-obra: mão de obra para a colocação dos painéis

custo $\left(\mathrm{R} \$ / \mathrm{m}^{3}\right)$ : $\quad$ custo $\quad$ mão_de_obra $=11,96$ 
equipamentos: aluguel de guindaste

$$
\text { custo }\left(\mathrm{R} \$ / \mathrm{m}^{3}\right): \quad \quad \text { custo_equipamento }=9,79
$$

$\therefore$ c_montagem $=$ custo_mão_de_obra + custo_equipamento

B. Custos do concreto para regularização (c_conc)

É a soma dos custos de material, mão-de-obra e equipamentos (depreciação). Considerou-se na análise dos custos um concreto de $4 \mathrm{~cm}$ de capa e com resistência de $20 \mathrm{MPa}$.

material: cimento, areia, brita, aditivo, etc custo $\left(\mathrm{R} \$ / \mathrm{m}^{3}\right)$ : $\quad$ custo__material $=123,75$

mão-de-obra: mão de obra de oito homens para o lançamento, o adensamento do concreto, a cura e desmoldagem custo $\left(\mathrm{R} \$ / \mathrm{m}^{3}\right)$ : $\quad$ custo_mão_de_obra $=41,68$

equipamentos: vibrador, fôrmas, desforma custo $\left(\mathrm{R} \$ / \mathrm{m}^{3}\right)$ : $\quad$ custo_equipamento $=1,67$

$\therefore$ c_conc $=$ custo_material + custo_mão_de_obra + custo_equipamento

C. Custos das ligações (c_liga)

É a soma dos custos de material e mão-de-obra. A Figura 4-4 mostra um tipo de ligação utilizada na ligação entre painéis.

material: argamassa (considerou-se o custo como 3 vezes o custo do concreto de regularização)

custo $\left(\mathrm{R} \$ / \mathrm{m}^{3}\right)$ : $\quad$ custo_material $=3 \cdot 123,75=371,25$

mão-de-obra: mão de obra de um homem para a efetuação das ligações

custo $\left(\mathrm{R} \$ / \mathrm{m}^{3}\right)$ : $\quad$ custo_mão_de_obra $=2,20$ 


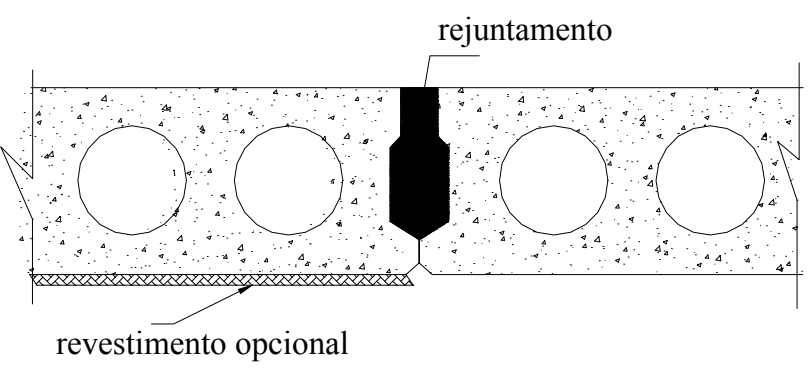

Figura 4-4. Rejunte entre painéis

$\therefore$ c_liga $=$ custo_material + custo_mão_de_obra

D. Custos indiretos administrativos (custo_adma)

Envolve os custos de: engenheiros, encarregados, recepcionista, execução do projeto, administração, encargos sociais, propaganda, energia, impostos, aluguéis, seguros, materiais de escritório, despesas de manutenção, fretes, combustível, depreciação, despesas tributárias.

custo $\left(\mathrm{R} \$ / \mathrm{m}^{3}\right)$ : $\quad$ custo_adma $=0,2\left(\mathrm{c} \_\right.$montagem $+\mathrm{c} \_$conc $+\mathrm{c} \_$liga $)$

\subsubsection{Função Custo Total}

Na subseção anterior os vários custos envolvidos na produção de um painel alveolar com capa de regularização foram discriminados. O dimensionamento de tal painel está apresentado em detalhes no Apêndice D. Com o objetivo de obter a função que representa o custo total de produção, considerando as etapas de execução, de transporte e de aplicação, os vários custos foram somados e a expressão final da função é:

$$
\begin{aligned}
& f(\mathbf{x})=11,578 \log \left(x_{1}\right)+12,663+0,0528 x_{1}+1,1\left(24,75 x_{3}+74,25\right)\left(0,063 \log \left(x_{1}\right)-0,0721\right)+ \\
& \left(0,0633 \log \left(x_{1}\right)-0,0721\right)+2,4075 x_{2}
\end{aligned}
$$

onde

$\mathrm{x}_{1}$ - altura do painel em $\mathrm{cm}$

$\mathrm{x}_{2}-$ armadura ativa em $\mathrm{cm}^{2}$

$\mathrm{x}_{3}-$ resistência do concreto em $\mathrm{kN} / \mathrm{cm}^{2}$ 
O problema de minimização do custo de produção de tal painel, portanto, se resume ao problema de minimização da função $\mathrm{f}(\mathbf{x})\left(\mathbf{x}=\left(\mathrm{x}_{1}, \mathrm{x}_{2}, \mathrm{x}_{3}\right)\right)$. $\mathrm{O}$ dimensionamento do painel deve respeitar os estados limites de utilização (estados limites de descompressão e de formação de fissuras, de controle da deformação, de controle da fissuração e ao cisalhamento) e ao estado limite último (solicitações normais e tangenciais), no caso de protensão limitada. O problema em questão se configura, portanto, como um problema de minimização sujeito a restrições e pode ser equacionado da seguinte forma:

\section{Minimizar:}

$\mathrm{f}(\mathbf{x})=11,578 \log \left(\mathrm{x}_{1}\right)+12,663+0,0528 \mathrm{x}_{1}+1,1\left(24,75 \mathrm{x}_{3}+74,25\right)\left(0,063 \log \left(\mathrm{x}_{1}\right)-0,0721\right)+$ $\left(0,0633 \log \left(\mathrm{x}_{1}\right)-0,0721\right)+2,4075 \mathrm{x}_{2}$

\section{Sujeita às seguintes restrições:}

\section{Verificação do estado em vazio}

a) após a desmoldagem:

$$
\begin{array}{lll}
\mathrm{g}_{1}\left(\mathrm{x}_{\mathrm{i}}\right)=\sigma_{1 \mathrm{P}_{\mathrm{o}}}+\sigma_{1 \mathrm{~g}_{1}}-\sigma_{\mathrm{ctj}} & \text { onde } & \mathrm{g}_{1}\left(\mathrm{x}_{\mathrm{i}}\right) \leq 0 \\
\mathrm{~g}_{2}\left(\mathrm{x}_{\mathrm{i}}\right)=\sigma_{2 \mathrm{P}_{\mathrm{o}}}+\sigma_{2 \mathrm{~g}_{1}}+\sigma_{\mathrm{cj}} & \text { onde } & \mathrm{g}_{2}\left(\mathrm{x}_{\mathrm{i}}\right) \geq 0
\end{array}
$$

b) fase de transporte:

$$
\begin{array}{lll}
\mathrm{g}_{3}\left(\mathrm{x}_{\mathrm{i}}\right)=\sigma_{{ }_{1} \mathrm{P}_{\mathrm{o}}}+\beta_{\mathrm{a}_{1}} \sigma_{1 \mathrm{~g}_{1}}-\sigma_{\mathrm{ctj}} & \text { onde } & \mathrm{g}_{3}\left(\mathrm{x}_{\mathrm{i}}\right) \leq 0 \\
\mathrm{~g}_{4}\left(\mathrm{x}_{\mathrm{i}}\right)=\sigma_{{ }^{2} \mathrm{P}_{\mathrm{o}}}+\beta_{\mathrm{a}_{1}} \sigma_{2 \mathrm{~g}_{1}}+\sigma_{\mathrm{cj}} & \text { onde } & \mathrm{g}_{4}\left(\mathrm{x}_{\mathrm{i}}\right) \geq 0 \\
\mathrm{~g}_{5}\left(\mathrm{x}_{\mathrm{i}}\right)=\sigma_{{ }_{1} \mathrm{P}_{\mathrm{o}}}+\beta_{\mathrm{a}_{2}} \sigma_{1 \mathrm{~g}_{1}}-\sigma_{\mathrm{ctj}} & \text { onde } & \mathrm{g}_{5}\left(\mathrm{x}_{\mathrm{i}}\right) \leq 0 \\
\mathrm{~g}_{6}\left(\mathrm{x}_{\mathrm{i}}\right)=\sigma_{2} \mathrm{P}_{\mathrm{o}}+\beta_{\mathrm{a}_{2} \sigma_{2 \mathrm{~g}_{1}}+\sigma_{\mathrm{cj}}} & \text { onde } & \mathrm{g}_{6}\left(\mathrm{x}_{\mathrm{i}}\right) \geq 0
\end{array}
$$

c) fase de armazenamento:

$$
\begin{array}{lll}
\mathrm{g}_{7}\left(\mathrm{x}_{\mathrm{i}}\right)=\sigma_{{ }^{1} \mathrm{P}_{\mathrm{oo}}}+\sigma_{\mathrm{gg}_{1}}-\sigma_{\mathrm{ctj}} & \text { onde } & \mathrm{g}_{7}\left(\mathrm{x}_{\mathrm{i}}\right) \leq 0 \\
\mathrm{~g}_{8}\left(\mathrm{x}_{\mathrm{i}}\right)=\sigma_{{ }^{2} \mathrm{P}_{\mathrm{oo}}}+\sigma_{2 \mathrm{~g}_{1}}+\sigma_{\mathrm{cj}} & \text { onde } & \mathrm{g}_{8}\left(\mathrm{x}_{\mathrm{i}}\right) \geq 0
\end{array}
$$

d) fase de montagem: 


$$
\begin{array}{lll}
\mathrm{g}_{9}\left(\mathrm{x}_{\mathrm{i}}\right)=\sigma_{1 \mathrm{P}_{\mathrm{o}}}+\sigma_{1 \mathrm{~g}_{1}}+\sigma_{1 \mathrm{~g}_{2}}-\sigma_{\mathrm{ct}} & \text { onde } & \mathrm{g}_{9}\left(\mathrm{x}_{\mathrm{i}}\right) \leq 0 \\
\mathrm{~g}_{10}\left(\mathrm{x}_{\mathrm{i}}\right)=\sigma_{2 \mathrm{P}_{\mathrm{o}}}+\sigma_{2 \mathrm{~g}_{1}}+\sigma_{2 \mathrm{~g}_{2}}+\sigma_{\mathrm{c}} & \text { onde } & \mathrm{g}_{10}\left(\mathrm{x}_{\mathrm{i}}\right) \geq 0
\end{array}
$$

Verificação do estado em serviço:

a) combinação freqüente de ações

$$
\begin{array}{lll}
\mathrm{g}_{11}\left(\mathrm{x}_{\mathrm{i}}\right)=\sigma_{\mathrm{gg}_{1}}+\sigma_{\mathrm{gg}_{2}}+\psi_{1} \sigma_{1_{\mathrm{q}}}+\sigma_{1 \mathrm{P}_{\mathrm{oo}}}-\sigma_{\mathrm{ct}} & \text { onde } & \mathrm{g}_{11}\left(\mathrm{x}_{\mathrm{i}}\right) \leq 0 \\
\mathrm{~g}_{12}\left(\mathrm{x}_{\mathrm{i}}\right)=\sigma_{2 \mathrm{~g}_{1}}+\sigma_{\mathrm{g}_{2}}+\psi_{1} \sigma_{2_{\mathrm{q}}}+\sigma_{2 \mathrm{P}_{\mathrm{oo}}}+\sigma_{\mathrm{c}} & \text { onde } & \mathrm{g}_{12}\left(\mathrm{x}_{\mathrm{i}}\right) \geq 0
\end{array}
$$

b) combinação quase-permanente de ações

$$
\begin{array}{lll}
\mathrm{g}_{13}\left(\mathrm{x}_{\mathrm{i}}\right)=\sigma_{\mathrm{g}_{1}}+\sigma_{\mathrm{1g}_{2}}+\psi_{2} \sigma_{1_{\mathrm{q}}}+\sigma_{1 \mathrm{P}_{\mathrm{oo}}}-\sigma_{\mathrm{ct}} & \text { onde } & \mathrm{g}_{13}\left(\mathrm{x}_{\mathrm{i}}\right) \leq 0 \\
\mathrm{~g}_{14}\left(\mathrm{x}_{\mathrm{i}}\right)=\sigma_{2 \mathrm{~g}_{1}}+\sigma_{2_{\mathrm{g}_{2}}+\psi_{2} \sigma_{2 \mathrm{q}}+\sigma_{2 \mathrm{P}_{\mathrm{oo}}}+\sigma_{\mathrm{c}}} \text { onde } & \mathrm{g}_{14}\left(\mathrm{x}_{\mathrm{i}}\right) \geq 0
\end{array}
$$

c) combinação rara de ações

$$
\begin{array}{lll}
\mathrm{g}_{15}\left(\mathrm{x}_{\mathrm{i}}\right)=\sigma_{\mathrm{gg}_{1}}+\sigma_{\mathrm{g}_{2}}+\sigma_{\mathrm{1}_{\mathrm{q}}}+\sigma_{1_{\mathrm{P}_{\mathrm{oo}}}}-\sigma_{\mathrm{ct}} & \text { onde } & \mathrm{g}_{15}\left(\mathrm{x}_{\mathrm{i}}\right) \leq 0 \\
\mathrm{~g}_{16}\left(\mathrm{x}_{\mathrm{i}}\right)=\sigma_{\mathrm{g}_{1}}+\sigma_{\mathrm{g}_{2}}+\sigma_{2_{\mathrm{q}}}+\sigma_{{ }_{2 \mathrm{P}_{\mathrm{oo}}}}+\sigma_{\mathrm{c}} & \text { onde } & \mathrm{g}_{16}\left(\mathrm{x}_{\mathrm{i}}\right) \geq 0
\end{array}
$$

Verificação do estado limite de utilização de controle da deformação:

a) contraflecha devido à protensão:

$$
\mathrm{g}_{17}\left(\mathrm{x}_{\mathrm{i}}\right)=\mathrm{a}_{\text {contflec }}+\mathrm{a}_{\text {lim ct }} \quad \text { onde } \quad \mathrm{g}_{17}\left(\mathrm{x}_{\mathrm{i}}\right) \geq 0
$$

b) flecha devido ao carregamento:

$$
\mathrm{g}_{18}\left(\mathrm{x}_{\mathrm{i}}\right)=\mathrm{a}_{\lim }-\mathrm{a} \quad \text { onde } \quad \mathrm{g}_{18}\left(\mathrm{x}_{\mathrm{i}}\right) \geq 0
$$

Verificação do estado limite último - solicitações normais:

$\mathrm{g}_{19}\left(\mathrm{x}_{\mathrm{i}}\right)=\mathrm{M}_{\mathrm{d}}-\mathrm{M}_{\mathrm{u}} \quad$ onde $\quad \mathrm{g}_{19}\left(\mathrm{x}_{\mathrm{i}}\right) \leq 0$

Verificação do estado limite último - solicitações tangenciais

$$
\mathrm{g}_{20}\left(\mathrm{x}_{\mathrm{i}}\right)=\mathrm{V}_{\mathrm{d}}-\mathrm{V}_{\mathrm{u}} \quad \text { onde } \quad \mathrm{g}_{20}\left(\mathrm{x}_{\mathrm{i}}\right) \leq 0
$$


onde

$\sigma_{1 \mathrm{~g}_{1}}, \sigma_{2 \mathrm{~g}_{1}}-$ tensão devido ao peso próprio da vigota no bordo inferior e superior

$\sigma_{1 \mathrm{~g}_{2}}, \sigma_{2 \mathrm{~g}_{2}}-$ tensão devido ao peso próprio do enchimento e do concreto moldado no local no bordo inferior e superior

$\sigma_{1 \mathrm{q}}, \sigma_{2 \mathrm{q}}-$ tensão devido à sobrecarga no bordo inferior e superior

$\sigma_{1 \mathrm{P}_{\mathrm{o}}}, \sigma_{2 \mathrm{P}_{\mathrm{o}}}-$ tensão devido à força de protensão instalada no concreto no bordo inferior e superior

$\beta_{\mathrm{a}_{1}}-$ coeficiente de ação dinâmica $\left(\beta_{\mathrm{a}_{1}}=0,8\right)$

$\beta_{\mathrm{a}_{2}}-$ coeficiente de ação dinâmica $\left(\beta_{\mathrm{a} 2}=1,3\right)$

$\sigma_{1 \mathrm{P}_{\mathrm{oO}}}, \sigma_{2 \mathrm{P}_{\mathrm{oo}}}-$ tensão devido à força de protensão após as perdas no bordo inferior e superior

$\sigma_{\text {ctj }}-$ tensão limite de tração em j dias

$\sigma_{\mathrm{ct}}-$ tensão limite de tração

$\sigma_{\mathrm{cj}}-$ tensão limite de compressão em $\mathrm{j}$ dias

$\sigma_{\mathrm{c}}-$ tensão limite de compressão

$\psi_{1}$ - fator de combinação freqüente de ações $\left(\psi_{1}=0,3\right)$

$\psi_{2}$ - fator de combinação quase permanente de ações $\left(\psi_{2}=0,2\right)$

$\mathrm{M}_{\mathrm{d}}$ - momento atuante da seção composta

$\mathrm{M}_{\mathrm{u}}$ - momento último da seção composta

$\mathrm{a}_{\text {contflec }}$ - contraflecha devido à protensão

$\mathrm{a}_{\text {limct }}$ - limite de contraflecha devido à protensão

$\mathrm{a}_{\lim }$ - flecha admissível devido ao carregamento

a - flecha total devido ao carregamento

$\mathrm{V}_{\mathrm{d}}$ - força cortante de cálculo

$\mathrm{V}_{\mathrm{u}}$ - resistência à força cortante

Além dessas restrições, as variáveis que definem a função devem satisfazer às seguintes desigualdades: 


$$
\begin{aligned}
& 10 \leq \mathrm{x}_{1} \leq 45 \quad(\mathrm{~cm}) \\
& 2,2 \leq \mathrm{x}_{2} \leq 12,0 \quad\left(\mathrm{~cm}^{2}\right) \\
& 30 \leq \mathrm{x}_{3} \leq 50(\mathrm{MPa})
\end{aligned}
$$

A escolha desses limites se justifica por:

- $\mathrm{x}_{1}$ : limite inferior e limite superior correspondem a limites arbitrados

- $\mathrm{x}_{2}$ : limite inferior e limite superior correspondem a limites arbitrados

- $\mathrm{x}_{3}$ : limite inferior e limite superior correspondem a limites arbitrados de resistência de concreto do elemento pré-moldado

Para o problema descrito aqui foi adotada a mesma estratégia de penalidade da Seção 4.3.3.

\subsubsection{A Busca da Solução do Problema via AG}

Como um dos objetivos nesta tese foi o de investigar as diferentes características e os diferentes valores que parâmetros genéticos podem assumir, buscando identificar a customização do AG mais conveniente para o problema em questão, o algoritmo AG típico descrito no Capítulo 2 serviu de base para a proposta de 22 AGs variantes. As definições de AGs variantes foram determinadas pelas diferentes combinações da estratégia de seleção, esquema de reprodução e restauração da população ao tamanho original, notado por $\mathrm{N}_{\text {pop }}$.

Para facilitar e sistematizar as referências a eles, os 22 AGs variantes foram agrupados em três famílias diferentes, usando como critério a estratégia de seleção utilizada por eles. Essas famílias são a MGA, ROLETA e TORNEIO. Os pseudocódigos que descrevem os algoritmos das três famílias estão descritos em detalhes no Anexo B. A seguir na Tabela 4-3 estão discriminados os valores de várias características relativas a AGs, adotadas na implementação. 
Tabela 4-3. Principais Características da Implementação do AG

\begin{tabular}{|l|l|}
\hline \multicolumn{1}{|c|}{ Características } & \multicolumn{1}{c|}{ Possíveis Valores } \\
\hline Elitismo & 1 indivíduo \\
\hline População & 100 \\
\hline Representação de dados & real \\
\hline Estratégia de seleção & MGA, roleta e torneio \\
\hline Cruzamento & Operadores aritméticos com $\lambda=2 / 3$ \\
\hline Probabilidade de cruzamento & 0,85 \\
\hline Probabilidade de mutação & 0,01 \\
\hline Critério de parada & 1000 gerações \\
\hline
\end{tabular}

A estratégia de seleção MGA é uma proposta desta tese [CASTILHO et al (2002b)] que adota algumas características da estratégia rank e é detalhada na Seção 4.4.4.1. Para os experimentos foram considerados três possíveis esquemas de reprodução: substituição, avaliador e steady_state. As principais características desses esquemas são:

- Substituição: substitui os pais, pelos filhos, a cada geração. Tem a desvantagem de perder indivíduos com boas características genéticas; isto, entretanto, pode ser contornado com a introdução de um processo elitista;

- Avaliador: na composição da nova população são considerados os valores da função de avaliação dos pais e dos filhos e, então, são escolhidos os melhores;

- Steady-state: gera dois indivíduos apenas a cada geração, resultado do cruzamento de dois indivíduos da população corrente. Nesta tese o esquema steady-state [BEASLEY (1993)] foi implementado de duas maneiras distintas:

Steady-state 1: os dois 'melhores' indivíduos da população corrente são selecionados para o cruzamento. Os dois filhos obtidos são avaliados e comparados com os dois 'piores' indivíduos da população corrente, substituindo-os ou não, dependendo dos resultados dos respectivos valores de aptidão.

Steady-state 2: dois indivíduos da população corrente são randomicamente selecionados para o cruzamento. Os dois filhos obtidos 
são avaliados e comparados com os dois 'piores' indivíduos da população corrente, substituindo-os ou não, dependendo dos resultados dos respectivos valores de aptidão.

Note que neste esquema de reprodução a próxima população permanece inalterada com substituição de, no máximo, dois elementos.

\subsubsection{Descrição dos Experimentos e Análise dos Resultados}

Uma vez que AGs são bastante sensíveis à população inicial, o valor relativo a cada um dos experimentos descrito nesta seção, é a média dos valores obtidos em dez execuções (run), cada uma delas tendo uma população inicial gerada randomicamente. A análise dos resultados focaliza, principalmente, os valores obtidos usando os AGs variantes das três famílias. Como comentado anteriormente, na definição dos diferentes elementos das três famílias, estão contemplados os diferentes esquemas de reprodução.

\subsubsection{Família MGA}

Como comentado anteriormente, a seleção MGA foi proposta baseada na seleção rank, descrita no Capítulo 2. A estratégia MGA se caracteriza por classificar a população usando o valor da função de avaliação de cada indivíduo. Se a taxa de cruzamento for de $\mathrm{x} \%$, os $\mathrm{x} \%$ primeiros indivíduos serão selecionados para $\mathrm{o}$ cruzamento.

A família MGA de AGs variantes é composta por seis elementos que diferem entre si com relação ao esquema de reprodução adotado e à maneira como a população é restaurada para $\mathrm{N}_{\text {pop }}$ elementos, após o cruzamento. A Tabela 4-4 nomeia e descreve os seis elementos da família MGA, identificando o esquema de reprodução adotado em cada um deles, bem como a estratégia usada para restaurar a população.

A seguir na Tabela 4-5 são apresentados o valor da função custo, o desvio padrão, o melhor e o pior absoluto, bem como os valores das três variáveis que definem a função custo para todas os AGs variantes da família MGA. 
Tabela 4-4. Elementos da Família MGA

\begin{tabular}{|c|c|l|}
\hline AG Variante & Esquema & $\begin{array}{c}\text { Como população é restaurada a } \\
\mathbf{N}_{\text {pop }} \text { elementos }\end{array}$ \\
\hline \hline MGA1 & substituição & indivíduos aleatórios da população corrente \\
MGA2 & substituição & indivíduos que não participaram do cruzamento \\
MGA3 & avaliador & indivíduos aleatórios da população corrente \\
MGA4 & avaliador & indivíduos que não participaram do cruzamento \\
MGA5 & steady-state 1 & \\
MGA6 & steady-state 2 & \\
\hline
\end{tabular}

Além disso, são exibidos dados referentes a duas implementações do AG básico, usando a estratégia de seleção rank como descrita no Capítulo 2 (rank1 e rank2) e o valor da função custo obtido via o método do Lagrangiano Aumentado (EASY). O rank1 e rank2 diferem apenas na maneira como a população é restaurada à população original. O primeiro usa indivíduos que não participaram do cruzamento e o segundo usa indivíduos da população corrente escolhidos aleatoriamente.

Tabela 4-5. Valores da função custo e das variáveis que a definem para a família MGA:

$\mathrm{x}_{1}$ - altura do painel, $\mathrm{x}_{2}-$ área de armadura e $\mathrm{x}_{3}$ - resistência do concreto

\begin{tabular}{|c|c|c|c|c|c|c|c|}
\hline \multicolumn{5}{|c|}{$\begin{array}{c}\text { FUNÇÃO CUSTO - vão=6m } \\
\left(R \$ / m^{2}\right)\end{array}$} & \multicolumn{3}{|c|}{ VARIÁVEIS } \\
\hline $\begin{array}{c}\text { AG } \\
\text { variante }\end{array}$ & $\begin{array}{c}\text { Valor } \\
\text { da } \\
\text { função }\end{array}$ & $\begin{array}{l}\text { Desvio } \\
\text { padrão }\end{array}$ & $\begin{array}{l}\text { Melhor } \\
\text { absoluto }\end{array}$ & $\begin{array}{c}\text { Pior } \\
\text { absoluto }\end{array}$ & $\begin{array}{c}x_{1} \\
(\mathrm{~cm})\end{array}$ & $\begin{array}{c}\mathbf{x}_{2} \\
\left(\mathbf{c m}^{2}\right)\end{array}$ & $\begin{array}{c}\mathrm{X}_{3} \\
\left(\mathrm{kN} / \mathrm{cm}^{2}\right)\end{array}$ \\
\hline MGA1 & 75,91 & 0,1613 & 75,80 & 76,34 & 21,47 & 2,67 & 3,07 \\
\hline MGA2 & 78,36 & 0,7857 & 76,96 & 79,11 & 21,27 & 2,84 & 3,76 \\
\hline MGA3 & 76,04 & 0,3601 & 75,75 & 76,85 & 21,56 & 2,62 & 3,12 \\
\hline MGA4 & 76,42 & 0,5942 & 75,76 & 77,53 & 21,49 & 2,54 & 3,32 \\
\hline MGA5 & 76,26 & 0,4919 & 75,85 & 77,40 & 21,45 & 2,59 & 3,24 \\
\hline MGA6 & 76,80 & 0,5004 & 75,89 & 77,61 & 21,76 & 2,82 & 3,13 \\
\hline Rank1 & 76,06 & 0,2091 & 75,86 & 76,45 & 21,77 & 2,66 & 3,03 \\
\hline Rank2 & 76,10 & 0,0853 & 76,00 & 76,27 & 21,53 & 2,70 & 3,08 \\
\hline EASY & 75,75 & & & & 21,49 & 2,69 & 3,00 \\
\hline
\end{tabular}

Pode ser evidenciado na Tabela 4-5 que os dados relativos aos AGs variantes estão bastante próximos e que o melhor resultado foi o obtido com o MGA1. O único valor de função que destoa ligeiramente dos demais é o obtido pelo MGA2. O comportamento deste variante versus os demais, pode ser visualizado na Figura 4-5. Pode se conjecturar duas razões que justifiquem os resultados obtidos. A primeira se deve ao fato do MGA2 restaurar a população a seu tamanho original, usando 
indivíduos que não participaram do cruzamento (indivíduos que, provavelmente, não tiveram bons valores de função de aptidão). A segunda (que não exclui a primeira), seria o esquema de reprodução de substituição, que não leva em consideração valor de aptidão quando substitui pais por filhos. Por outro lado, esse esquema é também utilizado pelo variante MGA1, que obteve os melhores resultados dentre os algoritmos da família. Isso nos leva a pensar que é o mecanismo de restauração que influencia negativamente o desempenho do MGA2. Como mostra a Tabela 4-5, o EASY obteve o melhor desempenho que todos os outros variantes.

Analisando os resultados obtidos pelos variantes MGA2 e MGA4 e pelos variantes MGA1 e MGA3 pode-se inferir que, com o uso da estratégia avaliador o desempenho piora. Com relação aos resultados obtidos pelos variantes MGA1 e MGA2 (que compartilham o mesmo esquema substituição) e pelos variantes MGA3 e MGA4 (que compartilham o mesmo esquema avaliador) pode-se concluir que o mecanismo de restauração que adota indivíduos que não participaram do cruzamento não é bom. O MGA2 foi o que teve o pior resultado da família.

\section{Custo X Geração}

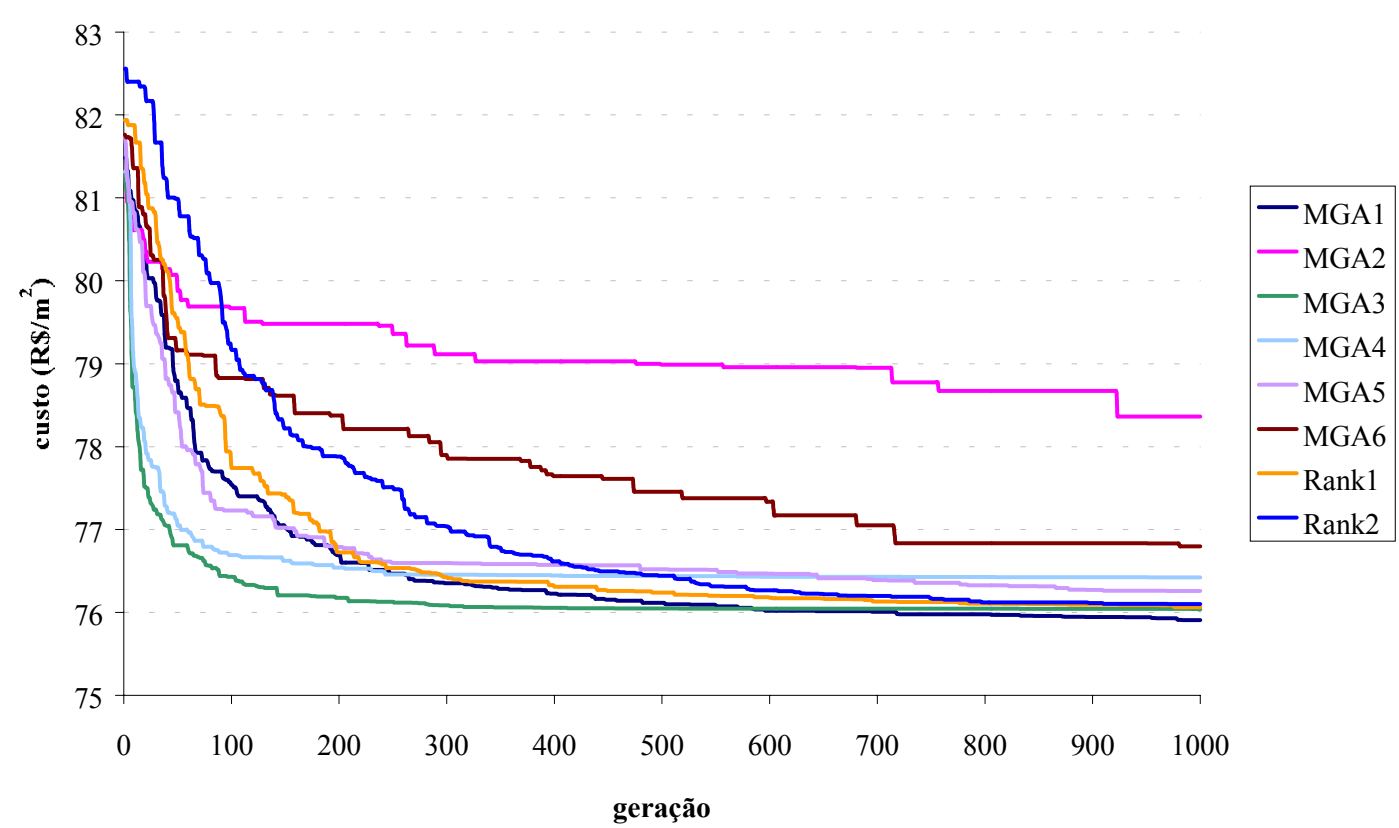

Figura 4-5. Valores médios de função aptidão para família MGA, rank1 e rank2 
Ainda com relação ao uso do EASY, é interessante salientar que, para este particular problema, foram usados vários pontos iniciais (o ponto inicial deve ser fornecido ao EASY pelo usuário). Para valores iniciais razoavelmente distantes do ótimo, o EASY não converge e informa ao usuário. Quando foram adotados valores obtidos por qualquer dos AGs variantes, como ponto inicial, o EASY convergiu para o valor mostrado na Tabela 4-5. Com base nessas considerações, pode se afirmar que o desempenho do EASY é fortemente dependente do valor inicial fornecido pelo usuário.

Quando não se tem conhecimento do ponto ótimo ou mesmo da região em que ele se encontra, esse método de otimização fica mais limitado. Uma abordagem interessante é a da combinação de um método heurístico para a determinação da vizinhança do ponto ótimo e, então, usar qualquer dos pontos desta região como ponto inicial do método de otimização. Todas essas considerações feitas para o EASY são válidas para as discussões das próximas duas subseções.

\subsubsection{Família ROLETA}

A estratégia de seleção da roleta foi descrita no Capítulo 2. As diferentes combinações do esquema de reprodução adotado e da maneira como a população é restaurada a $\mathrm{N}_{\text {pop }}$ elementos dão origem aos quatro elementos básicos desta família. (Roleta1, Roleta2, Roleta3 e Roleta4). A decisão pelo uso de uma população intermediária, de maneira a poder avaliar seus efeitos, fez com que cada elemento básico desta família tivesse uma versão que implementa o uso de uma população intermediária. Essas versões são chamadas de Roleta1A, Roleta2A, Roleta3A e Roleta4A e são partes da subfamília ROLETAA. Além desses foi também considerada nos experimentos a implementação de um AG simples exatamente como sugerido na referência MICHALEWICZ (1997), com estratégia de seleção da roleta, referenciada aqui como Michalewicz. A Tabela 4-6 apresenta as suas principais características identificando o esquema de reprodução adotado bem como a estratégia usada para restaurar a população a $\mathrm{N}_{\text {pop }}$ elementos. 
Tabela 4-6. Elementos da Família ROLETA

\begin{tabular}{|c|c|c|}
\hline AG variante & Esquema & $\begin{array}{c}\text { Como população é restaurada a } \mathbf{N}_{\text {pop }} \\
\text { elementos }\end{array}$ \\
\hline $\begin{array}{c}\text { Roleta1 } \\
\text { Roleta1A }\end{array}$ & $\begin{array}{l}\text { substituição } \\
\text { substituição }\end{array}$ & $\begin{array}{l}\text { indivíduos aleatórios da população corrente } \\
\text { indivíduos aleatórios da população corrente. Uso de } \\
\text { população intermediária }\end{array}$ \\
\hline $\begin{array}{c}\text { Roleta2 } \\
\text { Roleta2A }\end{array}$ & $\begin{array}{l}\text { substituição } \\
\text { substituição }\end{array}$ & $\begin{array}{l}\text { indivíduos que não participaram do cruzamento } \\
\text { indivíduos que não participaram do cruzamento. Uso } \\
\text { de população intermediária }\end{array}$ \\
\hline $\begin{array}{c}\text { Roleta3 } \\
\text { Roleta3A }\end{array}$ & $\begin{array}{l}\text { avaliador } \\
\text { avaliador }\end{array}$ & $\begin{array}{l}\text { indivíduos aleatórios da população corrente } \\
\text { indivíduos aleatórios da população corrente. Uso de } \\
\text { população intermediária }\end{array}$ \\
\hline $\begin{array}{c}\text { Roleta4 } \\
\text { Roleta4A }\end{array}$ & $\begin{array}{l}\text { avaliador } \\
\text { avaliador }\end{array}$ & $\begin{array}{l}\text { indivíduos que não participaram do cruzamento } \\
\text { indivíduos que não participaram do cruzamento. Uso } \\
\text { de população intermediária }\end{array}$ \\
\hline
\end{tabular}

A Tabela 4-7 apresenta os valores da função custo, do desvio padrão, do melhor e do pior absoluto e das três variáveis que definem a função custo para todos os AGs variantes da família ROLETA. É também apresentado o valor da função custo obtido via o método do Lagrangiano Aumentado (EASY).

Tabela 4-7. Valores da função custo e das variáveis que a definem para a família ROLETA:

$\mathrm{x}_{1}$ - altura do painel, $\mathrm{x}_{2}$ - área de armadura e $\mathrm{x}_{3}$ - resistência do concreto

\begin{tabular}{|c|c|c|c|c||c|c|c|}
\hline \multicolumn{9}{|c|}{ FUNÇÃO CUSTO-vão=6m } \\
$\left(\boldsymbol{R} \$ \mathbf{m}^{\mathbf{2}}\right)$
\end{tabular}

Considerando os valores mostrados na Tabela 4-7, referentes à Família ROLETA, pode ser evidenciado que o melhor valor da função custo foi obtido pelo 
variante Roleta3 e o pior pelo Roleta2. A única diferença entre esses dois variantes é o esquema de reprodução: avaliador e substituição respectivamente. Pode ser visualizado na Figura 4-6 que as várias curvas que representam a função custo minimizada por variantes que usam substituição como esquema de reprodução, não tiveram um bom desempenho, quando comparados com os demais da mesma família.

Os variantes Roleta1 e Roleta2 diferem apenas com relação ao procedimento adotado para restaurar a população a $\mathrm{N}_{\text {pop }}$ indivíduos. Embora os valores encontrados por ambos variantes estejam relativamente próximos e o variante implementado por Roleta1 tenha obtido um melhor resultado, não se pode afirmar que, para o problema em questão, usando a estratégia da roleta, o procedimento de restauração mais indicado é aquele que considera indivíduos aleatórios, dado que para os valores obtidos por Roleta3 e Roleta4, que também diferem apenas com relação ao esquema de restauração, verificou-se tendência oposta. Também, fica difícil fazer qualquer afirmação categórica neste caso dado que os esquemas implementados por Roleta1 e Roleta2 diferem do implementado por Roleta3 e Roleta4.

Quando são comparados os desempenhos dos variantes da subfamília ROLETAA pode ser verificado que o melhor resultado nesta subfamília é obtido pelo Roleta4A e o pior, por Roleta1A, o que confirma a tendência observada quando da análise do Roleta4 e Roleta2. Muito embora os resultados estejam bem próximos, o uso de uma população intermediária no geral produz resultados ligeiramente melhores.

Os resultados fornecidos pelo EASY foram melhores que os resultados obtidos pela família ROLETA e pela subfamília ROLETAA. Quando o esquema de reprodução utilizado é o avaliador, os valores obtidos pelos variantes que utilizam esse esquema foram melhores. Curiosamente, o AG simples implementando a seleção roleta, identificado como Michalewicz, teve melhor resultado que Roletala, Roleta1 e Roleta2. 


\section{Custo X Geração}

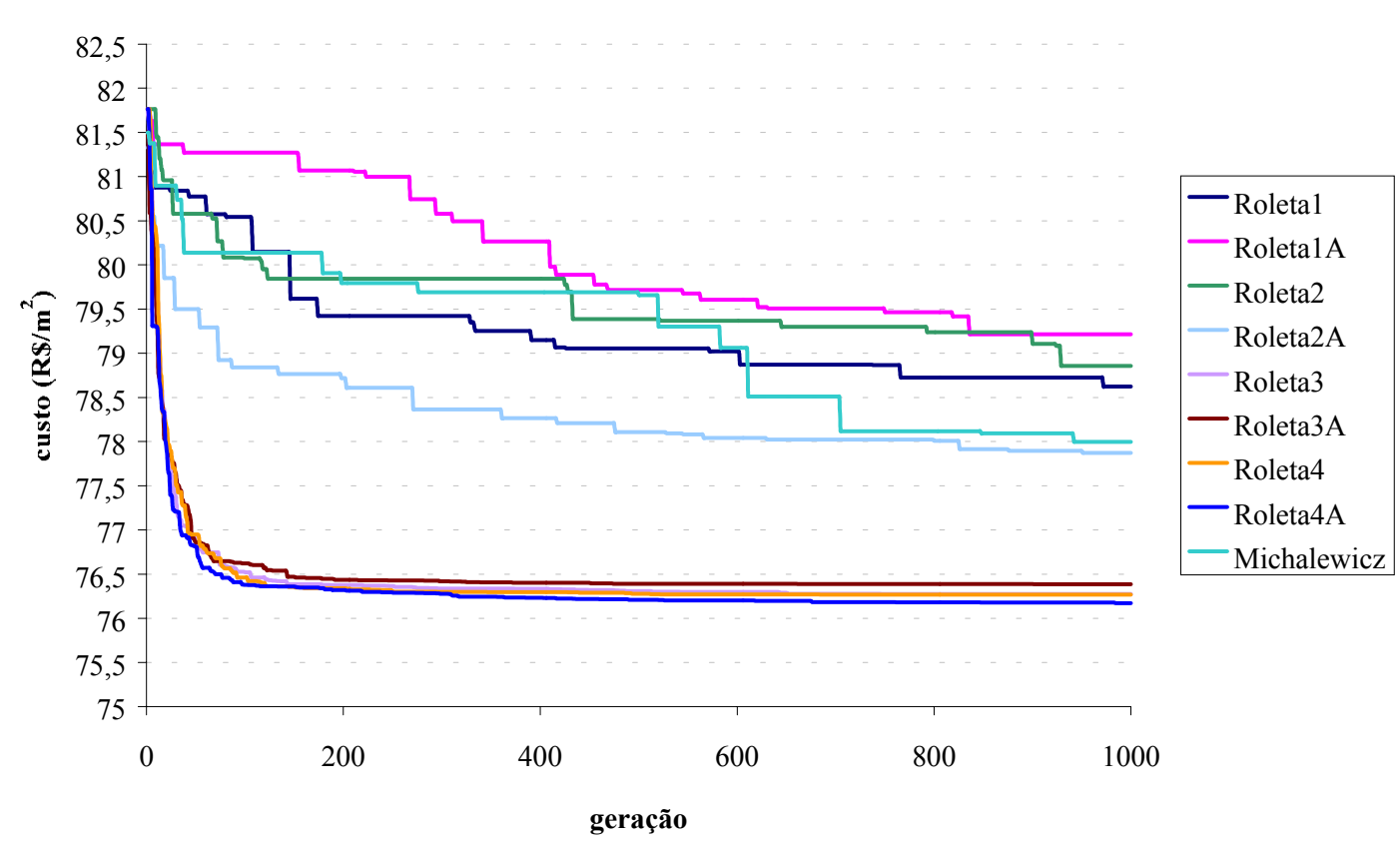

Figura 4-6. Valores médios de função aptidão para família ROLETA, Michalewicz

\subsubsection{Família TORNEIO}

A estratégia de seleção do torneio foi descrita no Capítulo 2. As diferentes combinações do esquema de reprodução adotado e da maneira como a população é restaurada a $\mathrm{N}_{\text {pop }}$ elementos dão origem aos quatro elementos desta família (Torneio1, Torneio2, Torneio3 e Toneio4). A decisão pelo uso de uma população intermediária, de maneira a poder avaliar seus efeitos, fez com que cada elemento básico desta família tivesse uma versão que implementa o uso de uma população intermediária. Essas versões são chamadas de Torneio1A, Torneio2A, Torneio3A e Torneio4A e são partes da subfamília TORNEIOA. A Tabela 4-8 apresenta as suas principais características, identificando o esquema de reprodução adotado bem como a estratégia usada para restaurar a população a $\mathrm{N}_{\text {pop }}$ elementos.

A Tabela 4-9 apresenta os valores da função custo, desvio padrão, melhor e pior absoluto e das três variáveis que definem a função custo para todos os AGs variantes da família TORNEIO. É também apresentado o valor da função custo obtido via o método do Lagrangiano Aumentado (EASY). 
Tabela 4-8. Elementos da Família TORNEIO

\begin{tabular}{|c|c|c|}
\hline AG variante & Esquema & $\begin{array}{c}\text { Como população é restaurada a } \mathbf{N}_{\text {pop }} \\
\text { elementos }\end{array}$ \\
\hline $\begin{array}{c}\text { Torneio1 } \\
\text { Torneio1A }\end{array}$ & $\begin{array}{l}\text { substituição } \\
\text { substituição }\end{array}$ & $\begin{array}{l}\text { indivíduos aleatórios da população corrente } \\
\text { indivíduos aleatórios da população corrente. Uso de } \\
\text { população intermediária }\end{array}$ \\
\hline $\begin{array}{c}\text { Torneio2 } \\
\text { Torneio2A }\end{array}$ & $\begin{array}{l}\text { substituição } \\
\text { substituição }\end{array}$ & $\begin{array}{l}\text { indivíduos que não participaram do cruzamento } \\
\text { indivíduos que não participaram do cruzamento. Uso } \\
\text { de população intermediária }\end{array}$ \\
\hline $\begin{array}{c}\text { Torneio3 } \\
\text { Torneio3A }\end{array}$ & $\begin{array}{l}\text { avaliador } \\
\text { avaliador }\end{array}$ & $\begin{array}{l}\text { indivíduos aleatórios da população corrente } \\
\text { indivíduos aleatórios da população corrente. Uso de } \\
\text { população intermediária }\end{array}$ \\
\hline $\begin{array}{c}\text { Torneio4 } \\
\text { Torneio4A }\end{array}$ & $\begin{array}{l}\text { avaliador } \\
\text { avaliador }\end{array}$ & $\begin{array}{l}\text { indivíduos que não participaram do cruzamento } \\
\text { indiíduos que não participaram do cruzamento. Uso } \\
\text { de população intermediária }\end{array}$ \\
\hline
\end{tabular}

Tabela 4-9. Valores da função custo e das variáveis que a definem para a família TORNEIO:

$\mathrm{x}_{1}$ - altura do painel, $\mathrm{x}_{2}$ - área de armadura e $\mathrm{x}_{3}$ - resistência do concreto

\begin{tabular}{|c|c|c|c|c||c|c|c|}
\hline \multicolumn{9}{|c||}{ FUNÇÃO CUSTO- vão=6m } \\
$\left(\mathbf{R} \$ \mathbf{m}^{\mathbf{2}}\right)$
\end{tabular}




\section{Custo X Geração}

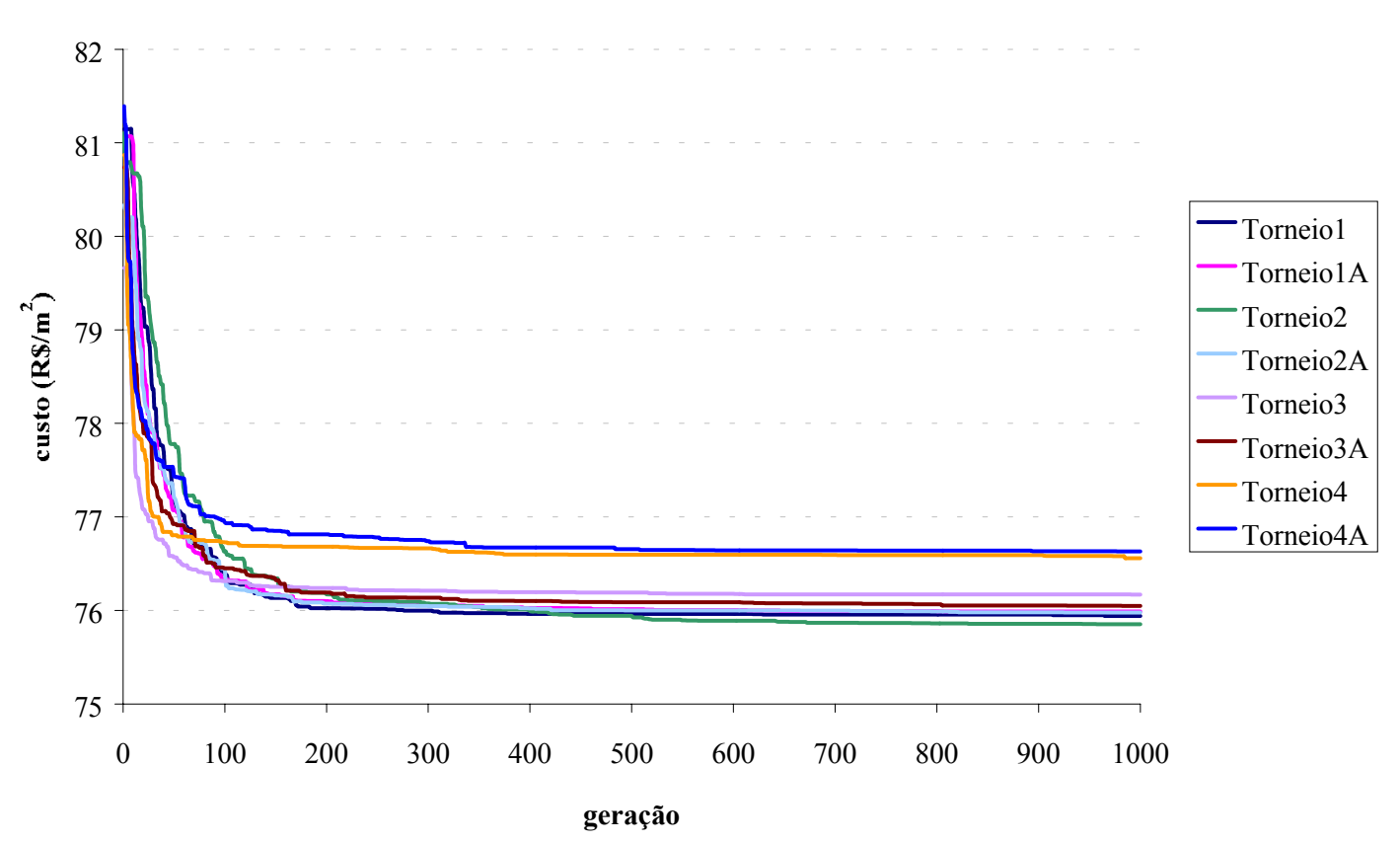

Figura 4-7. Valores médios de função aptidão para família TORNEIO

Como pode ser verificado na Tabela 4-9 e a correspondente Figura 4-7, os resultados encontrados por todos os variantes desta família estão bastante próximos, o que impossibilita a identificação e recomendação do melhor variante, quando a estratégia de seleção usada é o torneio. Embora os resultados estejam muito próximos, os piores resultados são obtidos pelo esquema de restauração que adota indivíduos que não participaram do cruzamento. Da forma como o torneio foi implementado, os esquemas de reprodução e de restauração da população a $\mathrm{N}_{\text {pop }}$ indivíduos e eventual uso de população intermediária pouco influenciam o resultado final. De qualquer forma, qualquer dos variantes não teve um melhor desempenho que o EASY.

\subsubsection{Considerações sobre os Resultados dos Experimentos de Minimização da Função Custo do Elemento}

Analisando os experimentos descritos nas três seções anteriores fica evidente que, dentre todos os variantes propostos, aqueles agrupados nas famílias MGA e Torneio foram os que obtiveram os melhores resultados. $\mathrm{Na}$ próxima seção, onde é 
investigado um problema de otimização semelhante, será avaliado apenas o melhor elemento de cada uma das três famílias, identificados pelos valores obtidos nos experimentos realizados, ie, o MGA1, o Roleta3 e o Torneio2.

Para tornar a investigação das características genéticas mais ampla, decidiu-se também por investigar dois outros tipos de cruzamento: o cruzamento simples e cruzamento uniforme. Além disso, decidiu-se por experimentar diversos valores do parâmetro $\lambda$, usado pelo operador aritmético, dado que esse valor foi mantido constante $(2 / 3)$ em todos experimentos descritos nas seções anteriores.

Apesar de alguns experimentos realizados terem contemplado mudanças no tamanho de população, os resultados obtidos não provocaram uma mudança substancial que merecesse uma análise mais detalhada e conseqüentemente não foram relatados. Entretanto, como o próximo problema a ser investigado é representado por uma função envolvendo mais variáveis, a investigação do impacto do tamanho da população nos resultados se tornou mais interessante.

\subsection{OTIMIZAÇÃO DE PAINEL ALVEOLAR COM CAPA ESTRUTURAL}

Nesta seção é investigado o uso de algoritmo genético na busca da solução para o problema de minimização do custo de um painel alveolar com capa de concreto estrutural, moldada no local. Foram considerados os mesmos critérios definidos no experimento anterior: protensão limitada e armadura localizada em um nível apenas.

Os resultados obtidos quando da busca da solução para o problema anterior serviram de subsídios para direcionar a escolha de determinadas estratégias de seleção, definir o tamanho de população mais conveniente bem como identificar a maneira mais eficiente de restaurar a população a $\mathrm{N}_{\text {pop }}$ elementos, na busca da solução para o problema aqui tratado. Os experimentos descritos nesta seção buscam evidenciar qual o impacto causado por diferentes cruzamentos e diferentes tamanhos de populações, ao longo do processo evolutivo. São apresentados e discutidos também os resultados obtidos para a solução do mesmo problema, usando o Método do Lagrangiano Aumentado. 


\subsubsection{Definição do Problema}

Os critérios para o dimensionamento de um painel alveolar com capa estrutural são apresentados no Apêndice E. O problema de otimização a ser tratado é o da minimização da função custo total de um painel alveolar considerando uma capa estrutural para o vão de $6 \mathrm{~m}$. No equacionamento desta função serão inseridos os custos das etapas transitórias (produção, transporte e montagem) do painel, usando os mesmos valores relatados na Seção 4.3.1.

As variáveis do problema são a altura do painel $\left(\mathrm{x}_{1}\right)$, a armadura $\left(\mathrm{x}_{2}\right)$, a resistência do concreto $\left(\mathrm{x}_{3}\right)$, a altura da capa de concreto $\left(\mathrm{x}_{4}\right)$ e a resistência do concreto moldada no local $\left(\mathrm{x}_{5}\right)$. A seção transversal do painel é mostrada na Figura 4-8. Os custos referentes à execução (I-Custos de Execução) e ao transporte externo (II- Custos de Transporte Externo) são os mesmos adotados na Seção 4.3.1. O próximo item (III-Custo de Aplicação) discrimina os diferentes custos envolvidos no problema que, combinados com os custos discriminados em I e II definem a função custo total, a ser minimizada. O custo final corresponde aos custos referentes ao custo de execução, de transporte e de aplicação.

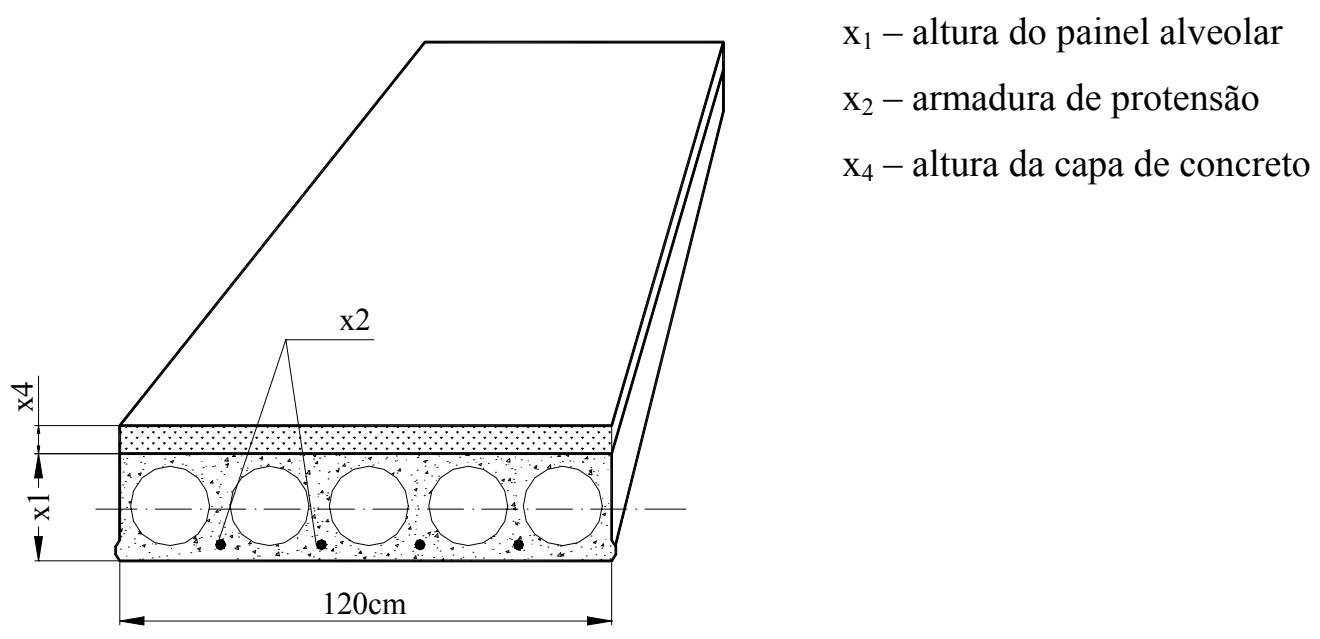

Figura 4-8. Painel alveolar com capa estrutural

Para a obtenção da função custo total, os custos de mão-de-obra e depreciação de equipamento, como descritos na Seção 4.3.1 foram considerados, com exceção dos custos tributários que foi assumido de $74 \mathrm{R} \$ \mathrm{~m}^{3}$. O item III é definido a seguir. 


\section{III) CUSTOS DA APLICAÇÃO}

Os custos envolvidos na aplicação do elemento englobam:
A. Custos da montagem do painel alveolar
B. Custos do concreto da capa
C. Custos das ligações
D. Custos indiretos administrativos

A. Custos da montagem do painel alveolar (c_montagem)

É a soma dos custos de mão-de-obra e equipamentos.

mão-de-obra: mão de obra para a colocação dos painéis

custo $\left(\mathrm{R} \$ / \mathrm{m}^{3}\right)$ : $\quad$ custo_mão_de_obra $=11,96$

equipamentos: aluguel de guindaste

custo $\left(\mathrm{R} \$ / \mathrm{m}^{3}\right)$ : $\quad$ custo_equipamento $=9,79$

$\therefore$ c_montagem $=$ custo_mão_de_obra + custo_equipamento

B. Custos do concreto da capa (c_conc)

É a soma dos custos de material, mão-de-obra e equipamentos.

material: cimento, areia, brita, aditivo, etc

custo $\left(\mathrm{R} \$ / \mathrm{m}^{3}\right)$ : $\quad$ custo_material $=\left(24,75 \mathrm{x}_{5}+74,25\right)$

onde $\quad \mathrm{x}_{5}-$ resistência do concreto da capa em $\mathrm{kN} / \mathrm{cm}^{2}$

mão-de-obra: mão de obra de vinte homens para o lançamento, o adensamento do concreto e a cura, desmoldagem. Foi considerada mão-de-obra para preparação da superfície, nivelamento entre painéis.

custo $\left(\mathrm{R} \$ / \mathrm{m}^{3}\right)$ : $\quad$ custo_mão_de_obra $=104,20$

equipamentos: vibrador, fôrmas, desforma

custo $\left(\mathrm{R} \$ / \mathrm{m}^{3}\right)$ : $\quad$ custo_equipamento $=1,67$

$\therefore$ c_conc $=$ custo_material + custo_mão_de_obra + custo_equipamento 
C. Custos das ligações (c_liga)

É a soma dos custos de material e mão-de-obra.

material: argamassa (considerou-se o custo de 3 vezes o custo do concreto de regularização)

custo $\left(\mathrm{R} \$ / \mathrm{m}^{3}\right)$ : $\quad$ custo_material $=3\left(24,75 \mathrm{x}_{5}+74,25\right)$

onde $\quad \mathrm{x}_{5}-$ resistência do concreto da capa em $\mathrm{kN} / \mathrm{cm}^{2}$

mão-de-obra: mão de obra de um homem para a efetuação das ligações

custo $\left(\mathrm{R} \$ / \mathrm{m}^{3}\right)$ : $\quad$ custo__mão_de_obra $=2,20$

$\therefore$ c_liga $=$ custo_material + custo_mão_de_obra

D. Custos indiretos administrativos (custo_adma)

Envolve os custos de: engenheiros, encarregados, recepcionista, execução do projeto, administração, encargos sociais, propaganda, energia, impostos, aluguéis, seguros, materiais de escritório, despesas de manutenção, fretes, combustível, depreciação, despesas tributárias.

custo $\left(\mathrm{R} \$ / \mathrm{m}^{3}\right)$ : $\quad$ custo_adma $=0,2\left(\mathrm{c} \_\right.$montagem $+\mathrm{c} \_$conc $+\mathrm{c}$ _liga $)$

\subsubsection{Função Custo Total}

Na subseção anterior os vários custos envolvidos na produção de um painel alveolar com capa estrutural foram discriminados. O dimensionamento de tal painel está apresentado em detalhes no Apêndice E. Com o objetivo de obter a função que representa o custo total de produção, considerando as etapas de execução, de transporte e de aplicação, os vários custos foram somados e a expressão final da função é:

$$
\begin{aligned}
& \mathrm{f}(\mathbf{x})=11,578 \ln \left(\mathrm{x}_{1}\right)-13,178+0,048\left(24,75 \mathrm{x}_{5}+74,25\right) \mathrm{x}_{4}+0,0528 \mathrm{x}_{1}+1,27 \mathrm{x}_{4}+ \\
& +1,1\left(24,75 \mathrm{x}_{3}+74,25\right)\left(0,0633 \ln \left(\mathrm{x}_{1}\right)-0,0721\right)+2,407 \mathrm{x}_{2} \\
& \text { onde }
\end{aligned}
$$


$\mathrm{x}_{1}$ - altura do painel em $\mathrm{cm}$

$\mathrm{x}_{2}$ - armadura ativa $\mathrm{em}^{2} \mathrm{~cm}^{2}$

$\mathrm{x}_{3}$ - resistência do concreto do elemento pré-moldado em $\mathrm{kN} / \mathrm{cm}^{2}$

$\mathrm{x}_{4}$ - altura da capa de concreto em $\mathrm{cm}$

$\mathrm{x}_{5}-$ resistência do concreto da capa em $\mathrm{kN} / \mathrm{cm}^{2}$

O problema de minimização do custo de produção de tal painel, portanto, se resume ao problema de minimização de $\mathrm{f}(\mathbf{x})\left(\mathbf{x}=\left(\mathrm{x}_{1}, \mathrm{x}_{2}, \mathrm{x}_{3}, \mathrm{x}_{4}, \mathrm{x}_{5}\right)\right)$. O dimensionamento do painel deve respeitar os mesmos estados limites de utilização e estados limites últimos vistos na seção anterior. Portanto, o problema em questão se configura como um problema de minimização da função objetivo sujeito a restrições e pode ser equacionado da seguinte forma:

\section{Minimizar:}

$f(x)=11,578 \ln \left(x_{1}\right)-13,178+0,048\left(24,75 x_{5}+74,25\right) x_{4}+0,0528 x_{1}+1,27 x_{4}+$ $+1,1\left(24,75 \mathrm{x}_{3}+74,25\right)\left(0,0633 \ln \left(\mathrm{x}_{1}\right)-0,0721\right)+2,407 \mathrm{x}_{2}$

\section{Sujeita às seguintes restrições:}

Verificação do estado em vazio

Verificação do estado limite último - solicitações normais

Verificação do estado limite último - solicitações tangenciais

a) Verificação ao esforço cortante

b) Verificação da interface entre os dois concretos

$\mathrm{T}_{\mathrm{d}}-\mathrm{T}_{\mathrm{u}}<0$

onde $T_{d}-$ tensão solicitante dos dois concretos

$\mathrm{T}_{\mathrm{u}}$ - tensão solicitante última

Além dessas restrições, as variáveis devem satisfazer às seguintes desigualdades: 


$$
\begin{aligned}
& 10 \leq \mathrm{x}_{1} \leq 45 \quad(\mathrm{~cm}) \\
& 2,2 \leq \mathrm{x}_{2} \leq 12,0 \quad\left(\mathrm{~cm}^{2}\right) \\
& 30 \leq \mathrm{x}_{3} \leq 50(\mathrm{MPa}) \\
& 4 \leq \mathrm{x}_{4} \leq 10(\mathrm{~cm}) \\
& 15 \leq \mathrm{x}_{5} \leq 30(\mathrm{MPa})
\end{aligned}
$$

A escolha desses limites se justifica por:

$\mathrm{x}_{1}$ : limite inferior e limite superior correspondem a limites toleráveis

$\mathrm{x}_{2}$ : limite inferior e limite superior correspondem a limites toleráveis

$\mathrm{x}_{3}$ : limite inferior e limite superior correspondem a limites toleráveis de concreto pré-moldado

$\mathrm{x}_{4}$ : o limite inferior é dado por norma e o superior é um limite tolerável

$\mathrm{x}_{5}$ : limite inferior e limite superior correspondem a limites toleráveis

Para o problema descrito aqui foi adotada a mesma estratégia da penalidade adotada na Seção 4.3.3.

\subsubsection{Busca da Solução do Problema via AG}

Nessa seção é investigada a busca da solução para o problema de otimização de custos via $A G$ usando o melhor AG variante de cada uma das famílias, identificados na seção anterior, ie, MGA1, Roleta3 e Torneio2.

Para cada um desses AGs variantes, esta seção investiga o impacto de diferentes tipos de cruzamento (aritmético, uniforme e simples), diferentes tamanhos de população (20, 100 e 500) e diferentes valores de $\lambda(2 / 3,1 / 3,1 / 2$ e aleatório). Por $\lambda$ aleatório deve-se entender um valor de $\lambda$ que varia aleatoriamente, entre 0 e 1 , a cada geração durante o processo evolutivo.

Este trabalho propõe uma variante do cruzamento uniforme, referenciado como uniforme 1 que, ao invés de apenas um filho, gera dois filhos aleatórios a partir de dois pais.

A Tabela 4-10 discrimina os valores de várias características relativas a AGs que foram adotadas para os experimentos descritos nesta seção. 
Tabela 4-10. Principais Características

\begin{tabular}{|l|l|}
\hline \multicolumn{1}{|c|}{ Características } & \multicolumn{1}{c|}{ Possíveis Valores } \\
\hline elitismo & 1 indivíduo \\
\hline população & $20,100,500$ \\
\hline Representação de dados & real \\
\hline Estratégia de seleção & MGA1, Roleta3 e Torneio2 \\
\hline cruzamento & $\begin{array}{l}\text { Aritmético, uniforme, uniforme1, } \\
\text { simples }\end{array}$ \\
\hline Probabilidade de cruzamento & 0,85 \\
\hline Probabilidade de mutação & 0,01 \\
\hline Critério de parada & 1000 gerações \\
\hline
\end{tabular}

\subsubsection{Descrição dos Experimentos e Análise dos Resultados}

Como estabelecido para os experimentos descritos na seção anterior, o valor relativo a cada um dos experimentos descrito nesta seção, é a média dos valores obtidos em dez execuções (run), cada uma delas tendo uma população inicial gerada randomicamente. A análise dos resultados focaliza os valores obtidos usando o melhor variante de cada uma das três famílias.

\subsubsection{O MGA1}

Na Tabela 4-11 são apresentados os resultados obtidos pelo MGA1 usando os quatro tipos de cruzamento, onde o cruzamento aritmético foi implementado para o valor de $\lambda=2 / 3$. O melhor resultado foi obtido com o uso do cruzamento uniforme1 e difere em $6,8 \%$ quando comparado com o valor obtido pelo EASY, que teve o pior desempenho dentre todos, a menos do operador de cruzamento uniforme.

O cruzamento simples pode ser considerado como o crossover de um ponto da representação real, realizando a troca de informação entre cromossomos a partir de um ponto escolhido. Muito embora o cruzamento simples tenha obtido bons resultados, é importante notar que os resultados encontrados na literatura que usam cruzamento de um ponto na representação binária não são os que têm o melhor desempenho. Isso talvez se deva à representação adotada.

Dentre os quatro cruzamentos, o uniforme foi o que obteve o pior desempenho. O cruzamento uniforme é o que gera um indivíduo aleatório a partir de 
dois pais dentre dos limites de cada variável. O que pode se conjecturar neste caso específico, dado que os valores das variáveis se mantiveram razoavelmente próximos durante o processo evolutivo é que esse tipo de cruzamento não introduziu muita diversidade e, daí, o baixo desempenho.

Tabela 4-11. Valores da função custo e das variáveis que a definem para a família MGA1: $\mathrm{x}_{1}$ - altura do painel, $\mathrm{x}_{2}$ - área de armadura, $\mathrm{x}_{3}$ - resistência do concreto, $\mathrm{x}_{4}-$ altura da capa $\mathrm{e}$ $\mathrm{x}_{5}$ - resistência do concreto moldado no local

\begin{tabular}{|c|c|c|c|c|c|c|c|c|c|}
\hline \multicolumn{5}{|c|}{$\begin{array}{c}\text { FUNÇÃO CUSTO } \\
\left(R S / m^{2}\right)\end{array}$} & \multicolumn{5}{|c|}{ VARIÁVEIS } \\
\hline MGA1 & $\begin{array}{c}\text { Valor } \\
\text { da } \\
\text { função }\end{array}$ & $\begin{array}{l}\text { Desvio } \\
\text { padrão }\end{array}$ & $\begin{array}{c}\text { Melhor } \\
\text { absoluto }\end{array}$ & $\begin{array}{c}\text { Pior } \\
\text { absoluto }\end{array}$ & $\begin{array}{c}\mathbf{x}_{1} \\
(\mathbf{c m})\end{array}$ & $\mid \begin{array}{c}\mathbf{x}_{2} \\
\left(\mathbf{c m}^{2}\right)\end{array}$ & $\begin{array}{c}\mathbf{x}_{3} \\
\left(\mathbf{k N} / \mathbf{c m}^{2}\right)\end{array}$ & $\begin{array}{c}\mathbf{x}_{4} \\
(\mathbf{c m})\end{array}$ & $\begin{array}{c}\mathbf{x}_{5} \\
\left(\mathrm{kN} / \mathrm{cm}^{2}\right)\end{array}$ \\
\hline $\begin{array}{c}\text { Cruzamento } \\
\text { aritmético }\end{array}$ & 74,99 & 0,3799 & 74,51 & 75,55 & 20,99 & 2,70 & 3,03 & 4,02 & 1,52 \\
\hline $\begin{array}{c}\text { Cruzamento } \\
\text { uniforme }\end{array}$ & 90,47 & 3,9000 & 84,29 & 95,25 & 25,40 & 3,34 & 4,06 & 4,51 & 2,05 \\
\hline $\begin{array}{c}\text { Cruzamento } \\
\text { Uniforme1 }\end{array}$ & 74,78 & 0,3263 & 74,26 & 75,18 & 20,86 & 2,72 & 3,02 & 4,02 & 1,51 \\
\hline $\begin{array}{c}\text { Cruzamento } \\
\text { simples }\end{array}$ & 75,65 & 1,1090 & 74,08 & 77,61 & 22,39 & 2,50 & 3,00 & 4,00 & 1,50 \\
\hline$\overline{~ E A S Y ~}$ & 80,23 & & & & 27,41 & 2,36 & 3,10 & 4,00 & 1,50 \\
\hline
\end{tabular}

A Figura 4-9 mostra os valores obtidos relativos aos quatro tipos de cruzamentos, durante o processo evolutivo. O cruzamento aritmético e o uniforme1 foram os que tiveram o melhor desempenho e o uniforme, o pior. 


\section{Custo x Geração}

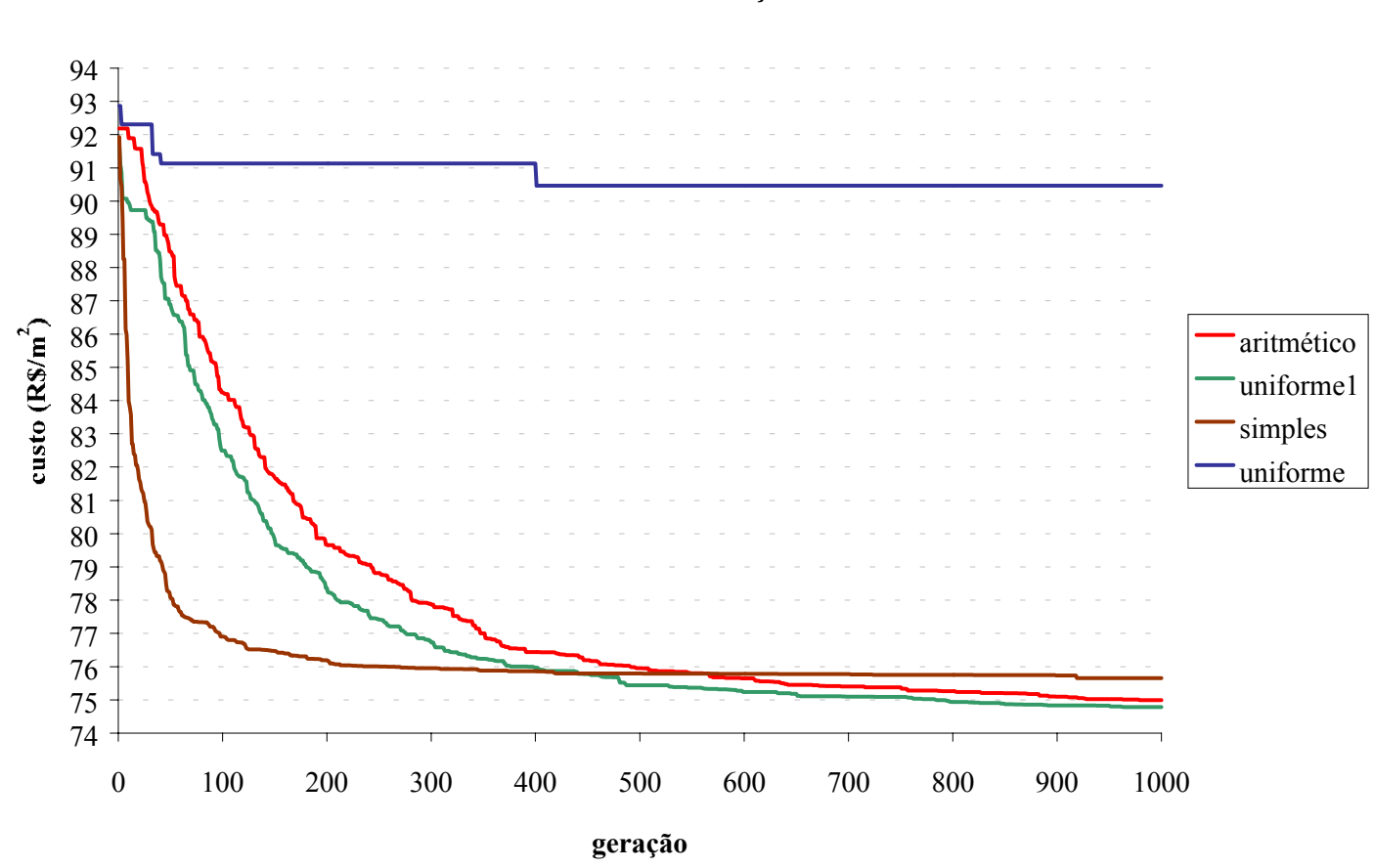

Figura 4-9. Valores médios da função custo para três tipos de cruzamento

Nota-se na Figura 4-9 que o cruzamento uniforme não introduz nenhuma diversidade à população.

Uma vez que o pior desempenho foi obtido com o cruzamento uniforme, decidiu-se, usando esse cruzamento, variar o tamanho da população, numa tentativa de investigar possíveis melhorias de desempenho. A Figura 4-10 representa o impacto dos diferentes tamanhos de população $(20,100$ e 500) usando o cruzamento uniforme e o cruzamento uniforme1. Para efeito de comparação esta figura acrescenta os dados relativos ao cruzamento simples, parte da figura anterior. Pode se verificar que o uso de diferentes tamanhos de população provocou uma pequena melhoria no desempenho do AG usando o uniforme ou o uniforme1. Entretanto, o AG usando o uniforme1 tem um desempenho bem superior que aquele usando o uniforme, para cada um dos tamanhos de população investigados. O que pode ser notar deste experimento foi que a diferença de desempenho dos AGs, para tamanho de população de 100 e de 500 não é significativa. 


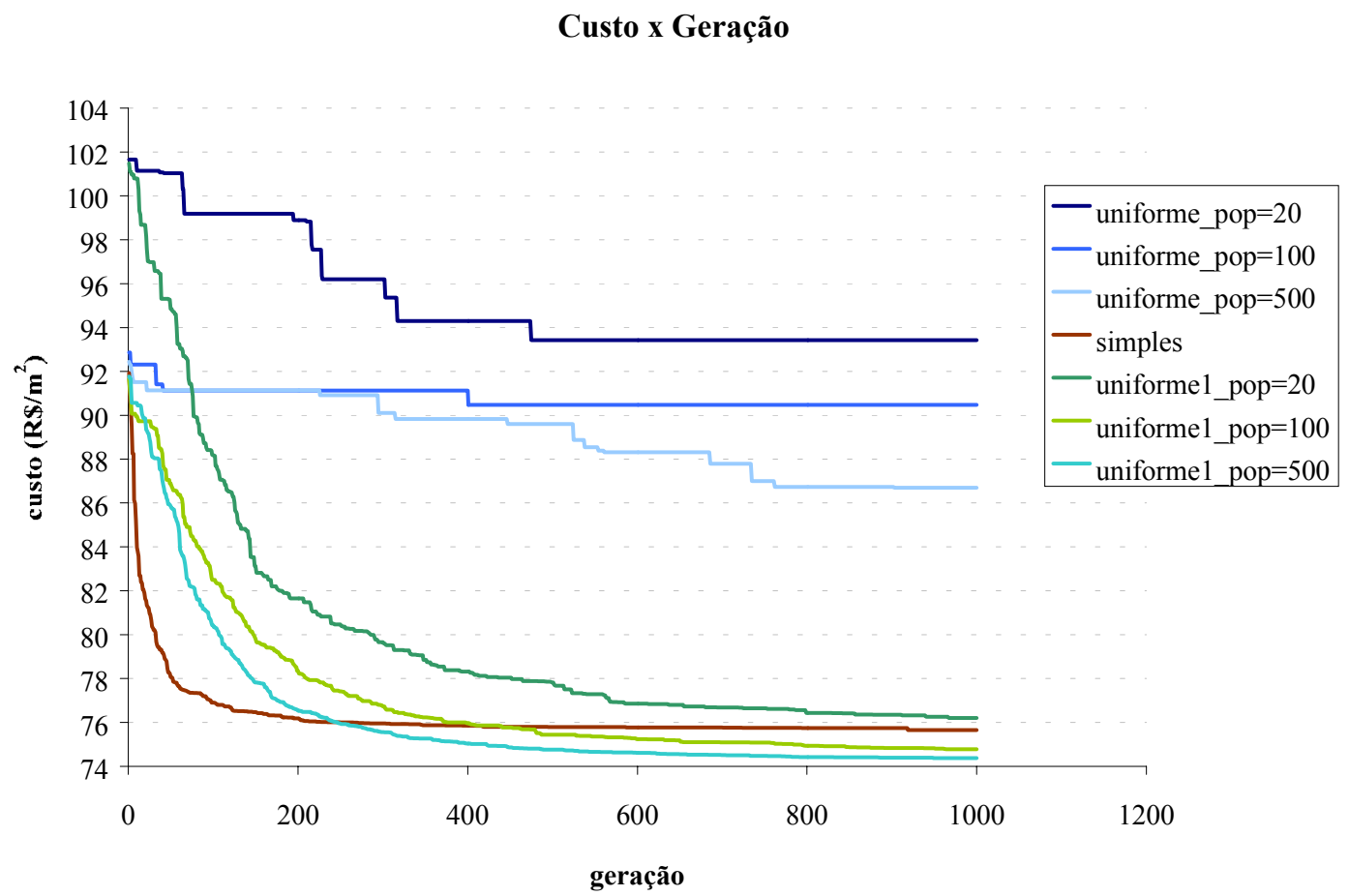

Figura 4-10. Valores médios da função custo para tamanhos de população diferentes

A Figura 4-11 mostra valores obtidos usando quatro diferentes valores de $\lambda$ para o cruzamento aritmético. Embora os resultados apresentados indiquem que o valor de $\lambda$ não tem muito impacto nos resultados obtidos, nota-se que os resultados foram ligeiramente melhores para $\lambda$ aleatório. 


\section{Custo x Geração}

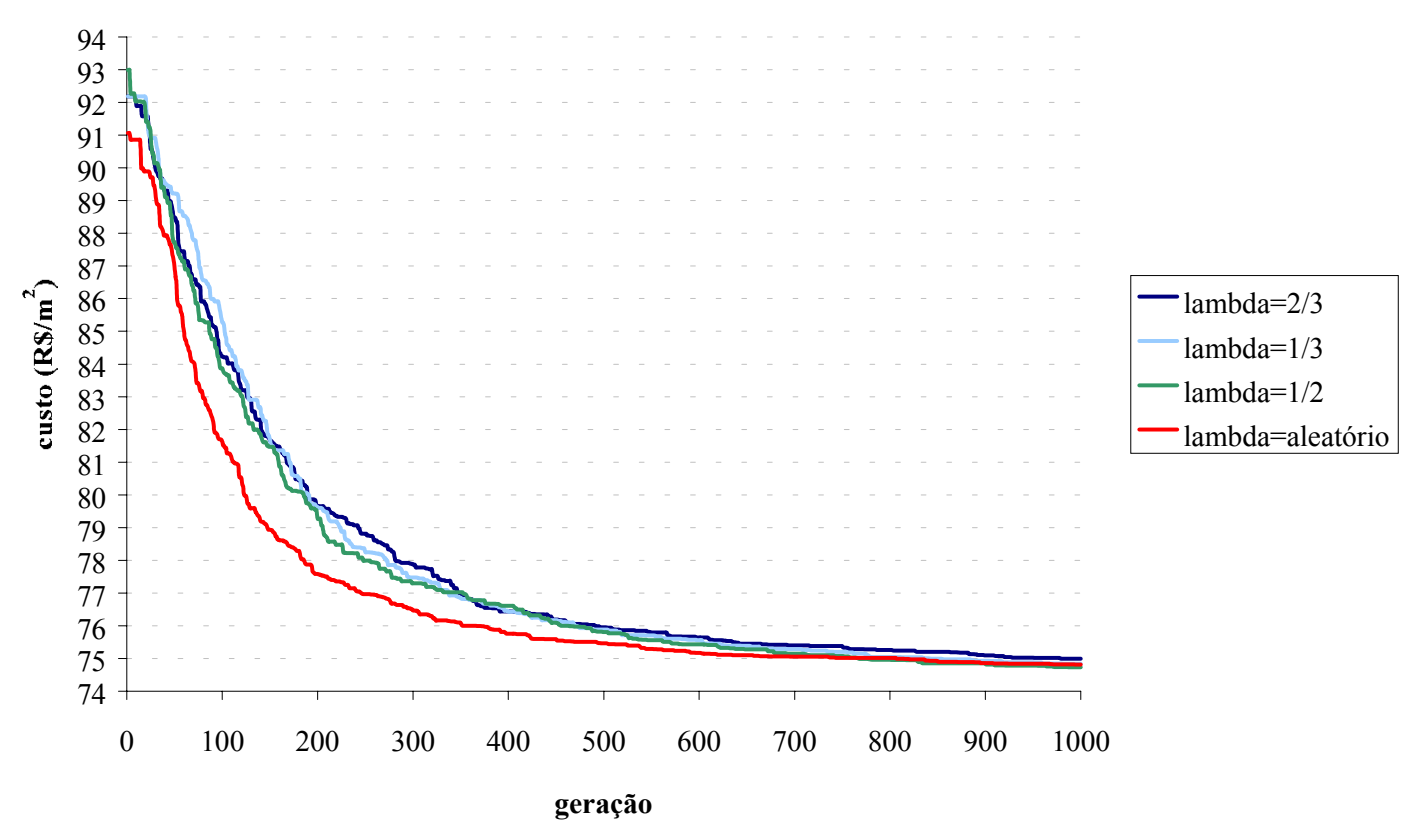

Figura 4-11. Valores médios da função custo para diversos valores de $\lambda$

\subsubsection{ROLETA3}

Na Tabela 4-12 são apresentados o valor da função, o desvio padrão, melhor e pior absoluto e variáveis do problema, referentes aos três tipos de cruzamento usando o Roleta3, bem como o valor obtido via método convencional. O melhor resultado foi obtido com o uso do cruzamento simples e difere em 7\% quando comparado com o valor obtido pelo EASY, que teve o pior desempenho dentre todos. Na Tabela 4-12 são apresentados os resultados obtidos usando os três tipos de cruzamento, onde o cruzamento aritmético foi implementado para o valor de $\lambda=2 / 3$.

O cruzamento simples foi, dentre os três, o que teve o melhor desempenho, muito embora os resultados obtidos pelos outros cruzamentos tenham ficado bem próximos. O cruzamento uniforme obteve o pior desempenho. 
Tabela 4-12. Valores da função custo e das variáveis que a definem para a família Roleta3: $\mathrm{x}_{1}$-altura do painel, $\mathrm{x}_{2}$ - área de armadura, $\mathrm{x}_{3}$ - resistência do concreto, $\mathrm{x}_{4}$ - altura da capa $\mathrm{e}$ $\mathrm{x}_{5}$ - resistência do concreto moldado no local

\begin{tabular}{|c|c|c|c|c|c|c|c|c|c|}
\hline \multicolumn{5}{|c|}{$\begin{array}{c}\text { FUNÇÃO CUSTO } \\
\left(R \$ / \mathrm{m}^{2}\right)\end{array}$} & \multicolumn{5}{|c|}{ VARIÁVEIS } \\
\hline Roleta3 & $\begin{array}{c}\text { Valor } \\
\text { da } \\
\text { função }\end{array}$ & $\begin{array}{l}\text { Desvio } \\
\text { padrão }\end{array}$ & $\begin{array}{l}\text { Melhor } \\
\text { absoluto }\end{array}$ & \begin{tabular}{|c|} 
Pior \\
absoluto
\end{tabular} & $\begin{array}{c}\mathrm{x}_{1} \\
(\mathrm{~cm})\end{array}$ & $\begin{array}{c}\mathbf{x}_{2} \\
\left(\mathrm{~cm}^{2}\right)\end{array}$ & $\begin{array}{c}\mathbf{x}_{3} \\
\left(\mathbf{k N} / \mathrm{cm}^{2}\right)\end{array}$ & $\begin{array}{c}\mathbf{x}_{4} \\
(\mathbf{c m})\end{array}$ & $\begin{array}{c}\mathbf{x}_{5} \\
\left(\mathrm{kN} / \mathrm{cm}^{2}\right)\end{array}$ \\
\hline $\begin{array}{l}\text { Cruzamento } \\
\text { aritmético }\end{array}$ & 74,78 & 0,4510 & 74,09 & 75,65 & 21,18 & 2,66 & 3,00 & 4,00 & 1,50 \\
\hline $\begin{array}{c}\text { Cruzamento } \\
\text { uniforme }\end{array}$ & 74,77 & 0,6277 & 74,07 & 75,93 & 21,19 & 2,65 & 3,00 & 4,00 & 1,50 \\
\hline $\begin{array}{c}\text { Cruzamento } \\
\text { Uniforme1 }\end{array}$ & 74,66 & 0,3482 & 74,08 & 75,18 & 20,76 & 2,72 & 3,07 & 4,00 & 1,50 \\
\hline $\begin{array}{c}\text { Cruzamento } \\
\text { simples }\end{array}$ & 74,38 & 0,3188 & 74,11 & 75,13 & 20,61 & 2,72 & 3,00 & 4,00 & 1,50 \\
\hline$\overline{\text { EASY }}$ & 80,23 & & & & 27,41 & 2,36 & 3,10 & 4,00 & 1,50 \\
\hline
\end{tabular}

A Figura 4-12 mostra os três tipos de cruzamentos utilizados na busca da solução do problema de um painel alveolar.

\section{Custo x Geração}

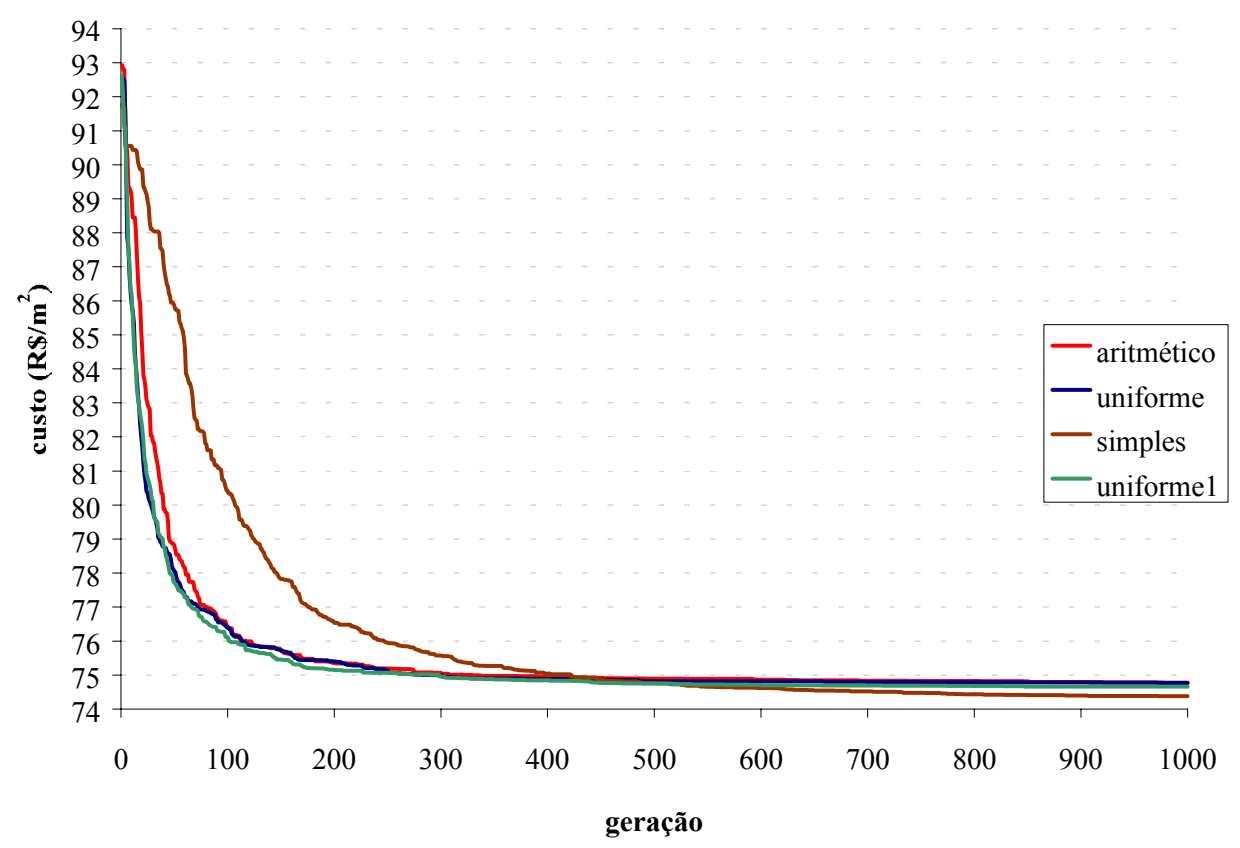

Figura 4-12. Valores médios da função custo para três diferentes cruzamentos 
Com o objetivo de explorar tamanhos de população diferentes, foram feitos experimentos para o operador de cruzamento uniforme cujos resultados são mostrados na Figura 4-13, usando como referência, o cruzamento simples.

\section{Custo x Geração}

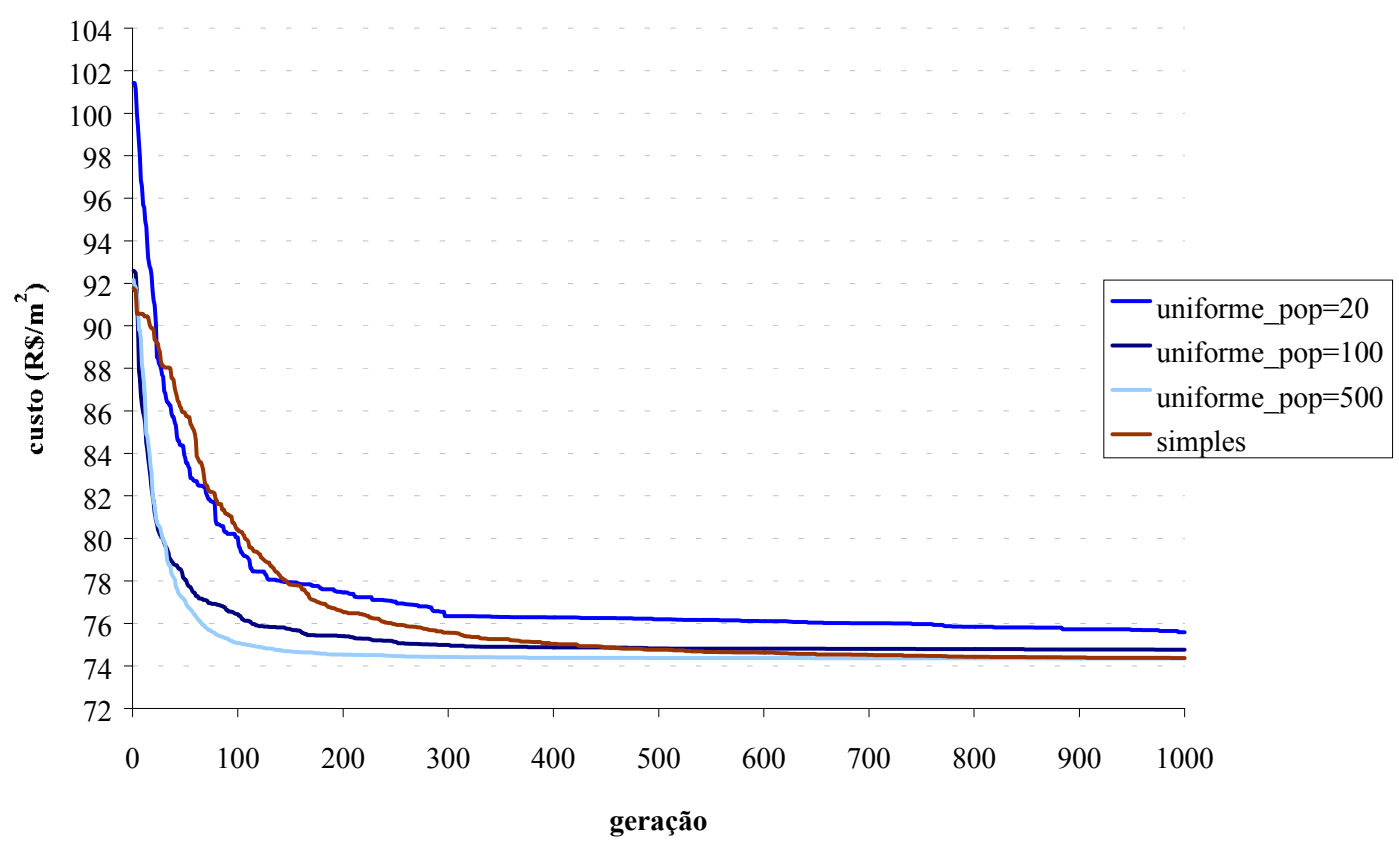

Figura 4-13. Valores médios da função custo para tamanhos de população diferentes

A Figura 4-14 mostra os quatro diferentes valores de $\lambda$ para o cruzamento aritmético utilizados na busca da solução do problema de um painel alveolar. Novamente, os resultados obtidos e mostrados na figura indicam que não houve uma discrepância muito grande entre os valores de $\lambda$. 


\section{Custo x Geração}

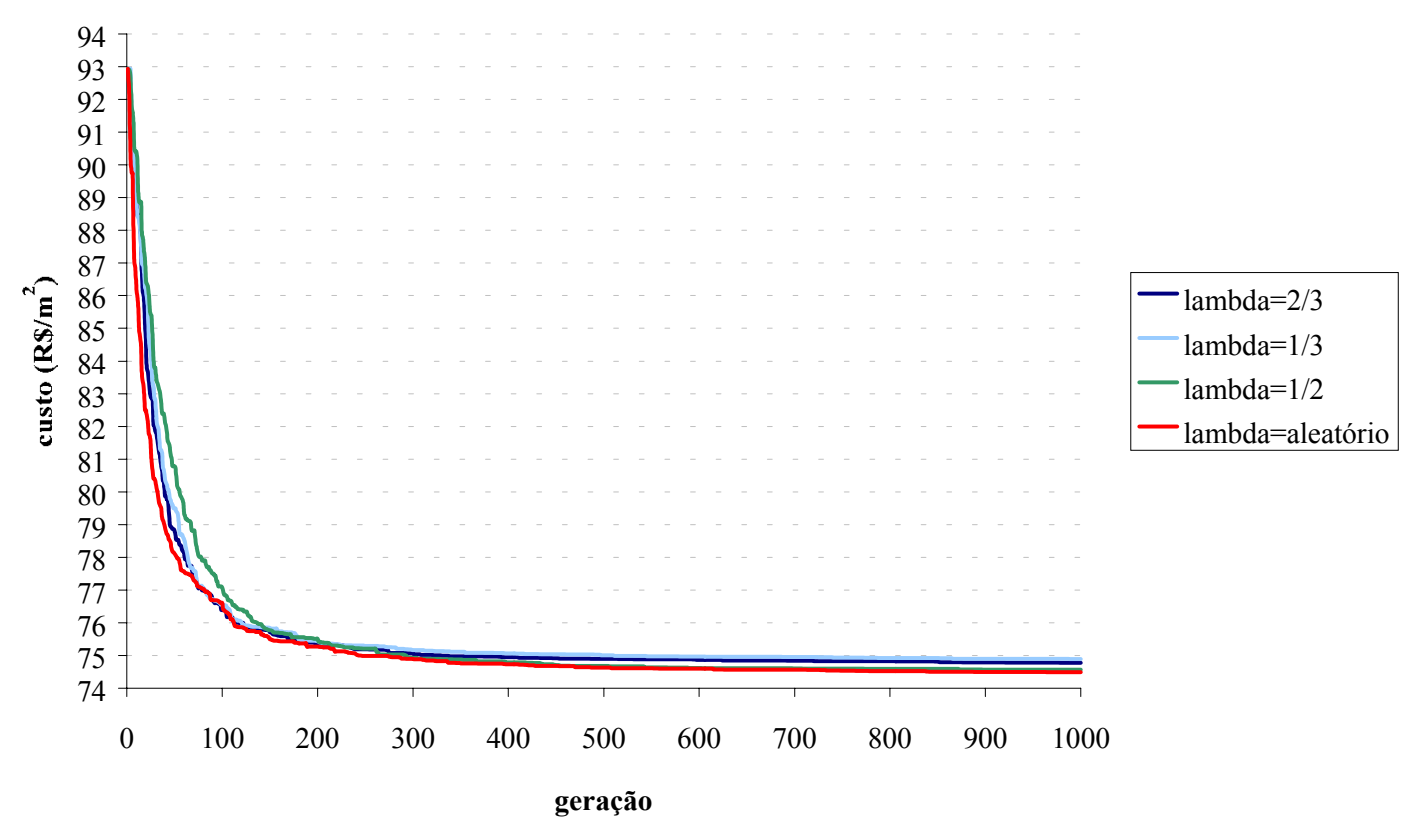

Figura 4-14. Valores médios da função custo para os diversos valores de $\lambda$

\subsubsection{TORNEIO2}

Na Tabela 4-13 são apresentados os resultados referentes aos quatro tipos de cruzamento usando o Torneio2, bem como aquele obtido via método convencional. Os resultados mostram que o cruzamento simples obteve o melhor resultado dentre todos, muito embora os valores obtidos pelos três tipos de cruzamento, o aritmético e o uniforme1 sejam muito próximos. Vale notar que esse valor difere em $7 \%$ quando comparado com o valor obtido pelo EASY, que teve o pior desempenho dentre todos. Dos quatro AGs, aquele que implementa o cruzamento uniforme obteve o pior desempenho. A Figura 4-15 exibe a função custo para AGs implementando os quatro diferentes tipos de cruzamento. 
Tabela 4-13. Valores da função custo e das variáveis que a definem para a família Torneio2: $\mathrm{x}_{1}$-altura do painel, $\mathrm{x}_{2}$ - área de armadura, $\mathrm{x}_{3}$ - resistência do concreto, $\mathrm{x}_{4}$ - altura da capa $\mathrm{e}$ $\mathrm{x}_{5}$ - resistência do concreto moldado no local

\begin{tabular}{|c|c|c|c|c|c|c|c|c|c|}
\hline \multicolumn{5}{|c|}{ 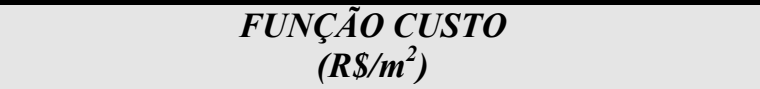 } & \multicolumn{5}{|c|}{ VARIÁVEIS } \\
\hline Torneio2 & $\begin{array}{c}\text { Valor } \\
\text { da } \\
\text { função }\end{array}$ & $\begin{array}{l}\text { Desvio } \\
\text { padrão }\end{array}$ & $\begin{array}{c}\text { Melhor } \\
\text { absoluto }\end{array}$ & \begin{tabular}{|c|} 
Pior \\
absoluto
\end{tabular} & $\begin{array}{c}x_{1} \\
(\mathbf{c m})\end{array}$ & $\begin{array}{c}\mathbf{x}_{2} \\
\left(\mathrm{~cm}^{2}\right)\end{array}$ & $\begin{array}{c}x_{3} \\
\left(k N / \mathbf{c m}^{2}\right)\end{array}$ & $\begin{array}{c}\mathbf{x}_{4} \\
(\mathbf{c m})\end{array}$ & $\begin{array}{c}\mathbf{x}_{5} \\
\left(\mathrm{kN} / \mathrm{cm}^{2}\right)\end{array}$ \\
\hline $\begin{array}{l}\text { Cruzamento } \\
\text { aritmético }\end{array}$ & 75,46 & 0,9023 & 74,45 & 77,46 & 20,49 & 2,81 & 3,16 & 4,06 & 1,54 \\
\hline $\begin{array}{l}\text { Cruzamento } \\
\text { uniforme }\end{array}$ & 80,29 & 1,3079 & 77,75 & 82,70 & 21,50 & 2,86 & 3,55 & 4,23 & 1,78 \\
\hline $\begin{array}{c}\text { Cruzamento } \\
\text { Uniforme1 }\end{array}$ & 74,49 & 0,2149 & 74,22 & 74,81 & 20,29 & 2,78 & 3,09 & 4,01 & 1,51 \\
\hline $\begin{array}{c}\text { Cruzamento } \\
\text { simples }\end{array}$ & 74,86 & 0,7399 & 74,12 & 76,09 & 21,36 & 2,63 & 3,00 & 4,00 & 1,50 \\
\hline$\overline{\text { EASY }}$ & 80,23 & & & & 27,41 & 2,36 & 3,10 & 4,00 & 1,50 \\
\hline
\end{tabular}

\section{Custo x Geração}

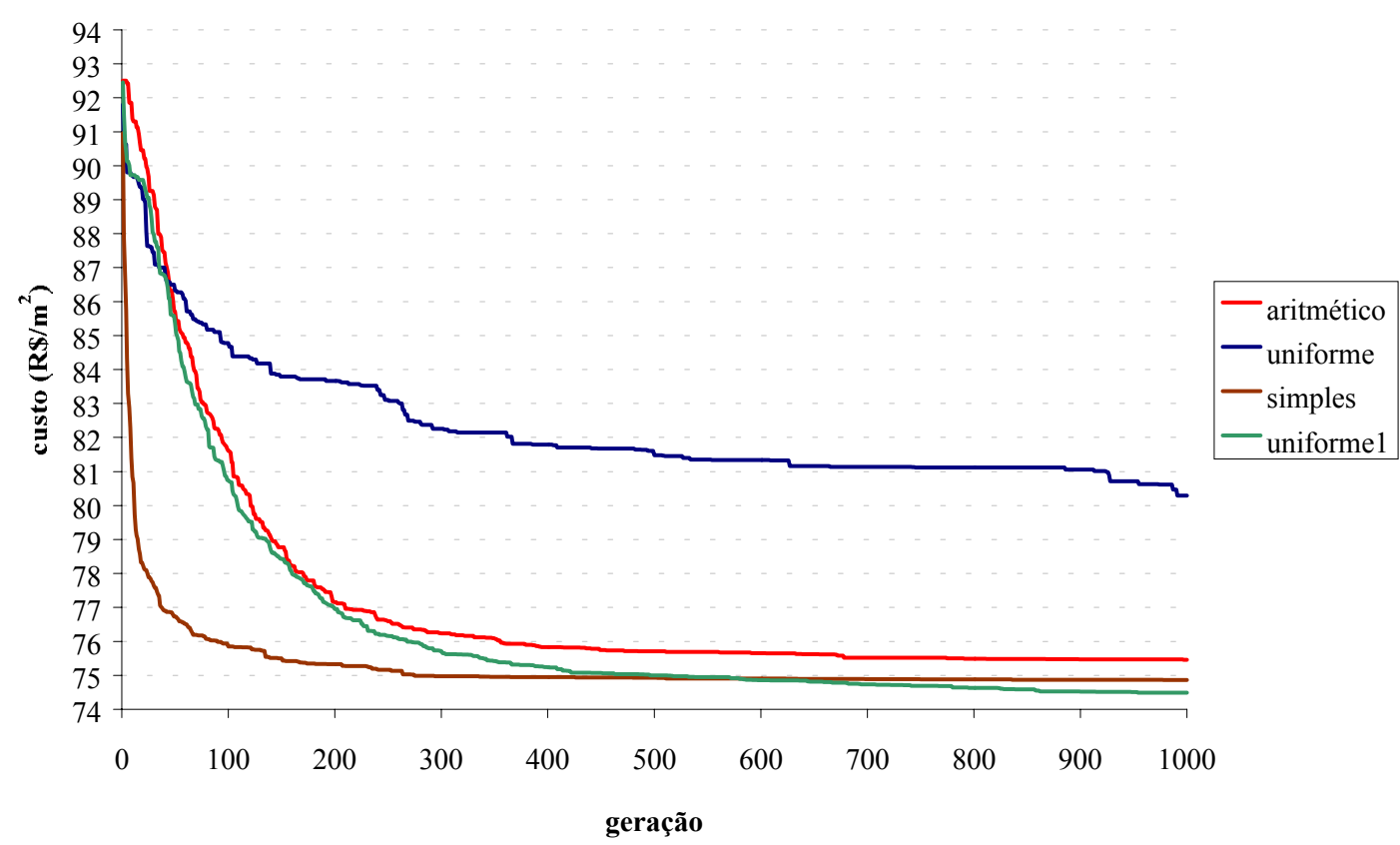

Figura 4-15. Valores médios da função custo para os três tipos de cruzamento

A Figura 4-16 mostra o resultado de experimentos realizados variando o tamanho da população, para os dois tipos de cruzamento, uniforme e uniformel. Como era de se esperar, uniformel continuou a ter um melhor desempenho que o uniforme, independentemente do tamanho de população considerado. Entretanto, 
quando a análise é focalizada apenas no uniforme, pode se verificar que, para tamanho de população de 100 e de 500 os valores obtidos estão bem próximos e, surpreendentemente, são valores piores que os obtidos quando usando uma população de tamanho 20. Com o objetivo de encontrar uma explicação para esses resultados, o experimento utilizando o operador uniforme versus diferentes tamanhos de população será refeito, para a otimização de uma outra função de custo, detalhada no Capítulo 5.

\section{Custo x Geração}

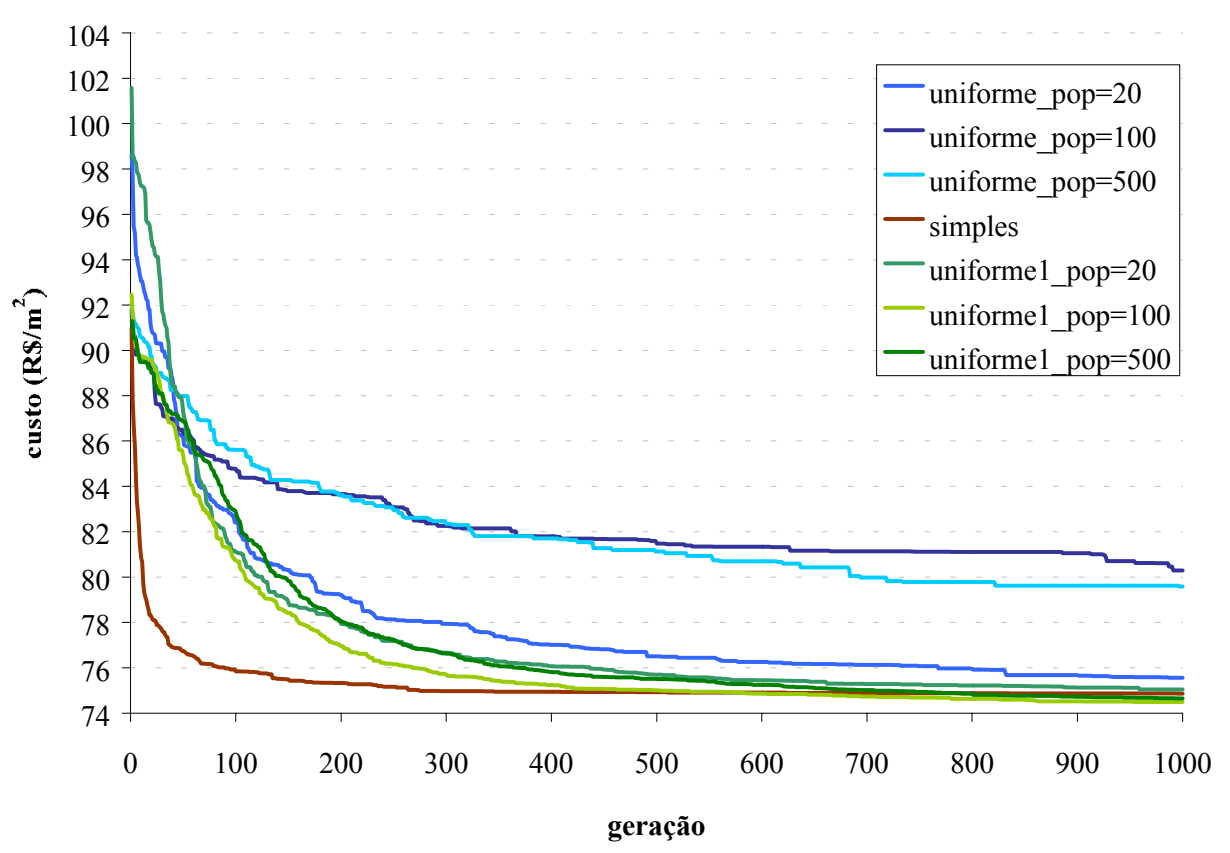

Figura 4-16. Valores médios da função custo para tamanhos de população diferentes

A Figura 4-17 mostra os resultados obtidos usando quatro diferentes valores de $\lambda$ para o cruzamento aritmético. Confirmando os resultados obtidos nas seções anteriores, na figura mostra que não houve uma discrepância entre os valores de $\lambda$. Embora não haja uma grande discrepância de resultados, vê-se que o melhor resultado foi obtido usando o $\lambda$ aleatório. 


\section{Custo x Geração}

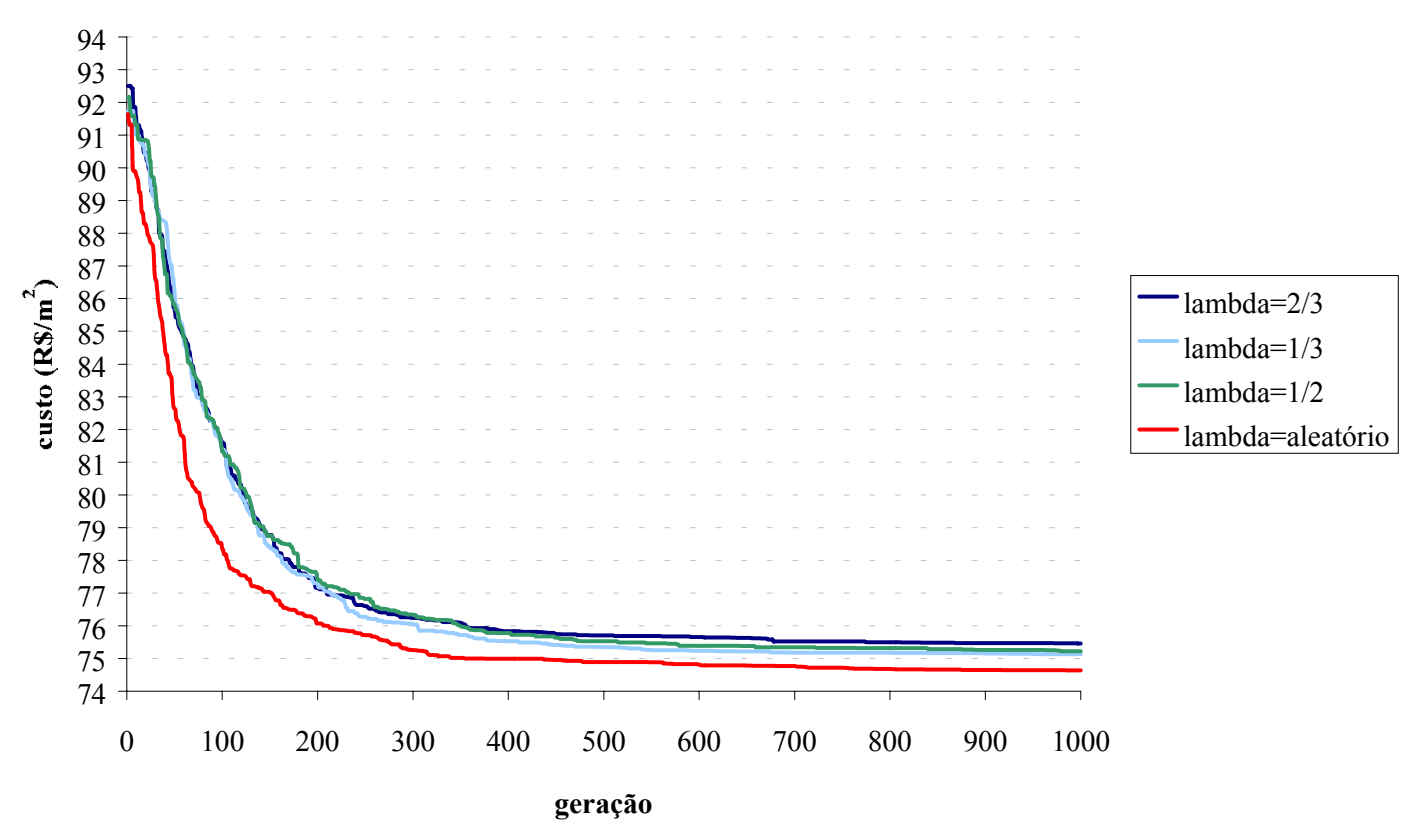

Figura 4-17. Valores médios da função custo para diversos valores de $\lambda$

\subsubsection{Considerações Sobre a Variação dos Valores do Custo Dos Materiais}

Nesta seção é avaliada a influência de alterações no valor da função custo total e de suas variáveis, para as seguintes variações: da distância da fábrica ao local da obra e do valor do custo do concreto. Os comentários que seguem são relativos ao ponto ótimo obtido para o caso da otimização do painel alveolar com capa estrutural para o variante MGA1 (4⿳亠丷⿵冂丶 custos de materiais, mão-de-obra, equipamentos, transporte, administrativos e tributários que foram obtidos no problema em questão.

Tabela 4-14. Valores em porcentagem do custo de cada etapa

\begin{tabular}{|c|c|}
\hline $\begin{array}{c}\text { Custos totais divididos } \\
\text { por etapa }\end{array}$ & $\%$ \\
\hline \hline Custos de materiais & 54,51 \\
Custos de mão-de-obra & 10,90 \\
Custos de equipamento & 3,50 \\
Custos de transporte & 8,58 \\
Custos administrativos & 10,30 \\
Custos tributários & 12,21 \\
\hline
\end{tabular}


Com o objetivo de avaliar a sensibilidade do desempenho da função custo diante das variações optou-se por aumentar cinco vezes a distância entre a fábrica e a obra. Portanto, com um aumento desta distância de $100 \mathrm{~km}$ para $500 \mathrm{~km}$, foi constatado que o custo aumenta em $25 \%$ (com relação ao custo obtido pelo ponto ótimo), e as variáveis que definem a função custo não se alteram (considerando o MGA1). Nesse caso esperava-se que a variável resistência de concreto da capa estrutural aumentasse para compensar o aumento da distância. $\mathrm{O}$ valor adotado para o custo do transporte externo fornecido pela empresa, em $\mathrm{R} \$ / \mathrm{m}^{2}$, não incorpora nenhuma variação da resistência do concreto moldado no local. A fim de se obter valores mais coerentes que representem a realidade, a parcela do custo do transporte externo deve incorporar outros parâmetros.

Avaliando um aumento de preço do concreto em 30\%, o custo final aumenta em 9,9\% e os valores para as variáveis que definem a função custo se mantêm inalterados com exceção do valor da variável referente à resistência do concreto do elemento pré-moldado que diminui em $8,4 \%$.

\subsection{AVALIAÇÃO GERAL DOS RESULTADOS OBTIDOS NOS EXPERIMENTOS DESCRITOS NO CAPÍTULO}

Nesta seção são resumidos os resultados obtidos nos experimentos descritos nas seções anteriores, com o objetivo de estabelecer conclusões parciais para cada um deles e fornecer subsídios para as decisões feitas quando da busca da solução para os problemas descritos no próximo capítulo.

\subsubsection{Otimização do Elemento}

O problema de otimização tratado é o da minimização da função custo total de uma laje com painel considerando uma capa de regularização de $4 \mathrm{~cm}$. As variáveis do problema são a altura da laje $(h)$, a armadura $\left(A_{p}\right)$ e a resistência do concreto $\left(f_{c k}\right)$.

Foram avaliadas características inerentes ao $\mathrm{AG}$ e que poderiam interferir nos resultados finais para a busca da solução. Foram avaliados 22 AGs variantes que combinam diferentes estratégias de seleção, esquemas de reprodução e esquemas de 
restauração da população. $\mathrm{O}$ AG variante que obteve o melhor resultado em cada uma das famílias é apresentado na Tabela 4-15.

Tabela 4-15. Quadro resumo dos valores médios da função custo e variáveis

\begin{tabular}{|c|c||c|c|c|}
\hline \multicolumn{2}{|c||}{$\begin{array}{c}\text { FUNÇÃO CUSTO } \\
\left(\mathbf{R} \$ / \mathbf{m}^{2}\right)\end{array}$} & \multicolumn{3}{c|}{ VARIÁVEIS } \\
\hline Estratégia & $\begin{array}{c}\text { Valor da } \\
\text { função }\end{array}$ & $\begin{array}{c}\mathbf{h} \\
(\mathbf{c m})\end{array}$ & $\begin{array}{c}\mathbf{A}_{\mathbf{p}_{\mathbf{p}}} \\
\left.\mathbf{( c m}^{2}\right)\end{array}$ & $\begin{array}{c}\mathbf{f}_{\mathrm{ck}} \\
(\mathbf{M P a})\end{array}$ \\
\hline $\begin{array}{c}\text { Família Rank } \\
\text { (MGA1) }\end{array}$ & 75,91 & 21,47 & 2,67 & 30,7 \\
\hline $\begin{array}{c}\text { Família Roleta } \\
\text { (Roleta3) }\end{array}$ & 76,27 & 21,66 & 2,54 & 32,2 \\
\hline $\begin{array}{c}\text { Família Torneio } \\
\text { (Torneio2) }\end{array}$ & 75,85 & 21,54 & 2,68 & 30,2 \\
\hline EASY & 75,75 & 21,49 & 2,69 & 30,0 \\
\hline
\end{tabular}

Os dados da tabela mostram que os valores obtidos pelos três melhores variantes estão bastante próximos. Entretanto, o AG Torneio2 foi o variante que obteve o melhor resultado de todos. Com o objetivo de condensar os resultados obtidos, pode-se dizer, com base nos experimentos, que:

\section{Família MGA}

Nesta família, o melhor variante foi o MGA1, com esquema de substituição e restauração da população usando indivíduos aleatórios da população corrente e o pior, o MGA2, também com esquema de substituição, mas com restauração da população usando indivíduos que não participaram do cruzamento.

Os 6 AGs variantes da família MGA obtiveram resultados próximos mas não superaram os resultados obtidos com o EASY. Os resultados mostram que a estratégia de reparação usando indivíduos que não participaram do cruzamento não contribui para uma melhoria de desempenho e, conseqüentemente, essa estratégia deve ser descartada. Pode-se concluir também que o uso da estratégia avaliador piora o desempenho.

\section{Família ROLETA}

Nesta família, o melhor variante foi o Roleta3 com esquema avaliador e restauração da população usando indivíduos aleatórios da população corrente. O pior foi o Roleta2, com esquema de substituição e indivíduos aleatórios da população corrente. 
Os 8 AGs variantes da família ROLETA obtiveram resultados que não superam os resultados obtidos com o EASY. O uso de uma população intermediária (implementada pelos algoritmos da subfamília ROLETAA) não contribuiu muito para uma sensível melhoria de desempenho.

\section{Família TORNEIO}

Os 8 AGs variantes da família TORNEIO obtiveram resultados muito próximos entre si e os resultados obtidos pelos 8 quase superam os resultados obtidos pelo EASY. Embora os resultados estejam muito próximos os piores valores foram obtidos usando o esquema que adota indivíduos que não participaram do cruzamento. Aparentemente, o esquema de reprodução, a estratégia de reparação a $\mathrm{N}_{\text {pop }}$ e a adoção de uma população intermediária não influem sensivelmente nos resultados finais.

\subsubsection{Otimização do elemento e da aplicação}

O problema de otimização tratado é o da minimização da função custo total de uma laje com painel alveolar considerando uma capa estrutural. As variáveis do problema são a altura da laje $(h)$, a armadura $\left(A_{p}\right)$, a resistência do concreto $\left(f_{c k}\right)$, a altura da capa de concreto $\left(h_{\text {capa }}\right)$ e a resistência do concreto moldada no local $\left(f_{\text {ckcml }}\right)$. A abordagem deste problema via AG foi feita usando já os melhores variantes de cada família, (MGA1, Roleta3,Torneio2) identificados nos experimentos anteriores. Por essa razão, o foco dos experimentos foi direcionado à avaliação de:

- diferentes tipos de cruzamento. Devido aos resultados obtidos pelo AG implementando o cruzamento uniforme, buscou-se variar o tamanho da população, na tentativa de obter um melhor desempenho com esse operador;

- três diferentes valores de $\lambda$, relativos ao cruzamento aritmético.

Os melhores resultados obtidos pelos AGs variantes de cada família são apresentados na Tabela 4-16. 
Tabela 4-16. Quadro resumo dos valores médios da função custo e variáveis

\begin{tabular}{|c|c|c||c|c|c|c|c|}
\hline \multicolumn{3}{|c||}{ FUNÇÃO CUSTO } & \multicolumn{5}{c|}{ VARIÁVEIS } \\
\hline Estratégia & $\begin{array}{c}\text { Tipo de } \\
\mathbf{T}^{2}\end{array}$ & $\begin{array}{c}\text { Valor da } \\
\text { cruzamento }\end{array}$ & $\begin{array}{c}\mathbf{h}_{\mathbf{n}} \\
(\mathbf{c m})\end{array}$ & $\begin{array}{c}\mathbf{A}_{\mathbf{p}} \\
\left(\mathbf{c m}^{2}\right)\end{array}$ & $\begin{array}{c}\mathbf{f}_{\text {ck }} \\
(\mathbf{M P a})\end{array}$ & $\begin{array}{c}\mathbf{h}_{\text {capa }} \\
(\mathbf{c m})\end{array}$ & $\begin{array}{c}\mathbf{f}_{\mathrm{ck}} \\
(\mathbf{M P a})\end{array}$ \\
\hline MGA1 & uniforme1 & 74,78 & 20,86 & 2,72 & 30,2 & 4,02 & 15,1 \\
\hline Roleta3 & simples & 74,38 & 20,61 & 2,72 & 30,0 & 4,00 & 15,0 \\
\hline Torneio2 & simples & 74,86 & 21,36 & 2,63 & 30,0 & 4,00 & 15,0 \\
\hline EASY & - & 80,23 & 27,41 & 2,36 & 31,0 & 4,00 & 15,0 \\
\hline
\end{tabular}

$\mathrm{Na}$ tabela pode ser verificado que o MGA1, Roleta3 e Torneio2 obtiveram melhores resultados, quando comparados com os resultados obtidos pelo EASY. Dentre os três tipos de cruzamento utilizados, os melhores resultados foram obtidos com o simples e, em seguida, pelo uniforme (independentemente do valor de $\lambda$ ).

Algumas conclusões parciais quando da solução do problema são:

- Em quase todos os experimentos, o pior desempenho foi obtido com o cruzamento uniforme. Os resultados obtidos com o simples, aritmético e o uniforme1, via de regra, sempre estiveram bem próximos;

- Valores de $\lambda$ não interferiram nos resultados finais obtidos pelos variantes das três famílias;

- Populações com um número maior de indivíduos não necessariamente produzem melhores resultados. 


\section{- Descrição, Representação e Solução do Problema de Minimização do Custo de Lajes com Vigotas Protendidas}

\subsection{PRELIMINARES}

Neste capítulo é investigado o uso de AG na solução do problema de otimização do custo de uma laje com vigota protendida considerando ou não o uso de escoras intermediárias.

Um dos objetivos básicos da investigação conduzida na busca de soluções dos problemas descritos neste capítulo foi o de experimentar outro tipo de representação de dados, quando da implementação de AGs, visando a avaliação não apenas da representação, mas também de uma gama maior de tipos de cruzamento. No capítulo anterior todos os experimentos foram realizados usando representação real que, aparentemente, é a representação mais natural para esses tipos de problemas. No entanto, como a representação binária é também largamente utilizada em problemas de engenharia e possibilita o uso de um número grande de operadores de cruzamento, decidiu-se por seu uso na busca da solução dos problemas descritos neste capítulo, com o objetivo de verificar sua adequabilidade aos problemas tratados. 
Dentre todos os AGs variantes propostos e investigados no Capítulo 4, neste capítulo optou-se pelo uso de apenas dois deles: o MGA1 e o Roleta1A. O MGA1 foi escolhido porque teve o melhor desempenho de todos e sua escolha foi motivada pela possibilidade de obter um desempenho ainda melhor via alteração de algumas de suas características. O Roleta1A foi escolhido por ser o variante que teve o pior desempenho dentre todos. Sua escolha foi motivada pela possibilidade de via alteração de alguma de suas características, obter um variante com melhor desempenho.

Assim sendo, as próximas três seções vão tratar da busca da solução via AG (por meio dos variantes MGA1 e Roleta1A) e via o EASY, dos problemas:

- otimização do elemento para uma determinada aplicação: será minimizado o custo de produção de uma laje com vigotas protendidas considerando como variáveis as três áreas de armadura e a posição dos dois níveis de armadura;

- otimização da aplicação para uma determinada seção transversal de vigota: será minimizado o custo da aplicação de uma laje com vigotas protendidas considerando como variáveis a altura da capa de concreto, a resistência do concreto da capa e o inter-eixo;

- otimização do elemento e da aplicação para uma determinada seção transversal de vigota: será minimizado o custo de produção, transporte e aplicação de uma laje com vigotas protendidas considerando como variáveis as áreas de armaduras, os dois níveis de armadura, a altura da capa de concreto, a resistência do concreto da capa e o inter-eixo;

A análise dos problemas de minimização de custos tratados neste capítulo pretende fornecer subsídios da aplicação dessas vigotas em lajes focalizando elementos que são bastante difundidos e utilizados pelo mercado brasileiro.

Para a obtenção dos resultados usando AGs foram feitas implementações em $\mathrm{C}++$, sob ambiente operacional Windows NT. 


\subsection{CONSIDERAÇÕES SOBRE O PROJETO E APLICAÇÃO DE VIGOTAS EM LAJES}

Além dos painéis alveolares vistos no Capítulo 4, outro sistema de laje é aquele conhecido por laje com vigotas pré-moldadas. Essas lajes são comumente utilizadas no Brasil com faixas de vãos relativamente pequenos. As informações descritas a seguir foram extraídas de EL DEBS (2000).

As lajes formadas por vigotas pré-moldadas são constituídas por elementos pré-moldados (as nervuras), elementos de enchimento tais como blocos vazados ou de poliestireno expandido (EPS), que são colocados sobre os pré-moldados e o concreto moldado no local. A Figura 5-1 ilustra cada um desses elementos.

As nervuras utilizadas no Brasil são de seção $\mathrm{T}$ invertido, em concreto armado ou concreto protendido ou com uma armadura em forma de treliça que projeta para fora da seção (a chamada laje com armação treliçada). Na Figura 5-2 são apresentados esses tipos de nervuras bem como os tipos de elementos de enchimento.

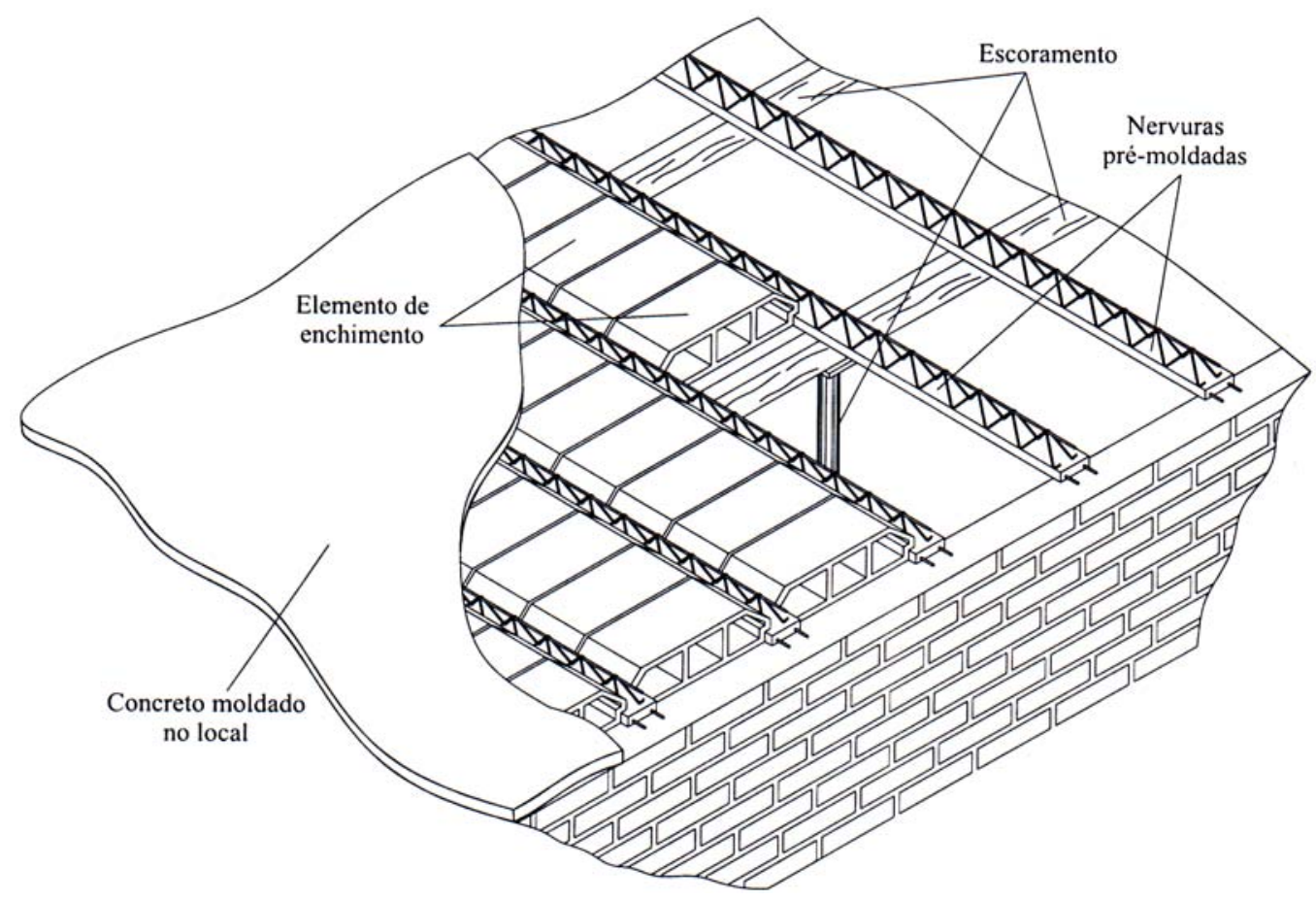

Figura 5-1. Esquema de laje formada de nervuras pré-moldadas [EL DEBS (2000)] 


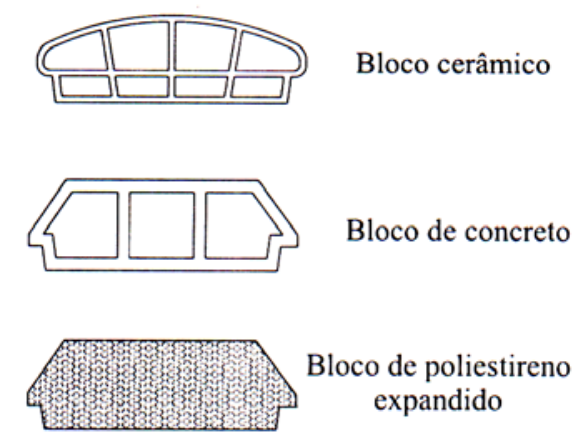

a) tipos de nervuras

b) tipos de enchimentos

Figura 5-2. Tipos de nervuras e elementos de enchimentos utilizadas nas lajes

[EL DEBS (2000)]

As vigotas pré-moldadas de concreto armado de seção $\mathrm{T}$ invertido são produzidas em fôrmas metálicas simples. As vigotas de concreto protendido, objeto de estudo deste trabalho, são produzidas em grandes pistas de protensão em fôrmas fixas ou fôrmas deslizantes, de maneira semelhante aos painéis alveolares. As vigotas treliçadas são produzidas como as nervuras de concreto armado de seção T invertido. A Figura 5-3 mostra uma pista de protensão para a produção de vigotas protendidas.

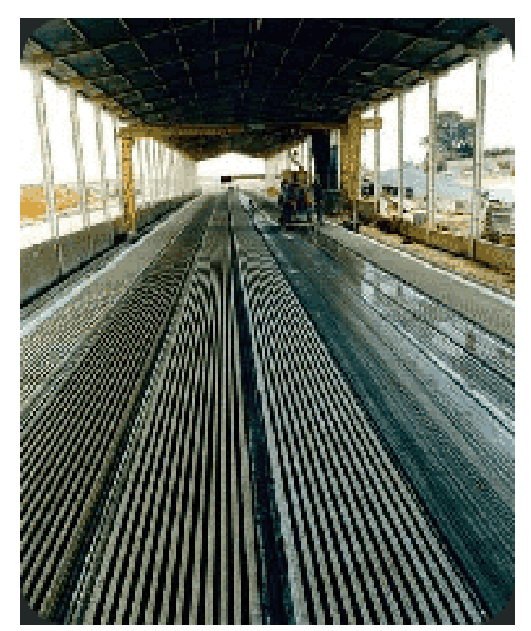

Figura 5-3. Pista de protensão de vigotas protendidas ${ }^{1}$

Geralmente, esse tipo de laje permite vãos da ordem de $5 \mathrm{~m}$ com nervuras em concreto armado, da ordem de $10 \mathrm{~m}$ com nervuras de concreto protendido e da ordem de $10 \mathrm{~m}$ com nervuras com armação treliçada.

\footnotetext{
${ }^{1}$ Fonte empresa Tatu localizada em Limeira, São Paulo.
} 
O comportamento estrutural das lajes formadas por vigotas pré-moldadas corresponde aos das lajes armadas em uma direção (lajes unidirecionais), com seção resistente composta pela parte pré-moldada e pelo concreto moldado no local. Cabe salientar que a partir de vigotas com armação treliçada pode se obter lajes armadas nas duas direções (lajes bidirecionais).

O manuseio desses elementos é feito sem o auxílio de equipamentos. $\mathrm{O}$ transporte é realizado por caminhões e a montagem realizada manualmente. Utiliza-se ainda cimbramento para receber as nervuras, que permanece até o concreto moldado no local endurecer. Recomenda-se utilizar uma armadura na capa de concreto disposta nas duas direções que é denominada armadura de distribuição.

No projeto estrutural desse tipo de laje, o cálculo das solicitações é normalmente feito considerando a laje como viga, simplesmente apoiada ou contínua, conforme o caso. Deve ser salientado que, no dimensionamento, a contribuição do material de enchimento na seção resistente geralmente não é considerada, salvo quando o módulo de elasticidade do bloco for superior a 8,0GPa. A seção resistente das nervuras pode ser considerada como a da parte pré-moldada somada à parte moldada no local.

Algumas diretrizes devem ser seguidas para o dimensionamento de lajes com vigotas protendidas. São elas:

- Verificação da vigota isolada - verificação do elemento após a transferência da força de protensão;

- Verificação da vigota na fase de construção - deve ser verificada a necessidade ou não de escoramento;

- Estado limite de fissuração - deve ser projetada de tal forma que previna os efeitos da fissuração;

- Estado limite de deformação - deve ser projetado levando em consideração os efeitos instantâneos e de retração e fluência;

- Estado limite último para solicitações tangenciais - verificação de resistência à força cortante de elementos sem armadura transversal e verificação do cisalhamento da interface entre os dois concretos;

- Estado limite último para solicitações normais - verificação da resistência para as solicitações normais. 
O dimensionamento das vigotas protendidas segue as recomendações das normas NBR 7197 da ABNT (1986), NBR 6118 da ABNT (2001), de um projeto de norma brasileira em andamento ${ }^{2}$ e das normas espanholas.

\subsection{OTIMIZAÇÃO DO ELEMENTO PARA UMA DETERMINADA APLICAÇÃO}

Nesta seção é investigado o uso de algoritmo genético na busca da solução para o problema de minimização do custo de produção de uma dada vigota protendida com ou sem a utilização de escoras intermediárias para uma determinada aplicação. São apresentados e discutidos também os resultados obtidos para a solução do mesmo problema, usando o Método do Lagrangiano Aumentado implementado via o software EASY.

\subsubsection{Definição do Problema}

O problema de otimização a ser tratado é o da minimização da função custo total de uma laje com vigota protendida com a utilização ou não de escoras intermediárias para dois vãos: 3 metros e 4 metros. No equacionamento desta função são inseridos os custos das etapas transitórias (produção, transporte e montagem) da vigota. Os critérios para o dimensionamento de uma laje com vigota protendida são apresentados no Apêndice F.

As variáveis envolvidas na definição da função custo são as áreas dos três níveis de armaduras de protensão $\left(\mathrm{x}_{1}, \mathrm{x}_{2}, \mathrm{x}_{3}\right)$ e as alturas do segundo e do terceiro nível da armadura no elemento $\left(\mathrm{x}_{4}, \mathrm{x}_{5}\right)$. A altura do primeiro nível é definida tendo como base o cobrimento mínimo. A seção transversal da laje é mostrada na Figura 5-4. Os próximos itens (I-Custo de Execução, II-Custo de Transporte Externo e IIICusto de Aplicação) discriminam os diferentes custos envolvidos no problema que, combinados, definem a função custo total, a ser minimizada. As dimensões da vigota e da laje são apresentadas na Figura 5-5. Foram adotados os seguintes valores: a resistência do concreto pré-moldado igual a $39 \mathrm{MPa}$ e a de concreto moldado no

\footnotetext{
${ }^{2}$ Laje pré-fabricada - Projeto 18:314.01-001/1
} 
local igual a $20 \mathrm{MPa}$ e a medida do inter-eixo igual a $30 \mathrm{~cm}$. Esses valores foram estipulados para este experimento após alguns testes iniciais.

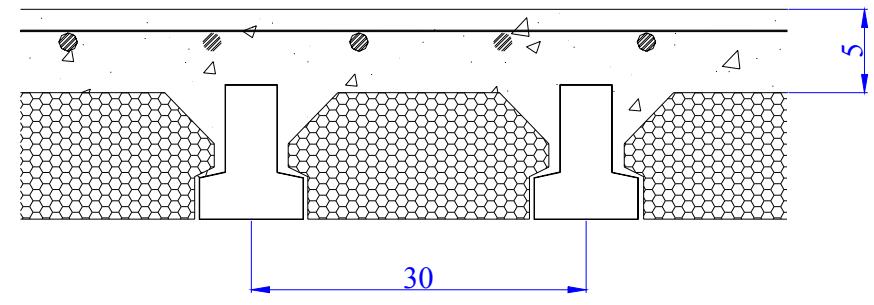

Figura 5-4. Seção de laje com vigota de concreto protendido, com enchimento e concreto moldado no local (medidas em $\mathrm{cm}$ )

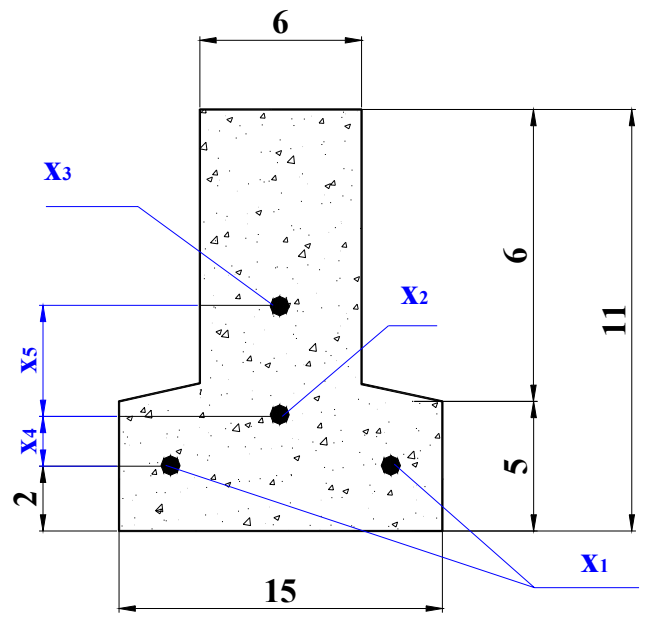

a) Seção da vigota protendida

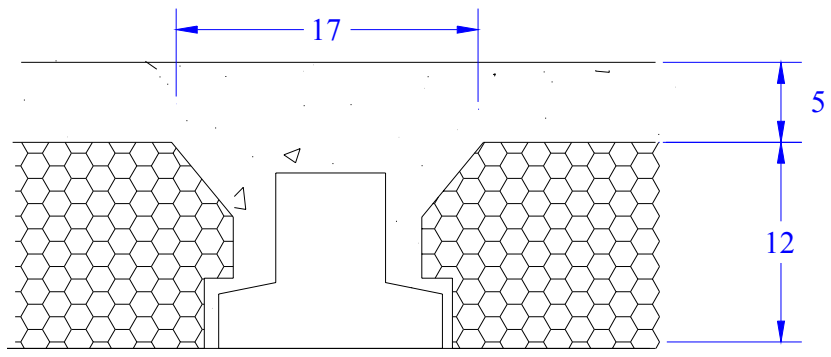

b) Seção de laje com vigota protendida

Figura 5-5. Dimensões das seções da laje e da vigota protendida (medidas em cm)

O processo de dimensionamento de uma laje com vigotas protendidas foi o mesmo adotado em MERLIN (2002). Os critérios de dimensionamento atendem os estados limites de utilização (estados limites de descompressão e de formação de 
fissuras, de controle da deformação, de controle da fissuração) e o estado limite último (solicitações normais e tangenciais).

Os custos utilizados nos itens I, II e III, descritos a seguir, consideram os mesmos valores adotados no Capítulo 4. Serão reescritos aqui, nessa seção, apenas para facilitar a leitura. São eles:

- Mão-de-obra com encargos sociais (5 homens)

$\mathrm{R} \$ 192,00$ por dia

Produção diária $=180 \mathrm{~m}^{2}$

- Depreciação de equipamentos: extrusora, usina de concreto, máquina de corte Valor investimento $=\mathrm{R} \$ 680.000,00$

Vida útil $=15$ anos

Valor Residual $=20 \%$

Produção Anual $=45.000 \mathrm{~m}^{2}$

\section{I) CUSTOS DE EXECUÇÃO}

Os custos envolvidos na execução englobam:
A. Custos de matéria-prima
B. Custos adicionais
C. Custos indiretos administrativos
D. Custos tributários

\section{A.Custos de matéria-prima}

É a soma dos custos de concreto (c_concreto), armadura (c_armadura) e enchimento (c_enchimento)

Concreto: material, mão de obra, equipamento

material: cimento, areia, brita, aditivo, etc

$$
\text { custo }\left(\mathrm{R} \$ / \mathrm{m}^{3}\right) \text { : } \quad \text { custo_material }=179,78
$$

mão-de-obra: mão-de-obra de dois homens utilizada na mistura de concreto, no transporte e na operação dos equipamento de moldagem

$$
\text { custo }\left(\mathrm{R} \$ / \mathrm{m}^{3}\right) \text { : } \quad \text { custo } \quad \text { mão_de_obra }=4,40
$$


equipamentos (depreciação): extrusora, betoneira

$$
\text { custo }\left(\mathrm{R} \$ / \mathrm{m}^{3}\right) \text { : } \quad \text { custo_equipamento }=8,35
$$

$\therefore$ c_concreto $=$ custo_material + custo_mão_de_obra + custo_equipamento

Armadura: material, mão de obra, equipamento

material: aço

$$
\text { custo }(\mathrm{R} \$ / \mathrm{kg}) \text { : } \quad \text { custo_material }=2,50
$$

mão-de-obra: mão de obra de um homem para utilização dos equipamentos e colocação dos cabos, efetuação da protensão e liberação da força.

custo $(\mathrm{R} \$ / \mathrm{kg}): \quad \quad$ custo_mão_de_obra $=0,25$

equipamentos: macaco hidráulico, máquina para cortar os fios custo $(\mathrm{R} \$ / \mathrm{kg})$ : $\quad$ custo_equipamento $=0,07$

$\therefore$ c_armadura $=$ custo_material + custo_mão_de_obra + custo_equipamento

Material de Enchimento: material, mão de obra, equipamento material: bloco EPS custo $\left(\mathrm{R} \$ / \mathrm{m}^{3}\right)$ : custo_material $=2,00$ mão-de-obra: mão de obra de um homem para utilização dos equipamentos.

custo $\left(\mathrm{R} \$ / \mathrm{m}^{3}\right)$ : $\quad$ custo $\_$mão_de_obra $=2,20$

equipamentos: macaco hidráulico, máquina para cortar os fios custo $\left(\mathrm{R} \$ / \mathrm{m}^{3}\right)$ : $\quad$ custo_equipamento $=1,00$

$\therefore$ c_enchimento $=$ custo_material + custo_mão_de_obra + custo_equipamento 
B. Custos adicionais (c_adicional)

Envolve os custos referentes às atividades após a moldagem e anterior ao envio à obra. O custo adicional é a soma dos custos de mão-de-obra e de equipamentos.

mão-de-obra: mão de obra para utilização dos equipamentos, cura, transporte, armazenamento

custo $\left(\mathrm{R} \$ / \mathrm{m}^{3}\right)$ : $\quad$ custo_mão_de_obra $=4,40$

equipamentos: empilhadeira, equipamentos para cura, energia, combustível

custo $\left(\mathrm{R} \$ / \mathrm{m}^{3}\right)$ : $\quad$ custo_equipamento $=1,67$

$\therefore$ c_adicional $=$ custo_mão_de_obra + custo_equipamento

C. Custos indiretos administrativos (custo_ind)

Envolve os custos de: engenheiros, encarregados, recepcionista, execução do projeto, encargos sociais, propaganda, energia, impostos, aluguéis, seguros, materiais de escritório, despesas de manutenção, fretes, combustível, depreciação, retorno de investimento.

custo $\left(\mathrm{R} \$ / \mathrm{m}^{3}\right)$ : custo_ind $=0,1$ (c_concreto $+\mathrm{c} \_$armadura $+\mathrm{c}$ _enchimento $+\mathrm{c} \_$adicional $)$

D. Custos tributários (c_tributario)

Envolve os custos de Confins, PIS, ICMS, IPI avaliados em $12 \%$ do preço final custo $\left(\mathrm{R} \$ / \mathrm{m}^{3}\right)$ : c_tributario $=115,00$

\section{II) CUSTOS DE TRANSPORTE EXTERNO}

Envolve os custos de transporte da fábrica ao local da obra. Com o intuito de melhor avaliar o custo, neste trabalho considerou-se uma obra hipotética sendo realizada a $100 \mathrm{~km}$ de Franca (custo_transp).

serviços: mão de obra, caminhões, combustível, seguros, despesas com manutenção

Considerando que: 
custo $\left(\mathrm{R} \$ / \mathrm{m}^{3} \mathrm{Km}\right): \quad$ custo $\_$transporte $=0,52$

e como o obra hipoteticamente está localizada a 100km de Franca, tem-se:

custo $\left(\mathrm{R} \$ / \mathrm{m}^{3}\right)$ : $\quad$ custo_transp $=52$

\section{III) CUSTOS DA APLICAÇÃO}

Os custos envolvidos na aplicação do elemento englobam:

A. Custos da montagem da vigota protendida

B. Custos do concreto da capa

C. Custos da armadura complementar

D. Custos indiretos administrativos

A.Custos da montagem da vigota protendida (c_montagem)

É a soma dos custos de mão-de-obra e equipamentos.

mão-de-obra: mão de obra para a colocação da vigota

custo $\left(\mathrm{R} \$ / \mathrm{m}^{3}\right)$ : $\quad$ custo_mão_de_obra $=4,4$

cimbramento: aluguel de cimbramento

custo $\left(\mathrm{R} \$ / \mathrm{m}^{3}\right)$ : $\quad$ custo_cimbramento $=6,00$

$\therefore$ c_montagem $=$ custo_mão_de_obra + custo_cimbramento

B. Custos do concreto da capa (c_conc)

É a soma dos custos de material, mão-de-obra e equipamentos para o lançamento do concreto moldado no local. Considerou-se uma resistência de 20MPa.

$\underline{\text { material: }}$ cimento, areia, brita, aditivo, etc

custo $\left(\mathrm{R} \$ / \mathrm{m}^{3}\right)$ : $\quad$ custo_material $=136,13$

mão-de-obra: mão de obra de vinte homens para o lançamento, o adensamento do concreto, a cura e a desmoldagem custo $\left(\mathrm{R} \$ / \mathrm{m}^{3}\right)$ : $\quad$ custo_mão_de_obra $=104,20$ 
equipamentos: vibrador, fôrmas, desforma

custo $\left(\mathrm{R} \$ / \mathrm{m}^{3}\right)$ : $\quad$ custo_equipamento $=8,35$

$\therefore$ c_conc $=$ custo_material + custo_mão_de_obra + custo_equipamento

C. Custos da armadura complementar (c_arma)

É a soma dos custos de material e de mão-de-obra.

material: armadura de diâmetro de $6,3 \mathrm{~mm}$

custo $(\mathrm{R} \$ / \mathrm{kg})$ : $\quad$ custo_ $\quad$ material $=1,13$

mão-de-obra: mão de obra de um homem

custo $(\mathrm{R} \$ / \mathrm{kg})$ : $\quad$ custo_mão_de_obra $=0,295$

$\therefore$ c_arma $=$ custo_material + custo_mão_de_obra

D. Custos indiretos administrativos (custo_adma)

Envolve os custos de engenheiros, encarregados, recepcionista, execução do projeto, administração, encargos sociais, propaganda, energia, impostos, aluguéis, seguros, materiais de escritório, despesas de manutenção, fretes, combustível, depreciação e despesas tributárias.

custo $\left(\mathrm{R} \$ / \mathrm{m}^{3}\right): \quad$ custo_adma $=0,2\left(\mathrm{c} \_\right.$montagem $+\mathrm{c} \_$conc $+\mathrm{c} \_$arma $)$

\subsubsection{Função Custo Total}

$\mathrm{Na}$ subseção anterior os vários custos envolvidos na produção de uma laje com vigota protendida foram discriminados. Mais detalhes da obtenção da função custo estão no Apêndice $\mathrm{F}$. As variáveis $\mathrm{x}_{4}$ e $\mathrm{x}_{5}$ que correspondem às distâncias dos níveis 2 e 3 de armadura, respectivamente, foram introduzidas na função custo apenas com o intuito de retratar todas as variáveis envolvidas. Vale salientar que tais variáveis interferem somente no cálculo das restrições do problema, não introduzindo um custo adicional à função objetivo. Com o objetivo de obter a função que representa o custo total de produção, considerando as etapas de execução, de transporte e de aplicação, os vários custos foram somados e a expressão final da função é: 


$$
f(\mathbf{x})=31,550+11,193\left(x_{1}+x_{2}+x_{3}\right)+\frac{0,143}{\left(2 x_{1}+x_{2}\left(2+x_{4}\right)+x_{3}\left(2+x_{4}+x_{5}\right)\right)}
$$

onde

$$
\begin{aligned}
& \mathrm{x}_{1}-\text { armadura nível } 1\left(\mathrm{~cm}^{2}\right) \\
& \mathrm{x}_{2}-\operatorname{armadura} \text { nível } 2\left(\mathrm{~cm}^{2}\right) \\
& \mathrm{x}_{3}-\text { armadura nível } 3\left(\mathrm{~cm}^{2}\right) \\
& \mathrm{x}_{4}-\text { distância da armadura do nível } 2(\mathrm{~cm}) \\
& \mathrm{x}_{5}-\text { distância da armadura no nível } 3(\mathrm{~cm})
\end{aligned}
$$

O problema de minimização do custo de produção de tal laje, portanto, se resume ao problema de minimização de $\mathrm{f}(\mathbf{x})\left(\mathbf{x}=\left(\mathrm{x}_{1}, \mathrm{x}_{2}, \mathrm{x}_{3}, \mathrm{x}_{4}, \mathrm{x}_{5}\right)\right)$. Portanto, o problema em questão se configura como um problema de minimização sujeito à restrições e pode ser equacionado da seguinte forma:

\section{Minimizar $\quad f(x)$}

Sujeita às seguintes restrições: as verificações equacionadas a seguir são apresentadas em detalhes no Apêndice F.

\section{Verificação do estado em vazio}

a) após a desmoldagem:

$$
\begin{array}{lll}
\mathrm{g}_{1}\left(\mathrm{x}_{\mathrm{i}}\right)=\sigma_{1 \mathrm{P}_{\mathrm{o}}}+\sigma_{1 \mathrm{~g}_{1}}-\sigma_{\mathrm{ctj}} & \text { onde } & \mathrm{g}_{1}\left(\mathrm{x}_{\mathrm{i}}\right) \leq 0 \\
\mathrm{~g}_{2}\left(\mathrm{x}_{\mathrm{i}}\right)=\sigma_{2 \mathrm{P}_{\mathrm{o}}}+\sigma_{2 \mathrm{~g}_{1}}+\sigma_{\mathrm{cj}} & \text { onde } & \mathrm{g}_{2}\left(\mathrm{x}_{\mathrm{i}}\right) \geq 0
\end{array}
$$

b) fase de transporte:

$$
\begin{array}{lll}
\mathrm{g}_{3}\left(\mathrm{x}_{\mathrm{i}}\right)=\sigma_{1 \mathrm{P}_{\mathrm{o}}}+\beta_{\mathrm{a}_{1}} \sigma_{1 \mathrm{~g}_{1}}-\sigma_{\mathrm{ctj}} & \text { onde } & \mathrm{g}_{3}\left(\mathrm{x}_{\mathrm{i}}\right) \leq 0 \\
\mathrm{~g}_{4}\left(\mathrm{x}_{\mathrm{i}}\right)=\sigma_{2 \mathrm{P}_{\mathrm{o}}}+\beta_{\mathrm{a}_{1}} \sigma_{2 \mathrm{~g}_{1}}+\sigma_{\mathrm{cj}} & \text { onde } & \mathrm{g}_{4}\left(\mathrm{x}_{\mathrm{i}}\right) \geq 0 \\
\mathrm{~g}_{5}\left(\mathrm{x}_{\mathrm{i}}\right)=\sigma_{1 \mathrm{P}_{\mathrm{o}}}+\beta_{\mathrm{a}_{2}} \sigma_{1 \mathrm{~g}_{1}}-\sigma_{\mathrm{ctj}} & \text { onde } & \mathrm{g}_{5}\left(\mathrm{x}_{\mathrm{i}}\right) \leq 0 \\
\mathrm{~g}_{6}\left(\mathrm{x}_{\mathrm{i}}\right)=\sigma_{2 \mathrm{P}_{\mathrm{o}}}+\beta_{\mathrm{a}_{2} \sigma_{2 \mathrm{~g}_{1}}+\sigma_{\mathrm{cj}}} & \text { onde } & \mathrm{g}_{6}\left(\mathrm{x}_{\mathrm{i}}\right) \geq 0 \\
\mathrm{c}) \text { fase de armazenamento: } & & \\
\mathrm{g}_{7}\left(\mathrm{x}_{\mathrm{i}}\right)=\sigma_{1 \mathrm{P}_{\mathrm{oo}}}+\sigma_{1 \mathrm{~g}_{1}}-\sigma_{\mathrm{ctj}} & \text { onde } & \mathrm{g}_{7}\left(\mathrm{x}_{\mathrm{i}}\right) \leq 0 \\
\mathrm{~g}_{8}\left(\mathrm{x}_{\mathrm{i}}\right)=\sigma_{2 \mathrm{P}_{\mathrm{oo}}}+\sigma_{2 \mathrm{~g}_{1}}+\sigma_{\mathrm{cj}} & \text { onde } & \mathrm{g}_{8}\left(\mathrm{x}_{\mathrm{i}}\right) \geq 0 \\
\text { d) fase de montagem: } & &
\end{array}
$$




$$
\begin{array}{lll}
\mathrm{g}_{9}\left(\mathrm{x}_{\mathrm{i}}\right)=\sigma_{1 \mathrm{P}_{\mathrm{o}}}+\sigma_{1 \mathrm{~g}_{1}}+\sigma_{1 \mathrm{~g}_{2}}-\sigma_{\mathrm{ct}} & \text { onde } & \mathrm{g}_{9}\left(\mathrm{x}_{\mathrm{i}}\right) \leq 0 \\
\mathrm{~g}_{10}\left(\mathrm{x}_{\mathrm{i}}\right)=\sigma_{2 \mathrm{P}_{\mathrm{o}}}+\sigma_{2 \mathrm{~g}_{1}}+\sigma_{2 \mathrm{~g}_{2}}+\sigma_{\mathrm{c}} & \text { nde } & \mathrm{g}_{10}\left(\mathrm{x}_{\mathrm{i}}\right) \geq 0
\end{array}
$$

Verificação de tensões na seção mais solicitada:

a) verificação da vigota isolada

$$
\begin{array}{lll}
\mathrm{g}_{1}\left(\mathrm{x}_{\mathrm{i}}\right)=\sigma_{1 \mathrm{P}_{\mathrm{o}}}+\sigma_{\mathrm{c}} & \text { onde } & \mathrm{g}_{1}\left(\mathrm{x}_{\mathrm{i}}\right) \geq 0 \\
\mathrm{~g}_{2}\left(\mathrm{x}_{\mathrm{i}}\right)=\sigma_{2 \mathrm{P}_{\mathrm{o}}} & \text { onde } & \mathrm{g}_{2}\left(\mathrm{x}_{\mathrm{i}}\right)<0
\end{array}
$$

b) verificação da vigota na fase de construção

\section{$\underline{\text { SEM CIMBRAMENTO }}$}

$$
\begin{array}{lll}
\mathrm{g}_{3}\left(\mathrm{x}_{\mathrm{i}}\right)=\sigma_{1 \mathrm{P}_{\mathrm{oo}}}+\left(\mathrm{M}_{\mathrm{g}_{1}}+\mathrm{M}_{\mathrm{g}_{2}}+\mathrm{M}_{\mathrm{q}_{\mathrm{ex}}}\right) \frac{1,2}{\mathrm{~W}_{\mathrm{lh}}} & \text { onde } & \mathrm{g}_{3}\left(\mathrm{x}_{\mathrm{i}}\right)<0 \\
\mathrm{~g}_{4}\left(\mathrm{x}_{\mathrm{i}}\right)=\sigma_{2 \mathrm{P}_{\mathrm{oo}}}+\left(\mathrm{M}_{\mathrm{g}_{1}}+\mathrm{M}_{\mathrm{g}_{2}}+\mathrm{M}_{\mathrm{qex}_{\mathrm{ex}}}\right) \frac{1,2}{\mathrm{~W}_{2 \mathrm{~h}}}+\sigma_{\mathrm{c}} & \text { onde } & \mathrm{g}_{4}\left(\mathrm{x}_{\mathrm{i}}\right) \geq 0
\end{array}
$$

1 PONTO DE CIMBRAMENTO - apoio situado no meio do vão:

- Momento positivo:

$$
\begin{array}{lll}
\mathrm{g}_{5}\left(\mathrm{x}_{\mathrm{i}}\right)=\sigma_{1 \mathrm{P}_{\mathrm{oo}}}+\left(\mathrm{M}_{\mathrm{g}_{12 \mathrm{pos}}}\right) \frac{1,2}{\mathrm{~W}_{1 \mathrm{~h}}} & \text { onde } & \mathrm{g}_{5}\left(\mathrm{x}_{\mathrm{i}}\right)<0 \\
\mathrm{~g}_{6}\left(\mathrm{x}_{\mathrm{i}}\right)=\sigma_{2 \mathrm{P}_{\mathrm{oo}}}+\left(\mathrm{M}_{\mathrm{g}_{12 \mathrm{pos}}}\right) \cdot \frac{1,2}{\mathrm{~W}_{2 \mathrm{~h}}}+\sigma_{\mathrm{c}} & \text { onde } & \mathrm{g}_{6}\left(\mathrm{x}_{\mathrm{i}}\right) \geq 0
\end{array}
$$

- Momento negativo:

$$
\begin{array}{lll}
\mathrm{g}_{7}\left(\mathrm{x}_{\mathrm{i}}\right)=\sigma_{1 \mathrm{P}_{\mathrm{oo}}}+\left(\mathrm{M}_{\mathrm{g}_{12 \mathrm{neg}}}\right) \frac{1,2}{\mathrm{~W}_{1 \mathrm{~h}}}+\sigma_{\mathrm{c}} & \text { onde } & \mathrm{g}_{7}\left(\mathrm{x}_{\mathrm{i}}\right) \geq 0 \\
\mathrm{~g}_{8}\left(\mathrm{x}_{\mathrm{i}}\right)=\sigma_{2 \mathrm{P}_{\mathrm{oo}}}+\left(\mathrm{M}_{\mathrm{g}_{12 \mathrm{neg}}}\right) \frac{1,2}{\mathrm{~W}_{2 \mathrm{~h}}} & \text { onde } & \mathrm{g}_{8}\left(\mathrm{x}_{\mathrm{i}}\right)>0
\end{array}
$$

2 PONTOS DE CIMBRAMENTO - apoios situados a 2/5 do vão a partir do apoio

$$
\mathrm{g}_{9}\left(\mathrm{x}_{\mathrm{i}}\right)=\sigma_{1 \mathrm{P}_{\mathrm{oo}}}+\left(\mathrm{M}_{\mathrm{g}_{12}}\right) \frac{1,2}{\mathrm{~W}_{1 \mathrm{~h}}} \quad \text { onde } \quad \mathrm{g}_{9}\left(\mathrm{x}_{\mathrm{i}}\right)<0
$$




$$
\mathrm{g}_{10}\left(\mathrm{x}_{\mathrm{i}}\right)=\sigma_{2 \mathrm{P}_{\mathrm{oo}}}+\left(\mathrm{M}_{\mathrm{g}_{12}}\right) \frac{1,2}{\mathrm{~W}_{2 \mathrm{~h}}}+\sigma_{\mathrm{c}} \quad \text { onde } \quad \mathrm{g}_{10}\left(\mathrm{x}_{\mathrm{i}}\right) \geq 0
$$

\section{Verificação do estado limite de fissuração:}

a) combinação freqüente de ações

$\mathrm{g}_{11}\left(\mathrm{x}_{\mathrm{i}}\right)=\sigma_{1_{\mathrm{P}} \mathrm{oO}}+\frac{\left(\mathrm{M}_{\mathrm{g}_{1}}+\mathrm{M}_{\mathrm{g}_{2}}\right)}{\mathrm{W}_{\mathrm{lh}}}+\frac{\left(\mathrm{M}_{\mathrm{kg}_{2}}+\mathrm{M}_{\mathrm{g}_{3}}+0,3 \mathrm{M}_{\mathrm{q}}\right)}{\mathrm{W}_{1 \mathrm{hh}}}-\sigma_{\mathrm{ct}} \quad$ onde $\quad \mathrm{g}_{11}\left(\mathrm{x}_{\mathrm{i}}\right) \leq 0$

$\mathrm{g}_{12}\left(\mathrm{x}_{\mathrm{i}}\right)=\sigma_{{ }_{2} \mathrm{PoO}_{\mathrm{oO}}}+\frac{\left(\mathrm{M}_{\mathrm{g}_{1}}+\mathrm{M}_{\mathrm{g}_{2}}\right)}{\mathrm{W}_{2 \mathrm{~h}}}+\frac{\left(\mathrm{M}_{\mathrm{kg}_{2}}+\mathrm{M}_{\mathrm{g}_{3}}+0,3 \mathrm{M}_{\mathrm{q}}\right)}{\mathrm{W}_{2 \mathrm{hh}}}+\sigma_{\mathrm{c}} \quad$ onde $\quad \mathrm{g}_{12}\left(\mathrm{x}_{\mathrm{i}}\right) \geq 0$

b) combinação quase-permanente de ações

$\mathrm{g}_{13}\left(\mathrm{x}_{\mathrm{i}}\right)=\sigma_{1_{\mathrm{P}}}+\frac{\left(\mathrm{M}_{\mathrm{g}_{1}}+\mathrm{M}_{\mathrm{g}_{2}}\right)}{\mathrm{W}_{\mathrm{hh}}}+\frac{\left(\mathrm{M}_{\mathrm{kg}_{2}}+\mathrm{M}_{\mathrm{g}_{3}}+0,2 \mathrm{M}_{\mathrm{q}}\right)}{\mathrm{W}_{\mathrm{lhh}}}-\sigma_{\mathrm{ct}} \quad$ onde $\quad \mathrm{g}_{13}\left(\mathrm{x}_{\mathrm{i}}\right) \leq 0$

$\mathrm{g}_{14}\left(\mathrm{x}_{\mathrm{i}}\right)=\sigma_{2 \mathrm{P}_{\mathrm{Oo}}}+\frac{\left(\mathrm{M}_{\mathrm{g}_{1}}+\mathrm{M}_{\mathrm{g}_{2}}\right)}{\mathrm{W}_{2 \mathrm{~h}}}+\frac{\left(\mathrm{M}_{\mathrm{kg}_{2}}+\mathrm{M}_{\mathrm{g}_{3}}+0,2 \mathrm{M}_{\mathrm{q}}\right)}{\mathrm{W}_{2 \mathrm{hh}}}+\sigma_{\mathrm{c}} \quad$ onde $\quad \mathrm{g}_{14}\left(\mathrm{x}_{\mathrm{i}}\right) \geq 0$

c) combinação rara de ações

$\mathrm{g}_{15}\left(\mathrm{x}_{\mathrm{i}}\right)=\sigma_{1 \mathrm{P}_{\mathrm{oO}}}+\frac{\left(\mathrm{M}_{\mathrm{g}_{1}}+\mathrm{M}_{\mathrm{g}_{2}}\right)}{\mathrm{W}_{\mathrm{lh}}}+\frac{\left(\mathrm{M}_{\mathrm{kg}_{2}}+\mathrm{M}_{\mathrm{g}_{3}}+\mathrm{M}_{\mathrm{q}}\right)}{\mathrm{W}_{1 \mathrm{hh}}}-\sigma_{\mathrm{ct}} \quad$ onde $\quad \mathrm{g}_{15}\left(\mathrm{x}_{\mathrm{i}}\right) \leq 0$

$\mathrm{g}_{16}\left(\mathrm{x}_{\mathrm{i}}\right)=\sigma_{2 \mathrm{P}_{\mathrm{oo}}}+\frac{\left(\mathrm{M}_{\mathrm{g}_{1}}+\mathrm{M}_{\mathrm{g}_{2}}\right)}{\mathrm{W}_{2 \mathrm{~h}}}+\frac{\left(\mathrm{M}_{\mathrm{kg}_{2}}+\mathrm{M}_{\mathrm{g}_{3}}+\mathrm{M}_{\mathrm{q}}\right)}{\mathrm{W}_{2 \mathrm{hh}}}+\sigma_{\mathrm{c}}$ onde $\mathrm{g}_{16}\left(\mathrm{x}_{\mathrm{i}}\right) \geq 0$

Dependendo da existência ou não de cimbramento, a verificação da fissuração é feita em duas seções:

- Sem cimbramento: verificação da seção no meio do vão;

- Um ponto de cimbramento: verificação da seção no meio do vão e localizada a $\mathrm{x}_{\mathrm{ma}}$;

- Dois pontos de cimbramento: verificação da seção no meio do vão e localizada a $\mathrm{x}_{\mathrm{ma}}$.

Verificação do estado limite de utilização de controle da deformação:

$\mathrm{g}_{17}\left(\mathrm{x}_{\mathrm{i}}\right)=\mathrm{a}_{\text {lim }}-\mathrm{a} \quad$ onde $\quad \mathrm{g}_{17}\left(\mathrm{x}_{\mathrm{i}}\right) \geq 0$ 
Verificação do estado limite último - solicitações normais:

$\mathrm{g}_{18}\left(\mathrm{x}_{\mathrm{i}}\right)=\mathrm{M}_{\mathrm{d}}-\mathrm{M}_{\mathrm{u}} \quad$ onde $\quad \mathrm{g}_{18}\left(\mathrm{x}_{\mathrm{i}}\right) \leq 0$

Verificação do estado limite último - solicitações tangenciais

a) cálculo ao esforço cortante

$\mathrm{g}_{19}\left(\mathrm{x}_{\mathrm{i}}\right)=\mathrm{V}_{\mathrm{d}}-\mathrm{V}_{\mathrm{u} 0} \quad$ onde $\quad \mathrm{g}_{19}\left(\mathrm{x}_{\mathrm{i}}\right) \leq 0$

b) cálculo do cisalhamento da interface entre os dois concretos

$\mathrm{g}_{20}\left(\mathrm{x}_{\mathrm{i}}\right)=\mathrm{V}_{\mathrm{d}}-\mathrm{V}_{\mathrm{u} 0_{\mathrm{c}}} \quad$ onde $\quad \mathrm{g}_{20}\left(\mathrm{x}_{\mathrm{i}}\right) \leq 0$

onde

$\sigma_{\mathrm{g}_{1}}, \sigma_{2_{\mathrm{g}_{1}}}-$ tensão devido ao peso próprio da vigota no bordo inferior e superior

$\sigma_{\mathrm{g}_{2}}, \sigma_{\mathrm{g}_{2}}-$ tensão devido ao peso próprio do enchimento e do concreto moldado no local no bordo inferior e superior

$\sigma_{1 q}, \sigma_{2 q}$ - tensão devido à sobrecarga no bordo inferior e superior

$\sigma_{1_{\mathrm{P}_{\mathrm{o}}}}, \sigma_{2_{\mathrm{P}_{\mathrm{o}}}}-$ tensão devido à força de protensão instalada no concreto no bordo inferior e superior

$\sigma_{1_{\mathrm{P}_{\mathrm{oo}}}}, \sigma_{2_{\mathrm{P}_{\mathrm{oo}}}}-$ tensão devido à força de protensão após as perdas no bordo inferior e superior

$\sigma_{\text {ctj }}-$ tensão limite de tração em j dias

$\sigma_{\mathrm{ct}}-$ tensão limite de tração

$\sigma_{\mathrm{cj}}-$ tensão limite de compressão em j dias

$\sigma_{\mathrm{c}}-$ tensão limite de compressão

$\beta_{\mathrm{a}_{1}}$ - coeficiente de ação dinâmica $\left(\beta_{\mathrm{a}_{1}}=0,8\right)$

$\beta_{\mathrm{a} 2}-$ coeficiente de ação dinâmica $\left(\beta_{\mathrm{a} 2}=1,3\right)$

$\mathrm{M}_{\mathrm{g}_{1}}, \mathrm{M}_{\mathrm{g}_{2}}, \mathrm{M}_{\mathrm{g}_{3}}-$ momento devido ao peso próprio da vigota, do concreto moldado no local e de revestimento respectivamente

$\mathrm{M}_{\mathrm{kg}_{2}}$ - momento devido ao apoio 
$\mathrm{M}_{\mathrm{g} 12 \mathrm{pos}}, \mathrm{M}_{\mathrm{g} 12 \mathrm{neg}}-$ momento positivo e negativo para 1 apoio respectivamente $\mathrm{M}_{\mathrm{g} 12 \mathrm{pos}}-$ momento positivo para 2 apoios

$\mathrm{M}_{\text {qex }}$ - momento devido à sobrecarga de execução

$\mathrm{W}_{1 \mathrm{~h}}, \mathrm{~W}_{1 \mathrm{~h}}-$ módulos resistentes da vigota nos bordos inferior e superior, respectivamente

$\mathrm{W}_{1 \mathrm{hh}}, \mathrm{W}_{1 \mathrm{hh}}$ - módulos resistentes da laje nos bordos inferior e superior, respectivamente

$\sigma_{\mathrm{q}}-$ tensão devido à sobrecarga

$\sigma_{{ }_{1_{\mathrm{P}}}}, \sigma_{{ }_{2 \mathrm{P}_{\mathrm{o}}}}-$ tensão devido à força de protensão instalada no concreto no bordo inferior e superior

$\sigma_{1_{\mathrm{P}_{\mathrm{oO}}}}, \sigma_{2_{\mathrm{P}_{\mathrm{oo}}}}-$ tensão devido à força de protensão após as perdas no bordos inferior e superior

$\sigma_{\mathrm{ct}}-$ tensão limite de tração

$\sigma_{\mathrm{c}}-$ tensão limite de compressão

$M_{d}$ - momento atuante da seção composta

$\mathrm{M}_{\mathrm{u}}-$ momento último da seção composta

$\mathrm{a}_{\text {lim }}$ - flecha admissível devido ao carregamento

a - flecha total devido ao carregamento

$\mathrm{V}_{\mathrm{d}}$ - força cortante de cálculo

$\mathrm{V}_{\mathrm{u} 0}-$ resistência à força cortante

$\mathrm{V}_{\mathrm{u} 0 \mathrm{c}}-$ resistência ao cisalhamento da interface

Além dessas restrições as variáveis devem satisfazer as desigualdades:

$$
\begin{aligned}
& 0,1 \leq x_{1} \leq 3,0 \quad\left(\mathrm{~cm}^{2}\right) \\
& 0,1 \leq x_{2} \leq 2,7 \quad\left(\mathrm{~cm}^{2}\right) \\
& 0 \leq \mathrm{x}_{3} \leq 1 \quad\left(\mathrm{~cm}^{2}\right) \\
& 0,5 \leq \mathrm{x}_{4} \leq 6 \quad(\mathrm{~cm}) \\
& 0,5 \leq \mathrm{x}_{5} \leq 8 \quad(\mathrm{~cm})
\end{aligned}
$$


Para as cinco variáveis os limites inferiores e superiores correspondem a limites arbitrados. Para o problema com restrição descrito aqui foi adotada a mesma estratégia de penalidade adotada na para a solução dos problemas do Capítulo 4.

\subsubsection{Busca da Solução do Problema via AG}

Os AGs variantes MGA1 e Roleta1A são utilizados para a minimização da função $\mathrm{f}(\mathbf{x})$. Os variantes compartilham os valores de várias características como mostrados na Tabela 5-1.

Tabela 5-1. Principais características dos MGA1 e Roleta1A

\begin{tabular}{|c|c|}
\hline Caracteristicas & Possiveis Valores \\
\hline elitismo & 1 indivíduo \\
\hline população & 100 \\
\hline Representação de dados & $\begin{array}{l}\text { Binária }-56 \text { bits (considerando } 2 \text { casas } \\
\text { decimais para cada variável) } \\
1^{\text {a }} \text {. variável }-10 \text { bits } \\
2^{\text {a }} \text {. variável }-10 \text { bits } \\
3^{\text {a }} \text { variável }-10 \text { bits } \\
4^{\text {a }} \text {. variável }-13 \text { bits } \\
5^{\text {a }} \text { variável }-13 \text { bits }\end{array}$ \\
\hline cruzamento & $\begin{array}{l}\text { Um-ponto }(1 \mathrm{X}), \text { dois pontos }(2 \mathrm{X}) \\
\text { multiponto }(3 \mathrm{X}, 4 \mathrm{X} \text { e } 5 \mathrm{X}) \text {, uniforme, } \\
\text { variável-a-variável }\end{array}$ \\
\hline Probabilidade de cruzamento & 0,85 \\
\hline Probabilidade de mutação & 0,1 \\
\hline Critério de parada & 1000 gerações \\
\hline
\end{tabular}

Os experimentos tratados nesta seção consideram, além dos operadores de cruzamento convencionais $(1 \mathrm{X}, \ldots, 5 \mathrm{X}$, uniforme), o operador de cruzamento proposto em HASANCEBI \& ERBATUR (1998) e referenciado como variável-a-variável. O Capítulo 2 descreve detalhadamente todos esses operadores.

\subsubsection{Descrição dos Experimentos e Análise dos Resultados}

Uma vez que AGs são bastante sensíveis à população inicial, o valor relativo a cada um dos experimentos descrito nesta seção é a média dos valores obtidos em 10 execuções (run), cada uma delas tendo uma população inicial gerada randomicamente. A análise dos resultados vai focalizar, principalmente, os valores obtidos usando cada uma das estratégias de cruzamento, listados nas Tabela 5-2 e Tabela 5-3 relativos a comprimento de laje de $3 \mathrm{~m}$ e $4 \mathrm{~m}$ respectivamente. 
Nas duas tabelas a coluna referente a escoras diz respeito ao número de escoras necessárias para o escoramento da laje. Essa variável não é uma variável do problema; seu valor está implícito no cálculo das restrições do problema. Também, quando do uso do EASY, foram feitas 'versões' do programa para zero escoras, uma escora e duas escoras. Essa mesma abordagem foi adotada em todos os outros experimentos descritos neste capítulo.

A Tabela 5-2 apresenta o valor da função custo e das cinco variáveis que a definem, para o comprimento de laje $3 \mathrm{~m}$, para cada uma das combinações variante/operador de cruzamento. A linha identificada por 'real' apresenta os valores obtidos usando a representação real, com o objetivo de estabelecer uma comparação com o restante de resultados, todos usando representação binária. Os resultados obtidos usando o operador uniforme, cada um dos $n-X(N=1, \ldots, 5)$ e o variável-avariável foram praticamente os mesmos. Usando representação binária, o MGA1 obteve praticamente os mesmos resultados, independentemente do operador de cruzamento utilizado. Além disso, o MGA1 apresentou um melhor desempenho quando comparado com o da Roleta1A, como era de se esperar.

Apesar da representação real ser a mais recomendada para problemas de otimização com restrições (ver (GEN \& CHENG 1997)), o resultado obtido considerando esta representação, para o problema em questão, não confirmou essa expectativa, como pode ser visto na Tabela 5-2. Além disso, apesar das diferenças serem pequenas quando comparados com os resultados obtidos pelo MGA1, o EASY obteve o melhor resultado de todos.

Quanto da análise dos resultados obtidos pelo Roleta1A, é importante notar que os valores das variáveis $\mathrm{x}_{4}$ e $\mathrm{x}_{5}$ incorporadas à função custo não introduzem variações muito perceptíveis nos resultados obtidos. Deve-se salientar que um aumento de excentricidade (aumento das distâncias entre níveis de armadura) não resulta em um aumento de custo.

Todos os resultados obtidos usando o Roleta1A foram piores que os do MGA1. O pior resultado do Roleta1A foi obtido usando o operador de cruzamento 3X e o melhor aquele considerando o cruzamento variável-a-variável. Note-se que o melhor valor obtido pelo RoletalA é ainda pior que o pior valor obtido com o MGA1. 
Tabela 5-2. Valores da função custo e das variáveis que a definem para a família MGA1: $\mathrm{x}_{1}, \mathrm{x}_{2}, \mathrm{X}_{3}$ - áreas das armaduras de protensão, $\mathrm{x}_{4}, \mathrm{x}_{5}$ - distâncias dos níveis de armadura $(\mathrm{L}=3 \mathrm{~m})$

\begin{tabular}{|c|c|c|c|c|c|c|c|c|c|c|}
\hline \multicolumn{5}{|c|}{ 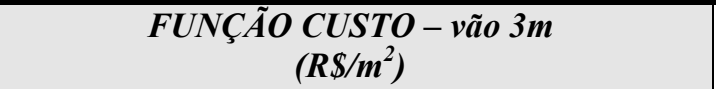 } & \multicolumn{6}{|c|}{ VARIÁVEIS } \\
\hline MGA1 & $\begin{array}{c}\text { Valor } \\
\text { da } \\
\text { função }\end{array}$ & $\begin{array}{l}\text { Desvio } \\
\text { padrão }\end{array}$ & \begin{tabular}{|c|} 
Melhor \\
absoluto
\end{tabular} & \begin{tabular}{|c|} 
Pior \\
absoluto
\end{tabular} & $\begin{array}{c}\mathrm{x}_{1} \\
\left(\mathrm{~cm}^{2}\right)\end{array}$ & $\begin{array}{c}\mathbf{x}_{2} \\
\left(\mathrm{~cm}^{2}\right)\end{array}$ & $\begin{array}{c}\mathbf{x}_{3} \\
\left(\mathrm{~cm}^{2}\right)\end{array}$ & $\begin{array}{c}\mathbf{x}_{4} \\
(\mathbf{c m})\end{array}$ & $\begin{array}{c}\mathbf{x}_{5} \\
(\mathbf{c m})\end{array}$ & escoras \\
\hline Uniforme & 37,68 & 0,0215 & 37,66 & 37,07 & 0,42 & 0,10 & 0,02 & 4,08 & 1,96 & 0 \\
\hline $1 X$ & 37,69 & 0,0084 & 37,67 & 37,70 & 0,41 & 0,11 & 0,02 & 3,80 & 2,42 & 0 \\
\hline $2 X$ & 37,68 & 0,0116 & 37,66 & 37,69 & 0,41 & 0,11 & 0,02 & 3,45 & 3,60 & 0 \\
\hline $3 X$ & 37,69 & 0,0181 & 37,67 & 37,73 & 0,41 & 0,11 & 0,02 & 3,80 & 3,13 & 0 \\
\hline $4 X$ & 37,68 & 0,0095 & 37,67 & 37,70 & 0,41 & 0,11 & 0,02 & 3,43 & 3,07 & 0 \\
\hline $5 X$ & 37,68 & 0,0118 & 37,66 & 37,69 & 0,41 & 0,11 & 0,02 & 3,72 & 3,73 & 0 \\
\hline Var_Var & 37,69 & 0,0144 & 37,68 & 37,73 & 0,42 & 0,11 & 0,01 & 4,25 & 1,91 & 0 \\
\hline real & 40,01 & 1,6759 & 38,41 & 44,23 & 0,42 & 0,18 & 0,13 & 2,87 & 3,71 & 0 \\
\hline \multicolumn{11}{|l|}{ Roleta1A } \\
\hline Uniforme & 41,13 & 1,9940 & 38,40 & 45,24 & 0,52 & 0,20 & 0,11 & 4,14 & 3,17 & 0 \\
\hline $1 \mathrm{X}$ & 40,66 & 2,3946 & 38,46 & 44,80 & 0,51 & 0,22 & 0,07 & 3,67 & 3,35 & 0 \\
\hline $2 X$ & 40,40 & 3,5675 & 37,76 & 47,81 & 0,49 & 0,19 & 0,11 & 3,37 & 3,23 & 0 \\
\hline $3 \mathbf{X}$ & 42,07 & 2,5905 & 38,17 & 46,34 & 0,59 & 0,14 & 0,20 & 4,06 & 3,39 & 0 \\
\hline $4 X$ & 40,57 & 1,8784 & 38,57 & 43,08 & 0,44 & 0,23 & 0,09 & 3,91 & 3,23 & 0 \\
\hline $5 X$ & 40,15 & 1,9738 & 38,17 & 44,06 & 0,48 & 0,18 & 0,09 & 3,88 & 3,30 & 0 \\
\hline Var_Var & 39,87 & 2,3767 & 38,16 & 45,98 & 0,48 & 0,15 & 0,10 & 3,76 & 3,84 & 0 \\
\hline$\overline{\text { EASY }}$ & 34,44 & & & & 0,40 & 0,11 & 0,00 & 4,32 & 2,23 & 0 \\
\hline
\end{tabular}

Os resultados obtidos na minimização da mesma função custo anterior, agora para uma laje de comprimento de $4 \mathrm{~m}$, são apresentados na Tabela 5-3. De maneira similar aos resultados anteriores, o MGA1 foi o variante que obteve os melhores resultados. O variante MGA1 obteve resultados bem próximos um dos outros independentemente do operador de cruzamento utilizado.

A Figura 5-6 mostra uma representação pictórica dos dados descritos na Tabela 5-3. Como pode ser verificado na tabela, os resultados obtidos pelo EASY foram os melhores e com uma grande margem sobre os demais.

Deve-se salientar que os valores de armadura $\mathrm{x}_{2}$ e $\mathrm{x}_{3}$ obtidos pelo EASY para o comprimento de laje de $4 \mathrm{~m}$ são valores mínimos, não tendo muito significado prático. 
Tabela 5-3. Valores da função custo e das variáveis que a definem para a família MGA1: $\mathrm{x}_{1}, \mathrm{x}_{2}, \mathrm{X}_{3}$ - áreas das armaduras de protensão, $\mathrm{x}_{4}, \mathrm{x}_{5}$ - distâncias dos níveis de armadura $(\mathrm{L}=4 \mathrm{~m})$

\begin{tabular}{|c|c|c|c|c|c|c|c|c|c|c|}
\hline \multicolumn{5}{|c|}{$\begin{array}{c}F U N C ̧ \tilde{A} O \text { CUSTO - vão } 4 m \\
\left(R S / m^{2}\right)\end{array}$} & \multicolumn{6}{|c|}{ VARIÁVEIS } \\
\hline MGA1 & $\begin{array}{l}\text { Valor } \\
\text { da } \\
\text { função }\end{array}$ & $\begin{array}{l}\text { Desvio } \\
\text { padrão }\end{array}$ & $\begin{array}{c}\text { Melhor } \\
\text { absoluto }\end{array}$ & $\begin{array}{c}\text { Pior } \\
\text { absoluto }\end{array}$ & $\begin{array}{c}\mathbf{x}_{1} \\
\left(\mathrm{~cm}^{2}\right)\end{array}$ & $\begin{array}{c}\mathbf{x}_{2} \\
\left(\mathrm{~cm}^{2}\right)\end{array}$ & $\begin{array}{c}\mathbf{x}_{3} \\
\left(\mathrm{~cm}^{2}\right)\end{array}$ & $\begin{array}{c}\mathbf{x}_{4} \\
(\mathbf{c m})\end{array}$ & $\begin{array}{c}\mathbf{x}_{5} \\
(\mathbf{c m})\end{array}$ & escoras \\
\hline Uniforme & 42,33 & 0,0233 & 42,31 & 42,37 & 0,53 & 0,29 & 0,13 & 3,05 & 1,98 & 1 \\
\hline $1 \mathrm{X}$ & 42,33 & 0,0163 & 42,31 & 42,36 & 0,56 & 0,24 & 0,14 & 2,85 & 2,78 & 1 \\
\hline $2 \mathrm{X}$ & 42,32 & 0,0211 & 42,31 & 42,36 & 0,53 & 0,26 & 0,15 & 2,65 & 2,85 & 1 \\
\hline $3 \mathbf{X}$ & 42,32 & 0,0186 & 42,31 & 42,35 & 0,55 & 0,28 & 0,12 & 3,50 & 1,91 & 1 \\
\hline $4 X$ & 42,33 & 0,0198 & 42,31 & 42,36 & 0,53 & 0,26 & 0,15 & 2,65 & 3,13 & 1 \\
\hline $5 X$ & 42,33 & 0,0145 & 42,31 & 42,35 & 0,56 & 0,26 & 0,10 & 3,93 & 2,01 & 1 \\
\hline Var_Var & 42,34 & 0,0182 & 42,31 & 42,38 & 0,56 & 0,27 & 0,11 & 3,31 & 2,88 & 1 \\
\hline \multicolumn{11}{|l|}{ Roleta1A } \\
\hline Uniforme & 43,71 & 0,4978 & 42,93 & 44,33 & 0,54 & 0,35 & 0,18 & 2,92 & 3,32 & 1 \\
\hline $1 \mathrm{X}$ & 43,36 & 0,8202 & 42,42 & 44,80 & 0,62 & 0,30 & 0,12 & 3,56 & 3,51 & 1 \\
\hline $2 X$ & 43,44 & 0,7385 & 42,40 & 44,68 & 0,56 & 0,23 & 0,18 & 3,45 & 3,83 & 1 \\
\hline $3 \mathbf{X}$ & 43,39 & 0,4964 & 42,79 & 44,42 & 0,66 & 0,29 & 0,15 & 3,64 & 3,22 & 1 \\
\hline $4 X$ & 43,53 & 0,5323 & 42,79 & 44,56 & 0,60 & 0,30 & 0,16 & 3,00 & 4,17 & 1 \\
\hline $5 X$ & 43,73 & 0,6787 & 42,49 & 44,76 & 0,64 & 0,32 & 0,11 & 3,90 & 3,37 & 1 \\
\hline Var_Var & 43,42 & 0,6199 & 42,71 & 44,92 & 0,56 & 0,39 & 0,10 & 3,56 & 3,36 & 1 \\
\hline EASY & 34,40 & & & & $\overline{0,40}$ & 0,10 & $\overline{0,01}$ & 4,00 & $\overline{4,00}$ & $\overline{1}$ \\
\hline
\end{tabular}

\section{Custo $x$ Tipo de cruzamento}

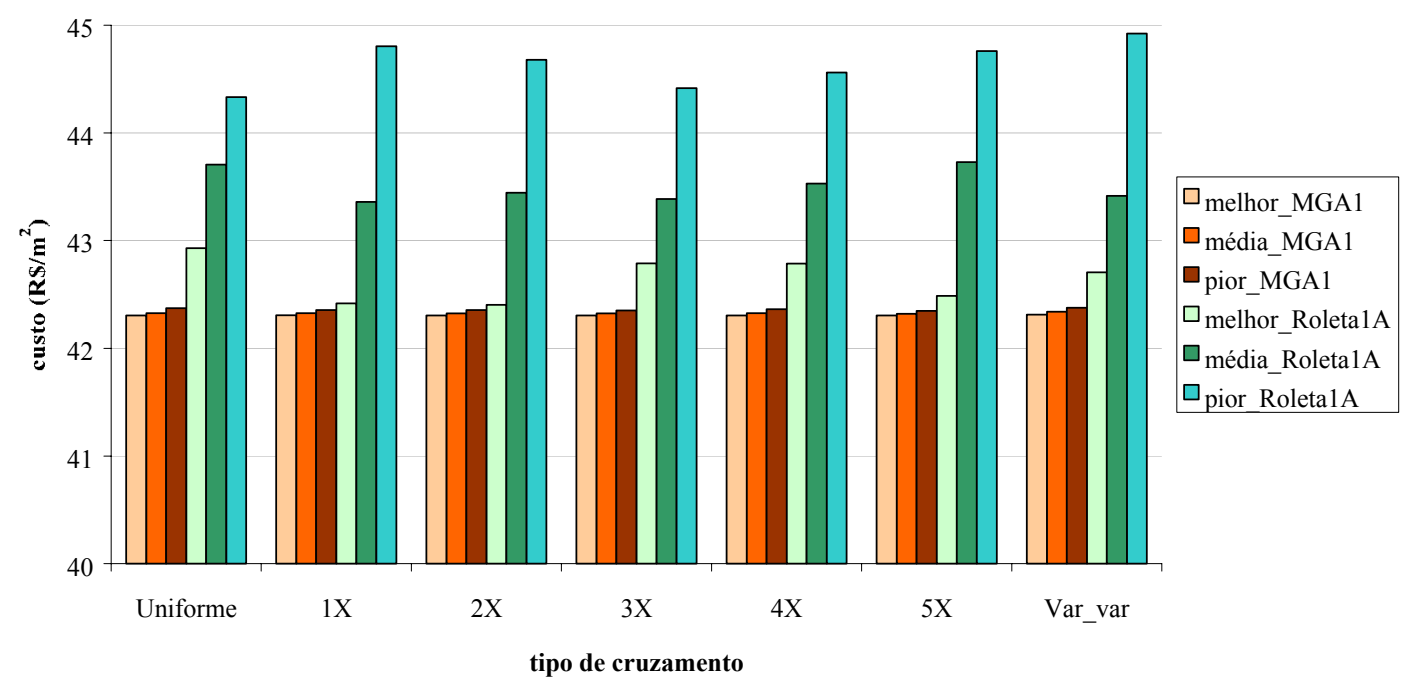

Figura 5-6. Valor da função custo obtida pelo MGA1 e Roleta1A para os diversos tipos de cruzamentos 
As análises apresentadas para o comprimento de laje de $3 \mathrm{~m}$ e $4 \mathrm{~m}$ buscaram avaliar o comportamento dos variantes MGA1 e Roleta1A usando representação binária. Pode-se dizer que para a solução do problema descrito, quando o variante é o MGA1, a busca da solução independe de qual operador de cruzamento utilizado (dos analisados). Já quando o variante é o Roleta1A, o mais promissor é o variável-avariável.

Ainda para o mesmo problema (vão de $4 \mathrm{~m}$ ), foi investigada a alteração dinâmica do operador de cruzamento, ao longo das gerações, como sugerido e recomendado em HASANCEBI \& ERBATUR (1998). A justificativa para esse procedimento é, segundo os autores, para viabilizar uma melhor exploração do espaço de busca. Os autores introduzem uma mistura de cruzamentos combinando um ponto, dois pontos e três pontos. Para um total fixo de gerações, o operador de cruzamento de três pontos é usado durante um certo número de gerações, a seguir é utilizado o 1 ponto e, por fim, o 2 pontos.

A idéia por trás dessa proposta, segundo os autores, é "realizar uma busca eficiente, a qual pode ser conseguida pela ativação de possíveis características das técnicas existentes, no lugar certo do processo de busca. Acredita-se que uma busca eficiente permite uma exploração sólida do espaço durante as primeiras gerações e, em estágios posteriores, explora as soluções obtidas para chegar a pontos melhores. Esta idéia é aplicada na determinação de seqüências de técnicas usadas na implementação de cruzamento misturado. Portanto, primeiro o cruzamento de 3 pontos é usado para obter uma vasta exploração do espaço (exploration). Então, o cruzamento um ponto é aplicado para aumentar a busca exploratória (exploitation). Finalmente o cruzamento de 2 pontos é ativado para fornecer uma busca exploratória completa (exploitation). Pode se notar que a inclusão de outras técnicas (além de três) em uma aplicação com uso mais misturado, pode afetar negativamente o desempenho. Isto se deve ao fato que, em tais casos, o uso de técnicas pode não mostrar sua efetividade durante um número limitado de gerações alocados para elas, durante um processo evolucionário com um total fixo de gerações." É importante lembrar que a exploração a que os autores se referem é aquela no sentido de visitar pontos desconhecidos no espaço de busca, ampliando-o. A 'técnica' a que os autores se referem é denominada, neste trabalho, operador de cruzamento. 
Para um número fixo de total de gerações, os autores usam uma determinada seqüência de operadores de cruzamentos com proporções diferentes: as primeiras $20 \%$ gerações são criadas usando cruzamento $3 \mathrm{X}$, as $40 \%$ gerações seguintes, usando cruzamento de um ponto e as $40 \%$ gerações finais, cruzamento $2 \mathrm{X}$.

Este trabalho investigou a proposta de seqüência de operadores, com alteração dinâmica durante o processo evolutivo como sugerido por HASANCEBI \& ERBATUR (1998), referenciada neste trabalho como seqüênciaHE. Além da seqüência de operadores descrita anteriormente este trabalho propôs e experimentou duas outras seqüências. São elas:

- Seqüência1: as primeiras $20 \%$ gerações são obtidas com cruzamento $3 \mathrm{X}$, as $40 \%$ seguintes com cruzamento uniforme e as $40 \%$ restantes com cruzamento variável-a-variável. A razão desta proposta se deve ao fato do cruzamento $3 \mathrm{X}$ ampliar bastante o espaço de busca, o cruzamento uniforme que se segue torna o espaço ainda mais amplo e o cruzamento variável-a-variável introduz uma busca mais localizada nos pontos do espaço;

- Seqüência aleatória: para um número total fixo de gerações e um número total fixo de operadores de cruzamento, enumerados $0 \ldots \mathrm{N}$, para cada geração foi gerado um número aleatório e o correspondente operador de cruzamento, utilizado. Neste trabalho o valor de $\mathrm{N}=6$ e os operadores de cruzamento utilizados foram: uniforme, variável-a-variável, $1 \mathrm{X}, \ldots, 5 \mathrm{X}$.

A Figura 5-7 mostra os resultados obtidos usando alteração dinâmica de operadores, para os variantes MGA1 e Roleta1A. Verifica-se na figura que tanto para a seqüênciaHE quanto para a seqüência1, o valor da função custo foi o pior, para ambos os variantes. 
Custo x Tipo de cruzamento

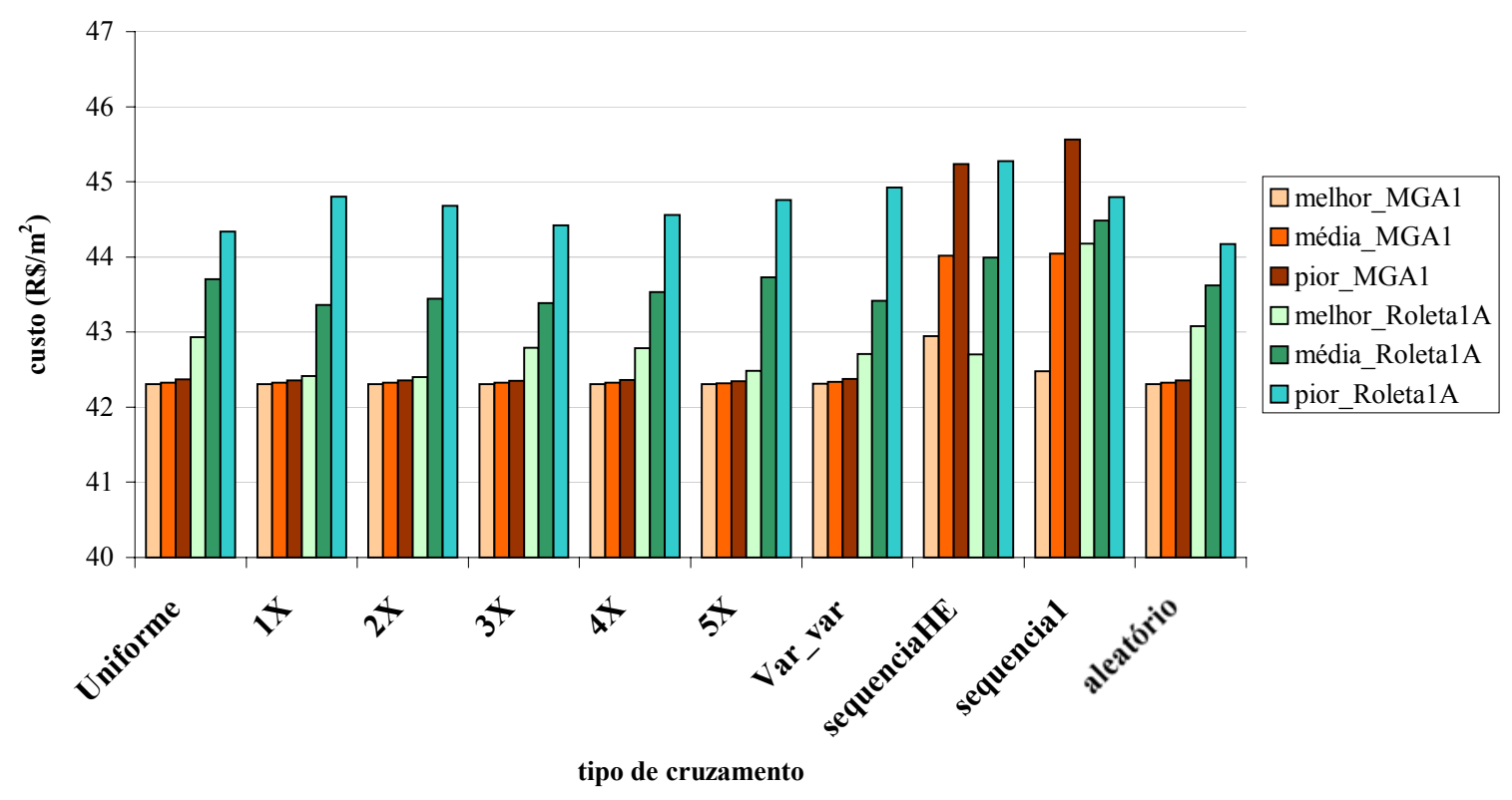

Figura 5-7. Valores médios da função custo para os diversos tipos de cruzamentos e diversas seqüências de operadores

A seqüência aleatória, proposta neste trabalho, apresentou os melhores resultados, para qualquer dos variantes. Isto talvez se deva à grande diversidade de exploração do espaço, não sistematizando uma ordem de exploração (mais longe, mais perto). É difícil uma análise dos resultados obtidos, em face às ótimas recomendações e justificativas utilizadas pelos autores para a proposta seqüenciaHE. De qualquer forma a seqüenciaHE embora recomendada na referência não teve bom desempenho para o problema em questão.

\subsection{OTIMIZAÇÃO DA APLICAÇÃO PARA UMA DETERMINADA VIGOTA}

Nesta seção é investigado o uso de algoritmo genético na busca da solução para o problema de minimização do custo da aplicação de uma laje com uma dada vigota protendida com ou sem escoras intermediárias. São apresentados e discutidos também os resultados obtidos para a solução do mesmo problema, usando o Método do Lagrangiano Aumentado (EASY). 


\subsubsection{Definição do Problema}

O problema de otimização a ser tratado é o da minimização da função custo total de uma laje com vigota protendida para uma dada vigota com ou sem a utilização de escoras intermediárias. No equacionamento desta função são inseridos os custos das etapas transitórias (produção, transporte e montagem) da vigota, usando os valores cedidos pela empresa Marka situada em Franca, SP e alguns obtidos na Revista Construção $^{3}$. De maneira semelhante ao problema anterior também serão considerandos dois vãos: 3 metros e 4 metros. Parte dos resultados desta seção estão descritos em CASTILHO et al (2001).

As variáveis envolvidas na definição da função custo são: a altura do capeamento $\left(\mathrm{x}_{1}\right)$, a resistência do concreto moldado no local $\left(\mathrm{x}_{2}\right)$ e a distância do intereixo $\left(\mathrm{x}_{3}\right)$. A seção transversal da laje é mostrada na Figura 5-8. As dimensões da vigota consideradas no dimensionamento da laje são apresentadas na Figura 5-9. A resistência do concreto foi considerada de $45 \mathrm{MPa}$.

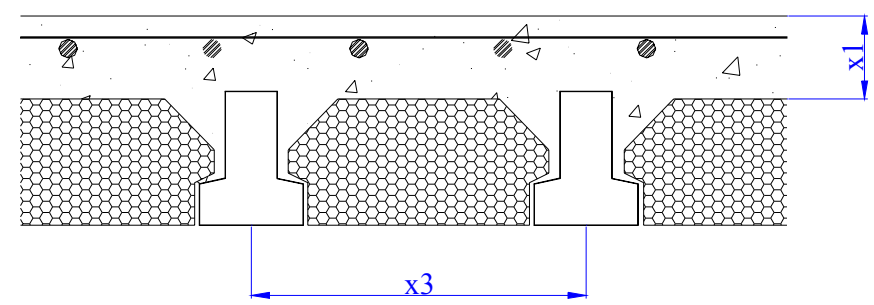

Figura 5-8. Seção de laje com vigota de concreto protendido, com enchimento e concreto moldado no local

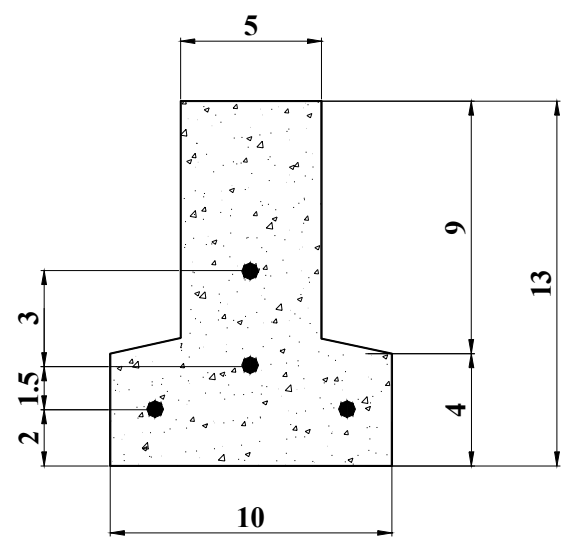

a) Seção da vigota protendida

\footnotetext{
${ }^{3}$ Construção, São Paulo, n ${ }^{0} 2782,4 / 6 / 2001$
} 


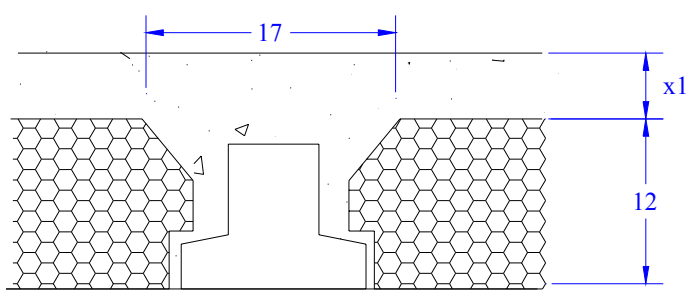

b) Seção de laje com vigota protendida

Figura 5-9. Dimensões das seções da laje e da vigota protendida (medidas em cm)

Conforme apresentado na seção anterior, o processo de dimensionamento de uma laje com vigotas protendidas foi o mesmo adotado em MERLIN (2002), seguindo os mesmos critérios de dimensionamento (verificações dos estados limites de utilização e do estado limite último).

Os valores dos custos de Execução, de Transporte Externo e de Aplicação são os mesmos valores discriminados na seção anterior com exceção de alguns valores que serão apresentados nesta seção.

\section{I) CUSTOS DE EXECUÇÃO}

\section{A. Custos de matéria- prima \\ D. Custos tributários}

\section{A.Custos de matéria-prima}

Concreto: material, mão de obra, equipamento

material: cimento, areia, brita, aditivo, etc

$$
\text { custo }\left(\mathrm{R} \$ / \mathrm{m}^{3}\right) \text { : } \quad \text { custo_material }=185,63
$$

mão-de-obra: mão-de-obra de dois homens utilizada na mistura de concreto, no transporte e na operação dos equipamento de moldagem

$$
\text { custo }\left(\mathrm{R} \$ / \mathrm{m}^{3}\right) \text { : } \quad \text { custo } \quad \text { mão_de_obra }=4,40
$$

equipamentos (depreciação): extrusora, betoneira

$$
\text { custo }\left(\mathrm{R} \$ / \mathrm{m}^{3}\right) \text { : } \quad \text { custo_equipamento }=8,35
$$

$\therefore$ c_concreto $=$ custo_material + custo_mão_de_obra + custo_equipamento 
D. Custos tributários (c_tributario)

Envolve os custos de Confins, PIS, ICMS, IPI avaliados em 12\% do preço final de venda para o concreto e armadura.

$$
\text { custo }\left(\mathrm{R} \$ / \mathrm{m}^{3}\right) \text { : c_tributario }=195,00
$$

\section{III) CUSTOS DA APLICAÇÃO}

\section{B. Custos do concreto da capa}

B. Custos do concreto da capa (c_conc)

material: cimento, areia, brita, aditivo, etc

custo $\left(\mathrm{R} \$ / \mathrm{m}^{3}\right)$ : $\quad$ custo_ material $=\left(24,75 \mathrm{x}_{2}+74,25\right)$

mão-de-obra: mão de obra de vinte homens para o lançamento, o adensamento do concreto e a cura, desmoldagem custo $\left(\mathrm{R} \$ / \mathrm{m}^{3}\right)$ : $\quad$ custo_mão_de_obra $=102,4$ equipamentos: vibrador, fôrmas, desforma custo $\left(\mathrm{R} \$ / \mathrm{m}^{3}\right)$ : $\quad$ custo_equipamento $=8,35$ $\therefore$ c_conc $=$ custo_material + custo_mão_de_obra + custo_equipamento

\subsubsection{Função Custo Total}

$\mathrm{Na}$ subseção anterior os vários custos envolvidos na produção de uma laje com vigota protendida foram discriminados. Maiores detalhes da obtenção da função custo estão no Apêndice F. Com o objetivo de obter a função que representa o custo total de sua produção, considerando as etapas de execução, de transporte e de aplicação, os vários custos foram somados e a expressão final da função é:

$f(x)=\frac{669,376}{x_{3}}+1,552 x_{1}+0,012 x_{1}\left(24,75 x_{2}+74,25\right)+0,0592 x_{3}$

onde $\mathrm{x}_{1}-$ altura da capa de concreto em $\mathrm{cm}$ $\mathrm{x}_{2}-$ resistência do concreto moldado no local em $\mathrm{kN} / \mathrm{cm}^{2}$ 
$\mathrm{x}_{3}-$ distância do inter-eixo em cm

O problema de minimização do custo de tal laje, portanto, se resume ao problema de minimização de $\mathrm{f}(\mathbf{x})\left(\mathbf{x}=\left(\mathrm{x}_{1}, \mathrm{x}_{2}, \mathrm{x}_{3}\right)\right)$. Portanto, o problema em questão se configura como um problema de minimização sujeito a restrições e pode ser equacionado da seguinte forma:

\section{Minimizar $\quad f(\mathbf{x})$}

Sujeita às mesmas restrições que o problema anterior, que estão descritas na subseção 5.3.2

Além dessas restrições as variáveis devem satisfazer às desigualdades:

$$
\begin{aligned}
& 4 \leq \mathrm{x}_{1} \leq 10 \quad(\mathrm{~cm}) \\
& 15 \leq \mathrm{x}_{2} \leq 30 \quad(\mathrm{MPa}) \\
& 30 \leq \mathrm{x}_{3} \leq 50 \quad(\mathrm{~cm})
\end{aligned}
$$

A escolha desses limites se justifica por:

- $\mathrm{x}_{1}$ : limite inferior estipulado por norma; limite superior corresponde a um limite arbitrado;

- $\mathrm{x}_{2}$ : limites inferior e superior correspondem a valores permitidos de resistência para o concreto moldado no local;

- $\mathrm{x}_{3}$ : limites inferior arbitrado e superior estipulado por norma;

Para o problema descrito aqui foi adotada a mesma estratégia da penalidade adotada para a solução dos problemas do Capítulo 4.

\subsubsection{Busca da Solução do Problema via AG}

Para a busca da solução da minimização da função custo de uma laje com vigota protendida via AG, os variantes usados foram o MGA1 e o Roleta1A. Na Tabela 5-4 estão discriminados os valores de várias características relativas a AGs, adotadas nas implementações. 
Tabela 5-4. Principais Características da Implementação do AG

\begin{tabular}{|c|c|}
\hline Características & Possiveis Valores \\
\hline elitismo & 1 indivíduo \\
\hline população & 100 \\
\hline Representação de dados & $\begin{array}{l}\text { Binária }-32 \text { bits (11-11-10) } \\
1^{\mathrm{a}} . \text { variável }-11 \text { bits } \\
2^{\mathrm{a}} . \text { variável }-11 \text { bits } \\
3^{\mathrm{a}} \text { variável }-10 \text { bits } \\
\text { Binária }-56 \text { bits }(18-18-20) \\
1^{\mathrm{a}} . \text { variável }-18 \text { bits } \\
2^{\mathrm{a}} \text {. variável }-18 \text { bits } \\
3^{\mathrm{a}} \text { variável }-20 \text { bits } \\
\text { Binária }-75 \text { bits }(24-25-26) \\
1^{\mathrm{a}} . \text { variável }-24 \text { bits } \\
2^{\mathrm{a}} . \text { variável }-25 \text { bits } \\
3^{\mathrm{a}} \text { variável }-26 \text { bits }\end{array}$ \\
\hline Estratégia de seleção & MGA1, Roleta1A \\
\hline cruzamento & $\begin{array}{l}\text { Um ponto }(1 X) \text {, dois pontos }(2 X) \text {, } \\
\text { multiponto }(3 X, 4 X \text { e } 5 X) \text {, uniforme, } \\
\text { variável-a-variável }\end{array}$ \\
\hline Probabilidade de cruzamento & 0,85 \\
\hline Probabilidade de mutação & 0,1 \\
\hline Critério de parada & 1000 gerações \\
\hline
\end{tabular}

\subsubsection{Descrição dos Experimentos e Análise dos Resultados}

O foco principal dos experimentos conduzidos nesta seção foi a quantidade de bits usada para representar cada uma das variáveis. O objetivo foi verificar a influência do número de bits usado para a representação de cada variável, no resultado obtido.

Na Tabela 5-5 é apresentado o valor da função custo e das três variáveis que a definem, para o comprimento de laje $3 \mathrm{~m}$, para cada uma das combinações variante/operador de cruzamento, usando uma configuração binária de 32 bits $(11,11$ e 10 bits associados às variáveis $\mathrm{x}_{1}, \mathrm{x}_{2}$ e $\mathrm{x}_{3}$ respectivamente).

Pode se notar na tabela que os valores obtidos por MGA1/operador de cruzamento, Roleta1A/operador de cruzamento e EASY são praticamente iguais, indicando que, para este problema em particular, tanto o EASY quanto qualquer dos variantes obtém o mesmo resultado, independentemente do operador de cruzamento utilizado. 
Tabela 5-5. Valores da função custo e das variáveis que a definem: $\mathrm{x}_{1}$ - altura da capa de concreto moldado no local, $\mathrm{x}_{2}$ - resistência do concreto moldado no local e $\mathrm{x}_{3}$ - distância do intereixo $(\mathrm{L}=3 \mathrm{~m})$

\begin{tabular}{|c|c|c|c|c|c|c|c|c|}
\hline \multicolumn{5}{|c|}{$\begin{array}{c}\text { FUNÇÃO CUSTO - vão } 3 m \\
\left(R \$ / m^{2}\right)\end{array}$} & \multicolumn{4}{|c|}{ VARIÁVEIS } \\
\hline MGA1 & $\begin{array}{c}\text { Valor } \\
\text { da } \\
\text { função }\end{array}$ & $\begin{array}{l}\text { Desvio } \\
\text { padrão }\end{array}$ & $\begin{array}{l}\text { Melhor } \\
\text { absoluto }\end{array}$ & $\begin{array}{c}\text { Pior } \\
\text { absoluto }\end{array}$ & $\begin{array}{c}\mathrm{x}_{1} \\
(\mathrm{~cm})\end{array}$ & $\begin{array}{c}\mathrm{x}_{2} \\
\left(\mathrm{kN} / \mathrm{cm}^{2}\right)\end{array}$ & $\begin{array}{c}\mathrm{x}_{3} \\
(\mathrm{~cm})\end{array}$ & escoras \\
\hline Uniforme & 28,01 & 0,0000 & 28,01 & 28,01 & 4,00 & 1,60 & 50,00 & 0 \\
\hline $1 \mathrm{X}$ & 28,01 & 0,0000 & 28,01 & 28,01 & 4,00 & 1,60 & 50,00 & 0 \\
\hline $2 X$ & 28,01 & 0,0000 & 28,01 & 28,01 & 4,00 & 1,60 & 50,00 & 0 \\
\hline $3 \mathbf{X}$ & 28,01 & 0,0000 & 28,01 & 28,01 & 4,00 & 1,60 & 50,00 & 0 \\
\hline $4 X$ & 28,01 & 0,0000 & 28,01 & 28,01 & 4,00 & 1,60 & 50,00 & 0 \\
\hline $5 X$ & 28,01 & 0,0000 & 28,01 & 28,01 & 4,00 & 1,60 & 50,00 & 0 \\
\hline Var_Var & 28,01 & 0,0001 & 28,01 & 28,05 & 4,00 & 1,60 & 50,00 & 0 \\
\hline \multicolumn{9}{|l|}{ Roleta1A } \\
\hline Uniforme & 28,02 & 0,0059 & 28,01 & 28,03 & 4,00 & 1,60 & 49,97 & 0 \\
\hline $1 \mathrm{X}$ & 28,02 & 0,0067 & 28,01 & 28,03 & 4,00 & 1,60 & 49,98 & 0 \\
\hline $2 X$ & 28,02 & 0,0070 & 28,01 & 28,03 & 4,00 & 1,61 & 49,99 & 0 \\
\hline $3 \mathbf{X}$ & 28,02 & 0,0086 & 28,01 & 28,01 & 4,00 & 1,60 & 49,98 & 0 \\
\hline $4 X$ & 28,02 & 0,0094 & 28,01 & 28,01 & 4,00 & 1,60 & 49,98 & 0 \\
\hline $5 X$ & 28,02 & 0,0066 & 28,01 & 28,03 & 4,00 & 1,60 & 49,99 & 0 \\
\hline Var_Var & 28,02 & 0,0055 & 28,01 & 28,03 & 4,00 & 1,60 & 49,98 & 0 \\
\hline $\begin{array}{l}\text { EASY } \\
\end{array}$ & 28,02 & & & & 4,00 & 1,60 & $\overline{50,00}$ & 0 \\
\hline
\end{tabular}

Na Tabela 5-6 são apresentados os valores da função custo e de suas variáveis para o comprimento de laje $4 \mathrm{~m}$. Os resultados confirmam a tendência observada para o comprimento de laje de $3 \mathrm{~m}$, uma vez que não há variações significativas entre os dois variantes.

Embora os resultados obtidos por ambos variantes tenham sido próximos, está claro na tabela que o variante RoletalA teve os piores resultados quando comparado com o MGA1. O melhor resultado do MGA1 foi obtido usando cruzamento de um ponto e 5X e o pior usando o operador variável-a-variável. Com o Roleta1A, o melhor desempenho foi com o operador de cruzamento variável-a-variável e o pior, com o cruzamento 5X. Apesar dessas considerações, os resultados estão muito próximos o que impede uma avaliação mais refinada. 
Tabela 5-6. Valores da função custo e das variáveis que a definem: $\mathrm{x}_{1}$ - altura da capa de concreto moldado no local, $\mathrm{x}_{2}$ - resistência do concreto moldado no local e $\mathrm{x}_{3}$ - distância do intereixo $(\mathrm{L}=4 \mathrm{~m})$

\begin{tabular}{|c|c|c|c|c|c|c|c|c|}
\hline \multicolumn{5}{|c|}{$\begin{array}{c}\text { FUNÇÃO CUSTO - vão } 4 m \\
\left(R \$ / m^{2}\right)\end{array}$} & \multicolumn{4}{|c|}{ VARIÁVEIS } \\
\hline MGA1 & $\begin{array}{c}\text { Valor } \\
\text { da } \\
\text { função }\end{array}$ & $\begin{array}{l}\text { Desvio } \\
\text { padrão }\end{array}$ & $\begin{array}{l}\text { Melhor } \\
\text { absoluto }\end{array}$ & $\begin{array}{c}\text { Pior } \\
\text { absoluto }\end{array}$ & $\begin{array}{c}\mathbf{x}_{1} \\
(\mathrm{~cm})\end{array}$ & $\begin{array}{c}\mathbf{x}_{2} \\
\left(\mathrm{kN} / \mathrm{cm}^{2}\right)\end{array}$ & $\begin{array}{c}x_{3} \\
(\mathrm{~cm})\end{array}$ & escoras \\
\hline Uniforme & 42,40 & 0,6594 & 41,97 & 43,64 & 6,28 & 2,92 & 34,16 & 0 \\
\hline $1 \mathrm{X}$ & 41,90 & 0,0657 & 41,82 & 41,97 & 6,18 & 2,98 & 34,74 & 0 \\
\hline $2 X$ & 41,96 & 0,1513 & 41,82 & 42,32 & 6,17 & 2,97 & 34,49 & 0 \\
\hline $3 X$ & 42,39 & 0,8196 & 41,82 & 44,01 & 6,26 & 2,98 & 35,28 & 0 \\
\hline $4 X$ & 42,24 & 0,7157 & 41,97 & 44,27 & 6,22 & 2,97 & 34,81 & 0 \\
\hline $5 X$ & 42,42 & 0,8134 & 41,82 & 44,24 & 6,31 & 2,94 & 35,00 & 0 \\
\hline Var Var & 43,25 & 0,6768 & 41,88 & 44,11 & 6,53 & 2,93 & 35,24 & 0 \\
\hline \multicolumn{9}{|l|}{ Roleta1A } \\
\hline Uniforme & 42,70 & 0,5299 & 42,00 & 43,60 & 6,27 & 2,87 & 33,45 & 0 \\
\hline $1 X$ & 42,76 & 0,6439 & 42,13 & 44,18 & 6,19 & 2,91 & 33,37 & 0 \\
\hline $2 X$ & 43,18 & 0,6063 & 42,46 & 44,34 & 6,43 & 2,80 & 33,26 & \\
\hline $3 \mathrm{X}$ & 43,49 & 1,1096 & 42,02 & 44,92 & 6,54 & 2,87 & 35,20 & 0 \\
\hline $4 X$ & 42,87 & 0,9209 & 41,90 & 44,47 & 6,42 & 2,86 & 34,41 & 0 \\
\hline $5 X$ & 43,26 & 0,8121 & 42,44 & 45,01 & 6,48 & 2,84 & 34,19 & 0 \\
\hline Var_Var & 42,41 & 0,4470 & 42,07 & 43,47 & 6,21 & 2,91 & 33,69 & 0 \\
\hline EASY & 41,78 & & & & 6,28 & 3,00 & 35,73 & 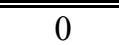 \\
\hline
\end{tabular}

Pode ser verificado que o uso de qualquer dos operadores de cruzamento uniforme e n-X não provocou uma variação grande no resultado final. É fato, entretanto, que com o uso do operador variável-a-variável só foram obtidos bons resultados quando tal operador foi utilizado com o variante Roleta1A. Isso nos leva a conjecturar sobre as vantagens do uso desse operador, quando aplicado a problemas de otimização de estruturas de concreto usando qualquer outra estratégia de seleção. Vale lembrar que o operador variável-a-variável foi proposto e recomendado em HASANCEBI \& ERBATUR (1998), quando da solução de problemas em estruturas de aço.

Considerando os comentários anteriores e também o fato do variante Roleta1A não ter tido bons desempenhos ao longo de todos os experimentos, a partir deste ponto apenas o variante MGA1 será utilizado para a solução dos problemas descritos. 
Um ponto importante levantado no Capítulo 2 com relação à representação binária é o relativo ao número de bits utilizado para a representação de cada variável do problema, uma vez que esse número tem uma relação direta com a precisão.

No que segue, então, decidiu-se tratar o mesmo problema (i.e. minimização da função custo de lajes com vigotas protendidas para vão de 4m) usando duas outras representações binárias mais refinadas onde as variáveis $\mathrm{x}_{1}, \mathrm{x}_{2}$ e $\mathrm{x}_{3}$ são representadas por 18,18 e 20 bits respectivamente (nomeada neste trabalho $18-18-20$ com um total de 56 bits) e por 24, 25 e 26 bits, respectivamente (nomeada 24-25-26 com um total de 75 bits). Os resultados finais relativos ao valor da função custo estão apresentados na Figura 5-10. Tais valores foram obtidos pelo MGA1 usando os diversos operadores de cruzamento, para um comprimento de laje de $4 \mathrm{~m}$.

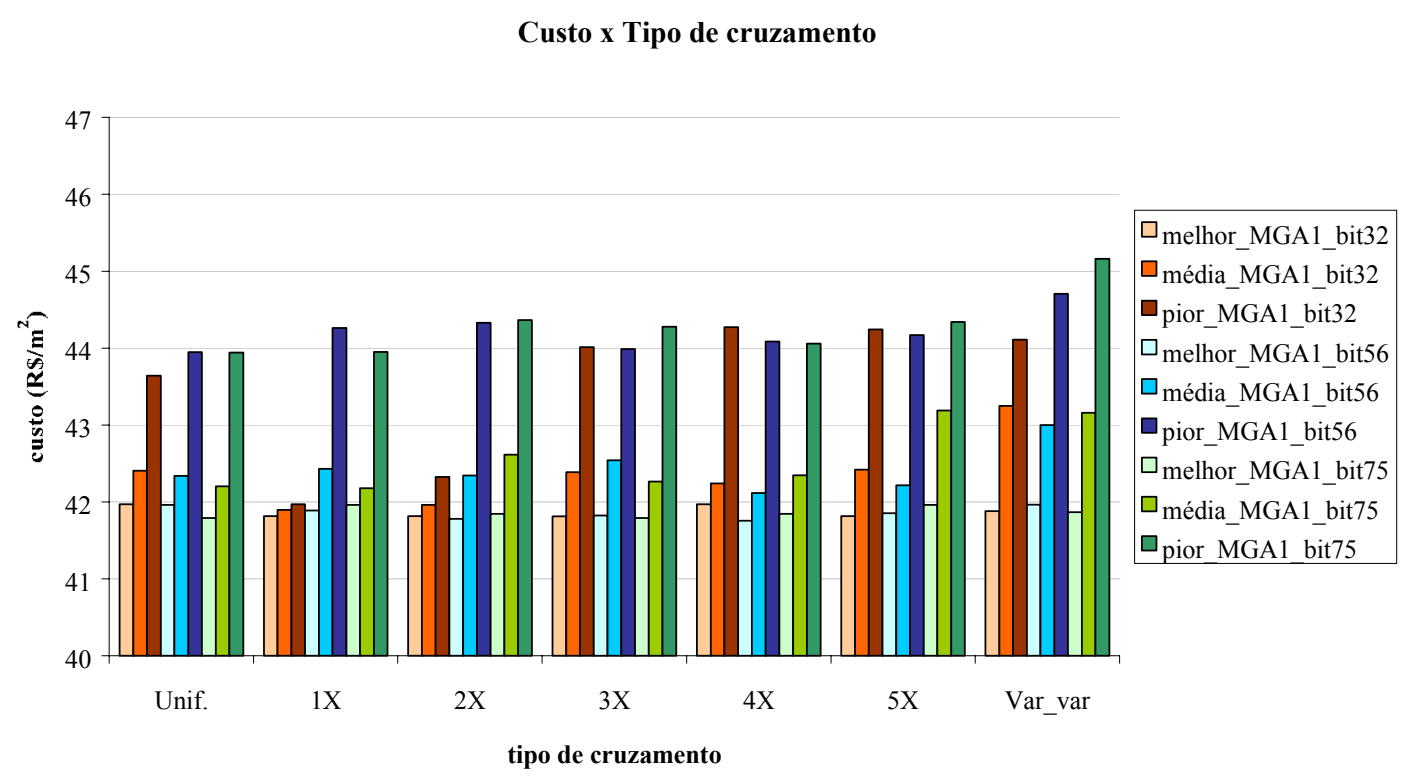

Figura 5-10. Resultados do valor da função custo obtidos usando o MGA1, para diferentes tipos de cruzamentos e comprimento de cromossomo $(\mathrm{L}=4 \mathrm{~m})$

Pela figura nota-se que o uso do cruzamento uniforme produz bons resultados quando o tamanho de cromossomo é aumentado. Avaliando os resultados obtidos com os três diferentes tamanhos de cromossomos resumido na Figura 5-11 pode-se dizer que:

- Os resultados obtidos com 56 bits só foram melhores que os resultados obtidos com 32 bits no cruzamento uniforme, 4X, 5X e var-a-var. Verifica-se 
que aumentando o número de bits o operador de cruzamento uniforme obtém um melhor desempenho;

- Os resultados obtidos com 75 bits só foram melhores do que os obtidos com 32 bits no cruzamento uniforme, $3 X$ e variável-a-variável;

- Os resultados com 56 bits foram melhores que com 75 com exceção do operador de cruzamento uniforme, $1 \mathrm{X}$ e $3 \mathrm{X}$.

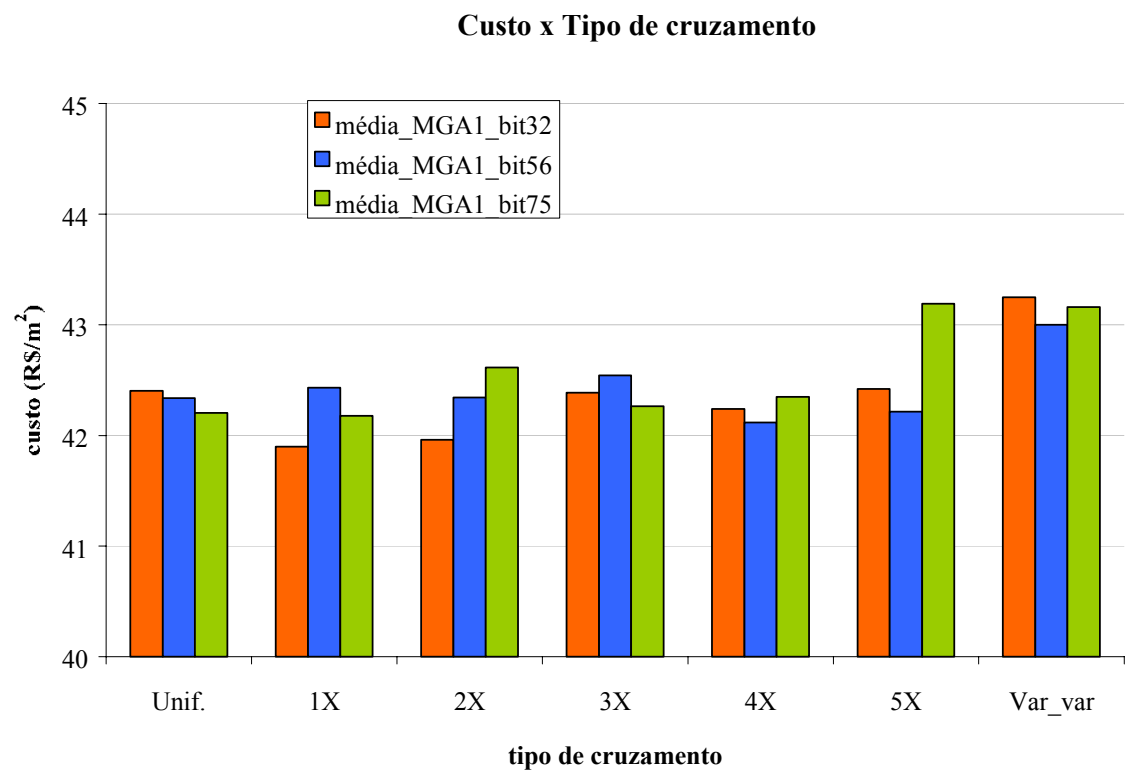

Figura 5-11. Resumo de valores médios da função custo $(\mathrm{L}=4 \mathrm{~m})$

Pode-se conjecturar neste experimento que usando o MGA1 o aumento do número de bits para a representação do cromossomo quase sempre não influencia no resultado final. Um aumento grande de bits não necessariamente implica em uma melhora dos resultados finais da função custo.

É importante notar também que um aumento do comprimento do cromossomo pode facilmente inviabilizar o seu uso, devido a restrições de tempo e memória.

\subsection{OTIMIZAÇÃO DO ELEMENTO E DA APLICAÇÃO}

Nesta seção é investigado o uso de algoritmo genético na busca da solução para o problema de minimização do custo de produção, transporte e aplicação de uma laje com uma dada vigota protendida com ou sem a utilização de escoras intermediárias. 
Este problema é uma composição dos dois problemas abordados anteriormente neste capítulo, descritos na Seção 5.3 e Seção 5.4 respectivamente. São apresentados e discutidos também os resultados obtidos para a solução do mesmo problema, usando o Método do Lagrangiano Aumentado.

\subsubsection{Definição do Problema}

O problema de otimização a ser tratado é o da minimização da função custo total de uma laje com vigota protendida com ou sem a utilização de escoras intermediárias para dois vãos: 3 metros e 4 metros. No equacionamento desta função serão inseridos os custos das etapas transitórias (produção, transporte e montagem) do painel, como visto na Seção 5.3.1.

As variáveis envolvidas na definição da função custo são: as armaduras de protensão $\left(\mathrm{x}_{1}, \mathrm{x}_{2}, \mathrm{x}_{3}\right)$, a altura de cada armadura no elemento $\left(\mathrm{x}_{4}, \mathrm{x}_{5}\right)$, a resistência do concreto moldado no local $\left(\mathrm{x}_{6}\right)$, a distância do intereixo $\left(\mathrm{x}_{7}\right)$ e a altura do capeamento $\left(\mathrm{x}_{8}\right)$. A seção transversal da laje é mostrada na Figura 5-12. Os custos de execução, de transporte e de aplicação são os mesmos discriminados na seção 5.3, com exceção dos custos tributários que assumem o valor de $145,00 \mathrm{R} \$ / \mathrm{m}^{3}$. As dimensões da vigota e da laje são apresentadas na Figura 5-13.

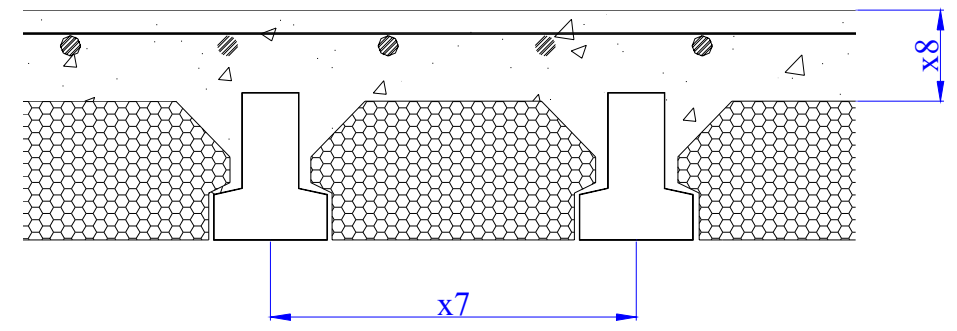

Figura 5-12. Seção de laje com vigota de concreto protendido, com enchimento e concreto moldado no local 


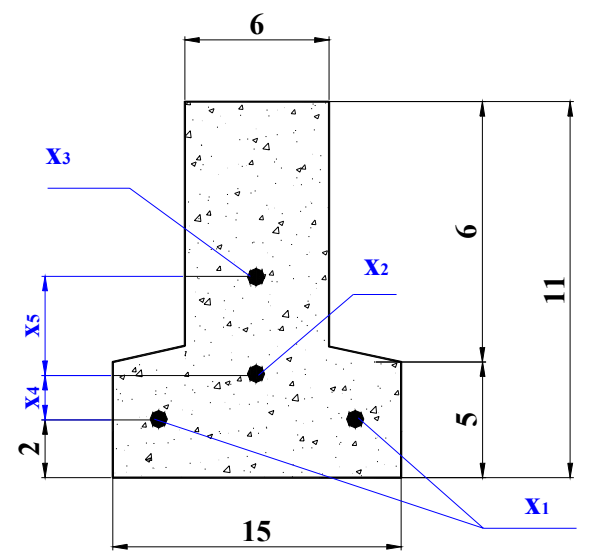

a) Seção da vigota protendida

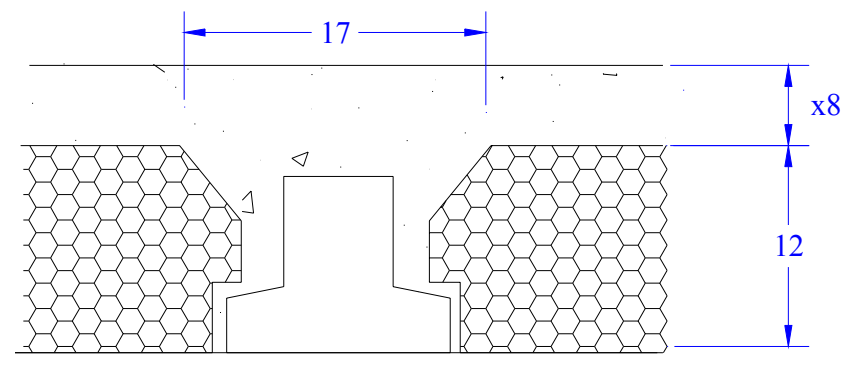

b) Seção de laje com vigota protendida

Figura 5-13. Dimensões das seções da laje e da vigota protendida (medidas em $\mathrm{cm}$ )

Os custos referentes à execução, ao transporte externo e à aplicação são os mesmos apresentados na Seção 5.3.1.

\subsubsection{Função Custo Total}

$\mathrm{Na}$ subseção anterior os vários custos envolvidos na produção de uma vigota protendida foram discriminados. Maiores detalhes da obtenção custo são apresentados no Apêndice F. Com o objetivo de obter a função que representa o custo total de produção, considerando as etapas de execução, de transporte e de aplicação, os vários custos foram somados e a expressão final da função é:

$$
\begin{aligned}
& f(x)=\frac{473,42}{x_{7}}+1,552 x_{8}+0,012\left(24,75 x_{6}+74,25\right) x_{8}+\frac{335,78\left(x_{1}+x_{2}+x_{3}\right)}{x_{7}}+ \\
& \frac{0,00476 x_{7}}{\left(2 x_{1}+x_{2}\left(2+x_{4}\right)+x_{3}\left(2+x_{4}+x_{5}\right)\right)}+0,057 x_{7}
\end{aligned}
$$


onde

$\mathrm{x}_{1}-$ armadura nível $1\left(\mathrm{~cm}^{2}\right)$

$\mathrm{x}_{2}-$ armadura nível $2\left(\mathrm{~cm}^{2}\right)$

$\mathrm{x}_{3}$ - armadura nível $3\left(\mathrm{~cm}^{2}\right)$

$\mathrm{x}_{4}$ - distância da armadura do nível $2(\mathrm{~cm})$

$\mathrm{x}_{5}$ - distância da armadura no nível $3(\mathrm{~cm})$

$\mathrm{x}_{6}-$ resistência do concreto moldado no local em $\mathrm{kN} / \mathrm{cm}^{2}$

$\mathrm{x}_{7}$ - distância do inter-eixo em cm

$\mathrm{x}_{8}-$ altura da capa de concreto em $\mathrm{cm}$

O problema de minimização do custo de produção de tal laje, portanto, se resume ao problema de minimização de $\mathrm{f}(\mathbf{x}) \quad\left(\mathbf{x}=\left(\mathrm{x}_{1}, \mathrm{x}_{2}, \mathrm{x}_{3}, \mathrm{x}_{4}, \mathrm{x}_{5}, \mathrm{x}_{6}, \mathrm{x}_{7}, \mathrm{x}_{8}\right)\right)$. $\mathrm{O}$ dimensionamento da laje deve respeitar os mesmos estados limites definidos na Seção 5.3.2. Portanto, o problema em questão se configura como um problema de minimização sujeito a restrições e pode ser equacionado da seguinte forma:

Minimizar $\quad f(\mathbf{x})$

Sujeita às mesmas restrições descritas na subseção 5.3.2

Além dessas restrições as variáveis devem satisfazer às desigualdades:

$$
\begin{aligned}
& 0,4 \leq \mathrm{x}_{1} \leq 3,0 \quad\left(\mathrm{~cm}^{2}\right) \\
& 0,1 \leq \mathrm{x}_{2} \leq 2,6\left(\mathrm{~cm}^{2}\right) \\
& 0 \leq \mathrm{x}_{3} \leq 1 \quad\left(\mathrm{~cm}^{2}\right) \\
& 0,5 \leq \mathrm{x}_{4} \leq 6 \quad(\mathrm{~cm}) \\
& 0,5 \leq \mathrm{x}_{5} \leq 8 \quad(\mathrm{~cm}) \\
& 1,5 \leq \mathrm{x}_{6} \leq 3 \quad\left(\mathrm{kN} / \mathrm{cm}^{2}\right) \\
& 30 \leq \mathrm{x}_{7} \leq 50 \quad(\mathrm{~cm}) \\
& 4 \leq \mathrm{x}_{8} \leq 10 \quad(\mathrm{~cm})
\end{aligned}
$$

A escolha desses limites se justifica por:

- $\mathrm{x}_{1}$ : limite inferior e superior correspondem a um limite tolerável;

- $\mathrm{x}_{2}$ : limite inferior e superior correspondem a um limite tolerável;

- $\mathrm{x}_{3}$ : limite inferior e superior correspondem a um limite tolerável;

- $\mathrm{x}_{4}$ : limite inferior e superior correspondem a um limite tolerável;

- $\mathrm{x}_{5}$ : limite inferior e superior correspondem a um limite tolerável; 
- $\mathrm{x}_{6}$ : limites inferior e superior correspondem a valores permitidos de resistência para o concreto moldado no local;

- $\mathrm{x}_{7}$ : limite inferior arbitrado e superior estipulado por norma;

- $\mathrm{x}_{8}$ : limites inferior estipulado por norma; limite superior correspondem a um limite tolerável.

Para o problema descrito aqui foi adotada a mesma estratégia da penalidade adotada para a solução dos problemas descritos no Capítulo 4.

\subsubsection{Busca da Solução do Problema via AG}

Para a busca da solução da minimização da função custo que equaciona o problema em questão, via AG, o variante usado foi o MGA1. Na Tabela 5-7 estão discriminados os valores de várias características relativas a AGs adotadas na implementação.

Tabela 5-7. Principais Características da Implementação do AG

\begin{tabular}{|c|c|}
\hline Características & Possiveis Valores \\
\hline elitismo & 1 indivíduo \\
\hline população & 100 \\
\hline Representação de dados & $\begin{array}{l}\text { Binária }-88 \text { bits } \\
1^{\mathrm{a}} \text {. variável }-10 \text { bits } \\
2^{\mathrm{a}} \text {. variável }-10 \text { bits } \\
3^{\mathrm{a}} \text { variável }-10 \text { bits } \\
4^{\mathrm{a}} \text {. variável }-13 \text { bits } \\
5^{\mathrm{a}} \text {. variável }-13 \text { bits } \\
6^{\mathrm{a}} \text {. variável }-11 \text { bits } \\
7^{\mathrm{a}} \text {. variável }-11 \text { bits } \\
8^{\mathrm{a}} \text { variável }-10 \text { bits }\end{array}$ \\
\hline Estratégia de seleção & MGA1 \\
\hline cruzamento & $\begin{array}{l}\text { Um-ponto (1X), 2X, 3X, 4X, 5X, } \\
\text { uniforme, variável-a-variável }\end{array}$ \\
\hline Probabilidade de cruzamento & 0,85 \\
\hline Probabilidade de mutação & 0,1 \\
\hline Critério de parada & 1000 gerações \\
\hline
\end{tabular}

\subsubsection{Descrição dos Experimentos e Análise dos Resultados}

Na Tabela 5-8 são apresentados os resultados obtidos pelo variante MGA1 usando os diversos operadores de cruzamento para o problema em questão, considerando o comprimento de laje de $3 \mathrm{~m}$. 
Tabela 5-8. Valores da função custo e das variáveis que a definem: $\mathrm{x}_{1}, \mathrm{x}_{2}, \mathrm{x}_{3}-$ armaduras de protensão, $\mathrm{x}_{4}, \mathrm{x}_{5}$ - distâncias dos níveis de armadura e $\mathrm{x}_{6}$ - resistência do concreto moldado no local, $\mathrm{x}_{7}$ - distância do intereixo e $\mathrm{x}_{8}$ - altura da capa de concreto moldado no local

\begin{tabular}{|c|c|c|c|c|c|c|c|c|c|}
\hline & & \multicolumn{8}{|c|}{ VARIÁVEIS - vão $3 m$} \\
\hline MGA1 & \begin{tabular}{|c|}
$\begin{array}{l}\text { Valor da } \\
\text { função } \\
\left(\mathrm{R} \$ \mathbf{m}^{2}\right)\end{array}$ \\
\end{tabular} & $\begin{array}{c}x_{1} \\
\left(\mathrm{~cm}^{2}\right)\end{array}$ & $\begin{array}{c}\mathbf{x}_{2} \\
\left(\mathrm{~cm}^{2}\right)\end{array}$ & $\begin{array}{c}\mathbf{x}_{3} \\
\left(\mathrm{~cm}^{2}\right)\end{array}$ & $\begin{array}{c}\mathbf{x}_{4} \\
(\mathrm{~cm})\end{array}$ & $\begin{array}{c}\mathbf{x}_{5} \\
(\mathbf{c m})\end{array}$ & $\begin{array}{c}\mathrm{x}_{6} \\
\left(\mathrm{kN} / \mathrm{cm}^{2}\right)\end{array}$ & $\begin{array}{c}\mathbf{x}_{7} \\
(\mathbf{c m})\end{array}$ & $\begin{array}{c}\mathrm{x}_{8} \\
(\mathrm{~cm})\end{array}$ \\
\hline Uniforme & 28,44 & 0,40 & 0,10 & 0,00 & 5,93 & 1,89 & 1,50 & 49,98 & 4,00 \\
\hline $1 \mathrm{X}$ & 28,45 & 0,40 & 0,10 & 0,01 & 5,85 & 2,20 & 1,50 & 49,97 & 4,00 \\
\hline $2 X$ & 28,48 & 0,40 & 0,10 & 0,01 & 5,78 & 2,29 & 1,50 & 49,98 & 4,00 \\
\hline $3 \mathrm{X}$ & 28,44 & 0,40 & 0,10 & 0,01 & 5,92 & 2,33 & 1,50 & 49,98 & 4,00 \\
\hline $4 X$ & 28,47 & 0,40 & 0,10 & 0,01 & 5,79 & 2,13 & 1,50 & 50,00 & 4,00 \\
\hline $5 X$ & 28,48 & 0,40 & 0,10 & 0,01 & 5,53 & 2,69 & 1,50 & 50,00 & 4,00 \\
\hline Var_Var & 28,57 & 0,40 & 0,10 & 0,01 & 5,56 & 1,75 & 1,51 & 49,86 & 4,00 \\
\hline$\overline{\text { EASY }}$ & 28,36 & 0,40 & 0,10 & 0,00 & 4,00 & 4,00 & 1,50 & 50,00 & 4,00 \\
\hline
\end{tabular}

Verifica-se na figura que todos os resultados foram bem próximos. O melhor desempenho foi obtido com o uso do cruzamento uniforme e o pior com o uso do cruzamento variável-a-variável. Todos os valores obtidos, com exceção do variávela-variável, foram praticamente os mesmos. Vale salientar que essa configuração evidenciou o uso de uma escora.

A Figura 5-14 apresenta os valores da função custo para o comprimento de laje $4 \mathrm{~m}$ considerando os vários tipos de cruzamento. Nota-se novamente que o operador de cruzamento variável-a-variável obteve o pior desempenho.

Ainda para este problema foi investigado ainda o uso de variáveis discretas para a representação de dados. Na literatura o uso de variáveis discretas para o equacionamento do problema é amplamente empregado em estruturas de aço. Às vezes fica muito mais fácil associar às variáveis um conjunto discreto de valores, dado que esses valores são os mais fáceis de serem empregados. 


\section{Custo $x$ Tipo de cruzamento}

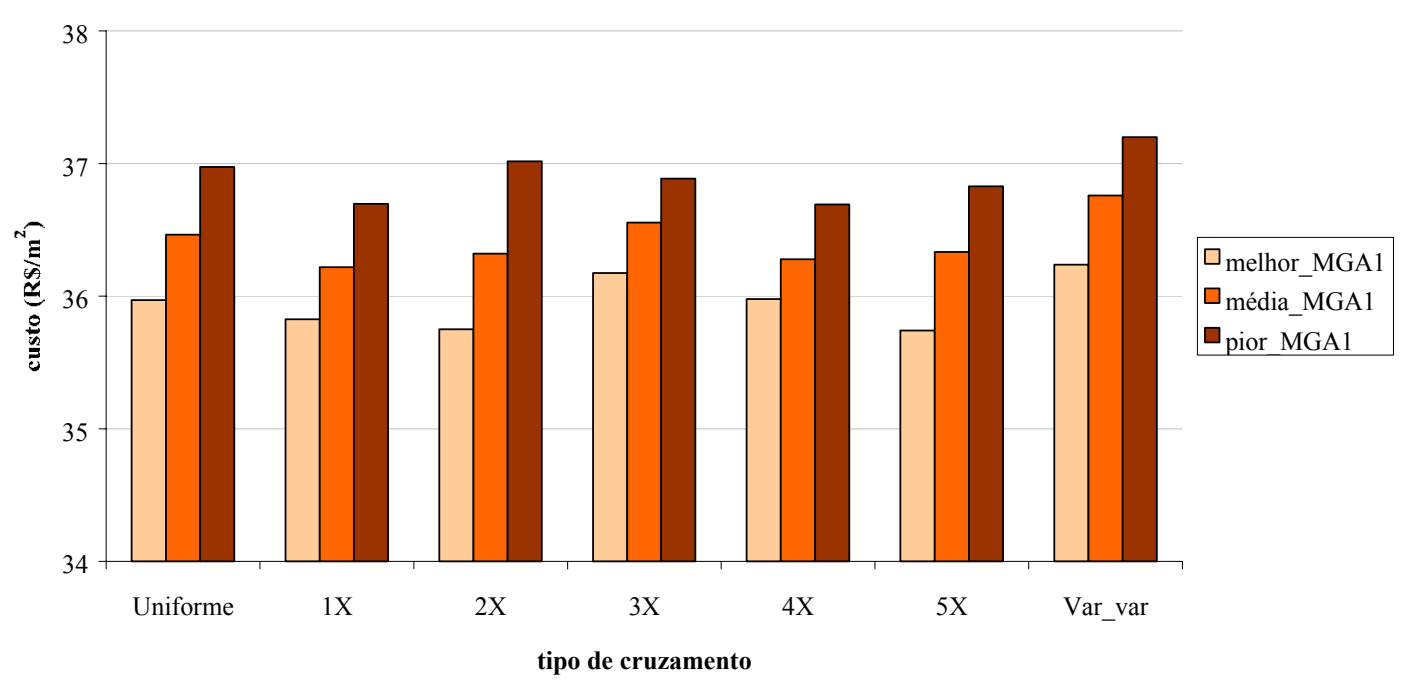

Figura 5-14. Resultados do desempenho da função custo para diferentes tipos de cruzamento $(\mathrm{L}=4 \mathrm{~m})$

Para efeito de comparação são apresentados e discutidos dados relativos à solução do mesmo problema usando variação dinâmica do operador de cruzamento (seqüência aleatória) e representação real.

Vale salientar que a definição do tamanho do cromossomo respeitou os limites do cálculo do comprimento do cromossomo dado por: $2^{\text {nb }}=$ nv (nb é o número de bits e nv é o número dos possíveis valores), descrito no Capítulo 2. O comprimento em bits de cada variável discreta utilizada na solução do problema é definido da seguinte maneira:

- O conjunto ordenado área contém os 16 possíveis valores de armadura de protensão que, no problema, é representada pelas variáveis $\mathrm{x}_{1}, \mathrm{x}_{2}$ e $\mathrm{x}_{3}$ (armaduras nível 1, armadura nível 2 e armadura nível 3 respectivamente). Vale salientar que esses valores correspondem a números múltiplos de uma barra de diâmetro de $5 \mathrm{~mm}$, cuja área é de $0,196 \mathrm{~cm}^{2}(0,393=0,196 \times 2$ barras; $0,589=0,196 \times 3$ barras; e assim por diante).

área $=(0,196 ; 0,393 ; 0,589 ; 0,785 ; 0,982 ; 1,178 ; 1,374 ; 1,571 ; 1,767 ; 1,963 ; 2,16$; $2,356 ; 2,553 ; 2,749 ; 2,945 ; 3,142)$.

Para a representação binária desses 16 possíveis valores, portanto, basta usar um conjunto de 4 bits $\left(2^{4}=16\right)$ para cada variável: $4+4+4=\mathbf{1 2}$ bits. 
- O conjunto ordenado distância contém os 64 possíveis valores das distâncias entre níveis de armadura, representadas pelas variáveis $\mathrm{x}_{4}$ e $\mathrm{x}_{5}$. distância $=(0,0 ; 0,5 ; 0,6 ; 0,7 ; 0,8 ; 0,9 ; 1,0 ; 1,1 ; 1,2 ; 1,3 ; 1,4 ; 1,5 ; 1,6 ; 1,7 ; 1,8$; 1,$9 ; 2,0 ; 2,1 ; 2,2 ; 2,3 ; 2,4 ; 2,5 ; 2,6 ; 2,7 ; 2,8 ; 2,9 ; 3,0 ; 3,1 ; 3,2 ; 3,3 ; 3,4 ; 3,5$; 3,$6 ; 3,7 ; 3,8 ; 3,9 ; 4,0 ; 4,1 ; 4,2 ; 4,3 ; 4,4 ; 4,5 ; 4,6 ; 4,7 ; 4,8 ; 4,9 ; 5,0 ; 5,1 ; 5,2$; $5,3 ; 5,4 ; 5,5 ; 5,6 ; 5,7 ; 5,8 ; 5,9 ; 6,0 ; 6,1 ; 6,2 ; 6,3 ; 6,4 ; 6,5 ; 6,6 ; 6,7)$.

Para a representação binária desses 64 possíveis valores, portanto, basta usar um conjunto de 6 bits $\left(2^{6}=64\right)$ para cada variável: $6+6=\mathbf{1 2}$ bits.

- O conjunto ordenado $f_{c k}$ contém os 16 possíveis valores da resistência do concreto moldado no local, definido pela variável $\mathrm{x}_{6}$. $f_{c k}=(1,5 ; 1,6 ; 1,7 ; 1,8 ; 1,9 ; 2,0 ; 2,1 ; 2,2 ; 2,3 ; 2,4 ; 2,5 ; 2,6 ; 2,7 ; 2,8 ; 2,9 ; 3,0)$ Portanto, bastam 4 bits $\left(2^{4}=16\right)$ para a variável: 4 bits.

- O conjunto ordenado inteixo contém os 32 possíveis valores do inter-eixo, definido pela variável $\mathrm{x}_{7}$.

inteixo $=(30,0 ; 30,5 ; 31,0 ; 31,5 ; 32,0 ; 32,5 ; 33,0 ; 33,5 ; 34,0 ; 34,5 ; 35,0 ; 35,5$; 36,$0 ; 36,5 ; 37,0 ; 37,5 ; 38,0 ; 38,5 ; 39,0 ; 39,5 ; 40,0 ; 40,5 ; 41,0 ; 42,0 ; 43,0 ; 44,0$; $45,0 ; 46,0 ; 47,0 ; 48,0 ; 49,0 ; 50,0)$

Portanto bastam 5 bits $\left(2^{5}=32\right)$ para a variável: 5 bits.

- O conjunto ordenado capa $_{C M L}$ contém os 8 possíveis valores da altura da capa de concreto moldado no local, definido pela variável $\mathrm{x}_{8}$.

$\operatorname{capa}_{C M L}=(4,0 ; 5,0 ; 6,0 ; 7,0 ; 8,0 ; 9,0 ; 10,0 ; 11,0)$

Portanto bastam 3 bits $\left(2^{3}=8\right)$ para a variável: 3 bits.

Na Tabela 5-9 são apresentados os valores da função custo e das variáveis para o comprimento de laje $4 \mathrm{~m}$. Nota-se pelos resultados que os valores da função custo, para as variáveis discretas com cruzamento uniforme e variáveis discretas com seqüência aleatória, são iguais.

Foi avaliado também o impacto da representação real e da seqüência aleatória (visto na Seção 5.3.4) na solução do problema no caso de variáveis discretas. Verifica-se que com a representação real os resultados obtidos são piores que aqueles obtidos com variáveis discretas. 
Tabela 5-9. Valores da função custo e das variáveis que a definem: $\mathrm{x}_{1}, \mathrm{x}_{2}, \mathrm{x}_{3}$ - armadura de protensão, $\mathrm{x}_{4}, \mathrm{x}_{5}$ - distâncias dos níveis de armadura e $\mathrm{x}_{6}$ - resistência do concreto moldado no local, $\mathrm{x}_{7}$ - distância do intereixo e $\mathrm{x}_{8}$ - altura da capa de concreto moldado no local

\begin{tabular}{|c|c|c|c|c|c|c|c|c|c|}
\hline & & \multicolumn{8}{|c|}{ VARIÁVEIS - vão $4 m$} \\
\hline $\begin{array}{l}\text { Representação } \\
\text { binária }\end{array}$ & $\begin{array}{c}\text { Valor da } \\
\text { função } \\
\left(\mathrm{R} \$ \mathrm{~m}^{2}\right)\end{array}$ & $\begin{array}{c}\mathrm{x}_{1} \\
\left(\mathrm{~cm}^{2}\right)\end{array}$ & $\begin{array}{c}\mathbf{x}_{2} \\
\left(\mathrm{~cm}^{2}\right)\end{array}$ & $\begin{array}{c}\mathbf{x}_{3} \\
\left(\mathrm{~cm}^{2}\right)\end{array}$ & $\begin{array}{c}\mathbf{x}_{4} \\
(\mathbf{c m})\end{array}$ & $\begin{array}{c}\mathbf{x}_{5} \\
(\mathbf{c m})\end{array}$ & $\begin{array}{c}\mathbf{x}_{6} \\
\left(\mathbf{k N} / \mathrm{cm}^{2}\right)\end{array}$ & $\begin{array}{c}\mathbf{x}_{7} \\
(\mathbf{c m})\end{array}$ & $\begin{array}{c}\mathbf{x}_{8} \\
(\mathbf{c m})\end{array}$ \\
\hline $\begin{array}{l}\text { Variáveis discretas: } \\
\text { Cruzamento uniforme }\end{array}$ & 36,90 & 0,393 & 0,196 & 0,196 & 3,1 & 4,1 & 2,5 & 39,5 & 5,0 \\
\hline $\begin{array}{l}\text { Variáveis discretas: } \\
\text { Seqüência aleatória }\end{array}$ & 36,90 & 0,393 & 0,196 & 0,196 & 3,3 & 3,6 & 2,5 & 39,5 & 5,0 \\
\hline $\begin{array}{l}\text { Variáveis contínuas: } \\
\text { Cruzamento uniforme }\end{array}$ & 35,46 & 0,41 & 0,11 & 0,07 & 3,38 & 3,61 & 2,48 & 40,56 & 5,18 \\
\hline \multicolumn{10}{|l|}{$\begin{array}{c}\text { Representação } \\
\text { real }\end{array}$} \\
\hline $\begin{array}{l}\text { Variáveis contínuas: } \\
\text { Cruzamento aritmético }\end{array}$ & 40,45 & 0,49 & 0,39 & 0,24 & 2,48 & 3,28 & 2,41 & 39,50 & 5,27 \\
\hline EASY & 34,78 & 0,40 & 0,10 & 0,02 & 4,00 & 4,00 & 2,50 & 39,86 & $\overline{5,06}$ \\
\hline
\end{tabular}

Nota-se na tabela que novamente os valores de $\mathrm{x}_{2}$ e $\mathrm{x}_{3}$ correspondem a valores mínimos obtidos pelo EASY e pelo AG para variáveis contínuas. Comparando esses com os valores discretos vê-se que realmente os valores discretos representam de maneira mais coerente a solução do problema.

A título de uma investigação paralela, conforme adiantado no Capítulo 4, o variante Torneio2 com cruzamento uniforme (representação real) será usado para o problema em questão, numa tentativa de validar (ou não) os resultados obtidos no Capítulo 4, com relação a esse variante versus tamanho da população. A Figura 5-15 apresenta os valores da função custo usando o Torneio2 com cruzamento uniforme para o comprimento de laje $4 \mathrm{~m}$ considerando os diferentes tamanhos de população. Como pode ser observado, o resultado evidenciado no Capítulo 4, ie, o variante Torneio2 com cruzamento uniforme e população de 20 indivíduos ter tido o melhor desempenho, não se verifica para esse problema. Pode-se pensar, então, que aquele resultado foi atípico e talvez determinado pelas características da própria função sendo minimizada. 


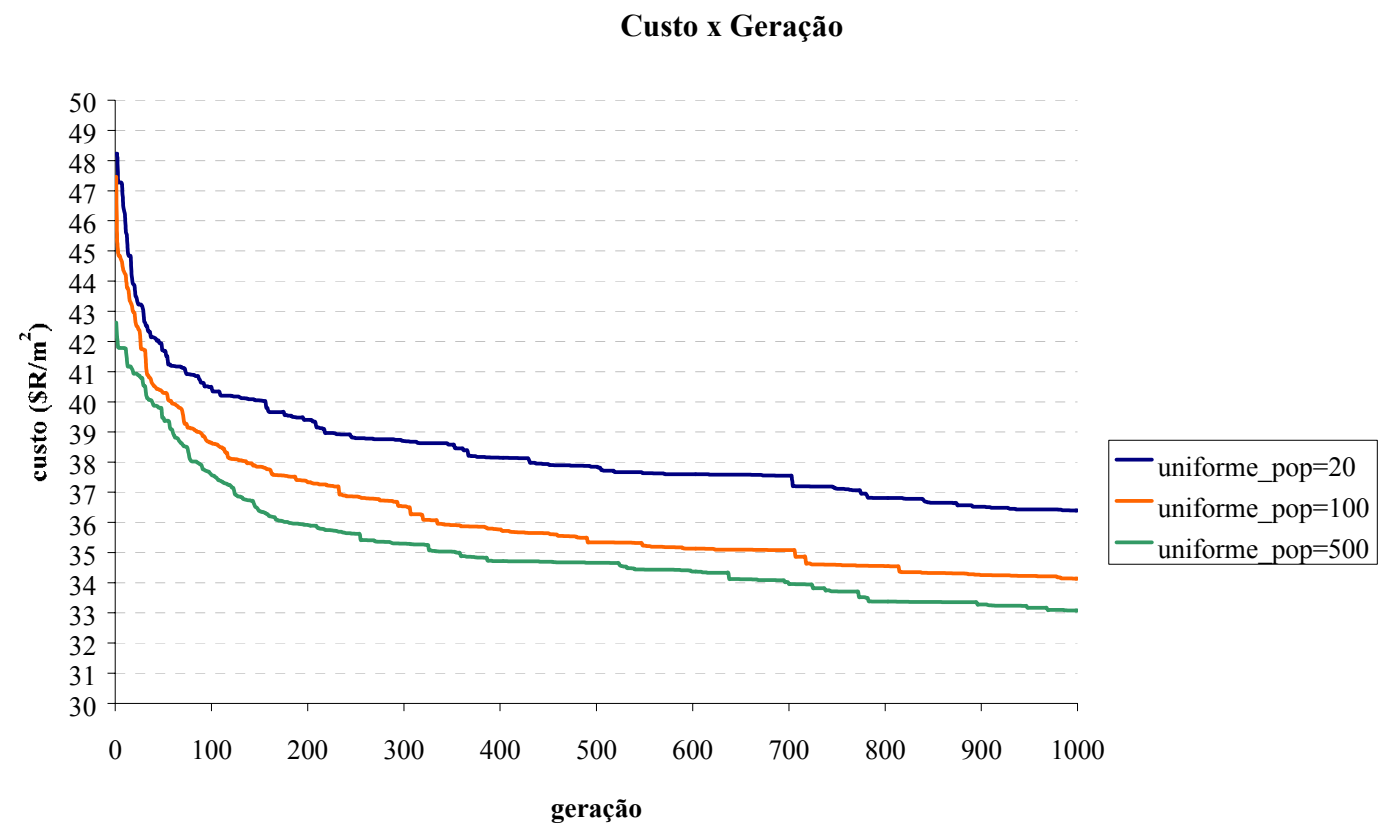

Figura 5-15. Valores médios da função custo para tamanhos de população diferentes para o variante Torneio2 $(\mathrm{L}=4 \mathrm{~m})$

\subsubsection{Considerações Sobre a Variação dos Valores do Custo dos Materiais}

Nesta seção é avaliada a influência de alterações no valor da função custo total e de suas variáveis, para as seguintes variações: da distância da fábrica ao local da obra, do valor do custo do concreto e do valor do custo do aço. Os comentários que seguem são relativos ao ponto ótimo obtido para o caso de otimização do elemento e da aplicação para variáveis contínuas (ver $3^{\mathrm{a}}$ linha da Tabela 5-9). A Tabela 5-10 mostra os valores dos custos de materiais, mão-de-obra, equipamentos, transporte, administrativos e tributários que foram obtidos no problema em questão.

Tabela 5-10. Valores de custo em porcentagem relativo a cada etapa

\begin{tabular}{|c|c|}
\hline $\begin{array}{c}\text { Custos totais divididos } \\
\text { por etapa }\end{array}$ & $\%$ \\
\hline \hline Custos de materiais & 49,61 \\
Custos de mão-de-obra & 20,15 \\
Custos de equipamento & 3,44 \\
Custos de transporte & 4,10 \\
Custos administrativos & 11,27 \\
Custos tributários & 11,43 \\
\hline
\end{tabular}


A fim de avaliar o desempenho da função custo diante das alterações optou-se por aumentar cinco vezes a distância entre a fábrica e a obra. Portanto, com o aumento desta distância de $100 \mathrm{~km}$ para $500 \mathrm{~km}$ foi constatado que o custo aumenta em $15 \%$. Os valores das variáveis se mantêm constante, com exceção do inter-eixo e da altura da capa que aumentam em média 5\%. Vale notar que o aumento da distância não interfere na resistência do concreto moldado no local.

Avaliando um aumento de preço do concreto de $30 \%$ o custo final aumenta de $10 \%$ e o valor das variáveis mantém-se inalterado com exceção das variáveis relativas ao inter-eixo e altura da capa que diminuem em média 5,5\%.

Verifica-se que aumentando o preço do aço de $30 \%$, o custo final aumenta $3 \%$. Nesse caso, os valores das variáveis se mantêm constante com exceção do inter-eixo e da altura da capa que diminuem em média $4 \%$.

\subsection{AVALIAÇÃO GERAL DOS RESULTADOS OBTIDOS NOS EXPERIMENTOS DESCRITOS NO CAPÍTULO}

Nesta seção são resumidos os resultados obtidos nos experimentos descritos neste capítulo, com o objetivo de agrupar aqueles que foram conclusivos e estabelecer algumas conclusões.

\subsubsection{Otimização do elemento para uma determinada aplicação}

Problema: minimização da função custo total de uma vigota protendida com ou sem a utilização de escoras intermediárias. As variáveis envolvidas na definição da função custo são os três níveis de armaduras de protensão $\left(\mathrm{A}_{\mathrm{p} 1}, \mathrm{~A}_{\mathrm{p} 2}, \mathrm{~A}_{\mathrm{p} 3}\right)$ e as alturas do segundo e do terceiro nível da armadura no elemento $\left(\mathrm{d}_{2}, \mathrm{~d}_{3}\right)$.

Devido ao desempenho dos variantes usados para os problemas tratados no Capítulo 4, para o problema em questão foram usados o MGA1 e o Roleta1A. Na busca da solução do problema de cada variante foi avaliado o impacto de diferentes operadores de cruzamento: $1 \mathrm{X}, 2 \mathrm{X}, 3 \mathrm{X}, 4 \mathrm{X}, 5 \mathrm{X}$, uniforme e variável-a-variável.

Os melhores resultados obtidos pelos dois variantes são apresentados na Tabela 5-11 e na Tabela 5-12. 
Tabela 5-11. Quadro resumo dos valores da função custo para diferentes vãos

\begin{tabular}{|c|c|c|c|}
\hline \multicolumn{4}{|c|}{ FUNÇÃO CUSTO } \\
$\left(\boldsymbol{R} \$ \mathbf{m}^{\mathbf{2}}\right)$ \\
\hline Vão & MGA1 & Roleta1A & EASY \\
\hline L=3m & 37,68 & 39,87 & 34,44 \\
\hline L=4m & 42,32 & 43,36 & 34,40 \\
\hline
\end{tabular}

Ainda para esse problema foram investigadas três alterações dinâmicas dos operadores de cruzamento: uma proposta por HASANCEBI \& ERBATUR (1998) (seqüênciaHE) e as outras duas propostas neste trabalho (seqüêncial e seqüência aleatória) .

Tabela 5-12. Quadro resumo dos valores da função custo para as diferentes seqüências

\begin{tabular}{|c|c|c|}
\hline \multicolumn{3}{|c|}{$\begin{array}{c}\text { FUNÇÃO CUSTO - } L=4 m \\
\left(\boldsymbol{R} \$ \mathbf{m}^{\mathbf{2}}\right)\end{array}$} \\
\hline Operador dinâmico & MGA1 & Roleta1A \\
\hline seqüênciaHE & 44,02 & 43,99 \\
\hline seqüência1 & 44,01 & 44,49 \\
\hline seqüência aleatória & 42,32 & 43,62 \\
\hline
\end{tabular}

Pode-se dizer, com base nos experimentos, que:

- O melhor variante foi o MGA1 se comparado com o Roleta1A. Os resultados obtidos pelo MGA1 ficaram bem próximos independentemente do operador cruzamento usado. O operador de cruzamento variável-a-variável obteve os piores resultados quando associado a este variante. $\mathrm{O}$ cuidado que sempre deve ser tomado no uso desse variante é evitar que indivíduos com aptidão alta (superindivíduos), mas não ótima, dominem a população. Por isso, optouse manter a diversidade da população, usando uma taxa maior de mutação (de $0,01$ para 0,1$)$;

- É com o Roleta1A que o operador variável-a-variável obteve os melhores resultados;

- A seqüência de operadores proposta por HASANCEBI \& ERBATUR (1998) (seqüênciaHE) não melhora o desempenho do MGA1 ou do Roleta1A. O uso das estratégias dinâmicas de operador de cruzamento, seqüênciaHE e seqüência1 não colaboraram para uma melhor solução. A seqüência aleatória, 
proposta neste trabalho, apresentou os melhores resultados, para qualquer dos variantes;

- Com relação à utilização do método convencional pode-se dizer que a definição das restrições dos problemas foi uma das dificuldades quando do seu uso. Cada uma delas deve estar em função das variáveis, o que tornou o trabalho extremamente árduo, pois cada uma das restrições é expressa por uma função de tamanho razoável;

- Uma outra dificuldade apresentada que é inerente ao próprio método convencional está relacionada à definição do ponto inicial, a partir do qual o método é inicializado. Caso esse ponto inicial não apresente boas informações do ótimo, o processo pode não convergir podendo estacionar em um mínimo local. No caso da convergência, o processo pode apresentar um alto custo computacional. Uma alternativa bem interessante e plausível em problemas semelhantes seria obter o ponto inicial a partir de uma heurística, por exemplo, o AG.

\subsubsection{Otimização da aplicação para uma determinada vigota}

Problema: minimização da função custo total da aplicação de uma laje com vigota protendida com ou sem a utilização de escoras intermediárias. As variáveis envolvidas na definição da função custo são: a altura do capeamento $\left(\mathrm{h}_{\text {capa }}\right)$, a resistência do concreto moldado no local $\left(\mathrm{f}_{\mathrm{ck}}\right)$ e a distância do intereixo $\left(\mathrm{d}_{\text {inteixo }}\right)$.

Os dois AGs variantes utilizados foram o MGA1 e Roleta1A. Na busca da solução do problema foram avaliados o impacto de diferentes operadores de cruzamento: $1 \mathrm{X}, 2 \mathrm{X}, 3 \mathrm{X}, 4 \mathrm{X}, 5 \mathrm{X}$, uniforme e variável-a-variável e o impacto de diferentes tamanho de representação binária: 32, 56 e 75 bits. Os melhores resultados obtidos pelos dois variantes são apresentados na Tabela 5-13, para os dois comprimento de vãos estudados. 
Tabela 5-13. Quadro resumo dos valores médios da função custo para dois vãos

\begin{tabular}{|c|c|c|c|}
\hline \multicolumn{4}{|c|}{ FUNÇÃO CUSTO $\left(\mathbf{R} \$ \mathbf{m}^{\mathbf{2}}\right)$} \\
\hline Vão & MGA1 & Roleta1A & EASY \\
\hline L=3m & 28,01 & 28,02 & 28,02 \\
\hline L=4m & 41,90 & 42,41 & 41,78 \\
\hline
\end{tabular}

Os dois variantes e o EASY convergiram praticamente para o mesmo valor.

Pode-se dizer, com base nos experimentos conduzidos e resultados obtidos, que o desempenho do MGA1 e Roleta1A estão bem próximos. Não se têm informações suficientes para definir qual seria o operador de cruzamento recomendável.

Com relação ao impacto de duas outras representações binárias, pode-se concluir que no caso do variante MGA1, o operador de cruzamento variável-avariável obteve os melhores resultados quando associado a um maior tamanho de cromossomo.

\subsubsection{Otimização do elemento e da aplicação}

Problema: minimização da função custo total de uma laje com vigota protendida com ou sem a utilização de escoras intermediárias. As variáveis envolvidas na definição da função custo são: as armaduras de protensão $\left(A_{p 1}, A_{p 2}, A_{p 3}\right)$, a altura de cada armadura no elemento $\left(\mathrm{d}_{2}, \mathrm{~d}_{3}\right)$, a resistência do concreto moldado no local $\left(\mathrm{f}_{\mathrm{ck}}\right)$, a distância do intereixo $\left(\mathrm{d}_{\text {inteixo }}\right)$ e a altura do capeamento $\left(\mathrm{h}_{\text {capa }}\right)$.

Foi avaliado apenas o variante MGA1. Na busca da solução do problema foram avaliados o impacto de diferentes operadores de cruzamento: $1 \mathrm{X}, 2 \mathrm{X}, 3 \mathrm{X}, 4 \mathrm{X}, 5 \mathrm{X}$, uniforme e variável-a-variável; o impacto das representações binária e real; o impacto de variáveis discretas e avaliação da seqüência aleatória. Foram também realizados experimentos para analisar e o impacto da representação real na combinação Torneio2/cruzamento uniforme para diferentes tamanhos de população. Os melhores resultados e a porcentagem com relação ao EASY são apresentados na Tabela 5-14. 
Tabela 5-14. Quadro resumo dos valores médios da função custo

\begin{tabular}{|c|c|c||c|c|c||}
\cline { 2 - 6 } \multicolumn{1}{c|}{} & \multicolumn{2}{c||}{ Variáveis discretas } & \multicolumn{3}{c||}{ Variáveis contínuas } \\
\cline { 2 - 6 } \multicolumn{1}{c|}{} & $\begin{array}{c}\text { Cruzamento } \\
\text { uniforme } \\
\text { (binária) }\end{array}$ & $\begin{array}{c}\text { Seqüência } \\
\text { aleatória } \\
\text { (binária) }\end{array}$ & $\begin{array}{c}\text { Cruzamento } \\
\text { uniforme } \\
\text { (binária) }\end{array}$ & $\begin{array}{c}\text { MGA1 } \\
\text { Aritmético } \\
\text { (real) }\end{array}$ & EASY \\
\hline L=4m & 36,90 & 36,90 & 35,46 & 40,45 & 34,78 \\
\hline$\%$ & $6 \%$ maior & $6 \%$ maior & $2 \%$ maior & $14 \%$ maior & - \\
\hline
\end{tabular}

Pode-se dizer, com base nos experimentos, que:

- Nenhum variante obtém um resultado melhor que o EASY;

- A tendência observada com Torneio2 com tamanho de população 20 não se verifica para esse problema. 


\section{Considerações Finais e 6 Conclusões}

Este trabalho de pesquisa investigou o uso de Algoritmos Genéticos na busca da solução de menor custo relativa a problemas de engenharia estrutural envolvendo elementos de concreto protendido. Para subsidiar uma análise comparativa, o trabalho investiu também na obtenção da solução dos problemas usando o método convencional de otimização do Lagrangiano Aumentado.

O trabalho focalizou cinco problemas diferentes, tendo como base dois elementos ie, o painel alveolar e a vigota protendida. Foram investigados cinco problemas de minimização de custo:

a) de painel alveolar sem capa estrutural;

b) de painel alveolar com capa estrutural;

c) da vigota protendida para uma determinada aplicação;

d) da aplicação para uma dada vigota; e

e) da vigota e da aplicação.

A partir do primeiro problema discriminado acima, foram realizados experimentos buscando identificar configuração de AG que encontrasse o melhor resultado, no caso, o menor custo. Ao longo do desenvolvimento do trabalho de 
pesquisa foram propostos vinte e dois variantes do AG típico; estes variantes foram classificados em três diferentes famílias, usando como critério de classificação, a estratégia de seleção que o variante implementa. $\mathrm{O}$ alto número de variantes foi conseqüência das várias combinações entre estratégia de seleção, esquema de reprodução e mecanismo de restauração da população ao tamanho original.

Quando da minimização da função custo relativa a painel alveolar sem capa estrutural usando AGs (Seção 4.4), a pesquisa focalizou principalmente o impacto da representação real usando os vinte e dois variantes propostos, buscando evidenciar aquele(s) com melhor desempenho buscando, com isso, identificar a melhor combinação de características genéticas para a solução do problema em questão. Os resultados obtidos com o conjunto de experimentos realizados apontaram para três variantes específicos: o MGA1, o Roleta3 e o Torneio2. Tais variantes foram, em seguida, usados na busca da solução do problema de minimização do custo de painel alveolar com capa, descrito na Seção 4.5. Nesta seção foram investigados os impactos de diferentes tamanhos de população, diferentes tipos de cruzamento e diferentes valores de $\lambda$.

Para a investigação do problema de minimização do custo vigotas protendidas, tratado na Seção 5.3, foram escolhidos dois variantes: o MGA1, devido ao bom desempenho obtido nos experimentos anteriores e o Roleta1A, por ter tido o pior desempenho dentre todos. A escolha do Roleta1A foi motivada pela possibilidade de, com algumas das características usadas nos experimentos, ter o seu desempenho melhorado. Foram analisados 7 diferentes tipos de cruzamento bem como a alteração dinâmica do operador de cruzamento, via implementação de um mecanismo proposto na literatura e dois outros propostos nesta tese. O foco dos experimentos realizados na Seção 5.4, quando da minimização da função custo da aplicação de vigotas protendidas, foi investigar o impacto do número de bits usados para representar cada uma das variáveis, na solução final. A Seção 5.5 trata do problema de minimização de lajes com vigotas protendidas usando apenas o variante MGA1 e investiga o uso da representação via variáveis discretas.

Os resultados obtidos nos experimentos para a solução dos cinco problemas tratados mostraram a flexibilidade e robustez dos AGs. Geralmente as soluções encontradas pelo AG foram melhores do que as obtidas pelo método convencional. 
Vale comentar que uma das dificuldades no uso desses métodos está na definição tanto do ponto inicial quanto da representação das restrições como função. Particularmente, o uso do EASY deve ser bastante controlado dado que a definição tanto da função objetivo quanto de todas as que representam as restrições do problema, devem ser inseridas pelo usuário do programa, no código fonte. Deve-se salientar que todas as soluções obtidas nos experimentos descritos nesta tese correspondem a pontos factíveis.

Deve-se ter sempre em mente, contudo, que a otimização da função custo é bastante trabalhosa. Como comentado no Capítulo 4, embora alguns custos tenham sido fornecidos pela empresa, há uma grande dificuldade no levantamento e na definição de alguns valores adotados neste trabalho. Caso esses valores estejam mais próximos da realidade, os resultados finais não apresentarão mudanças que alterem as conclusões deste trabalho.

Em virtude do grande volume de dados e de um número significativo de experimentos conduzidos, ao abordar cada um dos problemas nesta tese, optou-se por apresentar as conclusões parciais estabelecidas para cada um deles. Portanto, as principais conclusões do trabalho, agrupadas por capítulo, são descritas a seguir:

- Na família MGA o melhor variante foi o MGA1, que implementa a seleção MGA, baseada na seleção rank e proposta nesta tese. Este variante usa o esquema de substituição e a restauração da população é feita via escolha de indivíduos aleatórios da população corrente. O pior variante foi o MGA2 que também usa o esquema de substituição, mas com restauração da população usando indivíduos que não participaram do cruzamento. Os resultados mostram que a estratégia de reparação usando indivíduos que não participaram do cruzamento e a estratégia avaliador não contribuem para uma melhoria de desempenho do AG;

- Na família ROLETA, o melhor variante foi o Roleta3, que implementa o esquema avaliador e restaura a população usando indivíduos aleatórios da população corrente. O pior foi o Roleta2, que implementa o esquema de substituição e restaura a população usando indivíduos que não participaram do cruzamento. Um conjunto de experimentos evidenciou que o uso de uma 
população intermediária não contribui para uma sensível melhoria de desempenho;

- Todos os variantes da família TORNEIO obtiveram resultados muito próximos entre si. Embora os resultados estejam bem próximos, os piores valores foram aqueles onde o esquema de restauração adota indivíduos que não participaram do cruzamento. Aparentemente, o esquema de reprodução, a estratégia de reparação a $\mathrm{N}_{\text {pop }}$ e a adoção de uma população intermediária não influem sensivelmente nos resultados finais desta família;

- Os variantes que obtiveram os melhores desempenhos de cada família foram o MGA1, o Roleta3 e o Torneio2. Dentre os quatro tipos de cruzamento utilizados na análise dos três variantes, os melhores resultados foram obtidos com o simples e com o uniforme1. O pior desempenho foi obtido com o cruzamento uniforme. Valores de $\lambda$ não interferiram nos resultados finais obtidos pelos variantes das três famílias;

- Dentre os variantes MGA1 e Roleta1A, o melhor foi o MGA1 independentemente do operador de cruzamento utilizado. O operador de cruzamento variável-a-variável obteve os piores resultados quando associado com o variante MGA1 e os melhores quando associado com o variante Roleta1A;

- A seqüência de operadores proposta por HASANCEBI \& ERBATUR (1998) (seqüênciaHE), contrário aos resultados mostrados na referência, não colabora para uma melhor solução para o problema de minimização do custo de vigota protendida. A seqüência aleatória, proposta neste trabalho, apresentou os melhores resultados, independentemente do variante usado;

- Um aumento do número de bits na representação do cromossomo no variante MGA1, quase sempre não interfere nos resultados obtidos;

- A análise do problema envolvendo variáveis discretas fornece valores usuais para problemas típicos de engenharia. A utilização dessa representação permite o tratamento do problema de uma forma mais natural

Com base nos resultados obtidos nos vários experimentos descritos nesta tese, pode-se dizer que o AG é uma técnica perfeitamente viável em problemas de 
Engenharia Estrutural. Sua flexibilidade, robustez e facilidade de implementação são características positivas quanto da solução de problemas práticos, dado que os resultados obtidos com o seu uso foram, em alguns casos, melhores que aqueles obtidos via método convencional. Além disso, este trabalho servirá de referência àqueles que quiserem usar a técnica de AGs para problemas semelhantes.

Como comentado em alguns trechos da tese, muito embora a técnica de AGs tenha se mostrado perfeitamente adequada e factível para problemas de otimização tratados, não pode esquecido que seu sucesso é fortemente dependentemente da definição da função custo a ser otimizada. Por essa razão, para o tipo de problema tratado aqui é essencial que a expressão final da função que representa o custo de estruturas de concreto pré-moldado seja cuidadosamente elaborado, refinado e avaliado empiricamente.

As principais contribuições deste trabalho podem ser enumeradas:

- Soluções de problemas com variáveis contínuas utilizando as representações real e binária e problemas com variáveis discretas para representação binária;

- Propostas de alguns variantes que utilizam a combinação de diferentes estratégias de seleção e diferentes tipos de esquema de reparação;

- Propostas de alguns tipos de seqüências de operadores de cruzamento;

- Avaliação do impacto de diferentes tipos de operadores de cruzamento para as representações real e binária;

- Implementação de AG na busca da solução de problemas de interesse prático em Engenharia Estrutural;

- Discussão dos mesmos experimentos usando um método convencional de otimização;

Dentre as possíveis linhas de pesquisa para a continuidade do trabalho realizado nesta tese estão:

- Análises de diferentes funções penalidades;

- Avaliação da contribuição de hibridização do AG com outras técnicas heurísticas;

- Investigação do impacto da introdução de tamanho de população flexível; 
- Análise do impacto nos resultados de duas estratégias para o tratamento de restrições - rejeição e reparação;

- Uso de populações iniciais não randômicas;

- Análise de critérios de convergência e de parada do AG;

- A otimização do painel alveolar considerando dois níveis de armadura;

- Fazer um levantamento de custos mais refinado que efetivamente represente uma situação real como mencionado no Capítulo 4; a definição de alguns custos foi sujeita a uma série de aproximações. 


\section{REFERÊNCIAS BIBLIOGRÁFICAS}

ARAÚJO, M. G. (1980). Otimização estrutural de pórticos planos. Dissertação (Mestrado) Pontifícia Universidade Católica do Rio de Janeiro.

ARGOLO, W. P. (2000). Otimização de seções de concreto armado submetida a flexocompressão reta utilizando algoritmos genéticos. Dissertação (Mestrado) - Universidade Federal do Rio de Janeiro, COPPE.

ASSOCIAÇÃO BRASILEIRA DE NORMAS TÉCNICAS - ABNT (1986). NBR 7197 Projeto de estruturas de concreto protendido. Rio de Janeiro.

ASSOCIAÇÃO BRASILEIRA DE NORMAS TÉCNICAS - ABNT (2001). Texto conclusivo do projeto de revisão da NBR 6118 - Projeto de estruturas de concreto. Rio de Janeiro.

BEASLEY, D.; RALPH, R. M. ; DAVID, R. B. (1993a). An overview of genetic algorithms: Part 2, Research Topics. University Computing, v.15, n.4, p.170-181.

BEASLEY, D.; RALPH, R. M. ; DAVID, R. B. (1993b). An overview of genetic algorithms: part 1, Fundamentals. University Computing, v.15, n.2, p.58-69.

BRAMLETTE, M. F. (1991). Initialization, mutation and selection methods in genetic algorithms for function optimization. In: INTERNATIONAL CONFERENCE ON GENETIC ALGORITHMS, METHODS IN ENGINEERING, $4^{\text {th }}$, Morgan Kaufmann. Proceedings.

BENNETT, A. P. (1997). Finite population effects for ranking and tournament selection. Complex Systems, v.11, p.1-24.

CASTILHO, V. C. ; EL DEBS, M. K (2000). Aplicação de algoritmos genéticos na otimização estrutural dos elementos de concreto pré-moldado. In: JORNADAS SUDAMERICANAS DE INGENIERIA ESTRUCTURAL, 29., Punta Del Leste. Memorias [CD-ROM]. Montevideo, Universidad de la República/ASAIE, 2000.

CASTILHO, V. C.; EL DEBS, M. K. ; NICOLETTI, M. C. (2001). Application of genetic algorithm for optimization slabs of prestressed concrete joists. In: IBERIAN LATIN- 
AMERICAN CONGRESS ON COMPUTATIONAL METHODS IN ENGINEERING, $22^{\text {th }}$, Campinas. Anais [CD-ROM]. Campinas.

CASTILHO, V. C.; EL DEBS, M. K. ; NICOLETTI, M. C. (2002a). Investigação do impacto da estratégia de seleção na solução de problemas de otimização do custo de painéis alveolares usando algoritmos genéticos. In: CONGRESSO BRASILEIRO DE COMPUTAÇÃO - CBComp, 2., Itajaí. Anais [CD-ROM]. Itajaí.

CASTILHO, V. C.; NICOLETTI, M. C. ; EL DEBS, M. K. (2002b). Using genetic algorithms for minimizing the production costs of hollow core slabs. In: SECOND INTERNATIONAL CONFERENCE ON HYBRID INTELLIGENT SYSTEMS, $2^{\text {nd }}$, Universidad de Chile. Anais [CD-ROM]. Chile.

CERANIC, B. ; FRYER, C. (1998). A genetic algorithm approach to the minimum cost design of reinforced concrete flanged beams under multiple loading conditions. In: AUSTRALIAN CONFERENCE ON STRUCTURAL OPTIMIZATION, Sydney, Austrália. Proceedings. p.11-13.

CHAKRABARTY, B. K. (1992). Models for optimal design of reinforced concrete beams. Computers \& Structures, v.42, n.3, p.447-451.

CHEN, T.-Y. ; CHEN, C.-J. (1997). Improvements of simple genetic algorithm in structural design. International Journal for Numerical Methods in Engineering, v.40, p.1323-1334, April.

CHENG, F. Y. ; LI, D. (1998). Genetic algorithm for multiobjective optimization of structures. AIAA Journal, v.36, n.6, p.1105-1112, June.

COELlO, C. C.; HeRnÁNDEZ, F. S. ; FARRERA, F. A. (1997). Optimal design of reinforced concrete beams using genetic algorithm. Expert Systems with Applications, v.12, n.1, p.101-108.

COHN, M. Z.; FELOW, ASCE ; LOUNIS, Z. (1994). Optimal design of structural concrete bridge systems. Journal of Structural Engineeing, ASCE, v.120, n.9, p.2653-2674, Sept.

COLEY, D. A. (1999). An introduction to genetic algorithms for scientists and engineers. Singapore, World Scientific. 
DIAZ, A. et al. (1996). Optimizacion heuristica y redes neuronales. Madrid, Editorial Paranifo.

EL DEBS, M. K. (2000). Concreto pré-moldado: fundamentos e aplicações. São Carlos. Projeto Reenge EESC-USP.

GEN, M. ; CHENG, R. (1997). Genetic algorithms and engineering design. New York, John Wiley.

GOLDBERG, D. E. (1989). Genetic algorithms in search, optimization and machine learning. Reading, U.S.A., Addison-Wesley Publishing.

HANAI, J. B. (1999). Fundamentos do concreto protendido. São Carlos, EESC-USP. (Notas de aulas da disciplina "SET 5809 - Complementos de Concreto Protendido).

HASANCEBI, O. ; ERBATUR, F. (1998). Evaluation of crossover techniques based optimum structural design. In: TOPPING, B.H.V. (ed.) Advances in Engineering Computational Technology. Edinburgh, Civil-Comp Press, p.111-113.

HASSANAIN, M. A. ; LOOV, R. E. (1999). Design of prestressed girder bridges using high performance concrete - an optimization approach. PCI Journal, v.123, n.3, p.40-55, March-April.

HOLLAND, J. H. (1975). Adaptation in natural and artificial systems. Ann Arbor, University of Michigan Press.

JENKIS, W. M. (1991). Steady-state towards structural optimization via the genetic algorithm. Computers \& Structures, v.40, n.5, p.1321-1327.

JENKIS, W. M. (1992). Plane frame optimum design environment based on genetic algorithm. Journal of Strctural Engineering, ASCE, v.118, n.11, p.3103-3112, Nov.

JENKIS, W. M. (1997). On the application of natural algorithms to structural design optimization. Engineering Structures, v.19, n.4, p.302-308, April.

KALLASSY, A. ; MARCELIN, J.-L. (1997). Optimization of stiffened plates by genetic search. Structural Optimization, v.13, p.134-141.

KONCZ, T. (1975). Manual de la construccion prefabricada. Madrid, Hermann Blume. 
KOSKISTO, O. J. ; ELLINGWOOD, B. R. (1997). Reliability-based optimization of plant precast concrete structures. Journal of Structural Engineeing, ASCE, v.123, n.3, p.298304, March.

KOUMOUSIS, V. K. ; ARSENIS, S. J. (1998). Genetic algorithm in optimal detailed design of reinforced concrete members. Computer-Aided Civil and Infrastructure Engineering, v.13, p.43-52.

KRAKOVSKI (1997). Optimization of reinforced structures using design of experiments. Computer \& Structures. v.63, n.1, p.119-132, April.

KRIPKA, M. (1998). Determinação do posicionamento ótimo em edificações analisadas pelo modelo de grelha. Tese (Doutorado) - Escola de Engenharia de São Carlos, Universidade de São Paulo.

KWAN, A. S. (1998). An evolutionary approach for layout-optimization of truss structures. International Journal of Space Structures, v.13, n.3, p.145-155.

LACERDA, E. G. M. ; CARVALHO, A. C. P. L. F. (1999). Introdução aos algoritmos genéticos. In: GALVÃO, C. O. ; VALENÇA, M. J. S. (org.) (1999). Sistemas inteligentes: aplicações a recursos hídricos e ciências ambientais. Porto Alegre: Ed. Universidade/UFRG/ABRH. p. 99-150.

LEITE, J. P. B. ; TOPPING, B. H. V. (1998). Improved genetic operators for structural engineering optimization. Advances in Engineering Software, v.29, n.7-9, p.529-562, Aug-Nov.

LEMONGE, A. C. C. ; BARBOSA, H. J. C. (1998). A genetic algorithm for optimal bridge pillar location. In: WOLRD CONGRESS ON COMPUTATIONAL MECHANICS, $4^{\text {th }}$, Buenos Aires, Argentina. p.1-17.

LEMONGE, A. C. C. (1999). Aplicação de algoritmos genéticos em otimização estrutural. Tese (Doutorado) - Universidade Federal do Rio de Janeiro, COPPE.

LI, H. ; LOVE, P. (1997). Using improved genetic algorithms to facilitate time-cost optimization. Journal of Construction Engineering and Management, v.123, n.3, p.233237, Sept. 
LIN, C. Y. ; HAJELA, P. (1992). Genetic algorithms in optimization problems with discrete and integer design variables. Engineering Optimization, v.19, p.309-327.

LOUNIS, Z. ; COHN, M. Z. (1993). Optimization of precast prestressed concrete bridge girder systems. PCI Journal, v.123, n.3, p.60-77, July-August.

MARTÍNEZ, J.M. (1997). Augmented Lagrangians and the resolution of packing problems. Campinas, Institute of Mathematics, University of Campinas. (Technical report 08/97)

MARTÍNEZ, J.M. (1998). A two-phase model algorithm with global convergence for nonlinear programming. Journal of Optimization Theory and Applications, v.96, p.397436.

MEDRANO, M. S. (1994). Aplicações de programação matemática em análise estrutural. Dissertação (Mestrado) - Escola Politécnica, Universidade de São Paulo.

MERLIN, A. J. (2002). Momentos fletores negativos nos apoios de lajes formadas por vigotas de concreto protendido. Dissertação (Mestrado) - Escola de Engenharia de São Carlos, Universidade de São Paulo.

MICHALEWICZ, Z. (1996). Genetic algorithms + data structures = evolution programs. Berlin, Springer-Verlag.

MITCHELL, M. (1997). Machine learning, New York, McGraw-Hill.

NAGENDRA, S. et al. (1996). Improved genetic algorithm for the design of stiffened composite panels. Computers \& Structures, v.58, n.3, p.543-555.

OHSAKI, M. (1995). Genetic algorithm for topology optimization of trusses. Computers \& Structures, v.57, n.2, p.219-225. Oct.

PRAKASH, A.; AGARWALA, S. K. ; SINGER, K. K. (1988). Optimum design of reinforced concrete sections. Computers \& Structures, v.30, n.4, p.1009-1011.

PRESTRESSED/PRECAST CONCRETE INSTITUTE - PCI (1992). PCI design handbook: precast and prestressed concrete. 4 ed. Chicago.

PRUDENTE, M. (1999). Otimização de estruturas de aço treliçadas planas com variáveis discretas. Tese (Doutorado) - Escola de Engenharia de São Carlos, Universidade de São Paulo. 
RAFIQ, M. Y. ; SOUTHCOMBE, C. (1998). Genetic algorithm in optimal design and detailing of reinforced concrete biaxial columns supported by a declarative approach for capacity checking. Computers \& Structures, v.69, p.443-457.

RAJEV, S. ; KRISHNAMOORTHY, C. S. (1992). Discrete optimization of structures using genetic algorithm. Journal of Structural Engineeing, ASCE, v.118, n.5, p.1233-1250.

RAJEV, S. ; KRISHNAMOORTHY, C. S. (1998). Genetic algorithm-based methodology for design optimization of reinforced concrete frames. Computer-Aided Civil and Infrastructure Engineering, v.13, p.63-74.

REEVES, C. R. (1995). Modern heuristic techniques for combinatorial problems. London, McGraw-Hill.

RIGO, E. (1999). Métodos de otimização aplicados à analise de estruturas. Dissertação (Mestrado) - Escola de Engenharia de São Carlos, Universidade de São Paulo.

RODRIGUES, R. O. (1992). Automatização do projeto estrutural de pilares de concreto armado. Dissertação (Mestrado) - Escola de Engenharia de São Carlos, Universidade de São Paulo.

SANÁBIO, L. M. M. (1984). Análise limite de pórticos via otimização. Dissertação (Mestrado) - Pontifícia Universidade Católica do Rio de Janeiro.

SANTOS, M. D. G. (1989). Aplicação de um algoritmo de subgradiente reduzido a problemas de engenharia estrutural. Dissertação (Mestrado) - Universidade Federal de Pernambuco.

SARMA, K. C. ; ADELI, H. (1998). Cost optimization of concrete structures. Journal of Structural Engineeing, ASCE, v.124, n.5, p.570-578, May.

SOARES, R. C. (1997). Otimização de seções transversais de concreto armado sujeitas à flexão - aplicação a pavimentos. Dissertação (Mestrado) - Escola de Engenharia de São Carlos, Universidade de São Paulo.

SRINIVAS, M. ; PATNAIK, L. (1994). Genetic algorithms: a survey. IEEE Computers, v.27, n.6, p.17-26. 
TEMPLEMAN, A. B. (1988). Discrete optimum structural design. Computers \& Structures, v.30, n.3, p.551-515.

ZHU, D. M. (1986). An improved Templeman's algorithm for optimum design of trusses with discrete member sizes. Engineering Optimization, v.9, p.303-312.

WU,S.-J. ; CHOW, P.-T. (1995a). Integrade discrete and configuration optimization of trusses using genetic algorithm. Computers \& Structures, v.55, n.4, p.695-702, May.

WU,S.-J. ; CHOW, P.-T. (1995b). Steady-state genetic algorithm for discrete optimization of trusses. Computers \& Structures, v.56, n.6, p.979-991, Sept.. 


\section{APÊNDICE A}

O uso de AG em engenharia estrutural: caso da otimização de uma viga de concreto armado 


\section{O USO DE AG EM ENGENHARIA ESTRUTURAL: CASO DA OTIMIZAÇÃO DE UMA VIGA DE CONCRETO ARMADO}

Com o objetivo de avaliar as possibilidades e praticidade da técnica de AGs em Engenharia Estrutural, foi escolhido um problema típico de otimização na área. Buscou-se um problema que já tivesse sido abordado via métodos tradicionais de maneira a viabilizar uma comparação com os resultados já obtidos. O problema escolhido foi o apresentado no trabalho de SOARES (1997) onde foi analisada uma viga biapoiada de concreto armado com seção retangular ilustrada na Figura 1. Tendo como referência os valores obtidos neste trabalho, pôde-se avaliar a aplicabilidade e a eficiência dos AGs.
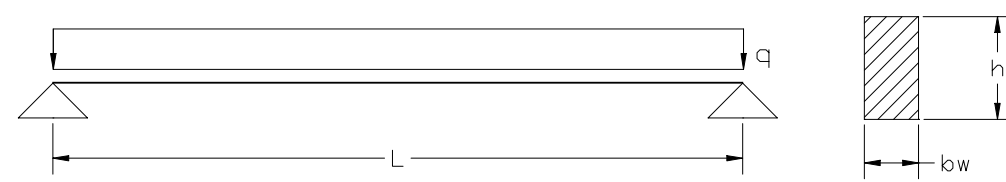

Figura 1. Viga biapoiada [SOARES (1997)]

A formulação adotada para resolver o problema está definida a seguir pelas equações (A.1) e (A.2). As variáveis do problema são a altura da viga ( $\left.\mathrm{x}_{1}\right)$ e a área de aço $\left(\mathrm{x}_{2}\right)$. O objetivo é minimizar o custo dos materiais na produção da viga biapoiada. É importante lembrar que as restrições $\left(g_{1}, g_{2}\right.$ e $\left.g_{3}\right)$ relativas a este problema específico devem sempre ser negativas.

$$
\begin{array}{ll}
\text { Minimizar } & \mathrm{F}(\mathrm{x})=4,5\left(\mathrm{x}_{1}+3\right)+2,25\left(10^{-5}\right) \mathrm{x}_{2}+\left(15+2 \mathrm{x}_{1}\right) 0,4 \\
\text { sujeito a } & \left\{\begin{array}{l}
\frac{\delta_{\mathrm{i}}}{\delta_{\text {admissivel }}}-1 \leq 0 \\
\frac{\mathrm{x}_{2}}{0,075 \mathrm{x}_{1}}-1 \leq 0 \\
\frac{\mathrm{M}_{\mathrm{d}}}{\mathrm{M}_{\mathrm{u}}}-1 \leq 0
\end{array}\right.
\end{array}
$$

onde

$$
\mathrm{x}_{1}-\text { altura da viga }
$$




$$
\begin{aligned}
& \mathrm{x}_{2}-\text { área de armadura } \\
& \delta_{\mathrm{i}}-\text { flecha máxima para cada indivíduo } \\
& \delta_{\text {admissível }}-\text { flecha admissível }(\mathrm{L} / 300) \\
& \mathrm{M}_{\mathrm{d}}-\text { momento atuante de cálculo } \\
& \mathrm{M}_{\mathrm{u}}-\text { momento último }
\end{aligned}
$$

Além dessas restrições, as variáveis não podem ultrapassar os seguintes limites:

$$
\begin{aligned}
& 50 \leq \mathrm{x}_{1} \leq 80 \quad(\mathrm{~cm}) \\
& 3,1 \leq \mathrm{x}_{2} \leq 6,2 \quad\left(\mathrm{~cm}^{2}\right)
\end{aligned}
$$

Foram consideradas ainda, as seguintes características geométricas:

$$
\begin{aligned}
& \mathrm{E}_{\mathrm{c}}=26000 \mathrm{MPa} \\
& \mathrm{E}_{\mathrm{s}}=210000 \mathrm{MPa} \\
& \mathrm{M}_{\mathrm{d}}=11200 \mathrm{kNcm} \\
& \mathrm{C} 20 \text { e } \quad \mathrm{CA}-50 \mathrm{~A} \\
& \mathrm{~L}=800 \mathrm{~cm} \\
& \mathrm{~b}_{w}=15 \mathrm{~cm}
\end{aligned}
$$

onde $\quad E_{c}$ - módulo de elasticidade do concreto

$\mathrm{E}_{\mathrm{s}}-$ módulo de elasticidade do aço

$\mathrm{M}_{\mathrm{d}}$ - momento atuante

L - vão da viga

$\mathrm{b}_{\mathrm{w}}-$ seção transversal da viga

Na abordagem deste problema utilizando AG, foram considerados, numa primeira aproximação, os seguintes parâmetros genéticos:

- elitismo (2 melhores indivíduos);

- $\quad$ tamanho da população =10 indivíduos;

- $\quad$ comprimento do cromossomo $=21$ bits;

- cruzamento uniforme;

- critério de parada: obtenção do valor ótimo da referência; 
- probabilidade de cruzamento e mutação respectivamente iguais a 0,80 e 0,01 .

Os valores para elitismo e para as probabilidades de cruzamento e mutação foram extraídos de RAJEEV \& KRISHNAMOORTHY (1992). O número de bits para representar o cromossomo foi calculado usando a equação (3) (Seção 2.3.1). A escolha do número de indivíduos na população foi arbitrária, mas procurou-se mantêlo pequeno; como nesse momento a implementação não havia sido inicializada ainda, adotou-se o valor 10, uma vez que tal valor facilitava o uso da técnica sem o auxílio de recursos computacionais.

O coeficiente de violação (C) associado a cada cromossomo foi calculado como sugerido em RAJEEV \& KRISHNAMOORTHY (1992) e descrito a seguir. Note que a soma $\mathrm{C}$ definida a seguir é um valor usado para penalizar aqueles cromossomos para os quais alguma(s) das restrições não foi satisfeita. Como os valores de $g_{1}, g_{2}$ e $g_{3}$ devem ser negativos, serão penalizados aqueles indivíduos para os quais esses valores forem positivos.

$$
\begin{aligned}
& \text { se } g_{i}(x)>0 \\
& \text { então } c_{i}=g_{i}(x) \\
& \text { senão } c_{i}=0
\end{aligned}
$$

onde

$$
\begin{aligned}
& \mathrm{g}_{\mathrm{i}}(\mathrm{x}) \text { - i-ésima restrição } \\
& \mathrm{C}=\sum_{\mathrm{j}=1}^{\mathrm{m}} \mathrm{c}_{\mathrm{j}} \\
& \mathrm{m}-\text { número de restrições }
\end{aligned}
$$

A função aptidão $(\phi)$ que considera todas violações é dada pela equação (A.3) [RAJEEV \& KRISHNAMOORTHY (1992)], onde 10 foi um valor arbitrário escolhido:

$$
\varphi(\mathrm{x})=\mathrm{F}(\mathrm{x})(1+10 \mathrm{C})
$$

De acordo com GOLDBERG (1989) com o objetivo de evitar valores negativos, a função $\varphi(x)$ pode ser substituída por uma outra $(\Phi(x))$, que garanta valores apenas positivos, expressa como a própria função $\varphi(x)$ subtraída de uma constante grande, como mostra a fórmula (A.4). Entretanto, para este problema 
específico, a redefinição proposta a seguir não seria necessária. Optou-se por adotá-la apenas para seguir o procedimento sugerido na referência.

$$
\Phi_{\mathrm{i}}=\left(\varphi_{\text {máx }}+\varphi_{\text {mín }}\right)-\varphi_{\mathrm{i}}
$$

A partir da equação acima, pode-se, agora, avaliar todos os indivíduos da população, considerando todas as restrições do problema. A Tabela 1 mostra o cálculo para a primeira geração. Os doze primeiros bits correspondem à primeira variável, a altura $\left(\mathrm{x}_{1}\right)$ e os nove bits restantes à segunda variável, a armadura $\left(\mathrm{x}_{2}\right)$. A Figura 2 mostra as duas substrings que respectivamente correspondem aos dois valores de variáveis e cada bit assume valores 1 ou 0 . Cada cromossomo apresentado na figura representa uma possível solução do problema. Foram gerados aleatoriamente os 10 indivíduos com o intuito de completar toda a população.

Comprimento total do cromossomo $=21$ bits

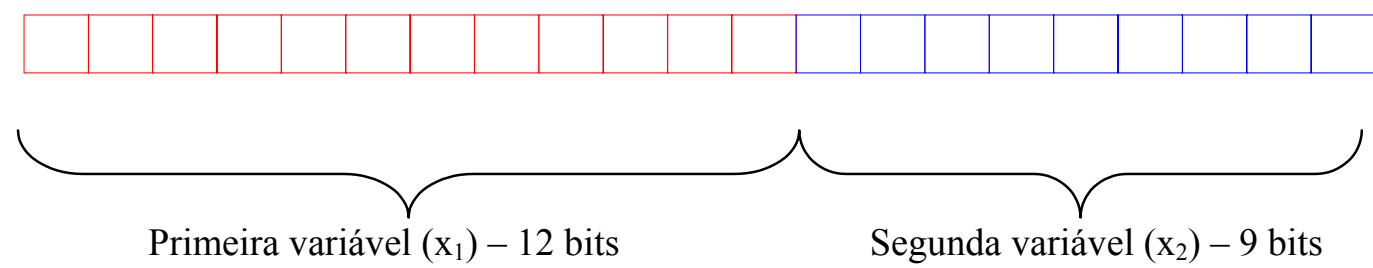

Figura 2. Cromossomo de um indivíduo da população

A função objetivo, $\mathrm{F}(\mathrm{x})$, é calculada pela equação (A.1). A somatória dos valores de $\mathrm{F}$ é 12425,14 e a sua média $(\overline{\mathrm{F}})$ é 1242,51 . A última coluna mostra que um indivíduo é descartado; isso acontece devido ao fato que o valor de $\mathrm{F} / \overline{\mathrm{F}}$ associado a esses indivíduo é menor que 0,5. Estes indivíduos são substituídos por cromossomos aleatórios. No próximo passo foram escolhidos dois indivíduos que irão permanecer na população (elitismo=2) e quatro pares para o cruzamento, onde cada par foi escolhido aleatoriamente. Os indivíduos participantes da próxima geração são os dois indivíduos selecionados pelo elitismo e os oito filhos dos quatro pares participantes do cruzamento. Com a próxima geração escolhida, fez-se a mutação em dois bits escolhidos aleatoriamente na população. 
O processo foi repetido até a sua convergência. Neste caso, como era sabido o valor do ótimo global [SOARES (1997)], o processo terminou quando se atingiu esse valor, na nona geração. A tabela 2 ilustra as características da última geração.

Tabela 1. Cálculo das características genéticas para a primeira geração

\begin{tabular}{|c|c|c|c|c|c|c|c|c|c|}
\hline Indivíduo & População & $\mathrm{x}_{1}$ & $\mathrm{x}_{2}$ & $\mathrm{~F}(\mathrm{x})$ & $\mathrm{C}$ (restrição) & $\varphi(\mathrm{x})$ & $\mathrm{F}$ & $F / \bar{F}$ & sobreviventes \\
\hline 1 & 101001101000011011001 & 69,516 & 4,204 & 387,935 & 0 & 387,935 & 1623,000 & 1,30 & 1 \\
\hline 2 & 111000100100110111001 & 76,520 & 5,344 & 425,056 & 0 & 425,056 & 1585,878 & 1,28 & 1 \\
\hline 3 & 000110110001010011010 & 53,172 & 3,884 & 301,312 & 0,29 & 1175,117 & 835,816 & 0,67 & 1 \\
\hline 4 & 011001111110110110000 & 62,176 & 5,298 & 349,033 & 0,365 & 1623,000 & 387,936 & 0,31 & 0 \\
\hline 5 & 111011111110000100001 & 78,177 & 3,268 & 433,520 & 0,05 & 650,280 & 1360,653 & 1,09 & 1 \\
\hline 6 & 010100010110111001101 & 59,538 & 5,446 & 335,052 & 0,019 & 398,711 & 1612,221 & 1,30 & 1 \\
\hline 7 & 011001110110000011100 & 62,117 & 3,242 & 348,720 & 0,281 & 1328,623 & 682,307 & 0,55 & 1 \\
\hline 8 & 110010001111001010011 & 73,553 & 3,522 & 409,331 & 0,04 & 573,063 & 1437,871 & 1,16 & 1 \\
\hline 9 & 110101111000110110111 & 75,260 & 5,334 & 418,378 & 0 & 418,378 & 1592,56 & 1,28 & 1 \\
\hline 10 & 100010101000001110111 & 66,234 & 3,705 & 370,543 & 0,09 & 704,031 & 1306,904 & 1,05 & 1 \\
\hline
\end{tabular}

Tabela 2. Cálculo das características genéticas para a última geração $\left(9^{\circ}\right)$

\begin{tabular}{|c|c|c|c|c|c|c|c|c|c|}
\hline Indivíduo & População & $\mathrm{x}_{1}$ & $\mathrm{x}_{2}$ & $\mathrm{~F}(\mathrm{x})$ & $\mathrm{C}$ (restrição) & $\varphi(\mathrm{x})$ & $\mathrm{F}$ & $F / \bar{F}$ & sobreviventes \\
\hline 1 & 111011110110110101001 & 78,06 & 5,68 & 433,21 & 0 & 433,21 & 750,73 & 1,04 & 1 \\
\hline 2 & 110000100110001111011 & 72,78 & 3,85 & 405,25 & 0,043 & 580,38 & 603,56 & 0,84 & 1 \\
\hline 3 & 101011111011100101101 & 70,59 & 4,93 & 393,65 & 0 & 393,65 & 790,29 & 1,10 & 1 \\
\hline 4 & 110111111001010111101 & 76,21 & 4,25 & 423,39 & 0 & 423,39 & 760,55 & 1,05 & 1 \\
\hline 5 & 110100111010011011101 & 74,81 & 4,44 & 415,97 & 0 & 415,97 & 767,97 & 1,07 & 1 \\
\hline 6 & 110100011100111110101 & 74,59 & 6,14 & 414,81 & 0,097 & 819,22 & 364,72 & 0,51 & 1 \\
\hline 7 & 110101110011100010001 & 75,22 & 4,76 & 418,18 & 0,0002 & 417,56 & 766,38 & 1,06 & 1 \\
\hline 8 & 110000100100011100001 & 72,77 & 4,46 & 405,18 & 0 & 405,18 & 778,76 & 1,08 & 1 \\
\hline 9 & 100000010010101101100 & 65,14 & 5,31 & 364,72 & 0 & 680,56 & 819,22 & 1,14 & 1 \\
\hline $\mathbf{1 0}$ & $\mathbf{1 0 0 1 0 0 1 1 0 0 1 1 0 1 1 0 0 1 0 1 1}$ & $\mathbf{6 7 , 2 5}$ & $\mathbf{4 , 3 3}$ & $\mathbf{3 7 5 , 9 4}$ & $\mathbf{0}$ & $\mathbf{3 7 5 , 9 4}$ & $\mathbf{8 0 8 , 0 0}$ & $\mathbf{1 , 1 2}$ & $\mathbf{1}$ \\
\hline
\end{tabular}

Os ótimos globais conhecidos, extraídos de SOARES (1997) e os obtidos por AG, estão listados na Tabela 3. Observa-se que o valor obtido por ambos os métodos, referente à altura da viga, foram os mesmos.

Tabela 3. Valores ótimos obtidos via os dois métodos

\begin{tabular}{|c|c|c|c|}
\hline & $\begin{array}{l}\text { altura da viga } \\
(\mathrm{cm})\end{array}$ & $\begin{array}{c}\text { área de armadura } \\
\qquad\left(\mathrm{cm}^{2}\right)\end{array}$ & $\begin{array}{l}\text { custo total } \\
\left(\$ / \mathrm{cm}^{3}\right)\end{array}$ \\
\hline $\begin{array}{c}\text { SOARES (1997) } \\
\text { (método do gradiente) }\end{array}$ & 67,25 & 4,13 & $\begin{array}{l}375,93 \\
\end{array}$ \\
\hline $\mathrm{AG}$ & 67,25 & 4,33 & 375,94 \\
\hline
\end{tabular}




\section{APÊNDICE B}

Pseudocódigos das implementações 


\section{PSEUDOCÓDIGOS DAS IMPLEMENTAÇÕES}

A seguir são apresentados os pseudocódigos utilizados na execução dos experimentos dos Capítulos 4 e 5.

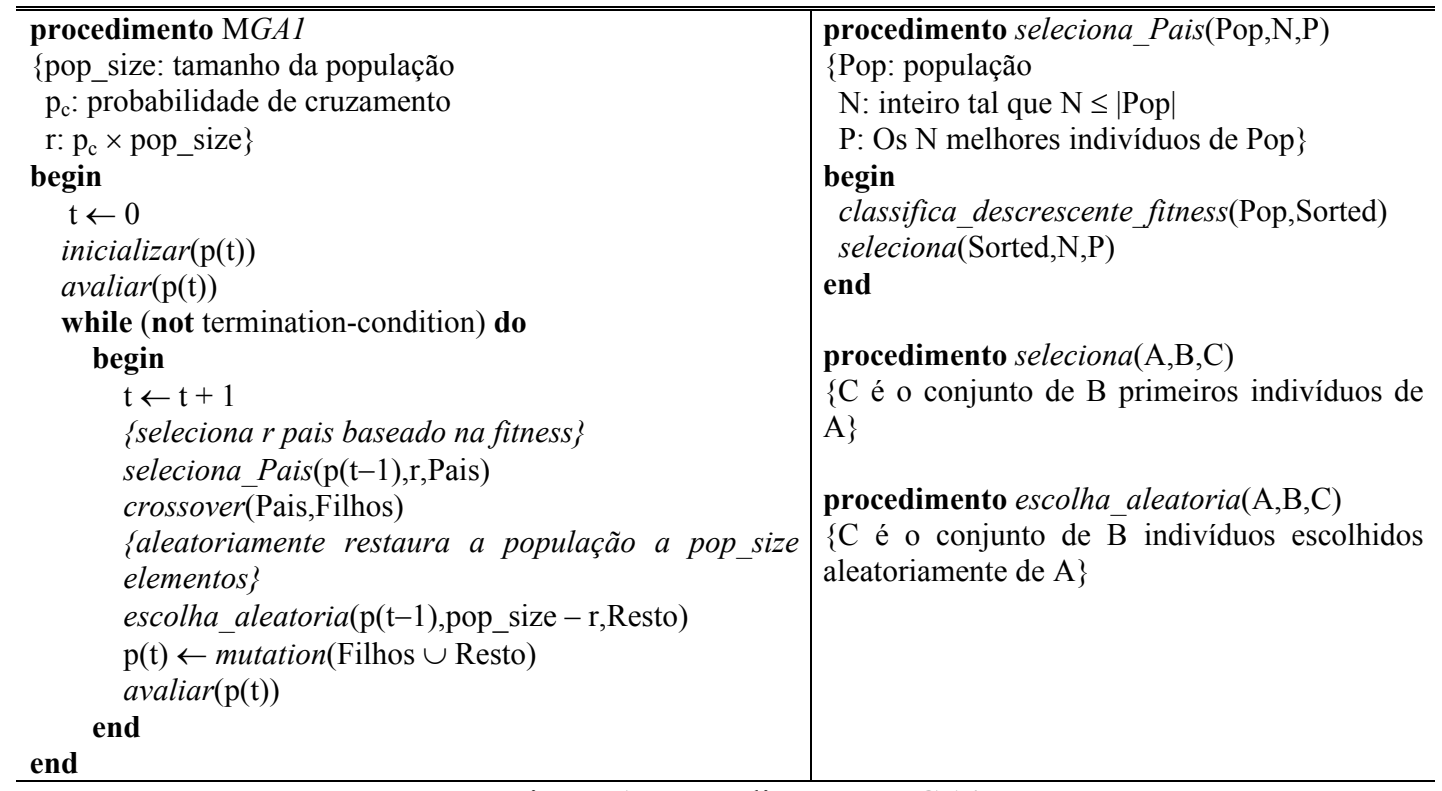

Figura 1. Procedimento MGA1

\begin{tabular}{|c|c|}
\hline $\begin{array}{l}\text { procedimento } M G A 2 \\
\text { \{pop_size: tamanho da população } \\
\mathrm{p}_{\mathrm{c}} \text { : probabilidade de cruzamento } \\
\left.\mathrm{r}: \mathrm{p}_{\mathrm{c}} \times \text { pop_size }\right\} \\
\text { begin } \\
\mathrm{t} \leftarrow 0 \\
\text { inicializar }(\mathrm{p}(\mathrm{t})) \\
\text { avaliar }(\mathrm{p}(\mathrm{t})) \\
\text { while }(\text { not termination-condition }) \text { do } \\
\quad \text { begin } \\
\quad \mathrm{t} \leftarrow \mathrm{t}+1 \\
\quad\{\text { seleciona r pais baseado na fitness\} } \\
\quad \text { seleciona_Pais }(\mathrm{p}(\mathrm{t}-1), \mathrm{r}, \text { Pais, Resto }) \\
\quad \text { rrossover }(\text { Pais,Filhos }) \\
\quad\{\text { Restaura a população a pop_size elementos usando } \\
\quad \text { cromossomos que não tenham sido Pais\} } \\
\quad \mathrm{p}(\mathrm{t}) \leftarrow \text { mutation }(\text { Filhos } \cup \text { Resto }) \\
\text { avaliar }(\mathrm{p}(\mathrm{t}))\end{array}$ & $\begin{array}{l}\text { procedimento seleciona_Pais(Pop,N,P,R) } \\
\text { \{Pop: população } \\
\mathrm{N} \text { : inteiro tal que } \mathrm{N} \leq|\mathrm{Pop}| \\
\mathrm{P} \text { : Os } \mathrm{N} \text { melhores indivíduos de Pop } \\
\mathrm{R} \text { : o restante }|\mathrm{Pop}|-\mathrm{N} \text { indivíduos de Pop\} } \\
\text { begin } \\
\text { classifica_descrescente_fitness(Pop,Sorted) } \\
\text { seleciona(Sorted,N,P,R) } \\
\text { end } \\
\text { procedimento seleciona(A,B,C,D) } \\
\{\text { transfere os primeiros elementos de A a C } \\
\text { e os elementos restantes a D }\}\end{array}$ \\
\hline
\end{tabular}

Figura 2. Procedimento $M G A 2$

\begin{tabular}{l}
\hline procedimento $M G A 3$ \\
$\{$ pop_size: tamanho da população \\
$\mathrm{p}_{\mathrm{c}}$ : probabilidade de cruzamento \\
$\mathrm{r}: \mathrm{p}_{\mathrm{c}} \times$ pop_size \\
begin \\
$\mathrm{t} \leftarrow 0$
\end{tabular}

procedimento seleciona_Pais(Pop,N,P)

\{Pop: população

$\mathrm{N}$ : inteiro tal que $\mathrm{N} \leq|\mathrm{Pop}|$

$\mathrm{P}$ : Os $\mathrm{N}$ melhores indivíduos de Pop\}

begin

classifica_descrescente fitness(Pop,Sorted) 


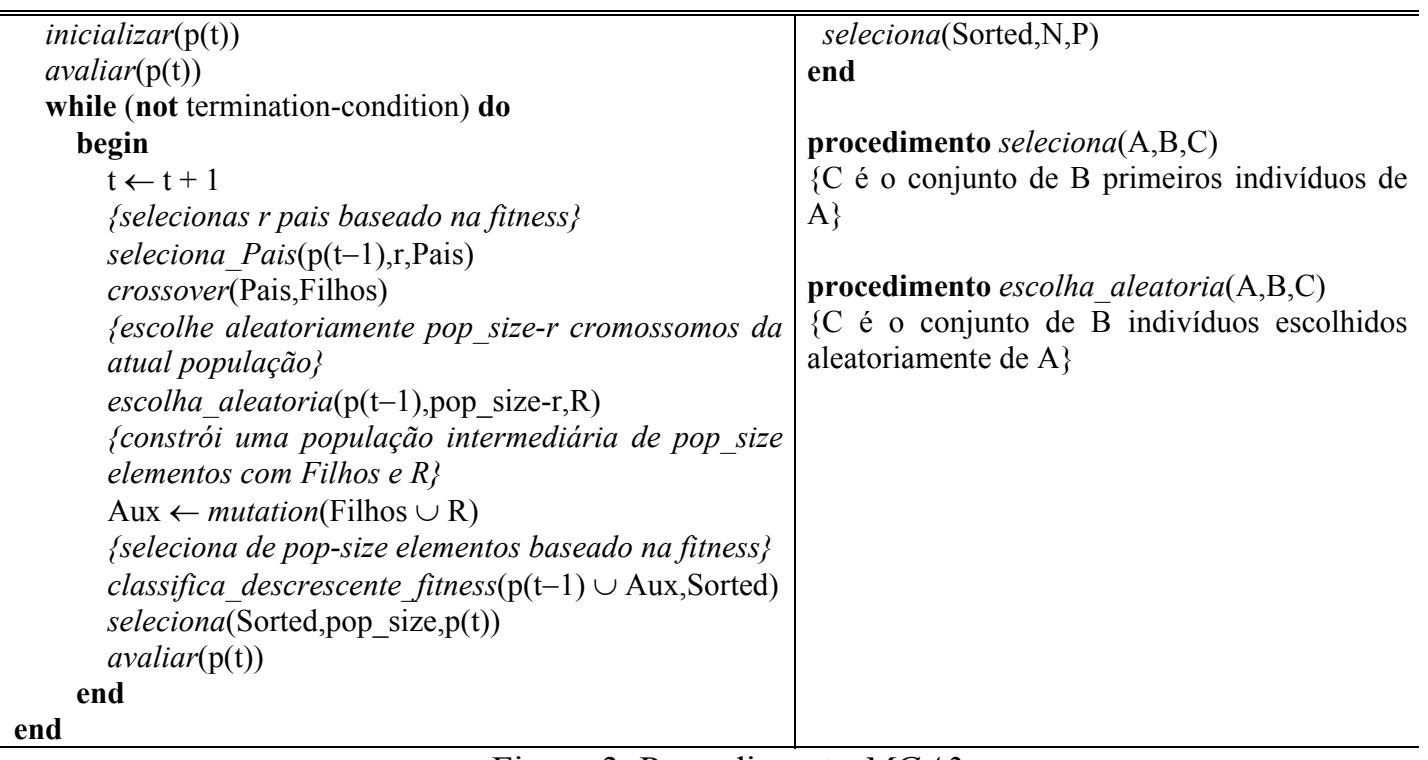

Figura 3. Procedimento $M G A 3$

\begin{tabular}{|c|c|}
\hline $\begin{array}{l}\text { procedimento } M G A 4 \\
\text { \{pop_size: tamanho da população } \\
\mathrm{p}_{\mathrm{c}} \text { : probabilidade de cruzamento } \\
\left.\mathrm{r}: \mathrm{p}_{\mathrm{c}} \times \text { pop_size }\right\} \\
\text { begin } \\
\mathrm{t} \leftarrow 0 \\
\text { inicializar }(\mathrm{p}(\mathrm{t})) \\
\text { avaliar }(\mathrm{p}(\mathrm{t})) \\
\text { while }(\mathbf{n o t} \text { termination-condition }) \mathrm{do} \\
\quad \text { begin } \\
\quad \mathrm{t} \leftarrow \mathrm{t}+1 \\
\quad\{\text { divide a população corrente, baseado na fitness, em } \\
\quad \text { um conjunto de } r \text { Pais e o resto, R\} } \\
\quad \text { seleciona_Pais }(\mathrm{p}(\mathrm{t}-1), \mathrm{r}, \text { Pais, } \mathrm{R}) \\
\quad \text { crossover }(\text { Pais,Filhos }) \\
\quad \text { Aux } \leftarrow \text { mutation }(\text { Filhos } \cup \mathrm{R}) \\
\quad\{\text { seleciona de pop-size elementos baseado na fitness\} } \\
\quad \text { classifica_descrescente_fitness }(\mathrm{p}(\mathrm{t}-1) \cup \text { Aux,Sorted }) \\
\quad \text { seleciona }(\text { Sorted,pop_size, } \mathrm{p}(\mathrm{t})) \\
\quad \text { avaliar }(\mathrm{p}(\mathrm{t})) \\
\quad \text { end } \\
\text { end }\end{array}$ & $\begin{array}{l}\text { procedimento seleciona_Pais(Pop,N,P,R) } \\
\text { \{Pop: população } \\
\text { N: inteiro tal que } \mathrm{N} \leq|\mathrm{Pop}| \\
\mathrm{P} \text { : Os } \mathrm{N} \text { melhores indivíduos de Pop } \\
\text { R: o restante }|\mathrm{Pop}|-\mathrm{N} \text { indivíduos de Pop }\} \\
\text { begin } \\
\text { classifica_descrescente_fitness(Pop,Sorted) } \\
\text { seleciona(Sorted,N,P,R) } \\
\text { end } \\
\text { procedimento seleciona(A,B,C) } \\
\{\text { C é o conjunto de B primeiros indivíduos de } \\
\text { A\} }\end{array}$ \\
\hline
\end{tabular}

Figura 4. Procedimento $M G A 4$

\begin{tabular}{|c|c|}
\hline $\begin{array}{l}\text { procedimento } M G A 5 \\
\text { \{pop_size: tamanho da população } \\
\text { número of Pais }-\mathrm{r}=2 \text { \} } \\
\text { begin } \\
\mathrm{t} \leftarrow 0 \\
\text { inicializar }(\mathrm{p}(\mathrm{t})) \\
\text { avaliar }(\mathrm{p}(\mathrm{t})) \\
\text { while }(\text { not termination-condition) do } \\
\text { begin } \\
\quad \mathrm{t} \leftarrow \mathrm{t}+1 \\
\quad\{\text { seleciona de } \mathrm{r} \text { Pais }- \text { substituição steady-state } \\
\quad \text { seleciona_Pais }(\mathrm{p}(\mathrm{t}-1), \mathrm{r}, \text { Pais,Piores_Candidatos }) \\
\quad \text { crossover(Pais,Filhos) } \\
\quad \text { Set_of_2r } \leftarrow \text { Piores_Candidatos } \cup \text { Filhos } \\
\text { classifica descrescente fitness }(\text { Set of } 2 \mathrm{r}, \text { New set o }\end{array}$ & $\begin{array}{l}\text { procedimento seleciona_Pais(Pop,N,P,U) } \\
\text { \{Pop: população } \\
\mathrm{N} \text { : inteiro tal que } \mathrm{N} \leq|\mathrm{Pop}| \\
\mathrm{P} \text { : Os } \mathrm{N} \text { melhores indivíduos de Pop\} } \\
\text { begin } \\
\text { classifica_descrescente_fitness(Pop,Sorted) } \\
\text { seleciona(Sorted,N,P) } \\
\text { seleciona(inv(Sorted),N,U) } \\
\text { end } \\
\text { procedimento seleciona(A,B,C,D) } \\
\text { \{transfere os primeiros elementos de A a C } \\
\text { e os elementos restante a D } \\
\text { procedimento } \operatorname{inv}(\mathrm{L})\end{array}$ \\
\hline
\end{tabular}




\begin{tabular}{|c|c|}
\hline $\begin{array}{l}\text { f_2r }) \\
\text { seleciona }(\text { New_set_of_2r,r,Melhor_r,Pior_r }) \\
\text { Aux } \leftarrow \mathrm{p}(\mathrm{t}-1)-\text { Piores_Candidatos } \\
\text { Pop } \leftarrow \text { Aux } \cup \text { Best_r } \\
\mathrm{p}(\mathrm{t}) \leftarrow \text { mutation }(\text { Pop }) \\
\text { avaliar }(\mathrm{p}(\mathrm{t})) \\
\text { end }\end{array}$ & $\{$ inverte a ordem de $\mathrm{L}\}$ \\
\hline
\end{tabular}

Figura 5. Procedimento $M G A 5$

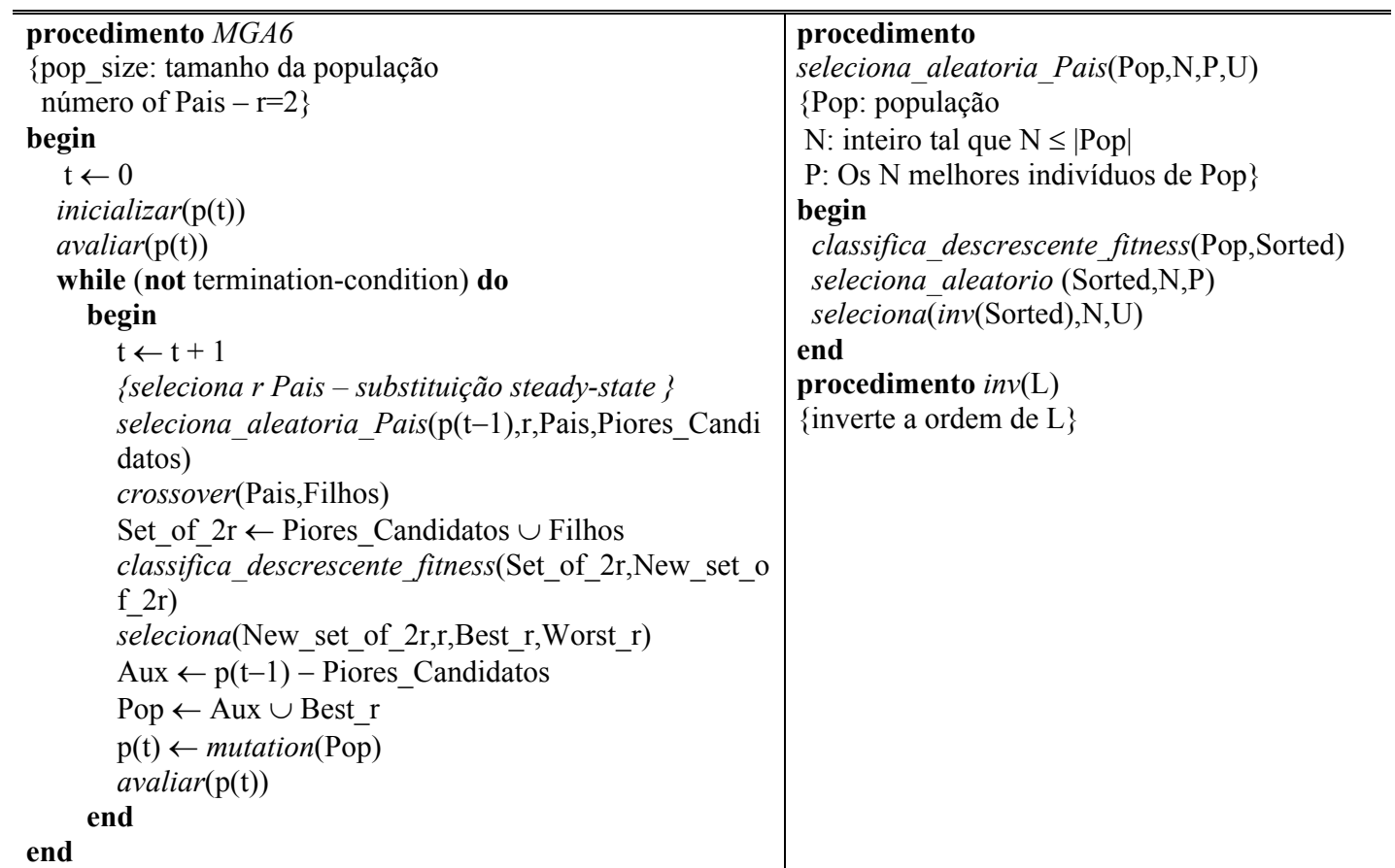

Figura 6. Procedimento $M G A 6$

\begin{tabular}{|c|c|}
\hline 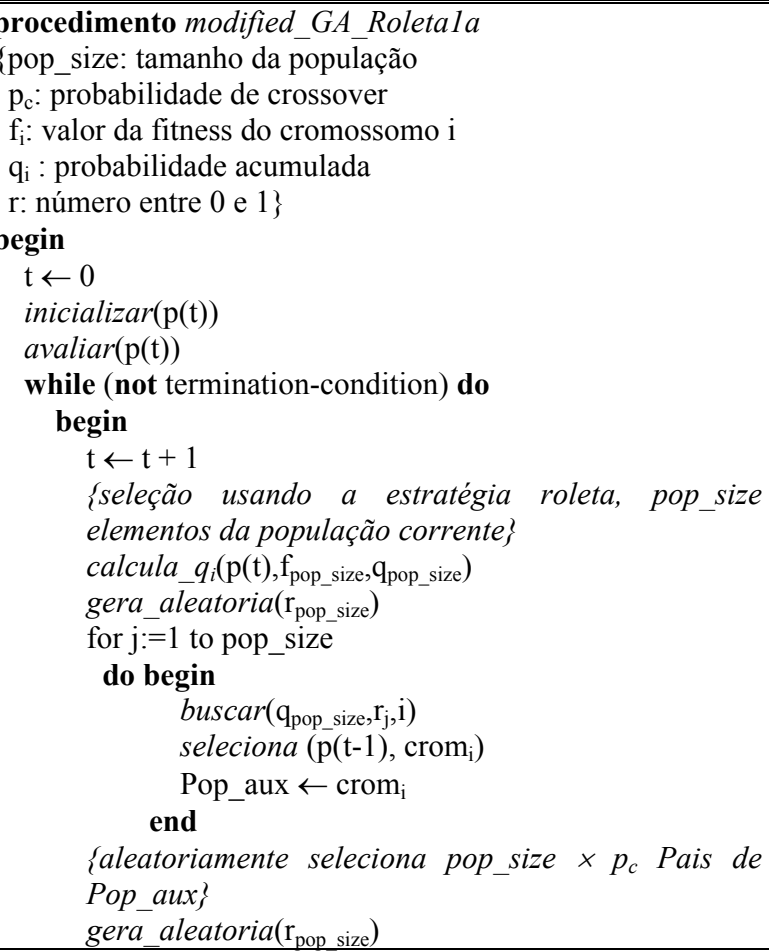 & 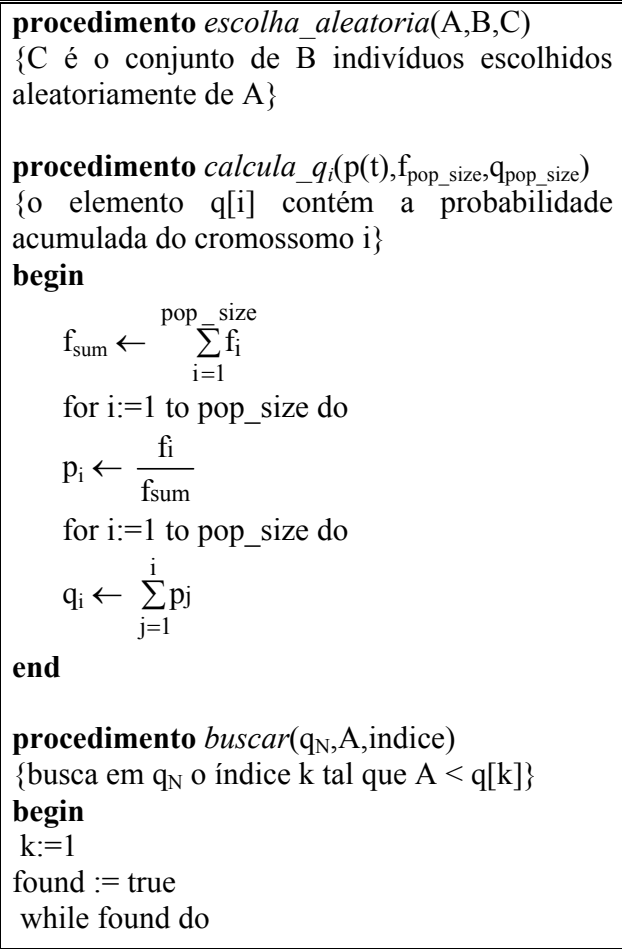 \\
\hline
\end{tabular}




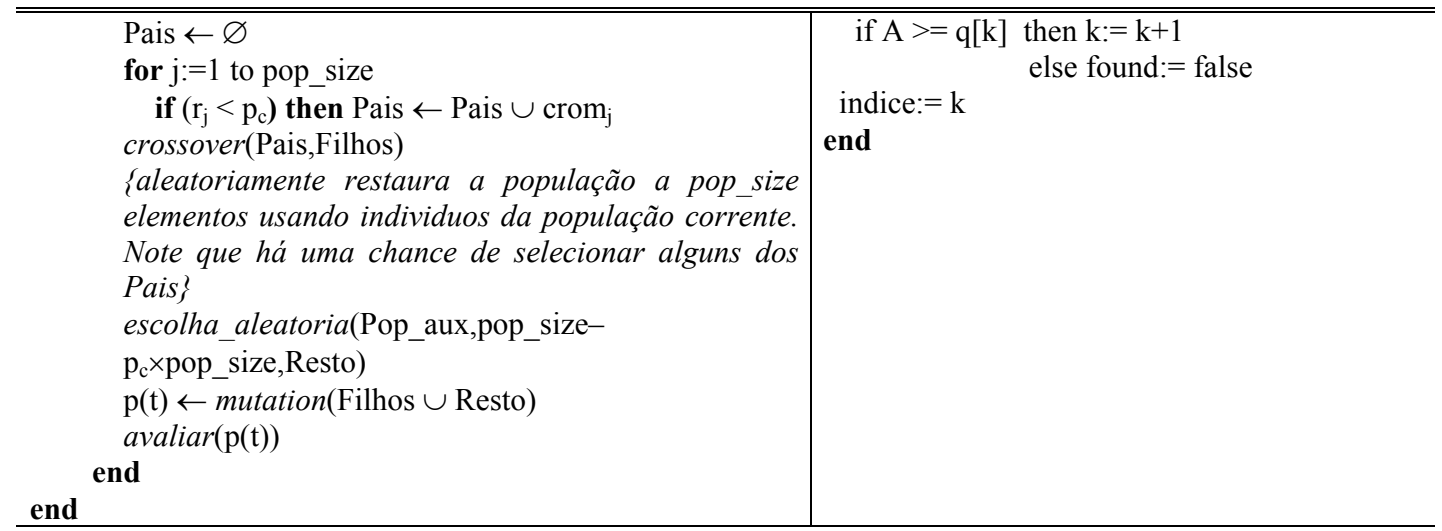

Figura 7. Procedimento modified_Roletala

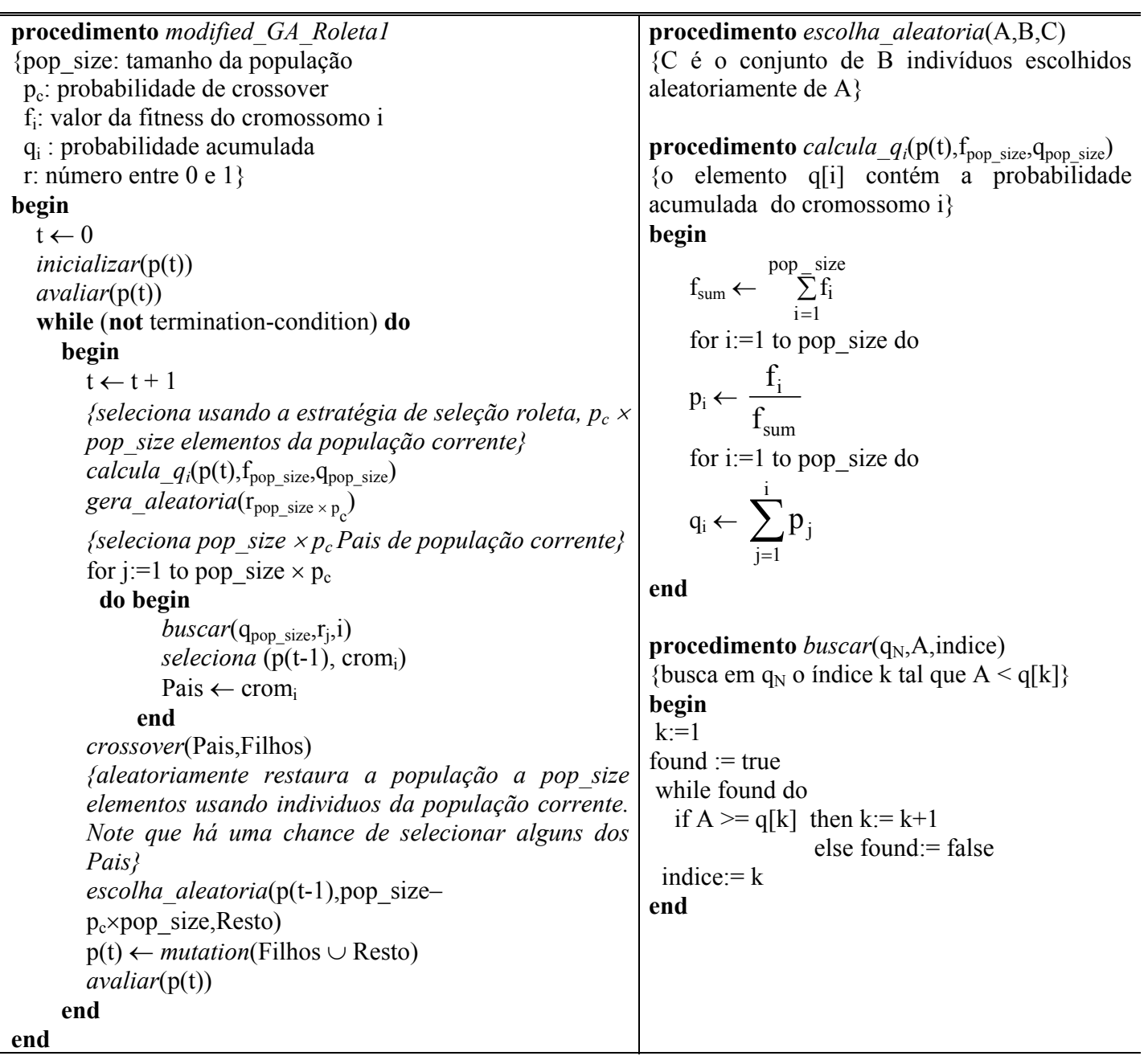

Figura 8. Procedimento modified_Roletal

\begin{tabular}{|c|c|}
\hline $\begin{array}{l}\text { procedimento } \text { modified_GA_Roleta2a } \\
\text { \{pop_size: tamanho da população } \\
\mathrm{p}_{\mathrm{c}}: \text { probabilidade de crossover } \\
\mathrm{f}_{\mathrm{i}}: \text { valor da fitness do cromossomo i } \\
\mathrm{q}_{\mathrm{i}}: \text { probabilidade acumulada } \\
\text { r: número entre } 0 \text { e } 1 \text { \} } \\
\text { begin } \\
\quad \mathrm{t} \leftarrow 0 \\
\text { inicializar }(\mathrm{p}(\mathrm{t}))\end{array}$ & $\begin{array}{l}\text { procedimento escolha_aleatoria }(\mathrm{A}, \mathrm{B}, \mathrm{C}) \\
\{\mathrm{C} \text { é o conjunto de } \mathrm{B} \text { indivíduos escolhidos } \\
\text { aleatoriamente de } \mathrm{A}\} \\
\text { procedimento } \text { calcula_q } q_{i}\left(\mathrm{p}(\mathrm{t}), \mathrm{f}_{\mathrm{pop} \_ \text {size }}, \mathrm{q}_{\mathrm{pop} \text { size }}\right) \\
\{\mathrm{o} \text { elemento } \mathrm{q}[\mathrm{i}] \text { contém a probabilidade } \\
\text { acumulada do cromossomo i\} } \\
\text { begin }\end{array}$ \\
\hline
\end{tabular}




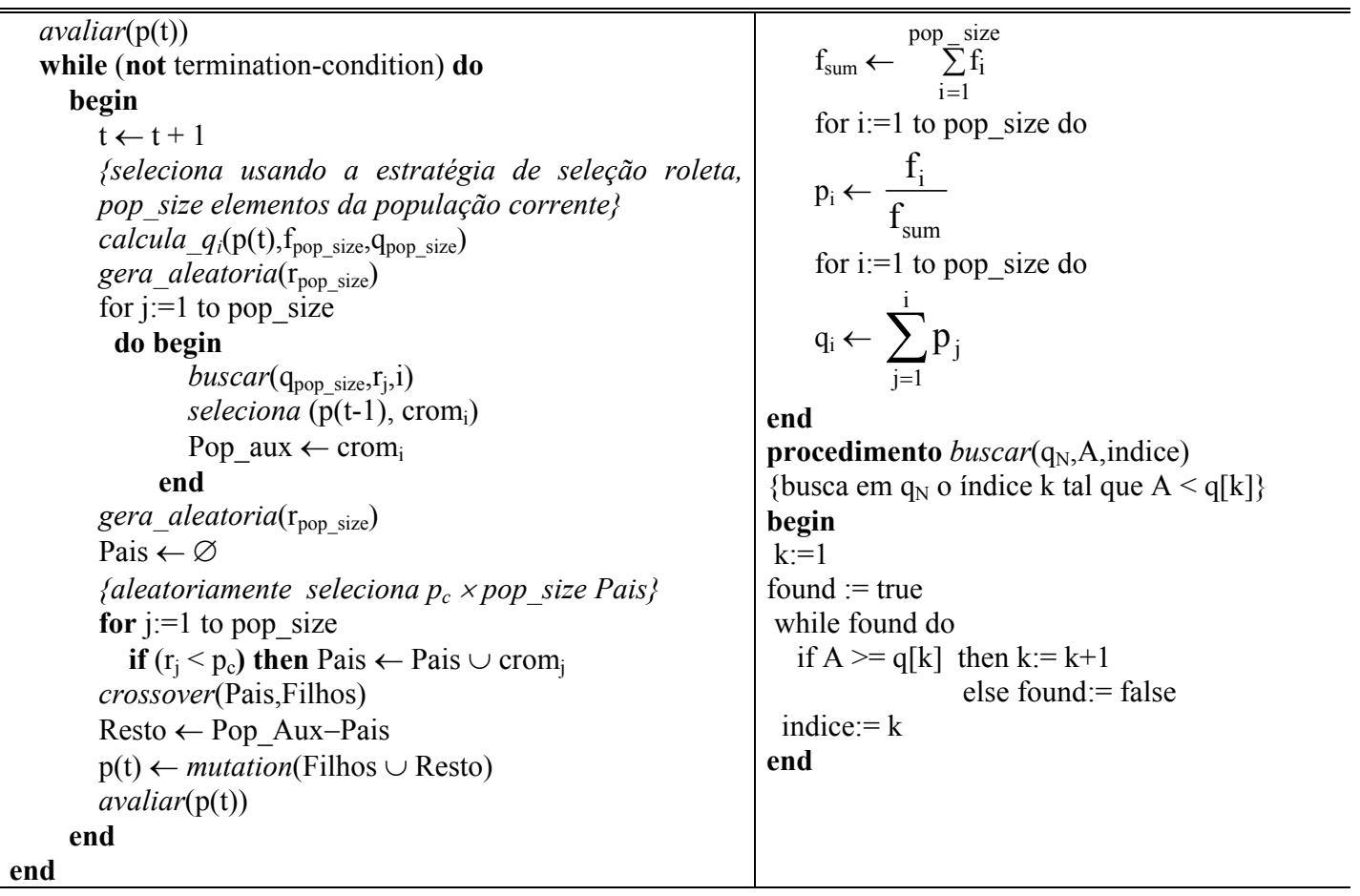

Figura 9. Procedimento modified_Roleta2a

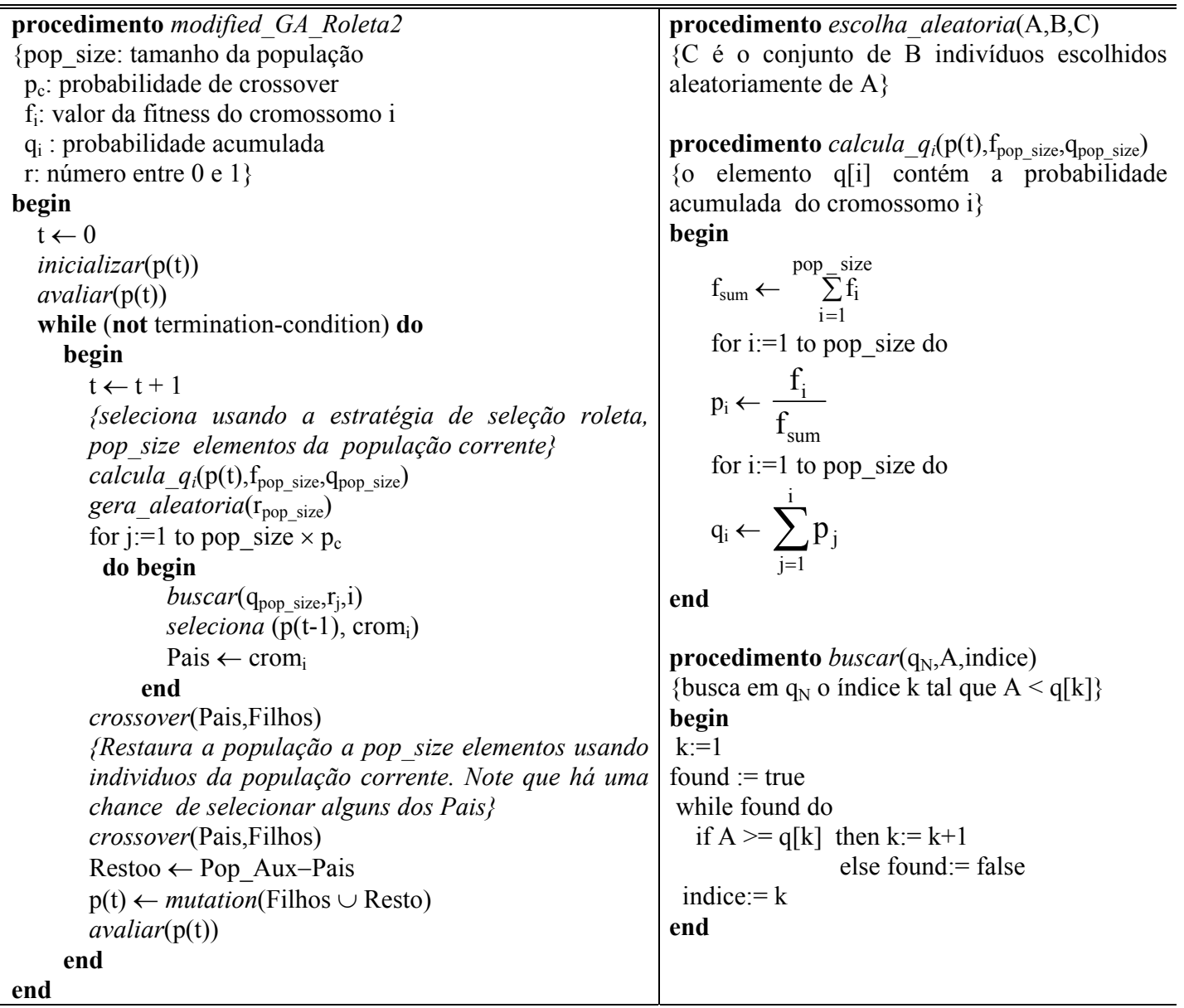

Figura 10. Procedimento modified_Roleta 2 


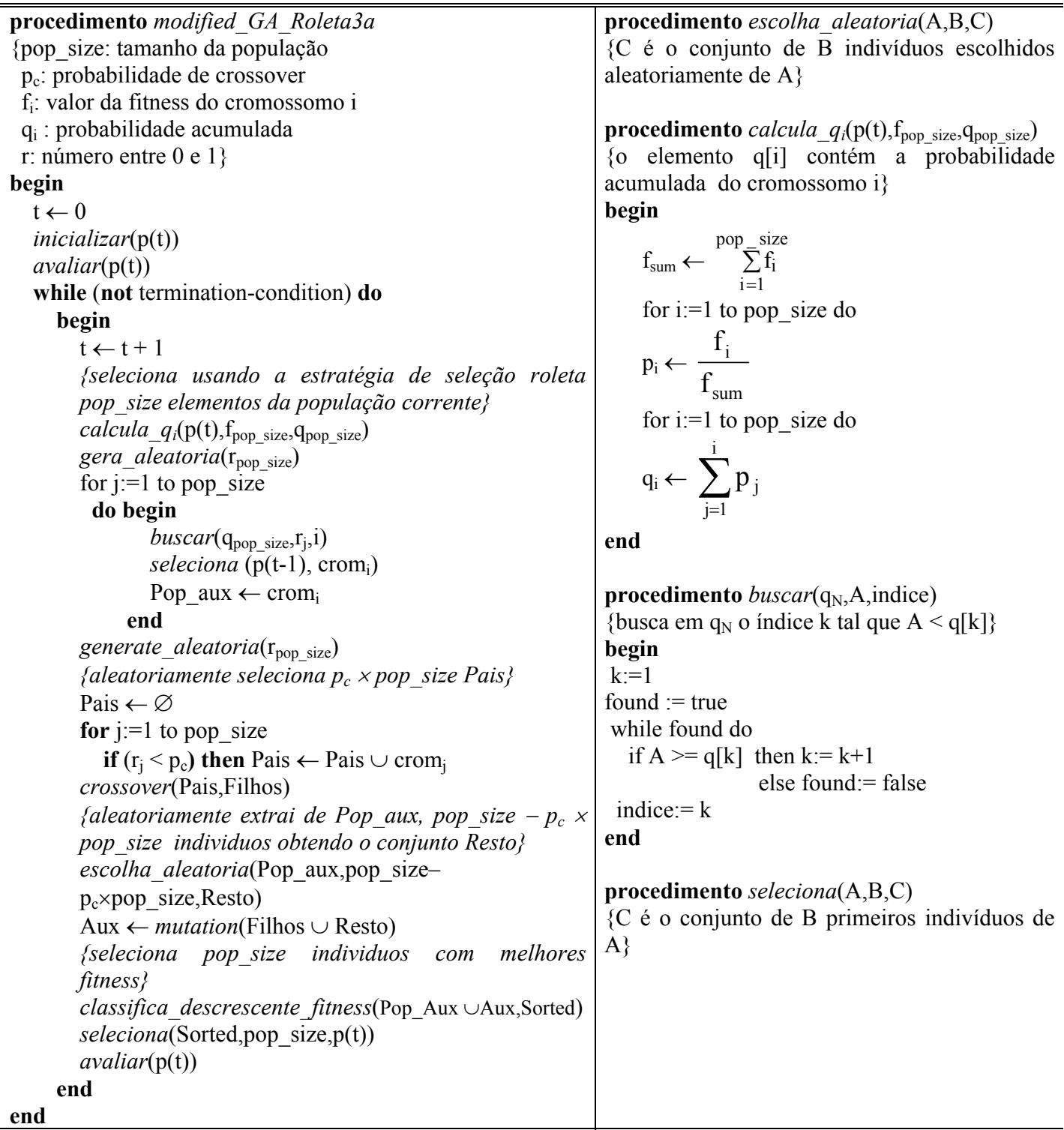

Figura 11. Procedimento modified_Roleta3a

\begin{tabular}{|c|c|}
\hline 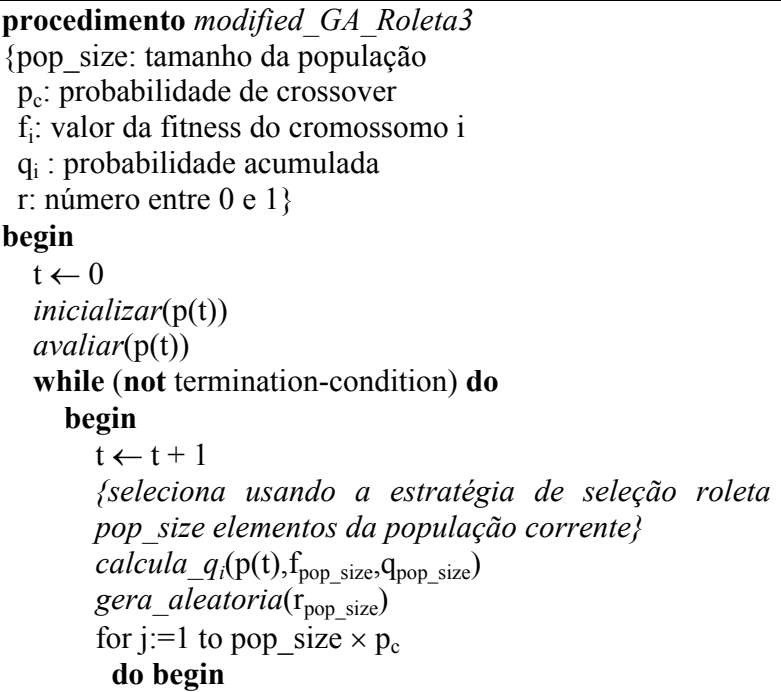 & 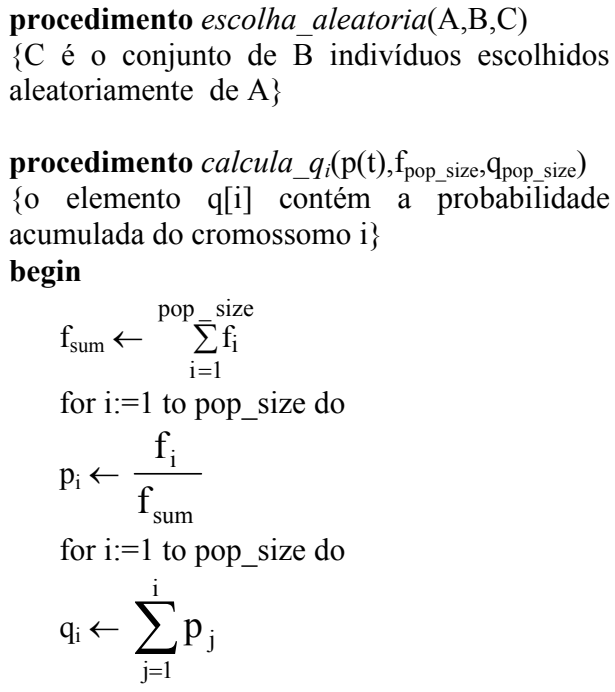 \\
\hline
\end{tabular}




\begin{tabular}{|c|c|}
\hline 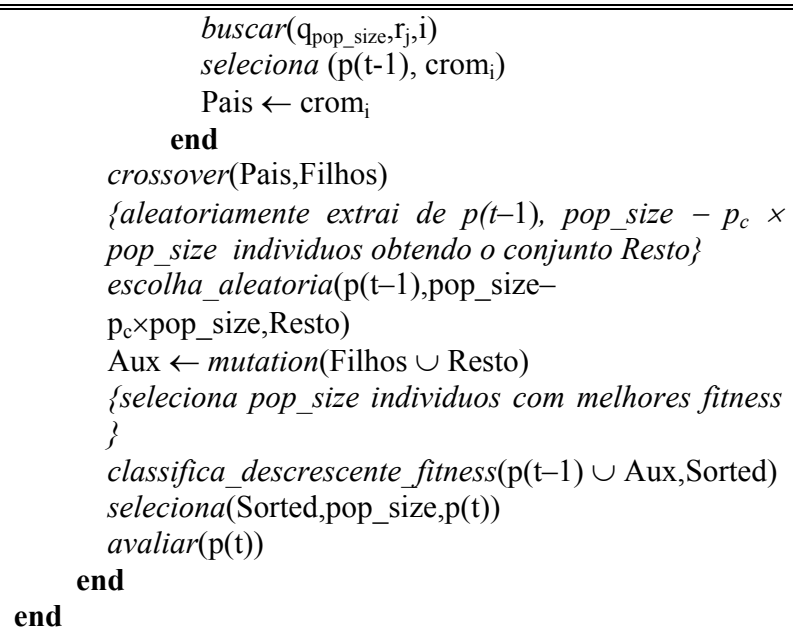 & $\begin{array}{l}\text { end } \\
\text { procedimento } \operatorname{buscar}\left(\mathrm{q}_{\mathrm{N}}, \mathrm{A} \text {,indice }\right) \\
\left\{\text { busca em } \mathrm{q}_{\mathrm{N}} \mathrm{O} \text { índice } \mathrm{k} \text { tal que } \mathrm{A}<\mathrm{q}[\mathrm{k}]\right\} \\
\text { begin } \\
\mathrm{k}:=1 \\
\text { found }:=\text { true } \\
\text { while found do } \\
\quad \text { if } \mathrm{A}>=\mathrm{q}[\mathrm{k}] \text { then } \mathrm{k}:=\mathrm{k}+1 \\
\quad \text { else found:= false } \\
\text { indice: }=\mathrm{k} \quad \text { end } \\
\text { procedimento seleciona }(\mathrm{A}, \mathrm{B}, \mathrm{C}) \\
\{\mathrm{C} \text { é o conjunto de B primeiros indivíduos de } \\
\mathrm{A}\}\end{array}$ \\
\hline
\end{tabular}

Figura 12 Procedimento modified_Roleta 3

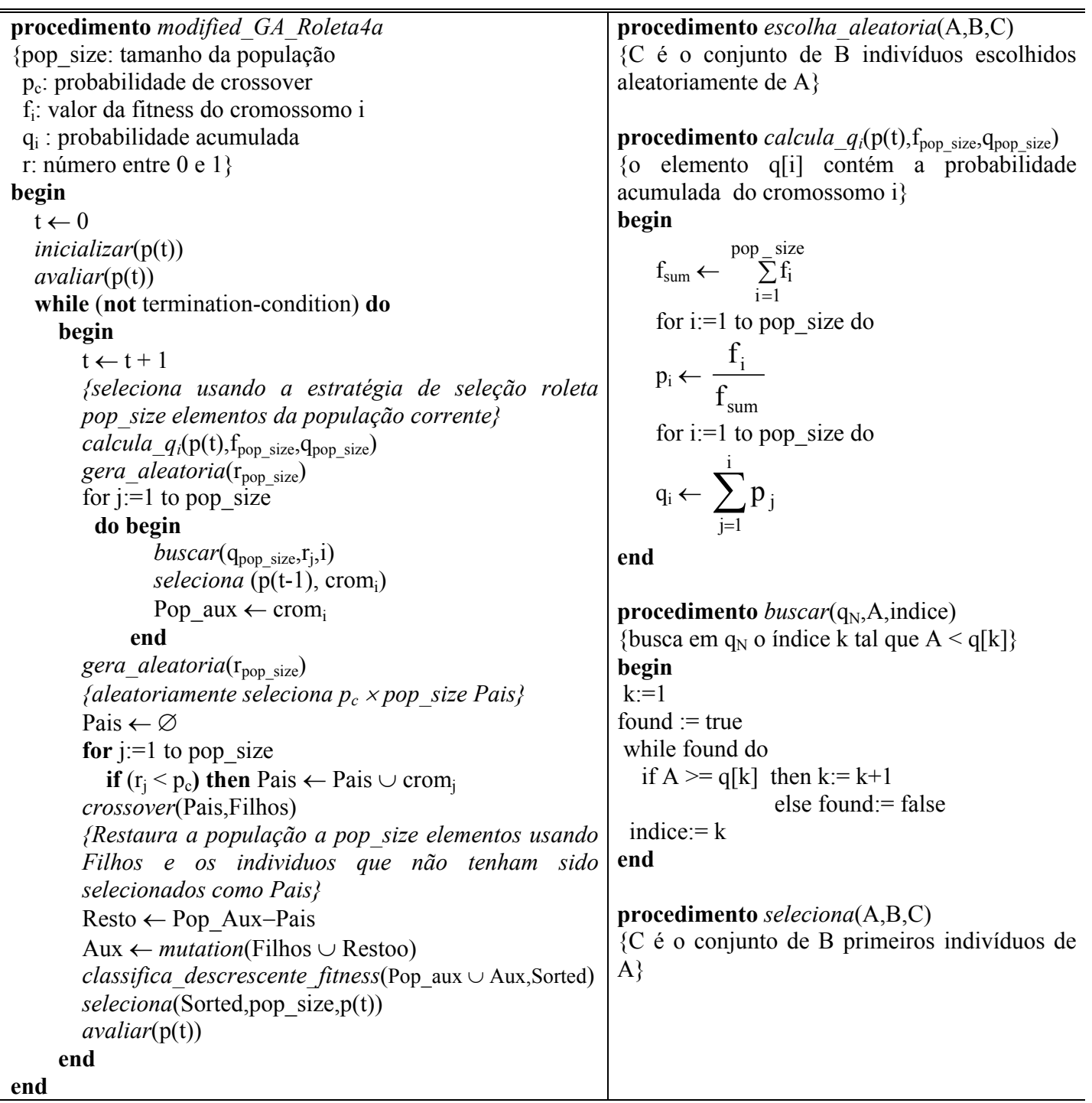




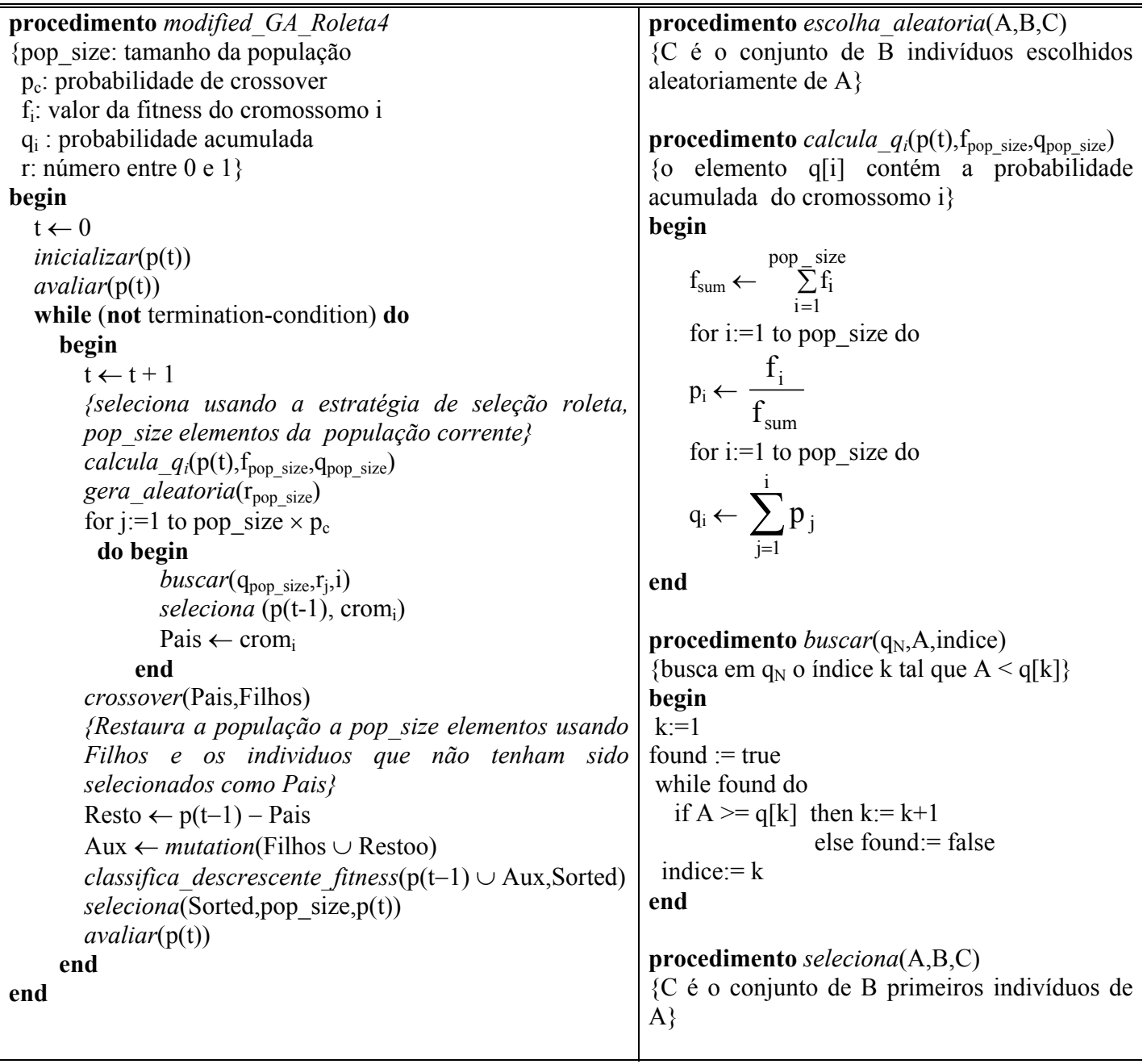

Figura 14. Procedimento modified_Roleta4

\begin{tabular}{|c|c|}
\hline 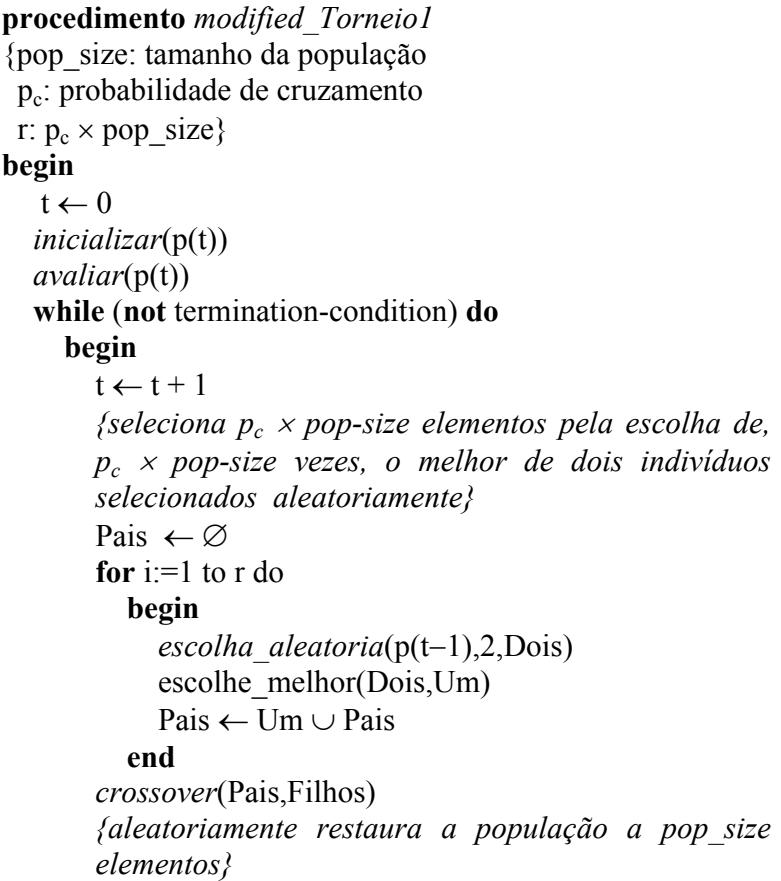 & $\begin{array}{l}\text { procedimento seleciona_Pais(Pop,N,P,U) } \\
\text { \{Pop: população } \\
\mathrm{N} \text { : inteiro tal que } \mathrm{N} \leq|\mathrm{Pop}| \\
\mathrm{P} \text { : Os } \mathrm{N} \text { melhores indivíduos de Pop\} } \\
\text { begin } \\
\text { classifica_descrescente_fitness(Pop,Sorted) } \\
\text { seleciona(Sorted,N,P) } \\
\text { seleciona(inv(Sorted),N,U) } \\
\text { end } \\
\text { procedimento seleciona(A,B,C,D) } \\
\text { \{transfere os primeiros elementos de A a C } \\
\text { e os elementos restante ao D } \\
\text { procedimento } \text { inv }(\mathrm{L}) \\
\text { \{inverte a ordem de } \mathrm{L}\}\end{array}$ \\
\hline
\end{tabular}


escolha aleatoria $(\mathrm{p}(\mathrm{t}-1)$,pop size $-\mathrm{r}$,Resto $)$

$\mathrm{p}(\mathrm{t}) \leftarrow \overline{\text { mutation }}($ Filhos $\cup$ Resto $)$

$\operatorname{avaliar}(\mathrm{p}(\mathrm{t}))$

end

end

Figura 15. Procedimento modified_Torneio1

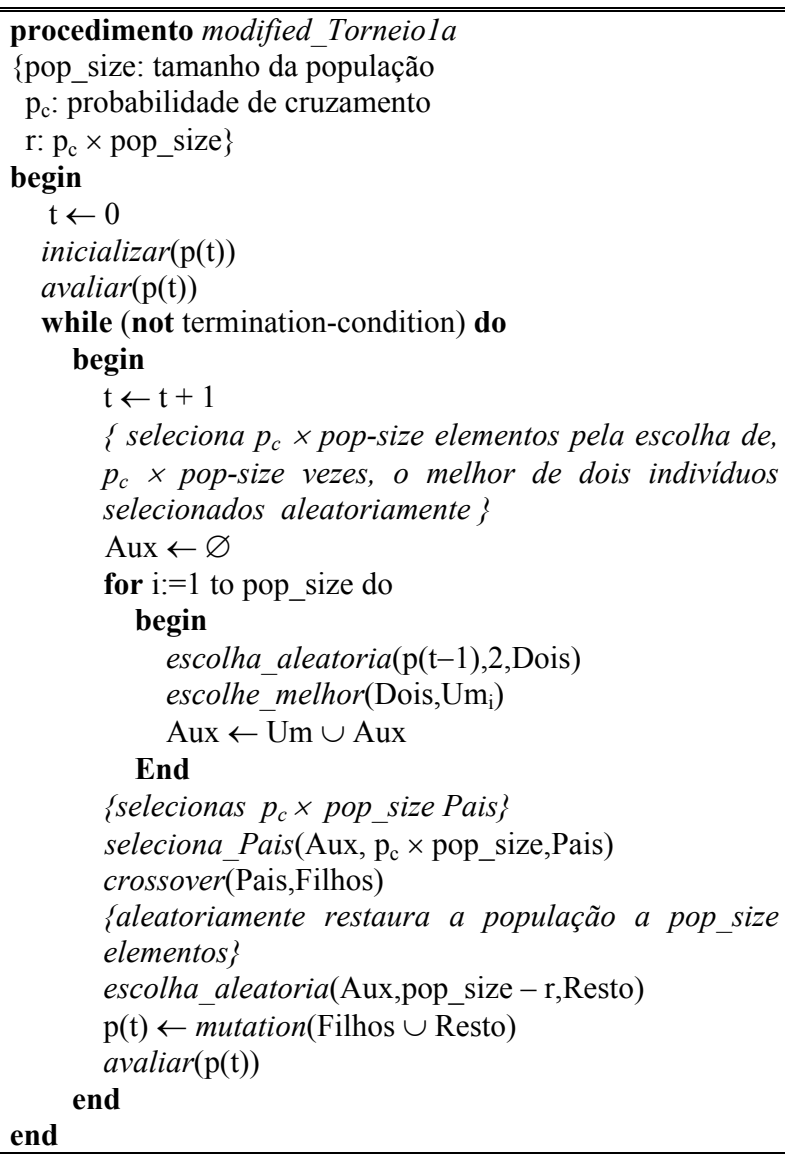

procedimento seleciona Pais(Pop,N,P,U)

\{Pop: população

$\mathrm{N}$ : inteiro tal que $\mathrm{N} \leq|\mathrm{Pop}|$

$\mathrm{P}$ : Os $\mathrm{N}$ melhores indivíduos de Pop\}

begin

classifica descrescente fitness(Pop,Sorted)

seleciona $($ Sorted,N,P)

seleciona (inv(Sorted), N,U)

end

procedimento seleciona (A,B,C,D)

\{transfere os primeiros elementos de $\mathrm{A}$ a $\mathrm{C}$

e os elementos restante ao $\mathrm{D}\}$

procedimento $\operatorname{inv}(\mathrm{L})$

\{inverte a ordem de $\mathrm{L}$ \}

Figura 16. Procedimento modified_Torneiola

\begin{tabular}{|c|c|}
\hline $\begin{array}{l}\text { procedimento } \text { modified_Torneio } 2 \\
\text { \{pop_size: tamanho da população } \\
\mathrm{p}_{\mathrm{c}} \text { : probabilidade de cruzamento } \\
\mathrm{r}: \mathrm{p}_{\mathrm{c}} \times \text { pop_size } \\
\text { begin } \\
\mathrm{t} \leftarrow 0 \\
\text { inicializar }(\mathrm{p}(\mathrm{t})) \\
\text { avaliar }(\mathrm{p}(\mathrm{t})) \\
\text { while }(\mathbf{n o t} \text { termination-condition) do } \\
\text { begin } \\
\mathrm{t} \leftarrow \mathrm{t}+1 \\
\left\{\text { seleciona } p_{c} \times \text { pop-size elementos pela escolha de, }\right. \\
\quad p_{c} \times \text { pop-size vezes, o melhor de dois individuos } \\
\quad \text { selecionados aleatoriamente }\} \\
\quad \text { Pais } \leftarrow \varnothing \\
\quad \text { for } \mathrm{i}:=1 \text { to } \mathrm{r} \text { do } \\
\quad \text { begin }\end{array}$ & $\begin{array}{l}\text { procedimento seleciona_Pais(Pop,N,P,U) } \\
\text { \{Pop: população } \\
\mathrm{N} \text { : inteiro tal que } \mathrm{N} \leq|\mathrm{Pop}| \\
\mathrm{P} \text { : Os } \mathrm{N} \text { melhores indivíduos de Pop\} } \\
\text { begin } \\
\text { classifica_descrescente_fitness(Pop,Sorted) } \\
\text { seleciona(Sorted,N,P) } \\
\text { seleciona(inv(Sorted),N,U) } \\
\text { end } \\
\text { procedimento seleciona(A,B,C,D) } \\
\text { \{transfere os primeiros elementos de A a C } \\
\text { e os elementos restante a D } \\
\text { procedimento inv }(\mathrm{L}) \\
\text { inverte a ordem de L }\end{array}$ \\
\hline
\end{tabular}




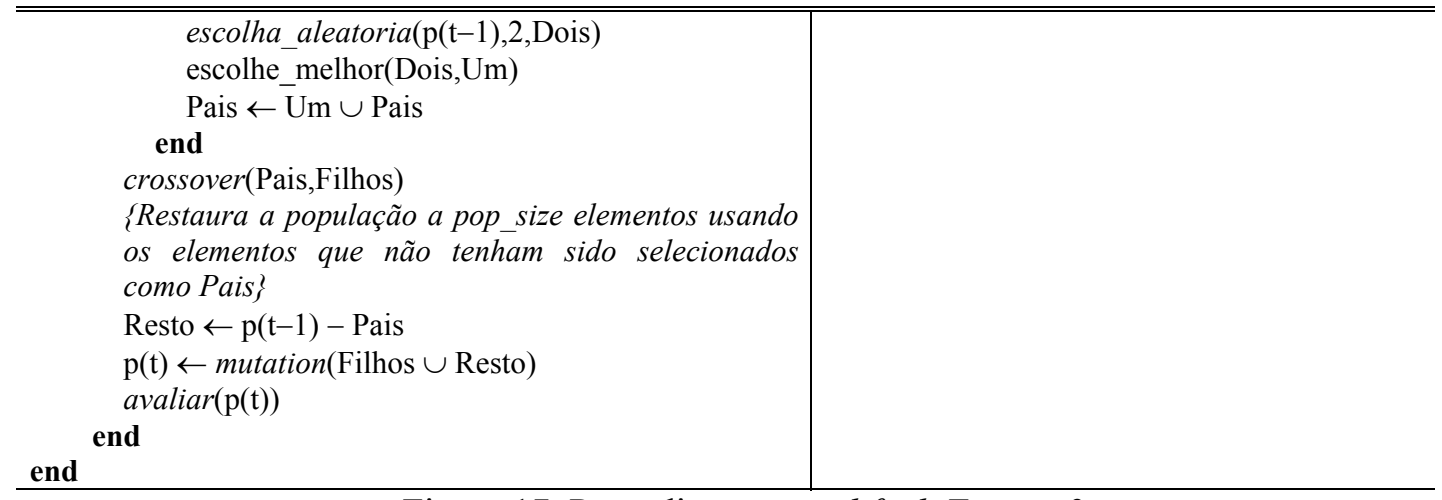

Figura 17. Procedimento modified_Torneio2

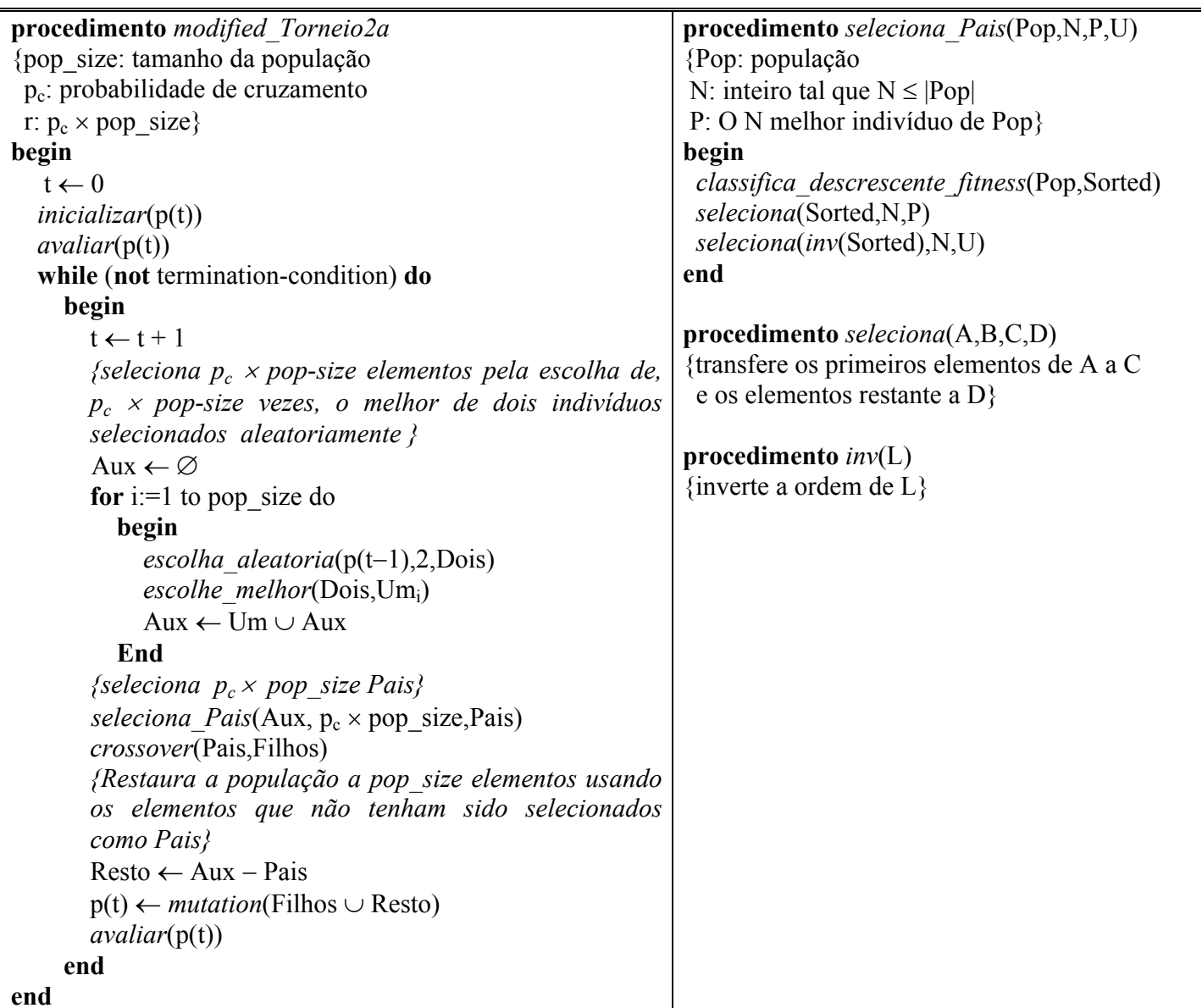

Figura 18. Procedimento modified_Torneio2a

\begin{tabular}{|c|c|}
\hline $\begin{array}{l}\text { procedimento } \text { modified_Torneio } 3 \\
\text { \{pop_size: tamanho da população } \\
\mathrm{p}_{\mathrm{c}} \text { : probabilidade de cruzamento } \\
\mathrm{r}: \mathrm{p}_{\mathrm{c}} \times \text { pop_size } \\
\text { begin } \\
\quad \mathrm{t} \leftarrow 0 \\
\text { initializar }(\mathrm{p}(\mathrm{t})) \\
\text { avaliar }(\mathrm{p}(\mathrm{t})) \\
\text { while }(\text { not termination-condition) do } \\
\quad \text { begin }\end{array}$ & $\begin{array}{l}\text { procedimento seleciona_Pais(Pop,N,P,U) } \\
\text { \{Pop: população } \\
\mathrm{N} \text { : inteiro tal que } \mathrm{N} \leq|\mathrm{Pop}| \\
\mathrm{P} \text { : Os } \mathrm{N} \text { melhores indivíduos de Pop }\} \\
\text { begin } \\
\text { classifica_descrescente_fitness(Pop,Sorted) } \\
\text { seleciona_aleatoria }(\text { Sorted,N,P) } \\
\text { seleciona(inv(Sorted),N,U) } \\
\text { end } \\
\text { procedimento } \operatorname{inv}(\mathrm{L})\end{array}$ \\
\hline
\end{tabular}


$\mathrm{t} \leftarrow \mathrm{t}+1$

\{inverte a ordem de L\}

$\left\{\right.$ seleciona $p_{c} \times$ pop-size elementos pela escolha de,

$p_{c} \times$ pop-size vezes, o melhor de dois individuos

selecionados aleatoriamente\}

for $i:=1$ to $r$ do

begin

escolha_aleatoria $(\mathrm{p}(\mathrm{t}-1), 2$, Dois $)$

escolhe_melhor(Dois,Um)

Pais $\leftarrow \overline{\mathrm{Um}} \cup$ Pais

end

crossover(Pais,Filhos)

\{aleatoriamente escolhe da população corrente,

pop_size $-r$ individuos)

escolha_aleatoria $(\mathrm{p}(\mathrm{t}-1)$,pop_size-r,Resto $)$

Aux $\leftarrow$ mutation (Filhos $\cup$ Resto)

\{seleciona os melhores pop_size elementos\}

classifica_descrescente fitness $(\mathrm{p}(\mathrm{t}-1) \cup$ Aux,Sorted $)$

seleciona $($ Sorted,pop_size,p $(\mathrm{t}))$

$\operatorname{avaliar}(\mathrm{p}(\mathrm{t}))$

end

end

Figura 19. Procedimento modified_Torneio3

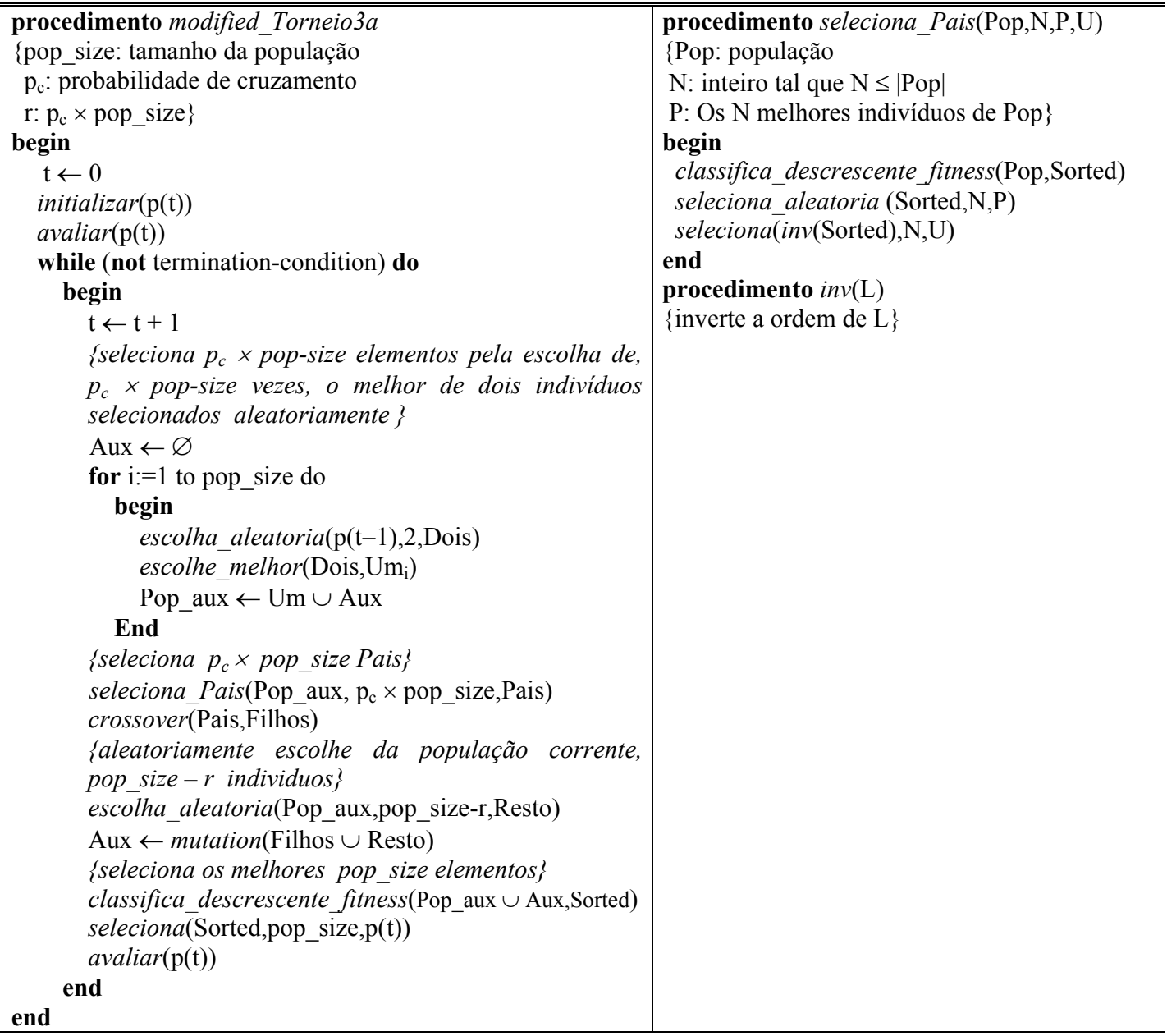

Figura 20. Procedimento modified_Torneio3a 


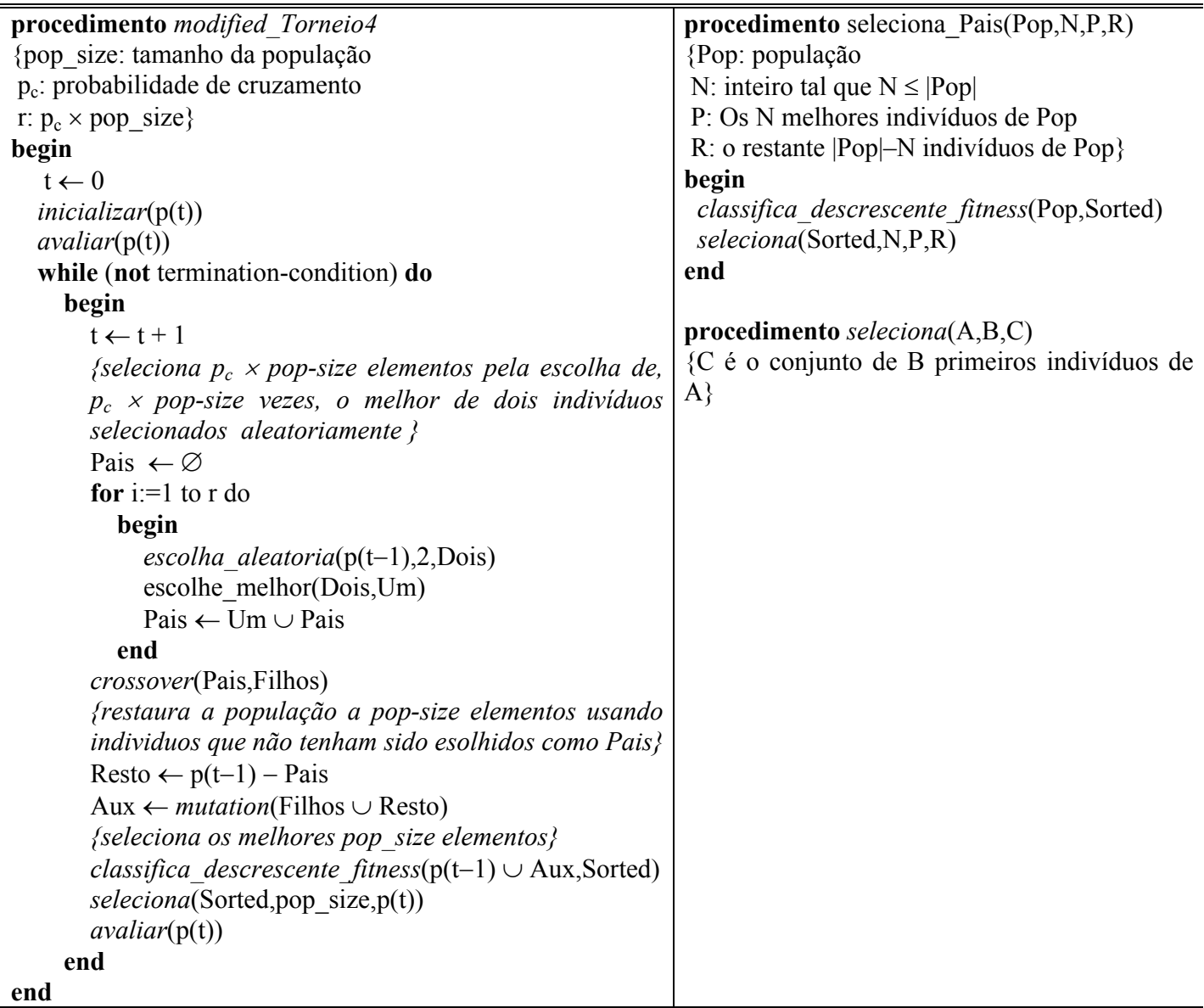

Figura 21. Procedimento modified_Torneio 4

\begin{tabular}{|c|c|}
\hline 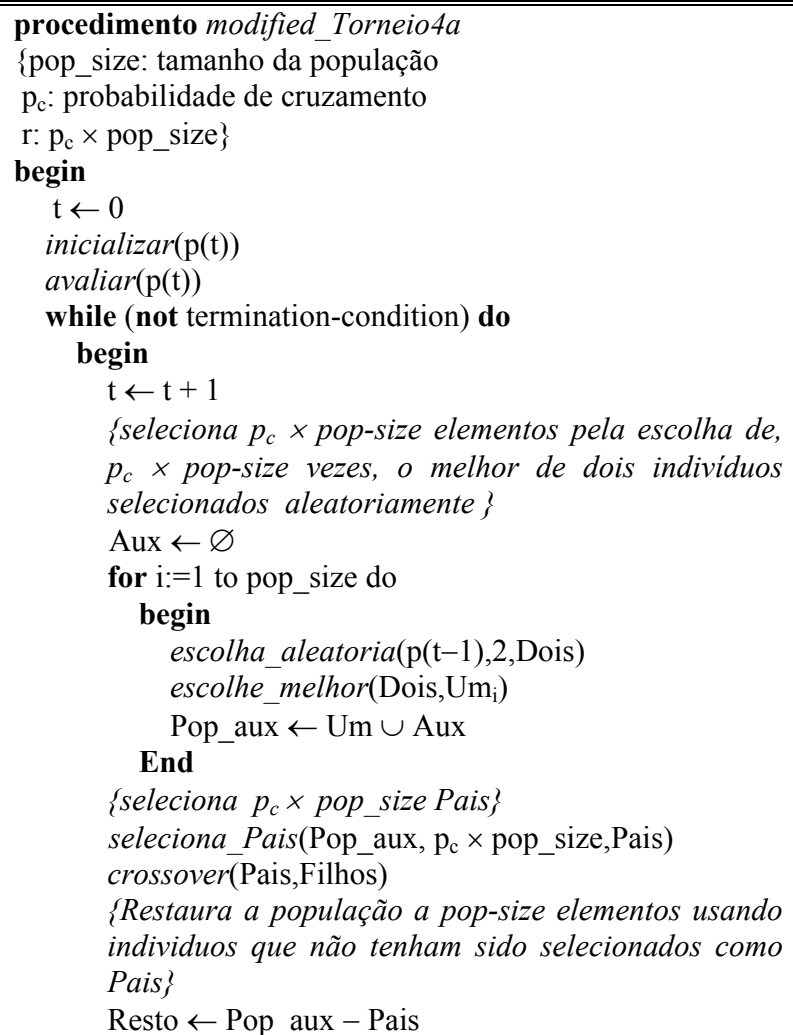 & $\begin{array}{l}\text { procedimento seleciona_Pais(Pop,N,P,R) } \\
\text { \{Pop: população } \\
\mathrm{N} \text { : inteiro tal que } \mathrm{N} \leq|\mathrm{Pop}| \\
\mathrm{P} \text { : Os } \mathrm{N} \text { melhores indivíduos de Pop } \\
\text { R: o restante }|\mathrm{Pop}|-\mathrm{N} \text { indivíduos de Pop } \\
\text { begin } \\
\text { classifica_descrescente fitness(Pop,Sorted) } \\
\text { seleciona(Sorted,N,P,R) } \\
\text { end } \\
\text { procedimento seleciona(A,B,C) } \\
\{\mathrm{C} \text { é o conjunto de B primeiros indivíduos de } \\
\text { A } \text { \} }\end{array}$ \\
\hline
\end{tabular}




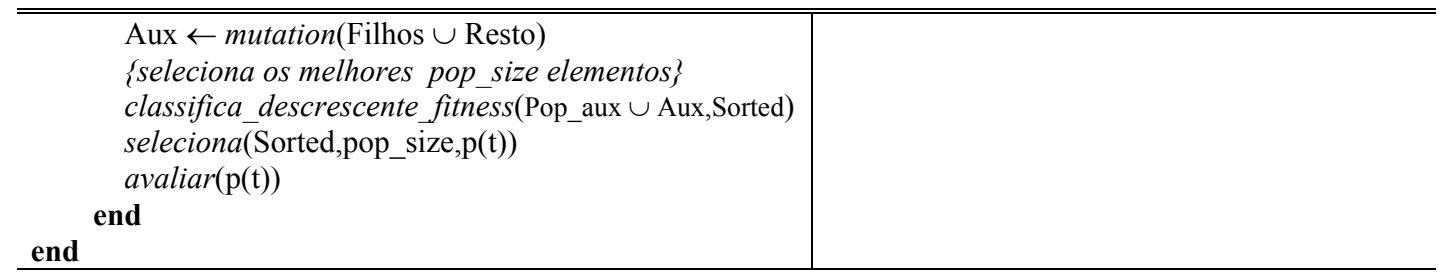

Figura 22. Procedimento modified_Torneio $4 a$

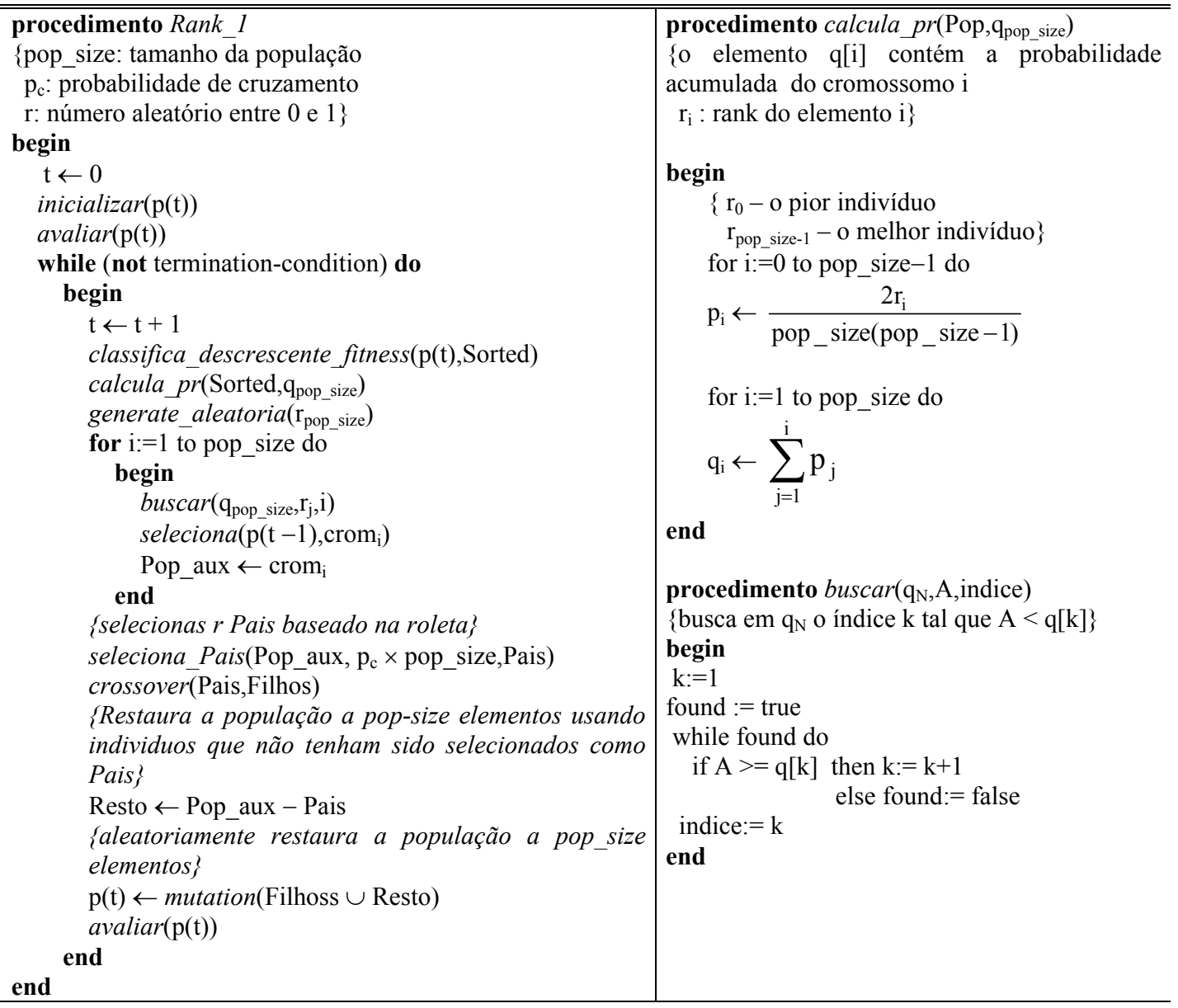

Figura 23. Procedimento Rank_l

\begin{tabular}{|c|c|}
\hline 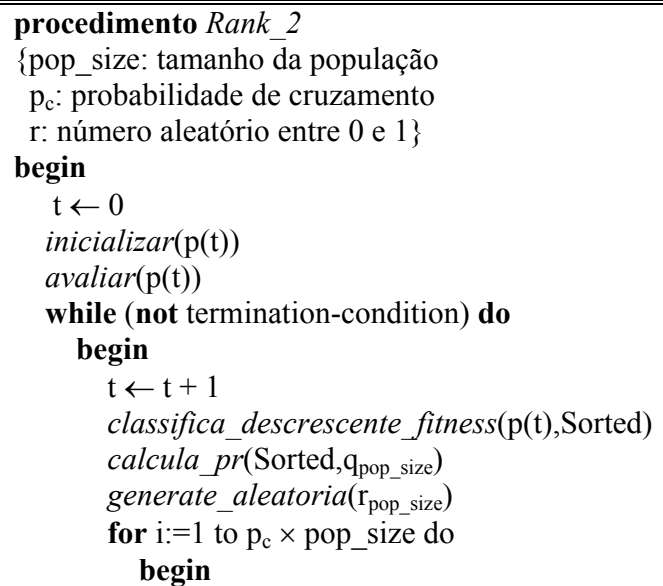 & $\begin{array}{l}\text { procedimento calcula_pr }\left(\mathrm{Pop}, \mathrm{q}_{\mathrm{pop} \_s i z e}\right) \\
\{\mathrm{o} \text { elemento } \mathrm{q}[\mathrm{i}] \text { contém a probabilidade } \\
\text { acumulada do cromossomo } \mathrm{i} \\
\left.\mathrm{r}_{\mathrm{i}} \text { : rank do elemento } \mathrm{i}\right\} \\
\text { begin } \\
\quad\left\{\mathrm{r}_{0}-\mathrm{o} \text { pior indivíduo }\right. \\
\left.\quad \mathrm{r}_{\mathrm{pop} \_ \text {size- }-1}-\mathrm{o} \text { melhor indivíduo }\right\} \\
\quad \text { for } \mathrm{i}:=0 \text { to pop_size-1 do } \\
\quad \mathrm{p}_{\mathrm{i}} \leftarrow \frac{2 \mathrm{r}_{\mathrm{i}}}{\text { pop_size }\left(\mathrm{pop}_{-} \text {size }-1\right)} \\
\quad \text { for } \mathrm{i}:=1 \text { to pop_size do }\end{array}$ \\
\hline
\end{tabular}




\begin{tabular}{|c|c|}
\hline $\begin{array}{l}\text { buscar }\left(\mathrm{q}_{\mathrm{pop} \_ \text {size, }} \mathrm{r}_{\mathrm{j}}, \mathrm{i}\right) \\
\text { seleciona }\left(\mathrm{p}(\mathrm{t}-1), \mathrm{crom}_{\mathrm{i}}\right) \\
\quad \text { Pais } \leftarrow \operatorname{crom} \mathrm{i} \\
\text { end } \\
\text { crossover(Pais,Filhos }) \\
\text { \{aleatoriamente Restaura a população a pop_size } \\
\text { elementos\} } \\
\text { escolha_aleatoria }\left(\mathrm{p}(\mathrm{t}-1), \text { pop_size- } \mathrm{p}_{\mathrm{c}} \times\right. \\
\text { pop_size,Resto }) \\
\mathrm{p}(\mathrm{t}) \leftarrow \text { mutation }(\text { Filhoss } \cup \text { Resto }) \\
\text { avaliar }(\mathrm{p}(\mathrm{t})) \\
\text { end }\end{array}$ & $\begin{array}{l}\quad \mathrm{q}_{\mathrm{i}} \leftarrow \sum_{\mathrm{j}=1}^{\mathrm{i}} \mathrm{p}_{\mathrm{j}} \\
\text { end } \\
\text { procedimento } \text { buscar }\left(\mathrm{q}_{\mathrm{N}}, \mathrm{A} \text {,indice }\right) \\
\left.\text { \{busca em } \mathrm{q}_{\mathrm{N}} \mathrm{O} \text { índice } \mathrm{k} \text { tal que } \mathrm{A}<\mathrm{q}[\mathrm{k}]\right\} \\
\text { begin } \\
\mathrm{k}:=1 \\
\text { found }:=\text { true } \\
\text { while found do } \\
\quad \text { if } \mathrm{A}>=\mathrm{q}[\mathrm{k}] \text { then } \mathrm{k}:=\mathrm{k}+1 \\
\quad \text { else found:= false } \\
\text { indice:= } \mathrm{k} \\
\text { end } \\
\text { procedimento seleciona(A,B,C) } \\
\{\mathrm{C} \text { é o conjunto de B primeiros indivíduos de } \\
\mathrm{A}\} \\
\text { procedimento escolha aleatoria(A,B,C) } \\
\{\mathrm{C} \text { é o conjunto de } \mathrm{B} \text { indivíduos escolhidos } \\
\text { aleatoriamente de } \mathrm{A} \text { \} }\end{array}$ \\
\hline
\end{tabular}

Figura 24. Procedimento Rank_2

As inúmeras variações do AG típico descritas neste apêndice contemplam algumas das seguintes características:

1. seleção de uma população intermediária, com pop_size elementos;

2. seleção direta, a partir da população corrente, de pop_size $\times p_{c}$ pais que participarão do cruzamento;

3. processo final de Restauração da população ao seu tamanho original de pop_size elementos usando uma escolha randômica;

4. processo final de Restauração da população ao seu tamanho original de pop_size elementos usando indivíduos que não participaram do cruzamento;

5. criação de uma população intermediária que contém os filhos. Esta população é expandida a pop_size elementos aleatoriamente escolhendo elementos da população corrente. 
5.1. A população intermediária como criada em 5. é expandida a $2 \times$ pop_size, por meio da adição de todos os elementos da população corrente (ou intermediária);

5.2 A população de 5.1 é classificada por ordem de fitness e os melhores pop_size indivíduos são escolhidos;

6. criação de uma população intermediária que contém os filhos. Esta população é expandida a pop_size elementos por meio da adição dos indivíduos que não fizeram parte do cruzamento.

6.1. A população intermediária como criada em 6 . é expandida a $2 \times$ pop_size, por meio da adição de todos os elementos da população corrente (ou intermediária);

6.2 A população de 6.1 é classificada por ordem de fitness e os melhores pop_size indivíduos são escolhidos;

7. uso de estratégia steady-state com número de pais=2, escolhidos aleatoriamente;

8. uso de estratégia steady-state com número de pais $=2$ escolhidos com base na fitness.

São apresentados nas Tabelas a seguir, as principais características para cada variante. 


\begin{tabular}{|c|c|c|c|c|}
\hline Variante & $\begin{array}{l}\text { Critério de seleção } \\
\text { dos pais }\end{array}$ & $\begin{array}{c}\text { Seleção de uma população } \\
\text { intermediária }\end{array}$ & $\begin{array}{c}\text { Critério para Restauração } \\
\text { da população a pop_size } \\
\text { elementos }\end{array}$ & Observações \\
\hline MGA1 & $\begin{array}{l}\text { Baseado na fitness: } \\
\text { seleção direta de } \mathrm{p}_{\mathrm{c}} \times \\
\text { pop_size elementos da } \\
\text { população corrente }\end{array}$ & - & $\begin{array}{l}\text { Escolha aleatória de } \\
\left.\text { pop_size-(p } \text { p }_{\mathrm{c}} \times \text { pop_size }\right) \\
\text { indivíduos a partir da } \\
\text { população corrente }\end{array}$ & $\begin{array}{l}\text { Todos os filhos gerados fazem parte } \\
\text { da nova geração }\end{array}$ \\
\hline MGA2 & $\begin{array}{l}\text { Baseado na fitness: } \\
\text { seleção direta de } \mathrm{p}_{\mathrm{c}} \times \\
\text { pop_size elementos da } \\
\text { população corrente }\end{array}$ & - & $\begin{array}{l}\text { Os pop_size- }\left(\mathrm{p}_{\mathrm{c}} \times \text { pop_size }\right) \\
\text { indivíduos que não } \\
\text { participaram do cruzamento }\end{array}$ & $\begin{array}{c}\text { Todos os filhos gerados fazem parte } \\
\text { da nova geração }\end{array}$ \\
\hline MGA3 & $\begin{array}{l}\text { Baseado na fitness: } \\
\text { seleção direta de } \mathrm{p}_{\mathrm{c}} \times \\
\text { pop_size elementos da } \\
\text { população corrente }\end{array}$ & $\begin{array}{l}\text { • uma população intermediária de } \\
\text { pop_size elementos é formada com } \\
\text { todos os filhos e indivíduos da } \\
\text { população corrente escolhidos } \\
\text { aleatoriamente. } \\
\text { •• a população intermediária (•) é } \\
\text { expandida a } 2 \times \text { pop_size, por meio } \\
\text { da incorporação dos indivíduos da } \\
\text { população corrente }\end{array}$ & $\begin{array}{l}\text { Os pop_size indivíduos de }(\bullet \bullet) \\
\text { com melhor fitness formam a } \\
\text { nova população }\end{array}$ & $\begin{array}{l}\text { Não necessariamente os filhos } \\
\text { obtidos fazem parte da nova } \\
\text { população }\end{array}$ \\
\hline
\end{tabular}




\begin{tabular}{|c|c|c|c|c|}
\hline MGA4 & $\begin{array}{l}\text { Baseado na fitness: } \\
\text { seleção direta dos } \mathrm{p}_{\mathrm{c}} \times \\
\text { pop_size elementos da } \\
\text { população corrente }\end{array}$ & $\begin{array}{l}\text { • uma população intermediária de } \\
\text { pop_size elementos é formada com } \\
\text { todos os filhos e indivíduos da } \\
\text { população corrente que não } \\
\text { participaram do cruzamento. } \\
\text { - a população intermediária é } \\
\text { expandida a } 2 \times \text { pop_size, por meio } \\
\text { da incorporação dos indivíduos da } \\
\text { população corrente }\end{array}$ & $\begin{array}{l}\text { Os pop_size indivíduos com } \\
\text { melhor } f i t n e s s \text { formam a nova } \\
\text { população }\end{array}$ & $\begin{array}{c}\text { Não necessariamente os filhos } \\
\text { obtidos fazem parte da nova } \\
\text { população }\end{array}$ \\
\hline MGA5 & $\begin{array}{l}\text { Baseada na fitness: } \\
\text { são escolhidos os } 2 \\
\text { melhores elementos da } \\
\text { população corrente }\end{array}$ & - & - & $\begin{array}{l}\text { São comparados os dois piores } \\
\text { indivíduos da população e os dois } \\
\text { filhos: os } 2 \text { melhores indivíduos } \\
\text { dentre esses } 4 \text { fazem parte da nova } \\
\text { população. }\end{array}$ \\
\hline MGA6 & $\begin{array}{c}\text { Seleção randômica de } 2 \\
\text { elementos da população } \\
\text { corrente }\end{array}$ & - & - & $\begin{array}{l}\text { São comparados os dois piores } \\
\text { indivíduos da população e os dois } \\
\text { filhos: os } 2 \text { melhores indivíduos } \\
\text { dentre esses } 4 \text { fazem parte da nova } \\
\text { população. }\end{array}$ \\
\hline
\end{tabular}




\begin{tabular}{|c|c|c|c|c|}
\hline Modified_Roleta_1a & $\begin{array}{l}\text { Seleção randômica de } \\
\text { p }_{c} \times \text { pop_size pais a } \\
\text { partir da população } \\
\text { intermediária }\end{array}$ & $\begin{array}{c}\text { População intermediária de pop_size elementos } \\
\text { criados a partir da população corrente, usando } \\
\text { roleta }\end{array}$ & $\begin{array}{l}\text { Escolha aleatória de } \\
\text { pop_size- }\left(\mathrm{p}_{\mathrm{c}} \times \text { pop_size }\right) \\
\text { indivíduos a partir da } \\
\text { população intermediária }\end{array}$ & $\begin{array}{c}\text { Todos os filhos } \\
\text { gerados fazem parte } \\
\text { da nova geração }\end{array}$ \\
\hline Modified_Roleta_1 & $\begin{array}{c}\text { Seleção de } \\
\text { p }_{\mathrm{c}} \times \text { pop_size pais da } \\
\text { população corrente } \\
\text { usando a roleta }\end{array}$ & - & $\begin{array}{c}\text { Escolha aleatória de } \\
\text { pop_size- }\left(\mathrm{p}_{\mathrm{c}} \times \text { pop_size }\right) \\
\text { indivíduos a partir da } \\
\text { população corrente }\end{array}$ & $\begin{array}{c}\text { Todos os filhos } \\
\text { gerados fazem parte } \\
\text { da nova geração }\end{array}$ \\
\hline Modified_Roleta_2a & $\begin{array}{l}\text { Seleção randômica de } \\
\text { p }_{\mathrm{c}} \times \text { pop_size pais a } \\
\text { partir da população } \\
\text { intermediária }\end{array}$ & $\begin{array}{l}\text { População intermediária de pop_size elementos } \\
\text { criados a partir da população corrente, usando } \\
\text { roleta }\end{array}$ & $\begin{array}{c}\text { Escolha de } \\
\text { pop_size- } \text { p }_{c} \times \text { pop_size } \\
\text { indivíduos da população } \\
\text { intermediária que não } \\
\text { participaram do } \\
\text { cruzamento }\end{array}$ & $\begin{array}{l}\text { Todos os filhos } \\
\text { gerados fazem parte } \\
\text { da nova geração }\end{array}$ \\
\hline Modified_Roleta_2 & $\begin{array}{c}\text { Seleção de } \\
p_{c} \times \text { pop_size pais a } \\
\text { partir da população } \\
\text { corrente usando a roleta }\end{array}$ & - & $\begin{array}{c}\text { Escolha de } \\
\left.\text { pop_size-(p } p_{c} \times \text { pop_size }\right) \\
\text { indivíduos da população } \\
\text { corrente que não } \\
\text { participaram do } \\
\text { cruzamento }\end{array}$ & $\begin{array}{c}\text { Todos os filhos } \\
\text { gerados fazem parte } \\
\text { da nova geração }\end{array}$ \\
\hline
\end{tabular}




\begin{tabular}{|c|c|c|c|c|}
\hline Modified_roleta_3a & $\begin{array}{c}\text { Seleção randômica de } p_{c} \\
\times \text { pop_size pais a partir } \\
\text { da população } \\
\text { intermediária }(\bullet)\end{array}$ & 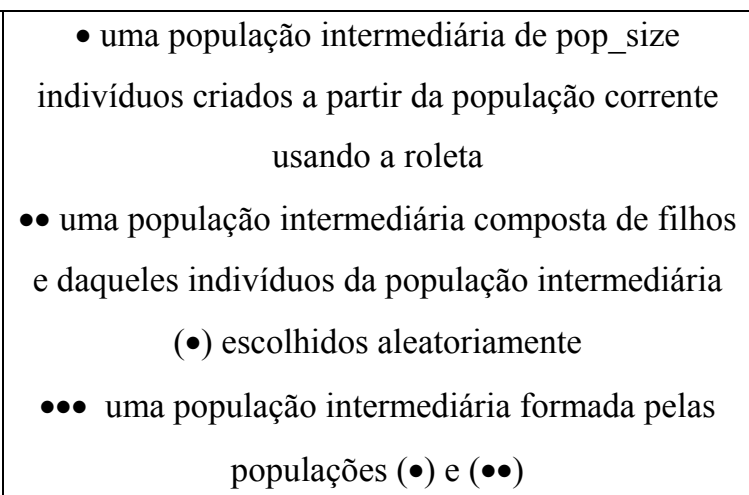 & $\begin{array}{l}\text { Os pop_size melhores } \\
\text { indivíduos da população } \\
\text { (•••) formam a nova } \\
\text { população }\end{array}$ & $\begin{array}{l}\text { Não necessariamente } \\
\text { os filhos obtidos } \\
\text { fazem parte da nova } \\
\text { população }\end{array}$ \\
\hline Modified_roleta_3 & $\begin{array}{c}\text { Seleção de } p_{c} \times \text { pop_size } \\
\text { pais a partir da } \\
\text { população corrente } \\
\text { usando a roleta }\end{array}$ & $\begin{array}{l}\text { • uma população intermediária de pop_size } \\
\text { elementos formada com todos os filhos e } \\
\text { indivíduos da população corrente escolhidos } \\
\text { aleatoriamente. } \\
\text { •• a população intermediária }(\bullet) \text { é expandida a } \\
\text { 2×pop_size, por meio da incorporação de todos os } \\
\text { indivíduos da população corrente }\end{array}$ & $\begin{array}{l}\text { Os pop_size indivíduos } \\
\text { de }(\bullet \bullet) \text { com melhor } \\
\text { fitness formam a nova } \\
\text { população }\end{array}$ & $\begin{array}{l}\text { Não necessariamente } \\
\text { os filhos obtidos } \\
\text { fazem parte da nova } \\
\text { população }\end{array}$ \\
\hline
\end{tabular}




\begin{tabular}{|c|c|c|c|c|}
\hline Modified_roleta_4a & $\begin{array}{c}\text { Seleção randômica de } p_{c} \\
\times \text { pop_size pais a partir } \\
\text { da população } \\
\text { intermediária }(\bullet)\end{array}$ & 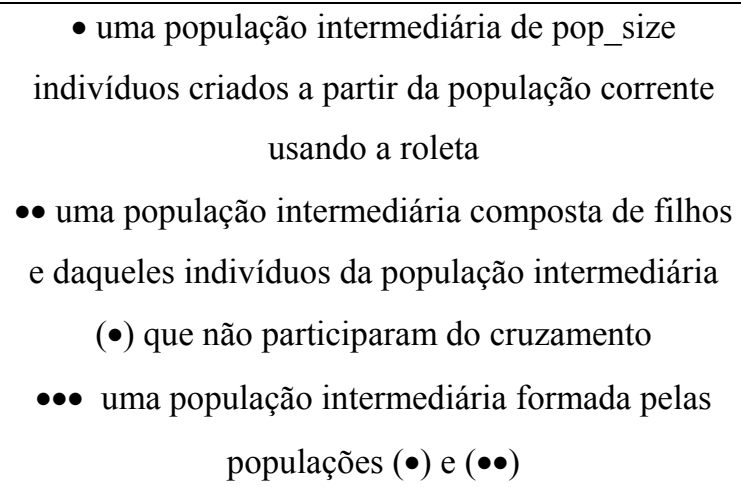 & $\begin{array}{l}\text { Os pop_size melhores } \\
\text { indivíduos da população } \\
(\bullet \bullet \bullet) \text { formam a nova } \\
\text { população }\end{array}$ & $\begin{array}{l}\text { Não necessariamente } \\
\text { os filhos obtidos } \\
\text { fazem parte da nova } \\
\text { população }\end{array}$ \\
\hline Modified_roleta_4 & $\begin{array}{c}\text { Seleção de } \\
\mathrm{p}_{\mathrm{c}} \times \text { pop_size pais a } \\
\text { partir da população } \\
\text { corrente usando a roleta }\end{array}$ & $\begin{array}{l}\text { • uma população intermediária de pop_size } \\
\text { elementos formada com todos os filhos e } \\
\text { indivíduos da população corrente que não } \\
\text { participaram do cruzamento } \\
\text { •• a população intermediária }(\bullet) \text { é expandida a } \\
2 \times \text { pop_size, por meio da incorporação de todos os } \\
\text { indivíduos da população corrente }\end{array}$ & $\begin{array}{l}\text { Os pop_size indivíduos } \\
\text { de }(\bullet \bullet) \text { com melhor } \\
\text { fitness formam a nova } \\
\text { população }\end{array}$ & $\begin{array}{l}\text { Os filhos obtidos não } \\
\text { necessariamente } \\
\text { fazem parte da nova } \\
\text { população }\end{array}$ \\
\hline
\end{tabular}




\begin{tabular}{|c|c|c|c|c|}
\hline Modified_Torneio_1 & $\begin{array}{c}\text { Seleção de } \\
\mathrm{p}_{\mathrm{c}} \times \text { pop_size pais da } \\
\text { população corrente } \\
\text { usando o torneio }\end{array}$ & - & $\begin{array}{l}\text { Escolha aleatória de } \\
\text { pop_size- }\left(\mathrm{p}_{\mathrm{c}} \times\right. \\
\text { pop_size }) \text { indivíduos a } \\
\text { partir da população } \\
\text { corrente }\end{array}$ & $\begin{array}{c}\text { Todos os filhos } \\
\text { gerados fazem parte } \\
\text { da nova geração }\end{array}$ \\
\hline Modified_Torneio_1a & $\begin{array}{l}\text { Seleção randômica dos } \\
\text { p }_{\mathrm{c}} \times \text { pop_size pais da } \\
\text { população intermediária }\end{array}$ & $\begin{array}{c}\text { População intermediária de pop_size elementos } \\
\text { criados a partir da população corrente, usando o } \\
\text { torneio }\end{array}$ & $\begin{array}{c}\text { Escolha aleatória de } \\
\text { pop_size- }\left(\mathrm{p}_{\mathrm{c}} \times\right. \\
\text { pop_size }) \text { indivíduos a } \\
\text { partir da população } \\
\text { intermediária }\end{array}$ & $\begin{array}{c}\text { Todos os filhos } \\
\text { gerados fazem parte } \\
\text { da nova geração }\end{array}$ \\
\hline Modified_Torneio_2 & $\begin{array}{l}\text { Seleção dos } p_{c} \times \\
\text { pop_size pais da } \\
\text { população corrente } \\
\text { usando o torneio }\end{array}$ & - & $\begin{array}{c}\text { Os pop_size }-\left(\mathrm{p}_{\mathrm{c}} \times\right. \\
\text { pop_size }) \text { indivíduos que } \\
\text { não participaram do } \\
\text { cruzamento }\end{array}$ & $\begin{array}{c}\text { Todos os filhos } \\
\text { gerados fazem parte } \\
\text { da nova geração }\end{array}$ \\
\hline Modified_Torneio_2a & $\begin{array}{l}\text { Seleção randômica dos } \\
\text { p }_{\mathrm{c}} \times \text { pop_size pais da } \\
\text { população intermediária }\end{array}$ & $\begin{array}{c}\text { População intermediária de pop_size elementos } \\
\text { criados a partir da população corrente, usando o } \\
\text { torneio }\end{array}$ & $\begin{array}{c}\text { Os pop_size- }\left(\mathrm{p}_{\mathrm{c}} \times\right. \\
\text { pop_size }) \text { indivíduos da } \\
\text { população intermediária } \\
\text { que não participaram do } \\
\text { cruzamento }\end{array}$ & $\begin{array}{c}\text { Todos os filhos } \\
\text { gerados fazem parte } \\
\text { da nova geração }\end{array}$ \\
\hline
\end{tabular}




\begin{tabular}{|c|c|c|c|c|}
\hline Modified_Torneio_3 & $\begin{array}{l}\text { Seleção dos } \mathrm{p}_{\mathrm{c}} \times \\
\text { pop_size pais da } \\
\text { população corrente } \\
\text { usando o torneio }\end{array}$ & $\begin{array}{l}\text { • uma população intermediária de pop_size } \\
\text { elementos é formada com todos os filhos e } \\
\text { indivíduos da população corrente escolhidos } \\
\text { aleatoriamente. } \\
\text { •• a população intermediária (•) é expandida } \\
\text { a } 2 \times \text { pop_size, por meio da incorporação dos } \\
\text { indivíduos da população corrente. }\end{array}$ & $\begin{array}{c}\text { Os pop_size } \\
\text { indivíduos de }(\bullet \bullet) \\
\text { com melhor fitness } \\
\text { formam a nova } \\
\text { população }\end{array}$ & $\begin{array}{c}\text { Os filhos obtidos não } \\
\text { necessariamente fazem parte da } \\
\text { nova população }\end{array}$ \\
\hline Modified_Torneio_3a & $\begin{array}{l}\text { Seleção randômica } \\
\text { dos } p_{c} \times \text { pop_size } \\
\text { pais da população } \\
\text { intermediária }\end{array}$ & $\begin{array}{l}\text { • População intermediária de pop_size } \\
\text { elementos criados a partir da população } \\
\text { corrente, usando o torneio } \\
\text { •• uma população intermediária de pop_size } \\
\text { elementos é formada com todos os filhos e } \\
\text { indivíduos da população }(\bullet) \text { escolhidos } \\
\text { aleatoriamente. } \\
\text { •• a população intermediária }(\bullet \bullet) \text { é } \\
\text { expandida a } 2 \times \text { pop_size, por meio da } \\
\text { incorporação dos indivíduos da população } \\
\text { corrente. }\end{array}$ & $\begin{array}{c}\text { Os pop_size } \\
\text { indivíduos de }(\bullet \bullet) \\
\text { com melhor fitness } \\
\text { formam a nova } \\
\text { população }\end{array}$ & $\begin{array}{c}\text { Os filhos obtidos não } \\
\text { necessariamente fazem parte da } \\
\text { nova população }\end{array}$ \\
\hline
\end{tabular}




\begin{tabular}{|c|c|c|c|c|}
\hline Modified_Torneio_4 & $\begin{array}{l}\text { Seleção dos } \mathrm{p}_{\mathrm{c}} \times \\
\text { pop_size pais da } \\
\text { população corrente } \\
\text { usando o torneio }\end{array}$ & $\begin{array}{l}\text { • uma população intermediária de pop_size } \\
\text { elementos é formada com todos os filhos e } \\
\text { indivíduos da população corrente que não } \\
\text { participaram do cruzamento } \\
\text { • a população intermediária (•) é expandida } \\
\text { a 2×pop_size, por meio da incorporação dos } \\
\text { indivíduos da população corrente. }\end{array}$ & $\begin{array}{c}\text { Os pop_size } \\
\text { indivíduos de }(\bullet \bullet) \text { com } \\
\text { melhor fitness formam } \\
\text { a nova população }\end{array}$ & $\begin{array}{c}\text { Os filhos obtidos não } \\
\text { necessariamente fazem parte da } \\
\text { nova população }\end{array}$ \\
\hline Modified_Torneio_4a & $\begin{array}{l}\text { Seleção randômica } \\
\text { dos } p_{c} \times \text { pop_size } \\
\text { pais da população } \\
\text { intermediária }\end{array}$ & $\begin{array}{c}\text { • População intermediária de pop_size } \\
\text { elementos criados a partir da população } \\
\text { corrente, usando o torneio } \\
\text { •• uma população intermediária de pop_size } \\
\text { elementos é formada com todos os filhos e } \\
\text { indivíduos da população }(\bullet) \text { que não } \\
\text { participaram do cruzamento } \\
\text { •• a população intermediária }(\bullet \bullet) \text { é } \\
\text { expandida a } 2 \times \text { pop_size, por meio da } \\
\text { incorporação dos indivíduos da população } \\
\text { corrente. }\end{array}$ & $\begin{array}{c}\text { Os pop_size } \\
\text { indivíduos de }(\bullet \bullet) \text { com } \\
\text { melhor fitness formam } \\
\text { a nova população }\end{array}$ & $\begin{array}{c}\text { Os filhos obtidos não } \\
\text { necessariamente fazem parte da } \\
\text { nova população }\end{array}$ \\
\hline
\end{tabular}




\begin{tabular}{|c|c|c|c|c|}
\hline Rank1 & $\begin{array}{c}\text { Seleção de } \mathrm{p}_{\mathrm{c}} \times \text { pop_size } \\
\text { pais da população } \\
\text { intermediária usando o } \\
\text { rank }\end{array}$ & $\begin{array}{l}\text { População intermediária de pop_size } \\
\text { elementos criados a partir da população } \\
\text { corrente }\end{array}$ & $\begin{array}{l}\text { Indivíduos da } \\
\text { população } \\
\text { intermediária que não } \\
\text { participaram do } \\
\text { cruzamento }\end{array}$ & $\begin{array}{c}\text { Todos os filhos participam da } \\
\text { próxima população }\end{array}$ \\
\hline Rank2 & $\begin{array}{l}\text { Seleção de } p_{c} \times \text { pop_size } \\
\text { pais da população } \\
\text { corrente usando o rank }\end{array}$ & - & $\begin{array}{l}\text { Indivíduos da } \\
\text { população corrente } \\
\text { escolhidos } \\
\text { aleatoriamente. }\end{array}$ & $\begin{array}{c}\text { Todos os filhos participam da } \\
\text { próxima população }\end{array}$ \\
\hline
\end{tabular}




\section{APÊNDICE C}

Programação não-linear: método do Lagrangeano Aumentado 


\section{PROGRAMAÇÃO NÃO-LINEAR: MÉTODO DO LAGRANGEANO AUMENTADO}

\section{INTRODUÇÃO}

Encontrar a solução de um problema de otimização significa descobrir o(s) ponto(s) de máximo ou de mínimo da função que o descreve. Como o problema focalizado nesta tese se caracteriza como um problema de otimização não-linear, sujeito a várias restrições, no que segue estaremos discutindo um método convencional para a solução deste tipo de problema, mais especificamente, o Método do Lagrangeano Aumentando.

\section{CONSIDERAÇÕES PRELIMINARES}

Programação não-linear trata de problemas onde a função objetivo ou alguma(s) das restrições do problema são funções não-lineares das variáveis envolvidas. Um problema de otimização com restrições abordado via programação não-linear pode ser equacionado como:

$$
\begin{aligned}
& \text { minimizar } \mathrm{f}(\mathrm{x}) \\
& \text { sujeita a: } \\
& \qquad \mathrm{g}_{\mathrm{i}}(\mathrm{x}) \leq 0, \mathrm{i}=1,2, \ldots, \mathrm{m}_{1} \\
& \mathrm{~h}_{\mathrm{i}}(\mathrm{x})=0, \mathrm{i}=\mathrm{m}_{1}+1, \ldots, \mathrm{m}\left(=\mathrm{m}_{1}+\mathrm{m}_{2}\right) \\
& \mathrm{x} \in \Omega \subset \mathrm{R}^{\mathrm{n}} \\
& \Gamma=\left\{\mathrm{x} \in \Omega \mid \mathrm{g}_{\mathrm{i}}(\mathrm{x}) \leq 0, \mathrm{i}=1,2, \ldots, \mathrm{m}_{1} \& \mathrm{~h}_{\mathrm{i}}(\mathrm{x})=0, \mathrm{i}=\mathrm{m}_{1}+1, \ldots, \mathrm{m}\right. \\
& \left.\left(=\mathrm{m}_{1}+\mathrm{m}_{2}\right)\right\}
\end{aligned}
$$

onde: $\Gamma$ é denominada de região viável. As funções $f, g_{1}, g_{2}, \ldots, g_{m 1}, h_{m 1+1}$, $\mathrm{h}_{\mathrm{m} 1+2}, \ldots, \mathrm{h}_{\mathrm{m}}$ são funções com valores reais definidas $\mathrm{em} \mathrm{R}^{\mathrm{n}} \mathrm{e} \mathrm{x}$ é um vetor $\mathrm{n}$ dimensional real com componentes $\mathrm{x}_{1}, \mathrm{x}_{2}, \ldots, \mathrm{x}_{\mathrm{n}}$. Este problema pode ser resolvido para valores das variáveis $\mathrm{x}_{1}, \mathrm{x}_{2}, \ldots, \mathrm{x}_{\mathrm{n}}$ que satisfazem às restrições do problema $\mathrm{e}$, ao mesmo tempo, minimizam a função $f$. 
A função f é chamada função objetivo. Cada uma das restrições $\mathrm{g}_{\mathrm{i}}(\mathrm{x}) \leq 0$ é chamada de restrição de desigualdade. Cada uma das restrições $\mathrm{h}_{\mathrm{i}}(\mathrm{x})=0$ é chamada de restrição de igualdade. $\mathrm{O}$ conjunto $\mathrm{X}$ é chamado de domínio restrito. Um vetor $\mathrm{x}$ $\in \mathrm{X}$ que satisfaz todas as restrições é chamado de solução factível. A coleção de todas essas soluções forma a região factível.

O problema de programação não-linear é então encontrar um ponto factível $\overline{\mathrm{x}}$ tal que $\mathrm{f}(\mathrm{x}) \leq \mathrm{f}(\overline{\mathrm{x}})$, para cada ponto factível $\mathrm{x}$. O ponto $\overline{\mathrm{x}}$ é chamado de ponto ótimo, ie, é o ponto caracterizado pelo vetor $\overline{\mathrm{x}}=\left(\mathrm{x}_{1}, \mathrm{x}_{2}, \ldots, \mathrm{x}_{\mathrm{n}}\right)$, cujo valor minimiza a função objetivo e satisfaz as restrições do problema. O par constituído por $(\bar{x}, f(\bar{x}))$ é chamado de solução ótima.

GEN \& CHENG (1997) comentam que “ ...métodos convencionais de programação não-linear são muito complexos e não muito eficientes. Nos últimos anos, tem havido um esforço crescente na aplicação de algoritmos genéticos a problemas de programação não-linear."

Geralmente os problemas que envolvem programação não-linear podem ser caracterizados como problemas restritos ou não-restritos Para cada caso existem disponíveis uma grande variedade de métodos que geralmente são referenciados como métodos de otimização sem restrições e com restrições.

A abordagem utilizada por métodos com restrições é a de transformar o problema com restrição em um problema sem restrição e resolve-lo usando um dos métodos convencionais de programação não-linear sem restrição. Dependendo do tipo de restrição do problema, os métodos com restrições se subdividem em: métodos com restrição de igualdade, métodos com restrições de desigualdade e métodos com restrições mistas.

As próximas subseções apresentam, respectivamente, considerações e definições relativas à otimização com restrições de igualdade; a descrição do método do de Newton-lagrangeano para a solução de tais problemas e o método do lagrangeano aumentado, que é o método de otimização não-linear para o tratamento de problemas com restrições mistas e que foi utilizado neste trabalho. 


\section{OTIMIZAÇÃO COM RESTRIÇÃO DE IGUALDADE}

Antes da apresentação dos métodos de otimização do Lagrangeano, penalidade e Lagrangeano aumentado, é importante o estabelecimento de algumas definições que são relevantes para esses métodos:

- $\delta \in \mathrm{R}^{\mathrm{n}}$ é um incremento viável em um ponto $\mathrm{x} \in \Gamma \leftrightarrow \mathrm{x}+\delta \in \Gamma$.

- uma direção d é uma direção de decréscimo em $x \leftrightarrow \mathrm{d}^{\mathrm{T}} \nabla \mathrm{f}(\mathrm{x})<0$. Se o ponto x* é um ponto de mínimo local, não existe d tal que:

$$
\left\{\begin{array}{l}
d^{T} \cdot \Delta g_{i}\left(x^{*}\right)=0 \\
d^{T} \cdot \Delta f\left(x^{*}\right)<0
\end{array} i=1, \ldots, m\right.
$$

- um ponto $\mathrm{x}^{*}$ que satisfaz às restrições $\mathrm{g}\left(\mathrm{x}^{*}\right)=0, \mathrm{i}=1, \ldots, \mathrm{m}$ é um ponto regular se os vetores gradientes $\nabla \mathrm{g}_{1}\left(\mathrm{x}^{*}\right), \nabla \mathrm{g}_{2}\left(\mathrm{x}^{*}\right), \ldots, \nabla \mathrm{g}_{\mathrm{m}}\left(\mathrm{x}^{*}\right)$ forem linearmente independentes.

- $\quad$ se $\mathrm{x}^{*}$ é um ponto regular e como o sistema:

$$
\left\{\begin{array}{l}
\mathrm{d}^{\mathrm{T}} \cdot \Delta \mathrm{g}_{\mathrm{i}}\left(\mathrm{x}^{*}\right)=0 \\
\mathrm{~d}^{\mathrm{T}} \cdot \Delta \mathrm{f}\left(\mathrm{x}^{*}\right)<0
\end{array} \mathrm{i}=1,,, \mathrm{~m}\right.
$$

não tem solução, podemos garantir que existem $\lambda_{i}{ }^{*} \operatorname{com} i=1, \ldots, m$, tais que $\nabla \mathrm{f}\left(\mathrm{x}^{*}\right)-\sum_{\mathrm{i}=1}^{\mathrm{m}} \lambda_{\mathrm{i}}^{*} \cdot \mathrm{g}_{\mathrm{i}}\left(\mathrm{x}^{*}\right)=0$, onde os números $\lambda_{\mathrm{i}}^{*}$ com $\mathrm{i}=1, \ldots, \mathrm{m}$ são denominados Multiplicadores de Lagrange.

- a função $\mathrm{L}(\mathrm{x}, \lambda)=\mathrm{f}(\mathrm{x})-\sum_{\mathrm{i}=1}^{\mathrm{m}} \lambda_{\mathrm{i}} \cdot \mathrm{g}_{\mathrm{i}}(\mathrm{x})$ é chamada de Função Lagrangeana

- a condição necessária de primeira ordem para que um ponto viável seja um mínimo local é dada por $\nabla \mathrm{f}\left(\mathrm{x}^{*}\right)-\sum_{\mathrm{i}=1}^{\mathrm{m}} \lambda_{\mathrm{i}}^{*} \cdot \mathrm{g}_{\mathrm{i}}\left(\mathrm{x}^{*}\right)=0$, ou seja, o gradiente da 
função objetivo deve ser uma combinação linear dos gradientes das restrições.

- a condição necessária de primeira ordem para que um ponto $\left(x^{*}, \lambda^{*}\right)$ seja um ponto estacionário da Função Lagrangeana é dada por $\nabla \mathrm{L}\left(\mathrm{x}^{*}, \lambda^{*}\right)=0$, com $\nabla=\left[\begin{array}{l}\Delta_{\mathrm{x}} \\ \Delta \lambda\end{array}\right]$

\subsection{Método de Newton-Lagrangeano}

O método de Newton para a resolução de sistemas de equações pode ser usado para analisar as condições necessárias de primeira ordem da função lagrangeana. Considere o problema geral de otimização com restrições de igualdade, expresso por:

$$
\text { minimizar } \mathrm{f}(\mathrm{x})
$$

sujeita a:

$$
\begin{aligned}
& \mathrm{g}_{\mathrm{i}}(\mathrm{x})=0, \mathrm{i}=1,2, \ldots, \mathrm{m} \\
& \mathrm{x} \in \Omega \subset \mathrm{R}^{\mathrm{n}} \\
& \Gamma=\left\{\mathrm{x} \in \Omega \mid \mathrm{g}_{\mathrm{i}}(\mathrm{x})=0, \mathrm{i}=1, \ldots, \mathrm{m}\right\}
\end{aligned}
$$

Associado ao problema descrito acima, pode ser definida a seguinte função Lagrangeana:

$$
\mathrm{L}(\mathrm{x}, \lambda)=\mathrm{f}(\mathrm{x})-\sum_{\mathrm{i}=1}^{\mathrm{m}} \lambda_{\mathrm{i}} \cdot \mathrm{g}_{\mathrm{i}}(\mathrm{x})
$$

onde $\lambda_{\mathrm{i}}$ é o multiplicador de Lagrange associado à restrição $\mathrm{g}_{\mathrm{i}}(\mathrm{x})$.

O processo consiste em determinar valores, para $\mathrm{x}$ e $\lambda$, que satisfaçam as condições necessárias de otimalidade sobre a função Lagrangeana (1). Assim,

$$
\frac{\partial \mathrm{L}}{\partial \mathrm{x}}=0
$$




$$
\frac{\partial \mathrm{L}}{\partial \lambda}=0
$$

O método de Newton resolve (2) de forma direta. Utilizando Taylor de primeira ordem em torno de $\mathrm{x}^{\mathrm{k}} \mathrm{e} \lambda^{\mathrm{k}}$ nas equações (2), as expressões obtidas são linearizadas da seguinte forma:

$$
\begin{aligned}
& \nabla_{\mathrm{x}} \mathrm{L}\left(\mathrm{x}^{\mathrm{k}}, \lambda^{\mathrm{k}}\right)+\nabla_{\mathrm{xx}}^{2} \mathrm{~L}\left(\mathrm{x}^{\mathrm{k}}, \lambda^{\mathrm{k}}\right) \Delta \mathrm{x}^{\mathrm{k}}+\nabla_{\mathrm{x} \lambda}^{2} \mathrm{~L}\left(\mathrm{x}^{\mathrm{k}}, \lambda^{\mathrm{k}}\right) \Delta \lambda^{\mathrm{k}}=0 \\
& \nabla_{\lambda} \mathrm{L}\left(\mathrm{x}^{\mathrm{k}}, \lambda^{\mathrm{k}}\right)+\nabla_{\lambda \mathrm{x}}^{2} \mathrm{~L}\left(\mathrm{x}^{\mathrm{k}}, \lambda^{\mathrm{k}}\right) \Delta \mathrm{x}^{\mathrm{k}}+\nabla_{\lambda \lambda}^{2} \mathrm{~L}\left(\mathrm{x}^{\mathrm{k}}, \lambda^{\mathrm{k}}\right) \Delta \lambda^{\mathrm{k}}=0
\end{aligned}
$$

$\mathrm{Ou}$

$$
\begin{aligned}
& \nabla_{\mathrm{x}} \mathrm{L}\left(\mathrm{x}^{\mathrm{k}}, \lambda^{\mathrm{k}}\right)+\nabla_{\mathrm{xx}}^{2} \mathrm{~L}\left(\mathrm{x}^{\mathrm{k}}, \lambda^{\mathrm{k}}\right) \Delta \mathrm{x}^{\mathrm{k}}+\nabla_{\mathrm{x}} \mathrm{g}\left(\mathrm{x}^{\mathrm{k}}\right)^{\mathrm{t}} \Delta \lambda^{\mathrm{k}}=0 \\
& \Delta \mathrm{g}\left(\mathrm{x}^{\mathrm{k}}\right)+\nabla_{\mathrm{x}} \mathrm{g}\left(\mathrm{x}^{\mathrm{k}}\right) \Delta \mathrm{x}^{\mathrm{k}}=0
\end{aligned}
$$

onde $\nabla_{\mathrm{x}} \mathrm{g}\left(\mathrm{x}^{\mathrm{k}}\right)^{\mathrm{t}}=\left(\nabla_{\mathrm{x}} \mathrm{g}_{1}(\mathrm{x}), \ldots, \nabla_{\mathrm{x}} \mathrm{g}_{\mathrm{m}}(\mathrm{x})\right)$

O novo ponto é obtido por:

$$
\begin{aligned}
& x^{k+1}=x^{k}+\Delta x^{k} \\
& \lambda^{k+1}=\lambda^{k}+\Delta \lambda^{k}
\end{aligned}
$$

onde $\Delta \mathrm{x}$ e $\Delta \lambda$ são denominados vetores de direções de busca.

O sistema (3) pode ser representado na forma matricial por:

$$
\left[\begin{array}{cc}
\nabla_{x x}^{2} \mathrm{~L}\left(\mathrm{x}^{\mathrm{k}}, \lambda^{\mathrm{k}}\right) & \nabla_{\mathrm{x}} \mathrm{g}\left(\mathrm{x}^{\mathrm{k}}\right)^{\mathrm{t}} \\
\nabla_{\mathrm{x}} \mathrm{g}\left(\mathrm{x}^{\mathrm{k}}\right) & 0
\end{array}\right]\left(\begin{array}{c}
\Delta \mathrm{x}^{\mathrm{k}} \\
\Delta \lambda^{\mathrm{k}}
\end{array}\right)=-\left(\begin{array}{c}
\nabla_{\mathrm{x}} \mathrm{L}\left(\mathrm{x}^{\mathrm{k}}, \lambda^{\mathrm{k}}\right) \\
\mathrm{g}\left(\mathrm{x}^{\mathrm{k}}\right)
\end{array}\right)
$$

Ou, na forma simplificada:

$$
\left[\begin{array}{cc}
\mathrm{H} & \mathrm{J}^{\mathrm{t}} \\
\mathrm{J} & 0
\end{array}\right]\left(\begin{array}{c}
\Delta \mathrm{x} \\
\Delta \lambda
\end{array}\right)=-\left(\begin{array}{c}
\nabla_{\mathrm{x}} \mathrm{L} \\
\nabla_{\lambda} \mathrm{L}
\end{array}\right)
$$


onde a matriz dos coeficientes do sistema é denominada matriz Lagrangeana e encontra-se dividida em quatro sub-matriz: a matriz Hessiana $\mathrm{H}$, a matriz Jacobiana $\mathrm{J}=\Delta^{2}{ }_{\lambda \mathrm{x}}$ e sua transposta e uma matriz nula. O mínimo da função será atingido quando os novos valores de $\mathrm{x}$ e $\lambda$ satisfizerem as condições necessárias de primeira ordem para o problema original.

É importante lembrar que o método de Newton exige que o ponto inicial esteja na vizinhança de $x^{*}$ e $\lambda^{*}$ o que, muitas vezes, pode inviabilizar o método, pois não existe garantia de convergência.

\section{MÉTODO DO LAGRANGEANO AUMENTADO}

Considerando o seguinte problema de otimização:

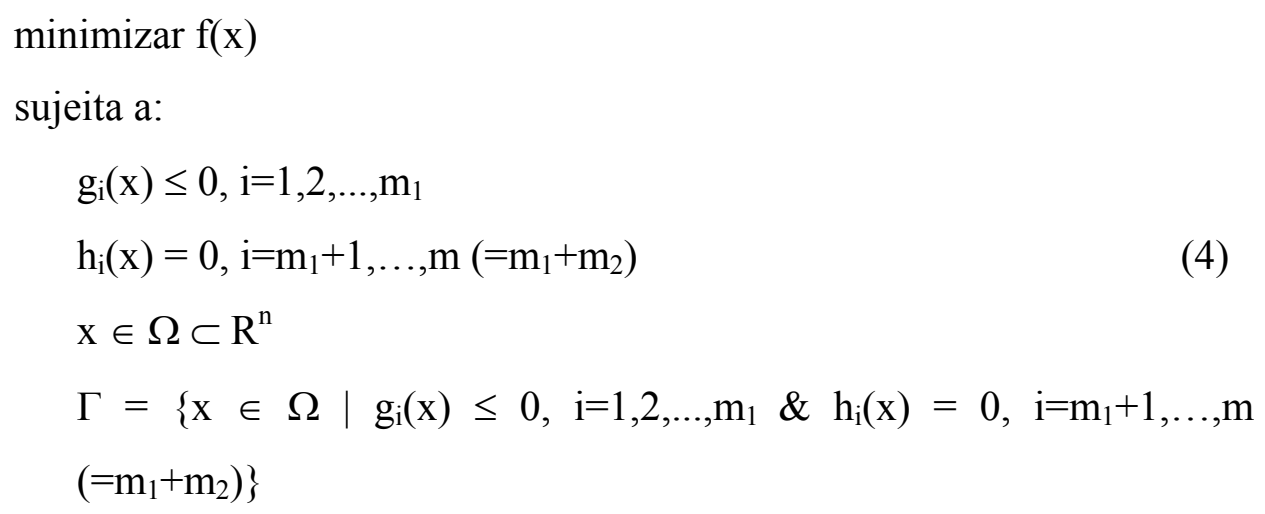

Para um melhor entendimento do método Lagrangeano aumentado, inicia-se a apresentação do método utilizando o problema acima descrito somente com restrições de igualdade; depois, a seguir, apresenta-se o problema para restrições de desigualdade.

Considerando o problema (4) somente com restrições de igualdade: associado a ele tem-se o problema de penalidade quadrática:

$$
\text { Minimizar } \quad f(x)+c \sum_{i=1}^{m} g_{i}^{2}(x)
$$


Onde $\mathrm{c} \geq 0$. Para obter o ótimo restrito do problema original é necessário que $\mathrm{c} \rightarrow \infty$ e $\mathrm{g}_{\mathrm{i}}(\mathrm{x}) \rightarrow 0$. Com o intuito de determinar o mínimo do problema inicial para um valor finito de $\mathrm{c}$ trabalhou-se com um problema perturbado:

$$
\begin{array}{ll}
\text { Minimizar } & \mathrm{f}(\mathrm{x}) \\
\text { Sujeito a } & \mathrm{g}_{\mathrm{i}}(\mathrm{x})=\varepsilon, \mathrm{i}=1, \ldots, \mathrm{m}
\end{array}
$$

O problema acima tem a seguinte função auxiliar denominada função Lagrangeana aumentada:

$$
\mathrm{La}(\mathrm{x}, \mathrm{c})=\mathrm{f}(\mathrm{x})+\mathrm{c} \sum_{\mathrm{i}=1}^{\mathrm{m}}\left(\mathrm{g}_{\mathrm{i}}(\mathrm{x})-\varepsilon_{\mathrm{i}}\right)^{2}
$$

onde $\mathrm{c} \geq 0$ é um fator de penalidade e $\varepsilon$ é um vetor de perturbações.

Expandido (5) obtêm-se:

$$
\mathrm{La}(\mathrm{x}, \mathrm{c})=\mathrm{f}(\mathrm{x})+\mathrm{c} \sum_{\mathrm{i}=1}^{\mathrm{m}} \mathrm{g}_{\mathrm{i}}^{2}(\mathrm{x})-2 \mathrm{c} \sum_{\mathrm{i}=1}^{\mathrm{m}} \mathrm{g}_{\mathrm{i}}(\mathrm{x}) \varepsilon_{\mathrm{i}}+\mathrm{c} \sum_{\mathrm{i}=1}^{\mathrm{m}} \varepsilon_{\mathrm{i}}^{2}
$$

Assumindo que $\lambda=-2 c \varepsilon_{\mathrm{i}}$ e desprezando o termo constante $\mathrm{c} \sum_{\mathrm{i}=1}^{\mathrm{m}} \varepsilon_{\mathrm{i}}^{2}$, pode-se reescrever (6) da seguinte forma:

$$
\mathrm{La}(\mathrm{x}, \mathrm{c})=\mathrm{f}(\mathrm{x})+\sum_{\mathrm{i}=1}^{\mathrm{m}} \lambda \mathrm{g}_{\mathrm{i}}(\mathrm{x})+\mathrm{c} \sum_{\mathrm{i}=1}^{\mathrm{m}} \mathrm{g}_{\mathrm{i}}^{2}(\mathrm{x})
$$

onde $\lambda_{\mathrm{i}}, \mathrm{i}=1, \ldots ., \mathrm{m}$ são os multiplicadores de Lagrange e c é o fator penalidade.

Considerando o problema (4) somente com restrições de desigualdade:

$$
\begin{aligned}
& \text { Minimizar } f(x) \\
& \text { Sujeito a } h_{j}(x) \leq 0, j=1, \ldots, r
\end{aligned}
$$

Transformam-se as restrições de desigualdade em igualdade a partir da introdução de uma variável de folga $\mathrm{z}_{\mathrm{j}}$ da seguinte forma:

$$
\text { Minimizar } \mathrm{f}(\mathrm{x})
$$




$$
\begin{gathered}
\text { Sujeito } a h_{j}(x)+z_{j}=0, j=1, \ldots, r \\
z_{j} \geq 0, j=1, \ldots, r
\end{gathered}
$$

O problema (7) pode ser transformado no seguinte problema equivalente:

$$
\begin{gathered}
\text { Minimizar } f(x)+\frac{1}{2} c \sum_{j=1}^{r}\left(h_{j}(x)+z_{j}\right)^{2} \\
\text { Sujeito } h_{j}(x)+z_{j}=0, j=1, \ldots, r \\
\qquad z_{j} \geq 0, j=1, \ldots, r
\end{gathered}
$$

onde $\mathrm{c} \geq 0$ é um fator de penalidade

A função Lagrangeana associada a (8) é definida por:

$$
\operatorname{La}(x, \mu, z)=f(x)+\sum_{j=1}^{r} \mu_{j}\left(h_{j}(x)+z_{j}\right)+\frac{1}{2} c \sum_{j=1}^{r}\left(h_{j}(x)+z_{j}\right)^{2}
$$

onde $\mu$ é o vetor dos multiplicadores de Lagrange.

Minimizando (9) com relação a $z_{j}, j=1, \ldots, r$, e aplicando as condições necessárias de otimalidade:

$$
\nabla_{z_{j}} \operatorname{La}(x, \mu, z)=0, j=1, \ldots, r
$$

isto é:

$$
\mu_{j}+c\left(h_{j}(x)+z_{j}\right)=0, j=1, \ldots ., r
$$

resultando em:

$$
z_{j}=-\frac{\mu_{j}}{c}-h_{j}(x), j=1, \ldots, r
$$

Como $z_{j}, \geq 0, j=1, \ldots ., r$, então: 


$$
z_{j}=\left\{\begin{array}{cc}
-\frac{\mu_{j}}{c}-h_{j}(x) & \text { se }-\frac{\mu_{j}}{c}-h_{j}(x) \geq 0 \\
0 & \text { se }-\frac{\mu_{j}}{c}-h_{j}(x) \leq 0
\end{array} \quad j=1, \ldots, r,\right.
$$

Substituindo (10) em (9) obtêm-se a função Lagrangeana Aumentada:

$$
\operatorname{La}(x, \mu)=f(x)+\sum_{j=1}^{r} \begin{cases}\mu_{j} h_{j}(x)+\frac{c}{2} h_{j}^{2}(x) & \text { se } h_{j}(x) \geq-\frac{\mu_{j}}{c} \\ -\frac{\mu_{j}^{2}}{2 c} & \text { se } h_{j}(x) \leq-\frac{\mu_{j}}{c}\end{cases}
$$

\section{O PROGRAMA EASY}

O programa EASY é um software escrito em Fortran, disponibilizado para download no endereço www.ime.unicamp/ martinez; que implementa o método de otimização do Lagrangeano aumentado, possibilitando assim a resolução de problemas não lineares. Soluciona problemas do tipo:

$$
\begin{aligned}
& \text { minimizar } \mathrm{f}(\mathrm{x}) \text { sujeito a: } \\
& \mathrm{h}(\mathrm{x})=0 \\
& \mathrm{e} \\
& l \leq \mathrm{x} \leq u
\end{aligned}
$$

onde

$$
\begin{aligned}
& \mathrm{f}: \mathrm{R}^{\mathrm{n}} \rightarrow \mathrm{R}, \\
& \mathrm{h}: \mathrm{R}^{\mathrm{n}} \rightarrow \mathrm{R}^{\mathrm{m}},
\end{aligned}
$$

$l, u$ são dois vetores dados n-dimensionais e correspondem aos limites superior e inferior respectivamente das variáveis.

Pode se dizer então que f é uma função escalar de $\mathrm{n}$ variáveis e h é uma função de restrição de $\mathrm{n}$ variáveis e m componentes.

Para a solução de problemas que são definidos com restrições de desigualdade, antes de mais nada tais restrições devem ser transformadas em restrições de igualdade por meio do seguinte procedimento. Se a restrição de desigualdade for do tipo: 
1. $\mathrm{r}(\mathrm{x}) \leq 0$, ela é transformada na restrição $\mathrm{r}(\mathrm{x})+\mathrm{z}=0$, onde $\mathrm{z}$ é uma variável positiva $(\mathrm{z} \geq 0)$

2. $\mathrm{r}(\mathrm{x}) \geq 0$, ela é transformada na restrição $\mathrm{r}(\mathrm{x})+\mathrm{z}=0$, onde $\mathrm{z}$ é uma variável negativa $(\mathrm{z} \leq 0)$

3. $\mathrm{a} \leq \mathrm{r}(\mathrm{x}) \leq \mathrm{b}$, ela é transformada na restrição $\mathrm{r}(\mathrm{x})-\mathrm{z}=0$ onde $\mathrm{a} \leq \mathrm{z} \leq \mathrm{b}$.

Para aquelas variáveis do problema que não têm limite inferior ou superior estabelecidos, deve-se, artificialmente, defini-los como o menor ou maior possível, respectivamente. Por exemplo, se a variável $\mathrm{x}_{1}$ não possui limite inferior, ele pode ser definido como $l=-10^{9}$, dado que se garanta que tal valor nunca vai ser obtido para essa variável.

Via transformação dos possíveis tipos de restrições, o programa se torna abrangente o suficiente para permitir a busca da solução para todo problema de otimização com restrições.

As principais características do programa $E A S Y$ são:

a) tanto a função objetivo quanto as restrições devem ter derivadas contínuas;

b) o número máximo de variáveis é 1000 e o número máximo de restrições é 500 . O programa permite, entretanto, que se trabalhe com um número superior de variáveis e restrições, via alteração de algumas declarações Fortran;

c) pode ser usado para problemas sem restrições (caso em que $\mathrm{m}=0$ ).

O EASY espera como input um arquivo de nome easy.dat, que deve conter as seguintes informações:

a) a primeira linha deve conter dois inteiros $\mathrm{n}$ e $\mathrm{m}$, onde $\mathrm{n}$ é o número de variáveis e m o número de restrições, separados por branco;

b) a segunda linha deve fornecer os limites inferiores das variáveis, separados por brancos;

c) a terceira linha deve fornecer os limites superiores das variáveis, separados por brancos 
d) a quarta linha (última) deve fornecer uma estimativa inicial da solução.

A título de exemplo, considere um problema definido em função de quatro variáveis, com duas restrições. Suponha que os limites inferiores das quatro variáveis são, $-10,-10,-10,-10$ e os superiores $10,10,10,10$, respectivamente. Considere ainda que a estimativa inicial da solução seja 1,1,1,1. O arquivo easy.dat deverá conter as seguintes informações, dispostas na seguinte maneira:

$$
\begin{array}{rrrr}
4 & 2 & & \\
-10 & -10 & -10 & -10 \\
10 & 10 & 10 & 10 \\
1 & 1 & 1 & 1
\end{array}
$$

Definido o arquivo de entrada, deve-se fornecer a função objetivo a ser minimizada (f) bem as restrições (h) do problema no próprio arquivo fonte do programa Easy, como comandos Fortran. O código Fortran do Easy aponta, via comentários, os locais onde tais comandos devem ser inseridos.

Num dos problemas tratados neste tese (o relativo à minimização dos custos de uma laje alveolar), a função objetivo é introduzida no código fonte do Easy como o comando Fortran:

$\mathrm{f}=(0.1 * 6 * \mathrm{x}(1)+1.59 * 6 * \mathrm{x}(2)+0.144 * 6 * \mathrm{x}(1) * \mathrm{x}(3)+1.31 * 6 * \mathrm{x}(1) / \mathrm{x}(3)+14.44 * 6 * \mathrm{x}(2) /(\mathrm{x}(3) * * 2))$ onde $x(1), x(2)$ e $x(3)$ são respectivamente a altura do painel alveolar, armadura de protensão e resistência do concreto protendido.

O problema em questão exige a definição de 22 restrições de desigualdade que, para serem tratadas no Easy, foram convertidas em restrições de igualdade. Cada uma delas deve ser especificada no código fonte. Segue um exemplo da especificação da restrição relativa ao momento:

$\mathrm{h}=(0.01 * \mathrm{x}(2) *(31080.67256 /(((120.0-2.0 * \operatorname{int}(116.19 /(\mathrm{x}(1)-1.27)) *$

$\operatorname{sqrt}(((120.0 * x(1)-760.05 * \log (x(1))+865.05) /(3.1416 * \operatorname{int}(116.19 /$ 


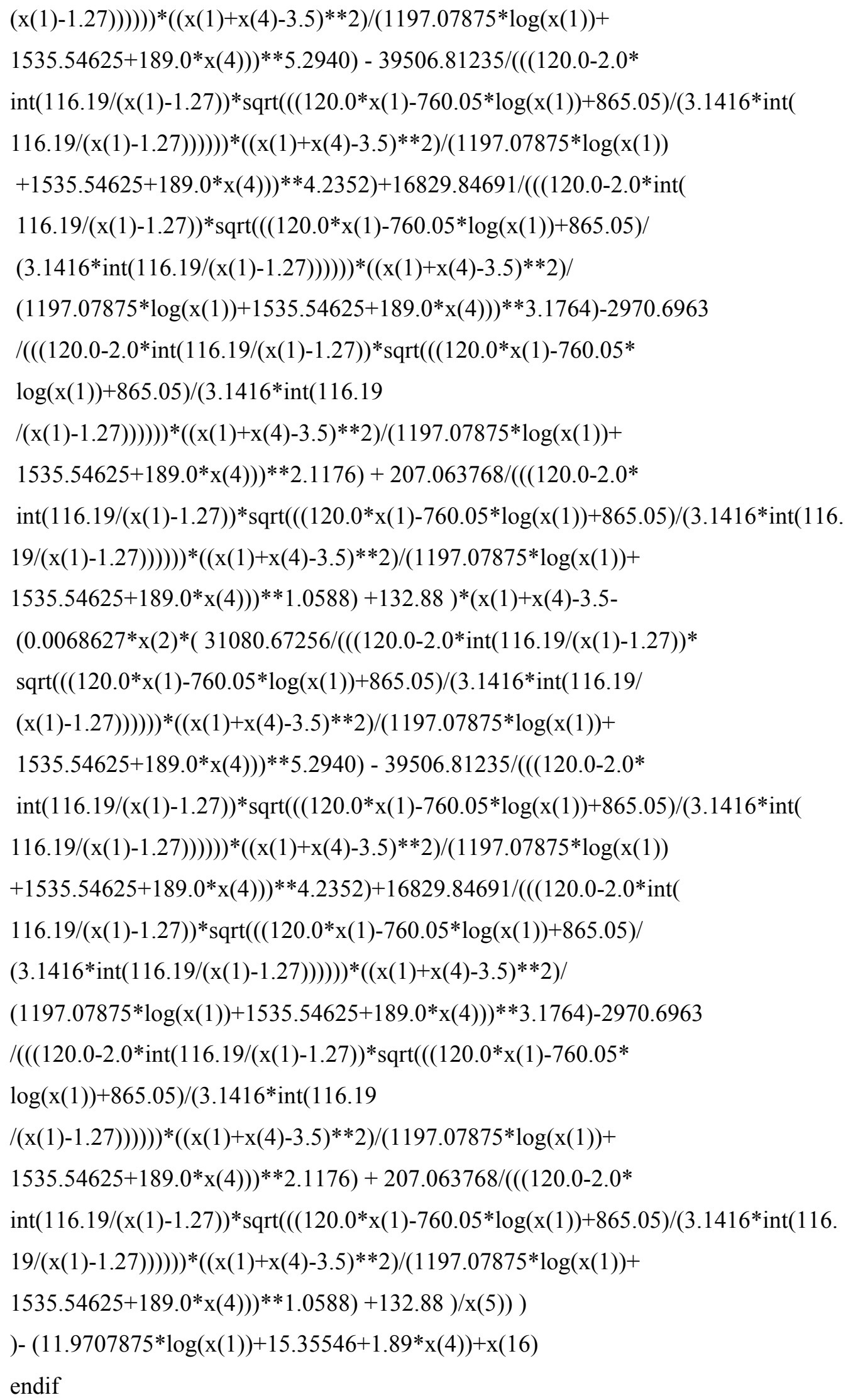




\section{APÊNDICE D}

Dimensionamento de um painel alveolar sem capa estrutural 


\section{DIMENSIONAMENTO DE UM PAINEL ALVEOLAR SEM CAPA ESTRUTURAL}

\section{DEFINIÇÃO DO PROBLEMA}

Deve-se salientar que todo o dimensionamento foi feito utilizando o software Mathcad 2000 Professional. Entretanto, com o objetivo de facilitar a compreensão do dimensionamento, achou-se necessário apresentar um roteiro de cálculo em texto corrido.

O problema de otimização tratado neste apêndice é o da minimização da função custo de um painel alveolar sem capa estrutural. A seção transversal do painel é mostrada na Figura 1.

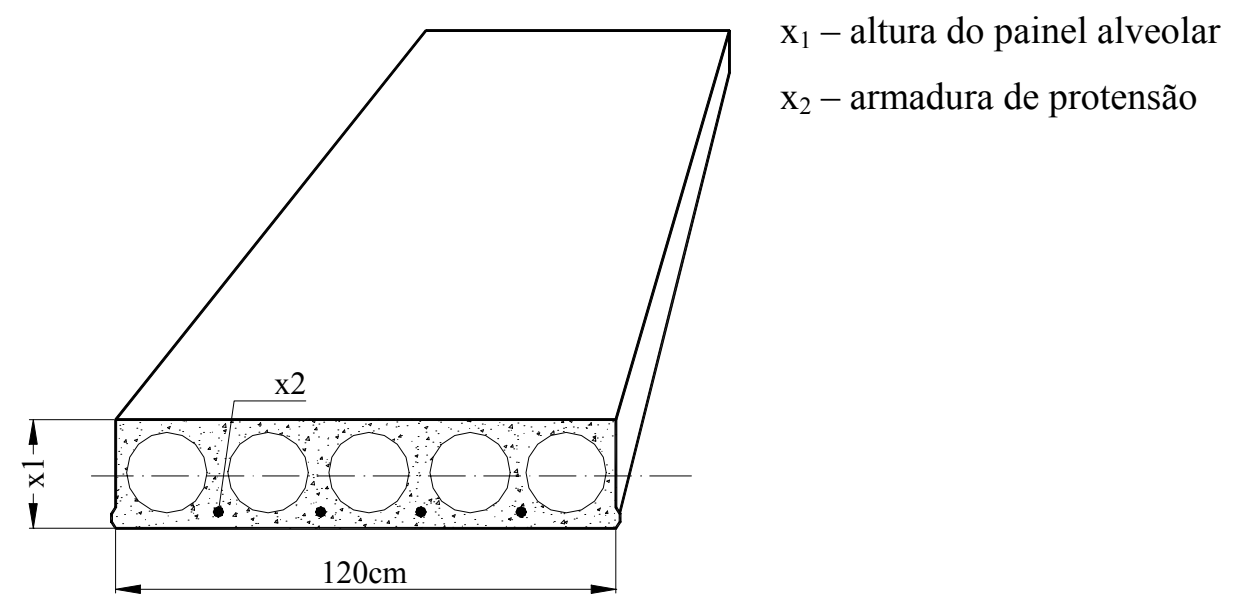

Figura 1. Painel alveolar sem capa estrutural

As variáveis envolvidas no equacionamento do problema, conforme apresentado na figura, são definidas a seguir.

- $\mathrm{x}_{1}$ - altura do painel alveolar

- $\mathrm{x}_{2}$ - área de armadura de protensão

- $\mathrm{x}_{3}$ - resistência do concreto do elemento pré-moldado

Serão consideradas no dimensionamento ainda as seguintes características:

- vão do painel - $\mathrm{L}=6 \mathrm{~m}$

- Largura do painel $-\mathrm{b}=120 \mathrm{~cm}$ 
- Um nível de armadura localizada no bordo inferior

- Protensão limitada

- Resistência do concreto moldado no local $-\mathrm{f}_{\mathrm{ck} 2}=20 \mathrm{MPa}$

- Altura da capa de concreto de regularização $-\mathrm{h}_{\text {capa }}=4 \mathrm{~cm}$

- Cordoalhas de 7 fios - relaxação baixa

- $\mathrm{CP}-175 \mathrm{RB} 9,5$

O dimensionamento segue as recomendações das normas brasileiras e de HANAI (1999).

\section{CARACTERÍSTICAS GEOMÉTRICAS}

$\mathrm{Na}$ definição da área de concreto do painel alveolar será considerada uma aproximação no cálculo de seu valor tendo como base as características geométricas das seções apresentadas nas tabelas do PCI (1992). No cálculo, serão considerados painéis alveolares com vazamento circular.

a) a partir dos valores de áreas obtidas das tabelas do PCI (1992) foi definida uma função que representasse de forma aproximada, a área dos vários tipos de painéis alveolares para este trabalho. Nesse caso, a função que melhor representou a área de um painel alveolar $\left(A_{c}\right)$ foi uma função neperiana que depende da altura do painel $\left(\mathrm{x}_{1}\right)$, apresentada a seguir.

$$
A_{c}=760,05 \ln \left(x_{1}\right)-865,05
$$

Podem-se definir a quantidade de furos (n) que o painel alveolar terá para a altura $\mathrm{x}_{1}$ e o raio do círculo (r). Então tem-se:

$$
\begin{aligned}
& \mathrm{n}=\frac{116,19}{\mathrm{x}_{1}-1,27} \\
& \mathrm{r}=\sqrt{\frac{\left(\mathrm{x}_{1} \mathrm{~b}-\mathrm{A}_{\mathrm{c}}\right)}{\pi \mathrm{n}}}
\end{aligned}
$$

b) a inércia da seção $\left(I_{c}\right)$ é dada por: 


$$
I_{c}=\frac{b\left(x_{1}\right)^{3}}{12}-\frac{\pi(2 r)^{4} n}{64}
$$

c) a distância da armadura de protensão $\left(\mathrm{e}_{\mathrm{p}}\right)$ ao centro de gravidade (CG) corresponde a distância do CG da armadura até o centro de gravidade da laje e é definida a seguir. A Figura 2 mostra em detalhes as distâncias da armadura e do painel.

$$
\begin{aligned}
& e_{p}=y_{c g}-c-\phi / 2 \\
& y_{c g}=\frac{x_{1}}{2} \\
& \text { onde } \quad c-\text { cobrimento }(c=30 \mathrm{~mm}) \\
& \qquad \phi-\text { diâmetro da armadura }(\phi / 2=5 \mathrm{~mm})
\end{aligned}
$$

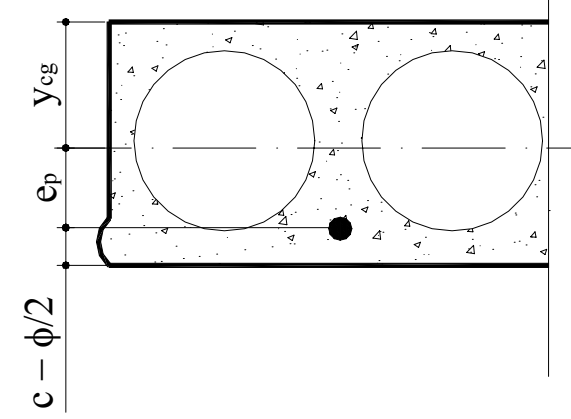

Figura 2. Centro de gravidade do painel e da armadura

d) os módulos resistentes são:

$$
\begin{array}{ll}
\mathrm{y}_{1}=\mathrm{y}_{\mathrm{cg}} & \mathrm{y}_{2}=\mathrm{y}_{\mathrm{cg}}-\mathrm{x}_{1} \\
\mathrm{w}_{1}=\frac{\mathrm{I}_{\mathrm{c}}}{\mathrm{y}_{1}} & \mathrm{w}_{2}=\frac{\mathrm{I}_{\mathrm{c}}}{\mathrm{y}_{2}}
\end{array}
$$

Deve-se salientar que se adotou índice 1 para as variáveis que se referem à borda inferior e índice 2 à superior.

\section{CÁLCULO DOS ESFORÇOS SOLICITANTES E TENSÕES NO MEIO DO VÃO}

a) as cargas atuantes no painel são as seguintes: 


\section{Carga permanente:}

- Peso próprio do painel $(\mathrm{kN} / \mathrm{m}): \mathrm{g}_{1}=\mathrm{A}_{\mathrm{c}} \gamma_{\mathrm{c}}$ onde $\gamma_{\mathrm{c}}=25 \mathrm{kN} / \mathrm{m}^{3}$

- Peso próprio da capa de regularização $(\mathrm{kN} / \mathrm{m}): \mathrm{g}_{2}=\mathrm{A}_{\text {capa }} \gamma_{\mathrm{cs}}$ onde $\gamma_{\mathrm{cs}}=24 \mathrm{kN} / \mathrm{m}^{3}$

\section{Sobrecarga:}

- Adotado a partir da NBR-6120 uma carga de estacionamentos de $3 \mathrm{kN} / \mathrm{m}^{2}$ $(\mathrm{kN} / \mathrm{m}): \mathrm{q}=3 \mathrm{~b}$

b) os momentos fletores no meio do vão para cada carregamento:

$$
\mathrm{M}_{\mathrm{g} 1}=\frac{\mathrm{g}_{1} \mathrm{~L}^{2}}{8} \quad \mathrm{M}_{\mathrm{g}_{2}}=\frac{\mathrm{g}_{2} \mathrm{~L}^{2}}{8} \quad \mathrm{M}_{\mathrm{q}}=\frac{\mathrm{qL}^{2}}{8}
$$

c) as tensões no meio do vão para cada carregamento:

bordo superior

$$
\sigma_{1_{\mathrm{g}_{1}}}=\frac{\mathrm{M}_{\mathrm{g} 1}}{\mathrm{w}_{1}} \quad \sigma_{1_{\mathrm{g}_{2}}}=\frac{\mathrm{M}_{\mathrm{g} 2}}{\mathrm{w}_{1}} \quad \sigma_{{ }_{1} \mathrm{q}_{1}}=\frac{\mathrm{M}_{\mathrm{q}}}{\mathrm{w}_{1}}
$$

bordo inferior:

$$
\sigma_{\mathrm{g}_{1}}=\frac{\mathrm{M}_{\mathrm{g}_{1}}}{\mathrm{w}_{2}} \quad \sigma_{\mathrm{g}_{2}}=\frac{\mathrm{M}_{\mathrm{g}_{2}}}{\mathrm{w}_{2}} \quad \sigma_{2} \mathrm{q}_{1}=\frac{\mathrm{M}_{\mathrm{q}}}{\mathrm{w}_{2}}
$$

\section{CÁlCULO DA FORÇA DE PROTENSÃO}

a) estimativa da força de protensão:

Foi adotado cordoalhas de 7 fios CP-175 RB. As principais propriedades mecânicas são descritas a seguir.

$$
\begin{aligned}
& \mathrm{f}_{\mathrm{ptk}}=175 \mathrm{kN} / \mathrm{cm}^{2} \\
& \mathrm{f}_{\mathrm{pyk}}=158 \mathrm{kN} / \mathrm{cm}^{2} \\
& \mathrm{E}_{\mathrm{p}}=19500 \mathrm{kN} / \mathrm{cm}^{2}
\end{aligned}
$$


onde: $\quad f_{\text {ptk }}$ - resistência característica à ruptura por tração do aço de protensão

$\mathrm{f}_{\text {pyk }}$ - limite de escoamento convencional do aço de protensão

$\mathrm{E}_{\mathrm{p}}$ - valor médio do módulo de elasticidade do aço de protensão

A tensão $\sigma_{\text {Pi }}$ é calculada como o menor dos dois valores definidos abaixo

$$
\begin{gathered}
\sigma_{\mathrm{Pi}} \leq\left\{\begin{array}{l}
0,81 \mathrm{f}_{\mathrm{ptk}}=141,75 \mathrm{kN} / \mathrm{cm}^{2} \\
0,90 \mathrm{f}_{\mathrm{pyk}}=142,20 \mathrm{kN} / \mathrm{cm}^{2}
\end{array}\right. \\
\text { logo: } \sigma_{\mathrm{Pi}}=141,75 \mathrm{kN} / \mathrm{cm}^{2}
\end{gathered}
$$

Na definição do problema, a área da armadura é uma das variáveis e, portanto terá seu valor será arbitrado.

$$
\mathrm{P}_{\mathrm{i}, \mathrm{ef}}=-\mathrm{A}_{\mathrm{p}} \sigma_{\mathrm{Pi}} 0,97=-\mathrm{x}_{2} \sigma_{\mathrm{Pi}} 0,97
$$

b) determinação de $\mathrm{P}_{\mathrm{a}}$ : o valor de $\mathrm{P}_{\mathrm{a}}$ que corresponde ao valor da força de protensão imediatamente anterior à transferência de tensões ao concreto. Determina-se o valor de $\mathrm{P}_{\mathrm{a}}$ a partir das seguintes perdas:

- Escorregamento dos fios na ancoragem: se a pista de protensão for longa a perda de protensão será muito pequena. Considerando então: comprimento da pista $=120000 \mathrm{~mm}$;

valor aproximado da deformação do aço, por ocasião do estiramento $=0,007$;

valor aproximado do alongamento do cabo na pista de $120 \mathrm{~m}$ é então: $120000 \times$ x $0,007=840 \mathrm{~mm}$;

Se houver um recuo do ponto de ancoragem, por acomodação da ancoragem, da ordem de $6 \mathrm{~mm}$ a perda percentual será:

$\Delta \mathrm{P}_{\mathrm{anc}}=\frac{6 \mathrm{~mm}}{840 \mathrm{~mm}}=0,714 \%$

- Relaxação inicial da armadura: o cálculo da perda de protensão por relaxação do aço de protensão é feito pela determinação do coeficiente $\psi\left(\mathrm{t}, \mathrm{t}_{\mathrm{o}}\right)$ definido por:

$$
\psi\left(\mathrm{t}, \mathrm{t}_{\mathrm{o}}\right)=\frac{\Delta \sigma_{\mathrm{pr}}\left(\mathrm{t}, \mathrm{t}_{\mathrm{o}}\right)}{\sigma_{\mathrm{pi}}}
$$


onde: $\Delta \sigma_{\mathrm{pr}}\left(\mathrm{t}, \mathrm{t}_{\mathrm{o}}\right)-$ perda de tensão por relaxação pura (com comprimento constante) desde o instante $t_{o}$ do estiramento da armadura até o instante t considerado $\sigma_{\mathrm{pi}}-$ tensão da armadura de protensão no instante de seu estiramento

portanto: $\frac{\sigma_{\mathrm{pi}}}{\mathrm{f}_{\mathrm{ptk}}}=0,81$ da tabela 5 da NBR-7197 o valor de $\psi_{1000}=3,5$

Supondo $\quad \mathrm{T}_{\max }=75^{\circ}$

$$
\begin{aligned}
& \mathrm{T}_{\mathrm{o}}=23^{\mathrm{o}} \\
& \mathrm{T}=13 \mathrm{~h}
\end{aligned}
$$

Então $\mathrm{t}-\mathrm{t}_{\mathrm{o}}=\frac{\mathrm{T}_{\max }}{\mathrm{t}_{\mathrm{o}}} \mathrm{t}=42,39 \mathrm{~h}$

$$
\begin{aligned}
& \psi\left(\mathrm{t}, \mathrm{t}_{\mathrm{o}}\right)=\psi_{1000} \cdot\left(\frac{\mathrm{t}-\mathrm{t}_{\mathrm{o}}}{1000}\right)^{0,15} ; \\
& \text { tem-se: } \Delta \mathrm{P}_{\mathrm{csi}}=\psi(\mathrm{t}, \mathrm{to})=2,178 \%
\end{aligned}
$$

Logo as perdas finais são: $\quad \Delta \mathrm{P}_{\mathrm{P}_{\mathrm{i}} \rightarrow \mathrm{Pa}_{\mathrm{a}}}=\Delta \mathrm{P}_{\text {anc }}+\Delta \mathrm{P}_{\text {csi }}=2,983$

Então: $\mathrm{P}_{\mathrm{a}}=\frac{\left(100-\Delta \mathrm{P}_{\mathrm{P}_{\mathrm{i}} \rightarrow \mathrm{P}_{\mathrm{a}}}\right) \mathrm{P}_{\text {ief }}}{100}$

c) determinação de $\mathrm{P}_{\mathrm{o}}$ : o valor de $\mathrm{P}_{\mathrm{o}}$ corresponde ao instante imediatamente posterior à transferência de tensões ao concreto. A força de protensão por deformação imediata de concreto é decorrente do próprio processo de transferência da força de protensão ao concreto, que sofre a necessária deformação para ficar protendido.

A tensão do concreto é calculada da seguinte maneira: $\sigma_{c p}=\frac{P_{a}}{A_{c}}+\frac{P_{a}\left(e_{p}\right)^{2}}{I_{c}}$. Esta expressão é utilizada no caso de protensão aplicada numa única fibra, com excentricidade $\mathrm{e}_{\mathrm{p}}$.

A tensão da armadura, logo após a transferência de tensões ao concreto resulta em: $\sigma_{P_{0}}=\sigma_{P_{a}}+\frac{E_{p}}{E_{c}} \sigma_{c p}=\left(\frac{P_{a}}{A_{c}}+\frac{P_{a} e_{p}}{w_{1}}\right)+\frac{E_{p}}{E_{c}} \sigma_{c p}$

Logo: $\mathrm{P}_{\mathrm{o}}=\mathrm{P}_{\mathrm{a}}-\mathrm{x}_{2} \sigma_{\mathrm{P}_{\mathrm{O}}}$ 
As tensões devido à $\mathrm{P}_{\mathrm{o}}$ no bordo inferior e superior são:

$$
\sigma_{1 \mathrm{P}_{\mathrm{o}}}=\frac{\mathrm{P}_{\mathrm{o}}}{\mathrm{A}_{\mathrm{c}}}+\frac{\mathrm{P}_{\mathrm{o}} \mathrm{e}_{\mathrm{p}}}{\mathrm{w}_{1}} \quad \sigma_{2 \mathrm{P}_{\mathrm{o}}}=\frac{\mathrm{P}_{\mathrm{o}}}{\mathrm{A}_{\mathrm{c}}}+\frac{\mathrm{P}_{\mathrm{o}} \mathrm{e}_{\mathrm{p}}}{\mathrm{w}_{2}}
$$

A NBR-7197 estabelece que ao término das operações de protensão, a tensão $\sigma_{P o}$ não deve superar o menos dos seguintes limites:

$\sigma_{\mathrm{P}_{\mathrm{i}}} \leq\left\{\begin{array}{l}0,77 \mathrm{f}_{\mathrm{ptk}} \\ 0,86 \mathrm{f}_{\mathrm{pyk}}\end{array}\right.$

c) determinação de $\mathrm{P}_{\mathrm{oo}}$ : o valor de $\mathrm{P}_{\mathrm{oo}}$ corresponde ao valor final da força de protensão, consideradas todas as perdas. A fim de facilitar os cálculos, as perdas progressivas devidas à retração e fluência do concreto e relaxação do aço de protensão não serão calculadas neste trabalho. As perdas finais foram estimadas em 30\%. Portanto, o valor de $\mathrm{P}_{\mathrm{oo}}$ que corresponde ao valor do final da força de protensão é: $\mathrm{P}_{\mathrm{oo}}=0,7 \mathrm{P}_{\text {ief }}$

As tensões devido a $\mathrm{P}_{\mathrm{oo}}$ no bordo inferior e superior são:

$$
\sigma_{1 \mathrm{P}_{\mathrm{oo}}}=\frac{\mathrm{P}_{\mathrm{oo}}}{\mathrm{A}_{\mathrm{c}}}+\frac{\mathrm{P}_{\mathrm{oo}} \mathrm{e}_{\mathrm{p}}}{\mathrm{w}_{1}} \quad \sigma_{{ }_{2} \mathrm{P}_{\mathrm{oo}}}=\frac{\mathrm{P}_{\mathrm{oo}}}{\mathrm{A}_{\mathrm{c}}}+\frac{\mathrm{P}_{\mathrm{oo}} \mathrm{e}_{\mathrm{p}}}{\mathrm{w}_{2}}
$$

\section{VERIFICAÇÃO DAS TENSÕES NA SEÇÃO MAIS SOLICITADA}

A seguir serão feitas verificações do elemento no estado em vazio e em serviço para os bordos inferiores e superiores.

a) Verificação do estado em vazio:

- após a desmoldagem: atuam $\left(\mathrm{P}_{\mathrm{o}}+\mathrm{g}_{1}\right)$

$$
\sigma_{1_{\mathrm{d}}}=\sigma_{{ }^{1} \mathrm{P}_{\mathrm{o}}}+\sigma_{1 \mathrm{~g}_{1}} \quad \sigma_{2 \mathrm{~d}}=\sigma_{2 \mathrm{P}_{\mathrm{o}}}+\sigma_{2 \mathrm{~g}_{1}}
$$

- fase de transporte (efeito dinâmico $\left.-\beta_{\mathrm{a} 1}=0,8\right)$ : atuam $\left(\mathrm{P}_{\mathrm{o}}+\beta_{\mathrm{a} 1} \mathrm{~g}_{1}\right)$

$$
\sigma_{1_{\mathrm{t}}}=\sigma_{1 \mathrm{P}_{\mathrm{o}}}+\beta_{\mathrm{a}_{1}} \sigma_{1 \mathrm{~g}_{1}} \quad \sigma_{2 \mathrm{t}}=\sigma_{2 \mathrm{P}_{\mathrm{o}}}+\beta_{\mathrm{a}_{1}} \sigma_{2 \mathrm{~g}_{1}}
$$

- fase de transporte (efeito dinâmico $\left.-\beta_{\mathrm{a} 2}=1,3\right)$ : atuam $\left(\mathrm{P}_{\mathrm{o}}+\beta_{\mathrm{a} 2} \mathrm{~g}_{1}\right)$ 


$$
\sigma_{1 \mathrm{tt}}=\sigma_{1} \mathrm{P}_{\mathrm{o}}+\beta_{\mathrm{a}_{2}} \sigma_{1 \mathrm{~g}_{1}} \quad \sigma_{2_{\mathrm{tt}}}=\sigma_{2 \mathrm{P}_{\mathrm{o}}}+\beta_{\mathrm{a}_{2}} \sigma_{2 \mathrm{~g}_{1}}
$$

- fase de armazenamento: atuam $\left(\mathrm{P}_{\mathrm{oo}}+\mathrm{g}_{1}\right)$

$$
\sigma_{1_{\mathrm{a}}}=\sigma_{{ }^{1} \mathrm{PoO}_{\mathrm{oo}}}+\sigma_{1 \mathrm{~g}_{1}} \quad \sigma_{2_{\mathrm{a}}}=\sigma_{2 \mathrm{P}_{\mathrm{oo}}}+\sigma_{2_{\mathrm{g}_{1}}}
$$

- fase de montagem: atuam $\left(\mathrm{P}_{\mathrm{o}}+\mathrm{g}_{1}+\mathrm{g}_{2}\right)$

$$
\sigma_{1_{\mathrm{m}}}=\sigma_{{ }_{1} \mathrm{P}_{\mathrm{o}}}+\sigma_{1 \mathrm{~g}_{1}}+\sigma_{1 \mathrm{~g}_{2}}
$$

$$
\sigma_{2 \mathrm{~m}}=\sigma_{2 \mathrm{P}_{\mathrm{o}}}+\sigma_{2 \mathrm{~g}_{1}}+\sigma_{2 \mathrm{~g}}
$$

b) Verificação do estado em serviço: os fatores de utilização $\psi$ são valores adotados pela norma de ações.

- combinação freqüente de ações $\left(\psi_{1}=0,3\right)$

$$
\sigma_{1 \mathrm{f}}=\sigma_{1 \mathrm{~g}_{1}}+\sigma_{\mathrm{gg}_{2}}+\psi_{1} \sigma_{1_{\mathrm{q}}}+\sigma_{1 \mathrm{P}_{\mathrm{oo}}} \quad \sigma_{2 \mathrm{f}}=\sigma_{2 \mathrm{~g}_{1}}+\sigma_{2 \mathrm{~g}_{2}}+\psi_{1} \sigma_{2 \mathrm{q}}+\sigma_{2 \mathrm{P}_{\mathrm{oo}}}
$$

- $\quad$ combinação quase-permanente de ações $\left(\psi_{2}=0,2\right)$

$$
\sigma_{1_{\mathrm{qp}}}=\sigma_{\mathrm{g}_{1}}+\sigma_{\mathrm{g}_{\mathrm{g}}}+\psi_{2} \sigma_{1_{\mathrm{q}}}+\sigma_{1 \mathrm{P}_{\mathrm{oo}}} \quad \sigma_{2 \mathrm{qp}}=\sigma_{2 \mathrm{~g}_{1}}+\sigma_{2_{\mathrm{g}_{2}}}+\psi_{2} \sigma_{2_{\mathrm{q}}}+\sigma_{2 \mathrm{P}_{\mathrm{oo}}}
$$

- combinação rara de ações

$$
\sigma_{1_{\mathrm{r}}}=\sigma_{\mathrm{g}_{1}}+\sigma_{\mathrm{g}_{2}}+\sigma_{1_{\mathrm{q}}}+\sigma_{1 \mathrm{P}_{\mathrm{oo}}} \quad \sigma_{2_{\mathrm{r}}}=\sigma_{2 \mathrm{~g}_{1}}+\sigma_{2_{\mathrm{g}_{2}}}+\sigma_{2 \mathrm{q}}+\sigma_{2 \mathrm{P}_{\mathrm{oo}}}
$$

Essas tensões apresentadas em a) e em b) devem satisfazer os limites de descompressão e de formação de fissuras. A seguir é calculada a resistência característica à compressão e à tração na data da protensão e aos 28 dias.

Para o estado limite em vazio:

Na data da protensão

$\mathrm{f}_{\text {ckj }}=0,70 \mathrm{f}_{\text {ck }}$

compressão: $\sigma_{\text {cj,lim }}=0,70 f_{\text {ckj }}=0,49 \mathrm{x}_{3}$

tração : $\quad \sigma_{\text {ctj,lim }}=0,3 \sqrt[3]{\left(\mathrm{f}_{\text {ckj }}\right)^{2}}=0,3 \sqrt[3]{\left(\mathrm{x}_{3}\right)^{2}}$

$\underline{\text { Para o estado limite em serviço: }}$

Aos 28 dias 


$$
\begin{aligned}
& \sigma_{\mathrm{c}, \lim }=0,70 \mathrm{f}_{\mathrm{ck}}=0,70 \mathrm{x}_{3} \\
& \sigma_{\mathrm{ct}, \lim }=0,3 \sqrt[3]{\left(\mathrm{f}_{\mathrm{ck}}\right)^{2}}=0,3 \sqrt[3]{\left(\mathrm{x}_{3}\right)^{2}}
\end{aligned}
$$

onde

$\sigma_{1 \mathrm{~d}}, \sigma_{2 \mathrm{~d}}-$ tensão na fase de desmoldagem no bordo inferior e superior $\sigma_{1 \mathrm{t}}, \sigma_{2 \mathrm{t}}, \sigma_{1 \mathrm{tt}}, \sigma_{2 \mathrm{tt}}$ - tensão na fase de transporte no bordo inferior e superior $\sigma_{1 \mathrm{a}}, \sigma_{2 \mathrm{a}}-$ tensão na fase de armazenamento no bordo inferior e superior $\sigma_{1 \mathrm{~m}}, \sigma_{2 \mathrm{~m}}-$ tensão na fase de montagem no bordo inferior e superior $\sigma_{\mathrm{gg}_{2}}, \sigma_{2 \mathrm{~g}_{2}}-$ tensão devido ao peso próprio do enchimento e do concreto moldado no local no bordo inferior e superior $\sigma_{1 q}, \sigma_{2 q}-$ tensão devido à sobrecarga no bordo inferior e superior $\sigma_{1 \mathrm{P}_{\mathrm{o}}}, \sigma_{2 \mathrm{P}_{\mathrm{o}}}-$ tensão devido à força de protensão instalada no concreto no bordo inferior e superior

$\beta_{\mathrm{a}_{1}}-$ coeficiente de ação dinâmica $\left(\beta_{\mathrm{a}_{1}}=0,8\right)$

$\beta_{\mathrm{a}_{2}}-$ coeficiente de ação dinâmica $\left(\beta_{\mathrm{a} 2}=1,3\right)$

$\sigma_{1 f}, \sigma_{2 f}-$ tensão na fase em serviço para a combinação freqüente de ações no bordo inferior e superior

$\sigma_{1 \mathrm{qp}}, \sigma_{2 \mathrm{qp}}-$ tensão na fase em serviço para a combinação quase-permanente de ações no bordo inferior e superior

$\sigma_{1 \mathrm{r}}, \sigma_{2 \mathrm{r}}$ - tensão na fase em serviço para a combinação rara de ações no bordo inferior e superior

$\sigma_{1 \mathrm{P}_{\mathrm{oo}}}, \sigma_{2 \mathrm{P}_{\mathrm{oo}}}-$ tensão devido à força de protensão após as perdas no bordo inferior e superior

$\sigma_{\mathrm{ctj}, \lim }-$ tensão limite de tração em j dias

$\sigma_{c t, \lim }-$ tensão limite de tração

$\sigma_{\mathrm{cj}, \mathrm{lim}}-$ tensão limite de compressão em j dias

$\sigma_{\mathrm{c}, \mathrm{lim}}-$ tensão limite de compressão

$\psi_{1}$ - fator de combinação freqüente de ações $\left(\psi_{1}=0,3\right)$

$\psi_{2}$ - fator de combinação quase permanente de ações $\left(\psi_{2}=0,2\right)$ 


\section{VERIFICAÇÃO DAS TENSÕES AO LONGO DO VÃO}

Nessa seção limita-se à verificação da seção do apoio uma vez que a armadura não apresenta interrupção. A tensão da armadura $\sigma_{\mathrm{P}_{\mathrm{Oo}}}$ não pode ultrapassar os seguintes limites: $\begin{aligned} & \sigma_{\mathrm{c}, \mathrm{lim}}=0,70 \mathrm{f}_{\mathrm{ck}}=0,70 \mathrm{x}_{3} \\ & \sigma_{\mathrm{ct}, \lim }=0,3 \sqrt[3]{\left(\mathrm{f}_{\mathrm{ck}}\right)^{2}}=0,3 \sqrt[3]{\left(\mathrm{x}_{3}\right)^{2}}\end{aligned}$

\section{VERIFICAÇÃO DO ESTADO LIMITE DE DEFORMAÇÃO}

A seguir serão feitas verificações quanto ao estado limite de deformação.

a) contraflecha devido à protensão: o limite adotado para a contraflecha é estipulado pelo projeto de revisão da NBR-6118.

\section{Contraflecha instantânea:}

$a_{c t}=\frac{P_{o} e_{p} L}{8 E_{c i} I_{c}}$

onde $\quad a_{\mathrm{ct}}-$ contraflecha instantânea

$\mathrm{P}_{\mathrm{o}}$ - força de protensão instalada no concreto

$\mathrm{e}_{\mathrm{p}}$ - distância do centro de gravidade da armadura ao centro de gravidade do elemento

$\mathrm{L}$ - vão do painel

$\mathrm{E}_{\mathrm{ci}}$ - módulo de elasticidade do concreto na data da protensão

$I_{c}$ - inércia da seção de concreto

\section{Contraflecha diferida:}

$a_{c d}=\frac{\left(P_{o}+P_{o o}\right) e_{p} L}{8 E_{c} I_{c}}$

onde $\quad a_{\mathrm{cd}}-$ contraflecha instantânea

$\mathrm{P}_{\mathrm{oo}}$ - força de protensão

$\mathrm{E}_{\mathrm{c}}$ - módulo de elasticidade do concreto ao 28 dias

$I_{c}$ - inércia da seção de concreto 
A contraflecha total é a soma das duas deformações: $a_{\text {cont }}=a_{c t}+a_{c d}$. Portanto deve-se respeitar o limite imposto: $a_{\text {contflec }} \leq a_{\text {limct }}=\frac{\mathrm{L}}{350}$

b) flecha devido ao carregamento: o limite adotado da flecha é estipulado pelo projeto de revisão da NBR-6118. Os deslocamentos foram determinados usando a combinação quase-permanente de ações.

$$
\mathrm{F}_{\mathrm{d}, \text { útil }}=\mathrm{F}_{\mathrm{g}, \mathrm{k}}+0,2 \mathrm{~F}_{\mathrm{q}, \mathrm{k}}
$$

Flecha instantânea: formada pela flecha produzida por todas as cargas

$$
\begin{aligned}
& \mathrm{a}_{\text {inst }}=\frac{5\left(\mathrm{~g}_{1}+\mathrm{g}_{2}+0,2 \mathrm{q}\right) \mathrm{L}^{4}}{384 \mathrm{E}_{\mathrm{c}} \mathrm{I}_{\mathrm{c}}} \\
& \text { onde } \quad a_{\text {inst }}-\text { flecha instantânea } \\
& \mathrm{g}_{1} \text { - carga devido ao peso próprio do painel } \\
& \mathrm{g}_{2} \text { - carga devido ao peso próprio do painel } \\
& \mathrm{q} \text { - sobrecarga } \\
& \text { L - vão do painel } \\
& \mathrm{E}_{\mathrm{c}} \text { - módulo de elasticidade do concreto } \\
& I_{c} \text { - inércia da seção de concreto }
\end{aligned}
$$

Flecha diferida: formada pela flecha produzida pelo carregamento permanente

$\mathrm{a}_{\text {dif }}=\frac{5\left(\mathrm{~g}_{1}+\mathrm{g}_{2}\right) \mathrm{L}^{4}}{384 \mathrm{E}_{\mathrm{c}} \mathrm{I}_{\mathrm{c}}}(1+\varphi)$ onde $\varphi$ é o coeficiente de deformação lenta

$\mathrm{O}$ valor de $\varphi$ foi calculado pelas equações apresentadas no Anexo $A$ no projeto de revisão na NBR-6118. A fim de facilitar os cálculos de $\varphi$ foi adotada uma linha de tendência em função da altura do painel. Considerando uma umidade de $60 \%$ a função que melhor representou o problema foi um polinômio do quarto grau:

$$
\begin{aligned}
& \varphi=8.10^{-8}\left(\mathrm{x}_{1}\right)^{4}-1 \cdot 10^{-5}\left(\mathrm{x}_{1}\right)^{3}+8.10^{-4}\left(\mathrm{x}_{1}\right)^{2}-0,0223 \mathrm{x}_{1}+3,437 \\
& \text { onde } \quad \mathrm{a}_{\mathrm{dif}}-\text { flecha instantânea } \\
& \qquad \mathrm{x}_{1}-\text { altura do painel }
\end{aligned}
$$


Portanto, a flecha final corresponde à soma das duas deformações:

$\mathrm{a}_{\text {total }}=\mathrm{a}_{\text {inst }}+\mathrm{a}_{\mathrm{dif}}$

Portanto deve-se respeitar o limite imposto: $\mathrm{a}_{\text {total }} \leq \mathrm{a}_{\lim }=\frac{\mathrm{L}}{350}$

\section{VERIFICAÇÃO DO ESTADO LIMITE ÚLTIMO - SOLICITAÇÕES NORMAIS}

A seguir serão feitas verificações quanto ao estado limite último de solicitações normais.

a) cálculo da deformação de pré-alongamento $\left(\varepsilon_{\text {pnd }}\right)$ : a deformação da armadura ativa correspondente à força de neutralização $\mathrm{P}_{\mathrm{n}}$ é o chamado pré-alongamento é calculado a seguir.

$$
\begin{aligned}
& \sigma_{\mathrm{cp}}=\frac{\mathrm{P}_{\mathrm{oo}}\left(\mathrm{e}_{\mathrm{p}}\right)^{2}}{\mathrm{I}_{\mathrm{c}}}+\frac{\mathrm{P}_{\mathrm{oo}}}{\mathrm{A}_{\mathrm{c}}} \\
& \mathrm{P}_{\mathrm{nd}}=\gamma_{\mathrm{p}}\left(\mathrm{P}_{\mathrm{oo}}+\alpha_{\mathrm{p}} \mathrm{x}_{2} \mid \sigma_{\mathrm{cp}}\right) \quad \text { onde } \gamma_{\mathrm{p}}=0,9
\end{aligned}
$$

A partir daí pode-se calcular $\varepsilon_{\mathrm{pn}}: \quad \varepsilon_{\mathrm{pnd}}=\frac{\mathrm{P}_{\mathrm{nd}}}{\mathrm{x}_{2} \mathrm{E}_{\mathrm{p}}}$

b) cálculo de $\left(\varepsilon_{\mathrm{pd}}\right)$ : a deformação total de cálculo da armadura ativa corresponde à soma do pré-alongamento e de um acréscimo da armadura ativa $\left(\varepsilon_{\mathrm{pld}}\right)$. Será considerado como referência no cálculo de $\mathrm{k}_{\mathrm{c}}, \beta_{\mathrm{x}}, \sigma_{\mathrm{pd}}, \varepsilon_{\mathrm{p} 1 \mathrm{~d}}$, a Tabela para o cálculo à flexão de seções retangulares de concreto protendido apresentado em HANAI (1999).

- Determinação do momento atuante $\mathrm{M}_{\mathrm{d}}: \mathrm{M}_{\mathrm{d}}=1,4\left(\mathrm{M}_{\mathrm{g} 1}+\mathrm{M}_{\mathrm{g}_{2}}+\mathrm{M}_{\mathrm{q}}\right)$

- Determinação de $\mathrm{k}_{\mathrm{c}}: \mathrm{k}_{\mathrm{c}}=\frac{\mathrm{b}_{\mathrm{a}} \mathrm{d}^{2}}{\mathrm{M}_{\mathrm{d}}}$

$$
\begin{aligned}
& \text { onde } \mathrm{b}_{\mathrm{a}}=\mathrm{b}-\mathrm{n}(2 \mathrm{r}) \\
& \qquad \begin{aligned}
\mathrm{d} & - \text { altura útil: } \mathrm{d}=\mathrm{x}_{1}-\mathrm{c} \\
\mathrm{b} & =120
\end{aligned}
\end{aligned}
$$




$$
\begin{aligned}
& \mathrm{n} \text { - número de furos } \\
& \mathrm{r} \text { - raio do círculo } \\
& \mathrm{c} \text { - cobrimento }
\end{aligned}
$$

- A partir de $\mathrm{k}_{\mathrm{c}}$ calcula-se $\beta_{\mathrm{x}}$ : a fim de facilitar os cálculos, definiu-se uma linha de tendência para $\beta_{\mathrm{x}}$ para cada classe do concreto. A melhor função que representou o problema foi uma função de potência.

$$
\begin{array}{ll}
\text { C-30: } & \beta_{\mathrm{x}}=0,8174\left(\mathrm{k}_{\mathrm{c}}\right)^{-1,0588} \\
\mathrm{C}-35: & \beta_{\mathrm{x}}=0,6982\left(\mathrm{k}_{\mathrm{c}}\right)^{-1,0626} \\
\mathrm{C}-40: & \beta_{\mathrm{x}}=0,6068\left(\mathrm{k}_{\mathrm{c}}\right)^{-1,0616} \\
\mathrm{C}-45: & \beta_{\mathrm{x}}=0,5362\left(\mathrm{k}_{\mathrm{c}}\right)^{-1,0619}
\end{array}
$$

A tensão da armadura ativa para o aço CP-175 é então estimada da mesma forma. Considerou-se uma linha de tendência e a melhor função que representou o problema foi um polinômio do quinto grau:

$$
\sigma_{\mathrm{Pd}}=85176\left(\beta_{\mathrm{x}}\right)^{5}-88498\left(\beta_{\mathrm{x}}\right)^{4}+30816\left(\beta_{\mathrm{x}}\right)^{3}-4446,2\left(\beta_{\mathrm{x}}\right)^{2}+253,32 \beta_{\mathrm{x}}+132,88
$$

- $\quad$ A partir de $\beta_{\mathrm{x}}$ pode-se calcular $\varepsilon_{\mathrm{pld}}$ :

$\varepsilon_{\mathrm{p} 1 \mathrm{~d}}=10$ se $\beta_{\mathrm{x}} \leq 0,24$

$\varepsilon_{\text {pld }}=285,72\left(\beta_{\mathrm{x}}\right)^{4}-617,02\left(\beta_{\mathrm{x}}\right)^{3}+522,87\left(\beta_{\mathrm{x}}\right)^{2}-217,05 \beta_{\mathrm{x}}+40,579$ se $\beta_{\mathrm{x}}>0,24$

Então $\varepsilon_{\mathrm{pd}}=\varepsilon_{\mathrm{pld}}+\varepsilon_{\mathrm{pnd}}$

- Cálculo do braço de alavanca: considerou-se que a mesa de compressão não corta a seção vazada

$$
\begin{aligned}
& \beta_{x}=\frac{x}{d} \Rightarrow x=\beta_{x} d \\
& z_{p}=d-0,4 x \\
& y=0,8 x
\end{aligned}
$$
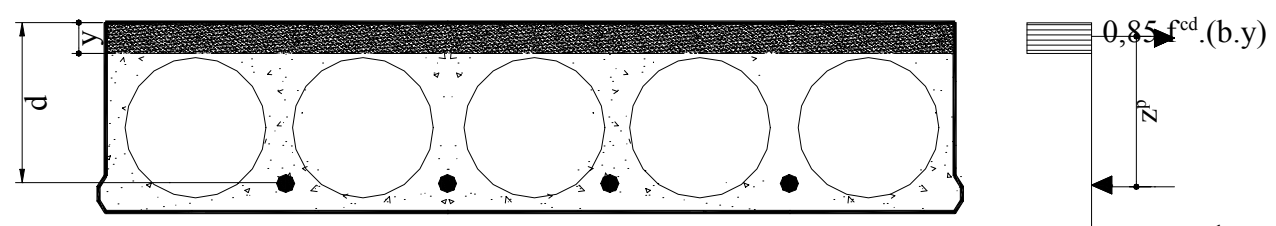
- Cálculo da armadura ativa necessária:

$$
A_{p_{\text {neces }}}=\frac{M_{d}}{\sigma_{P d} z_{p}}
$$

Portanto: $\mathrm{A}_{\text {pneces }} \leq \mathrm{x}_{2}$

$$
\text { onde } \mathrm{x}_{2}=\mathrm{A}_{\mathrm{p}}
$$

c) cálculo do momento resistente, $\mathrm{M}_{\mathrm{u}}$ :

$$
\begin{aligned}
& \mathrm{M}_{\mathrm{u}}=\mathrm{A}_{\mathrm{p}} \sigma_{\mathrm{Pd}} \mathrm{z}_{\mathrm{p}}=\mathrm{x}_{2} \sigma_{\mathrm{Pd}} \mathrm{z}_{\mathrm{p}} \\
& \text { Portanto } \mathrm{M}_{\mathrm{d}} \leq \mathrm{M}_{\mathrm{u}}
\end{aligned}
$$

\section{VERIFICAÇÃO DO ESTADO LIMITE ÚLTIMO - SOLICITAÇÕES}

\section{TANGENCIAIS}

A seguir serão feitas verificações quanto ao estado limite último de solicitações tangenciais.

a) tensão do concreto $\left(\tau_{\mathrm{wd}}\right)$ :

$$
\begin{array}{cl}
\tau_{\mathrm{wd}}=\frac{\mathrm{V}_{\mathrm{d}}}{\mathrm{b}_{\mathrm{w}} \mathrm{d}} & \\
\text { onde } & \mathrm{V}_{\mathrm{d}}=\frac{1,4\left(\mathrm{~g}_{1}+\mathrm{g}_{2}+\mathrm{q}\right)}{2} \\
& \mathrm{~b}_{\mathrm{w}}=\mathrm{b}_{\mathrm{a}}=\mathrm{b}-\mathrm{n}(2 \mathrm{r}) \\
& \mathrm{d}=\mathrm{x}_{1}-\mathrm{c}
\end{array}
$$

b) tensão última resistente:

$$
\tau_{\mathrm{Rd} 1}=\left(1+\frac{\mathrm{M}_{\mathrm{o}}}{\mathrm{M}_{\mathrm{d}, \max }}\right) \psi_{4} \sqrt[3]{\mathrm{x}_{3}} \text { respeitando o valor absoluto } \tau_{\mathrm{Rd} 1} \leq 1,2 \mathrm{MPa}
$$

sendo: $\psi_{4}=0,14 \frac{\alpha \mathrm{k}}{1-3 \mathrm{~d} / \mathrm{L}}$

onde

$\mathrm{M}_{\mathrm{o}}$ - valor do momento fletor que anula a tensão normal na borda menos comprimida 
$\mathrm{M}_{\mathrm{d}, \text { Max }}$ - momento fletor da seção transversal que está mais solicitada à flexão, no trecho considerado pelo cálculo (maior valor do semi-tramo considerado)

$\mathrm{x}_{3}$ - resistência do concreto do elemento pré-moldado $\left(\mathrm{f}_{\mathrm{ck}}\right)$ em $\mathrm{MPa}$

$\mathrm{d}$ - altura útil

$\mathrm{k}=1,6-\mathrm{d} \quad \mathrm{d}$ em metros

$\alpha=1+50 \rho$

$\rho=x_{2} / A_{c}$

Portanto, $\tau_{\mathrm{WD}} \leq \tau_{\mathrm{RD} 1}$

\section{CÁlCULO DA FUNÇÃO CUSTO}

Os vários custos envolvidos na produção de um painel alveolar com capa de regularização foram discriminados e apresentados em detalhes a seguir. Os custos para cada parcela são obtidos a partir dos insumos apresentados no Capítulo 4. Portanto cada valor final de parcela corresponderá ao custo em $\mathrm{R} \$ / \mathrm{m}^{2}$.

Conforme apresentado no Capítulo 4, no equacionamento da função custo foram utilizados valores cedidos pela empresa Marka situada em Franca, SP, e pela Revista Construção ${ }^{1}$. Os valores utilizados no cálculo da função custo são:

$$
\begin{aligned}
& \mathrm{h}_{\text {capa }}=4 \mathrm{~cm} \\
& \mathrm{f}_{\mathrm{ck}, 2}=20 \mathrm{MPa}
\end{aligned}
$$

As variáveis do problema são:

$$
\begin{aligned}
& \mathrm{x}_{1} \text { - altura do painel em } \mathrm{cm} \\
& \mathrm{x}_{2}-\text { armadura ativa em } \mathrm{cm}^{2} \\
& \mathrm{x}_{3}-\text { resistência do concreto em } \mathrm{kN} / \mathrm{cm}^{2}
\end{aligned}
$$

\section{I) CUSTOS DE EXECUÇÃO (R\$/m $\left.\mathbf{m}^{2}\right)$}

A.Custos da matéria-prima:

$$
\text { Concreto ( } \left.\text { Tcust }_{\text {conc }}\right) \text { : }
$$

\footnotetext{
${ }^{1}$ Construção, São Paulo, no 2782, 4/6/2001.
} 
A área de concreto do painel $\left(\mathrm{A}_{\mathrm{c}}\right)$ está $\mathrm{em}^{2} \mathrm{~cm}^{2}$, portanto dividiu-se a área por 10000 , com o objetivo de transformá-la para $\mathrm{m}^{2}$. Os insumos apresentados no Capítulo $4 \mathrm{e}$ utilizados nesta seção são os seguintes:

$$
\begin{aligned}
& \text { Custo_material }=24,75 \times 3+74,25 \mathrm{R} \$ / \mathrm{m}^{3} \\
& \text { Custo_mão_de_obra }=4,4 \mathrm{R} \$ / \mathrm{m}^{3} \\
& \text { Custo_equipamento }=8,35 \mathrm{R} \$ / \mathrm{m}^{3}
\end{aligned}
$$

$\underline{\text { material: }} \quad$ cust $_{\mathrm{cl}}=$ custo_material $\frac{\mathrm{A}_{\mathrm{c}}}{\mathrm{b}}=\left(24,75 \mathrm{x}_{3}+74,25\right) \frac{\left(760,05 \ln \left(\mathrm{x}_{1}\right)-865,05\right)}{10000.1,20}$ mão-de-obra: $\quad$ cust $_{\text {c2 }}=$ custo_mão_de_obra $\frac{\mathrm{A}_{\mathrm{c}}}{\mathrm{b}}=4,4 \frac{\left(760,05 \ln \left(\mathrm{x}_{1}\right)-865,05\right)}{10000.1,20}$ equipamentos: $\quad$ cust $_{\mathrm{c} 3}=$ custo_equipamento $\frac{\mathrm{A}_{\mathrm{c}}}{\mathrm{b}}=8,35 \frac{\left(760,05 \ln \left(\mathrm{x}_{1}\right)-865,05\right)}{10000.1,20}$ $\therefore$ Tcust $_{\text {conc }}=$ cust $_{\mathrm{c} 1}+$ cust $_{\mathrm{c} 2}+$ cust $_{\mathrm{c} 3}$

\section{Armadura (Tcust ${ }_{\text {arm}}$ ):}

Os insumos apresentados no Capítulo 4 e utilizados nesta seção são os seguintes:

$$
\begin{aligned}
& \text { Custo_material }=2,95 \mathrm{R} \$ / \mathrm{kg} \\
& \text { Custo_mão_de_obra }=0,295 \mathrm{R} \$ / \mathrm{kg} \\
& \text { Custo_equipamento }=0,07 \mathrm{R} \$ / \mathrm{kg}
\end{aligned}
$$

$$
\begin{array}{ll}
\text { material: } & \text { cust }_{\mathrm{a} 1}=\text { custo_material.0,66 } \mathrm{x}_{2}=2,95.0,66 \mathrm{x}_{2} \\
\underline{\text { mão-de-obra: }} & \text { cust }_{\mathrm{a} 2}=\text { custo_mão_de_obra.0,66 } \mathrm{x}_{2}=0,295.0,66 \mathrm{x}_{2} \\
\underline{\text { equipamentos: }} & \text { cust }_{\mathrm{a} 3}=\text { custo_equipamento.0,66 } \mathrm{x}_{2}=0,07.0,66 \mathrm{x}_{2} \\
\therefore \text { Tcust }_{\mathrm{arm}}=\text { cust }_{\mathrm{a} 1}+\text { cust }_{\mathrm{a} 2}+\text { cust }_{\mathrm{a} 3}
\end{array}
$$

\section{B. Custos adicionais (Tcust $\left.t_{a d c}\right)$ :}

Os insumos apresentados no Capítulo 4 e utilizados nesta seção são os seguintes:

Custo_mão_de_obra $=4,4 \mathrm{R} \$ / \mathrm{m}^{3}$

Custo_equipamento $=1,67 \mathrm{R} \$ / \mathrm{m}^{3}$ 
$\underline{\text { mão-de-obra: }}$ cust $_{\text {adcl }}=$ custo_mão_de_obra $\frac{\mathrm{A}_{\mathrm{c}}}{\mathrm{b}}=4,4 \frac{\left(760,05 \ln \left(\mathrm{x}_{1}\right)-865,05\right)}{10000.1,20}$

equipamentos: $\quad$ cust $_{\text {adc2 }}=$ custo_equipamento $\frac{\mathrm{A}_{\mathrm{c}}}{\mathrm{b}}=1,67 \frac{\left(760,05 \ln \left(\mathrm{x}_{1}\right)-865,05\right)}{10000.1,20}$

$\therefore$ Tcust $_{\text {adc }}=$ cust $_{\text {adc1 }}+$ cust $_{\text {adc2 }}$

C. Custos indiretos administrativos (Tcust $\left.{ }_{\text {ind }}\right)$

$\therefore$ Tcust $_{\text {ind }}=0,1\left(\right.$ Tcust $_{\text {conc }}+$ Tcust $_{\text {arm }}+$ Tcust $\left._{\text {adc }}\right)$

D. Custos tributários (cust trib)

Os insumos apresentados no Capítulo 4 e utilizados nesta seção são os seguintes:

c_tributario $=84 \mathrm{R} \$ / \mathrm{m}^{3}$

$\therefore$ cust $_{\text {trib }}=\mathrm{c}_{-}$tributario $\frac{\mathrm{A}_{\mathrm{c}}}{\mathrm{b}}=84 \frac{\left(760,05 \ln \left(\mathrm{x}_{1}\right)-865,05\right)}{10000.1,20}$

\section{II) CUSTOS DE TRANSPORTE EXTERNO $\left(\mathrm{R} \$ / \mathrm{m}^{2}\right)$}

Os insumos apresentados no Capítulo 4 e utilizados nesta seção são os seguintes:

$$
\text { custo_transp }=52 \mathrm{R} \$ / \mathrm{m}^{3}
$$

serviços:

$$
\text { cust }_{\text {tr }}=\text { custo }_{-} \operatorname{transp} \frac{\mathrm{A}_{\mathrm{c}}}{\mathrm{b}}=52 \frac{\left(760,05 \ln \left(\mathrm{x}_{1}\right)-865,05\right)}{10000.1,20}
$$

\section{III) CUSTOS DA APLICAÇÃO (R\$/m²)}

A. Custos da montagem do painel alveolar (Tcust ${ }_{m o n}$ )

Os insumos apresentados no Capítulo 4 e utilizados nesta seção são os seguintes:

Custo_mão_de_obra $=11,96 \mathrm{R} \$ / \mathrm{m}^{3}$

Custo_equipamento $=9,79 \mathrm{R} \$ / \mathrm{m}^{3}$

$\underline{\text { mão-de-obra: }}$ cust ${ }_{\text {mo }}=$ custo_mão_de_obra $\frac{A_{c}}{b}=11,96 \frac{\left(760,05 \ln \left(\mathrm{x}_{1}\right)-865,05\right)}{10000.1,20}$ 
equipamentos: $\quad$ cust $_{\mathrm{eq}}=$ custo_equipamento $\frac{\mathrm{A}_{\mathrm{c}}}{\mathrm{b}}=9,79 \frac{\left(760,05 \ln \left(\mathrm{x}_{1}\right)-865,05\right)}{10000.1,20}$

$$
\therefore \text { Tcust }_{\text {mon }}=\text { cust }_{\mathrm{mo}}+\text { cust }_{\mathrm{eq}}
$$

\section{B. Custos do concreto para regularização (Tcust reg $_{\text {) }}$}

Os insumos apresentados no Capítulo 4 e utilizados nesta seção são os seguintes:

$$
\begin{aligned}
& \text { custo_material }=123,75 \mathrm{R} \$ / \mathrm{m}^{3} \\
& \text { custo_mão_de_obra }=41,68 \mathrm{R} \$ / \mathrm{m}^{3} \\
& \text { custo_equipamento }=1,67 \mathrm{R} \$ / \mathrm{m}^{3}
\end{aligned}
$$

$\underline{\text { Material: }} \quad$ cust $_{\text {regl }}=$ custo_material $\frac{\mathrm{h}_{\text {capa }}}{100}=123,75 \frac{\mathrm{h}_{\text {capa }}}{100}$

$$
\begin{array}{ll}
\text { mão-de-obra: } & \text { cust }_{\text {reg2 }}=\text { custo_mão_de_obra } \frac{\mathrm{h}_{\text {capa }}}{100}=41,68 \frac{\mathrm{h}_{\text {capa }}}{100} \\
\text { equipamentos: } & \text { cust }_{\text {reg3 }}=\text { custo_equipamento } \frac{\mathrm{h}_{\text {capa }}}{100}=1,67 \frac{\mathrm{h}_{\text {capa }}}{100}
\end{array}
$$

$$
\therefore \text { Tcust }_{\text {reg }}=\text { cust }_{\text {reg1 }}+\text { cust }_{\text {reg2 }}+\text { cust }_{\text {reg3 }}
$$

\section{Custos das ligações (Tcust lig )}

Os insumos apresentados no Capítulo 4 e utilizados nesta seção são os seguintes:

$$
\begin{aligned}
& \text { custo_material }=371,25 \mathrm{R} \$ / \mathrm{m}^{3} \\
& \text { custo_mão_de_obra }=2,20 \mathrm{R} \$ \mathrm{~m}^{3}
\end{aligned}
$$

material: $\quad$ cust $_{\text {lig1 }}=$ custo_material $\frac{\mathrm{h}_{\text {capa }}}{100}=371,25 \frac{\mathrm{h}_{\text {capa }}}{100}$

mão-de-obra:

$$
\text { cust }_{\text {lig2 }}=\text { custo_mão_de_obra } \frac{\mathrm{x}_{1}}{100}=2,20 \frac{\mathrm{x}_{1}}{100}
$$

$$
\therefore \text { Tcust }_{\text {lig }}=\text { cust }_{\text {lig1 }}+\text { cust }_{\text {lig } 2}
$$

D. Custos indiretos administrativos (Tcust $t_{\text {adma }}$ )

$$
\left.\therefore \text { Tcust }_{\text {adma }}=0,2 \text { (cust }_{\text {mon }}+\text { Tcust }_{\text {reg }}+\text { Tcust }_{\text {lig }}\right)
$$


Portanto, os vários custos envolvidos na produção de um painel alveolar com capa estrutural foram somados e a expressão final da função em $\mathrm{R} \$ / \mathrm{m}^{2}$ é:

$\mathrm{f}(\mathbf{x})=11,578 \ln \left(\mathrm{x}_{1}\right)+12,663+0,0528+1,1\left(24,75 \mathrm{x}_{3}+74,25\right)\left(0,063 \ln \left(\mathrm{x}_{1}\right)-0,0721\right)+$ $\left(0,0633 \ln \left(\mathrm{x}_{1}\right)-0,0721\right)+2,407 \mathrm{x}_{2}$

onde

$\mathrm{x}_{1}$ - altura do painel em $\mathrm{cm}$

$\mathrm{x}_{2}-$ armadura ativa em $\mathrm{cm}^{2}$

$\mathrm{x}_{3}-$ resistência do concreto em $\mathrm{kN} / \mathrm{cm}^{2}$

Supondo por exemplo que as variáveis sejam:

$$
\begin{aligned}
& \mathrm{x}_{1}=21,47 \mathrm{~cm} ; \\
& \mathrm{x}_{2}=2,67 \mathrm{~cm}^{2} ; \\
& \mathrm{x}_{3}=3,07 \mathrm{kN} / \mathrm{cm}^{2},
\end{aligned}
$$

Então o custo final é de $\mathrm{f}(\mathrm{x})=75,91 \mathrm{R} \$ / \mathrm{m}^{2}$ 


\section{APÊNDICE E}

Dimensionamento de um painel alveolar com capa estrutural 


\section{DIMENSIONAMENTO DE UM PAINEL ALVEOLAR COM CAPA ESTRUTURAL}

\section{DEFINIÇÃO DO PROBLEMA}

Conforme apresentado no Apêndice $\mathrm{D}$, todo o dimensionamento foi feito utilizando o software Mathcad 2000 Professional. Entretanto, com o objetivo de facilitar a compreensão do dimensionamento, achou-se necessário apresentar um roteiro de cálculo em texto corrido.

O problema de otimização tratado neste apêndice é o da minimização da função custo de um painel alveolar com capa estrutural. A seção transversal do painel é mostrada na Figura 1. Deve salientar que pela complexidade do problema proposto neste trabalho, somente serão consideradas apenas as verificações das fases transitórias correspondente ao elemento pré-moldado e as verificações no estado limite último da seção composta.

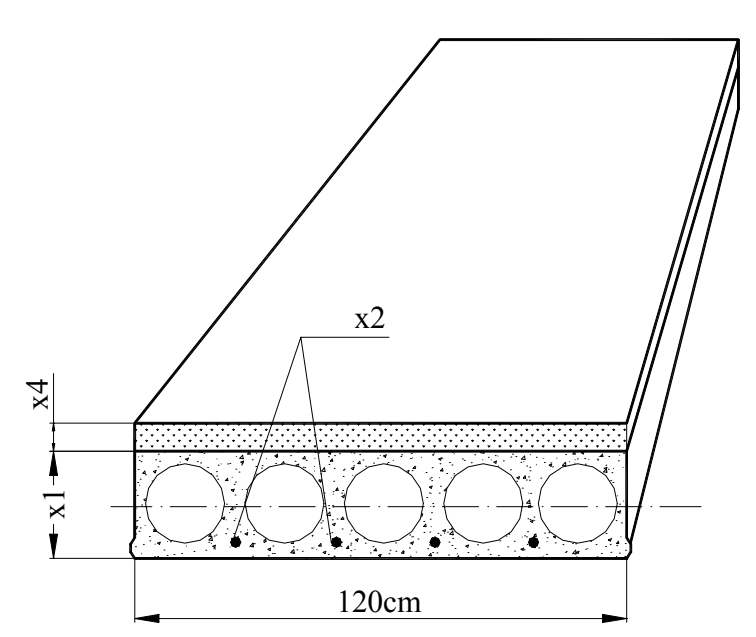

$\mathrm{x}_{1}$ - altura do painel alveolar

$\mathrm{x}_{2}-$ armadura de protensão

$\mathrm{x}_{4}$ - altura da capa de concreto

Figura 1. Painel alveolar com capa estrutural

As variáveis envolvidas no equacionamento do problema, conforme apresentado na figura, são definidas a seguir.

- $\mathrm{x}_{1}$ - altura do painel alveolar

- $\mathrm{x}_{2}$ - área de armadura de protensão

- $\mathrm{x}_{3}-$ resistência do concreto do elemento pré-moldado 
- $\mathrm{X}_{4}$ - altura da capa de concreto

- $\mathrm{x}_{5}$ - resistência do concreto da capa

Serão consideradas no dimensionamento ainda as seguintes características:

- vão do painel $-\mathrm{L}=6 \mathrm{~m}$

- Largura do painel $-\mathrm{b}=120 \mathrm{~cm}$

- Um nível de armadura localizada no bordo inferior

- Protensão limitada

- Cordoalhas de 7 fios - relaxação baixa

- $\mathrm{CP}-175 \mathrm{RB} 9,5$

\section{CARACTERÍSTICAS GEOMÉTRICAS}

$\mathrm{Na}$ definição da área de concreto do painel alveolar será considerada a mesma aproximação apresentada no Apêndice D. No cálculo do valor da área de concreto serão consideradas as mesmas características geométricas das seções apresentadas nas tabelas do PCI. No cálculo serão considerados painéis alveolares com vazamento circular. No cálculo da seção composta considerou-se a seção homogeneizada.

a) a partir dos valores de áreas obtidas das tabelas do PCI foi definida a mesma função aproximada da área para os vários tipos de painéis alveolares:

$$
\begin{aligned}
& \mathrm{A}_{\mathrm{c}}=760,05 \ln \left(\mathrm{x}_{1}\right)-865,05 \text { área do elemento pré-moldado } \\
& \mathrm{A}_{\mathrm{ch}}=\mathrm{A}_{\mathrm{c}}+\mathrm{m} \cdot \mathrm{A}_{\mathrm{cm}} \quad \text { área da seção homogeneizada } \\
& \text { onde } \mathrm{m}=\sqrt{\frac{\mathrm{f}_{\mathrm{ck} 2}}{\mathrm{f}_{\mathrm{ck}}}}=\sqrt{\frac{\mathrm{x}_{5}}{\mathrm{x}_{3}}}
\end{aligned}
$$

Conforme visto no Apêndice D, a quantidade de furos (n) e o raio do círculo (r) são dados por:

$$
\begin{aligned}
& \mathrm{n}=\frac{116,19}{\mathrm{x}_{1}-1,27} \\
& \mathrm{r}=\sqrt{\frac{\left(\mathrm{x}_{1} \mathrm{~b}-\mathrm{A}_{\mathrm{c}}\right)}{\pi \mathrm{n}}}
\end{aligned}
$$


b) a inércia da seção é dada por:

$$
\begin{aligned}
& I_{c}=\frac{b\left(x_{1}\right)^{3}}{12}-\frac{\pi(2 r)^{4} n}{64} \text { inércia da seção do elemento pré-moldado } \\
& I_{c h}=I_{c}+m I_{c m} \quad \text { inércia da seção composta }
\end{aligned}
$$

c) a distância da armadura de protensão $\left(\mathrm{e}_{\mathrm{p}}\right)$ ao centro de gravidade (CG) corresponde a distância do CG da armadura até o centro de gravidade da laje e é definida a seguir. A Figura 2 mostra em detalhes as distâncias da armadura e do painel, considerando o painel isolado e a seção composta.

Seção isolada do painel

$$
\begin{aligned}
& \mathrm{e}_{\mathrm{p}}=\mathrm{y}_{\mathrm{cg}}-\mathrm{c}-\phi / 2 \\
& \mathrm{y}_{\mathrm{cg}}=\frac{\mathrm{x}_{1}}{2}
\end{aligned}
$$

seção composta

$$
\begin{aligned}
& \mathrm{e}_{\mathrm{pc}}=\mathrm{y}_{\mathrm{cgc}}-\mathrm{c}-\phi / 2 \\
& \mathrm{y}_{\mathrm{cgc}}=\frac{\mathrm{A}_{\mathrm{c}} \mathrm{y}_{\mathrm{cg}}+\mathrm{A}_{\mathrm{capa}}\left(\mathrm{x}_{1}+0,5 \mathrm{x}_{4}\right)}{\mathrm{A}_{\mathrm{c}}+\mathrm{A}_{\text {capa }}}
\end{aligned}
$$

$$
\begin{aligned}
& \text { onde } \quad \mathrm{c}-\text { cobrimento }(\mathrm{c}=30 \mathrm{~mm}) \\
& \phi \text { - diâmetro da armadura }(\phi / 2=5 \mathrm{~mm}) \\
& \mathrm{A}_{\mathrm{capa}} \text { - área da capa de concreto } \\
& \mathrm{y}_{\mathrm{cg}}-\text { centro de gravidade do elemento isolado } \\
& \mathrm{y}_{\mathrm{cgc}}-\text { centro de gravidade da seção composta } \\
& \mathrm{e}_{\mathrm{pc}}-\text { distância da armadura de protensão ao } \mathrm{CG} \text { da seção } \\
& \text { composta }
\end{aligned}
$$

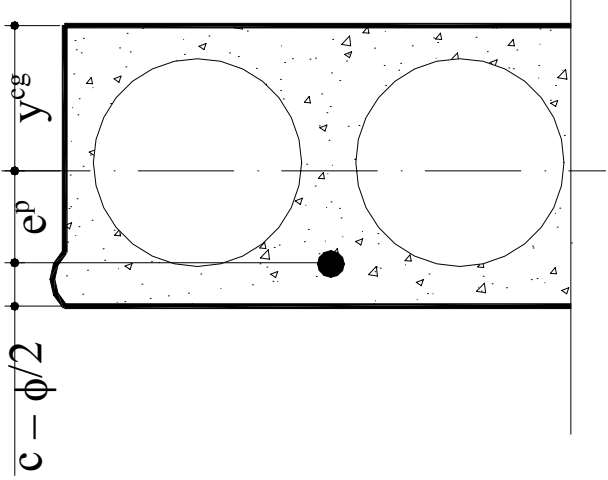

a) centro de gravidade do elemento

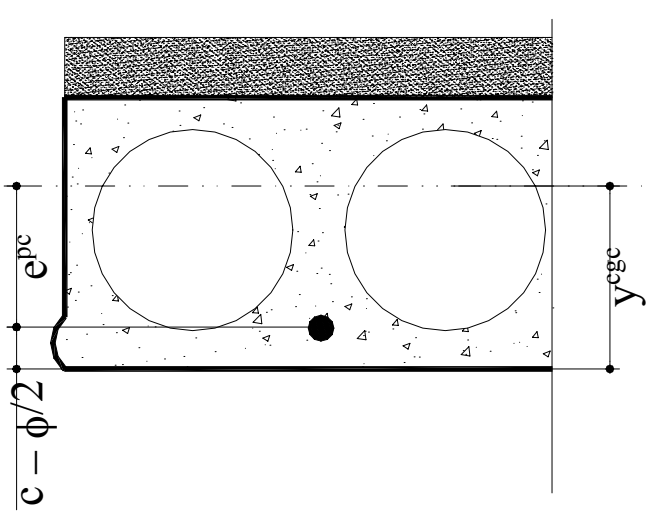

b) centro de gravidade da seção composta

Figura 2. Centro de gravidade do elemento e da seção composta 
d) os módulos resistentes são:

- do elemento isolado:

$$
\mathrm{w}_{1}=\frac{\mathrm{I}_{\mathrm{c}}}{\mathrm{y}_{\mathrm{cg}}} \quad \mathrm{w}_{2}=\frac{\mathrm{I}_{\mathrm{c}}}{\mathrm{y}_{\mathrm{cg}}}
$$

- da seção composta:

$$
\begin{array}{ll}
\mathrm{y}_{1}=\mathrm{y}_{\mathrm{cgc}} & \mathrm{y}_{2}=\mathrm{y}_{\mathrm{cgc}}-\left(\mathrm{x}_{1}-\mathrm{x}_{4}\right) \\
\mathrm{W}_{\mathrm{c} 1}=\frac{\mathrm{I}_{\mathrm{ch}}}{\mathrm{y}_{1}} & \mathrm{~W}_{\mathrm{c} 2}=\frac{\mathrm{I}_{\mathrm{ch}}}{\mathrm{y}_{2}}
\end{array}
$$

Deve-se salientar que se adotou índice 1 para as variáveis que se referem à borda inferior e índice 2 à superior.

\section{CÁLCULO DOS ESFORÇOS SOLICITANTES E TENSÕES NO MEIO DO VÃO}

a) as cargas atuantes no painel são as seguintes:

\section{Carga permanente:}

- Peso próprio do painel $(\mathrm{kN} / \mathrm{m}): \mathrm{g}_{1}=\mathrm{A}_{\mathrm{c}} \gamma_{\mathrm{c}}$ onde $\gamma_{\mathrm{c}}=25 \mathrm{kN} / \mathrm{m}^{3}$

- Peso próprio da capa de regularização $(\mathrm{kN} / \mathrm{m}): \mathrm{g}_{2}=\mathrm{A}_{\text {capa }} \gamma_{\mathrm{cs}}$ onde $\gamma_{\mathrm{cs}}=24 \mathrm{kN} / \mathrm{m}^{3}$

- Carga devido ao revestimento $(\mathrm{kN} / \mathrm{m}): \mathrm{g}_{3}=1$

\section{Sobrecarga:}

- Adotado a partir da NBR-6120 uma carga de estacionamentos de $3 \mathrm{kN} / \mathrm{m}^{2}$ $(\mathrm{kN} / \mathrm{m}): \mathrm{q}=3 \mathrm{~b}$

b) os momentos fletores no meio do vão para cada carregamento:

$$
\mathrm{M}_{\mathrm{g} 1}=\frac{\mathrm{g}_{1} \mathrm{~L}^{2}}{8} \quad \mathrm{M}_{\mathrm{g}_{2}}=\frac{\mathrm{g}_{2} \mathrm{~L}^{2}}{8} \quad \mathrm{M}_{\mathrm{g}_{3}}=\frac{\mathrm{g}_{3} \mathrm{~L}^{2}}{8} \quad \mathrm{M}_{\mathrm{q}}=\frac{\mathrm{qL}^{2}}{8}
$$

c) as tensões no meio do vão devido a cada carregamento:

\section{bordo superior}




$$
\begin{aligned}
& \left.\sigma_{\mathrm{g}_{1}}=\frac{\mathrm{M}_{\mathrm{g}_{1}}}{\mathrm{w}_{1}} \quad \sigma_{\mathrm{g}_{2}}=\frac{\mathrm{M}_{\mathrm{g}_{2}}}{\mathrm{w}_{1}} \quad \text { seção do elemento pré-moldado ( } \mathrm{w}_{1}\right) \\
& \sigma_{1_{\mathrm{g}}}=\frac{\mathrm{M}_{\mathrm{g} 3}}{\mathrm{~W}_{\mathrm{cl}}} \quad \sigma_{{ }_{\mathrm{q} 1}}=\frac{\mathrm{M}_{\mathrm{q}}}{\mathrm{W}_{\mathrm{cl}}} \quad \text { seção composta }\left(\mathrm{W}_{\mathrm{cl}}\right)
\end{aligned}
$$

bordo inferior:

$$
\begin{aligned}
& \left.\sigma_{\mathrm{g}_{1}}=\frac{\mathrm{M}_{\mathrm{g}_{1}}}{\mathrm{w}_{2}} \quad \sigma_{\mathrm{g}_{2}}=\frac{\mathrm{M}_{\mathrm{g}_{2}}}{\mathrm{w}_{2}} \quad \text { seção do elemento pré-moldado ( } \mathrm{w}_{2}\right) \\
& \sigma_{2 \mathrm{~g} 3}=\frac{\mathrm{M}_{\mathrm{g} 3}}{\mathrm{~W}_{\mathrm{c} 2}} \quad \sigma_{2} \mathrm{q}_{1}=\frac{\mathrm{M}_{\mathrm{q}}}{\mathrm{W}_{\mathrm{c} 2}} \quad \text { seção composta }\left(\mathrm{W}_{\mathrm{c} 2}\right)
\end{aligned}
$$

\section{CÁLCULO DA FORÇA DE PROTENSÃO}

a) estimativa da força de protensão:

Foi adotado cordoalhas de 7 fios CP-175 RB. As principais propriedades mecânicas são descritas a seguir.

$$
\begin{aligned}
& \mathrm{f}_{\text {ptk }}=175 \mathrm{kN} / \mathrm{cm}^{2} \\
& \mathrm{f}_{\text {pyk }}=158 \mathrm{kN} / \mathrm{cm}^{2} \\
& \mathrm{E}_{\mathrm{p}}=19500 \mathrm{kN} / \mathrm{cm}^{2}
\end{aligned}
$$

onde: $\quad \mathrm{f}_{\mathrm{ptk}}$ - resistência característica à ruptura por tração do aço de protensão

$\mathrm{f}_{\text {pyk }}$ - limite de escoamento convencional do aço de protensão

$\mathrm{E}_{\mathrm{p}}$ - valor médio do módulo de elasticidade do aço de protensão

A tensão $\sigma_{P i}$ é calculada como o menor dos dois valores definidos abaixo

$$
\begin{gathered}
\sigma_{\mathrm{Pi}} \leq\left\{\begin{array}{l}
0,81 \mathrm{f}_{\mathrm{ptk}}=141,75 \mathrm{kN} / \mathrm{cm}^{2} \\
0,90 \mathrm{f}_{\mathrm{pyk}}=142,20 \mathrm{kN} / \mathrm{cm}^{2}
\end{array}\right. \\
\text { logo: } \sigma_{\mathrm{Pi}}=141,75 \mathrm{kN} / \mathrm{cm}^{2}
\end{gathered}
$$

$\mathrm{Na}$ definição do problema, a área da armadura é uma das variáveis e, portanto terá seu valor será arbitrado.

$$
\mathrm{P}_{\mathrm{i}, \text { ef }}=-\mathrm{A}_{\mathrm{p}} \sigma_{\mathrm{Pi}} 0,97=-\mathrm{x}_{2} \sigma_{\mathrm{Pi}} 0,97
$$


b) determinação de $\mathrm{P}_{\mathrm{a}}$ : o valor de $\mathrm{P}_{\mathrm{a}}$ que corresponde ao valor da força de protensão imediatamente anterior à transferência de tensões ao concreto. Determina-se o valor de $\mathrm{P}_{\mathrm{a}}$ a partir das seguintes perdas:

- Escorregamento dos fios na ancoragem: se a pista de protensão for longa a perda de protensão será muito pequena. Considerando então: comprimento da pista $=120000 \mathrm{~mm}$;

valor aproximado da deformação do aço, por ocasião do estiramento $=0,007$;

valor aproximado do alongamento do cabo na pista de $120 \mathrm{~m}$ é então: $120000 \times 0,007=840 \mathrm{~mm}$;

Se houver um recuo do ponto de ancoragem, por acomodação da ancoragem, da ordem de $6 \mathrm{~mm}$ a perda percentual será:

$\Delta \mathrm{P}_{\mathrm{anc}}=\frac{6 \mathrm{~mm}}{840 \mathrm{~mm}}=0,714 \%$

- Relaxação inicial da armadura: o cálculo da perda de protensão por relaxação do aço de protensão é feito pela determinação do coeficiente $\psi\left(\mathrm{t}, \mathrm{t}_{\mathrm{o}}\right)$ definido por:

$$
\psi\left(\mathrm{t}, \mathrm{t}_{\mathrm{o}}\right)=\frac{\Delta \sigma_{\mathrm{pr}}\left(\mathrm{t}, \mathrm{t}_{\mathrm{o}}\right)}{\sigma_{\mathrm{pi}}}
$$

onde: $\Delta \sigma_{\mathrm{pr}}\left(\mathrm{t}, \mathrm{t}_{\mathrm{o}}\right)-$ perda de tensão por relaxação pura (com comprimento constante) desde $o$ instante $t_{o}$ do estiramento da armadura até o instante t considerado $\sigma_{\mathrm{pi}}-$ tensão da armadura de protensão no instante de seu estiramento

portanto: $\frac{\sigma_{\mathrm{pi}}}{\mathrm{f}_{\mathrm{ptk}}}=0,81$ da tabela 5 da NBR-7197 o valor de $\psi_{1000}=3,5$

$$
\begin{array}{cc}
\text { Supondo } & \mathrm{T}_{\max }=75^{\circ} \\
& \mathrm{T}_{\mathrm{o}}=23^{\circ} \\
\mathrm{T}=13 \mathrm{~h} & \\
\text { Então } \mathrm{t}-\mathrm{t}_{\mathrm{o}}= & \frac{\mathrm{T}_{\max }}{\mathrm{t}_{\mathrm{o}}} \mathrm{t}=42,39 \mathrm{~h}
\end{array}
$$




$$
\begin{aligned}
& \psi\left(\mathrm{t}, \mathrm{t}_{\mathrm{o}}\right)=\psi_{1000} \cdot\left(\frac{\mathrm{t}-\mathrm{t}_{\mathrm{o}}}{1000}\right)^{0,15} ; \\
& \text { tem-se: } \Delta \mathrm{P}_{\mathrm{csi}}=\psi(\mathrm{t}, \mathrm{to})=2,178 \%
\end{aligned}
$$

Logo as perdas finais são: $\quad \Delta \mathrm{P}_{\mathrm{P}_{\mathrm{i}} \rightarrow \mathrm{P}_{\mathrm{a}}}=\Delta \mathrm{P}_{\text {anc }}+\Delta \mathrm{P}_{\text {csi }}=2,983$

$$
\text { Então: } \mathrm{P}_{\mathrm{a}}=\frac{\left(100-\Delta \mathrm{P}_{\mathrm{P}_{\mathrm{i}} \rightarrow \mathrm{P}_{\mathrm{a}}}\right) \mathrm{P}_{\text {ief }}}{100}
$$

c) determinação de $\mathrm{P}_{\mathrm{o}}$ : o valor de $\mathrm{P}_{\mathrm{o}}$ corresponde ao instante imediatamente posterior à transferência de tensões ao concreto. A força de protensão por deformação imediata de concreto é decorrente do próprio processo de transferência da força de protensão ao concreto, que sofre a necessária deformação para ficar protendido.

A tensão do concreto é calculada da seguinte maneira: $\sigma_{c p}=\frac{P_{a}}{A_{c}}+\frac{P_{a}\left(e_{p}\right)^{2}}{I_{c}}$. Esta expressão é utilizada no caso de protensão aplicada numa única fibra, com excentricidade $\mathrm{e}_{\mathrm{p}}$.

A tensão da armadura, logo após a transferência de tensões ao concreto resulta em: $\sigma_{P_{0}}=\sigma_{P_{a}}+\frac{E_{p}}{E_{c}} \sigma_{c p}=\left(\frac{P_{a}}{A_{c}}+\frac{P_{a} e_{p}}{w_{1}}\right)+\frac{E_{p}}{E_{c}} \sigma_{c p}$ Logo: $\mathrm{P}_{\mathrm{o}}=\mathrm{P}_{\mathrm{a}}-\mathrm{x}_{2} \sigma_{\mathrm{P}_{\mathrm{o}}}$ As tensões devido a $\mathrm{P}_{\mathrm{o}}$ no bordo inferior e superior são:

$$
\sigma_{1 P_{0}}=\frac{P_{o}}{A_{c}}+\frac{P_{o} e_{p}}{w_{1}} \quad \sigma_{2 P_{o}}=\frac{P_{o}}{A_{c}}+\frac{P_{o} e_{p}}{w_{2}}
$$

A NBR 7197 estabelece que ao término das operações de protensão, a tensão $\sigma_{P o}$ não deve superar o menos dos seguintes limites: $\sigma_{\mathrm{P}_{\mathrm{i}}} \leq\left\{\begin{array}{l}0,77 \mathrm{f}_{\mathrm{ptk}} \\ 0,86 \mathrm{f}_{\mathrm{pyk}}\end{array}\right.$

c) determinação de $\mathrm{P}_{\mathrm{oo}}$ : o valor de $\mathrm{P}_{\mathrm{oo}}$ corresponde ao valor final da força de protensão, consideradas todas as perdas. A fim de facilitar os cálculos, as perdas progressivas devidas à retração e fluência do concreto e relaxação do aço de protensão não serão calculadas neste trabalho. As perdas finais foram estimadas em 30\%. Portanto, o valor de $\mathrm{P}_{\mathrm{oo}}$ que corresponde ao valor do final da força de protensão é: $\mathrm{P}_{\mathrm{oo}}=0,7 \mathrm{P}_{\text {ief }}$ 
As tensões devido à $\mathrm{P}_{\mathrm{oo}}$ no bordo inferior e superior são:

$$
\sigma_{1 \mathrm{P}_{\mathrm{oO}}}=\frac{\mathrm{P}_{\mathrm{oO}}}{\mathrm{A}_{\mathrm{c}}}+\frac{\mathrm{P}_{\mathrm{oo}} \mathrm{e}_{\mathrm{p}}}{\mathrm{w}_{1}} \quad \sigma_{2 \mathrm{P}_{\mathrm{oO}}}=\frac{\mathrm{P}_{\mathrm{oo}}}{\mathrm{A}_{\mathrm{c}}}+\frac{\mathrm{P}_{\mathrm{oo}} \mathrm{e}_{\mathrm{p}}}{\mathrm{w}_{2}}
$$

\section{VERIFICAÇÃO DAS TENSÕES AO LONGO DO VÃO}

Nessa seção limita-se à verificação da seção do apoio uma vez que a armadura não apresenta interrupção. A tensão da armadura $\sigma_{\mathrm{P}_{\mathrm{Oo}}}$ não pode ultrapassar os seguintes limites: $\begin{aligned} & \sigma_{\mathrm{c}, \lim }=0,70 \mathrm{f}_{\mathrm{ck}}=0,70 \mathrm{x}_{3} \\ & \sigma_{\mathrm{ct}, \lim }=0,3 \sqrt[3]{\left(\mathrm{f}_{\mathrm{ck}}\right)^{2}}=0,3 \sqrt[3]{\left(\mathrm{x}_{3}\right)^{2}} .\end{aligned}$

\section{VERIFICAÇÃO DAS TENSÕES NA SEÇÃO MAIS SOLICITADA}

A seguir serão feitas verificações no estado em vazio e em serviço para os bordos inferiores e superiores.

a) Verificação do estado em vazio:

- após a desmoldagem: atuam $\left(\mathrm{P}_{\mathrm{o}}+\mathrm{g}_{1}\right)$

$$
\sigma_{1_{\mathrm{d}}}=\sigma_{{ }_{1} \mathrm{P}_{\mathrm{o}}}+\sigma_{1 \mathrm{~g}_{1}} \quad \sigma_{2_{\mathrm{d}}}=\sigma_{2 \mathrm{P}_{\mathrm{o}}}+\sigma_{2 \mathrm{~g}_{1}}
$$

- fase de transporte (efeito dinâmico $\left.-\beta_{\mathrm{a} 1}=0,8\right)$ : atuam $\left(\mathrm{P}_{\mathrm{o}}+\beta_{\mathrm{a} 1} \mathrm{~g}_{1}\right)$

$$
\sigma_{1_{\mathrm{t}}}=\sigma_{1} \mathrm{P}_{\mathrm{o}}+\beta_{\mathrm{a}_{1}} \sigma_{1 \mathrm{~g}_{1}} \quad \sigma_{2_{\mathrm{t}}}=\sigma_{2} \mathrm{P}_{\mathrm{o}}+\beta_{\mathrm{a}_{1}} \sigma_{2 \mathrm{~g}_{1}}
$$

- fase de transporte (efeito dinâmico $\left.-\beta_{\mathrm{a} 2}=1,3\right)$ : atuam $\left(\mathrm{P}_{\mathrm{o}}+\beta_{\mathrm{a} 2} \mathrm{~g}_{1}\right)$

$$
\sigma_{1_{\mathrm{tt}}}=\sigma_{{ }_{1} \mathrm{P}_{\mathrm{o}}}+\beta_{\mathrm{a}_{2}} \sigma_{1 \mathrm{~g}_{1}} \quad \sigma_{2_{\mathrm{tt}}}=\sigma_{2 \mathrm{P}_{\mathrm{o}}}+\beta_{\mathrm{a}_{2}} \sigma_{2 \mathrm{~g}_{1}}
$$

- fase de armazenamento: atuam $\left(\mathrm{P}_{\mathrm{oo}}+\mathrm{g}_{1}\right)$

$$
\sigma_{1_{\mathrm{a}}}=\sigma_{{ }^{1} \mathrm{P}_{\mathrm{oo}}}+\sigma_{\mathrm{g}_{1}}
$$

$$
\sigma_{2 \mathrm{a}}=\sigma_{2 \mathrm{P}_{\mathrm{oo}}}+\sigma_{2 \mathrm{~g}_{1}}
$$

- fase de montagem: atuam $\left(\mathrm{P}_{\mathrm{o}}+\mathrm{g}_{1}+\mathrm{g}_{2}\right)$

$$
\sigma_{1_{\mathrm{m}}}=\sigma_{1_{\mathrm{P}_{\mathrm{o}}}}+\sigma_{1 \mathrm{~g}}+\sigma_{1 \mathrm{~g}} \quad \sigma_{2 \mathrm{~m}}=\sigma_{2 \mathrm{P}_{\mathrm{o}}}+\sigma_{2 \mathrm{~g}_{1}}+\sigma_{2 \mathrm{~g}_{2}}
$$


Essas tensões apresentadas em a) devem satisfazer os limites de descompressão e de formação de fissuras. A seguir é calculada a resistência característica à compressão e à tração na data da protensão e aos 28 dias.

Para o estado limite em vazio:

Na data da protensão

$\mathrm{f}_{\text {ckj }}=0,70 \mathrm{f}_{\text {ck }}$

compressão: $\sigma_{\mathrm{cj}, \mathrm{lim}}=0,70 \mathrm{f}_{\mathrm{ckj}}=0,49 \mathrm{x}_{3}$

tração: $\quad \sigma_{\text {ctj,lim }}=0,3 \sqrt[3]{\left(f_{\text {ckj }}\right)^{2}}=0,3 \sqrt[3]{\left(x_{3}\right)^{2}}$

$\underline{\text { Para o estado limite em serviço: }}$

Aos 28 dias

$\sigma_{\mathrm{c}, \lim }=0,70 \mathrm{f}_{\mathrm{ck}}=0,70 \mathrm{x}_{3}$
$\sigma_{\mathrm{ct}, \lim }=0,3 \sqrt[3]{\left(\mathrm{f}_{\mathrm{ck}}\right)^{2}}=0,3 \sqrt[3]{\left(\mathrm{x}_{3}\right)^{2}}$

onde

$\sigma_{1 \mathrm{~d}}, \sigma_{2 \mathrm{~d}}-$ tensão na fase de desmoldagem no bordo inferior e superior

$\sigma_{1 \mathrm{t}}, \sigma_{2 \mathrm{t}}, \sigma_{1 \mathrm{tt}}, \sigma_{2 \mathrm{tt}}-$ tensão na fase de transporte no bordo inferior e superior

$\sigma_{1 \mathrm{a}}, \sigma_{2 \mathrm{a}}-$ tensão na fase de armazenamento no bordo inferior e superior

$\sigma_{1 \mathrm{~m}}, \sigma_{2 \mathrm{~m}}-$ tensão na fase de montagem no bordo inferior e superior

$\sigma_{1 \mathrm{~g}_{2}}, \sigma_{2 \mathrm{~g}_{2}}-$ tensão devido ao peso próprio do enchimento e do concreto

moldado no local no bordo inferior e superior

$\sigma_{1 q}, \sigma_{2 q}-$ tensão devido à sobrecarga no bordo inferior e superior

$\sigma_{1 \mathrm{P}_{\mathrm{o}}}, \sigma_{2 \mathrm{P}_{\mathrm{o}}}-$ tensão devido à força de protensão instalada no concreto no bordo inferior e superior

$\beta_{\mathrm{a} 1}-$ coeficiente de ação dinâmica $\left(\beta_{\mathrm{a}_{1}}=0,8\right)$

$\beta_{\mathrm{a} 2}-$ coeficiente de ação dinâmica $\left(\beta_{\mathrm{a} 2}=1,3\right)$

$\sigma_{1 \mathrm{P}_{\mathrm{oo}}}, \sigma_{2 \mathrm{P}_{\mathrm{oo}}}-$ tensão devido à força de protensão após as perdas no bordo inferior e superior

$\sigma_{\text {ctj,lim }}$ - tensão limite de tração em j dias

$\sigma_{\mathrm{ct}, \lim }-$ tensão limite de tração 


$$
\begin{aligned}
& \sigma_{\mathrm{cj}, \mathrm{lim}}-\text { tensão limite de compressão em j dias } \\
& \sigma_{\mathrm{c}, \mathrm{lim}}-\text { tensão limite de compressão }
\end{aligned}
$$

\section{VERIFICAÇÃO DO ESTADO LIMITE ÚLTIMO - SOLICITAÇÕES NORMAIS}

A seguir serão feitas verificações quanto ao estado limite último de solicitações normais.

a) cálculo da deformação de pré-alongamento $\left(\varepsilon_{\text {pnd }}\right)$ : a deformação da armadura ativa correspondente à força de neutralização $\mathrm{P}_{\mathrm{n}}$ é o chamado pré-alongamento é calculado a seguir.

$$
\begin{aligned}
& \sigma_{\mathrm{cp}}=\frac{\mathrm{P}_{\mathrm{oo}}\left(\mathrm{e}_{\mathrm{p}}\right)^{2}}{\mathrm{I}_{\mathrm{ch}}}+\frac{\mathrm{P}_{\mathrm{oo}}}{\mathrm{A}_{\mathrm{ch}}} \\
& \mathrm{P}_{\mathrm{nd}}=\gamma_{\mathrm{p}}\left(\mathrm{P}_{\mathrm{oo}}+\alpha_{\mathrm{p}} \mathrm{x}_{2}\left|\sigma_{\mathrm{cp}}\right|\right) \quad \text { onde } \gamma_{\mathrm{p}}=0,9
\end{aligned}
$$

A partir daí pode-se calcular $\varepsilon_{\mathrm{pn}}: \quad \varepsilon_{\mathrm{pnd}}=\frac{\mathrm{P}_{\mathrm{nd}}}{\mathrm{x}_{2} \mathrm{E}_{\mathrm{p}}}$

b) cálculo de $\left(\varepsilon_{\mathrm{pd}}\right)$ : a deformação total de cálculo da armadura ativa corresponde à soma do pré-alongamento e de um acréscimo da armadura ativa $\left(\varepsilon_{\mathrm{p} 1 \mathrm{~d}}\right)$. Será considerado como referência no cálculo de $\mathrm{k}_{\mathrm{c}}, \beta_{\mathrm{x}}, \sigma_{\mathrm{pd}}, \varepsilon_{\mathrm{pld}}$, a Tabela para o cálculo à flexão de seções retangulares de concreto protendido apresentado em HANAI (1999).

- Determinação do momento atuante $\mathrm{M}_{\mathrm{d}}: \mathrm{M}_{\mathrm{d}}=1,4\left(\mathrm{M}_{\mathrm{g}_{1}}+\mathrm{M}_{\mathrm{g}_{2}}+\mathrm{M}_{\mathrm{g}_{3}}+\mathrm{M}_{\mathrm{q}}\right)$

- Determinação de $\mathrm{k}_{\mathrm{c}}: \mathrm{k}_{\mathrm{c}}=\frac{\mathrm{b}_{\mathrm{a}} \mathrm{d}^{2}}{\mathrm{M}_{\mathrm{d}}}$

$$
\text { onde } \begin{aligned}
\mathrm{b}_{\mathrm{a}} & =\mathrm{b}-\mathrm{n}(2 \mathrm{r}) \\
\mathrm{d} & - \text { altura útil: } \mathrm{d}=\left(\mathrm{x}_{1}+\mathrm{x}_{4}\right)-\mathrm{c} \\
\mathrm{b} & =120 \mathrm{~cm} \\
\mathrm{n} & - \text { número de furos } \\
\mathrm{r} & - \text { raio do círculo }
\end{aligned}
$$




$$
\mathrm{c} \text { - cobrimento }
$$

A partir de $k_{c}$ calcula-se $\beta_{\mathrm{x}}$ : a fim de facilitar os cálculos, definiu-se uma linha de tendência para $\beta_{\mathrm{x}}$ para cada classe do concreto. A melhor função que representou o problema foi uma função de potência.

$$
\begin{array}{ll}
\text { C-30: } & \beta_{\mathrm{x}}=0,8174\left(\mathrm{k}_{\mathrm{c}}\right)^{-1,0588} \\
\text { C-35: } & \beta_{\mathrm{x}}=0,6982\left(\mathrm{k}_{\mathrm{c}}\right)^{-1,0626} \\
\mathrm{C}-40: & \beta_{\mathrm{x}}=0,6068\left(\mathrm{k}_{\mathrm{c}}\right)^{-1,0616} \\
\mathrm{C}-45: & \beta_{\mathrm{x}}=0,5362\left(\mathrm{k}_{\mathrm{c}}\right)^{-1,0619}
\end{array}
$$

A tensão da armadura ativa para o aço CP-175 é então estimada da mesma forma. Considerou-se uma linha de tendência e a melhor função que representou o problema foi um polinômio do quinto grau:

$\sigma_{\mathrm{Pd}}=85176\left(\beta_{\mathrm{x}}\right)^{5}-88498\left(\beta_{\mathrm{x}}\right)^{4}+30816\left(\beta_{\mathrm{x}}\right)^{3}-4446,2\left(\beta_{\mathrm{x}}\right)^{2}+253,32 \beta_{\mathrm{x}}+132,88$

- $\quad$ A partir de $\beta_{\mathrm{x}}$ pode-se calcular $\varepsilon_{\mathrm{pld}}$ :

$\varepsilon_{\mathrm{p} 1 \mathrm{~d}}=10$ se $\beta_{\mathrm{x}} \leq 0,24$

$\varepsilon_{\mathrm{pld}}=285,72\left(\beta_{\mathrm{x}}\right)^{4}-617,02\left(\beta_{\mathrm{x}}\right)^{3}+522,87\left(\beta_{\mathrm{x}}\right)^{2}-217,05 \beta_{\mathrm{x}}+40,579$ se $\beta_{\mathrm{x}}>0,24$

Então $\varepsilon_{\mathrm{pd}}=\varepsilon_{\mathrm{pld}}+\varepsilon_{\mathrm{pnd}}$

- Cálculo da altura da mesa de compressão:

Supondo inicialmente que a linha neutra passe pela capa de concreto moldado no local tem-se a configuração da Figura 3.

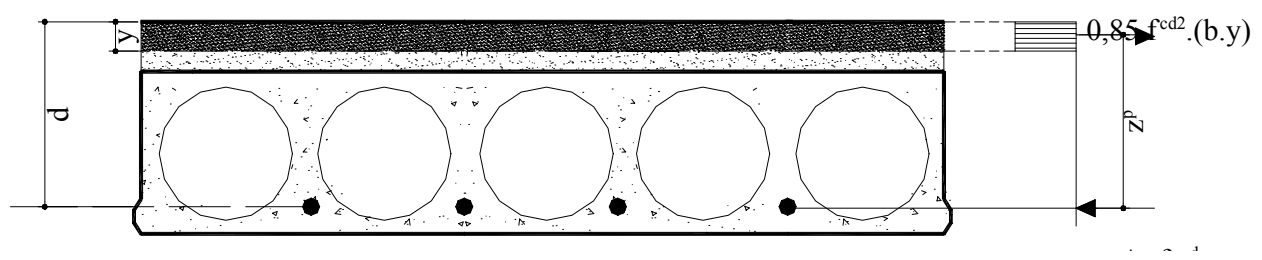

Figura 3. Momento último para mesa de compressão cortando a capa

$$
\mathrm{A}_{\mathrm{p}} \sigma_{\mathrm{Pd}}=0,85 . \mathrm{f}_{\mathrm{cd} 2} \mathrm{~b} \cdot \mathrm{y}
$$


Caso a mesa comprimida corta o elemento pré-moldado tem-se a configuração da Figura 4.

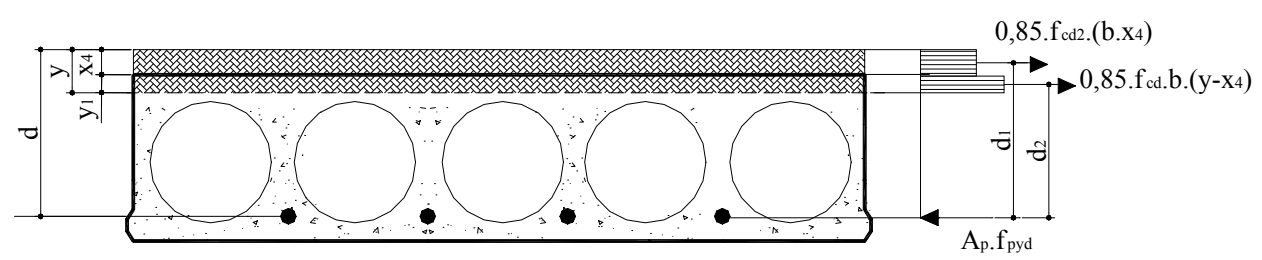

Figura 4. Momento último para mesa de compressão cortando o elemento

$$
\mathrm{A}_{\mathrm{p}} \sigma_{\mathrm{Pd}}=0,85 \cdot \mathrm{f}_{\mathrm{cd} 2} \mathrm{~b} \cdot \mathrm{x}_{4}+0,85 \cdot \mathrm{f}_{\mathrm{cd} 1} \mathrm{~b} \cdot\left(\mathrm{y}-\mathrm{x}_{4}\right)
$$

c) cálculo do momento resistente, $\mathrm{M}_{\mathrm{u}}$ :

- caso que a mesa de compressão se localiza na capa:

$$
\mathrm{M}_{\mathrm{u}}=\mathrm{A}_{\mathrm{p}} \sigma_{\mathrm{Pd}} \mathrm{z}_{\mathrm{p}}=\mathrm{x}_{2} \sigma_{\mathrm{Pd}} \mathrm{z}_{\mathrm{p}}
$$

- caso que a mesa de compressão se localiza no elemento:

$$
\begin{aligned}
& \mathrm{R}_{\mathrm{cl}}=0,85 \cdot \mathrm{f}_{\mathrm{cd}} \mathrm{b} \cdot\left(\mathrm{y}-\mathrm{x}_{4}\right) \\
& \mathrm{d}_{1}=\mathrm{d}-0,5 \cdot\left(\mathrm{y}-\mathrm{x}_{4}\right)
\end{aligned}
$$

Força do concreto da capa

$$
\begin{aligned}
& R_{c 2}=0,85 \cdot f_{c d 2} b \cdot x_{4} \\
& d_{2}=d+0,5 \cdot x_{4} \\
& M_{u}=R_{c 1} \cdot d_{1}+R_{c 2} \cdot d_{2}
\end{aligned}
$$

Portanto $\mathrm{M}_{\mathrm{d}} \leq \mathrm{M}_{\mathrm{u}}$

\section{VERIFICAÇÃO DO ESTADO LIMITE ÚLTIMO - SOLICITAÇÕES TANGENCIAIS}

A seguir serão feitas verificações do elemento pré-moldado quanto ao estado limite último de solicitações tangenciais.

a) tensão do concreto $\left(\tau_{w d}\right)$ : 


$$
\begin{array}{cl}
\tau_{\mathrm{wd}}=\frac{\mathrm{V}_{\mathrm{d}}}{\mathrm{b}_{\mathrm{w}} \mathrm{d}} & \\
\text { onde } & \mathrm{V}_{\mathrm{d}}=\frac{1,4\left(\mathrm{~g}_{1}+\mathrm{g}_{2}+\mathrm{q}\right)}{2} \\
& \mathrm{~b}_{\mathrm{w}}=\mathrm{b}_{\mathrm{a}}=\mathrm{b}-\mathrm{n}(2 \mathrm{r}) \\
& \mathrm{d}=\left(\mathrm{x}_{1}+\mathrm{x}_{4}\right)-\mathrm{cob}
\end{array}
$$

b) tensão última resistente:

$$
\tau_{\mathrm{Rd} 1}=\left(1+\frac{\mathrm{M}_{\mathrm{o}}}{\mathrm{M}_{\mathrm{d}, \max }}\right) \psi_{4} \sqrt[3]{\mathrm{x}_{3}} \text { respeitando o valor absoluto } \tau_{\mathrm{Rd} 1} \leq 1,2 \mathrm{MPa}
$$

sendo: $\psi_{4}=0,14 \frac{\alpha \mathrm{k}}{1-3 \mathrm{~d} / \mathrm{L}}$

onde

$\mathrm{M}_{\mathrm{o}}$ - valor do momento fletor que anula a tensão normal na borda menos comprimida

$\mathrm{M}_{\mathrm{d}, \mathrm{Max}}$ - momento fletor da seção transversal que está mais solicitada à flexão, no trecho considerado pelo cálculo (maior valor do semi-tramo considerado)

$\mathrm{x}_{3}$ - resistência do concreto do elemento pré-moldado $\left(\mathrm{f}_{\mathrm{ck}}\right)$ em $\mathrm{MPa}$

$\mathrm{d}$ - altura útil

$\mathrm{k}=1,6-\mathrm{d} \quad \mathrm{d}$ em metros

$\alpha=1+50 \rho$

$\rho=x_{2} / A_{c}$

Portanto, $\tau_{\mathrm{WD}} \leq \tau_{\mathrm{RD} 1}$

\section{VERIFICAÇÃO DO CISALHAMENTO DA INTERFACE ENTRE OS DOIS CONCRETOS}

De acordo com a NBR-9062/85, o cálculo da tensão solicitante de cisalhamento da interface é dado pela seguinte expressão: 
$\tau_{\mathrm{d}}=\frac{\mathrm{F}_{\mathrm{hd}}}{\mathrm{b}_{\text {int }} \ell_{\mathrm{o}}}$

se $R_{c}<R_{c, l o c}-F_{h d}=R_{c}$
se $R_{c}>R_{c, l o c}-F_{h d}=R_{c, l o c}$

onde $\quad \mathrm{F}_{\mathrm{hd}}-$ força horizontal de cisalhamento

$b_{\text {int }}-$ largura da interface $\left(b_{\text {int }}=b\right)$

$\ell_{\mathrm{o}}$ - comprimento dos trechos relativos ao cisalhamento

$\mathrm{R}_{\mathrm{c}, \text { loc }}$ - valor de referência da resultante de compressão na parte do concreto moldado no local que vale $0,85 f_{c d} A_{c, l o c}$

O valor último da tensão de cisalhamento é fornecido pela seguinte expressão:

$\tau_{\mathrm{u}}=\beta_{\mathrm{s}} \rho \mathrm{f}_{\mathrm{yd}}+\beta_{\mathrm{c}} \mathrm{f}_{\mathrm{td}}$

onde

$\mathrm{A}_{\mathrm{st}}$ - área de armadura atravessando, perpendicularmante, a interface e totalmente ancorada nos elementos

$\mathrm{f}_{\mathrm{yd}}$ - resistência de cálculo do aço

$\mathrm{s}$ - espaçamento da armadura

$b_{\text {int }}-$ largura da interface

$\mathrm{f}_{\mathrm{td}}$ - resistência à tração de cálculo, para o menos resistente dos concretos em contato

$\beta_{\mathrm{s}}, \beta_{\mathrm{c}}-$ coeficientes multiplicativos para as parcelas do aço e do concreto, respectivamente com valores fornecidos na Tabela 1, válidos para superfícies ásperas interpolando-se linearmente para valores intermediários

Tabela 1. Coeficientes multiplicativos, $\beta_{\mathrm{s}}$ e $\beta_{\mathrm{C}}$ segundo a NBR-9062/85

\begin{tabular}{|c|c|c|}
\hline$\rho(\%)$ & $\beta_{\mathbf{s}}$ & $\beta_{\mathbf{c}}$ \\
\hline$<\mathbf{0 , 2 0}$ & 0 & 0,3 \\
\hline$>\mathbf{0 , 5 0}$ & 0,9 & 0,6 \\
\hline
\end{tabular}




\section{CÁlCULO DA FUNÇÃO CUSTO}

Os vários custos envolvidos na produção de um painel alveolar com capa de regularização foram discriminados e apresentados em detalhes a seguir. Os custos para cada parcela são obtidos a partir dos insumos apresentados no Capítulo 4. Portanto cada valor de parcela corresponderá ao custo em $\mathrm{R} \$ / \mathrm{m}^{2}$.

Conforme apresentado no Capítulo 4, no equacionamento da função custo foram utilizados valores cedidos pela empresa Marka situada em Franca, SP, e pela Revista Construção ${ }^{1}$.

As variáveis do problema são:

$\mathrm{x}_{1}$ - altura do painel em $\mathrm{cm}$

$\mathrm{x}_{2}-$ armadura ativa em $\mathrm{cm}^{2}$

$\mathrm{x}_{3}$ - resistência do concreto do elemento pré-moldado em $\mathrm{kN} / \mathrm{cm}^{2}$

$\mathrm{x}_{4}$ - altura da capa de concreto $\mathrm{cm}$

$\mathrm{x}_{5}-$ resistência do concreto da capa em $\mathrm{kN} / \mathrm{cm}^{2}$

\section{I) CUSTOS DE EXECUÇÃO (R $\left.\$ \mathrm{~m}^{2}\right)$}

A.Custos da matéria-prima:

\section{Concreto (Tcust conc $_{\text {c }}$ :}

A área de concreto do painel $\left(\mathrm{A}_{\mathrm{c}}\right)$ está $\mathrm{em}^{2} \mathrm{~cm}^{2}$, portanto dividiu-se a área por 10000 , com o objetivo de transformá-la para $\mathrm{m}^{2}$. Os insumos apresentados no Capítulo 4 e utilizados nesta seção são os seguintes:

$$
\begin{aligned}
& \text { Custo_material }=24,75 \times 3+74,25 \mathrm{R} \$ \mathrm{~m}^{3} \\
& \text { Custo_mão_de_obra }=4,4 \mathrm{R} \$ / \mathrm{m}^{3} \\
& \text { Custo_equipamento }=8,35 \mathrm{R} \$ / \mathrm{m}^{3}
\end{aligned}
$$

material: $\quad$ cust $_{\mathrm{cl}}=$ custo_material $\frac{\mathrm{A}_{\mathrm{c}}}{\mathrm{b}}=\left(24,75 \mathrm{x}_{3}+74,25\right) \frac{\left(760,05 \ln \left(\mathrm{x}_{1}\right)-865,05\right)}{10000.1,20}$ $\underline{\text { mão-de-obra: }} \quad$ cust $_{\mathrm{c} 2}=$ custo_mão_de_obra $\frac{\mathrm{A}_{\mathrm{c}}}{\mathrm{b}}=4,4 \frac{\left(760,05 \ln \left(\mathrm{x}_{1}\right)-865,05\right)}{10000.1,20}$ equipamentos: $\quad$ cust $_{\mathrm{c3} 3}=$ custo_equipamento $\frac{\mathrm{A}_{\mathrm{c}}}{\mathrm{b}}=8,35 \frac{\left(760,05 \ln \left(\mathrm{x}_{1}\right)-865,05\right)}{10000.1,20}$

\footnotetext{
${ }^{1}$ Construção, São Paulo, no 2782, 4/6/2001.
} 


$$
\therefore \text { Tcust }_{\text {conc }}=\text { cust }_{\mathrm{c} 1}+\text { cust }_{\mathrm{c} 2}+\text { cust }_{\mathrm{c} 3}
$$

\section{Armadura (Tcust $t_{\text {arm }}$ ):}

Os insumos apresentados no Capítulo 4 e utilizados nesta seção são os seguintes:

Custo_material $=2,95 \mathrm{R} \$ / \mathrm{kg}$

Custo_mão_de_obra $=0,295 \mathrm{R} \$ / \mathrm{kg}$

Custo_equipamento $=0,07 \mathrm{R} \$ / \mathrm{kg}$

material:

mão-de-obra:

equipamentos:

$$
\begin{aligned}
& \text { cust }_{\mathrm{a} 1}=\text { custo_material.0,66 } \mathrm{x}_{2}=2,95.0,66 \mathrm{x}_{2} \\
& \text { cust }_{\mathrm{a} 2}=\text { custo_mão_de_obra.0,66 } \mathrm{x}_{2}=0,295.0,66 \mathrm{x}_{2} \\
& \text { cust }_{\mathrm{a} 3}=\text { custo_equipamento.0,66 } \mathrm{x}_{2}=0,07.0,66 \mathrm{x}_{2}
\end{aligned}
$$$$
\therefore \text { Tcust }_{\mathrm{arm}}=\text { cust }_{\mathrm{a} 1}+\text { cust }_{\mathrm{a} 2}+\text { cust }_{\mathrm{a} 3}
$$

B. Custos adicionais $\left(\right.$ Tcust $\left._{\text {adc }}\right)$ :

Os insumos apresentados no Capítulo 4 e utilizados nesta seção são os seguintes:

$$
\begin{aligned}
& \text { Custo_mão_de_obra }=4,4 \mathrm{R} \$ / \mathrm{m}^{3} \\
& \text { Custo_equipamento }=1,67 \mathrm{R} \$ / \mathrm{m}^{3}
\end{aligned}
$$

$\underline{\text { mão-de-obra: }}$ cust $_{\text {adcl }}=$ custo $\_$mão_de_obra $\frac{\mathrm{A}_{\mathrm{c}}}{\mathrm{b}}=4,4 \frac{\left(760,05 \ln \left(\mathrm{x}_{1}\right)-865,05\right)}{10000.1,20}$ equipamentos: $\quad$ cust $_{\text {adc2 }}=$ custo_equipamento $\frac{A_{c}}{b}=1,67 \frac{\left(760,05 \ln \left(x_{1}\right)-865,05\right)}{10000.1,20}$

$$
\therefore \text { Tcust }_{\mathrm{adc}}=\text { cust }_{\mathrm{adc} 1}+\text { cust }_{\mathrm{adc} 2}
$$

C. Custos indiretos administrativos (Tcust ${ }_{\text {ind }}$ )

$$
\therefore \text { Tcust }_{\text {ind }}=0,1\left(\text { Tcust }_{\text {conc }}+\text { Tcust }_{\text {arm }}+\text { Tcust }_{\text {adc }}\right)
$$

D. Custos tributários (cust ${ }_{\text {trib) }}$ )

Os insumos apresentados no Capítulo 4 e utilizados nesta seção são os seguintes:

$$
\text { c_tributario }=74 \mathrm{R} \$ / \mathrm{m}^{3}
$$




$$
\therefore \text { cust }_{\text {trib }}=\mathrm{c}_{-} \text {tributario } \frac{\mathrm{A}_{\mathrm{c}}}{\mathrm{b}}=74 \frac{\left(760,05 \ln \left(\mathrm{x}_{1}\right)-865,05\right)}{10000.1,20}
$$

\section{II) CUSTOS DE TRANSPORTE EXTERNO (R\$/ $\left.\mathbf{m}^{2}\right)$}

Os insumos apresentados no Capítulo 4 e utilizados nesta seção são os seguintes:

$$
\text { custo_transp }=52 \mathrm{R} \$ / \mathrm{m}^{3}
$$

serviços: $\quad$ cust $_{\text {tr }}=$ custo_transp $\frac{\mathrm{A}_{\mathrm{c}}}{\mathrm{b}}=52 \frac{\left(760,05 \ln \left(\mathrm{x}_{1}\right)-865,05\right)}{10000.1,20}$

\section{III) CUSTOS DA APLICAÇÃO $\left(\mathrm{R} \$ / \mathrm{m}^{2}\right)$}

A. Custos da montagem do painel alveolar (Tcust ${ }_{\text {mon }}$ )

Os insumos apresentados no Capítulo 4 e utilizados nesta seção são os seguintes:

Custo_mão_de_obra $=11,96 \mathrm{R} \$ / \mathrm{m}^{3}$

Custo_equipamento $=9,79 \mathrm{R} \$ / \mathrm{m}^{3}$

$\underline{\text { mão-de-obra: }}$ cust ${ }_{\mathrm{mo}}=$ custo_mão_de_obra $\frac{\mathrm{A}_{\mathrm{c}}}{\mathrm{b}}=11,96 \frac{\left(760,05 \ln \left(\mathrm{x}_{1}\right)-865,05\right)}{10000.1,20}$

equipamentos: $\quad$ cust $_{\text {eq }}=$ custo_equipamento $\frac{A_{c}}{b}=9,79 \frac{\left(760,05 \ln \left(x_{1}\right)-865,05\right)}{10000.1,20}$

$\therefore$ Tcust $_{\text {mon }}=$ cust $_{\text {mo }}+$ cust $_{\mathrm{eq}}$

B. Custos do concreto para regularização (Tcust $t_{\text {reg }}$ )

Os insumos apresentados no Capítulo 4 e utilizados nesta seção são os seguintes:

$$
\begin{aligned}
& \text { custo_material }=24,75 \mathrm{x}_{5}+74,25 \mathrm{R} \$ / \mathrm{m}^{3} \\
& \text { custo_mão_de_obra }=83,36 \mathrm{R} \$ / \mathrm{m}^{3} \\
& \text { custo_equipamento }=1,67 \mathrm{R} \$ / \mathrm{m}^{3}
\end{aligned}
$$

$\underline{\text { Material: }} \quad$ cust $_{\text {regl }}=$ custo_material $\frac{\mathrm{x}_{4}}{100}=\left(24,75 \mathrm{x}_{5}+74,25\right) \frac{\mathrm{x}_{4}}{100}$

mão-de-obra:

$$
\text { cust }_{\text {reg2 }}=\text { custo_mão_de_obra } \frac{\mathrm{x}_{4}}{100}=83,36 \frac{\mathrm{x}_{4}}{100}
$$


equipamentos: $\quad$ cust $_{\text {reg3 }}=$ custo_equipamento $\frac{\mathrm{x}_{4}}{100}=1,67 \frac{\mathrm{x}_{4}}{100}$

$\therefore$ Tcust $_{\text {reg }}=$ cust $_{\text {reg1 }}+$ cust $_{\text {reg2 }}+$ cust $_{\text {reg } 3}$

C. Custos das ligações (Tcust ${ }_{\text {lig }}$ )

Os insumos apresentados no Capítulo 4 e utilizados nesta seção são os seguintes:

$$
\begin{aligned}
& \text { custo_material }=3 \cdot\left(24,75 \mathrm{x}_{5}+74,25\right) \mathrm{R} \$ / \mathrm{m}^{3} \\
& \text { custo_mão_de_obra }=2,20 \mathrm{R} \$ / \mathrm{m}^{3}
\end{aligned}
$$

material: $\quad$ cust $_{\text {lig1 }}=$ custo $\quad$ material $\frac{\mathrm{x}_{4}}{100}=3 \cdot\left(24,75 \cdot \mathrm{x}_{5}+74,25\right) \frac{\mathrm{x}_{4}}{100}$

$\underline{\text { mão-de-obra: }} \quad$ cust $_{\text {lig2 }}=$ custo_mão_de_obra $\frac{\mathrm{x}_{4}}{100}=2,20 \frac{\mathrm{x}_{4}}{100}$

$\therefore$ Tcust $_{\text {lig }}=$ cust $_{\text {lig } 1}+$ cust $_{\text {lig2 }}$

D. Custos indiretos administrativos (Tcust ${ }_{a d m a}$ )

$\therefore$ Tcust $_{\text {adma }}=0,2$ (cust $_{\text {mon }}+$ Tcust $_{\text {reg }}+$ Tcust $\left._{\text {lig }}\right)$

Portanto, os vários custos envolvidos na produção de um painel alveolar com capa de regularização foram somados e a expressão final da função em $\mathrm{R} \$ / \mathrm{m}^{2}$ é:

$\mathrm{f}(\mathbf{x})=11,578 \ln \left(\mathrm{x}_{1}\right)-13,178+0,048 \cdot\left(24,75 \mathrm{x}_{5}+74,25\right) \mathrm{x}_{4}+0,0528 \mathrm{x}_{1}+1,27 \mathrm{x}_{4}+$ $1,1 .\left(24,75 \mathrm{x}_{3}+74,25\right)\left(0,063 \ln \left(\mathrm{x}_{1}\right)-0,0721\right)+2,407 \mathrm{x}_{2}$

onde

$\mathrm{x}_{1}$ - altura do painel em $\mathrm{cm}$

$\mathrm{x}_{2}$ - armadura ativa $\mathrm{em}^{2}$

$\mathrm{x}_{3}-$ resistência do concreto em $\mathrm{kN} / \mathrm{cm}^{2}$

$\mathrm{x}_{4}$ - altura da capa de concreto

$\mathrm{x}_{5}$ - resistência do concreto da capa

Supondo por exemplo que as variáveis sejam:

$\mathrm{x}_{1}=21,36 \mathrm{~cm}$;

$\mathrm{x}_{2}=2,63 \mathrm{~cm}^{2}$; 


$$
\begin{aligned}
& \mathrm{x}_{3}=3,00 \mathrm{kN} / \mathrm{cm}^{2}, \\
& \mathrm{x}_{4}=4,00 \mathrm{~cm} ; \\
& \mathrm{x}_{5}=1,50 \mathrm{kN} / \mathrm{cm}^{2},
\end{aligned}
$$

Então o custo final é de $\mathrm{f}(\mathrm{x})=71,86 \mathrm{R} \$ / \mathrm{m}^{2}$ 


\section{APÊNDICE F}

Dimensionamento de uma laje com vigota protendida 


\section{DIMENSIONAMENTO DE UMA LAJE COM VIGOTA PROTENDIDA}

\section{DEFINIÇÃO DO PROBLEMA}

Deve-se salientar que todo o dimensionamento foi feito utilizando o software Mathcad 2000 Professional. Entretanto, com o objetivo de facilitar a leitura de todos as etapas de dimensionamento, achou-se necessário apresentar o roteiro de cálculo usado no dimensionamento da laje com vigota protendida.

O problema de otimização tratado neste apêndice é o da minimização da função custo de uma laje com vigota protendida. A seção transversal da laje é mostrada na Figura 1. As dimensões da vigota são apresentadas na Figura 2. A Figura 2.a) refere-se à solução do problema que considera cinco e oito variáveis. A Figura 2.b) refere-se à solução do problema que considera três variáveis.

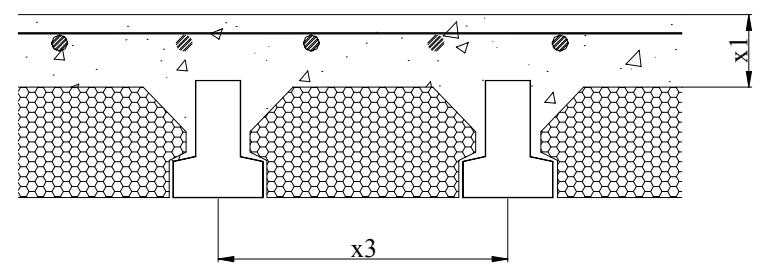

Figura 1. Seção de laje com vigota de concreto protendido, com enchimento e concreto moldado no local

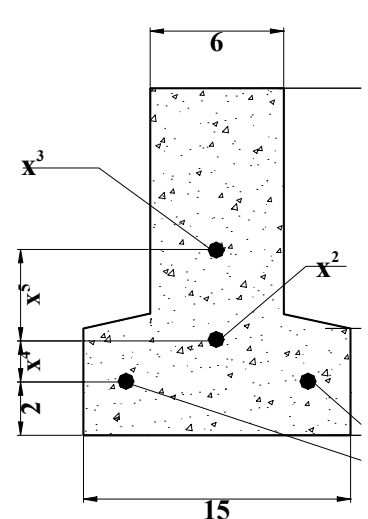

Seção da vigota protendida para 3 e 5 variáveis

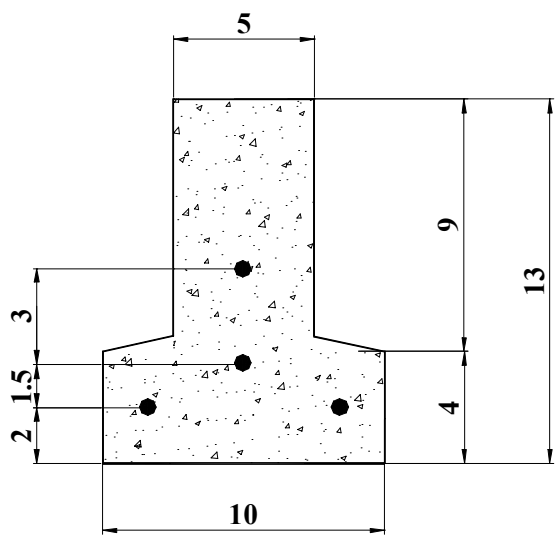

b) seção da vigota protendida para 3 variáveis

Figura 2. Dimensões das seções da laje e da vigota protendida (medidas em cm) 
As variáveis envolvidas no equacionamento do problema são definidas a seguir.

- otimização do elemento para uma determinada aplicação:

$$
\begin{aligned}
& \mathrm{x}_{1}-\text { armadura nível } 1\left(\mathrm{~cm}^{2}\right) \\
& \mathrm{x}_{2}-\text { armadura nível } 2\left(\mathrm{~cm}^{2}\right) \\
& \mathrm{x}_{3}-\text { armadura nível } 3\left(\mathrm{~cm}^{2}\right) \\
& \mathrm{x}_{4}-\text { distância da armadura do nível } 2(\mathrm{~cm}) \\
& \mathrm{x}_{5}-\text { distância da armadura no nível } 3(\mathrm{~cm})
\end{aligned}
$$

- otimização da aplicação para uma determinada seção de vigota:

$$
\begin{aligned}
& \mathrm{x}_{1}-\text { resistência do concreto moldado no local em } \mathrm{kN} / \mathrm{cm}^{2} \\
& \mathrm{x}_{2}-\text { distância do inter-eixo em } \mathrm{cm} \\
& \mathrm{x}_{3}-\text { altura da capa de concreto em cm }
\end{aligned}
$$

- otimização do elemento e da aplicação:

$$
\begin{aligned}
& \mathrm{x}_{1}-\text { armadura nível } 1\left(\mathrm{~cm}^{2}\right) \\
& \mathrm{x}_{2}-\text { armadura nível } 2\left(\mathrm{~cm}^{2}\right) \\
& \mathrm{x}_{3}-\text { armadura nível } 3\left(\mathrm{~cm}^{2}\right) \\
& \mathrm{x}_{4}-\text { distância da armadura do nível } 2(\mathrm{~cm}) \\
& \mathrm{x}_{5}-\text { distância da armadura no nível } 3(\mathrm{~cm}) \\
& \mathrm{x}_{6}-\text { resistência do concreto moldado no local em } \mathrm{kN} / \mathrm{cm}^{2} \\
& \mathrm{x}_{7}-\text { distância do inter-eixo em } \mathrm{cm} \\
& \mathrm{x}_{8}-\text { altura da capa de concreto em } \mathrm{cm}
\end{aligned}
$$

Serão consideradas no dimensionamento ainda as seguintes características:

- dois vãos: $\mathrm{L}=3 \mathrm{~m}$ e $\mathrm{L}=4 \mathrm{~m}$

- Protensão limitada

- Fios de $5 \mathrm{~mm}$ de diâmetro

- $\mathrm{CP}-160 \mathrm{RN} 5$

Deve-se salientar que o dimensionamento descrito neste apêndice é o mesmo apresentado no trabalho de MERLIN (2002). 


\section{CÁLCULOS INICIAS}

a) Características geométricas da vigota

Área da seção transversal da vigota: $\mathrm{A}_{\mathrm{V}}$

Área da seção de armadura protendida: $A_{p}$

Área da seção líquida de concreto: $\mathrm{A}_{\mathrm{c}}=\mathrm{A}_{\mathrm{v}}-\mathrm{A}_{\mathrm{p}}$

Área da seção homogeneizada: $\mathrm{A}_{\mathrm{ch}}=\mathrm{A}_{\mathrm{c}}+\alpha_{\mathrm{p}} \mathrm{A}_{\mathrm{p}}\left(\operatorname{com} \alpha_{\mathrm{p}}=10\right)$

Centro de gravidade da seção transversal bruta: $Y_{1 v}$

Centro de gravidade da seção de amadura protendida: $Y_{1 p}$

Centro de gravidade da seção líquida de concreto: $\mathrm{Y}_{1 \mathrm{c}}$

Centro de gravidade da seção homogeneizada: $\mathrm{Y}_{1 \mathrm{~h}}$

E portanto, a excentricidade da armadura protendida em relação ao centróide da seção líquida de concreto é dada por: $\mathrm{e}_{\mathrm{p}}=\mathrm{Y}_{1 \mathrm{c}}-\mathrm{Y}_{1 \mathrm{p}}$.

As características geométricas da seção líquida de concreto e da seção homogeneizada da vigota são apresentadas na Figura 3.

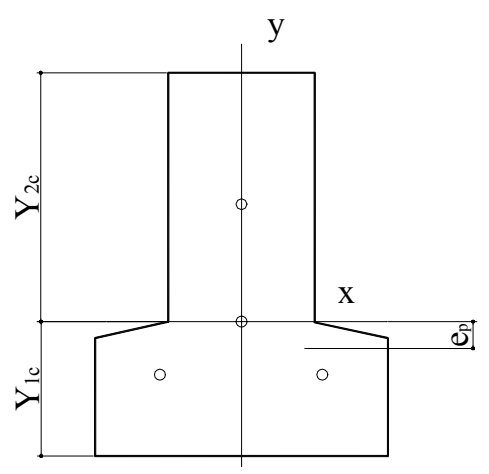

a) Seção líquida do concreto

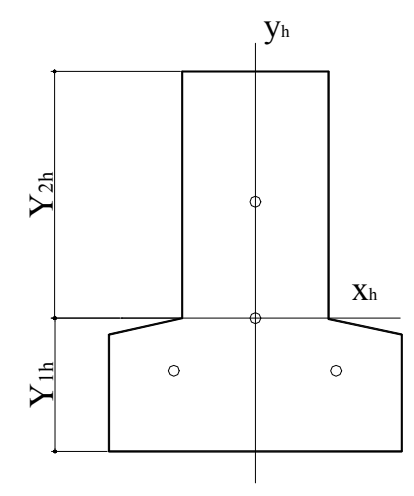

b) Seção homogeneizada

Figura 3. Centro de gravidade

Os momentos de inércia em relação ao eixo que passa pelo centróide da seção líquida de concreto são:

seção transversal bruta: $I_{V}$

seção de armadura protendida: $\mathrm{I}_{\mathrm{p}}$ 
seção líquida de concreto: $\mathrm{I}_{\mathrm{c}}=\mathrm{I}_{\mathrm{V}}-\mathrm{I}_{\mathrm{p}}$

seção homogeneizada: $\mathrm{I}_{\mathrm{ch}}=\mathrm{I}_{\mathrm{c}}+\alpha_{\mathrm{p}} \mathrm{I}_{\mathrm{p}}\left(\operatorname{com} \alpha_{\mathrm{p}}=10\right)$

Com isso, determinam-se os módulos resistentes:

$$
\begin{array}{lr}
\text { Seção líquida de concreto: } \mathrm{W}_{1}=\frac{\mathrm{I}_{\mathrm{c}}}{\mathrm{Y}_{1 \mathrm{c}}} & \mathrm{W}_{2}=\frac{\mathrm{I}_{\mathrm{c}}}{\mathrm{Y}_{2 \mathrm{c}}} \\
\text { Seção homogeneizada: } \mathrm{W}_{1 \mathrm{~h}}=\frac{\mathrm{I}_{\mathrm{ch}}}{\mathrm{Y}_{1 \mathrm{~h}}} & \mathrm{~W}_{2 \mathrm{~h}}=\frac{\mathrm{I}_{\mathrm{ch}}}{\mathrm{Y}_{2 \mathrm{~h}}}
\end{array}
$$

Deve-se salientar que se adotou índice 1 para as variáveis que se referem à borda inferior e índice 2 à superior.

b) Características geométricas da laje

Para determinar as características geométricas da laje, deve-se realizar a homogeneização da seção. Para isso, multiplicam-se as larguras do concreto moldado no local por:

$$
\mathrm{m}=\sqrt{\frac{\mathrm{f}_{\mathrm{ck}, 2}}{\mathrm{f}_{\mathrm{ck} 1}}}
$$

A partir disso, pode-se determinar as características da seção da laje:

Área da seção homogeneizada: $\mathrm{A}_{\mathrm{ch}}$,

Momento de inércia: $\mathrm{Y}_{1 \mathrm{~h}}$,

Centro de gravidade: $\mathrm{W}_{1 \mathrm{~h}}$,

Módulos resistentes: $\mathrm{W}_{2 \mathrm{~h}}$,

c) Definição da tensão da armadura de protensão

Foi adotado fio de $5 \mathrm{~mm}$ CP-16. As principais propriedades mecânicas são descritas a seguir.

$$
\begin{aligned}
& \mathrm{f}_{\text {ptk }}=160 \mathrm{kN} / \mathrm{cm}^{2} \\
& \mathrm{f}_{\text {pyk }}=136 \mathrm{kN} / \mathrm{cm}^{2} \\
& \mathrm{E}_{\mathrm{p}}=21000 \mathrm{kN} / \mathrm{cm}^{2}
\end{aligned}
$$

onde: $\quad f_{\text {ptk }}$ - resistência característica à ruptura por tração do aço de protensão 
$\mathrm{f}_{\text {pyk }}$ - limite de escoamento convencional do aço de protensão

$\mathrm{E}_{\mathrm{p}}$ - valor médio do módulo de elasticidade do aço de protensão

A tensão inicial $\sigma_{\mathrm{pi}}$ que a força de protensão $\mathrm{P}_{\mathrm{i}}$ introduz nas armaduras ativas, na saída do aparelho de tração, deve respeitar os seguintes valores:

$$
\begin{gathered}
\sigma_{\mathrm{Pi}} \leq\left\{\begin{array}{l}
0,81 \mathrm{f}_{\mathrm{ptk}}=129,6 \mathrm{kN} / \mathrm{cm}^{2} \\
0,95 \mathrm{f}_{\mathrm{pyk}}=129,2 \mathrm{kN} / \mathrm{cm}^{2}
\end{array}\right. \\
\text { logo: } \sigma_{\mathrm{Pi}}=129,2 \mathrm{kN} / \mathrm{cm}^{2}
\end{gathered}
$$

As perdas imediatas devidas ao escorregamento dos fios na ancoragem, relaxação inicial da armadura e retração inicial do concreto podem ser adotadas a grosso modo igual a 7\% para o caso de aço com relaxação normal, segundo HANAI (1999). Assim: $\sigma_{\mathrm{Pa}}=93 \% \sigma_{\mathrm{Pi}}$

A tensão inicial da armadura de protensão considerando também a perda por deformação imediata do concreto é dada por:

$$
\begin{aligned}
\sigma_{\mathrm{P}_{\mathrm{o}}}= & \sigma_{\mathrm{P}_{\mathrm{a}}}+\frac{\mathrm{E}_{\mathrm{p}}}{\mathrm{E}_{\mathrm{c}}} \sigma_{\mathrm{cp}} \text { onde } \sigma_{\mathrm{cp}}=\frac{\mathrm{P}_{\mathrm{a}}}{\mathrm{A}_{\mathrm{ch}}}+\frac{\mathrm{P}_{\mathrm{a}}\left(\mathrm{e}_{\mathrm{p}}\right)^{2}}{\mathrm{I}_{\mathrm{ch}}} \\
\text { onde }= & \sigma_{\mathrm{cp}}-\text { tensão no concreto ao nível do baricentro da armadura de } \\
& \text { protensão, devida a força } \mathrm{P}_{\mathrm{a}} \\
& \sigma_{\mathrm{pa}}-\text { tensão na armadura de protensão, devida a força } \mathrm{P}_{\mathrm{a}} \\
& \mathrm{Pa}-\text { força da armadura de protensão antes da liberação dos } \\
& \text { cabos } \\
& \mathrm{A}_{\mathrm{ch}}-\text { área da seção transversal homogeneizada da vigota } \\
& \mathrm{I}_{\mathrm{ch}}-\text { momento de inércia da seção transversal homogeneizada } \\
& \text { da vigota; } \\
& \mathrm{e}_{\mathrm{p}}-\text { excentricidade da armadura protendida }
\end{aligned}
$$

As perdas diferidas devidas à relaxação posterior da armadura, retração posterior do concreto e fluência do concreto são estimadas em $10 \%$. Com isso podese determinar a força na armadura protendida: $\mathrm{P}_{\mathrm{o}}=\mathrm{x}_{2} \cdot \sigma_{\mathrm{Po}}$ e $\mathrm{P}_{\mathrm{oo}}=\mathrm{x}_{2} \cdot \sigma_{\mathrm{Poo}}$ 
d) Verificação da vigota

Deve-se satisfazer as condições de verificação da vigota isolada:

$$
\begin{aligned}
& \sigma_{1}=\frac{P_{o}}{A_{c}}-\frac{P_{o} e_{p}}{W_{1}}<0,7 f_{c k j} \\
& \sigma_{2}=\frac{P_{o}}{A_{c}}+\frac{P_{o} e_{p}}{W_{2}}>0
\end{aligned}
$$

e) Verificação da vigota na fase de construção

Inicialmente, definiram-se as cargas que atuarão sobre os elementos prémoldados durante a fase de construção da laje:

- Peso próprio da vigota $(\mathrm{kN} / \mathrm{m}): \mathrm{g}_{1}=\mathrm{A}_{\mathrm{v}} \gamma_{\mathrm{c}}$ onde $\gamma_{\mathrm{c}}=25 \mathrm{kN} / \mathrm{m}^{3}$

- Peso próprio do concreto moldado no local $(\mathrm{kN} / \mathrm{m}): \mathrm{g}_{2}=\mathrm{A}_{\mathrm{CML}} \gamma_{\mathrm{cs}}$ onde $\gamma_{\mathrm{cs}}=24 \mathrm{kN} / \mathrm{m}^{3}$

- Sobrecarga de execução $\left(\mathrm{kN} / \mathrm{m}^{2}\right): \mathrm{q}_{\text {exe }}=1,0$

- Carga de utilização $\left(\mathrm{kN} / \mathrm{m}^{2}\right): \mathrm{q}=2,0$

Durante a fase de construção da laje, a vigota deve ser capaz de suportar seu peso próprio, trabalhando como viga simplesmente apoiada em ambos os extremos, e as demais cargas, nas mesmas condições ou como viga contínua sobre escoras quando for necessário dispor apoios intermediários.

Supondo que não utilize escoras, tem-se o seguinte diagrama apresentado na Figura 4 devendo ser satisfeitas as condições:

$$
\begin{aligned}
& \sigma_{1}=\frac{P_{o o}}{A_{c}}-\frac{P_{o o} e_{p}}{W_{1}}-\gamma_{f} \frac{M_{g_{1}+g_{2}+q_{\text {exe }}}}{W_{1 h}}>0 \\
& \sigma_{2}=\frac{P_{o o}}{A_{c}}+\frac{P_{o o} e_{p}}{W_{2}}+\gamma_{f} \frac{M_{g_{1}+g_{2}+q_{\text {exe }}}}{W_{2 h}}<0,7 f_{c k}
\end{aligned}
$$




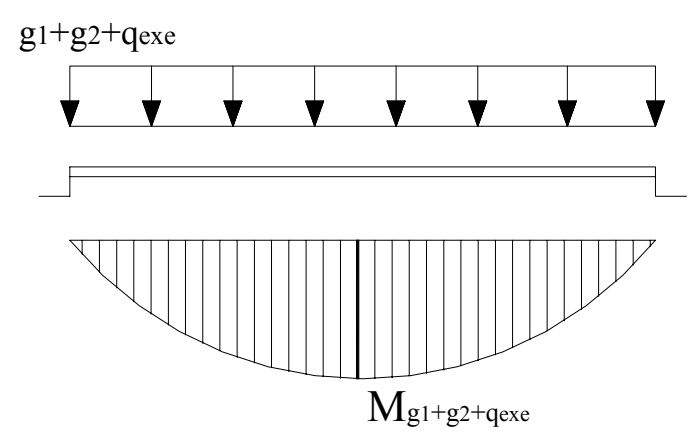

Figura 4. Diagrama de momento fletor não utilizando escoras

Se os valores resultantes das tensões forem superiores aos limites estabelecidos, devem-se utilizar escoras para diminuir o vão de cálculo que será utilizado na verificação das tensões. A figura mostra o novo diagrama de momento fletor, devendo verificar as seguintes relações:

sobre as escoras:

$$
\sigma_{1}=\frac{P_{o o}}{A_{c}}-\frac{P_{o o} e_{p}}{W_{1}}+\gamma_{f} \frac{M_{g_{1}+g_{2}+q_{e x e}}}{W_{1 h}}<0,7 f_{c k}
$$

$$
\sigma_{2}=\frac{P_{o o}}{A_{c}}+\frac{P_{o o} e_{p}}{W_{2}}-\gamma_{f} \frac{M_{g_{1}+g_{2}+q_{e x e}}}{W_{2 h}}>0
$$

no vão:

$$
\begin{aligned}
& \sigma_{1}=\frac{P_{o o}}{A_{c}}-\frac{P_{o o} e_{p}}{W_{1}}-\gamma_{f} \frac{M_{g_{1}+g_{2}+q_{\text {exe }}}}{W_{1 h}}>0 \\
& \sigma_{2}=\frac{P_{o o}}{A_{c}}+\frac{P_{o o} e_{p}}{W_{2}}+\gamma_{f} \frac{M_{g_{1}+g_{2}+q_{\text {exe }}}}{W_{2 h}}<0,7 f_{c k}
\end{aligned}
$$
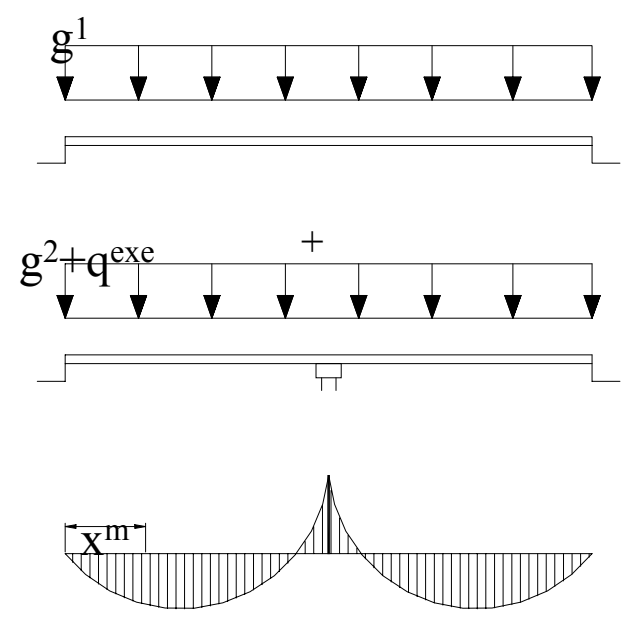

Figura 5. Diagrama de momento fletor para a utilização de uma linha de escoras 
Portanto, os valores extremos a serem calculados são (VASCONCELOS (1984)):

Momento máximo na seção $x_{m}$ do apoio:

máximo momento positivo: $\mathrm{M}_{\mathrm{g}_{1}+\mathrm{g}_{2}+\mathrm{q}_{\mathrm{exe}}}=4 \cdot\left[\mathrm{g}_{1}+\left(\mathrm{g}_{2}+\mathrm{q}_{\mathrm{exe}}\right)\right]\left(\frac{\mathrm{x}_{\mathrm{m}}}{\mathrm{L}}\right)^{2} \cdot \frac{\mathrm{L}^{2}}{8}$ onde $\mathrm{x}_{\mathrm{m}}=\frac{8 \mathrm{~g}_{1}+3\left(\mathrm{~g}_{2}+\mathrm{q}_{\mathrm{exe}}\right)}{\mathrm{g}_{1}+\left(\mathrm{g}_{2}+\mathrm{q}_{\mathrm{exe}}\right)} \cdot \frac{\mathrm{L}}{16}$

Momento na seção do apoio:

máximo momento negativo: $\mathrm{M}_{\mathrm{g}_{1}+\mathrm{g}_{2}+\mathrm{q}_{\mathrm{exe}}}=\left[\mathrm{g}_{1}-0,25 \cdot\left(\mathrm{g}_{2}+\mathrm{q}_{\mathrm{exe}}\right)\right] \cdot \frac{\mathrm{L}^{2}}{8}$

\section{VERIFICAÇÃO DO ESTADO LIMITE DE DEFORMAÇÃO}

$\mathrm{Na}$ verificação será calculado conforme apresentado na EP-80. Considerou-se que a flecha diferida é igual a instantânea multiplicada por um coeficiente (C) que leva em consideração o efeito do tempo, cujos valores são mostrados na Tabela 1. Neste trabalho considerou-se o valor $\mathrm{C}=3$.

Tabela 1. Valores do coeficiente $\mathrm{C}$

\begin{tabular}{|c|c|c|}
\hline \multirow{2}{*}{ Clima } & \multicolumn{2}{|c|}{ Idade de aplicação da carga } \\
\cline { 2 - 3 } & $<\mathbf{6}$ meses & $\geq \mathbf{6}$ meses \\
\hline Úmido & $\mathrm{C}=2$ & $\mathrm{C}=1,5$ \\
\hline Seco & $\mathrm{C}=3$ & $\mathrm{C}=2$ \\
\hline
\end{tabular}

Portanto são considerados os seguintes carregamentos:

- valor característico das cargas permanentes: peso próprio da vigota $\left(\mathrm{g}_{1}\right)$, peso próprio do concreto moldado no local $\left(\mathrm{g}_{2}\right): \mathbf{q}_{\mathbf{k} \mathbf{1}}=\mathbf{g}_{\mathbf{1}}+\mathbf{g}_{\mathbf{2}}$

- valor característico da sobrecarga: carga de utilização (q), carga de revestimento $\left(\mathrm{g}_{3}\right): \mathbf{q}_{\mathbf{k} \mathbf{2}}=\mathbf{q}+\mathbf{g}_{3}$

Flecha diferida: formada pela flecha produzida pelo carregamento permanente 


$$
a_{\text {dif }}=\frac{5 \cdot\left(\mathrm{C} \cdot \mathrm{q}_{\mathrm{k} 1}\right) \mathrm{L}^{4}}{384 \mathrm{E}_{\mathrm{c}} \mathrm{I}_{\text {chlaje }}}
$$

Flecha instantânea: formada pela flecha produzida por todas as outras cargas posteriores

$$
\begin{aligned}
& \mathrm{a}_{\text {inst }}=\frac{5\left(\mathrm{q}_{\mathrm{k} 2}\right) \mathrm{L}^{4}}{384 \mathrm{E}_{\mathrm{c}} \mathrm{I}_{\text {chlaje }}} \\
& \text { onde } \quad a_{\text {inst }}-\text { flecha instantânea } \\
& \mathrm{a}_{\mathrm{dif}} \text { - flecha diferida } \\
& \text { L - vão do painel } \\
& \mathrm{E}_{\mathrm{c}} \text { - módulo de elasticidade do concreto } \\
& \mathrm{I}_{\text {chlaje }} \text { - inércia da seção da laje }
\end{aligned}
$$

Portanto, a flecha final corresponde à soma das duas deformações:

$$
\mathrm{a}_{\text {total }}=\mathrm{a}_{\text {inst }}+\mathrm{a}_{\mathrm{dif}}
$$

Portanto deve-se respeitar o limite imposto: $\mathrm{a}_{\text {total }} \leq \mathrm{a}_{\lim }=\frac{\mathrm{L}}{530}$

\section{VERIFICAÇÃO DO ESTADO LIMITE ÚLTIMO - SOLICITAÇÕES NORMAIS}

A seguir serão feitas verificações da laje quanto ao estado limite último de solicitações normais.

a) determinação dos diagramas de momento fletor: inicialmente, atua sobre a vigota o seu peso próprio, o peso do concreto moldado no local. Após a solidarizarão entre o concreto da vigota e o concreto moldado no local, começa a atuar uma força equivalente devido à retirada do escoramento, além dos esforços oriundos da sobrecarga permanente e carga de utilização. Os diagramas de momento fletor dessas cargas são mostradas na Figura 6. 
$g_{1}$
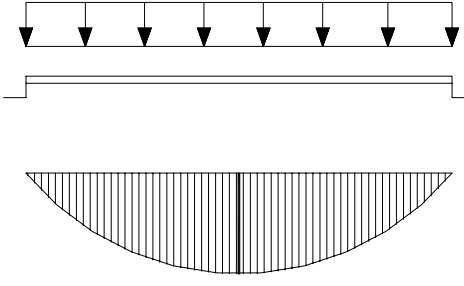

a) peso próprio da vigota

g2
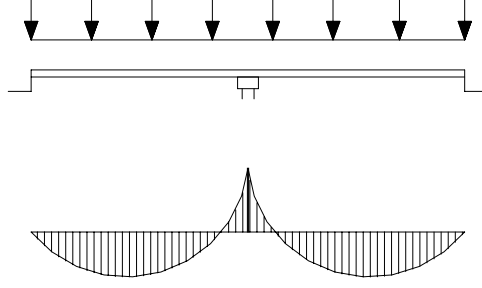

b) peso próprio do concreto moldado no local

g3
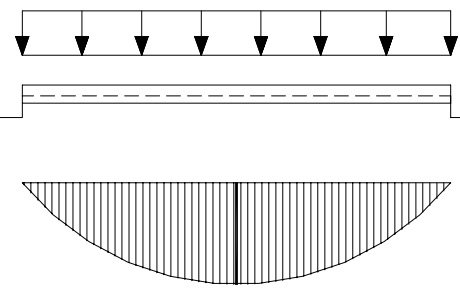

d) sobrecarga de revestimento
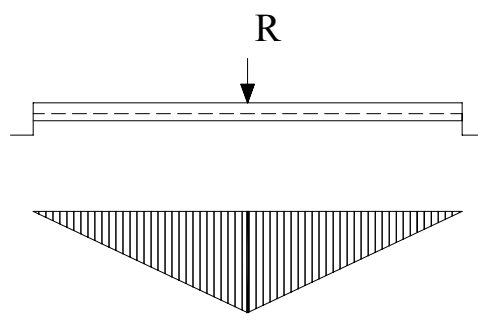

c) reação após retirar a escora

Figura 6. Diagramas de momento fletor atuantes na laje

Para a verificação do estado limite último para solicitações normais, inicialmente, será determinado o valor do momento último da seção composta. Para isso, defini-se os valores de resistência de cálculo dos materiais utilizados.

Concreto pré-moldado: $\mathrm{f}_{\mathrm{cd}, 1}=\frac{\mathrm{f}_{\mathrm{ck}, 1}}{1,3}$

Concreto moldado no local: $\mathrm{f}_{\mathrm{cd}, 2}=\frac{\mathrm{f}_{\mathrm{ck}, 2}}{1,4}$ 
Armadura de protensão: $\mathrm{f}_{\text {pyd }}=\frac{\mathrm{f}_{\mathrm{pyk}}}{1,15}$

Suponha inicialmente que a linha neutra passe pela capa de concreto moldada no local, ou seja, $\mathrm{y} \leq 4 \mathrm{~cm}$. Com esta hipótese, estabelecendo a equação de equilíbrio das forças atuantes na seção para $\mathrm{M}_{\mathrm{u}}$ positivo, como mostrado na Figura 7 , tem-se:

$0,85 \mathrm{f}_{\mathrm{cd}, 2} \mathrm{~A}_{\mathrm{c}^{\prime}}=\mathrm{A}_{\mathrm{p}} \mathrm{f}_{\text {pyd }} \quad$ onde $\mathrm{A}_{\mathrm{c}^{\prime}}=$ int $_{\text {eixo }} \cdot \mathrm{y}$

O braço de alavanca é então:

$$
\mathrm{z}_{\mathrm{p}}=\mathrm{h}-\mathrm{y}_{\mathrm{p}}-\mathrm{y} / 2
$$

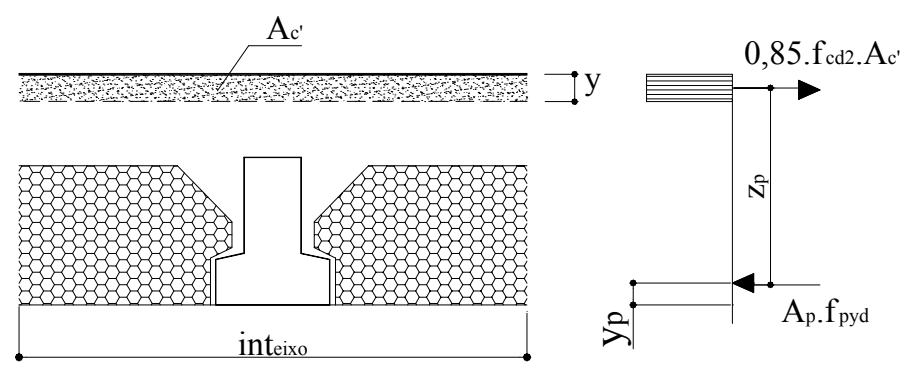

Figura 7. Equilíbrio das forças na seção da laje

Como a hipótese assumida é valida, deve-se verificar a validez de $\sigma_{p d}=f_{\text {pyd }}$, que exige respeitar a relação:

$$
\begin{aligned}
& \varepsilon_{\mathrm{pi}}+\varepsilon_{\mathrm{p}} \geq \frac{\mathrm{f}_{\mathrm{pyd}}}{\mathrm{E}_{\mathrm{p}}} \\
& \text { onde } \quad \varepsilon_{\mathrm{pi}}-\text { pré-alongamento da armadura protendida } \\
& \\
& \varepsilon_{\mathrm{p}}-\text { pré-alongamento da armadura devido à flexão }
\end{aligned}
$$

O valor do pré-alongamento da armadura protendida é dado por:

$$
\begin{aligned}
& \varepsilon_{\mathrm{pi}}=\varepsilon_{\mathrm{po}}+\varepsilon_{\mathrm{cp}} \\
& \text { onde: } \quad \varepsilon_{\mathrm{po}}=\frac{\gamma_{\mathrm{f}} \mathrm{P}_{\mathrm{oo}}}{\mathrm{A}_{\mathrm{p}} \mathrm{E}_{\mathrm{p}}} \quad \varepsilon_{\mathrm{cp}}=\frac{\gamma_{\mathrm{f}} \mathrm{P}_{\mathrm{oo}} \alpha_{\mathrm{p}}}{\mathrm{E}_{\mathrm{p}}}\left(\frac{1}{\mathrm{~A}_{\mathrm{c}}}+\frac{\left(\mathrm{e}_{\mathrm{p}}\right)^{2}}{\mathrm{I}_{\mathrm{c}}}\right)
\end{aligned}
$$

Utilizando semelhança de triângulo, pode-se encontrar o valor de $\varepsilon_{\mathrm{p}}$ : 


$$
\frac{\varepsilon_{\mathrm{p}}}{\mathrm{d}-\mathrm{x}}=\frac{0,0035}{\mathrm{x}}
$$

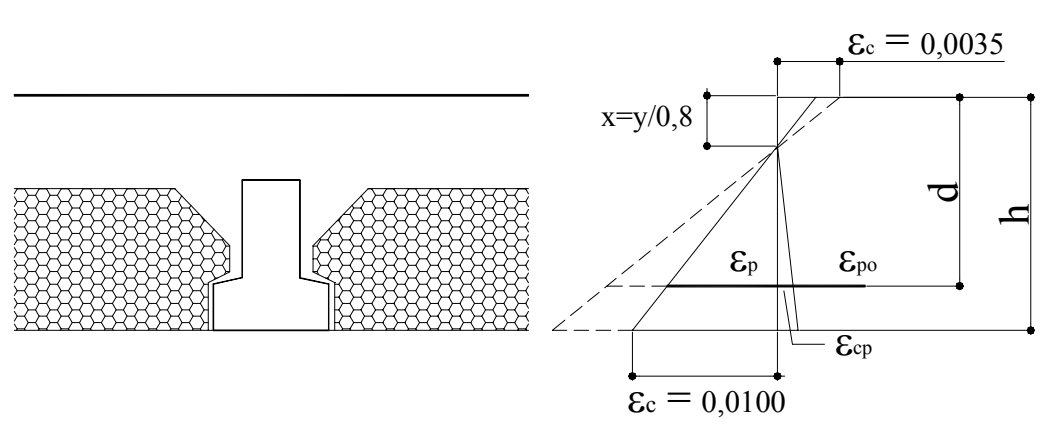

Figura 8. Deformações da seção composta

Se caso observar que $\varepsilon_{\mathrm{p}}>0,0100$, portanto o esgotamento da seção se produzirá por alongamento excessivo do bordo tracionado da seção, antes que o bordo comprimido alcance o encurtamento de $\varepsilon_{\mathrm{c}}$ igual a 0,0035 . Nesse caso podese corrigir o valor de $\varepsilon_{\mathrm{p}}$, de modo que a deformação $\varepsilon_{\mathrm{c}}$ fique menor que 0,0100 .

$$
\frac{\varepsilon_{\mathrm{p}}}{\mathrm{d}-\mathrm{x}}=\frac{0,0100}{\mathrm{~h}-\mathrm{x}} \quad \text { que confirma a validez } \sigma_{\mathrm{p}}=\mathrm{f}_{\mathrm{pyd}}
$$

O momento último da seção composta é o momento resistente por tal forças.

$$
\mathrm{M}_{\mathrm{u}}=\mathrm{A}_{\mathrm{p}} \mathrm{f}_{\mathrm{pyd}} \mathrm{z}_{\mathrm{p}}
$$

O valor do momento máximo atuante é:

$$
\mathrm{M}_{\mathrm{d}}=1,4\left(\mathrm{M}_{\mathrm{g} 1}+\mathrm{M}_{\mathrm{g}_{2}}+\mathrm{M}_{\mathrm{g}_{3}}+\mathrm{M}_{\mathrm{R}}+\mathrm{M}_{\mathrm{q}}\right)
$$

Portanto $\mathrm{M}_{\mathrm{d}} \leq \mathrm{M}_{\mathrm{u}}$

\section{VERIFICAÇÃO DO ESTADO LIMITE ÚLTIMO - SOLICITAÇÕES TANGENCIAIS}

A seguir serão feitas verificações da laje quanto ao estado limite último de solicitações tangenciais.

Para a verificação do estado limite último para solicitações tangenciais, deve-se utilizar a região de concreto moldado no local de $9 \mathrm{~cm}$ de largura. Assim, 


$$
\begin{aligned}
& V_{d} \leq 0,3 f_{c d, 2} \cdot b_{w} \cdot d \\
& V_{d} \leq V_{u 2}=2 f_{c v} \cdot b_{w} \cdot d
\end{aligned} \text { onde } f_{c v}=0,16 \sqrt{f_{c d, 2}}
$$

Além disso, para que não haja problema com o cisalhamento na interface entre os dois concretos, deve-se verificar ainda:

$\mathrm{V}_{\mathrm{d}} \leq \beta$. u.d.f $\mathrm{cv}_{\mathrm{c}}$

\section{VERIFICAÇÃO DO ESTADO LIMITE DE FISSURAÇÃO}

A verificação do estado limite de fissuração será realizada em duas seções da laje:

Seção 1: seção no meio do vão da laje;

Seção 2: seção localizada a $x_{m}$ do apoio, em que atua o maior valor de momento fletor devido às cargas $g_{1}$ e $g_{2}$.

Portanto tem-se que:

$$
\begin{aligned}
& \sigma_{1}=\frac{\mathrm{P}_{\mathrm{oo}}}{\mathrm{A}_{\mathrm{c}}}+\frac{\mathrm{P}_{\mathrm{oo}} \mathrm{e}_{\mathrm{p}}}{\mathrm{W}_{1}}-\frac{\mathrm{M}_{1}}{\mathrm{~W}_{\mathrm{lh}}}-\frac{\mathrm{M}_{2}}{\mathrm{~W}_{\mathrm{lh}}} \\
& \text { onde } \quad \mathrm{M}_{1}-\text { esforços de flexão na seção antes da solidarização dos } \\
& \quad \text { concretos } \\
& \mathrm{M}_{2}-\text { esforços de flexão na seção depois da solidarização dos } \\
& \quad \text { concretos }
\end{aligned}
$$

Portanto, as verificações das combinações rara e freqüente devem respeitar o estado limite de descompressão nas seções 1 e 2.

\section{CÁlCULO DA FUNÇÃO CUSTO}

Os vários custos envolvidos na produção da laje foram discriminados e apresentados em detalhes a seguir. Os custos para cada parcela são obtidos a partir dos insumos apresentados no Capítulo 5. Portanto cada valor de parcela corresponderá ao custo $\mathrm{em} \mathrm{R} \$ \mathrm{~m}^{2}$.

Conforme apresentado no Capítulo 5, no equacionamento da função custo foram utilizados valores cedidos pela empresa Marka situada em Franca, SP, e pela 
Revista Construção ${ }^{1}$. Será apresentada a função custo para os três experimentos analisados no Capítulo 5 em detalhes.

a) otimização do elemento para uma determinada aplicação

As variáveis do problema são:

$$
\begin{aligned}
& \mathrm{x}_{1}-\text { armadura nível } 1\left(\mathrm{~cm}^{2}\right) \\
& \mathrm{x}_{2}-\text { armadura nível } 2\left(\mathrm{~cm}^{2}\right) \\
& \mathrm{x}_{3}-\text { armadura nível } 3\left(\mathrm{~cm}^{2}\right) \\
& \mathrm{x}_{4}-\text { distância da armadura do nível } 2(\mathrm{~cm}) \\
& \mathrm{x}_{5}-\text { distância da armadura no nível } 3(\mathrm{~cm})
\end{aligned}
$$

Os dados considerados para este experimento foram:

$$
\begin{aligned}
& \text { int }_{\text {eixo }}=0,30 \mathrm{~m} \\
& \mathrm{~h}_{\text {capa }}=5 \mathrm{~cm} \\
& \mathrm{f}_{\text {ck }, 2}=20 \mathrm{MPa}
\end{aligned}
$$

\section{I) CUSTOS DE EXECUÇÃO (R\$/ $\left.\mathbf{m}^{2}\right)$}

\section{A.Custos da matéria-prima:}

\section{Concreto (Tcust conc $_{\text {) }}$}

A área de concreto da vigota $\left(\mathrm{A}_{\mathrm{c}}\right)$ está $\mathrm{em}^{2} \mathrm{~cm}^{2}$, portanto dividiu-se a área por 10000 , com o objetivo de transformá-la para $\mathrm{m}^{2}$. Os insumos apresentados no Capítulo $5 \mathrm{e}$ utilizados nesta seção são os seguintes:

$$
\begin{aligned}
& \text { Custo_material }=179,78 \mathrm{R} \$ / \mathrm{m}^{3} \\
& \text { Custo_mão_de_obra }=4,4 \mathrm{R} \$ \mathrm{~m}^{3} \\
& \text { Custo_equipamento }=8,35 \mathrm{R} \$ / \mathrm{m}^{3}
\end{aligned}
$$

material: $\quad$ cust $_{\mathrm{cl}}=$ custo_material $\frac{\mathrm{A}_{\mathrm{c}}}{10000 \cdot \text { int }_{\text {ereixo }}}=179,78 \frac{\mathrm{A}_{\mathrm{c}}}{10000 \cdot \text { int }_{\text {ereixo }}}$ $\underline{\text { mão-de-obra: }} \quad$ cust $_{\text {c2 }}=$ custo_mão_de_obra $\frac{\mathrm{A}_{\mathrm{c}}}{10000 \text { int }_{\text {ereixo }}}=4,4 \frac{\mathrm{A}_{\mathrm{c}}}{10000 \text {. int }_{\text {ereixo }}}$ equipamentos: $\quad$ cust $_{\mathrm{c} 3}=$ custo_equipamento $\frac{\mathrm{A}_{\mathrm{c}}}{10000 \cdot \text { int }_{\text {ereixo }}}=8,35 \frac{\mathrm{A}_{\mathrm{c}}}{10000 \cdot \text { int }_{\text {ereixo }}}$

\footnotetext{
${ }^{1}$ Construção, São Paulo, no 2782, 4/6/2001.
} 


$$
\therefore \text { Tcust }_{\text {conc }}=\text { cust }_{\mathrm{c} 1}+\text { cust }_{\mathrm{c} 2}+\text { cust }_{\mathrm{c} 3}
$$

\section{Armadura (Tcust $\left.{ }_{\text {arm }}\right)$ :}

Deve-se salientar que as variáveis $\mathrm{x}_{4}$ e $\mathrm{x}_{5}$ não introduzem nenhum custo adicional à função custo. Entretanto, neste trabalho, introduziu-se essas variáveis na obtenção da função custo, somente com o objetivo de retratar todas as variáveis envolvidas na solução do problema. A equação $\frac{x_{1} \cdot \operatorname{cg}_{1}+x_{2} \cdot \operatorname{cg}_{2}+x_{3} \cdot \operatorname{cg}_{3}}{3}$ introduz tais variáveis sem alterar quantitativamente o resultados final, pois a divisão tende ao valor da variável $\mathrm{A}_{\mathrm{p}}\left(\mathrm{x}_{1}+\mathrm{x}_{2}+\mathrm{x}_{3}\right)$. Os insumos apresentados no Capítulo 5 e utilizados nesta seção são os seguintes:

$$
\begin{aligned}
& \text { Custo_material }=2,5 \mathrm{R} \$ / \mathrm{kg} \\
& \text { Custo_mão_de_obra }=0,25 \mathrm{R} \$ / \mathrm{kg} \\
& \text { Custo_equipamento }=0,07 \mathrm{R} \$ / \mathrm{kg}
\end{aligned}
$$

material: $\quad$ cust $_{\mathrm{a} 1}=$ custo_material.1,1 $\frac{\left(\mathrm{x}_{1}+\mathrm{x}_{2}+\mathrm{x}_{3}\right)}{\text { int }_{\text {eixo }}}=\frac{2,75\left(\mathrm{x}_{1}+\mathrm{x}_{2}+\mathrm{x}_{3}\right)}{\text { int }_{\text {eixo }}}$

$$
\underline{\text { mão-de-obra: }} \text { cust } \text { a } 2=\text { custo_mão_de_obra. } \frac{1,1\left(\mathrm{x}_{1}+\mathrm{x}_{2}+\mathrm{x}_{3}\right)}{\text { int }_{\text {eixo }}}=\frac{0,275\left(\mathrm{x}_{1}+\mathrm{x}_{2}+\mathrm{x}_{3}\right)}{\text { int }_{\text {eixo }}}
$$

equipamentos:

$$
\begin{gathered}
\text { cust }_{\mathrm{a} 3}=\text { custo_e }_{-} \text {equipamento. } \frac{0,16 \cdot \text { int }_{\text {eixo }}}{1,1\left(\mathrm{x}_{1}+\mathrm{x}_{2}+\mathrm{x}_{3}\right)}=\frac{0,00144 \cdot \text { int }_{\text {eixo }}}{\left(\mathrm{x}_{1}+\mathrm{x}_{2}+\mathrm{x}_{3}\right)}=\frac{0,00144 \cdot \text { int }_{\text {eixo }}}{\left(\frac{\mathrm{x}_{1} \cdot \mathrm{cg}_{1}+\mathrm{x}_{2} \cdot \mathrm{cg}_{2}+\mathrm{x}_{3} \cdot \mathrm{cg}_{3}}{3}\right)} \\
\therefore \text { Tcust }_{\mathrm{arm}}=\text { cust }_{\mathrm{a} 1}+\text { cust }_{\mathrm{a} 2}+\text { cust }_{\mathrm{a} 3}
\end{gathered}
$$

\section{Enchimento (Tcust enc ):}

A área de concreto da vigota $\left(\mathrm{A}_{\mathrm{c}}\right)$ está $\mathrm{em}^{2} \mathrm{~cm}^{2}$, portanto dividiu-se a área por 10000 , com o objetivo de transformá-la para $\mathrm{m}^{2}$. Os insumos apresentados no Capítulo 5 e utilizados nesta seção são os seguintes:

$$
\begin{aligned}
& \text { Custo_material }=2,0 \mathrm{R} \$ / \mathrm{m}^{3} \\
& \text { Custo_mão_de_obra }=2,2 \mathrm{R} \$ / \mathrm{m}^{3} \\
& \text { Custo_equipamento }=1,0 \mathrm{R} \$ / \mathrm{m}^{3}
\end{aligned}
$$


material: $\quad$ cust $_{\mathrm{cl}}=$ custo_material.int $\mathrm{ereixo}_{-}=2,0$. int $_{\text {ereixo }}$

mão-de-obra: $\quad$ cust $_{\mathrm{c} 2}=$ custo_mão_de_obra. int $_{\text {ereixo }}=2,2$. int $_{\text {ereixo }}$

equipamentos: $\quad$ cust $_{\mathrm{c} 3}=$ custo_equipamento. int $_{\text {ereixo }}=1,0$. int $_{\text {ereixo }}$

$\therefore$ Tcust $_{\text {enc }}=$ cust $_{\mathrm{c} 1}+$ cust $_{\mathrm{c} 2}+$ cust $_{\mathrm{c} 3}$

B. Custos adicionais (Tcust $\left.t_{a d c}\right)$ :

Os insumos apresentados no Capítulo 5 e utilizados nesta seção são os seguintes:

Custo_mão_de_obra $=4,4 \mathrm{R} \$ / \mathrm{m}^{3}$

Custo_equipamento $=1,67 \mathrm{R} \$ / \mathrm{m}^{3}$

$\underline{\text { mão-de-obra: }}$ cust $_{\text {adcl }}=$ custo_mão_de_obra $\frac{\mathrm{A}_{\mathrm{c}}}{10000 . \text { int }_{\text {ereixo }}}=4,4 \frac{\mathrm{A}_{\mathrm{c}}}{10000 . \text { int }_{\text {ereixo }}}$ equipamentos: $\quad$ cust $_{\text {adc2 }}=$ custo_equipamento $\frac{\mathrm{A}_{\mathrm{c}}}{10000 \text { int }_{\text {ereixo }}}=1,67 \frac{\mathrm{A}_{\mathrm{c}}}{10000 . \text { int }_{\text {ereixo }}}$

$\therefore$ Tcust $_{\text {adc }}=$ cust $_{\text {adc } 1}+$ cust $_{\text {adc } 2}$

C. Custos indiretos administrativos (Tcust $\left.{ }_{\text {ind }}\right)$

$\therefore$ Tcust $_{\text {ind }}=0,1\left(\right.$ Tcust $_{\text {conc }}+$ Tcust $_{\text {arm }}+$ Tcust $_{\text {enc }}+$ Tcust $\left._{\text {adc }}\right)$

D. Custos tributários (cust ${ }_{\text {trib }}$ )

Os insumos apresentados no Capítulo 5 e utilizados nesta seção são os seguintes:

c_tributario $=115,00 \mathrm{R} \$ / \mathrm{m}^{3}$

$\therefore$ cust $_{\text {trib }}=\mathrm{c}_{-}$tributario $\frac{\mathrm{A}_{\mathrm{c}}}{10000 \text { int }_{\text {ereixo }}}=115,00 \frac{\mathrm{A}_{\mathrm{c}}}{10000 . \text { int }_{\text {ereixo }}}$

\section{II) CUSTOS DE TRANSPORTE EXTERNO $\left(\mathrm{R} \$ / \mathrm{m}^{2}\right)$}

Os insumos apresentados no Capítulo 5 e utilizados nesta seção são os seguintes:

custo_transp $=52 \mathrm{R} \$ / \mathrm{m}^{3}$ 
serviços: $\quad$ cust $_{\text {tr }}=$ custo $-\operatorname{transp} \frac{\mathrm{A}_{\mathrm{c}}}{10000 . \text { int }_{\text {ereixo }}}=52 \frac{\mathrm{A}_{\mathrm{c}}}{10000 . \text { int }_{\text {ereixo }}}$

\section{III) CUSTOS DA APLICAÇÃO (R\$/m²)}

A. Custos da montagem do painel alveolar (Tcust $_{\text {mon }}$ )

Os insumos apresentados no Capítulo 5 e utilizados nesta seção são os seguintes:

Custo_mão_de_obra $=4,4 \mathrm{R} \$ / \mathrm{m}^{3}$

Custo_cimb $=6,0 \mathrm{R} \$ / \mathrm{m}^{3}$

$\underline{\text { mão-de-obra: }}$ cust ${ }_{\text {mo }}=$ custo_mão_de_obra $\frac{\mathrm{A}_{\mathrm{c}}}{10000 . \text { int }_{\text {ereixo }}}=4,4 \frac{\mathrm{A}_{\mathrm{c}}}{10000 \text {. int }_{\text {ereixo }}}$

equipamentos: $\quad$ cust $_{\text {eq }}=$ custo_cimb $\frac{\mathrm{A}_{\mathrm{c}}}{10000 \text { int }_{\text {ereixo }}}=6,0 \frac{\mathrm{A}_{\mathrm{c}}}{10000 . \text { int }_{\text {ereixo }}}$

$\therefore$ Tcust $_{\text {mon }}=$ cust $_{\text {mo }}+$ cust $_{\text {eq }}$

B. Custos do concreto da capa (Tcust $t_{\text {capa }}$ )

Os insumos apresentados no Capítulo 5 e utilizados nesta seção são os seguintes:

$$
\begin{aligned}
& \text { custo_material }=136,13 \mathrm{R} \$ / \mathrm{m}^{3} \\
& \text { custo_mão_de_obra }=104,20 \mathrm{R} \$ / \mathrm{m}^{3} \\
& \text { custo_equipamento }=8,35 \mathrm{R} \$ / \mathrm{m}^{3}
\end{aligned}
$$

$$
\begin{aligned}
& \text { Material: } \\
& \text { cust }_{\text {cp1 }}=\text { custo_material } \frac{\mathrm{h}_{\text {capa }}}{100}=136,13 \frac{\mathrm{h}_{\text {capa }}}{100} \\
& \text { mão-de-obra: } \\
& \text { cust }_{\text {cp2 }}=\text { custo_mão_de_obra } \frac{\mathrm{h}_{\text {capa }}}{100}=104,20 \frac{\mathrm{h}_{\text {capa }}}{100} \\
& \text { equipamentos: } \quad \text { cust }_{\mathrm{cp} 3}=\text { custo_equipamento } \frac{\mathrm{h}_{\text {capa }}}{100}=8,35 \frac{\mathrm{h}_{\text {capa }}}{100} \\
& \therefore \text { Tcust }_{\text {reg }}=\text { cust }_{\mathrm{cp} 1}+\text { cust }_{\mathrm{pp} 2}+\text { cust }_{\mathrm{cp} 3}
\end{aligned}
$$

C. Custos da armadura complementar (Tcust ${ }_{\text {armc }}$ )

Os insumos apresentados no Capítulo 5 e utilizados nesta seção são os seguintes: custo_material $=1,13 \mathrm{R} \$ / \mathrm{kg}$ 


$$
\text { custo_mão_de_obra }=0,11 \mathrm{R} \$ / \mathrm{kg}
$$

Material: $\quad$ cust $_{\text {acl }}=$ custo_material $\frac{0,245\left(\mathrm{~A}_{\mathrm{d} 1}+\mathrm{A}_{\mathrm{d} 2}\right)}{0,312}=1,13 \frac{0,245\left(\mathrm{~A}_{\mathrm{d} 1}+\mathrm{A}_{\mathrm{d} 2}\right)}{0,312}$

mão-de-obra:

$$
\begin{aligned}
& \text { cust }_{\mathrm{ac} 2}=\text { custo } \text { mão }_{-} \mathrm{de}_{-} \text {obra } \frac{0,245\left(\mathrm{~A}_{\mathrm{d} 1}+\mathrm{A}_{\mathrm{d} 2}\right)}{0,312}=0,11 \frac{0,245\left(\mathrm{~A}_{\mathrm{d} 1}+\mathrm{A}_{\mathrm{d} 2}\right)}{0,312} \\
& \therefore \text { Tcust }_{\mathrm{armc}}=\text { cust }_{\mathrm{ac} 1}+\text { cust }_{\mathrm{ac} 2}
\end{aligned}
$$

D. Custos indiretos administrativos (Tcust $\left.{ }_{a d m a}\right)$

$$
\therefore \text { Tcust }_{\text {adma }}=0,2\left(\text { cust }_{\text {mon }}+\text { Tcust }_{\text {capa }}+\text { Tcust }_{\text {armc }}\right)
$$

Portanto, os vários custos envolvidos na produção de uma laje com vigota protendida foram somados e a expressão final da função em $\mathrm{R} \$ / \mathrm{m}^{2}$ é:

$$
\mathrm{f}(\mathbf{x})=31,55 \ln \left(\mathrm{x}_{1}\right)+11,93\left(\mathrm{x}_{1}+\mathrm{x}_{2}+\mathrm{x}_{3}\right)+\frac{0,173}{\left(2 \mathrm{x}_{1}+\mathrm{x}_{2}\left(\mathrm{x}_{4}+2\right)+\mathrm{x}_{3}\left(\mathrm{x}_{4}+\mathrm{x}_{5}+2\right)\right)}
$$

onde

$$
\begin{aligned}
& \mathrm{x}_{1}-\text { armadura nível } 1\left(\mathrm{~cm}^{2}\right) \\
& \mathrm{x}_{2}-\text { armadura nível } 2\left(\mathrm{~cm}^{2}\right) \\
& \mathrm{x}_{3}-\text { armadura nível } 3\left(\mathrm{~cm}^{2}\right) \\
& \mathrm{x}_{4}-\text { distância da armadura do nível } 2(\mathrm{~cm}) \\
& \mathrm{x}_{5}-\text { distância da armadura no nível } 3(\mathrm{~cm})
\end{aligned}
$$

b) otimização da aplicação para uma determinada vigota

As variáveis do problema são:

$$
\begin{aligned}
& \mathrm{x}_{1}-\text { altura da capa de concreto }(\mathrm{cm}) \\
& \mathrm{x}_{2}-\text { resistência da capa de concreto }\left(\mathrm{kN} / \mathrm{cm}^{2}\right) \\
& \mathrm{x}_{3}-\text { distância do intereixo }(\mathrm{cm})
\end{aligned}
$$

Os dados considerados para este experimento foram:

$$
\begin{aligned}
& \mathrm{A}_{\mathrm{p}}=0,785 \mathrm{~cm}^{2} \\
& \mathrm{f}_{\mathrm{ck}, 1}=45 \mathrm{MPa}
\end{aligned}
$$




\section{I) CUSTOS DE EXECUÇÃO (R\$/m $\left.\mathbf{m}^{2}\right)$}

A.Custos da matéria-prima:

Concreto (Tcust conc $_{\text {): }}$

A área de concreto da vigota $\left(\mathrm{A}_{\mathrm{c}}\right)$ está $\mathrm{em}^{2} \mathrm{~cm}^{2}$, portanto dividiu-se a área por 10000 , com o objetivo de transformá-la para $\mathrm{m}^{2}$. Os insumos apresentados no Capítulo 5 e utilizados nesta seção são os seguintes:

$$
\begin{aligned}
& \text { Custo_material }=185,63 \mathrm{R} \$ / \mathrm{m}^{3} \\
& \text { Custo_mão_de_obra }=4,4 \mathrm{R} \$ / \mathrm{m}^{3} \\
& \text { Custo_equipamento }=8,35 \mathrm{R} \$ / \mathrm{m}^{3}
\end{aligned}
$$

$\underline{\text { material: }} \quad$ cust $_{\mathrm{cl}}=$ custo_material $\frac{\mathrm{A}_{\mathrm{c}}}{10000 \cdot \mathrm{x}_{3}}=185,63 \frac{\mathrm{A}_{\mathrm{c}}}{10000 \cdot \mathrm{x}_{3}}$

mão-de-obra: $\quad$ cust $_{\mathrm{c} 2}=$ custo_mão_de_obra $\frac{\mathrm{A}_{\mathrm{c}}}{10000 \cdot \mathrm{x}_{3}}=4,4 \frac{\mathrm{A}_{\mathrm{c}}}{10000 \cdot \mathrm{x}_{3}}$

equipamentos: $\quad$ cust $_{\mathrm{c} 3}=$ custo_equipamento $\frac{\mathrm{A}_{\mathrm{c}}}{10000 \cdot \mathrm{x}_{3}}=8,35 \frac{\mathrm{A}_{\mathrm{c}}}{10000 \cdot \mathrm{x}_{3}}$

$\therefore$ Tcust $_{\text {conc }}=$ cust $_{\mathrm{c} 1}+$ cust $_{\mathrm{c} 2}+$ cust $_{\mathrm{c} 3}$

\section{Armadura (Tcust $\left.{ }_{\text {arm }}\right)$ :}

Os insumos apresentados no Capítulo 5 e utilizados nesta seção são os seguintes:

$$
\begin{aligned}
& \text { Custo_material }=2,5 \mathrm{R} \$ / \mathrm{kg} \\
& \text { Custo_mão_de_obra }=0,25 \mathrm{R} \$ / \mathrm{kg} \\
& \text { Custo_equipamento }=0,07 \mathrm{R} \$ / \mathrm{kg}
\end{aligned}
$$

material: $\quad$ cust $_{a 1}=$ custo_material. $1,1 \frac{A_{p}}{x_{3}}=\frac{2,75 A_{p}}{x_{3}}$

$\underline{\text { mão-de-obra: }}$ cust ${ }_{\mathrm{a} 2}=$ custo $\_$mão_de $\_$obra. $\frac{1,1 \mathrm{~A}_{\mathrm{p}}}{\mathrm{x}_{3}}=\frac{0,275 \mathrm{~A}_{\mathrm{p}}}{\mathrm{x}_{3}}$

equipamentos:

$$
\begin{aligned}
& \text { cust }_{\mathrm{a} 3}=\text { custo_equipamento. } \frac{0,16 \cdot \text { int }_{\text {eixo }}}{1,1 \mathrm{~A}_{\mathrm{p}}}=\frac{0,00144 \cdot \mathrm{x}_{3}}{\mathrm{~A}_{\mathrm{p}}}=\frac{0,00144 \cdot \mathrm{x}_{3}}{\mathrm{~A}_{\mathrm{p}}} \\
& \therefore \text { Tcust }_{\mathrm{arm}}=\text { cust }_{\mathrm{a} 1}+\text { cust }_{\mathrm{a} 2}+\text { cust }_{\mathrm{a} 3}
\end{aligned}
$$




\section{Enchimento (Tcust ${ }_{\text {enc }}$ ):}

A área de concreto da vigota $\left(\mathrm{A}_{\mathrm{c}}\right)$ está em $\mathrm{cm}^{2}$, portanto dividiu-se a área por 10000 , com o objetivo de transformá-la para $\mathrm{m}^{2}$. Os insumos apresentados no Capítulo $5 \mathrm{e}$ utilizados nesta seção são os seguintes:

Custo_material $=2,0 \mathrm{R} \$ / \mathrm{m}^{3}$

Custo_mão_de_obra $=2,2 \mathrm{R} \$ / \mathrm{m}^{3}$

Custo_equipamento $=1,0 \mathrm{R} \$ / \mathrm{m}^{3}$

$\underline{\text { material: }} \quad$ cust $_{\mathrm{c} 1}=$ custo__material. $\frac{\mathrm{x}_{3}}{100}=2,0 \cdot \frac{\mathrm{x}_{3}}{100}$

$\underline{\text { mão-de-obra: }} \quad$ cust $_{\mathrm{c} 2}=$ custo_mão_de_obra $\cdot \frac{\mathrm{x}_{3}}{100}=2,2 \cdot \frac{\mathrm{x}_{3}}{100}$

equipamentos: $\quad$ cust $_{\mathrm{c} 3}=$ custo_equipamento $\cdot \frac{\mathrm{x}_{3}}{100}=1,0 \cdot \frac{\mathrm{x}_{3}}{100}$

$\therefore$ Tcust $_{\text {enc }}=$ cust $_{\mathrm{c} 1}+$ cust $_{\mathrm{c} 2}+$ cust $_{\mathrm{c} 3}$

B. Custos adicionais (Tcust $\left.t_{\text {adc }}\right)$ :

Os insumos apresentados no Capítulo 5 e utilizados nesta seção são os seguintes:

Custo_mão_de_obra $=4,4 \mathrm{R} \$ / \mathrm{m}^{3}$

Custo_equipamento $=1,67 \mathrm{R} \$ / \mathrm{m}^{3}$

$\underline{\text { mão-de-obra: }}$ cust ${ }_{\text {adcl }}=$ custo_mão_de_obra $\frac{\mathrm{A}_{\mathrm{c}}}{10000 \cdot \mathrm{x}_{3}}=4,4 \frac{\mathrm{A}_{\mathrm{c}}}{10000 \cdot \mathrm{x}_{3}}$

equipamentos: $\quad$ cust $_{\text {adc2 }}=$ custo_equipamento $\frac{A_{c}}{10000 \cdot x_{3}}=1,67 \frac{A_{c}}{10000 \cdot x_{3}}$

$\therefore$ Tcust $_{\text {adc }}=$ cust $_{\text {adc1 }}+$ cust $_{\text {adc2 }}$

C. Custos indiretos administrativos (Tcust ${ }_{\text {ind }}$ )

$\therefore$ Tcust $_{\text {ind }}=0,1$ (Tcust $_{\text {conc }}+$ Tcust $_{\text {arm }}+$ Tcust $_{\text {enc }}+$ Tcust $\left._{\text {adc }}\right)$

D. Custos tributários (cust trib)

Os insumos apresentados no Capítulo 5 e utilizados nesta seção são os seguintes: 


$$
\begin{gathered}
\text { c_tributario }=195,0 \mathrm{R} \$ / \mathrm{m}^{3} \\
\therefore \text { cust }_{\text {trib }}=\mathrm{c}_{-} \text {tributario } \frac{\mathrm{A}_{\mathrm{c}}}{10000 \cdot \mathrm{x}_{3}}=195,0 \frac{\mathrm{A}_{\mathrm{c}}}{10000 \cdot \mathrm{x}_{3}}
\end{gathered}
$$

\section{II) CUSTOS DE TRANSPORTE EXTERNO (R $\left.\$ \mathrm{~m}^{2}\right)$}

Os insumos apresentados no Capítulo 5 e utilizados nesta seção são os seguintes:

$$
\text { custo_transp }=52 \mathrm{R} \$ / \mathrm{m}^{3}
$$

serviços:

$$
\text { cust }_{\text {tr }}=\text { custo_transp } \frac{\mathrm{A}_{\mathrm{c}}}{10000 \cdot \mathrm{x}_{3}}=52 \frac{\mathrm{A}_{\mathrm{c}}}{10000 \cdot \mathrm{x}_{3}}
$$

\section{III) CUSTOS DA APLICAÇÃO (R\$/ $\left.\mathbf{m}^{2}\right)$}

A. Custos da montagem do painel alveolar (Tcust ${ }_{m o n}$ )

Os insumos apresentados no Capítulo 5 e utilizados nesta seção são os seguintes:

Custo_mão_de_obra $=4,4 \mathrm{R} \$ / \mathrm{m}^{3}$

Custo_cimb $=6,0 \mathrm{R} \$ / \mathrm{m}^{3}$

$\underline{\text { mão-de-obra: }}$ cust ${ }_{\text {mo }}=$ custo_mão_de_obra $\frac{\mathrm{A}_{\mathrm{c}}}{10000 \cdot \mathrm{x}_{3}}=4,4 \frac{\mathrm{A}_{\mathrm{c}}}{10000 \cdot \mathrm{x}_{3}}$

equipamentos: $\quad$ cust $_{\text {eq }}=$ custo_cimb $\frac{A_{c}}{10000 \cdot x_{3}}=6,0 \frac{A_{c}}{10000 \cdot x_{3}}$

$$
\therefore \text { Tcust }_{\text {mon }}=\text { cust }_{\text {mo }}+\text { cust }_{\text {eq }}
$$

B. Custos do concreto da capa (Tcust $t_{\text {capa) }}$

Os insumos apresentados no Capítulo 5 e utilizados nesta seção são os seguintes:

$$
\begin{aligned}
& \text { custo_material }=\left(24,75 \cdot \mathrm{x}_{2}+74,25\right) \mathrm{R} \$ / \mathrm{m}^{3} \\
& \text { custo_mão_de_obra }=52,50 \mathrm{R} \$ / \mathrm{m}^{3} \\
& \text { custo_equipamento }=8,35 \mathrm{R} \$ / \mathrm{m}^{3}
\end{aligned}
$$

Material:

$$
\text { cust }_{\mathrm{cp} 1}=\text { custo_material } \frac{\mathrm{x}_{1}}{100}=\left(24,75 \cdot \mathrm{x}_{2}+74,25\right) \frac{\mathrm{x}_{1}}{100}
$$




$$
\begin{aligned}
& \text { mão-de-obra: } \quad \text { cust }_{\mathrm{cp} 2}=\text { custo_mão_de_obra } \frac{\mathrm{x}_{1}}{100}=52,50 \frac{\mathrm{x}_{1}}{100} \\
& \text { equipamentos: } \quad \text { cust }_{\mathrm{cp} 3}=\text { custo_equipamento } \frac{\mathrm{x}_{1}}{100}=8,35 \frac{\mathrm{x}_{1}}{100} \\
& \therefore \text { Tcust }_{\text {reg }}=\text { cust }_{\mathrm{cp} 1}+\text { cust }_{\mathrm{cp} 2}+\text { cust }_{\mathrm{cp} 3}
\end{aligned}
$$

\section{Custos da armadura complementar (Tcust ${ }_{\text {armc }}$ )}

Os insumos apresentados no Capítulo 5 e utilizados nesta seção são os seguintes:

$$
\begin{aligned}
& \text { custo_material }=1,13 \mathrm{R} \$ / \mathrm{kg} \\
& \text { custo_mão_de_obra }=0,11 \mathrm{R} \$ / \mathrm{kg}
\end{aligned}
$$

Material: $\quad$ cust $_{\text {ac1 }}=$ custo_material $\frac{0,245\left(\mathrm{~A}_{\mathrm{d} 1}+\mathrm{A}_{\mathrm{d} 2}\right)}{0,312}=1,13 \frac{0,245\left(\mathrm{~A}_{\mathrm{d} 1}+\mathrm{A}_{\mathrm{d} 2}\right)}{0,312}$

mão-de-obra:

$$
\begin{aligned}
& \text { cust }_{\mathrm{ac} 2}=\text { custo_mão_de_obra } \frac{0,245\left(\mathrm{~A}_{\mathrm{d} 1}+\mathrm{A}_{\mathrm{d} 2}\right)}{0,312}=0,11 \frac{0,245\left(\mathrm{~A}_{\mathrm{d} 1}+\mathrm{A}_{\mathrm{d} 2}\right)}{0,312} \\
& \therefore \text { Tcust }_{\text {armc }}=\text { cust }_{\mathrm{ac} 1}+\text { cust }_{\mathrm{ac} 2}
\end{aligned}
$$

D. Custos indiretos administrativos (Tcust $t_{\text {adma }}$ )

$$
\therefore \text { Tcust }_{\text {adma }}=0,2\left(\text { cust }_{\text {mon }}+\text { Tcust }_{\text {capa }}+\text { Tcust }_{\text {armc }}\right. \text { ) }
$$

Portanto, os vários custos envolvidos na produção de um painel alveolar com capa de regularização foram somados e a expressão final da função em $\mathrm{R} \$ / \mathrm{m}^{2}$ é:

$f(\mathbf{x})=\frac{669,376}{x_{3}}+1,552 x_{1}+0,012 x_{1}\left(24,75 x_{2}+74,25\right)+0,0592 x_{3}$

onde

$\mathrm{x}_{1}$ - altura da capa de concreto em $\mathrm{cm}$

$\mathrm{x}_{2}-$ resistência do concreto moldado no local em $\mathrm{kN} / \mathrm{cm}^{2}$

$\mathrm{x}_{3}$ - distância do intereixo em cm

c) otimização do elemento e da aplicação 
Esse item considerou as mesmas variáveis apresentadas em a). Considerou-se além das cinco variáveis definidas em a), mais três: resistência da capa de concreto, distância do intereixo e altura da capa de concreto. A somatória dos custos envolvidos é definida como se segue:

$$
\begin{aligned}
& \mathrm{f}(\mathbf{x})=\frac{473,42}{\mathrm{x}_{7}}+1,552 \mathrm{x}_{8}+0,012 \mathrm{x}_{8}\left(24,75 \mathrm{x}_{6}+74,25\right)+\frac{335,78\left(\mathrm{x}_{1}+\mathrm{x}_{2}+\mathrm{x}_{3}\right)}{\mathrm{x}_{7}}+ \\
& \frac{0,00476 \mathrm{x}_{7}}{\left(2 \mathrm{x}_{1}+\mathrm{x}_{2}\left(\mathrm{x}_{4}+2\right)+\mathrm{x}_{3}\left(\mathrm{x}_{4}+\mathrm{x}_{5}+2\right)\right)}+0,057 \mathrm{x}_{7}
\end{aligned}
$$

onde

$$
\begin{aligned}
& \mathrm{x}_{1}-\text { armadura nível } 1\left(\mathrm{~cm}^{2}\right) \\
& \mathrm{x}_{2}-\text { armadura nível } 2\left(\mathrm{~cm}^{2}\right) \\
& \mathrm{x}_{3}-\text { armadura nível } 3\left(\mathrm{~cm}^{2}\right) \\
& \mathrm{x}_{4}-\text { distância da armadura do nível } 2(\mathrm{~cm}) \\
& \mathrm{x}_{5}-\text { distância da armadura no nível } 3(\mathrm{~cm}) \\
& \mathrm{x}_{6}-\text { resistência do concreto moldado no local em } \mathrm{kN} / \mathrm{cm}^{2} \\
& \mathrm{x}_{7}-\text { distância do inter-eixo em } \mathrm{cm} \\
& \mathrm{x}_{8}-\text { altura da capa de concreto em } \mathrm{cm}
\end{aligned}
$$

